$$
\begin{aligned}
& D R-0520-7 \\
& I-17691
\end{aligned}
$$




\section{LECAL NOTICE}

This book was prepared as an account of work sponsored by an agency of the United States Government. Neither the United States Govern. ment nor any agency thereot, nor any of their employees, makes any warranty, express or implied. or assumes any legal liability or responsibility for the accuracy, completeness, or uselulness of any information, apparatus, product, or process disclosed, or represents that its use would not intringe privately owned rights. Reter'ence herein to any specific commercial product. process, or service by trade name. trademark. manufacturer, or otherwise, does not necessarily constitute or imply its endorsement, recommen. dation, or favoring by the United States Govern. ment or any agency thereot. The views and opin' ons of authors expressed herein do not necessarily state or reflect those of the United States Govern'nent or any agency thereof.

Primied in the United States of America Aviliable from

National Technisid Intormation Service

U.S. Department of Commerce 5285 Port Royal Road Springfield, VA 22161

Price Code: Al1 

available copy to permit the bruadest possibie availability.

\title{
EARTH SCIENCES DIVISION ANNUAL REPORT 1983
}

\author{
Lawrence Berkeley Laboratory \\ University of California \\ Berkeley, California 94720
}

July 1984

Prepared for the U.S. Department of Energy under Contract No. DE-AC03-76SF00098

\section{MASTER'}

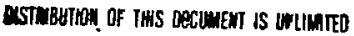

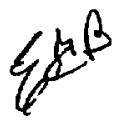




\section{ACKNOWLEDGMENTS}

This work was supported through U.S. Department of Energy Contract No. DE-AC03-76SF00098 by (1) the Assistant Secretary for Energy Research, Office of Basic Energy Sciences, Division of Engineering and Geosciences; (2) the Assistant Secretary for Conservation and Renewable Energy, Office of Renewable Technology, Division of Geothermal and Hydropower Technologies; (3) the Assistant Secretary for Conservation and Solar Energy, Office of Advanced Conservation Technology, Division of Thermal and Mechanical Storage Systems; (4) the Assistant Secretary for Fossil Energy. Office of Oil, Gas, and Shale Technology, Division of Oil; (5) the Assistant Secretary for Nuclear Energy, Office of Nuclear Waste Management, Division of Nuclear Waste Isolation; (6) the Assistant Secretary for Nuclear Energy, Office of Nuclear Waste Management, Division of Remedial Action Programs; (7) the Waste Management Research Branch, Division of Health, Siting and Waste Management. Office of Nuclear Regulatory Research, U.S. Nuclear Regulatory Commission, through Interagency Agreement DOE-50-80-97; (8) the Center for Seismic Studjes. through Order Number 4306 from the Division of Geophysical Studies of the Department of Defense Advanced Research Projects Agency: (9) the Assistant Director for Mining Research of the Department of Interior. Bureau of Mines. through Interagency Agreement WA-A-00590; and 110) the Groundwater Research Branch of the Robert S. Kerr Environmental Laboratory, U.S. Environmental Protection Agency, through Interagency Agreement DW 930198-01-0. 


\section{CONTENTS}

INTRODUCTION

RESERVOIR ENGINEERING AND HYDROGEOLOGY

Hydrologic Testing in the Klamath Falls, Oregon, Geothermal System S.M. Benson and R.D. Solbau

5

Review of Studies Carried Out on the Cerro Prieto Geothermal Field, Mexico

M.J. Lippmann, N.E. Goldstein, S.E. Halfman, and P.A. Witherspoon 7

Depositional Environments in the Cerro Prieto Geothermal Field, Mexico

S.E. Halfman, M.J. Lippmann, and J.A. Gilreath

10

The Krafla Geothermal Field, Iceland: A Modeling Case Study

G.S. Bodvarsson, K. Pruess, V. Stefansson, and E.T. Eliasson

14

A Modeling Study of the Natural State of the Heber Gcothermal Field, California M.J. Lippmann and G.S. Bodvarsson 18

High-Temperature Geothermal Downhole Flowmetel

R.D. Solbau and S.M. Benson

22

Injection in Fractured Reservoirs

K. Pruess and G.S. Bodvarsson

26

Front Tracking in Cold Water Injection Wells

S.M. Benson 28

A Test Facility to Investigate Two-Phase Steam/Water Flow in Porous Media

A. Verma. K. Pruess, G.S. Bodvarsson. C.F. Tsang, and P.A. Witherspoon

Fluid and Heat Flow in Gas-Rich Geothermal Reservoirs

M.J. O'Sullivan. G.S. Bodvarsson, and K. Pruess

34

TOUGH: A Numerical Model for Strongly Heat Driven Flow in Partially Saturated Media K. Pruess 39

A Study of Nonisothermal Chemical Transpor in Geothermal Systems by a Three-Dimensional. Coupled, Thermal and Hydrologic Parcel Model D.C. Mangold and C.F. Tsang 41

A Siudy of Contaminant Plume Control in Fractured Porous Media C.F. Tsang, D.C. Mangold, C. Deughty ana I. Jarandel 44

The Use of Ma iematical Models for Subsurface Contaminant Transport Assessment I. Javandel, C. Doughty, and C.F. Tsang 
The Dependence of Fracture Mechanical Properties on Fracture Roughness and Sample Size

Y.W. Tsang and P.A. Witherspoon $\quad 50$

Can Water-Injection Tests Reveal the Potential for Fault Movements?

$J$. Noorishad and P.A. Witherspoon 52

Well-Test Data Analysis from Naturally Fractured Reservoirs C.H. Lai, G.S. Bodvarsson, C.F. Tsang, and P.A. Witherspoon

A New Mechanical Transport Model for Networks of Fractures H.K. Endo 57

A Three-Dimensional Model for Fluid Flow in Nonextensive Fractures J.C.S Long, H.M. MacLean, and P.A. Witherspoon 60

A Novel Seven-Point Method for Modeling Displacements with Adverse Mobility Ratio $K$. Pruess and G.S. Bodvarsson 63

Detailed Field Validation of the Prediction for an ATES System C. Doughty and C.F. Tsang 66

Heat Storage in Unsaturated Soils: Initial Theoretical Analysis of Storage Design and Operational Methods C. Doughty, A. Nir, and C.F. Tsang $\quad \mathbf{7 0}$

A Model for Partially Saturated Flow in Fracturec' Porous Media T.N. Narasimhan and J.S.Y. Wang 72

Simulation of Evaporation from the Uranium Mill Tailings Pile at Riverton, Wyoming T. Tokunaga and T.N. Narasimhan 75

DYNAMIX: A Computer Program for Multiple-Species Chemical Transport with Precipitation and Dissolution

T.N. Narasimhan $\quad 77$

Thermomechanical Response of Salt and Hard Rocks to Thermal Loading by Wastes Over 10 Years Old

J.S.Y. Wang, D.C. Mangold, and C.F. Tsang

\section{GEOMECHANICS 83}

Extent and Hydrologic Properties of the Disturbed Rock Zone Around Underground Openings in Basalt

L.R. Myer 85

Evaluation of Technology for Detection of Anomalies Ahead of a Tunnel Face in Basalt L.R. Myer and E.L. Majer 88

Cross-Hole Acoustic Measurements in Basalt M.S. King, L.R. Myer, and J. Rezowalli

Laboratory Hydraulic Fracturing Stress Measurements in Salt

$T$ IF. Doe and G. Bouce 95 
Elastic Wave Velocities in Quartz Monzonite at Different Levels of Water Saturation M.S. King 97

The Influence of Clay-Sized Particles on Seismic Velocity in Permafrost M.S. King $\quad 100$

Technological Advances with Water-Jet-Assisted Cutting Systems

M. Hood and L. Tuthoglu 103

A. Ventilation Study of a Longwall District in a Coal Mine M.J. McPherson $\quad 106$

\section{GEOPHYSICS $\quad 109$}

\section{SEISMOLOGY 111}

Center for Computational Seismology

T.V. McEvilly and E.L. Majer

111

Acoustic Emission and Wave Propagation Monitoring at the Spent Fuel Test-Climax

E.L. Majer and T.V. McEvilly 113

Monitoring Hydrofractures Using Seismic Techniques
E.L. Majer
118

Detailed Micrnearthquake Studies at Long Valley Caldera, California

J.E. Peterson, E.L. Majer, and T.V. McEvilly 121

Tau Estimates of Lateral Variations in Mantle $P$-Wave Velocities

D.M. Tralli 124

Source Parameters of Coalinga Aftershocks from a UC Berkeley Temporary Digital Array D.R. O'Connell and P.E. Murtha 125

Seismic Attenuation and Crustal Structure near the San Andreas Fault Zone from Reflection Profiling

J.E. Scheiner 129

The Ideal Body Method for Static Earth Displacements

D.W. Vasco 131

Detailed Seismic Reflection Studies of Laterally Heterogeneous Media: Cerso Prieto S. Blakeslee 135

CCS/DARPA Seismic Data Base Development

D. Scherrer 139

Electromagnetic Soundings in the Long Valley Caldera, California

N.E. Goldstein. H.F. Morrison. M.J. Wilt, and J. Turnross 
Geothermal Injection Monitoring with dc Resistivity Methods

M.J. Wilt, K. Pruess, G.S. Bodvarsson, and N.E. Goldstein

Recent Results of Dipole-Dipole Resistivity Monitoring at the Cerro Prieto Geothermal Field, Mexico

M.J. Wilt and N.E. Goldsiein

150

A Study of the Finite-Element Solution of a 2-1/2-Dimensional Electromagnetic Problem K.H. Lee and H.F. Morrison 153

The Accuracy of Two Line Sources for Approximating the Fields of a Large Rectangular Loop: Frequency Domain M. Mackiewicz and H.F. Morrison 155

Electromagnetic Mapping of Sedimentary Sections Beneath Basalt Flows H.F. Morrison and J. Brzeski 157

Mass Changes Found from a Precise Gravity Survey over the Cerro Prieto Geothermal Field, Mexico

R.B. Grannell and R.M. Wyman

158

Quantitative Interpretation of the Bouguer Anomaly over the Cerro Prieto Geothermal Field, Mexico

R.B. Grannell, G. Randale, H. Zhou, and J.K. Phibbs

161

GEOCHEMISTRY

Thermodynamic Properties of Silicate Materials

I.S.E. Carmichael, F.C. Bishop, B. Lange, X. Mo, M.L. Rivers,

and J.F. Stebbins

167

Thermodynamics of the System NaCl- $\mathrm{H}_{2} \mathrm{O}$ to $823 \mathrm{~K}$ with Estimates to $3900 \mathrm{~K}$ K.S. Pitzer, Yi-gui Li, J.C. Peiper, R. Phutela, and J.M. Simonson 169

Hydrothermal Alteration of Host Rocks Near Buried High-Level Radioactive Waste J.A. Apps 172

Geochemistry Research Planning for Underground Repositories

J.A. Apps 174

Effect of a Second-Order Rate of Interphase Mass Transfer on Advective/Dispersive Solute Transport in Porous Media J.S. Remer and C.L. Carnahan 177

The Galera/Dichromate Solution Interaction and the Nature of the Resulting Chromium(III) Species: An Important Reaction System in the Froth Flotation Processing of Galena D.L. Perry and L Tsao 180

Thorium Species on Basalt Surfaces

D.L Perny and L. Tsao

183 
Analyt $\cdots$ n-formance Models for Geologic Repositories Containing Radioactive Waste

T.H. Ptgh'ri. P.L. Chambré, R. Kobayashi, C.L. Kim, H.C. Lung,

Y. Takagi, "J. Williams, and S.J. Zavoshy

185

The Behavior of Americium in Aqueous Carbonate Systems

R.J. Silva

192

A Chemical Mixing Model Describing Groundwater Contamination from an Inactive Uranium Mill Tailings Pile

A.F. White, J.M. Delany, T.N. Narasimhan, and A.R. Smith

196

Investigation of Natural Analogs of Nuclear Waste Repository Conditions in Columbia River Basalt

H.A. Wollenberg, D.G. Brookins, S. Flexser, and M. Murphy

199

Thermodynamic Coupling of Transport Processes in Near-Field Regions of

Nuclear Waste Repositories

C.L. Carnahan $\quad 202$

Radon-222 in Groundwater of the Long Valley Caldera. California

H.A. Wollenberg, S. Flexser, A.R. Smith, and D.F. Mosio"

205

Rock-Fluid Reactions in Enhanced Oil Recovery

W.H. Somerton 208

High-Resolution Magic-Angle-Spinning NMR Spectroscopy of Aluminosilicate Minerals and Glasses

J.B. Murdoch, J.F. Stebbins, I.S.E. Carmichael, and A. Pines

210

\section{APPENDIXES $\quad 215$}

Appendix A: Abstracts of Journal Articles

215

Appendix B: LBL Reports, Conferences, Proceedings 226

Appendix C: Earth Sciences Division Staff and Associates

229 


\section{INTRODUCTION}

The scientists and engineers of the Earth Sciences Division conduct research on a wide variety of geologic topics relevant to the nation's energy programs. This report summarizes the activities for 1983 and illustrates the breadth and relevance of scientific investigations appropriate to a National Laboratory research organization. The Earth Sciences Division has developed unique expertise in several of the research areas reported here and utilizes the special facilities available at the Lawrence Berkeley Laboratory in specific project applications.

Although University faculty members, graduate students, and visiting scientists participate with Laboratory staff in many investigations, the scientific results could not have been realized without the technical, computational, and managerial resources of the Laboratory. For example, the comprehensive analysis of the Cerro Prieto geothermal field rests heavily on data aquired in highly technical field investigations in the areas of reservoir engineering, geology, and geophysics. The numerical modeling codes applied to that study represent a long development process in an environment of accessible computing resources. Instrumentation for borehole geophysical measurements and for deep electromagnetic surveys must be fabricated by a competent and professional staff. Modern computational tools and data base management systems. including real-time processing systems, crucial for effective geoscience investigations, can be supporied in the Laboratory environment. In addition, interlaboratory research cooperation, joining of unique strengths, provides an unmatched national resource that can be brought to bear on the most complex problems.

This annual report presents the research activities conducted within the principal disciplines of the Earth Sciences Division: Reservoir Engineering and Hydrogeology, Geomechanics, Geophysics, and Geochemistry. We are proud to be able to bring you this summary of research highlights from the Division. and we hope in this report to convey a sense of enthusiasm and excitement for coming discoveries. 


\section{HYDROLOGIC TESTING IN THE KLAMATH FALLS, OREGON, GEOTHERMAL SYSTEM}

\section{S.M. Benson and R.D. Solbau}

The city of Klamath Falls, in southern Oregon, is underlain by a shallow, near-boiling-temperature geothermal resource. Although the city is located on the edge of the Cascade Range, the geothermal system is characteristic of the Basin and Range Province, which lies to the east. Hot water upwells along a steeply dipping normal fault and spreads laterally into permeable rock units near the surface. The subsurface lithology is extremely complex; rock units are faulted, fractured, and thermally altered, and sedimentary rocks of lacustrine and pyroclastic origin are interspersed with basaltic flows.

The geothermal rescurce has been used since the 1920 s for space heating, domestic hot water, and small industrial applications. At present, over 400 wells are being used. In 1979, the city of Klamath Falls established a Heating District, drilled several wells, and constructed a piping network through the city center in order to provide hot water for heating 14 buildings. Concern over the long-term effects of pumping hot water from these wells resulted in a scientific program to assess the resource potential. The assessment program, coordinated by the USGS, consisted of geochemical studies, tracer tests, extensive hydrologic testing, and long-term monitoringThe hydrologic tests will be discussed here.

The hydrologic testing included a multiwcll pressure interference test, downhoie teruperature monitoring, an injection test, and injection well logging. The tests began in June 1983 and were completed by September 1983.

\section{INTERFERENCE TESTIN?}

In order to evaluate the hydrologic parameters of the geothermal aquifer and determine the impact of pumping and reinjection on the water levels of the many wells alreatly in use, a 9-week interference test was conducted. This included I week of background monitoring 3 weeks of pumping a well at a rate of $720 \mathrm{gpm}, 4$ weeks of pumping at $690 \mathrm{gpm}$ with concurrent reinjection, and 1 week of recovery monitorins. During this time, 12 wells within a 1/2-mile radius of the pumped well $y=r e$ monitored for pressure and temperature changes with a highly sensitive downhole pressure and temperature measurement system designed and fabricated at Lawrence Berkeley Laboratory (Solbau et al., t981). The data from each of the 12 wells were transmitted to one of two central locauons for processing and recording. This allowed synchronous data collection and digital recording, which enhanced the data quality.

Data from two of the observation wells are showr: in Figs. 1 and 2. The Head well (Fig. 1) was located approximately $320 \mathrm{~m}$ from the pumped well and $640 \mathrm{~m}$ from the injection well. During the first 3 'weeks of the test, when no reinjection was taking place, the Head well drew down approximately $1.2 \mathrm{~m}$. Once reinjection began, the water rose to within $0.3 \mathrm{~m}$ of its pretest level. When both the injection well and the production well were shut in, the water quickly rose to its pretest level. Similar behavior is seen in the Page well (Fig. 2); since it is closer to the injection well, the water level rose above ile pretest level once injection began.

Because of the highly heterogeneous character of the reservoir, data were analyzed using a doubleporosity model (Bensori, 1983). Figure 3 shows one of the type curve matches obtained. The shape of the curve is characteristic of the pressure transients in a double-porosity medium in which the flow between the matrix and fractures may be described by a pseudo-steady-state model. On the basis of this type curve match, we calculate a permeabilitythickness of $1.4 \times 10^{6}$ mdarcy-ft and a storaivity of $7.7 \times 10^{-3} \mathrm{ft} / \mathrm{psi}$. It is also possible to estimate the parameters $\lambda$ and $\omega$, which quantify the distribution of permeatility and storage capacity between the fractures and the matrix. However, the values may not be unique, as was deteimined from the data.

Measurement of downhole temperatures in the observation wells indic ted nn systematic variations.

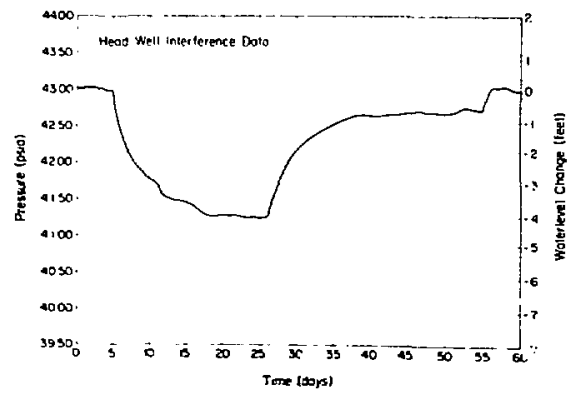

Figure 1. Interference data from the Head well. [X.BL $8311-4014 Y_{1}$ 


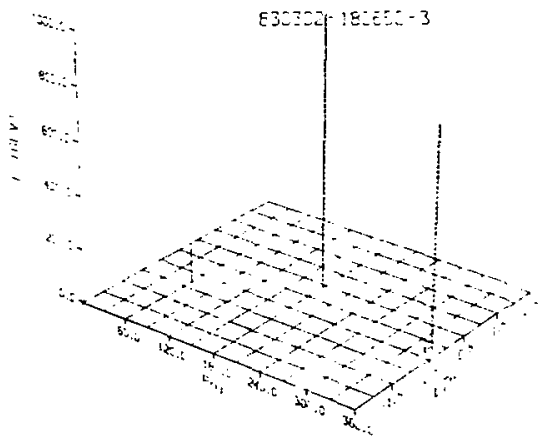

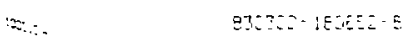

4

$\because \cdots$

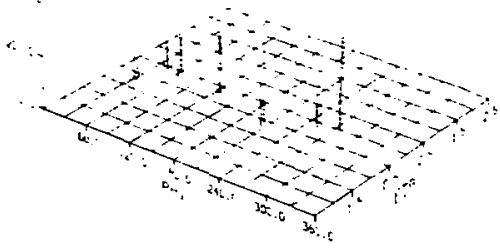

Figure 1. Caloriaeter plots of events with $P_{t}=1000 \mathrm{GeV}$, 


\section{SUMMARY}

Hydrologic tests conducted in the Klamath Falls hydrothermal resource indicate that the fracture system is highly permeable and that significant quantities of hot water are stored in the less-permeable matrix blocks. Overall, the system behaves in a hydrologically uniform manner. Our evaluation of the test data enables us to predict with confidence the impact of resource utilization. By carefully considering the impact of one user upon another and weighing the drawbacks and benefits of alternative development schemes, it is possible to optimize utilization of the resource.

Regardless of the resource development scheme chosen, it is now clear that reinjection of pumped fluid will minimize drawdown associated with pumping and prevent long-term depletion of the resource. However, reinjection sites should be chosen to minirnize thermal degradation of the reser-

\section{REVIEW OF STUDIES CARRIED OUT ON THE CERRO PRIETO GEOTHERMAL FIELD, MEXICO}

\author{
M.J. Lippmann, N.E. Goldstein, S.E. Halfman, and \\ P.A. Witherspoon
}

The Cerro Prieto geothermal field is located in the Mexicali Valley, Baja .California, Mexico, about $30 \mathrm{~km}$ south of the U.S. border (Fig. 1). It has been in production since 1973, when it became the first liquid-dominated geothermal system in North America from which significant electrical power was produced.

The general geologic similarity between Cerro Prieto and the geothermal fields of the neighhoring Imperial Valley (southern California) and the experience gained by the Comision Federal de Electricidad of Mexico (CFE) in locating and developing the resource were the main factors that led to the signing, in 1977, of a 5-year agreement between CFE and the U.S. Energy Research and Development Administration, now the U.S. Department of Energy (DOE), to conduct a cooperative study of Cerro Prieto (Witherspoon et al., 1978). The Lawrence Berkeley Laboratory coordinated U.S. technical activities carried out under the agreement. Because of the suocess of this couperative program, discus- voir and interference with the natural hydrodynamic system. Reinjection wells located on the periphery of the geothermal system will provide the required pressure support and ninirnize thermal degradation of the resource.

\section{RFFERETrCES}

Benson, S.M., 1983. Interpretation of interference data from the Klamath Falls Geothermal Resource. In Proceedings, 9th Annual Workshop on Geothermal Engineering, Stanford University, Stanford, California, December 13-15. 1983.

Solbau, R., Goranson, C.B., and Benson, S.M., 1981. Recently developed well test instrumentation for low-to-moderate temperature hydrothermal reservoirs. Lawrence Berkeley Laboratory, LBL-13260.

sions are being held to sign a new DOE/CFE agreement to study Cerro Prieto and other geothermal areas in Mexico.

Exploration for geothermal energy in the Сетro Prieto area began in the late 1950 s, and the first deep exploration wells were drilled in 1960/61 over the thermal anomaly. By early 1983, about 120 deep wells (up to $3550 \mathrm{~m}$ in depth) had been drilled, delineating a good portion of the geothermal reservoir

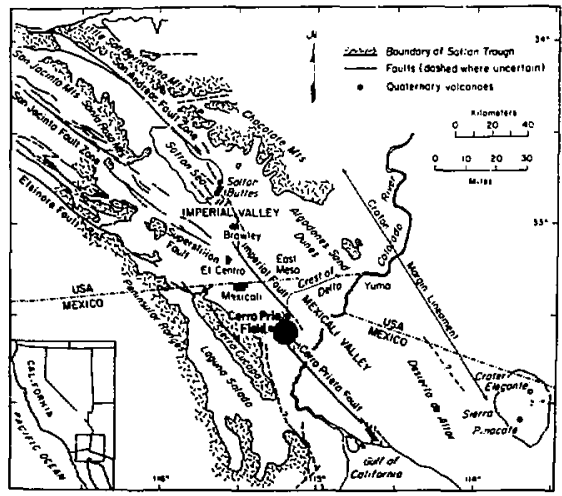

Fitsure 1. Regional geology of the Salton Trough and location of the Cerro Prieto field. [XBL 801-6718A] 
(Fig. 2). Today, $180 \mathrm{MW}$ of electricity is being generated; CFE, which manages and operates Cerro Prieto, is building two new power plants that will increase the output to $620 \mathrm{MW}_{e}$ by mid-I 985 .

Over the years, a vast amount of data on the subsurface of the area and on the characteristics of the producing wells has been gathered, making Cerro Prieto one of the more thoroughly cocumented and best understood geothermal systems.

The exploration effort that led first to the discovery of the field, then to the delineation of the resource, and finally to the definition of the subsurface fluid and heat circulation was reviewed during this year (Lippmann et al., 1983). The studies that resulted in the identification of the heat and mass sources at Cerro Prieto, the fluid flow paths, and the phenomena occurring in the field in its natural state and under exploilation were also summarized (Lippmann, 1983).

\section{EXPLORATION AND DEVELOPMENT STUDIES}

The Cerro Prieto case study has demonstrated the value of a multidisciplinary effort for exploring and developing a geothermal field.

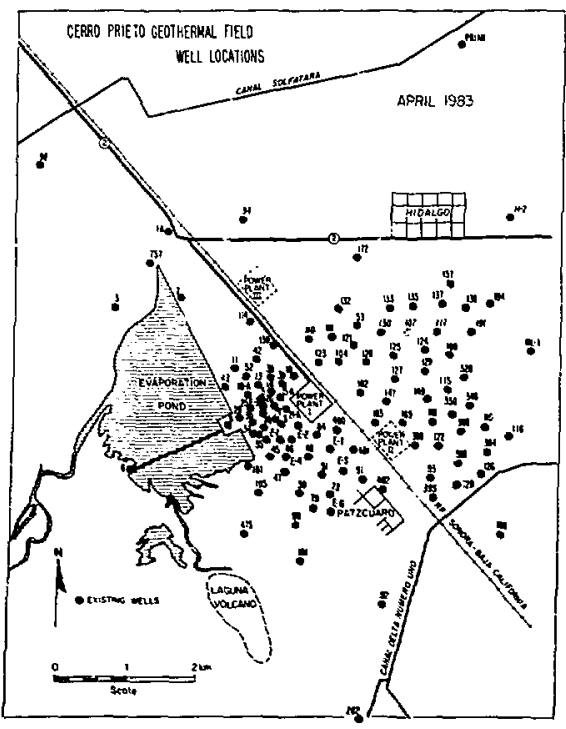

Fine 2. Location of geothermal wells in the Cerro Prieto field. [XBL 835-1804A]
There was no problem in recognizing the geothermal potential of the Cerro Prieto area because of the many obvious surface manifestations. However, the delineation of the geothermal reservoir at depth was not so straightforward. The first wells drilled near the abundant surface rianifestations produced only fluids of relatively low enthalpy. Later it was determined that these zones of high heat loss corresponded to discharge areas. where faults and fractures allowed thermal fluids io leak to the surface, and not to the main geothermal reservoir.

The early gravity and ieismic refraction surveys provided important information on the general structure of the area. Unaware of the existence of a higher-density zone of hydrothermally altered sediments capping the geothermal reservoir, CFE interpreted the gravity data as indicating the existence of a basement horst in the western part of the field and hypothesized that the bounding faults were controlling the upward flow of thermal fluids. Attempting to penetrate the sedimentary column to reach the "basement horst," CFE discovered the $\alpha$ seothermal reservoir (in well M-5). The continuation of the geothernal aquifer (actually the $\beta$ reservoir) east of the original well field was later confirmed by a deep exploration well (M-53).

The experience at Cerro Prieto has shown the importance of chemical ratios-and geothermometers in general-in establishing the subsurface temperatures and fluid flow patterns. Fluid chemical and isotopic compositions have also been helpful in determining the origin of the fluids, the fluidproduction mechanisms, and the production-induced effects on the reservoir.

Mineralogic and petrographic studies of well cultings and cores have established that the hydrothermal alteration of the sediments is due to temperature-dependent rock-fjuid interactions. The mineral zonation and isotopic ratios in the rocks helped to define the shape of the reservoir, the preproduction fluid flow patterns in the system, and its thermal history. The appearance of key hydrothermal minerals reflecting high su'surface temperatures was important in the design on new wells. Interpretation of temperature, geophysical, and lithologic well logs allowed CFE to improve the completion of Cerro Prieto geothermal wells. The analyses of these logs were also very useful in the development of a hydrogeologic model of the geothermal system. Well tests and reservoir modeling studies determined reservoir parameters and helped to define the role of certain geologic features in the transport and recharge of heat and mass in the geothermal system. 
Resistivity, gravity, and magnetic field surveys were used extensively to help define ancmalies in the region. Although these data permitted simple initial interpretations, it was generally found that they contained flaws. Experience at Cerro Prieto showed that the analyses of electrical resistivity (dipole-dipole and magnetotelluric) data were useful in defining the (resistivity) structure of the field and the location of faults and fronts of waters of different propertiss. These studies indicated that the reservoir region had higher resistivity than the surroundings because of the hydrothermal alteration of the shales in the reseryoir area. The low-resistivity zone associated with the field was shown to be due to highly conductive near-surface sediments, particularly in the discharge areas.

Self-potential surveys were useful for identifying a permeable zone that allowed the upflow of geothermal fluids. Gravimetry seems better than magnetometry to define the zone of hydrothermal alteration/metamorphism associated with the geothermal field. Cuttings and cores have shown magnetite and only sparse pyrrhotite, which explains the lack of a magnetic anomaly coincident with the reservoirs.

The occurrence of chaotic seismic reflections coincident with the hydrothermal alteration zone suggests that seismic reflection can be a useful exploration method. However, other geophysical data will be necessary to eliminate alternate sources of reflection-poor zones.

Self-potential, dc resistivity, and magnetotelluric surveys were useful for locating the reservoir regions, but the full significance of these data was not appi $2-$ ciated until they could be compared to seismic reflection, gravity, and geophysical and geologic well logging results. After the first wells had been completed, fluid geochemistry', mineralogy of cuttings and cores, geophysical well logs, and reservoir engineering studies played important roles in understanding the nature of the geothermal system, such as origin of the geofuids, fluid circulation, dilution, and location of the heat source.

\section{THE FIELD IN ITS NATURAL STATE}

The list below summarizes the present model for the natural (pre-exploitation) circulation of geothermal fluids in Cerro Prieto.

1. Mfixtures of Colorado River water and sea water penetrate d:eply into the sedimentary fill of the Mexicali Valley.

2. These fluids are heated by a thermal source consisting of diabase dikes and gabbroic cummulates presumed to have intrudtd the eastern part of the field $10^{3}-10^{4}$ years ago. Magmatic injection at i0-12 km depth may be occurring at present.

3. In response to pressure gradients and buoyancy effects, the hot fluids move westward through a sandy unit ( $\beta$ Reservoir) overlain by a thick shaly layer.

4. The geothermal fluids hydrothermally alter the sedimentary rocks, decreasing their primary porosity. In sandstones, some of this effect is offset by the removal by solution of unstable grains and cements (Lyons and van de Kamp, 1980).

5. During circulation, the composition of the fluids is extensively altered by high-temperature reactions with reservoir rocks.

6. As they move westward toward the present production area, the geothermal fluids tend to flow upward through faults and permeable gaps in the overlying shaly layers. Because of pressure reduction during the ascent, some boiling and mineral deposition occurs.

7. In the general area of well M-10, where a major sandy gap interrupts the lateral continuity of the shaly materials, some of the geothermal fluids mix with colder waters at shallower depths, causing secondary mineral precipitation and porosity reduction. However, most of the hot fluids move into the $\alpha$ and $\beta$ reservoirs in the western part of Cerro Prieto.

8. Along the western edge of the field, colder groundwaters are in lateral contact and mix with the geothermal fluids; precipitation of minerals occurs.

9. Some of the hot fluids, in the western areas of the field ascend to shallower depths through fault zones, eventually reaching ground level. This is evidenced by the abundant surface manifestations observed along the western edges of the producing area.

\section{THE RESPONSE OF THE FIELD TO EXPLOITATION}

A general decrease of pressure and temperature has been observed in the reservoir since fluid production began in 1973. However, because of the open nature of the reservoir, only localized boiling has occurred near the wells. An extensive two-phase zone does not develop, as there is ample recharge of colder, less saline waters from shallower layers and from the western edges. The near-well boiling causes enthalpy excesses in the produced fluids that decrease or disappear with time as the boiling front stabilizes. The boiling results in silica deficiencies in the produced fluids and deposition of quartz near the wells (Grant et al., 1984). Other changes in the 
characteristics of the produced fluids and interference effects between wells have $a^{\prime}$ so been detected (Truesdell et al., 1984).

The usefulness of fluid geochemistry and reservoir engineering studies, as well as electrical resistivity, passive seismic, precision gravi.y, and ground-surface deformation surveys, for monitoring the behavior of the Cerro Prieto geothermal field under production has been discussed by Lippmann et al. (1983).

\section{SUMMARY}

Great advances have been made toward understanding Cerro Prieto. We hope that many of the studies initiated under the 1977-1982 DOE/CFE agreement will continue and add important new information as the field is expanded. For example, more needs to be known about the hydraulic properties of the sandy and shaly layers; the hydrogeologic model should be updated as new results and field data become available; and the general monitoring of the behavior of the field should continue, especially as new areas come under production.

\section{REFERENCES}

Grant, M.A., Truesdell, A.H., and Mañón, M., A., 1984. Production induced boiling and cold

\section{DEPOSITIONAL ENVIRONMENTS IN THE CERRO PRIETO GEOTHERMAL FIELD, MEXICO}

\section{S.E. Halfman, M.J. Lippmann, and J.A. Gilreath*}

Mainly on the basis of dipmeter log data, Halfman et al. (1984a) have modified and updated their geologic model of the Cerro Prieto field. The depositional environment of the geologic units controlling the subsurface flow of geothermal fluids has been established, and new faults and uplifts (conternporaneous or postdepositional) have been identified.

Schlumberer Offishore Services, New Oteans, Louisinga 70112. water entry into the Cerro Prieto geotherma] reservoir indicated by chemical and physical measurements. Geothermics, v. 13, no. $1 / 2$, p. 117-140.

Lippmann, M.J., 1983. Overview of Cerro Prieto studies. Geothermics, v. 12, no. 4, p. 265-289.

Lippmann, M.J., Goldstein, N.E., Halfman, S.E., and Witherspoon, P.A., 1983. Exploration and development of the Cerro Prieto geothermal field. Presented at the 58th Annual Technical Conference and Exhibition, Society of Petroleum Engineers of AIME, San Francisco, California, October 5-8, SPE-12098 (LBL-15594).

Lyons, D.J., and van de Kamp, P.C., 1980. Subsurface geological and geophysical study of the Cerro Prieto geothermal field, Baja California, Mexico. Lawrence Berkeley Laboratory, LBL$10540,95 \mathrm{p}$.

Truesdell, A.H., Nehring, N.L., Thompson, J.M., Janik, CJ., and Coplen, T.B., 1984. A review of progress in understanding the fluid geochemistry of the Cerro Prieto geothermal system. Geothermics, v. 13, no. 1/2, p. 65-74.

Witherspoon, P.A., Alonso, H., Lippmann, M.J., Mañón, M., A., and Wollenberg, H.A., 1978. Mexican-American cooperative program at the Cerro Prieto geothermal field. Lawrence Berkeley Laboratory, LBL-7095, 33 p.

\section{GEOLOGIC SETTING AND RECENT HISTORY OF THE AREA}

The Mexicali Valley is part of the Salton Trough, an actively developing structural depression that resulted from tectonic activity that has sreated a series of spreading centers and transform faults that link the East Pacific Rise to the San Andreas fault system. The Cerro Prieto field is associated with one of these spreading centers, where the crust is being pulled apart by right-lateral stike-slip movement along the Cerro Prieto and Imperial Faults (Lomnitz et al, 1970; Elders et al., 1972).

During the early Pliocene (about $5 \mathrm{Ma}$ b.p.), the oresent configuration of the Gulf of California began to develop by major crustal extension, splitting Baja Califormia from the Mexican mainland (Saunders et al., 1982). At that time, the waters of the Gulf extended northward to about the present Salton Sea area. The propagation of he Colorado River delta into the Cer.. Prieto area began in mid- to late Pliocene (Ingle, 1980). 
By late Pliocene, the southwesterly advance of the delta was essentially complete, resulting in the conversion of the Salton basin to a nonmarine depositional basin (Lyons and van de Kamp, 1980). By mid-Pleistocene time, the marine connection between the Gulf of California to the south and the Imperial Valley to the north was severed (Ingle, 1980).

\section{GEOLOGIC AND HYDROGEOLOGIC MODELS OF THE CERRO PRIETO}

Halfman et al. (1984a) have developed five geologic cross sections for Cerro Prieto (e.g., Figs. 1 and 2) showing the distribution of sandstone, sandyshale, and shale lithofacies. After superimposing temperature profiles and well production intervals on these cross sections, they were able to identify two geologic units that largely controlled the subsurface flow of the geothermal fluids: Shale Unit $O$ and Sand Unit $Z$. Shale Unit $O$ is a thick, relatively impermeable, low-porosity body that locally forms a cap rock for the geothermal reservoir. This unit is classified mainly as a shale lithofacies group. Sand Unit $Z$, underlying Shale Unit $O$, contains thick, permeable, high-porosity sandstone beds that allow fluid circulation; it is the main stratigraphic unit of the geothermal reservoir.

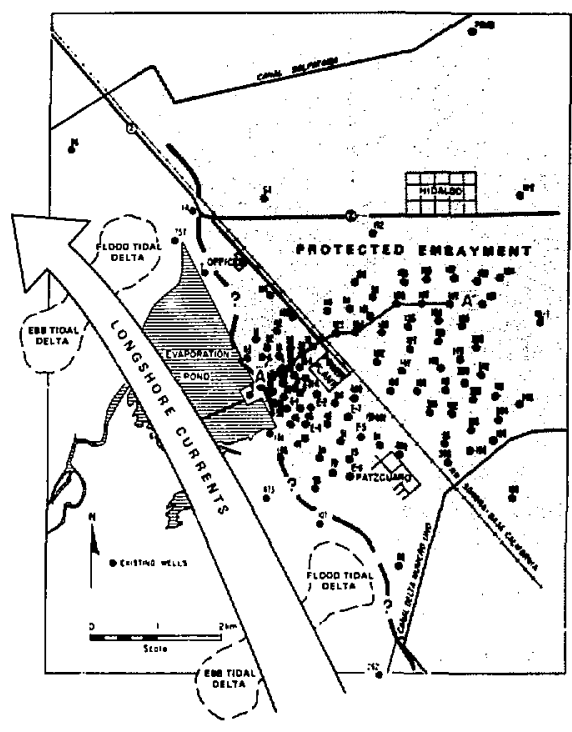

Figure 1. Schematic paleoenvironmental map for the deeper part of the Cerro Prieto section. Location of wells and cross section A-A'. [XBL 835-1804C,

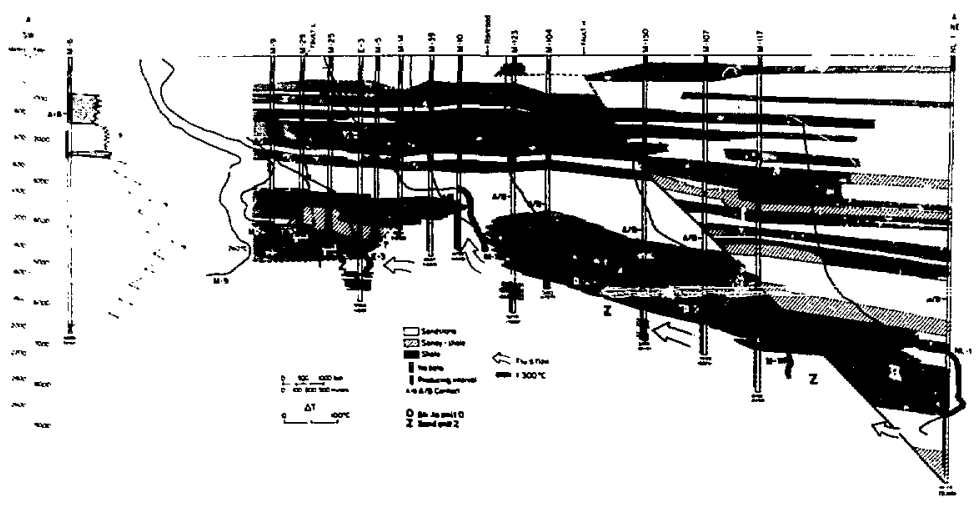

Figure 2. Lithofacies cross section $A-A^{\prime}$, showing well locations, lithofacies groups, faults, temperature profiles, producing intervals, A/B contacts, Shale Unit $O$, Sand Unit $Z$, and arrows indicating direction of fluid flow. On the temperature profiles, the points corresponding to $300^{\circ} \mathrm{C}$ are placed under the location of the respective wells. The parts of the temperature profiles shown by heavy lines indicate temperatures of $300^{\circ} \mathrm{C}$ or greater. [XBL 828-10945A] 
The hydrogeologic model discussed by Halfman et al. (1984a) shows that under natural conditions the geothermal fluids enter the Cerro Prieto field from the east at depths greater than $3000 \mathrm{~m}$ through Sand Unit $Z$. The fluids move westward through this unit, rising to shallower depths through fault zones and sandy gaps in overlying Shale Unit O. In the thick sandstones along the western margin of the producing field (west of well M-9), the geothermal fluids either mix with cold groundwaters or discharge to the surface as hot springs, mud volcanoes, and fumaroles.

\section{DEPOSITIONAL ENVIRONMENT OF CERRO PRIETO RESER VOIR ROCKS}

Critical to understanding the nature and characteristics of the geologic units governing to a large extent the flow of geoluermal flujds in the reservoir, in particular Sand Unit $Z$ and Shale Unit $O$, is an understanding of the depositional environment of these rock units. This environment controls largely the overall lithology of the units and the continuity, thickness, and intercalation of their sandstone and shale beds, all of which determine the hydraulic properties of the units.

Most researchers have first attempted to int $r$ pret the depositional environment of the unusually thick sandstones $(>900 \mathrm{~m}$ ) penetrated by wells $\mathrm{M}$ 96, M-3, M-6, and S-262 driled along the western margin of the field (Mañon) et al., 1977; Prian, 1978; and Lyons and van de Kamp, 1980).

A careful analysis of available dipmeter logs from 26 wells showed that the depositional environment of the thick sandstones, Shale Unit $O$, and Sand Unit $Z$ was once part of a coastal system (Halfman et al., 1984b). Along a west-to-east line, one would find, in succession, longshore current, shoreline, and prctected embayment deposits (Fig. 1). The significant sandstone thicknesses penetrated in the western part of the fieid are associated with northward-flowing longshore currents in an actively subsiding basin. The subsidence of this basin probably continues today, as Cerro Prieto is located on an active spreading center, menticned earlier (Lomnitz et al., 1970; Elders et al., 1972). Lyons and van de Kamp (1980) have shown from petrographic studies that the thick sandstones were derived from Colorado River sediments. Therefore, longshore currents must have been carrying sediments northward to the Cerro Prieto area from an ancient Colorado River delta located to the south of the field.

Interpretation of the dipmeter logs shows that at Cerro Prieto many of the deposits asseciated with the longshore currents were formed in flood-and-ebb tidal deltas. The dipmeter patterns corresponding to those deltaic deposits are sinilar to the distributary front patterns described by Gilreath and Stephens (1975). The dip patterns characteristically show high-angle dips decreasing to lower ones (about a $10-20^{\circ}$ span) over a depth interval of about 15-30 m. A good example of an ebb-tidal deltaic deposit is shown between 1143 and $1 ! 5 n \mathrm{~m}$ in the dipmeter $\log$ for well M-96 (Fig. 3). The long axis of this deposit is oriented in a west-northwest direction. The general direction of the longshore currents is to the north, as evidenced by the northward dip patterns betw en 1128 and $1143 \mathrm{~m}$ and between 1173 and $1211 \mathrm{~m}$ (Fig. 3). Also shown in this figure are tidal flat deposits between 1158 and $1173 \mathrm{~m}$. Other types of dipmeter patterns for these thick sandstones indicate shallow water (Gilreath et al, 1969) and river deposits (Schlumberger Limited, 1981) associated with a longshore current environment.

Once the depositional environment for the thick sandistones found in the western region of the field was established, it became easier to identify the environment of deposition of the sediments of Shale Unit $O$. The dipmeter $\log$ for well M-1 50 from 1524 to $1859 \mathrm{~m}$ illustrates some of the typical patterns for Shale Unit $O$ (Fig. 4). These dips show a repeating pattern oi high- to lower-angle dips, indicative of foreset bedding resulting from southwest- to northeast-flowing currents. The very orderly pattern shows that little if any reworking of the sediments occurred. To preserve the foreset beds, rapid deposition and burial must have occurred. The gamma-ray log for Shale Unit $O$ indicates typical thin

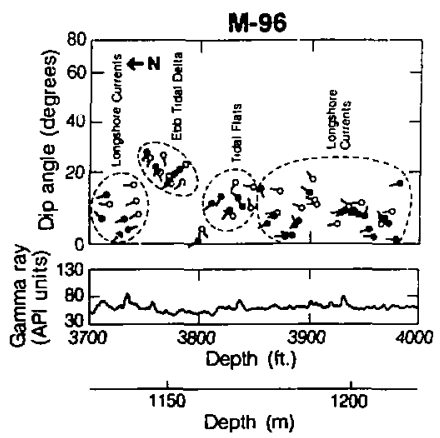

Figure 3. Dipmeter log for well M-96, representing an ebb-tidal delta (1143-1150 m), tidal flat (1158-1173 m), and longshore current (1128-1143 $\mathrm{m}$ and 1173-1212 m) deposits. [XBL 842-9592] 

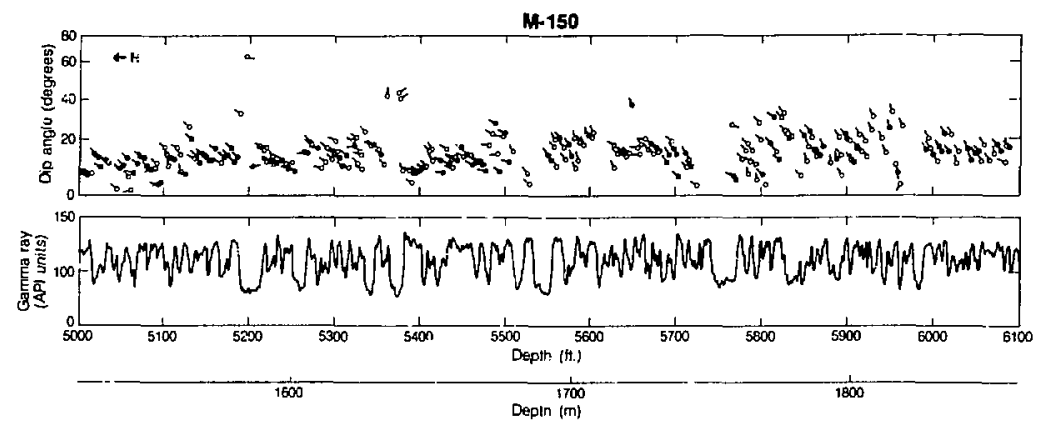

Figure 4. Dipmeter log for well M-150, representing foreset beds from 1524 to $1859 \mathrm{~m}$. |XBL 842 9595]

interbedded sandstone and shale layers. Considering that this unit was deposited in an area between the longshore currents to the west and the mainland to the east and that its thin interbedded sandstone and shale layers were laid down in a very quiet and undisturbed environment, it can be inferred that the sediments were probably deposited in a protected embayment, as shown in Fig. 1.

Sand Unit $\mathbf{Z}$ is also composed mostly of foreset beds deposited in a protected embayment. However, the sandstone and shale beds of the upper portion of Sand Unit $Z$ are generally much thicker than the beds of the lower portion of Shale Unit $O$. The source of sediments for both units was the Coiorado River (Lyons and van de Kamp, 1980). Moreover, the dipmeter fatterns of both units indicate that the energy of the currents transporting the sediments into the protected embayment must have been similar. Therefore, the greater thickness of the sandstone and shale beds may be due to alternating high and low energy conditions of the Coloraso River over longer periods of time and/or to erosion by the Colorado River through thicker sandstone and shale source rocks.

By establishing the characteristics of the coastal environment of deposition of the sedimentary rocks forming the Cerro Prieto geothermal reservoir and its (discontinuous or local) cap rock, it is easy to explain the sandier nature and eventual disappearance of Shale Unit $O$ in the western part of the field. The sandier western portion of Shale Unit $O$ (from well $M-10$ to $M-9$ ) represents the beginning of a transition from protected embayment deposits (to the east) to longshore current deposits (to the west). The sandy-shale group within Shale Unit $O$ (between wells M-5 and M-29) is permeable enough to allow somi geothermal fluids to flow westward through it.

The thick and highly permeable depnsits associated with longshore currents bounding the reservoir to the west lets westward-moving hot fluids mix with (colder) groundwaters, thus limiting the horizontal extent of the geothermal reservoir. Therefore, new wells should he drilled east to these thick sandy deposits, preferably south and southwest of NL-1, which is near the geothermal heat source.

\section{REFERENCES}

Elders, W.A., Rex, R.W., Meidav, T., Robinson, P.T., and Biehler, S., 1972. Crustal spreading in southern California. Science, v. 178, p. 15-24.

Gilreath, J.A., and Stephens, R.W., 1975. Interpretation of $\log$ responses in a deltaic environment. American Association of Petroleum Geologists Marine Geology Workshop, Dallas, Texas, April \$975, 31 p., C-11987.

Gilrelth, J.A., Healy, J.S., and Yelverton, J.N., 1969. L fopositional environments defined by dipmeter inferpretation. Transactions-Gulf Coast Association of Geological Studies, v. XIX, p. 1 ill-111.

Halfman. S.E., Lippmann, M.J., Zelwer, R.,, and Howaid, J.H., 1984a. A geological interpretation of the geothermal fluid movement in the Cerro grieto Field, Baja California. Mexico. American Association of Petroleum Geologists Bulletin, v. 68, p. 18-30.

Halfman, S.E., Lippmann, M.S., and Gilreath, J.A., 1984b. Cerro Prieto case history: Use of wireline logs to characterize a geothermal reservoir. 
Presented at 1984 Califormia Regional Meeting of the Society of Petroleum Engineers, Long Beach, California, April 11-13, 1984, SPE-12739 (LBL-17374).

Ingle, J.C., 1980. Microfaunal evidence of age and depositional environments of the Cerro Prieto section (Plio-Pleistocene), Baja California, Mexico. Lawrence Berkeley Laboratory, LBL-13897.

Lomnitz, C., Mooser, F., Allen, C.R., Brune, J.N., and Thatcher, W, 1970. Seismicity and tectonics of the northern Gulf of California region, Mexico-Preliminary results. Geofisica Internacional, v. 10, p. 37-48.

Ljons, D.J., and van de Kamp, P.C., 1980. Subsurface geological and geophysical study of the Cerro Prieto geothermal field, Baja California, Mexico. Lawrence Berkeley Laboratory, LBL10540.

Mañón, A., Mazor, E., Jiménez, M., Sánchez, A.,

\section{THE KRAFLA GEOTHERMAL FIELD, ICELAND: A MODELING CASE STUDY}

\author{
G.S. Bodvarsson, K. Pruess, V. Stefansson, \\ and E.T. Eliasson ${ }^{\dagger}$
}

Lawrence Berkeley Laboratory, in cooperation with the State Electric Power Works of lceland (SEPW) and the Icelandic National Energy Authority (NEA), conducted a comprehensive modeling study of the Krafla geothermal field in Iceland. The study consisted of four tasks: analyzing the well-test data, modeling the reservoir system in its natural (unexploited) state, determining the generating capacity of the different reservoir regions, and modeling the well performance on the basis of different exploitation schemes.

For detailed modeling of a geothermal system, one must know or estimate many parameters that characterize the system. One of the mosi important parameters is the transmissivity, $k H$, of the reservoir, which represents the relative ease of fluid movement within the reservoir. The existing well-test data from Krafla wells were analyzed to yield the transmissivity distribution in the reservoir. A modeling study of the natural state of Krafla reservoir was undertaken,

-Icelnndic National Energy Authority, Reykjavik, Iceland.

tstate Eectric Power Works of Iceiand, Reykjavik, Iceland.
Fausto, J., and Zenizo, C., 1977. Extensive geochemical studies in the geothermal field of Cerro Prieto, Mexico. Lawrence Berkeley Laboratory, LBL-7019.

Prian C., R., 1978. Lithologic correlations of the Cerro Prieto wells based on well log interprezation. In Proceedings, First Symposium on the Cerro Prieto Geothermal Field, Baja California, Mexico, September 20-22, 1978 . Lawrence Berkeley Laboratory, LBL-7098, p. 49-56.

Saunders, A.D., Fornari, D.J., and Morrison, M.S., 1982. The composition and emplacement of basaltic magmas produced during the development of continental-margin basis: The Gulf of California, Mexico. Journal of the Geological Society of London, v. 139, p. 335-346.

Schlumberger Limited, 1981. Schlumberger Dipmeter Interpretation Fundamentals. INew York, Schlumberger Limited, p, 61.

because this can provide important constraints on reservoir parameters.

The final two tasks deal with the generating capacity of the reservoir and the well performance. We develop a simple lumped-parameter model for approximate estimation of the generating capacity of the field, which allows for natural recharge and reinjection. Numerical methods are then employed in a two-dimensional areal simulation of the Krafla system. Finally, a quasi-three-dimensional model is developed in which all wells are represented individually. The model achieves an approximate match of past production rates and enthalpies of the wells. It is then used to predict future well behavior (flow rates and fluid enthalpy) and overall reservoir depletion under various reservoir management schemes.

The present article gives a rather brief summary of the modeling work; a more complete description is given in Bodvarsson et al. (1983a).

\section{THE KRAFLA GEOTHERMAL FIELD}

The Krafla geothermal field is located in the neovolcanic zone in northeastern Iceland. The zone is characterized by fissure swarms and central volcanoes. The Krafla field is located in a caldera ( 8 $\times 10 \mathrm{~km}$ ) with a large central volcano, named Krafla. The field has been under development for the past decade. At present, 23 wells have been drilled at the Krafla field (Fig. 1). In the "old" wellfield (west of the Hveragil gully), the wells have encountered two major reservoirs (Fig. 2); the upper reservoir (200-1000 $\mathrm{m}$ depth) contains single-phase 


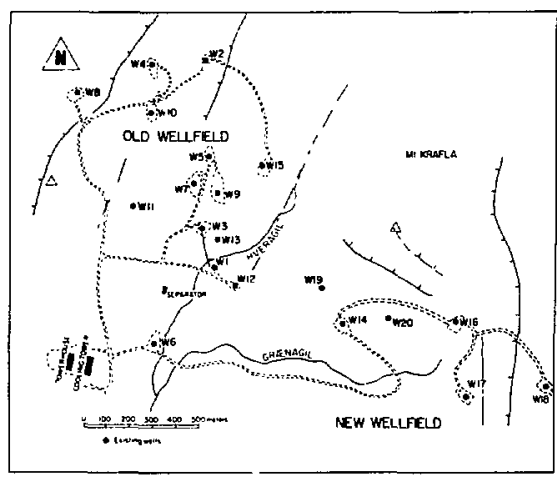

Figure 1. Well locations. Wells 21-23 (not shown) are located approximately $2 \mathrm{~km}$ south of the power plant. [XBL 812-2598A]

liquid water with a mean temperature of $205^{\circ} \mathrm{C}$. The deeper reservoir is two phase, with temperatures and pressures following the boiling curve with depth. The two reservoirs are separated by a thin $(200-500 \mathrm{~m})$ low-permeability layer, but seem to be connected near the Hveragil gully. In the new wellfield (east of Hveragil; wells 14 and i6-20), the twophase liquid-dominated reservoir extends close to the ground surface.

The production characteristics of the various reservoir zones at Krafla are vastly different. The low temperature of the fluids in the upper reservoir in the "old" wellfield makes it unfavorable for the production of high-pressure steam. Consequently, in most of the wells in the old wellfield, the upper zone is cased off. In the lower zone, the temperature of

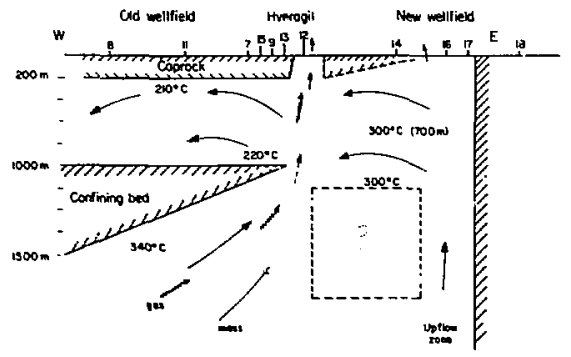

Fizare 2. Conceptual model of the Krafla field. XBL 837-1923] the reservoir fluids is high $\left(300-400^{\circ} \mathrm{C}\right)$, but silica scaling and iron deposits hamper effective utilization of the fluids. In the new wellfield, the chemical composition of the reservoir fluids is more favorable, and scaling problems are minimal. A detailed description of the Krafla system is given by Stefansson (1981).

\section{WELL-TEST DATA ANALYSIS}

Most of the Krafla well-test data have been obtained from injection tests performed following well completion. The purpose of the injection test is twofold: (1) to attempt to stimulate the well, i.e., increase the water losses, and (2) to obtain data that can be analyzed to yield the transmissivity of the formation. The injection-test data are compiicated by well-bore storage effects, nonisothermal and twophase effects, and the fractured nature of the Krafla reservoir system.

The injection-test data from other Krafla wells were analyzed on the basis of some theoretical work. The results show that the Krafla reservoir has a low average transmissivity ( 2.0 darcy-m), with values for most wells falling within the range 1.5-2.5 darcy-m. The data also give a high storativity value, which probably reflects the two-phase condition of the lower reservoir. A detailed description of this work is given by Bodvarsson et al. (1983b).

\section{MODELING OF THE NATURAL STATE OF THE KRAFLA FIELD}

Using the conceptual model of the Krafla rese: voirs (Fig. 2), we developed a two-dimensional natural-state model for the Krafla field. The natural-state modeling quantifies natural mass and heat flows in the reservoir and establishes mass and heat recharge to the system (boundary conditions), providing valuable constraints for modeling field behavior under exploitation. A vertical crosssectional model was considered adequate, since the equipotential lines in the upper reservoir indicate that the main fluid flow is in the E-W direction. Several models were developed using the numerical simulator MULKOM (Pruess, 1983) and a trial-anderror process.

The best model obtained agrees very well with all field data from the Krafla field. The calculated temperature profiles in both wellfields generally agree with the field data to within a few degrees. Similarly, the pressure profiles in the old and new wellfields agree to within 1-2 bars at all depths. Steam losses predicted by the model for the surface manifestations in Hveragil and the new wellfield agree 
very well with estimated values (Armannsson and Gislason, personal communication, 1982).

The primary conclusions from the natural-state modeling are as follows. Fluids from an upflow zone recharge the reservoir in the new wellfield at a rate of $0.010 \mathrm{~kg} / \mathrm{s}$ per meter of reservoir width. The fluids flow laterally along a high-permeability fracture zone at a depth of about $1 \mathrm{~km}$ and $\mathrm{mix}$ with fluids rising from the lower reservoir. The fluids mix in a ratio of about 3:2, with a higher mass flow coming from the lower reservoir in the old wellfield. The natural fluid flows are highest in the Hveragil fault zone, where about $0.008 \mathrm{~kg} / \mathrm{m}$-s of high-enthalpy steam is discharged to surface springs; the remainder (about $0.013 \mathrm{~kg} / \mathrm{m}-\mathrm{s}$ ) recharges the upper reservoir in the old wellfield. In the Hveragil fault zone, extensive boiling takes place, reducing the temperature of waters feeding the upper reservi $i r$. The temperatures in other parts of the reservoit. 2 high, about $300^{\circ} \mathrm{C}$ at a depth of $1000 \mathrm{~m}$ and $34 \mathrm{t} / \mathrm{C}$ at a depth of $2000 \mathrm{~m}$.

The heat losses through the cap rock are estimated to be $1 \mathrm{~W} / \mathrm{m}^{2}$ (26 HFU) and the heat flux from the bottom to be $2.0 \mathrm{~W} / \mathrm{m}^{2}$. A detailed description of the natural-state modeling is given in Bodvarsson et al. (1983c).

\section{THE GENERATING CAPACITY OF KRAFLA RESER VOIRS}

This section discusses the lumped-parameter model of the old wellfield and the distributedparameter models of the different s'servoir regions at Krafla.

\section{Lumped-Parameter Model}

The general lumped-parameter model developed for geothermal reservoirs (Bodvarsson et al., 1983d) considers the mass and energy depletion of a wellfield with specified mass recharge (natural or artificial) from surrounding regions. The model can give rough-and-ready estimates of the generating capacity of a given field in $\mathrm{MW}_{\mathrm{e}}$-years. In general, the results obtained with the lumped-parameter model show that: (1) if (natural or artificial) recharge is limited, the reservoir will be depleted of fluids rather than heat, and the generating capacity vill depend greatly on the porosity; (2) when the recharge factor exceeds $60 \%$, the field in general will be depleted of energy, and the generating capacity will be independent of porosity and the enthalpy of the produced fluids.

\section{Areal Distributed-Parameter Models}

As shown in the previous section, fluid recharge is an important factor controlling the generating capacity of a field. In order to study the rate of natural recharge to the Krafla reservoir system, we developed several two-dimensional areal models. The transmissivity values used were those determined from analysis of injection-test data. The mesh design and boundary conditions assigned were based on results from the natural-state modeling study.

Figure 3 shows the pressure decline in the whole wellfield vs time when fluids equivalent to $60 \mathrm{MW}_{\mathrm{e}}$ are produced. In this case, we assumed an average reservoir porosity of $5 \%$, which seems reasonable on the basis of core data $(\mathrm{H}$. Kristmannsdottir, personal communication, 1980). The two curves shown in Fig. 3 represent two rather extreme cases; the broken line represents the case of no fluid rechargc from depth to the new wellfield, and the solid line corresponds to $16.7 \mathrm{~kg} / \mathrm{s}$ recharge ficm depth to the new wellfield. Note that the natural-state modeling studies showed that $10 \mathrm{~kg} / \mathrm{s}$ of fluids from depth recharge the new wellfield. The results shown in Fig. 3 indicate that it is questionable whether 60 $\mathrm{MW}_{\mathrm{e}}$ (the designed capacity of the power plant) can be produced from the existing wellfields for 30 years. These results are sipported by the conciusions of the other area! models of the individual wellfields. The best assessment to date is that for a 30 -year period the old wellfield an supply steam for $30 \mathrm{MW}_{\mathrm{e}}$ and the new wellfiels $20 \mathrm{MW}_{\mathrm{e}}$, suggesting that steam pro-

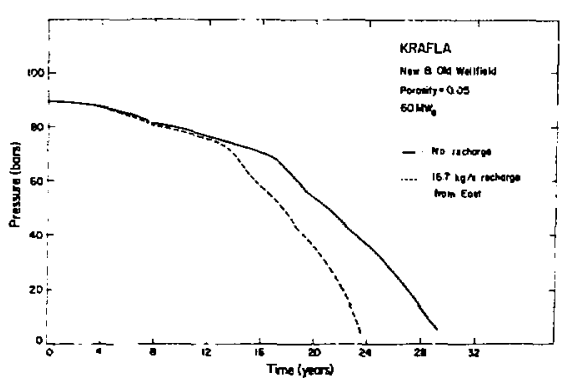

Figre 3. Comparison between observed and calculated water level data for injection test of well KJ-13. [XBL 8311-2303] 
duction from other areas is necessary to utilize the full capacity of the power plant.

A detailed description of the lumped-parameter model and the areal models for the Krafla reservoir is given by Bodvarsson et al. (1983d).

\section{WELL-BY-WELL MODELING}

We developed a quasi-three-dimensional model of the Krafla reservoir in which i:ll producing wells are represented individually. The main objectives of this work are to match well histories (flow rates and enthalpies) of all producing wells, predict their future performance, and study the overall reservoir depletion under various reservoir management schemes. This provides the field operator with data that can be used to determine the number of make-up wells required and help select the proper exploitation plan for the Krafla reservoir system.

In the reservoir model used, the upper and lower reservoir zones are each represented by single horizontal layers. Vertical flow within and between the layers is neglected.

The chief parameters adjusted in developing a detailed history match for well performance are reservoir porosities and permeabilities and productivity incices for wells. The permeabilities in the vicinity of wells are known from analysis of the short-term injection tests. Permeabilities farther away, especially in the two-phase zone, as well as the effects of major fractures and faults, are uncertain. Natural recharge through the system as established by the natural-state modeling is included in the modeling.

After many iterations, a reasonable history match with observed flow rates and enthalpies of all producing wells in the new and old wellfields was achieved. In all, 23 values of the rock properties were necessary for the match obtained. In the upper reservoir, six porosity-transmissivity combinations were sufficient. Several fluid flow barriers (faults) were necessary to obtain a reasonable match with both flow rates and enthalpies of weils. In general, the history match showed that pressure and vapor saturation changes are quite slow in the Krafla reservoir system because of the large compressibility of the two-phase fluids. The time constant for well-towell interference is about a year, but the long-term effects can be quite substantial. Some of the flow barriers inferred from the history match can be related to known faults, whereas others may be nonexistent.

Using different reservoir management criteria, the future performance of the Krafla wells was predicted. In general, the model predicts a very small decline in the flow rates of the Krafla wells in the future, or $1-4 \%$ annually for the no-injection cases. When injection is considered, the flow rates of the nearby wells increase drastically, but the enthalpy of the produced fluids declines similarly. These two effects tend to offset each other, yielding small net effects on the steam rate at the separators. This is in agreement with injection data from the field (Stefansson et al., 1982) as weli as recent theoretical work by Bodvarsson et al. (1983e).

The simulation studies show that during the next decade a steam zone of substantial volume will develop in the Krafla field. The stcam zone will grow rapidly if injection is not employed (Pruess et al., 1983).

The interference effects between wells show that some additional wells may be drilled in the existing wellfields. Thesc additional wells will decrease somewhat the energy output of the existing wells. but the total output will be increased.

\section{ACKNOWLEDGMENTS}

This research, performed as a part of a cooperative scientific investigation of the Krafla geothermal field by the INEA, the SEPW, the Engineering Research Institute, and the Science Institute of Iceland and LBL of U.S.A., was supported by the SEPW of Iceland and by the U.S. Department of Energy.

\section{REFERENCES}

Bodvarsson, G.S., Pruess, K., Stefansson, V., and Eliasson, E.T., 1983a. A reservoir evaluation study of the Krafla geothermal field, Iceland. Joint report by Lawrence Berkeley Laboratory, the Icelandic State Electric Power Woiks, and the Icelandic National Energy Authority. Lawrence Berkeley Laboratory, L.BL-16102.

Bodvarsson, G.S., Sigurdsson, O., Stefansson, V., and Eliasson, E.T., 1983b. The Krafla geothermal ficld, 1. Analysis of well test data. Submitted to Water Resources Research.

Bodvarsson, G.S., Pruess, K., Stefansson, V., and Eliasson, E.T., 1983c. The Krafla geothermal field, 2. The natural state of the reservoir. Submitted to Water Resources Research.

Bodvarsson, G.S., Pruess, K, Stefansson, V., and Eliasson, E.T., 1983d. The Krafla geothermal field, 3. The generating capacity of the field. Submitted to Water Resources Research.

Bodvarsson, G.S., Pruess, K., Stefansson, V., and O'Sullivan, M.J., 1983e. Injection and energy recovery in fractured geothermal reservoirs. 
Presented at the California Regional Meeting of the Society of Petroleum Engineers, Ventura, California, March 23-25, 1983, ST: j-11689.

Pruess, K., 1983. Development of the general purpose simulator MULKOM. Earih Sciences Division Annual Report, 1982. Lawrence Berkeley Laboratory, LBL-15500, p. 133-134.

Pruess, K., Bodvarsson, G.S., Stefansson, V., and Eliasson, E.T., 1983. The Krafla geothermal field, 4. Well períormance and reservoir deple- tion. Submitted to Water Rescurces Research. Stefansson, V., 1981. Th^ Krafla geothermal field, northeast Iceland. In L. Ryback and L.J.P. Muffler (eds.), Geothermal Systcms. London, John Wiley and Sons Ltd., p. 273-294.

Stefansson, V., Gudmundsson, A., Steingrimsson, B., Armannsson, H., Franzson, H., Sigurdsson, O., and Haunksson, T., 1982. Krafla weil KJ-13. Report by the Icelandic National Energy Authority, OS82046/JHDO7.

\section{A MODELING STUDY OF THE NATURAL STATE OF THE HEBER GEOTHERMAL FIELD, CALIFORNIA}

\section{M.J. Lippmann and G.S. Bodvarsson}

The Heber geothermal system is located in the southern part of the Imperial Valley, California, about $7 \mathrm{~km}$ north of the Mexican border (Fig. 1). The Heber geothermal anomaly is a circular-shaped, moderate-temperature, low-salinity, liquid-dominated system that is characterized by high heat flow, an electrical resistivity low, and a positive gravity

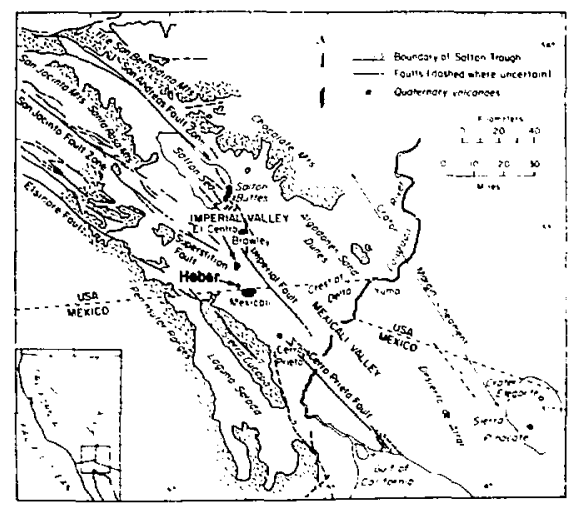

Figure 1. Regional geology of the Salton Trough and location of the Heber field, southeast of El Centro. California. [XBL 801-6718E] anomaly (Tansev and Wasserman, 1978). There are no surface manifestations in the area. The exploration and development of Heber has been summarized by Salveson and Cooper (1979).

A coarse model of the natural state of the Heber field has been developed. Because the field was assumed to be under steady-state conditions in its natural (pre-exploitation) state, the gradual cooling of the reservoir as indicated by mineralogic studies (Browne, 1977) was neglected. The Lawrence Berkeley Labotatory computer code PT (Bodvarsson, 1982) was used to calculate steady-state mass and heat flow conditions for various mudels. The resulting thermodynamic conditions (temperat'ire and pressure) in the reservoir system were then compared with field observations. Using a two-dimensional radial model, it was possible to match temperature and pressure data from the field reasonably well. The main differences between the observed pressures and temperatures and the calculated ones were due to the two-dimensional approximations used.

The modeling of a geothermal system in its natural state is a necessary step before sinulating field performance under exploitation. This type of modeling effort is time consuming, as many iterations are needed before a reasonable match with observed data is achieved. However, the information contained in the natural thermodynamic condjtions of a field can, if properly analyzed, help determine the permeability distribution in the field and the natural mass and heat recharge-parameters that can greatly affect the response of the geothermal system to full-scale exploitation.

\section{AVAILABLE DATA}

Relatively little information has been published on the subsurface characteristics of the Heber system. Tansev and Wasserman (1978) describe the Heber field as part of the Colorado River deltaic environment, which consists of interbedded sand- 
stones and shales. The shales are thick and predominant to about $610 \mathrm{~m}$ depth; below that, relatively thick sandstone layers prevail, and shale layers become thinner. From about 2400 to $300 \mathrm{~cm}$, sandstones are predominant with minor incerbeds of shale. The continuity of several sandstone layers has been confirmed by well tests. A few faults have beell identified, but according to these authors, any faults present in the more sandy section would not significantly hamper -jid flow. Measurements in Heber wells indicate that the pressure gradient in the reservoir is approximately $95.01 \mathrm{bar} / \mathrm{km}(0.42 \mathrm{psi} / \mathrm{ft})$, which is the lydrostatic pressure gradient for $170^{\circ} \mathrm{C}$ liquid water. As the temperatures in the main thermal anomaly at Heber are close to $190^{\circ} \mathrm{C}$, this indicates upflow from septh in the center of the anomaly.

Salves $n$ and Cooper (1979) show that temperature data from Heber wells outline a convective plume of hot water of $190^{\circ} \mathrm{C}$ temperature, or higher, rising from depths below $3000 \mathrm{~m}$. Above $1350 \mathrm{~m}$, horizontal fluid flow shifts the plume northerly. The hot plume centers near well Nowlin $\# 1$ at suout $600 \mathrm{~m}$ but shifts about $800 \mathrm{~m}$ toward the south at $1200 \mathrm{~m}$ depth. These authors state that the cap rock (predominantly shales) at Heber extends down to a depth of $600 \mathrm{~m}$ and that heat flow in the cap rock is predominantly conductive. Sandstones dominate (50-80\%) below $600 \mathrm{~m}$, with intergranular porosities of $15-30 \%$. To our knowledge, no other values of reservoir parameters at Heber have been published.

The heat source at Heber has not been identified. One well (Holtz $\# 1$, about $900 \mathrm{rn}$ southwest of $\mathrm{J}$ D. Jackson 11 ) penetrated a diabase dike or s.ll of prubable Pleistocene age at a depth of $1335-1366 \mathrm{~m}$. However, such a small rock body could not be the heat source for the present Hcber geothermal anomaly (Browne. 1977). It can be postulated that at the Heber field, as in the East Mesa field (Goyal and Kassoy, 1981), mass and heat are recharged through a more permeable zone, associated perhaps with one of the identified faults or with an intersection of these faults. However, it is difficult to $\operatorname{con} r m$ this hyp'sthesis, since a fault map for the system las not been published.

Mineralogic studies of well cuttings (Browne, 1977) indicate that temperatures have changed in the field during its evolution. Fluid inclusion data indicate that, at least locally, the reservoir has been cooling at an undetermined rate fron a maximum temperature of $240^{\circ} \mathrm{C}$ and that there have been at least two significant pulses of hot fluids.

\section{DESCRIPTION OF THE MODEL}

The model used in the simulation was radially symmetric. The outer boundary, $10 \mathrm{~km}$ from the axis, was assumed to be open to heat and mass flow and to have constar: temperatures and pressures. The temperatures at the outer boundary were assumed to increase linearly with depth with a gradient of $50^{\circ} \mathrm{C} / \mathrm{km}$. The pressures used at the outer boundary were hydrostatic for the assumed temperature distribution.

The top boundary was considered open only to heat flow; it was kept at a constanı temperature of $22^{\circ} \mathrm{C}$ (about the mean annual temperature in the area). The bottom boundary, at $495 \mathrm{U}$ in depth, was assumed to have a constant temperature of $269.5^{\circ} \mathrm{C}$, computed from the assumed geothermal gradient and surtace temperature. An upflow zone feeding hot water to the reservoir system was assumed to exist over a $1000-\mathrm{m}$ radius at the bottom of the reservoir system. The amount and temperature of the fluids recharging the system through the upflow zone were aried during the si. 1..."ons. The remainder of the bottom boundary was closed to fluid flow.

The model was divided into five zones with different rock properties, primarily different permeability values (Fig. 2). Zones 1 and 2 are $550 \mathrm{~m}$ thick and represent the cap rock. Zone 3 , representing a cylinder of $1000 \mathrm{~m}$ radius, is the hot water upflow zone. Zones 4 and 5 correspond to the outer regions of the field.

The single most important reservoir parameter controlling steady-state distribution of temperature

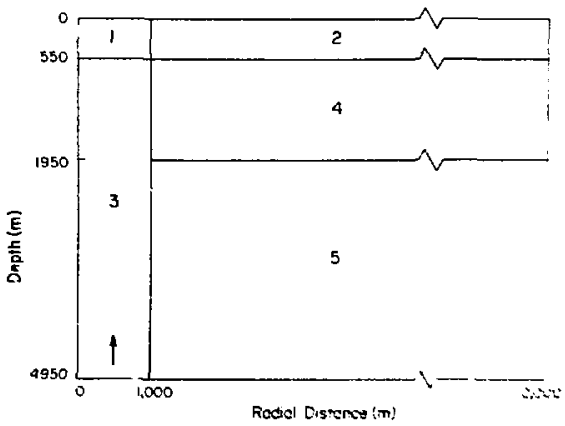

Fijore 2. Different zones usat in the aroditi. SWi 835-306] 
and pressure in the system is the permeability. The permeability values were changed for the different cases studied, and it was found that the best match between computer and observed temperature values was obtained when the permeability anisotropy $\left(k_{\text {hor }} / k_{\text {ver }}\right)$ in zones 1,3 , and 5 was kept at 10 and in zones 2 and 4 at 100 .

The anisotropic nature of the permeability of the different regions seems reasonable when one considers the general intercalation of sandstones and shales in the lithelogic column at Heber. The lower anisotropy of zones 1 and 3 could be due to a higher density of vertical fractures/faults, perhaps the faults postuiated with the upflow region. On the other hiend, in zone 5 , below the bottom of the deepest wells at Heber, the lower anisotropy could be related to a langer percentage of sandstone. This is consistent with an apparent increase of sandstone abundance with depth reported by Tansev and Wasserman (1978).

The thermal conductivity of the materials is another important parameter that greatly affects the steady-state thermodynamic conditions computed. Since no values of thermal conductivity of the various formations at Heber are available, we assumed a value of $2 \mathrm{~W} / \mathrm{m}-{ }^{\circ} \mathrm{C}$. This value seems reasonable for sandstone and shale. However, for the materials in zones 1 and 2 (shallow layers), a lower value was assigned $\left(1.088 \mathrm{~W} / \mathrm{m}-{ }^{\circ} \mathrm{C}\right)$ on the basis of the average thermal conductivity reported by Combs (1971) for 40 samples from 150-m-deep wells drilled in the Imperiai Valley. It should be emphasized that the thermal conductivity values assigned to the shallow zones (zones 1 and 2) are much more important than those assigned to deeper reservoir zones because of the predominantly conductive heat losses to the surface.

\section{RESULTS}

Several cases were studied (Lippmann and Bodvarsson, 1983), but only the model that best matched the observed values is discussed here. The various cases differed in the permeability distribution used, boundary conditions, and strength of the heat source.

The best match between observed and computed values was obtained when the following parameters were used.

1. The cap rock (zones 1 and 2, Fig. 2) has a horizontal permeability of 5 mdarcies; the upflow zone (zone 3), 125 mdarcies; the upper outer region (zone 4), 10 mdarcies; and the lower outer region (zone 5), 115 mdarcies. As mentioned earlier, a thermal conductivity of $2.0 \mathrm{~W} / \mathrm{m}^{\circ}{ }^{\circ} \mathrm{C}$ was used every- where, except in zones 1 and 2, where a value of 1.1 $\mathrm{W} / \mathrm{m}-{ }^{\circ} \mathrm{C}$ was used.

2. The recharge rate from below into the upflow zone (zone 3) is $14.6 \mathrm{~kg} / \mathrm{s}$ of $244.5^{\circ} \mathrm{C}$ water, or equivalent to $15 \mathrm{MW}$ (thermal).

The computed temperature distribution in the system is shown in Fig. 3 (only half of the cross section is depicted because of the radial symmetry of the model). The figure shows the typical mushroom shape due to the outward flow of hot fluids in the upper part of the reservoir system and the inflow of colder fluids below. Consequently, one finds large temperature inversions in wells drilled outside the main upflow zone.

The comparison between observed and calculated temperatures is shown in the cross section given in Fig. 4. The match obtained is reasonable when one considers the radial model used in the simulations. The calculated isotherms are symmetrical, whereas the observed data show some nonsymmetrical behavior, probably due to regional groundwater flow and variations in the permeability distribution in the various reservoir regions. Figure 4 shows that the calculated isotherms spread too far to the southeast in the upper regions of the reservoir but not far enough to the northwest. Similarly, the calculated temperature inversions are too large in the

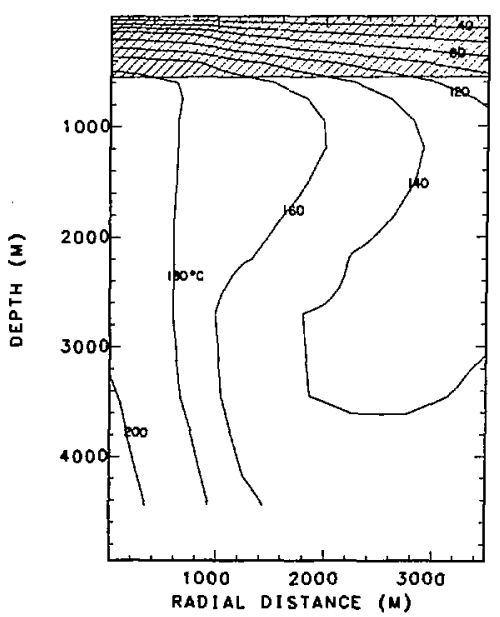

Figure 3. Best model. Computed steady-state temperature distribution. Hatched layer represents the cap rock (zones 1 and 2, see Fig. 2). [XBL 835-311] 


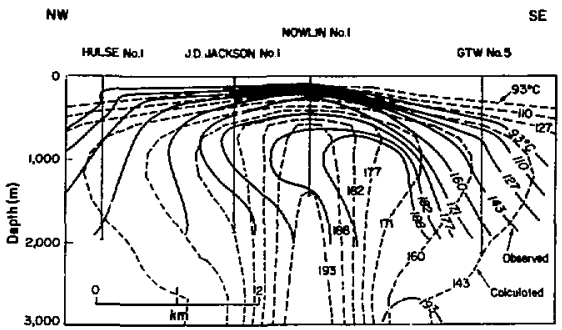

Figure 4. Best model. Comparison between observed and computed temperature distributions. [XBL 835-304]

lower part of the reservoir to the southeast but are less than those observed to the northwest. Overall, the calculated temperatures are close to those observed, hence the actual energy input into the system must be close to that used in the simulation.

The mushroom shape of the isotherms is the result of hot water from the convective heat source ascending through the central upflow zone (zone 3 ) and spreading laterally outward in the upper part of the system. Simultaneously, the colder water surrounding the geothermal anomaly flows toward the upflow zone because of its higher density. This cold water inflow is slowed significantly by the relatively low permeability of the upper outer region (zone 4).

Figure 5 shows the comparison between observed shallow temperatures (146 m depth) reported by Salveson and Cooper (1979) and the cal-

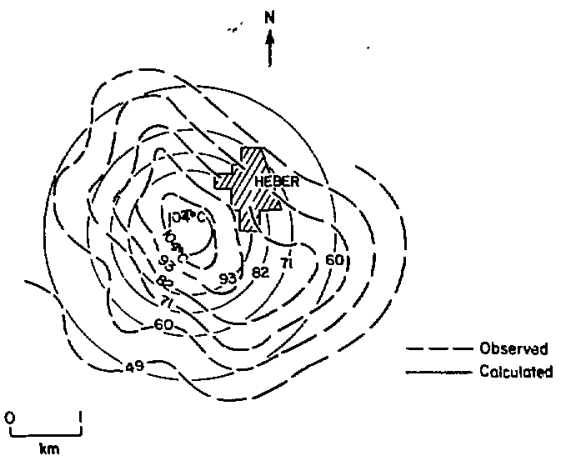

Figure 5. Best model. Comparison between obse-ved temperatures at $146 \mathrm{~m}$ depth (from Salveson and Cooper, 1979) and computed steady-state temperatures at 150 m. [XBL 835-305] culated values. The agreement is reasonable, indicating that heat losses to the surface are adequately modeled.

The computed pressure distribution in the upper $3000 \mathrm{~m}$ of the upflow zone is shown in Fig. 6. The matc: with the observed pressure gradient $(95.01$ $\mathrm{bar} / \mathrm{km}$ ) is good.

The model indicates that the so-called cap rock (zones 1 and 2) is quite permeable ( 5 mdarcies). If its permeability is decreased significantly, the shallow temperatures $(150 \mathrm{~m}$ depth) would drop below those reported by Salveson and Cooper (1979). This drop could be lessened by further decreasing the thermal conductivity of zones 1 and 2 . For the cap rock, however, a thermal conductivity value below 1 $\mathrm{W} / \mathrm{m}-{ }^{\circ} \mathrm{C}$ seems unrealistic.

The horizontal permeability of the upper outer regions of the field (zone 4) seems very low (10 mdarcies) when one considers the relatively high horizontal permeability in the upflow zone (125 mdarcies). However, if we use a significantly larger permeability in this zone, the inflow of cooler fluids from the outside floods the system and causes much greater temperature reversals than those observed. The low permeability of this predominantly sandy zone could be explained either by the precipitation of silica in the rock pores as the geothermal waters flow outward and cool or by the precipitation of carbonates from the heating of cold water during the evolution of the system.

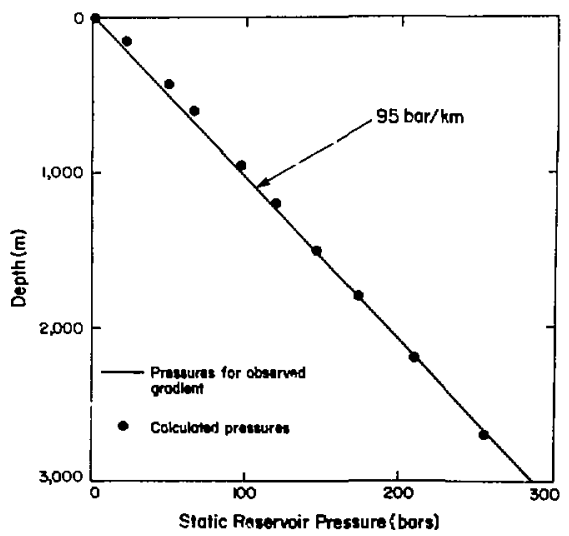

Figme 6. Best model. Comparison between pressures computed based on the reported gradient and those calculated near the axis of the model. [X.BL 835-308] 


\section{CONCLUSIONS}

The simulation studies of the natural state of the Heber geothermal field indicate that

1. The upflow zone at Heber is a region of relatively high permeability with an anisotropy of approximately 10 . In this zone, hot waters upwell from depth and ascend to shallower layers where they spread laterally. At depth, colder waters move laterally into this zone and $\mathrm{mix}$ with the hot, recharged waters.

2. The strength of the convective heat source is equivalent to about $15 \mathrm{MW}$ (thermal). No speculations can be made on the nature of this heat source before more field data become available.

3. Outside the central upflow zone, temperature reversals should be encountered by deeper wells.

4. The cap rock is quite permeable (approxin mately 5 mdarcies;, at least in the lower part. The high temperatures between 150 and $600 \mathrm{~m}$ depth cannot be explained by conduction alone.

5. The upper part of the outer region has a relatively low permeability (about 10 mdarcies). This low-permeability zone could be the result of mineral precipitation in the pores of the rock matrix.

\section{REFERENCES}

Bodvarsson, G.S., 1982. Mathematical modeling of the behavior of geothermal systems under exploitation (Ph.D. dissertation). Lawrence

\section{HIGH-TEMPERATURE GEOTHERMAL DOWNHOLE FLOWMETER}

\author{
R.D. Solbau and S.M. Benson
}

Downhole flowmeters (spinners) have been used by the petroleum industry for many years to delineate the rock strata that contribute to well productivity. The high temperatures, corrosive brines, and very high fluid velocities encountered in geothermal wells have prohibited the use of conventional downhule nowmeters. At Lawrence Berkeley Laboratory (LBL), a very simple design concept using a minimum of downhole electronic components has produced a reliable high-temperature $\left(300^{\circ} \mathrm{C}\right.$ ) downhole flowmeter (Figs. 1 and 2). The
Berkeley Laboratory, LBL-13937, p. 18-48.

Browne, P.R.L., 1977 Occurrence and hydrothermal alteration of diabase, Heber geothermal field, Imperial Valley, California. University of California, Riverside, Report UCR/IGPP 77/9,67 p.

Combs, J., 1971. Heat flow and geothermal resource estimate for the Imperial Valley. In R.W. Rex (Principal Investigator), Cooperative Geological-Geophysical-Geochemical Investigations of Geothermal Resources in the Imperial Valley Area of California. University of California, Riverside, p. 5-27.

Goyal, K.P., and Kassoy. D.R., 1981. A plausible two-dimensional vertical model of the East Mesa geothermal field, California. Journal of Geophysical Research, v. 86, p. 10719-10733.

Lippmann, M.J., and Bodvarsson, G.S., 1983. A modeling study of the natural state of the Heber geothermal field, California. Geothermal Resources Council, Transactions, v. 7, p. 441-447.

Salveson, J.O., and Cooper, A.M., 1979. Exploration and development of the Heber geothermal field, Imperial Valley, California. Geothermal Resources Council, Transactions, v. 3, p. $605-608$.

Tansev, E.O., and Wasserman, M.L., 1978. Modeling the Heber geothermal reservoir. Geothermal Resources Council, Transactions, v. 2, p. $645-648$.

availability of such an instrument gives the geothermal reservoir engineer a powerful tool for evaluating reservoir formations and studying well-bore dynamics. The LBL flowmeter has been successfully used in numerous geothermal wells at temperatures as high as $270^{\circ} \mathrm{C}$ and depths as great as $3960 \mathrm{~m}$ and has demonstrated its utility for several purposes:

1. Locating production and injection zones.

2. Indicating changes in production and injection zones resulting from acidizing or fracturing.

3. Locating the flash point or bubble point in a well bore.

4. Reflecting scale buildup, casing damage, plugged perforations, or thief zones.

The basic concept of the LBL spinner is that the fluid flowing up or down a well bore and passing through the flow passage of the instrument will rotate the impeller inside the flowmeter at a rate that 


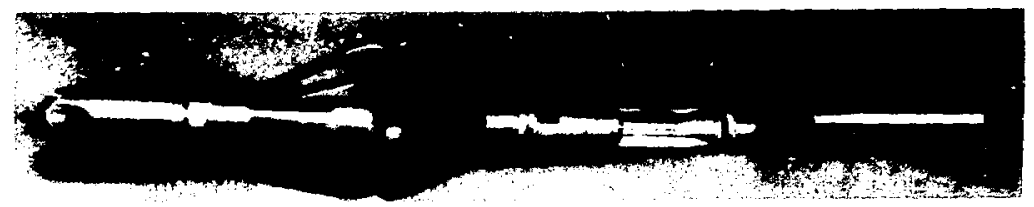

Figure 1. The downhole flowmeter. [CBB 796-8435A]

is proportional to the fluid velocity. The impeller, in turn, rotates a magnet assembly. The rotating magnet opens and closes a reed switch, thus generating a frequency signal that is recorded electronically at the surface. The frequency signal is proportional to the spin rate of the impeller, which rotates at approximately $150 \mathrm{rpm}$ for each foot per second of fluid velocity (for liquid water). The volumetric flow rate is calculated by multiplying the measured nuid velocity by the cross-sectional area of the bore.

\section{COMPONENTS}

Downhole geothermal environments are particularly harsh on instruments. High temperatures, cor-

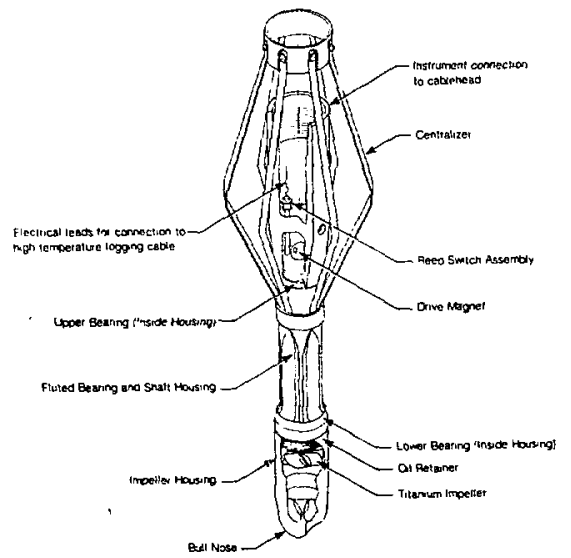

Figure 2. Schematic view of the downhole flowmeter. The total length of the instrument is $2 \mathrm{ft}$, and its maximum outside diameter is 2 in. without the centralizer. The flowmeter makes a pressure-tight connection to a high-temperature cablchead with the aid of metal-to-metal seals and high-temperature elastometer 0 -ring seals. [XBL 8311-719] rosive liquids and gases, scale formation, sand production, and very high fluid velocities in the flash zones all take their toll.

To design and fabricate a high-temperature flowmeter that will function reliably under these conditions, several design criteria must be met. First, the downhole electronics should be simple and should function reliably at high temperatures. Second, the bearings must be shock resistant, have a high operating temperature, and be protected from the geothermal brine. Thisd, all components exposed to the brine must be corrosion and abrasion resistant in the operating environment.

The first objective was accomplished by using a reed switch to sense the rotation of the impeller. This simple device eliminates the need for any active downhole electronics such as voltage regulators, voltage-to-frequency converters, or signal amplifiers, which may be temperature sensitive.

Reliable bearing performance was achieved by using two precision ball bearings, one close to the impeller and the other near the top of the shaft. These bearings let the 1/8-in. diameter impeller shaft rotate freely. An oil bath reservoir protects the bearings from the corrosive well-bore fluid. The oil is prevented from leaving the enclosure at the lower bearing by capillary action resulting from the close fit of the impeller shaft and the shaft exit port located below the bottom bearing. After the flow. meter is lowered into a well, the higher specific gravity and the pressure of the brine prevent the turbine oil from leaving the enclosure.

To protect the instrument from the corrosive and abrasive downhole environments in geothermal wells, the body was fabricated of type 304 stainless steel. Titanium was used to fabricate the impeller because of its very high strength-to-weight ratio and high resistance to corrosion in geothermal brincs. The aluminum and plastic impellers used in most other downhole flowmeters are usually destroyed within a short time by the brines and high temperatures. The critical components and the maximum temperatures at which they will operate are listed in Table 1. 
Table 1. Spinner components and temperature ratings.

\begin{tabular}{lll}
\hline Component & \multicolumn{1}{c}{ Type } & $\begin{array}{c}\text { Temperature } \\
\text { Rating }\end{array}$ \\
\hline Bearings & $\begin{array}{l}\text { Shielded precision ball bearings } \\
\text { (many manufacturers) }\end{array}$ & $480^{\circ} \mathrm{C}$ \\
Reed switch & $\begin{array}{l}\text { Hermetically sealed } \\
\text { (many manufacturers) }\end{array}$ & $300^{\circ} \mathrm{C}$ \\
Lubricating oil & $\begin{array}{l}\text { High-temperature turbine oil } \\
\text { (Union 32 or equivalent) }\end{array}$ & $300^{\circ} \mathrm{C}$ \\
Magnet & \begin{tabular}{l} 
Alnico 5 or Alnico 8 \\
\hline
\end{tabular}
\end{tabular}

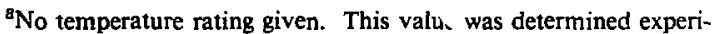
mentally; the true value may be significantly higher. The only reed switch tested at LBL is manufactured by the Calectro Company.

Development and use of the LBL flowmeter has demonstrated the utility of such instruments in geothermal well testing, formation evaluation, and well-bore dynamics.

\section{IMPERIAL VALLEY, CALIFORNIA: WELL 1}

The permeability distribution of wells completed in sandstone formations may be evenly distributed over the bore length or may be concentrated in discrete intervals. Wells in the Imperial Valley may have open intervals of up to several thousand feet. Detailed reservoir engineering studies and well workovers require knowledge of the permeability distribution in the formation(s) penetrated. Correlation of geophysical borehole logs can be used for this purpose but rarely with sufficient confidence. Spinner surveys provide a direct method of determining the distribution of well productivity over the borehole length. Comparison of the productivity distribution with cuttings and borehole log anaiyses can be used to infer both the formation permeability and nearbore permeability damage.

Figures 3 and 4 depict the information obtained from a typical spinner survey of such a well. The wel! completion is shown in Fig. 5. Figure 3 shows the casing profile. At the very top of the well, the fluid velocity is relatively high (reflected by the rotation rate of over $300 \mathrm{rmm}$ ). At $250 \mathrm{ft}$, the fluid velocity drops to zero. This reflects the transition from the flashed to the unflashed brine in the well bore (the flash depth). From $250 \mathrm{ft}$ to $1750 \mathrm{ft}$, the fluid velocity is below the starting velocity of the spinner, so that no fluid velocity is registered. From $1750 \mathrm{ft}$ to the bottom of the casing $(4700 \mathrm{ft})$, the fluid velocity remains nearly constant (with the exception of the higher velocities at the casing shoe).

Figure 4 shows data from the spinner survey in the slotted liner. Analysis of the data indicates that

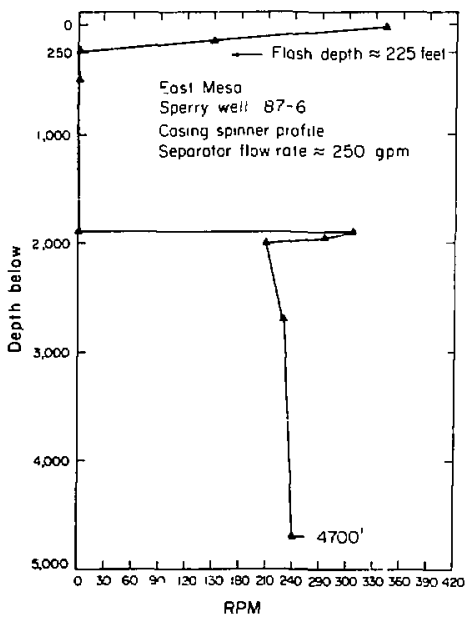

Figwre 3. Casing spinner survey from well 87-6, Imperial Valley, Califomia. [XBL 8010-2246] 


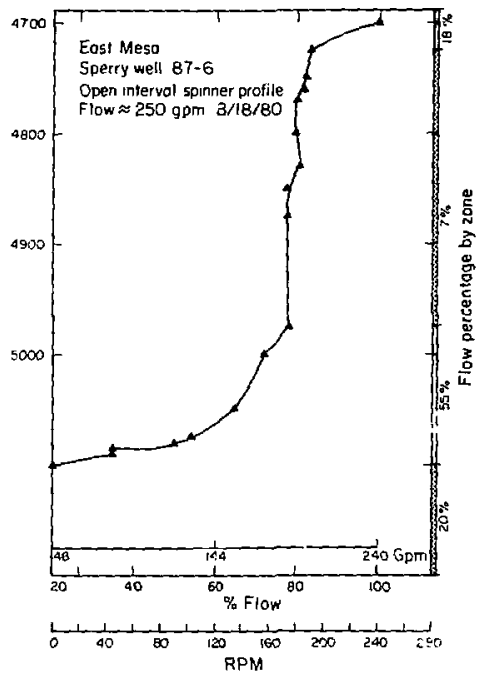

Figure 4. Open interval spinner survey from well 87-6, Imperial Valley, California. [XBL 8010-2247]

two intervals produce at least $73 \%$ of the fluid. The upper zone, located between $4700 \mathrm{ft}$ and $4720 \mathrm{ft}$, produces approximately $18 \%$ of the total flow. The lower zone, between $4720 \mathrm{ft}$ and $4980 \mathrm{ft}$, produces

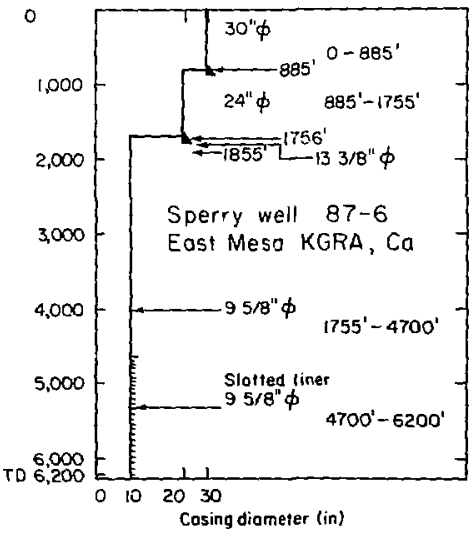

Figare 5. Casing schedule, well 87-6, Imperial Valley, California. [XBL 8010-2250] only $7 \%$ of the total flow. The second major productive interval lies between $4980 \mathrm{ft}$ and $5100 \mathrm{ft}$. At least $55 \%$ of the flow is produced from this interval). Because of the low fluid velocity below $5100 \mathrm{ft}$, it is not possible to determine if any fluid is being produced. Approximately $20 \%$ of the total fluid may be produced from below this depth.

This is a good example of a conventional spinner $\log$ interpretation, and several key points are illustrated. First, the spinner easily detected the flash depth in the well. Second, the low how rate (250 $\mathrm{gpm}$ ) at which the survey was conducted created a relatively large uncertainty in the quantity of flow that was coming from below $5100 \mathrm{ft}(20 \%$ uncertainty). Therefore, it would seem desirable to conduct the survey at a higher flow rate. However, there is a disadvantage to this, in that the flow regime in the vicinity of the perforations may become erratic at higher production rates, resulting in a further ambiguity in the interpretation of the survey.

The velocity of the fluid moving up the well bore is inversely proportional to the square of the bore radius. Therefore, even small changes in the radius can result in large changes in the fluid velocity. Since the downhole flowmeter is very sensitive to changes in well-bore velocities, it can be used as a production-mode borehole caliper. This has the advantage in that scale buildup or casing problems can be diagnosed without shutting in the well.

\section{CONCLUSION}

Existing technology has been used to construct a high-temperature $\left(300^{\circ} \mathrm{C}\right)$ downhole flowmeter. In addition to the conventional uses, the LBL flowmeter can be used for locating the flash point in a well and as a very sensitive production-mode borehole caliper. Careful anaiysis is required to avoid erroneous interpretation of the data and to extract the maximum amount of information from the survey.

The following guidelines should be used to obtain spinner data of high quality.

1. Ensure that the instrument is adequately centralized during the survey.

2. Use a combination of logging at constant line speed and with regular stops throughout the regions of interest to provide the most accurate record.

3. Conduct the survey at the maximum flow rate possible without developing a highly erratic flow regime around the perforations.

4. Expect to spend a fair amount of time on the analysis of the data. 


\section{INJECTION IN FRACTURED RESERVOIRS}

\section{K. Pruess and G.S. Bodvarsson}

At present, reinjection of spent geothermal brines is either employed or being considered as a method of waste disposal at most high-temperature geothermal fields in operation or under development. The majority of fields suitable for electric power generation are situated in fractured volcanic rocks. Fluid flow paths in fractured country can be very complex, and present understanding of injection effects is rather limited. Some of the questions addressed in our research are:

1. How will injection affect flow rates and enthalpies of the production wells?

2. Can injection increase the short-term usable energy output of wells?

3. What are the long-term effects of injection?

4. How does energy recovery in productioninjection systems depend upon such factors as well spacing and fracture spacing?

5. What is the potential for thermal interference along short-circuiting flow paths, such as major vertical fractures?

6. Can thermal interference be predicted from tracer tests or pressure-transient tests?

\section{ENERGY RECOVERY}

We consider a production-injection system like the one schematically depicted in Fig. 1. Two-phase fluid from a production well completed in a fractured reservoir enters a separator, which typically

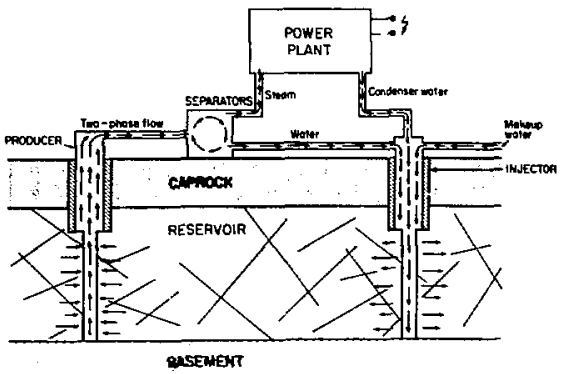

Fisure 1. Schematic diagram of production-injection system. [XBL 832-1 704] operates at a constant pressure of 9 bars. The flashed steam is transmitted to the power plant, and the liquid water is reinjected into the same reservoir zone. Possible additional sources of injection water are condensed steam and makeup water from external sources. We have carried out a parameter study to obtain insight into how the energy recovery from such a production-injection system depends upon reservoir parameters and operating conditions. To simplify the flow geometry, we assume that the wells are arranged in a five-spot pattern. This makes it possible to model just $1 / 8$ of a pattern; moreover, we neglect vertical flow in the reservoir. Reservoir parameters were chosen to represent typical fractured reservoirs of low permeability, such as Baca, New Mexico; Krafla, Iceland; and Olkaria, Kenya. The rock matrix was assumed porous with rather low permeability. Global flow in the reservoir occurs through a network of interconnected fractures, whereas rock matrix and fractures exchange fluid and heat locally. Calculations for fractured porous reservoirs were carried out with the method of "multiple interacting continua" (MINC; Pruess and Narasimhan, 1982), which is a generalization of the double-porosity model of Barenblatt et al. (1960) and Warren and Root (1963).

Production wells are placed on deliverability, so that flow rates shange in a realistic way with reservoir pressures. Our simulations show that production rates generally increase with increasing injection factor, as was to be expected. Produced enthalpies diminish when more fluid is injected. The enthalpy decline offsets the increased production rate to yield a net steam rate at the separators that is almost independent of injection factor. This somewhat surprising result agrees with field data from Krafla, Iceland, and it suggests thit the sum of liquid and vapor relative permeability is approximately equal to 1 , independent of flowing enthalpy. Although quantitative details depend upon reservoir and well parameters, our studies suggest that short-term effects of injection on usable steam output tend to be insignificant. In the long term, however, injection can substantially increase the recoverable energy by maintaining reservoir pressures as heat is being swept from the rocks. Figure 2 shows computed net electric output for a model reservoir as a function of fraction of produced fluids injected, using a realistic conversion factor of $2.2 \mathrm{~kg}$ steam per MWs of electrical energy. From the standpoint of energy recovery, then, it appears that there are no compelling reasons for reinjection at an early stage of field development, but full reinjection is certainly desirable in the long run. 


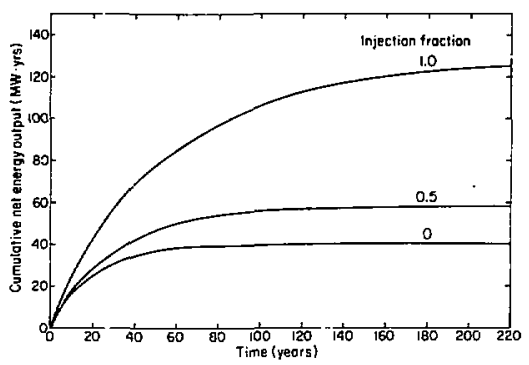

Figure 2. Cumulative net electric power output for a model reservoir with different injection fractions. [XBL 831-1615]

\section{THERMAL INTERFERENCE}

The calculations summarized above are applicable for reservoirs with ubiquitous "small" fractures. In this case the heat sweep from the rocks is sufficient to prevent an early thermal degradation of fluids at the production wells. However, there is plenty of field evidence for short-circuiting "preferential flow paths" from tracer tests. In fractured reservoirs, one often observes tracer migration speeds of $1-10 \mathrm{~m} / \mathrm{h}$ or more with cumulative tracer returns of $1-10 \%$. Such "fast paths" indicate the presence of major fractures, which may cause thermal interference in production-injection systems much earlier than would be expected from volumetrically averaged fracture models.

It should be emphasized that rapid tracer returns alone do not necessarily indicate a problem situation. As far as field management is concerned, the important parameter is the velocity of the thermal (cold) front. This depends on various characteristics of the preferential pathways, which are only partially determined by the speed of tracer migration. Tracer breakthrough time is essentially a measure of the total volume of the preferential path between production and injection wells. Thermal migration, on the other hand, is largely determined by the total available surface area for heal transfer. From an analysis of tracer dispersion, one can obtain an estimate of the effective fracture aperture, which in conjunction with an estimate of fracture volume defines the surface area. An uncertainty remains in this analysis, however, becauce the estimates depend on hypothetical assumptions auout the geometry of the flow path. In many geothermal reservoirs, major fractures tend to be vertical or nearly vertical. In view of the linear flow geometry, vertical fractures appear to be a plausible model for fast paths.
Under certain simplifying assumptions, we obtain the following expression for thermal breakthrough time in vertical fractures:

$$
t_{t h}=\tau\left(\frac{t_{b}}{\phi_{f} w}\right)^{2} \text {. }
$$

Here $t_{b}$ is tracer breakthrough time, $\phi_{f} w$ is the effertive fracture aperture, and $\tau$ is a group of rock and fluid parameters that depend little on the conditions encountered at a particular geothermal site. Equation (1), plotted in Fig. 3, permits a rough estimate of trends that though approximate, may be useful for an initial evaluation of injection sites. We have carried out some analysis of the tracer data and thermal breakthrough for one of the Los Alamos hot dry rock experiments, which supports the model behind Eq. (1) in that particular case.

Additional information can be obtained from pressure-transient tests, but a reliable prediction of thermal interference will in general require longerterm (months or years) nonisothermal injection with careful monitoring of production temperature. Numerical modeling techniques are required to obtain a realistic analysis of thermal interference data.

We have developed what we believe to be a "realistic" model of thermal interference in vertical fractures (see Fig. 4). Fluid and heat flow in such systems is three dimensional, which presents a formidable problem for numerical analysis. We have used numerical simulation for the two-dimensional llow in the fracture plane, combined with a semianalytical technique for heat flow perpendicular to the fracture plane (Vinsome and Westerveld, 1980).

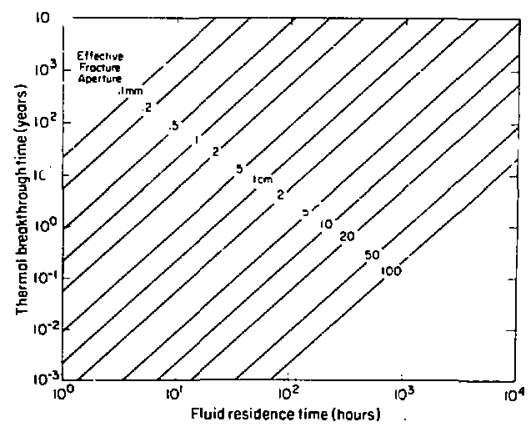

Figare 3. Thermal breakthrough time as a function of fluid residence time and effective fracture aperture. [XBL 839-2231] 


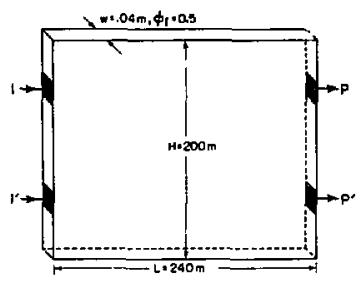

Figure 4. Schematic diagram of production-injection system in vertical fracture ( $I$ and $I^{\prime}$ are injection points; $P$ and $\mathrm{P}^{\prime}$ are production points). [XBL 839-2230]

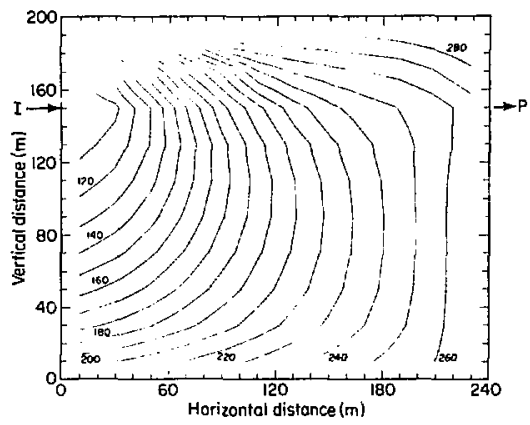

Figure 5. Temperature contours in fracture plane after 1 year of production and injection. [XBL 839-2235]

\section{FRONT TRACKING IN COID WATER INJECTION WELLS}

\section{S.M. Benson}

During both geothermal and waterflooding operations, it is important to know the position of the interface, or front, between the injected and in situ fluids. A pressure-transient technique for tracking the advance of fluid fronts during waterflooding
This approach reduces the computational effort to manageable proportions, so that we have been able to study a number of typical cases. Figure 5 gives an example of a temperature distribution in the fracture after 1 year of continuous injection. In this case, a good thermal sweep is obtained. Further analysis demonstrates that after an unacceptable temperature decline has occurred at ihe production well, a substantial recovery is possible in a matter of months if injection is stoppid. Several examples from operating geothermal fields support this conclusion. Therefore, thermal interference may not be as problematic as is often believed. Even if it cannot be prevented by proper injection design, it appears that it can be cured simply by shutting in an offending injection well.

\section{REFERENCES}

Barenblatt, G.E., Zheltov, I.P., and Kochina, I.N., 1960. Basic concepts in the theory of homogeneous liquids in fissured rocks. Journal of Applied Mathematics (USSR), v. 24, no. 5, p. 1286-1303.

Pruess, K., and Narasimhan, T.N., 1982. A practical method for modeling fluid and heat flow in fractured porous media. In Proceedings, 6th SPE Symposium on Reservoir Simulation, New Orleans, Louisiana, February 1-3, 1982, SPE-10509 (L.SL-13487).

Vinsome, P.K.W., and Westerveld, J., 1980. A simple method for predicting cap and base rock heat losses in thermal reservoir simulators. Journal of Canadian Petroleum Technology, July-September 1980, p. 87-90.

Warren, J.E., and Root, P.J., 1963. The behavior of naturally fractured reservoirs. Society of Petroleum Engineers Journal, September, p. 245-255.

and geothermal injection operations has been developed. The technique is based on the consepl that the steady-state pressure buildup in the reservoir region inside the front can be calculated by a fluid skin factor (Benson and Bodvarsson, 1983). By analyzing successive pressure falloff tests, the movement of the front into the reservoir can be monitored.

Pressure transients during injection of fluids with properties different from those of the in situ fluid are characterized by one of two types of behavior. 
1. Moving-front-dominated behavior, during which the very early time pressure transients correspond to the properties of the reservair fluid and the late time transients to the properties of the injected fluid (Tsang and Tsang, 1978; Bodvarsson and Tsang, 1980; Benson and Bodvarsson, 1982).

2. Composite reservoir (stationary front) behavior, which is characterized by two slopes, the first corresponding to the fluid properties of the region inside the front and the second to the properties of the reservoir fluid outside of the front (Benson and Bodvarsson, 1982).

This method of front tracking is applicable when the pressure transients behave like those of a composite reservoir system.

\section{FLUID SKIN FACTOR}

In composite systems in which the inner region is sufficiently small, the steady-state pressure buildup in response to injection can be calculated in terms of a fluid skin factor. The fluid skin factor can be derived in a manner analogous to that of the mechanical skin factor of a well (Benson and Bodvarsson, 1983). The mathematical expression is

$$
s_{f}=\left(\frac{k_{r o} \mu_{i} \rho_{o}}{k_{r i} \mu_{o} \rho_{i}}-1\right) \ln \frac{r_{f}}{r_{w}},
$$

where $s_{f}$ is the fluid skin factor, $k_{r o}$ and $k_{r i}$ are the rela 'e permeabilities of the fluids in the outer and inn regions, $\mu_{0}$ and $\mu_{i}$ are the fluid viscosities in the uuter and inner regions, $\rho_{o}$ and $\rho_{i}$ are the fluid densities, $r_{f}$ is the radius to the injected fluid front, and $r_{w}$ is the well radius. As the radius to the front increases, the magnitude of the fluid skin factor grows. If the fluid in the inner region is less mobile than that of the outer region, the fluid skin factor will be positive. Conversely, if the fluid in the inner region is more mobile, the fluid skin factor will be negative.

\section{FRONT TRACKING}

In porous medium systems in which the front moves at a rate that is inversely proportional to the radial distance to the front, the fluid skin factor can be expressed in another way (Benson and Bodvarsson, 1983):

$$
\begin{gathered}
s_{f}=1.151\left[\left(\frac{\mu_{i} \rho_{\mathfrak{o}} k_{r o}}{\mu_{o} \rho_{i} k_{r i}}-1\right) \log C\right. \\
\left.+\log \frac{b}{\pi H r_{w}^{2}}\right],
\end{gathered}
$$

where $C$ is the cumulative injection before the pressure-transient test, $H$ is the reservoir thickness, and $b$ is a constant that is determined by the displacement processes (i.e., waterflooding or thermal). From this expression, it can be seen that there is a log-linear relation between the cumulative injection and the value of the fluid skin factor. Furthermore, the slope of the line is simply a function of the f. id properties of the inner and outer regions.

If the correct fluid skin factor can be determined, then it is possible to calculate the distance to the front using Eq. (1), which can be rearranged as

$$
r_{f}=r_{w} e^{\left(1.151 s_{t} / n\right)}
$$

where $n$ is the slope of the line on a plot of $s_{f}$ vs log $C$. The correct value of the fluid skin factor is determined by subtracting the effects of the mechanical skin factor of the well from the apparent skin factor of the well, which is determined by the analysis of the pressure-transient test.

\section{EXAMPLE: STEP-RATE INJECTION TEST}

The following simulation was run to demonstrate front tracking during a step-rate injection test of cold water into a hot water reservoir. Three 6-h steps, with injection rates of $0.1 \mathrm{~kg} / \mathrm{s}, 0.2 \mathrm{~kg} / \mathrm{s}$, and $0.3 \mathrm{~kg} / \mathrm{s}$, were followed by a complete shutin. The simulated pressure data are shown in Fig. 1. The properties of the reservoir, injected fluid, and reservoir fluid are given in Table 1. The data were analyzed using conventional multirate theory; fluid skin factors of $14,18.9$, and 19.8 were calculated for steps 2, 3, and 4, respectively (Benson, 1982). These data are plotted in Fig. 2. The data form a singie straight line when plotted as a function of the logarithm of the cumulative injection. From these values of the fluid skin factor, the radial distance to the front can be calculated after each step; the calculated values of $0.6 \mathrm{~m}, 1.2 \mathrm{~m}$, and $1.5 \mathrm{~m}$ agree well with the simulated results of $0.7 \mathrm{~m}, 1.3 \mathrm{~m}$. and $1.6 \mathrm{~m}$. 


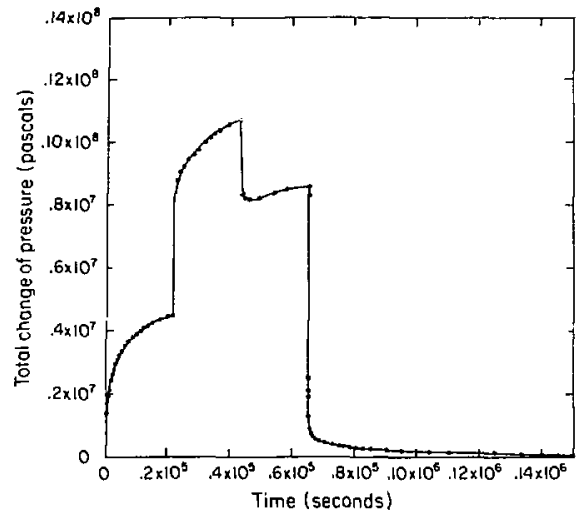

Figure 1. Simulated pressure buildup during nonisothermal injection. [XBL 841-9569)

Table 1. Reservoir and fluid properties used in the numerical simulations.

\begin{tabular}{lll}
\hline Parameter & Units & Step-rate test \\
\hline$k$ & $\left(\mathrm{~m}^{2}\right)$ & $10^{-14}$ \\
$H$ & $(\mathrm{~m})$ & 1 \\
$\phi$ & $(-)$ & 0.2 \\
$c_{r}$ & $\left(\mathrm{~J} / \mathrm{kg}^{\circ}{ }^{\circ} \mathrm{C}\right)$ & 1000 \\
$\rho_{r}$ & $\left(\mathrm{~kg}^{3} / \mathrm{m}^{3}\right)$ & 2200 \\
$\lambda$ & $\left(\mathrm{J} / \mathrm{kg}^{\circ}{ }^{\circ} \mathrm{C}-\mathrm{s}\right)$ & 2.0 \\
$\beta_{t}$ & $\left(\mathrm{~Pa}{ }^{-1}\right)$ & $1 \times 10^{-9}$ \\
$r_{w}$ & $(\mathrm{~m})$ & 0.1 \\
$T_{i n}$ & $\left({ }^{\circ} \mathrm{C}\right)$ & 20 \\
$T_{r}$ & $\left({ }^{\circ} \mathrm{C}\right)$ & 250 \\
$k_{r i}$ & $(-)$ & 1 \\
$\rho_{i}$ & $\left(\mathrm{~kg} / \mathrm{m}^{3}\right)$ & 1005 \\
$\mu_{i}$ & $(\mathrm{~Pa}-\mathrm{s})$ & $10^{-3}$ \\
$k_{r o}$ & $(-)$ & 1 \\
$\rho_{o}$ & $\left(\mathrm{~kg} / \mathrm{m}^{3}\right)$ & 800 \\
$\mu_{0}$ & $(\mathrm{~Pa}-\mathrm{s})$ & $10^{-4}$ \\
\hline & & \\
\hline & &
\end{tabular}

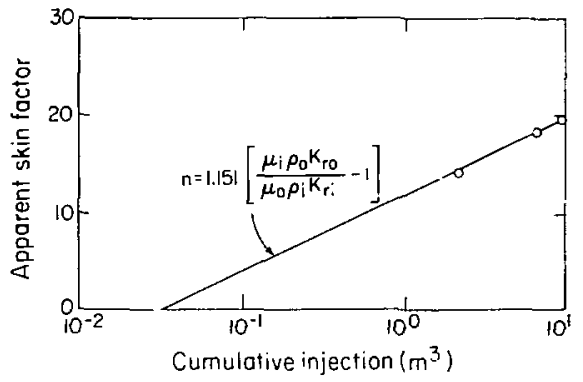

Figure 2. Apparent skin factors vs cumulative injection for the step-rate test. [XBL 841-9570]

\section{CONCLUSIONS}

A method for tracking fronts during waterflooding or geothermal injection operations has been developed. The method is based on the concept of using a fluid skin factor to account for the effects of the fluid heter zeneity around the injection well. This front tracking method requires that conventional pressure falloff tests be conducted after increasing periods of injection. The method is most successfully applied early during waterflooding or geothermal injection operations, when the resolution of the radial distance to the front is greatest. The technique is applicable to many two-fluid composite systems in which the movement of the front depends on $t / r^{2}$. It may also be possible, with minor modifications, to extend this method to fractured systems in which the front advances at a rate that is proportional to $t / r^{4}$.

\section{REFERENCES}

Benson, S.M., 1982. Analysis of nonisothermal steprate tests. In Proceedings, 8th Annual Workshop on Geothermal Reservoir Engineering, Stanford University, Stanford, Californie, December 14-16, 1982, p. 103-110, I.BL-14949.

Benson, S.M., and Bodvarsson, G.S., 1982. Nonisothermal effects dLring injection and falloff tests. Presented ai the 57th Annual Technical Conference and Exhibition, Society of Petroleum Engineers of ATME, New Orleans, Louisiana, Seprember 26-29, 1982, SPE-11137 (LBL14270).

Benson, S.M., and Bodvarsson, G.S., 1983. A pressure transient method for front tracking. 
Presented at the 58th Annual Technical Conference and Exhibition, Society of Petroleum Engineers of AIME, San Francisco, California, October 5-8, 1983, SPE-12130 (LBL-16574).

Bodvarsson, G.S., and Tsang, C.F., 1980. Thermal effects in well tests of fractured reservoirs. In Proceedings, Third Invitational Well-Testing Symposium, Lawrence Berkeley Laboratory. Berkeley, California, March 26-28, 1980, Lawrence Berkeley Labortory, LBL-12076.

\section{A TEST FACILITY TO INVESTIGATE TWO-PHASE STEAM/WATER FLOW IN POROUS MEDIA}

\author{
A. Verma, K Pruess, G.S. Bodvarsson, C.F. Tsang, \\ and P.A. Witherspoon
}

The concept of relative permeability is the key to extending Darcy's law for single-phase flow through porous media to the two-phase flow regime. Relative permeability functions are needed for simulation studies of two-phase geothermal reservoirs. These remain poorly known even though considerable theoretical and experimental investigations have been undertaken during the past decade. An effort is underway to develop a facility for determining these functions and their dependence on fluid and reservoir properties and the flow parameters. Our approach is summarized in Fig. 1. Thermodynamic studies are carried out to develop the equations governing two-phase steam/water flow in porous media and to analyze the relationship between mass flow rate and flowing enthalpy. These relationships will be verified agannst experimental results and subsequently will be used to develop a field analysis technique to obtain in situ relative permeability parameters.

Currently our effort is concentrated on thermodynamic analysis and development of an experimental facility. This article presents some of the findings of our theoretical work and describes the design and development effort for the experimental facility.

\section{BASIC STUDIES}

We discuss first the mechanism of phase trapping and the effect of pore geometry on the relative permeabìity functions.
Earlougher, Jr., R.C., 1977. Advances in Well Analysis. Society of Petroleum Enginers, Monograph 5.

Tsang, Y.W., and Tsang, C.F., 1978. An analytic study of geothermal reservoir pressure response to cold water reinjection. In Proceedings, 4th Workshop on Geothermal Reservoir Engineering, Stanford University, Stanford, California, December 13-15, 1978. SGP-TR-30, p. 322331 .

\section{Phase Trapping}

Phase trapping can occur when one of the phases becomes immobile under the action of capillary pressure in a channel full of the other phase, which flows around the trapped phase. Both water and steam can be trapped in flow channels when the thermodynamic conditions are such that the net rate of phase transformation, at the interface of the trapped phase and the flowing phase, equals zero. This phenomenon is important to our study for two reasons:

1. Phase trapping is a major mechanism of permeability reduction.

2. Phase trapping can lead to local changes that are hysteretic in nature (observed by Udell (1983) in his "Hot Wire" experiment).

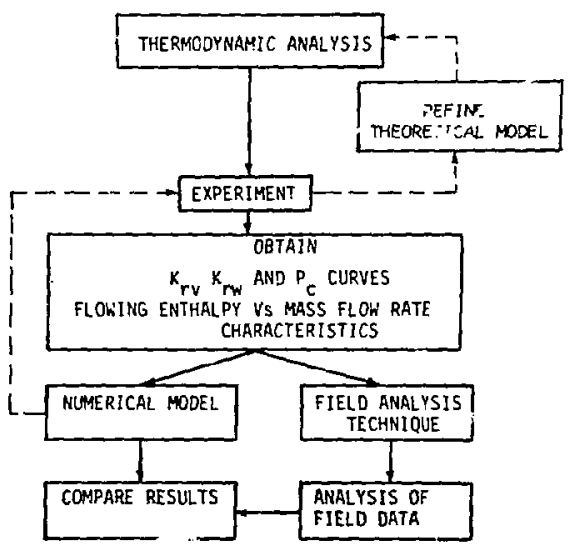

Figure 1. Overall approach to obtaining relative permea bility functions. [XBL 841-311] 
The thermodynamics of curved interfaces has been invoked (Verma et al., 1983) to show that (1) the vapor phase can be trapped when liquid is flowing in the direction of increasing temperature; and (2) the liquid phase can be trapped if vapor is flowing in the direction of decreasing temperature, and

$$
\frac{\partial}{\partial x}\left(T / P_{c}\right)<0
$$

where $T, x$, and $P_{\mathrm{c}}$ are temperature, linear distance, and capillary pressure, respectively. This indicates that the relative permeability of a phase may depend not just on saturation but also on the local temperature gradient.

\section{Effect of Pore Geometry}

To study the effect of porr geometry on relative permeability functions, we use an approach similar to that of Yuster (1951). The two cros sections considered are (1) a circular tube, and (2) a plane fracture. In both cases, the flow is assumed to be separated, with water being the wetting fluid. We also assume that the surface temperature distribution is such that no flashing or condensation can occur. Under these conditions, the relative permeability functions for the circular tube are (Yuster, 1951):

$$
k_{\mathrm{nw}}=\left(1-S_{v}\right)^{2}
$$

and

$$
k_{v v}=2 S_{v} \frac{\mu_{v}}{\mu_{w}}+S_{v}^{2}\left(1-2 \frac{\mu_{v}}{\mu_{w}}\right) .
$$

Following the same line of reasoning, we can show that for plane fractures

$$
k_{n w}=1-1.5 S_{v}+0.5 S_{v}^{3}
$$

and

$$
k_{n}=1.5 \frac{\mu_{v}}{\mu_{w}} S_{v}-S_{v}^{3}\left(1.5 \frac{\mu_{v}}{\mu_{w}}-1\right) .
$$

Figure 2 shows a plot of these relative permeability curves for

$$
\frac{\mu_{v}}{\mu_{w}}=0.4 \text { and } 0.1
$$

From these curves, we can see that for a given saturation the parallel-plate configuration has a

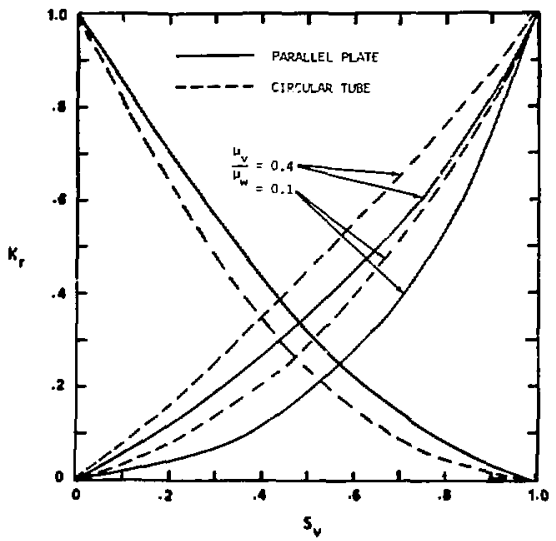

Figure 2. Relative permeability curves from idealized capillary models. [XBL 841-315]

higher relative permeability for the water phase than the circular tube model. However, the vapor phase relative permeability has the oppenite trend. The reason is that for a given saturation the parallel-plate configuration will have a thicker water layer than the circular tube model.

It is easy to show from Eqs. (1)-(4) that in the two-phase zone (i.e., $0<S_{v}<1$ ), the sum of relative permeabilities is less than 1 (i.e., $k_{n w}+k_{n}<1$ ) as long as the viscosity ratio $\left(\mu_{v} / \mu_{w}\right)$ remains less than unity. However, this model is rather simplistic, and further studies are needed to include the effects of phase transformation.

\section{EXPERIMENTAL SETUP: DESIGN AND OPERATING CONDITIONS}

The proposed experimental setup (Fig. 3) is similar to that of Reda and Eaton (1981). The test sample is a sand pack in a glass cylinder ( 3 in. I.D. $\times 36$ in. long) mounted vertically to avoid flow stratification. The outer surfaces of this cylinder are made adiabatic, with the aid of computer-controlled guard heaters. Liquid water at constant temperature is sumped into the inlet end of the test sample at a constant flow rate with the aid of a dual-cylinder. constant-flow-rate meten $\$$ pump.

Electric heaters are installed inside the porous matrix at the inlet end. A controlled amount of power is supplied to these heaters through a stabilized power supply to cause boiling, and the power 


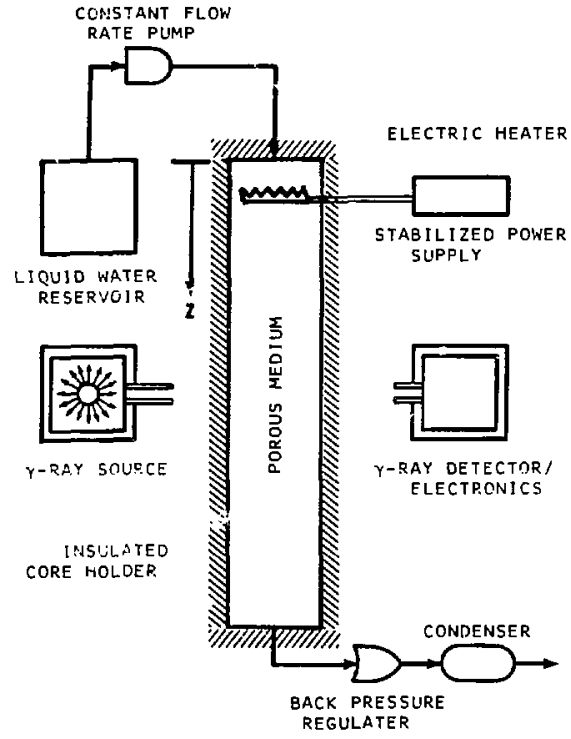

Figure 3. Schematic of the experimental setup. $\mathrm{XBL}$ $841-314 \mid$

input is adjusted to achieve the required flow quality. The mixture of steam and water leaves the test sample through an exit chamber designed to reduce the end effects. The exit end is maintained at constant pressure with the aid of a back pressurt regulator.

Pressure, temperature, capillary pressure, and saturation readings are taken at regular intervals in the central portion of the test column. Saturation readings are taken with the aid of a $\gamma$-ray densitometer, which avoids disturbing the flow.

Desirable operating conditions have been studied with the aid of numerical modeling. It was speculated that the effect of capillary pressure and the end effects resulting from it would be very significant. To study these effects, various capillar' pressure curves were incorporated in the numerical code MULKOM (Pruess, 1983) so that iest runs could be simulated. A typical result of a simulation with the end effects is shown in Fig. $4 a$, and for the purpose of comparison a typical iesult withou: the end effect is sinown in Fig. 4b. From these results, we can see that, although the four parameters of interest $\left(P_{v}, P_{c}, T\right.$, and $\left.S_{v}\right)$ vary monotonically with more or
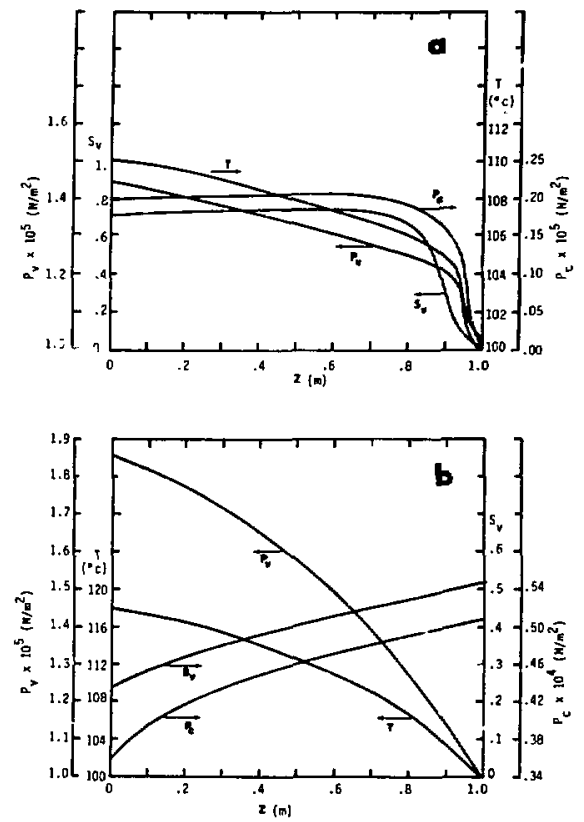

Figure 4. Simulated results of the experiment (a) with the end effects and (b) without the end effects. (a) XBL 841-313; (b) XBL 841-312]

less constant gradient in Fig. $4 b$, the end effects cause a very sharp gradient of $P_{v}, T, P_{c}$, and $S_{p}$ over the last $20 \mathrm{~cm}$ of the test column near the exit end. This phenomenon occurs because of the physical nature of the problem, which requires that the capillary pressure must equal zero at the exit.

We have also considered the effects of matrix properties, boundary conditions, and the relative permeability finctions on the simulated results of the proposed experiment. Results of simulations using many parameter combinations show that it is possible to obtain a region of almost constant saturation over an extended length of the test column. Readings taken in this region can be analyzed to yield relative permeabilities without much difficulty.

The analysis technique follows that of Reda and Eaisn (1981). By considering the conservation of mass and energy in a two-phase concurrent flow in a vertical test section, we derive the following relationships: 


$$
\begin{aligned}
f & =\frac{m_{0}\left(h_{0}-h_{w}\right)-m_{0} g z+q_{0}-q}{m_{0}\left(h_{v}-h_{w}\right)}, \\
k_{w} & =\frac{(f-1) m_{0} \mu_{v}, v_{w}}{k A \frac{d}{d z}\left(P_{w}+\rho_{w} g z\right)}, \\
k_{r v} & =\frac{f m_{0 \mu_{v} P_{v}}}{k A \frac{d P}{d z}} .
\end{aligned}
$$

In each of Eqs. (5)-(7), the right-hand side consists of quantities that are either known or can be measured from the experiment, hence Eqs. (6) and (7) can be used to calculate the relative permeabilities.

\section{SUMMARY}

Criteria for phase trapping in flow channels have been developed from the thermodynamics of curved interfaces. We show that the vapor phase can be trapped if liquid is flowing in the direction of higher temperature. On the other hand, liquid can be trapped if vapor is flowing in the direction of lower temperature. From ideal capillary analysis, we conclude that the shapes of the relative permeability functions depend on the pore geometry and the viscosity ratio of steam and water. We also show that the sum of the relative permeabilities in the two-phase zone is generally less than unity. Our analysis neglects phase change, and a more realistic treatment of steam-water flow is needed before conclusive results can be obtained. From the basic studies, we conclude that the relative permeability func-

\section{FLUID AND HEAT FLOW IN GAS-RICH GEOTHERMAL RESERVOIRS}

\section{M.J. O'Sullivan, * G.S. Bodvarsson, and K. Pruess}

Many geothermal reservoirs contain large amounts of noncondensible gases, particularly carbon dioxide. The proportion of noncondensible gas

Department of Engineering, University of Aukland, New Zealand. tions may depend, among other parameters, on the fluid properties, the pore geometry, and the flow conditions.

Results of the numerical studies show that the end effects can be very significant. However, it is possible to design an experiment in which a nearly constant vapor saturation region exists over an extended portion of the test sample. In this region, the capillary pressure gradient is small, and thus the experimental data can be easily interpreted.

\section{REFERENCES}

Pruess, K., 1982. Development of the general purpose simulator MULKOM. Earth Sciences Division Annual Report 1982. Lawrence Berkeley Laboratory, LBL-15500, p. 133-134.

Reda, D.C., and Eaton, R.R., 1981. Definition of a facility for experimental studies of two-phase flows and heat transfer in porous materials. AIAA 16th Thermophysics Conference, Paper No. AIAA-81-1190.

Udell, K., 1983. Heat transfer in porous media heated from above with evaporation, condensation and capillary effects. Journal of Heat Transfer, August 1983, p. 485-492.

Verma, A.K., Pruess, K., Bodvarsson, G.S., Tsang, C.F., and Witherspoon, P.A., 1983. Design and development of a test facility to study two-phase steam/water flow in porous media. Presented at the 9th Geothermal Workshop, Stanford University, Stanford, California, December 13-15, 1983.

Yuster, S.T., 1951. Theoretical considerations of multiphase flow in idealized capillary systems. In Proceedings, 3rd World Petroleum Congress, p. 437-445.

in the produced fluid is an extremely important factor in the design of separators, turbines, heat exchangers, and other surface equipment. In the reservoir itself, the presence of carbon dioxide signjficantly alters the distribution of temperature and gas saturation (volumetric fraction of gas phase) assnciated with given heat and mass flows. Therefore, when modeling gas-rich reservoirs, it is essential to keep track of the amount of $\mathrm{CO}_{2}$ in each grid block in addition to the customary fluid and heat content.

The simulations discussed here were carried out using the multicomponent, two-phase reservoir simulator MULKOM (Pruess, 1983). The $\mathrm{H}_{2} \mathrm{O}-\mathrm{CO}_{2}$ thermodynamic package used in this study is an improved version of the one used earlier by Zyvo- 
loski and O'Sullivan (1980) in a geothermal simulator developed at the University of Auckland. It is based mainly on work by Sutton and McNabb (1977) on the properties of a mixture of carbon dioxide and water. The $\mathrm{H}_{2} \mathrm{O}-\mathrm{CO}_{2}$ package is described by O'Sullivan et al. (1983).

The aim of this study is to investigate the effects of $\mathrm{CO}_{2}$ on the behavior of a reservoir in both its natural state and under exploitation. Several generic simulation studies are described. First, the effect of $\mathrm{CO}_{2}$ on the depletion of a single-block, lumpedparameter reservoir model is briefly examined. Second, the relationship between the mass fraction of $\mathrm{CO}_{2}$ in the produced fluid and the mass fraction in place in the reservoir is studied. Third, the effects of $\mathrm{CO}_{2}$ on the vertical distribution of gas saturation, temperature, and pressure of geothermal reservoirs in the natural state are investigated. The numerical simulator with the $\mathrm{H}_{2} \mathrm{O}-\mathrm{CO}_{2}$ thermodynamic package is applied to field data from the Ohaaki (formerly Broadlands) geothermal field in New Zealand.

\section{BASIC PROPERTIES OF $\mathrm{CO}_{2}-\mathrm{H}_{2} \mathrm{O}$ MIXTURES}

In Fig. 1, the mass fractions of $\mathrm{CO}_{2}$ in the liquid phase and gas phase, respectively, of a boiling $\mathrm{CO}_{2}$ $\mathrm{H}_{2} \mathrm{O}$ mixture are shown as functions of temperature (the partial pressure of $\mathrm{CO}_{2}$ is 10 bars). The figure shows that even for this moderately high partial pressure of $\mathrm{CO}_{2}$, the total amount of $\mathrm{CO}_{2}$ that can be dissolved in the liquid phase is small. Therefore, if a sufficiently large amount of $\mathrm{CO}_{2}$ is introduced into a body of liquid water at fixed temperature and total pressure, the mixture must boil and evolve a gas phase. The gas phase contains a mixture of the excess $\mathrm{CO}_{2}$ not dissolvable in the liquid and water

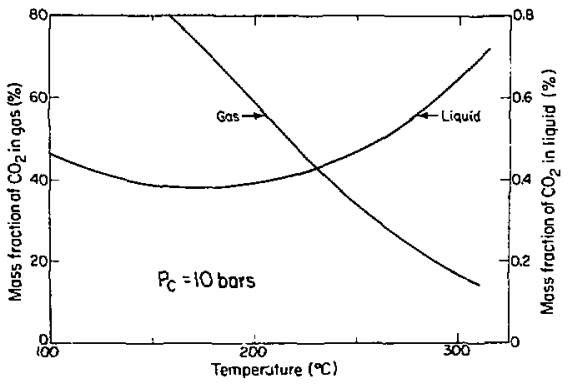

Figare 1. Mass fraction of $\mathrm{CO}_{2}$ in liquid and gaseous phase. [XBL 837-1900] vapor at a partial pressure correspondine to the system temperature. For conditions of interest in geothermal systems, the mass of $\mathrm{CO}_{2}$ present in a unit volume of gas phase is larger than that present in a unit volume of liquid phase. Therefore, if $\mathrm{CO}_{2}$ partial pressure is kept constant, an increase in the mass fraction of $\mathrm{CO}_{2}$ can be accommodated only by an increase in gas-phase saturation. The increase of gas saturation that accompanies an increase in the mass fraction of $\mathrm{CO}_{2}$ is the single most important effect of the $\mathrm{CO}_{2}$, as the total mixture mobility greatly depends upon the volumetric fractions of liquid and gaseous phases present. The changes in density, viscosity, and enthalpy of the individual phases caused by the presence of $\mathrm{CO}_{2}$ are comparatively minor.

It can be shown that, for fixed values of $p$ and $p_{c}$, there is a simple linear relationship between flowing enthalpy and flowing $\mathrm{CO}_{2}$ content. This relationship is shown in Fig. 2 for various values of the partial pressure of $\mathrm{CO}_{2}$ at a temperature of $260^{\circ} \mathrm{C}$. The exact positions on these curves for values obtained from production data from a particular well depend both on the gas saturation of the boiling mixture and on the relative permeability curves that apply. Also shown in Fig. 2 are data points representing monthly samples taken from several wells at Ohaaki (Ministry of Works and Development, 1977). The temperature at the feed zone for the different wells varies, but the corresponding curves are not very different from those given in Fig. 2. These points show production data after some initial degassing near the well has occurred and

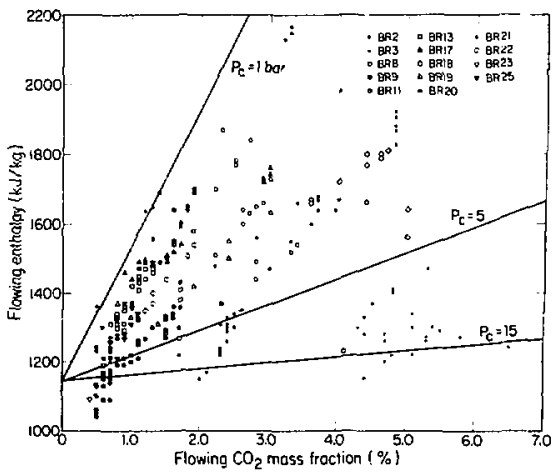

Figure 2. Variation of flowing enthalpy $\mathrm{CO}_{2}$ fraction. Monthly production data from Ohaaki is also shown. [XBL 837-1899] 
therefore are not inconsistent with estimates for the partial pressure in the main reservoir at Ohaaki of up to 30 bar.

To demonstrate the effect of $\mathrm{CO}_{2}$ in a geothermal reservoir in a very simple way, the depletion of a lumped-parameter reservoir model was simulated. A block of volume $1.0 \mathrm{~m}^{3}$ with forosity 0.15 , density $2500 \mathrm{~kg} / \mathrm{m}^{3}$, and specific heat $900 \mathrm{~J} / \mathrm{kg}-{ }^{\circ} \mathrm{C}$, initially at a temperature of $260^{\circ} \mathrm{C}$, a gas saturation of 0.2 , and $\mathrm{CO}_{2}$ partial pressures of either 0 or 30 bar was produced at a constant rate of $5 \mathrm{~kg} / \mathrm{s}$. The results obtained show that the pressure drop due to degassing occurs rapidly. The flowing $\mathrm{CO}_{2}$ mass fraction is much greater than the mixture or the inplace $\mathrm{CO}_{2}$ mass fraction for gas saturations of $\mathrm{O} . \mathrm{i}$ or greater, so that the $\mathrm{CO}_{2}$ is quickly exhausted. After the early degassing period, the pressure decline curves for both cases ( $P_{\mathrm{CO}}=0$ and 30 bars) are practically the same. The duration of the degassing period depends strongly on the relative permeability curves used; in general, curves that show high mobility of the gas phase will give shorter durations.

\section{$\mathrm{CO}_{2}$ CONTENT IN PRODUCED FLUIDS}

A calculation similar to that carried out by O'Sullivan (1981), who used asymptotic methods to show that production enthalpy must stabilize, can also be used to show that the $\mathrm{CO}_{2}$ content in the produced fluids must stabilize. Grant (1979) gave an approximate derivation of this result for the special case of gas-dominated reservoirs.

A number of well-test simulations were carried out to investigate the relationship between production enthalpy and production $\mathrm{CO}_{2}$ content. To make the results comparable to extensive field data from Ohaaki, New Zealand (Ministry of Works and Development, 1977), a number of different initial gas saturations and flow rates were tested at an initial temperature of $260^{\circ} \mathrm{C}$. Figure 3 shows the results of some of these simulations. The solid curves show the loci of late-time stable production enthalpies, $\mathrm{H}_{f}(\infty)$, with respect to initial partial pressure of $\mathrm{CO}_{2}$ and initial gas saturation for a constant and relatively high flow rate. The general effect of flow rate is shown by the dotted and broken curves, which indicate the change in location of the solid curve network as flow rate is reduced. For example, for an initial $\mathrm{CO}_{2}$ partial pressure of $p_{\mathrm{CO}}=5$ bars and an initial gas saturation of $S_{g o}=0.3, H_{r}(\infty)$ and $f_{c}(\infty)$ at the high flow rate are $1680 \mathrm{~kJ} / \mathrm{kg}$ and $2.8 \%$, respectively; at a very low flow rate, they are $1293 \mathrm{~kJ} / \mathrm{kg}$ and $2.3 \%$, respectively.

All the results shown in Fig. 3 were obtained using the Corey relative permeability curves. Other

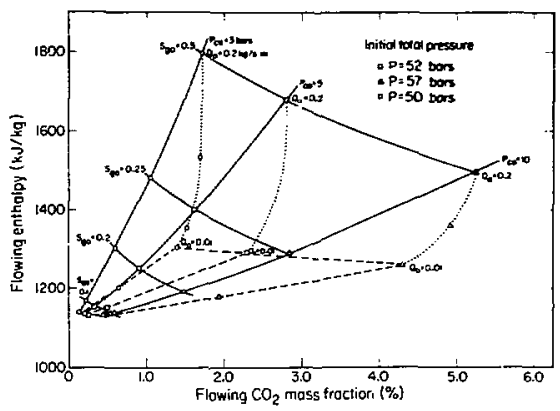

Figure 3. Stabilized flowing enthalpy vs stabilizing flowing $\mathrm{CO}_{2}$ content. $S_{g o}=$ initial gas saturation, $P_{\mathrm{CO}}=$ initial partial pressure of $\mathrm{CO}_{2}, P=$ initial total pressure, $Q=$ flow rate. Corey relative permeability curves. [XBL 8371903]

relative permeability curves will show the same general trends but at vastly different scales. We have also found that although the stable flowing enthalpy depends strongly upon porosity (Bodvarsson el al., 1980 ), the stable flowing $\mathrm{CO}_{2}$ mass fracture is only weakly dependent on porosity.

\section{DETERMINATION OF GAS SATURATION AND RELATIVE PERMEABILITIES}

The results presented above show how variations in initial in-place conditions affect the production enthalpy and $\mathrm{CO}_{2}$ mass fraction. In practice, the inverse problem is usually the important one: Given the production data, what can be deduced about the thermodynamic state of the reservoir? It. turns out that measurement of the flowing $\mathrm{CO}_{2}$ mass fraction can assist in determining in-place conditions. Bodvarsson et al. (1980) showed how data on flowing enthalpy during a well test could be used to deduce the ratio $k_{r g} / k_{r l}$ as a function of flowing enthslpy. It was pointed out, however, that this procedure did not give $k_{\mathrm{rg}} / k_{\mathrm{rl}}$ as a function of flowing $\mathrm{CO}_{2}$ mass ifaction.

What is really required is a means of deducing gas saturation or, equivalently, in-place enthalpy or in-place $\mathrm{CO}_{2}$ mass fraction. A careful examination of Fig. 3 indicates that it may be possible to deduce in-place gas saturation from the stable flowing $\mathrm{CO}_{2}$ mass fraction, $f_{\sigma f}(\infty)$. The key points to observe are that $f_{f f}(\infty)$ depends very weakly on both flow rate and porosity but strongly on initial saturation.

In view of these results, curves such as those shown in Fig. 4 can be used to calculate the in-place 


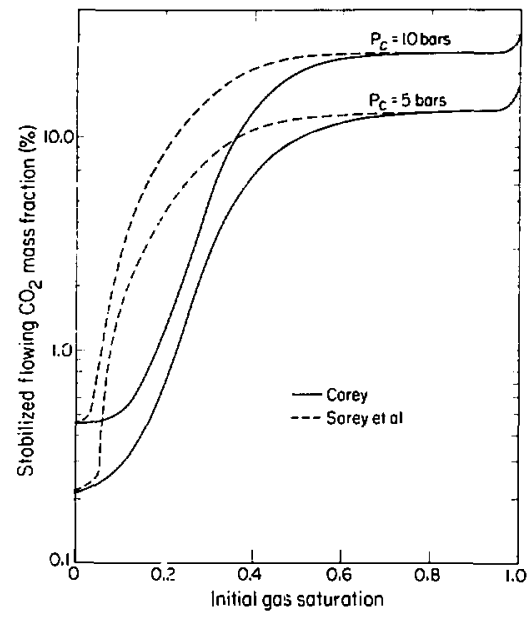

Figure 4. Variation of stabilized flowing $\mathrm{CO}_{2}$ mass fraction with flow rate. [XBL 837-1896]

gas saturation in a reservoir, even when the porosity and permeability (or the parameter group $Q / \mathrm{kh}$ ) are unknown. The partial pressure of $\mathrm{CO}_{2}$ can be determined from downhole pressure and temperature measurements, and then the $f_{c f}(\infty)$ vs $S_{g}$ curves for the correct temperature and partial pressure can be selected. Errors of a few degrees in temperature or a few bars in the partial pressure of $\mathrm{CO}_{2}$ will have a negligible effect on the results. A measurement of $f_{o f}(\infty)$ during a constant-rate production test can be used to obtain the in-place gas saturation. The only drawback of this process is that the shape of the $f_{f f}(\infty)$ vs $S_{g}$ curves depends on the choice of relative permeability curves.

If a number of tests are performed and the rise in flowing enthalpy is measured in each case, some progress can be made-but only if estimates of porosity and permeability are available. Plots such as those given by Bodvarsson et al. (1980) can be used to distinguish between the two rases. Flowing enthalpy will increase much more rapidly with increase in flow rate for the case of $S_{g}=0.3$ than for the case of $S_{g}=0.13$. However, in determining the correct scale for flow rate, it is necessary to know the permeability; and in choosing the relevant curve to match, the porosity must be known.

In summary, the measurement of stable flowing $\mathrm{CO}_{2}$ mass fraction enables vapor saturation to be determined for each set of relative permeability curves being considered. Distinguishing between the different options requires knowledge of porosity and permeability and observation of the change in stable flowing enthalpy with flow rate.

\section{WELL-TEST ANALYSIS}

Pritchett et al. (1981) showed that the addition of quite small amounts of $\mathrm{CO}_{2}$ produces large changes in the pressure drop during a constant-rate well test. In the example they considered, the initial total pressure and temperature were fixed while the $\mathrm{CO}_{2}$ content was accompanied by large changes in the initial gas saturation; this probably explains most of the observed differences in mobility. To examine the effects of $\mathrm{CO}_{2}$ on the pressure decline when the gas saturation effects are removed, a number of simulations were run with fixed initial temperature and gas saturation but different initial partial pressures of $\mathrm{CO}_{2}$ and therefore different initial total pressures. The presence of $\mathrm{CO}_{2}$ has two effects. First, degassing causes a more rapid pressure decline at early times; second, the lower flowing enthalpy with $\mathrm{CO}_{2}$ present causes a slower decline of temperature, and therefore pressure, at later times. Our results show that very different (by a factor of 2 or more) slopes of the semilog pressure plot can be obtained when the initial $\mathrm{CO}_{2}$ content is varied. Consequently, significant errors could easily be made in deducing $k h$ from the slope of the semilog pressure plot unless accurate information on the $\mathrm{CO}_{2}$ content is available.

\section{NATURAI-STATE STUDIES}

To determine the effect of $\mathrm{CO}_{2}$ on the natural thermodynamic state of geothermal systems, numerical studies of a simple vertical column model were carried out. The model consists of two zones, a "cap rcck" extending from ground surface to $300 \mathrm{~m}$ with a permeability of 0.5 mdarcy and an underlying 700-m-thick reservoir zone with a permeability of 20 mdarcies. The thermal conductivity of both zones was assumed to be $2.0 \mathrm{~W} / \mathrm{m}-{ }^{\circ} \mathrm{C}$; other reservoir parameters such as porosity and heat capacity (storage type parameters) do not affect steady-state results. Heat and mass were injected at the base of the model in order to simulate the upflow zone in a geothermal system. Ambient conditions were prescribed at ground surface $\left(T=10^{\circ} \mathrm{C}, P=1 \mathrm{bar}\right)$.

In the first series of simulations, the system was modeled without $\mathrm{CO}_{2}$; mass and energy flow through the system were adjusted until a small two-phase zone developed in the upper portion of the reservoir. This occurred when $2.0 \mathrm{~kg} / \mathrm{s}-\mathrm{km}^{2}$ of water, with an enthalpy of $1300 \mathrm{~kJ} / \mathrm{kg}$, was injected at the bottom of 
the model. Progressively larger and larger quantities of $\mathrm{CO}_{2}$ were then added to the injected fluid. The results show that quite small quantities of $\mathrm{CO}_{2}$ have a large effect on the thermodynamic state of the sys$\mathrm{um}$. In the case of $1 \%$ flowing $\mathrm{CO}_{2}$ mass fraction (corresponding to smaller in-place values), the boiling zone spreads throughout the whole column. For stili higher concentrations of $\mathrm{CO}_{2}$, gas saturation increases at the base of the cap rock and throughout most of the cap rock. In the reservoir, the gas saturation is close to the residual steam saturation. Thus, for a given heat flux, the higher the $\mathrm{CO}_{2}$ content in the fluids, the larger the two-phase zone that will develop. Moreover, the maximum gas saturation and partial pressure of $\mathrm{CO}_{2}$ can occur at shallow depths. This is consistent with field observations from some wells at the Krafla geothermal field, Iceland (V. Stefansson, personal communication, 1982).

\section{APPLICATION TO FIELD DATA}

When applied to the Ohaaki geothermal field in New Zealand, the vertical column model was found to agree very well with the natural thermodynamic state of that field (pressure and temperature profiles). The partial pressure of $\mathrm{CO}_{2}$ in the primary reservoir is calculated to be $15-25$ bars, with partial pressure increasing with depth. The behavior of the field during exploitation (1966-1971) and recovery was also modeled. Reasonable matches were obtained with the pressure drawdown, the produced enthalpy, and the produced $\mathrm{CO}_{2}$ content, which allowed determination of the vertical permeability distribution within the system. This work is described in O'Sullivan et al. (1983).

\section{CONCLUSIONS}

The results of this investigation show that the effects of a noncondensible gas such as $\mathrm{CO}_{2}$ on geothermal reservoir behavior can be extremely important. In the natural state, $\mathrm{CO}_{2}$ increases the size of the boiling zone considerably. During exploitation, the gas escapes rapidly, leading to a large, early pressure drop.

The presence of $\mathrm{CO}_{2}$ significantly affects the results of transient well tests. The pressure response is fastor at early times because of degassing and slower at later times because of a reduced flowing enthalpy. The measurement of the $\mathrm{CO}_{2}$ mass fraction in the produced fluid during a well test can be used to deduce the in-place gas saturation in the reservoir if the relative permeabilities are known. The model was successfully applied to the Ohaaki geothermal field in New Zealand.

\section{REFERENCES}

Bodvarsson, G.S., O'Sullivan, M.J., and Tsang, C.F., 1980. The sensitivity of geothermal reservoir behavior to relative permeability parameters. In Proceedings, 6th Annual Workshop on Geothermal Reservoir Engineering, Stanford University, Stanford, California, December 16-18, 1980, p. 224-237.

Grant, M.A., 1979. Water content of the Kawah Kamojang geothermal reservoir. Geothermics, v. 8, p. $21-30$.

Ministry of Works and Development, 1977. Broadlands Geothermal Investigation Report, M.W.D., Wellington, New Zealand.

O'Sullivan, M.J., 1981. A similarity method for geothermal well test analysis. Water Resources Research, v. 17, no. 2, p. 390-398.

O'Sullivan, M.J., Bodvarsson, G.S., Pruess, K., and Blakeley, M.R., 1983. Fluid and heat flow in gas-rich geothermal reservoirs. Presented at the 58th Annual Technical Conference and Exhibition, Society of Petroleum Engineers of AIME, San Francisco, California, October 5-8, 1983, SPE-12012 (LBL-16329).

Pritchett, J.W., Rice, M.H., and Riney, T.D., 1981. Equation-of-state for water-carbon dioxide mixtures: Implications for Baca reservoir. Topical report No. DOE/ET/27163-8, Systems, Science and Software, La Jolla, California.

Pruess K., 1983. Development of the general purpose simulator MULKOM. Earth Sciences Division Annual Report 1982. Lawrence Berkeley Laboratory, LBL-15500, p. 133-13.4.

Sutton, F.M., and McNabb, A., 1977. Boiling curves at Broadlands field, New Zealand. New Zealand Journal of Science, v. 20, 333-337.

Zyvoloski, G.A., and O'Sullivan, M.J., 1980. Simulation of a gas-dominated, two-phase geothermal reservoir. Society of Petroleum Engineers Journal, v. 20 , no. 1 , p. 52-58. 
TOUGH: A NUMERICAL MODEL FOR STRONGLY HEAT DRIVEN FLOW IN PARTIALLY SATURATED MEDIA

\section{K. Pruess}

TOUGH is a member of the MULKOM family of codes (Pruess, 1983); it was developed primarily for assessing the performance of a high-level nuclear waste repository in the unsaturated tuff formations at the Nevada Test Site. The name "TOUGH" is an acronym for Transport of Unsaturated Groundwater and Heat. The code can also be applied to the design and analysis of laboratory experiments in two-phase flow, to problems in the subsurface storage of compressed air, and to the study of geothermal reservoirs with a free surface.

\section{APPROACH}

Emplacement of high-level nuclear waste in partially saturated rocks of low permeability will give rise to a strongly heat driven problem, in which fluid flow occurs as a consequence of thermal expansion and phase change (boiling). Near the waste packages, solute temperatures may almost double (from ambient $300 \mathrm{~K}$ to near $600 \mathrm{~K}$ ). From the ideal gas law, $p V=n R T$, one expects large increases in pressure and/or volume of the gas phase, which will give rise to strong forced convection of the gas-phase from thermal expansion. Even stronger gas phase flow effects are expected from vaporization of water, which will become vigorous when the formation temperature exceeds $100^{\circ} \mathrm{C}$.

The conventional description of unsaturated flow assumes isothermal conditions (Narasimhan, 1982a), or "weakly" nonisothermal systems, in which the overall movement of the gas phase is negligible (Milly, 1982). This kind of approximation is not applicable to the nuclear waste isolation problem. The code TOUGH employs a multiphase approach to fluid and heat flow that fully accounts for the movement of gaseous and liquid phases and their transport of latent and sensible heat. The formulation used in TOUGH is analogous to the multiphase, multicomponent treatment customarily employed in simulators for geothermal reservoirs (Pruess, 1983) or for steamflooding of hydrocarbon reservoirs (Coats, 1978; Pruess and Bodvarsson, 1983). The gas phase will in general consist of a mixture of air and vapor, and both these components must be accounted for separately. Liquid and gas phases can flow in response to pressure gradients and gravity according to Darcy's law. Capillary pressure is considered to depend on saturation and temperature, but not on the flow history of the system. The interaction between flowing liquid and gaseous phases is represented by nonhysteretic relative permeability functions. Capillary pressures and relative permeabilities can be specified differently for different flow regions, which is considered an important capability for fractured rocks with spatially variable pore size distribution. Apart from Darcy flow, the code also includes a term for vapor transport via binary diffusion. Phase change effects are included both in the mass flux terms and in the heat transport. We have assumed local thermodynamic equilibrium; i.e., rock and fluid are always at the same temperature and pressure locally, and vapor partial pressure is always equal to the saturation pressure at the given local temperature. No allowance was made for vapor pressure lowering due to capillary and adsorptive effects. Temperature differences between connected fluid-filled pores and large chunks of solid rock can be handled through appropriate space discretization (see below). Heat transport is by means of conduction or convection.

The thermophysical properties of water substance, such as density, viscosity, and enthalpy, are represented within experimental accuracy by the steam table equations given by the International Formulation Committee (1967). Air is approximated as an ideal gas, and additivity of partial pressures is assumed for air and vapor. The (small) solubility of air in water is represented by Henry's law.

\section{METHODOLOGY}

The coupled fluid and heat flow processes are represented by mass balance equations for water and air substance, respectively, and by an energy balance on the rock-fluid mixture. The basic balance equations are valid for arbitrary irregular flow domains and for porous and fractured media alike. In TOUGH, the governing equations are discretized spatially by means of an integral finite-difference method, which facilitates treatment of multidimensional systems and fractured porous media (Narasimhan, 1982b; Pruess and Narasimhan, 1982). To provide the computational stability necessary for multiphase flow systems with phase transitions, time is discretized fully implicitly as a first-order finite difference. The discretized equations for a flow domain with $N$ volume elements form a set of $3 N$ coupled algebraic equations for the primary thermodynamic variables. These are solved completely 
simultaneously, using Newton-Raphson iteration. The linear equations arising at each iteration step are solved with the Harwell subroutine package "MA28," which employs Gaussian elimination and sparse storage techniques (Duff, 1977).

\section{APPLICATIONS}

A number of test calculations have been carried out that demonstrate that the mathematical and numerical methods employed in TOUGH can handle all the severe nonlinenrities arising in phase transitions and component appearances and disappearances. The accuracy of the code was verified by simulating sample problems from the soil science and geothermal literature for which analytical or numerical solutions are available (see Table 1). A guide for preparation of input decks bas been written that, together with the extensive internal documentation, should enable engineers with some experience in fluid and heat flow modeling to apply the code to practical problems. TOUGH has been transferred to the Nuclear Regulatory Commission, and a full user's documentation is being prepared.

\section{REFERENCES}

Coats, K.H., 1978. A highly implicit steam flood model. Society of Petroleum Engineers Joumal, October, p. 369-383.

Duff, I.S., 1977. MA28-A set of FORTRAN subroutines for sparse unsymmetric linear equations. AERE Hawell Report R 8730.

Garg, S.K., 1978. Pıessure transient analysis for two-phase (liquid water/steam) geothermal reservoirs. Presented at 53rd Annual Fall Technical Conference and Exhibition, Society of Petroleum Enginers of AIME, Houston, Texas, SPE-7479.

International Formulation Committee, 1967. A Formulation of the Thermodynamic Properties of Ordinary Water Substance. Dusseldorf, Germany, IFC Secretariat.

Milly, P.C.D., 1982. Moisture and heat transport in hysteretic, inhomogeneous porous media: A matric-head based formulation and a numerical model. Water Resources Research, v. 18, no. 3, p. 489-498.

Moench, A.F., 1980. Problem No. 3-2-D well test. In Proceedings, Special Panel on Geothermal

Table 1. Sampie problems for numerical simulator TOUGH.

\begin{tabular}{|c|c|c|c|}
\hline Problem & Dimensions & Features & 1ssues \\
\hline Infiltration & 1-D, linear & lsothermal & $\begin{array}{l}\text { Code verification against known semianalytical } \\
\text { solution (Philip, 1955) }\end{array}$ \\
\hline Infiltration & 2-D, vertical & $\begin{array}{l}\text { Two-dimensional } \\
\text { fronts; gravity } \\
\text { effects }\end{array}$ & $\begin{array}{l}\text { Demonstration of code capability } \\
\text { (Ross et al., 1982) }\end{array}$ \\
\hline $\begin{array}{l}\text { Flow to a } \\
\text { geothermal well }\end{array}$ & 1-D, radial & $\begin{array}{l}\text { Water and steam } \\
\text { only; no air }\end{array}$ & $\begin{array}{l}\text { Propagating boiling front; code verification } \\
\text { against known semianalytical and numerical } \\
\text { solutions (Garg, 1978) }\end{array}$ \\
\hline $\begin{array}{l}\text { Fow to a well } \\
\text { intercepting a } \\
\text { fracture }\end{array}$ & 2-D, vertical & $\begin{array}{l}\text { Flow between } \\
\text { rock matrix } \\
\text { and fracture }\end{array}$ & $\begin{array}{l}\text { Code verification against known semianalytical } \\
\text { and numerical solutions (Moench, 1980) }\end{array}$ \\
\hline
\end{tabular}


Model Intercomparison Study. Sixth Workshop on Geothermal Reservoir Engineering, Stanford University, Stanford, California, December 17, 1980.

Narasimhan, T.N., 1982a. Physics of saturatedunsaturated subsurface flow. In Recent Trends in Hydrogeology, The Geological Society of America, Special Paper 189.

Narasimhan, T.N., 1982b. Multi-dimensional numerical simulation of fluid flow in fractured porous media. Water Resources Research, v. 18 , no. 4 , p. $1235-1247$.

Philip, J.R., 1955. Numerical solution of equations of the diffusion type with diffusivity concentration dependent. Transactions of the Faraday Society, v. 51, p. 885-892.

Pruess, K., 1983. Development of the general pur- pose simulator MULKOM. Earth Sciences Division, Annual Report 1982, Lawrence Berkeley Laboratory, LBL-15500, p. 133-134.

Pruess, K., and Bodvarsson, G.S., 1983. A sevenpoint finite difference method for improved grid orientation performance in pattern steam floods. Presented at the Seventh SPE Symposium on Reservoir Simulation, San Francisco, California, November 16-18, 1983, SPE-12252.

Pruess, K., and Narasimhan, T.N., 1982. A practical method for modeling fluid and heat flow in fractured porous media. In Proceedings, Sixth SPE Symposium on Reservoir Simulation, New Orleans, Louisiana, February 1-3, 1982, SPE-10509.

Ross, B., Mercer, J.W., Thomas, S.D., and Lester. B.H., 1982. Benchmark problems for repositor: siting models. NRC Report NUREG/CR-309:

\section{A STUDY OF NONISOTHERMAL CHEMICAL TRANSPORT IN GEOTHERMAL SYSTEMS BY A THPEE-DIMENSIONAL, COUPLED, THERMAL AND HYDROLOGIC PARCEL MODEL}

\section{D.C. Mangold and C.F. Tsang}

Reservoir engineering in nonisothermal systems such as geothermal reservoirs presents a challenge to conventional well-testing, production, and injection techniques. This is particularly true because there are many phenomena that need to be understood as coupled physical processes (e.g., buoyancy flow, tracers that react with minerals in the reservoir matrix, and temperature-dependent chemical reactions in the reservoir). To analyze these complex coupled processes in the field is very difficult, but numerical modeling can offer a useful means to investigate their implications. The objective of this study was to indicate how numerical simulation can give valuable insights into the coupled thermal, hydrologic, and chenical processes in geothermal reservoirs.

\section{MODEL}

The numsrical model CPT employed in this s. Idy was develcoed at Lawrence Berkeley Labora- tory from an earlier code PT (Bodvarsson. 198:which has been extensively applied in geother reservoir engineering research studies. PT is a three-dimensional, single-phase simulator the: been validated against numerous analytical solu: as: for thermal and hydrologic processes, a number geothermal reservoir development studies. several field experiments (Tsang et al., 1931?. E: includes the capabilities to model complex trodimensional geometry, heterogeneous porous :-:fractured media, and temperature-dependent im and rock properties. The energy and mass equas are solved using an efficient sparse matrix solve:

CPT has the addition of a parcel modet in chemical transport and provides for changes : : permeability of the rock matrix due to eitser tans. perature changes or chemical reactions. time step, the parcel model calculates chemes : sport using the newly calculated values of ture and pressure. In this way, tice stermian transport is interlaced with the prese. perature calculations. Changes in pernessist sfftut pressure and mass flow on the nex: 20.1 ista $4 \mathrm{fta}$ they occur.

The use of model CPT is litestsus is thes

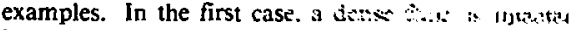
into a partially penetrating woll :- sto ator: mi:liu

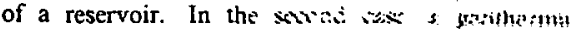

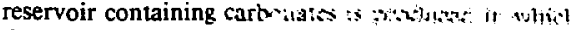

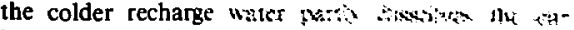

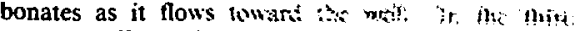

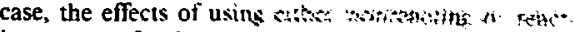

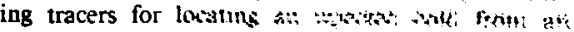


examined for injection and production wells connected by a fracture zone.

\section{CASE I: Partial-Penetration Injection Test with} a Dense Fluid

The fluid injected into a geothermal reservoir usually is different from the reservoir fluid. In addition to a temperature difference, the injected fluid may have a greater density, either from utilizing spent brine after flashing with a greater concentration of chemical constituents or because some solutes have been added to it for the purpose of the test. For a well that partially penetrates the upper portion of the reservoir, this may reduce recovery during the succeeding production period. A colder fluid tends to sink in a warm reservoir as a result of differences in density caused by temperature differences. However, such a temperature-dependent process does not account for density differences due to chemical composition, which may be equally great.

For this injection test, the difference in density between the reservoir water at $200^{\circ} \mathrm{C}\left(392^{\circ} \mathrm{F}\right)$ and the injected water at $100^{\circ} \mathrm{C}\left(212^{\circ} \mathrm{F}\right)$ is approximately $10 \%$. In this case in our exploratory study, the concentration of the solutes in the injected water was increased enough to increase the density of the injected fluid by another $10 \%$. The injection was performed for 3 months through a well penetrating the upper $100 \mathrm{~m}(\sim 300 \mathrm{ft})$ of a 300-m $(\sim 900 \mathrm{ft})$ thick geothermal reservoir. Afterwards, the well was produced for 3 months at the same rate as the injection, $20 \mathrm{~kg} / \mathrm{s}(\sim 300 \mathrm{gpm})$. A list of properties used for the reservoir in this case and the following cases is given in Table 1. A homogeneous reservoir bounded vertically by less permeable confining layers was modeled with a radially symmetric mesh.

Table 1. Reservoir properties.

\begin{tabular}{ll}
\hline Permeability & $5 \times 10^{-4} \mathrm{~m}^{2}$ (50 mdarcies) \\
Porosity & 0.20 \\
Compressibility & $2 \times 10^{-10} \mathrm{~Pa}^{-1}$ \\
& $\left(1.4 \times 10^{-6} \mathrm{psi}^{-1}\right)$ \\
Thermal conductivity & $2.0 \mathrm{~W} / \mathrm{m}-\mathrm{K}$ \\
& $\left(1.16 \mathrm{Btu} / \mathrm{h}-\mathrm{fl}^{2}-{ }^{\circ} \mathrm{F} / \mathrm{ft}\right)$ \\
Heat capacity & $1000 \mathrm{~J} / \mathrm{kg}-\mathrm{K}\left(240 \mathrm{Btu} / \mathrm{lbm}-{ }^{\circ} \mathrm{F}\right)$ \\
Density & $2650 \mathrm{~kg} / \mathrm{m}^{3}\left(166 \mathrm{lbm} / \mathrm{ft}^{3}\right)$ \\
\hline
\end{tabular}

Note: Fracture zone has 10 times reservoir permeability, with other properties the same. Cap rock and bedrock have 10 times less permeability than the reservoir, with other properties the same.
The results after injection and production are shown in Figs. 1 and 2. In Fig. 1, the solid lines indicate the temperature contours in increments of $20^{\circ} \mathrm{C}\left(36^{\circ} \mathrm{F}\right)$, and the broken lines indicate the concentration contours in increments of $20 \%$ of the initial injection concentration. It is apparent that the fluid moves downward more rapidly in response to chemical concentration effects on density than to temperature effects alone. Figure 2 illustrates the same contours after the production period: The downward movement of the denser fluid is clearly shown, despite $r^{\prime}$ : production of much of the cooler water injected in the first 3 months. The chemical substance(s) in the injected water are causing some of this water not only to sink deeper than predicted with temperature-induced density changes alone but even to remain in the reservoir during the production period. This shows that low recovery of the chemical constituents of the injected fluid may be due to the effect of chemical concentration on density in conjunction with a partially penetrating well rather than to chemical reactions, adsorption, or permeability inhomogeneities such as fractures.

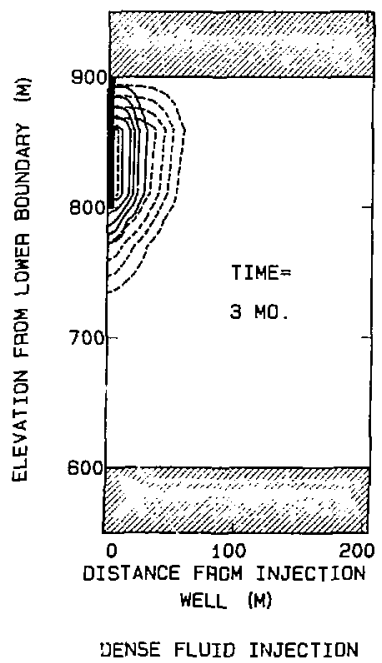

Figure 1. Temperature (solid) and concentration (broken) contours after 3 months of injection of $100^{\circ} \mathrm{C}\left(212^{\circ} \mathrm{F}\right)$ water into a $200^{\circ} \mathrm{C}\left(392^{\circ} \mathrm{F}\right)$ reservoir from a partially penetrating well. [XBL 84: 983] 


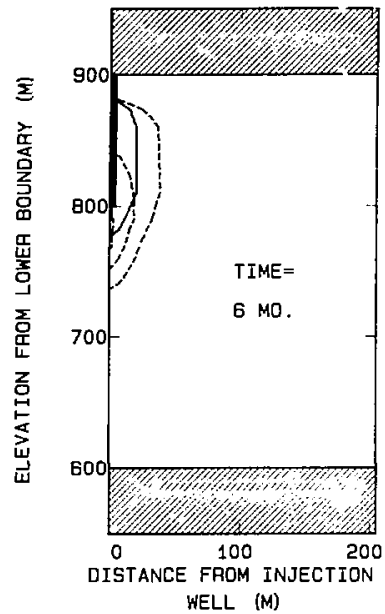

FLUIO PROOUCTION

Figure 2. Temperature (solid) and concentration (broken) contours after 3 months of production following 3 months of injection from a partially penetrating well. [XBL 843-982]

\section{CASE II: Production of a Reservoir Containing Carbonate}

A geothermal reservoir containing carbonates was produced and the effect of the recharge of cooler waters examined. It is well known that the solubility of carbc zate, contrary to that of many other substances, varies inversely with temperature; it changes by two orders of magnitude between $100^{\circ} \mathrm{C}$ and $200^{\circ} \mathrm{C}$ (Kharaka and Barnes, 1973). If some of the flow paths in the reservoir matrix are filled by carbonate, then the cooler water will dissolve it, increase the permeability, and allow a greater influx of the cold recharge water to penetrate the reservoir.

The results indicate that the carbonate dissolution induced by the advancing cold front does increase the permeability significantly. In this example, the greater permeability did not appear to cause more rapid advance of the thermal front. In addition to the permeability, the calculated front movement depends on the viscosity and density of the water, both of which have higher values at lower temperatures.

\section{CASE III: Locating a Thermal Front by Two Kinds of Tracers}

In reinjection schemes, it is desirable to know how far a thermal front has advanced toward the production wells. One means suggested for doing this is to inject a tracer along with the cooler water and use the tracer movements to estimate the location of the thermal front. The tracer will move faster than the thermal front as long as adsorption or other chemical processes do not retard it significantly. The tracer thus provides a warning of the thermal front's approach to the production wells. However, in some cases, chemical processes may inhibit the tracer movement, so that it may be of little use in predicting front location.

These two situations were modeled generically by a planar, two-dimensional, one-layer reservoir with a fracture zone joining two wells $1 \mathrm{~km}(\sim 0.63$ mile) apart. The fracture zone has 10 times the permeability of the surrounding porous medium. Cool water containing either a "reacting" or a "nonreacting" tracer is injectec into one well at $20 \mathrm{~kg} / \mathrm{s}(\sim 300$ gpm) while the other well is produced at the same rate.

The results for a nonreacting tracer indicate that the tracer follows the hydrologic front and could be detected at an observation well midway between the injection and production wells at $1 \%$ of its original injected concentration after 3 months. In that time, the temperature front had advanced only about $100 \mathrm{~m}(\sim 300 \mathrm{ft})$, which would give much adrance indication of the thermal front. For a strongly reacting tracer, there was no indication of the thermal front because the tracer had been significantly retarded.

These two situations show both the benefits and the difficulties with using tracers for locating thermal fronts. The modeling of such a technique, however, may help the reservoir engineer to understand actual field results and to evaluate tracer use by predicting their effects under different conditions before employing them.

\section{CONCLUSION}

The three cases modeled illustrate the use of model CPT for understanding the complex coupled physical processes that can occur in geothermal reservoirs. The model is equipped to investigate the many coupled processes operating in geothermal reservoirs. Depending on the temperatures of the different waters and the water-rock chemical interactions -especially with their effect on fluid viscosity and rock hydrologic parameters such as 
permeability and porosity-a number of different outcomes for producing the reservoir could be expected. A discussion of viscosity effects on welltest analysis was published earlier (Mangold et al., 1981). These various possible situations can be modeled by CPT over a range of different hydrologic parameter values, possible chemical reactions, and exploitation strategies in order to see the significance and implications of each of the potential factors. The model can thereby give insight into the dynamics of these coupled processes and their importance for reservoir engineering decisions.

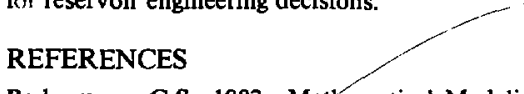

Bodvarsson, G.S., 1982. Mathernatical Modeling of the Behavior of Geothermal Systems under

\section{A STUDY OF CONTAMINANT PLUME CONTROL IN FRACTURED POTOUS MEDIA}

\author{
C.F. Tsang, D.C. Mangold, C. Doughty, \\ and $I$. Javandel
}

When a contaminant plume is encountered in an aquifer, several measures may be taken to control, contain, or remove the plume. One measure involves installation of a low-permeability barrier to contain the plume and prevent it from being carried away by natural regional groundwater flow. Questions often arise concerning the optimal length of the barrier and the possible need for more than one barrier for containment of the plume. Another measure involves extraction of the contaminant plume by means of one or more pumping wells. In this case, ond must decide on the optimal depths, locations, and pumping rates for the wells.

Numerical simulations for a series of scenarios involving the use of barriers or pumping wells have been made to contain or remove a contaminant plume from an aquifer. Important features of plume control that are considered include aquifer heterogeneity due to permeability layering or a fracture zone and density of the contaninant plume relative to the native groundwater. The calculational results are based on the numerical code CPT (Mangold and Tsang, 1983). The code includes a number of partial differential equations that describe the three-
Exploitation (Ph.D. dissertation). Lawrence Berkeley Laboratory, LBL-13937, p. 18-48.

Kharaka, Y.F., and Barnes, I., 1973. Solutionmineral equilibrium computations. U.S. Geological Survey, NTIS PB-215899, 82 p.

Mangold, D.C., Tsang, C.F., Lippmann, M.J., and Witherspoon, P.A., 1981. A study of a thermal discontinuity in well test analysis. Journal of Petroleum Technology, v. 33, no. 6, p. 1095-1105.

Tsang, C.F., Buscheck, T., and Doughty, C., 1981. Aquifer thernal energy storage-A numerical simulation of Auburn University field experiments. Water Resources Research, v. 17, no. 3, p. $647-658$.

dimensional flow of fluids in a complex porous medium with or without the presence of discrete fractures. The code CPT, which was developed at the Lawrence Berkeley Laboratory, employs the integral finite-difference numerical scheme (IFD) and calculates coupled thermohydrologic flows with simple chemical advective transport and reactions. The formulation includes the effects of density and viscosity variations of the fluid, gravitation or buoyancy effects, aquifer heterogeneity, and complex boundary conditions. Molecular diffusion and hydrodynamic dispersion are not considered. The code CPT was derived from an earlier version called PT, which has been verified against eight analytical or semianalytical solutions (Bodvarsson, 1982) and validated against several field experiments (Busch rk et al., 1983).

\section{COMPARATIVE STUDIES INVOLVING BARRIERS}

In these studies, we consider the evaluation of a two-dimensional $(x, y)$ contaminant plume in an aquifer with a uniform regional flow. The barriers studied are listed in Table 1 along with comments on the effectiveness of each. Case 4, using two barriers, provides the best plume containment. Figurc 1 shows the plume at its initial position, after 6 months with no barrier (case 1), and after 12 months with two barriers (case 4). After 6 months with no barrier, the whole plume has moved downstream with the regional flow. The spreading shown in the figure is due to numerical dispersion. In simple 
Table 1. List of cases involving barriers.

\begin{tabular}{lll}
\hline Case & \multicolumn{1}{c}{ Barrier } & \multicolumn{1}{c}{ Comments } \\
\hline 1 & No barrier & $\begin{array}{l}\text { Basic case for comparison; whole plume } \\
\text { moves downstream }\end{array}$ \\
2 & 300 -m barrier & $\begin{array}{l}\text { Short barrier upstream; whole plume } \\
\text { moves downstream, more slowly than in case } 1\end{array}$ \\
3 & $450-m$ barrier & $\begin{array}{l}\text { Long barrier upstream; whole plume } \\
\text { moves downstream, more slowly than in case } 2 \\
\text { Short barriers upstream and downstream; }\end{array}$ \\
5 & $\begin{array}{l}\text { Two barriers } \\
\text { fracture zone }\end{array}$ & $\begin{array}{l}\text { plume moves downstream } \\
\text { Fracture zone } 10 \text { m wide with 10 times } \\
\text { fracture zone }\end{array}$ \\
\hline
\end{tabular}

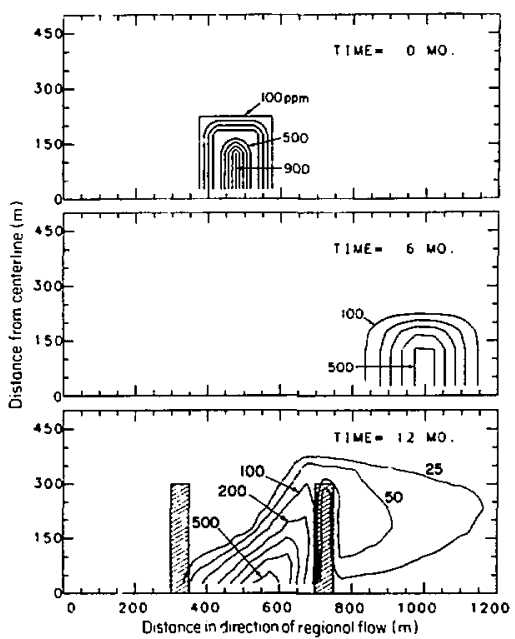

Figare 1. Concentration contours for the $(x, y)$ plume in its initial condition, after 6 months with nu barrier, and after 12 months with two barriers. [XBL 841-9503] geometries such as this, numerical dispersion produces results that qualitatively resemble physical dispersion. After 12 months with two barriers, only a small amount of contaminant at low concentration has escaped.

\section{COMPARATIVE STUDIES INVOLVING ONE OR MORE EXTRACTION WELLS}

In these studies, we assume an axisymmetric system and study contaminant plume evolution in an $(r, z)$ vertical section of a confined aquifer. For the one-well studies, the contaminant plume is formed by infiltration into the top of the aquifer for a period of one year. After infiltration stops, extraction begins through a well located at $r=0$ using various well-screen intervals. For the multiwell studies. the contaminant plume is formed by injection into a single fully penetrating well for a period of $40 \mathrm{~d}$. Extraction occurs through the same well using various well-screen intervals; a ring of auxilliary injection wells at $r=60 \mathrm{~m}$ is used to push the plume toward the extraction well.

A measure of the effectiveness of contaminant extraction is called the recovery factor, $\epsilon$, which is the percentage of contaminant extracted when the volume of fluid extracted is equal to the total volume of infiltrated contaminated fluid. If $\epsilon$ is much less than 1 , it indicates that there is much mix- 
ing between contaminated and aquifer water, so that the cleanup action is not very effective. One then has to produce a large volume of water to extract a sufficient amount of the contaminant.

Table 2 lists the extraction schemes studied and the recovery factor for each. Cases 1-6 consider aquifer permeability variations, and cases $7-13$ consider plume density variations. Figure 2 shows the plumes to be extracted for each case. By comparing Table 2 and Fig. 2, two general trends may be noted.

1. When the plume extends farther into a highpermeability region than into adjacent regions, no extra effort need be made to extract it from the high-permeability zone; instead, extraction should be centered at adjoining lower-permeability regions. For example, case 4 , with the well screened in the low-permeability region, yields a higher recovery factor than case 3, with a fully penetrating well which in turn yields a higher value than case 2 , with the well screened in the high-permeability region. Similarly, case 5 , with the well screened in the upper part of the aquifer, yields a higher recovery factor than case 6 , with the well screened at the fracture zone; case 11 , with the auxiliary injection wells screened in the upper (low-permeability) layer, yields a higher

Table 2. Summary of extraction cases.

\begin{tabular}{ll}
\hline Oxtraction well-screen interval \\
(percent of aquifer thickness)
\end{tabular}

Homogeneous aquit :
Case i
Upper 38

Lower half of aquife with double permeability

$\begin{array}{ccc}\text { Case } 2 & \text { Lower } 33 & 0.85 \\ \text { Case } 3 & 100 & 0.87 \\ \text { Case } 4 & \text { Upper } 38 & 0.89\end{array}$

Horizontal fracture with 10 times aquifer permeability
Case 5
Upper 38
0.85
Case 6
Middle 10 (at fracture)

Heavy contaminant in a homogeneous aquifer

Case 7

100

Case 8

Lowe: 33

0.36

Case 9

Lower 10

0.37

\begin{tabular}{cccc}
\hline Multiwell cases & $\begin{array}{c}\text { Extraction well- } \\
\text { screen interval }\end{array}$ & $\begin{array}{c}\text { Auxilliary injection } \\
\text { well-screen interval }\end{array}$ \\
\hline $\begin{array}{l}\text { Light contaminant in a three-layer aquifer } \\
\text { (middle layer is } 2.5 \text { times as permeable as other two) }\end{array}$ & & & \\
Case 10 & 100 & 100 & 0.65 \\
Case 11 & 100 & upper 20 & 0.68 \\
Case 12 & upper 20 & lower 20 & 0.77 \\
Case 13 & upper 20 & upper 20 & 0.80 \\
\hline
\end{tabular}



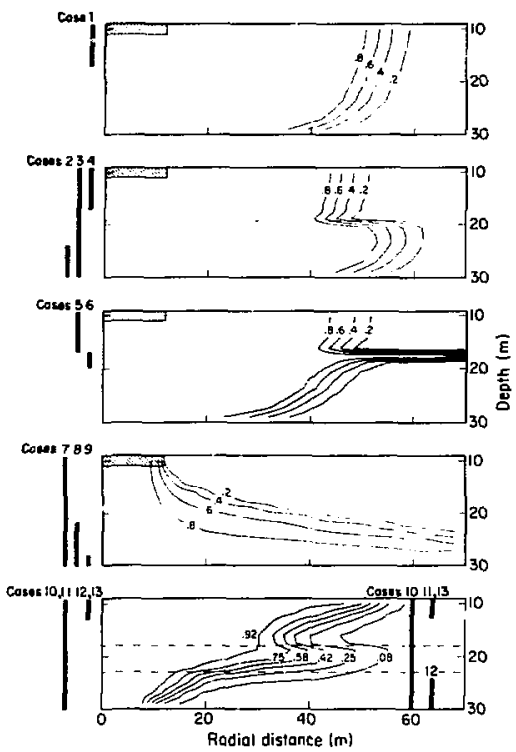

Figure 2. Relative concentration contours for the $(r, z)$ plumes in their initial conditions, before extraction. The shaded region shows the fluid inlet for plume formation. The heavy vertical bars show the depths of the well-screen intervals for the various extraction schemes. |XBL 841. 9504]

\section{THE USE OF MATHEMATICAL MODELS FOR SUBSURFACE CONTAMINANT TRANSPCRT ASSESSMENT}

\section{Javandel, C. Doughty, and C.F. Tsang}

Enormous amounts of potentially hazardous waste materials are stored or disposed of on or beneath the land surface. The presence of numerous contaminants such as organic and inorganic chemicals and bacteriological substances in groundwater indicates that many of the waste-disposal sites communicate with underground water resources. Even value than case 10 , with the auxiliary wells fully penetrating.

2. When the plume is distorted because $c$ ? buoyancy flow due to a density difference between plume and native waters, extraction efforts must be concentrated on the location of the maximum extend of the plume. Thus case 9 , with the well screened over the lower $10 \%$ of the aquifer thickness, yields a higher recovery factor than case 8 , with the well screened over the lower $33 \%$, which in turn yields a higher value than case 7 , with a fully penetrating well. Similarly, the recovery factors for cases 10-13 increase as the well-srreen intervals of the extraction and auxiliary wells are moved closer to the upper aquifer layer, where the maximum extent of the plun - occurs.

\section{REFERENCES}

Bodvarsson, G.S., 1982. Mathematical Modeiing of the Behavior of Geothermal Systems Under Exploitation (Ph.D. dissertation). Lawrence Berkeley Laboratory, LBL-13937, p. 18-48.

Buscheck, T.A., Doughty, C., and Tsang, C.F., 1983. Prediction and analysis of a field experiment on a multilayered aquifer thermal energy storage system with strong buoyancy flow. Water Resources Research, v. 19, no. 5, p. 1307-1315.

Mangold, D.C., and Tsang, C.F., 1983. A study of nonisothermal transport in geothermal systems by a three-dimensional coupled thermal and hydrologic parcel model. Geothermal Resources Council, Transactions, v. 7, p. 455-459.

though no comprehensive national survey of groundwater contamination has been undertaken, incidents of contamination have been reported from every state. For example, New Jersey, which consumes about 790 million gallons of groundwater every day has reported 374 known contamination incidents, and water supplies were threatened in 198 of those cases (Pye and Patrick, 1983). In a recen: investigation in the San Francisco Bay Area, at least 57 incidents were reported where hazardous materials leaked from underground facilities and caused, or threatened to cause, contamination of groundwater (Olivieri and Eisenberg, 1983).

The study of the extent of subsurface contamination from these and other sources is an imporiant task of the regulatory offices throughout the world. One way to obtain this information is by drilling 
many observation wells and testing the water samples taken from these wells. This procedure is usually very expensive and time consuming. Another approach to this problem is to apply mathematical models.

We have prepared a document (Javandel et al., 1983) that serves as a guide to the state-of-the-art methodology in modeling contaminant transport in the subsurface. This guide enables the user to make initial estimates of contaminant transport at a given site and, if the need arises and the data justify it, to select and to make use of sophisticated numerical models. The American Geophysical Union has accepted the guide for publication as a Water Resources Monograph. The present article is a summary of that work.

\section{OBJECTIVE AND APPROACH}

The objectives of our work were to select the best and most usable mathematical models for predicting the extent of subsurface contamination and to make information on their use available in a format useful to field response personnel. The models presented range from simple analytical and semianalytical models to complex numerical codes. Detailed discussions of the assumptions underlying application of the models are given. Primary emphasis is on the use of simple formulas and comprehensive tables, so that the manual is practically oriented and readily usable as a guide in the field.

Three different levels of complexity and sophistication are used to address the prediction of contaminant transport in groundwater:

Level 1. Simple analytical methods based on the solution of applicable differential equations are used to make a simplified idealization of the field and to give qualitative estimates of the extent of contaminant transport.

Level 2. Semianalytical methods are used to provide streamlines of steady-state fluid flow and the corresponding contaminant movement in the presence of an arbitrary number of constant strength sources and sinks. An average geologic environment is assumed and a schematic chemical retardation factor considered.

Level 3. Sophisticated numerical models are used to account for complex geometry and heterogeneous media, as well as dispersion, diffusion, and chemical retardation processes (e.g., sorption, precipitation, radioactive decay, ion exchange, degradation).
At the first two levels, appropriate methods are given, comprehensive tables and figures ane presented, and computer program listings and their user's guides are included as appendixes. At the third level, different numerical approaches are introduced, and information currently available on numerical codes is tabulated from recent surveys by various groups. These tables include model names, key characteristics, and the personnel involved in their developmeni. As an illustration, one of these sophisticated models is described and an example of its application is demonstrated.

This brief summary gives only the sources of contamination and a brief discussion of the analytical and semianalytical methods. The reader is referred to the full document for discussion of the numerical techniques.

\section{SOURCES OF CONTAMINATION}

A report to Congress by the Environmental Protection Agency in 1977 states that over 17 million waste-disposal facilities in the United States are emplacing at least 6.5 billion $\mathrm{m}^{3}$ of contaminated liquid into the ground each year. Although 16.6 million of these sites are domestic septic tanks, they are responsible for only about 3 billion $\mathrm{m}^{3}$ of effluent. The other 400,000 disposal facilities are responsible for the remaining 3.5 billion $\mathrm{m}^{3}$. They include industrial wastewater impoundments; land disposal sites for solid wastes; wells used for waste disposal, septic tanks and cesspools; underground tanks for storing industrial waste and raw materials; plants for the collection, treatment, and disposal of municipal wastewater; land sites for spreading of sludges; and wells for disposal of brines from petroleum exploration and development. Other sources of contamination include mine wastes, agricultural land leachates, and chemical spills.

\section{ANALYTICAL METHODS}

Analytical methods that handle solute transport in porous media are relatively easy to use. However, because of the complexity of the equations involved, the types of analytical solutions available are generally restricted to cases in which velocity is uniform (or radially symmetric )over the area of interest. Numerous analytical solutions are available for time-dependent solute transport within media having steady and uniform flow. Some one- and twodimensional plane and radial flow solutions having practical application are reviewed in this work. Since some of these solutions have forms that render 
them difficult to use, extensive tables of numerical cvaluations of these solutions are given to facilitate their application. Simple computer programs with user's guides are given to evaluate the solutions for other ranges of parameters for which no table is provided. Examples are given to show how the solutions can be applied. Figure 1 shows the extent of a plume, calculated by an analytica: method, due to a finite strip-type source located at $x=0$.

\section{SEMIANALYTICAL METHODS}

The semianalytical techniques apply a wellknown concept of fluid mechanics-the complex velccity potential-and extend it by emplacing numerical tools and computer plotting capabilities. In summary, execution of the semianalytical methods to determine the exterit of contamination includes the following steps:

1. Identify simple flow components of the systers, such as uniform regional flow, point sources reptesenting recharging wells, sinks representing discharging wells, and finite-radius circular sources representing waste-storage ponds.

2. Combine the expressions for each of the identified simple flow components to obtain the overall complex velocity potential of the system.

3. Construct the expressions for the velocity potential and stream function of the system.

4. Calculate the velocity field by taking the derivative of the velocity potential.

5. Construct flow patterns, and identify locations of any contaminant fronts for various values of time.

6. Using the stream function of the system, calculate the time variation of the rate at which a contaminant reaches any desired outflow boundary.

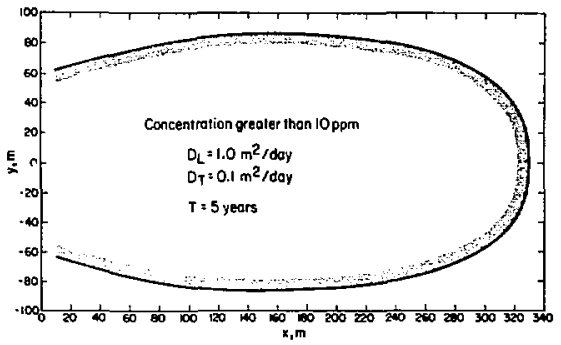

Higure 1. A map showing the zone of ccntamination for an example in which the pore water velocity is $0.1 \mathrm{~m} / \mathrm{d} 5$ years after the solute has reached the aquifer. [XBL 8351835]
A computer code called RESSQ is available that can be used to perform the above calculation numerically. This code is capable of calculating the location of the contaminant front around an injection well at any given time. Contaminant transport is limited to convection and adsorption; dispersion and diffusion are not considered. Since the length of the flow lines connecting any pair of recharge and discharge wells is variable, the time required for transport of a contaminant from the recharge well to the producing well will depend upon the path length. This code calculates the concentration of a given solute as a function of time after the arrival $o^{x}$ streamlines at a production well. Figure 2 illustrates the pattern of streamlines and fronts calculated by the RESSQ in a region encompassing a pond, production well, and a recharge well.

\section{DISCUSSION}

In general, there are two types of problems that may be solved by employing the contaminant transport theory:

1. Assessment of the environmental impact of subsurface waste disposal at a proposed site.

2. Assessment of the long-term consequences or the effects of remedial measures at an operating site where a contaminant plume has already been detected.

The first problem may be solved in two or three stages. In the preliminary stages of study, one needs

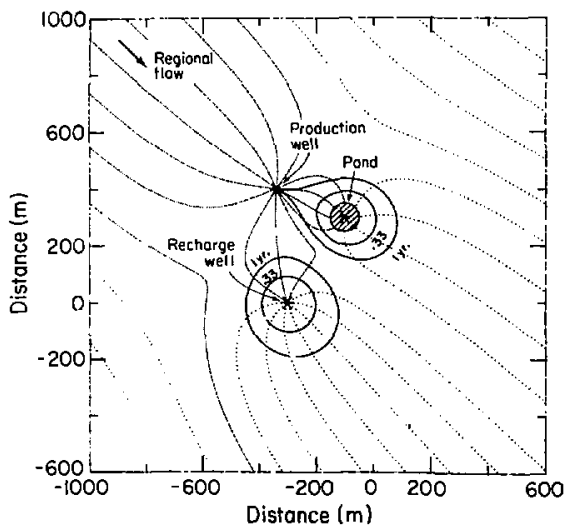

Fizure 2. Flow-lize pattern and front positions. [XBL 832-1701] 
a very rough estimate of the probable extent of contamination at some point in the future. This can help determine whether the potential site should be eliminatid or kept for further extensive studies. Because initial data are usually sparse, the analytical method is the investigator's most useful tool. The amount of data required for this method is relatively smail, and application of the technique is fast and simple, so that the effect of uncertainties in the data can be casily evaluated in a short period of time merely by rerunning the problem with different estimates.

If the site involves several sources of contamination and one or more production wells, one has to resort to the semianalytical method. This method also offers the two advantages mentioned above.

Once it is established that the site is relatively safe but further study is needed, the problem enters the next stage, which requires a vetailed site characterization and further application of the analytical and semianalytical methods using more reliable data. Application of simple numerical methods may also be advisable at this stage.

Often little or no information about prior hydrologic or contaminant transport is available at such proposed sites. Furthermore, the few data accumulated during a relatively short period of study are generally insufficient to justify applying a complete numerical model. By contrast, at presently operating sites, one would try to obtain the history of operation of the site. It is still advisable to begin with a semianalytical or analytical method and then apply numerical simulations. Since the amount of available data is not usually sufficient for application of a numerical contaminant transpor model, modelers usually first calibrate the model using historical data and then use the calibrated model to predict the future extent of contamination.

\section{REFERENCES}

Javandel, I., Doughty, C., and Tsang, C.F., 1983. A handbook for the use of mathematical models for subsurface contaminant transport assessment. Lawrence Berkeley Laboratory, LBL16307.

Olivieri, A., and Eisenberg, D., 1983. Underground tank leak detection program. Internal Memo, Regional Water Quality Board, San Francisco Bay Region.

Pye, V.I., and Patrick, R., 1983. Groundwater contamination in the United States. Science, v. 221 , p. $713-221$.

\section{THE DEPENDENCE OF FRACTURE MECHANICAL PROPERTIES ON FRACTURE ROUGHINESS AND SAMPLE SIZE}

\section{Y.W. Tsang and H.A. Witherspoon}

A parameter study has been carried out to investigate the dependence of the mechanical properties of a fracture upon fracture roughness and sample size. A rough fracture is described mainematically by the aperture density distribution, $n(b)$, which is the probability of occurrence of aperture $b$ in the rough fracture. In our earlier work (Tsang and Witherspoon, 1981), we formulated a theory that allows us to deduce the fracture closure as a function of normal stress applied to the fracture once the $n(b)$ for the fracture is known. To find the correlation between the fracture geometrical roughness and the fracture mechanical properties, a large sampling of fractures with known roughness characteristics is needed. We derived $n(b)$ from the actual joint profiles shown in Fig. 1, which includes a selection of joint surface profiles from natural exposures of sandstone, siltstone, and limestone. If each joint surface profile were to represent both the top and the bottom halves of a fracture, then different fracture apertures could be simulated from each profile when the upper and lower joints are mismatched to varying degrees. Note that the roughness of each joint surface in Fig. 1 is characterized by a large-scale undulation on which is superimposed a small-scale roughness whose average amplitude and wavelength are much smaller than that of the large-scale undulation. The profiles range from rough undulation to almost smooth and planar.

Figures 2 and 3 show the aperture density $n(b)$ versus aperture $b$ for two different simulated fractures. Though the aperture distributions show that a lot of noise arises from the small-scale roughness of the joint surface, an overall envelope for each distribution is discernible. The envelope arises from the 
LARGE SCALE UNDULATION + SMALL SCALE ROJGHNESS

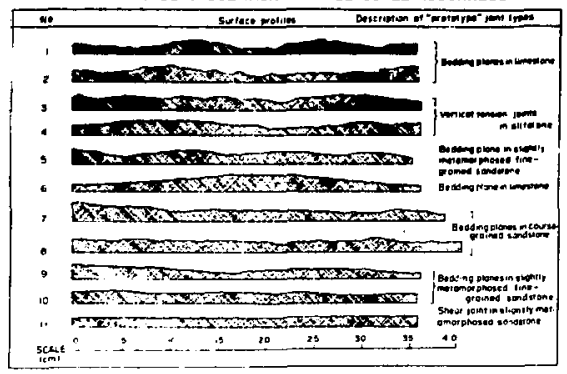

Figure 1. Selection of typical joint surface profiles (after Bandis and Barton, 1981). [XBL 828-2353]

.ge-scale undulation of the joint; it assumes a narIuw, peaked shape in Fig. 2 and a flat, almost uniform shape in Fig. 3. The normal stress, $\sigma$, vs fracture closure, $\Delta V$, calculated from the respective $n(b)$ are also plotted together with the distribution of $n(b)$ vs $b$. Figure 2 corresponds to a fracture with wellmatched surfaces, and Fig. 3 corresponds to a fracture with ill-matched surfaces.

Our study of many such calculations shows that the lack of density in $n(b)$ at small apertures correlates with very soft mechanical properties at low stresses, while the peaking of $n(b)$ with $b$ correlates with rapid stiffening of the fractured rock upon fracture closure. Since the well-matched fracture is characterized by a peaked $n(b)$ (Fig. 2$)$, it has a very

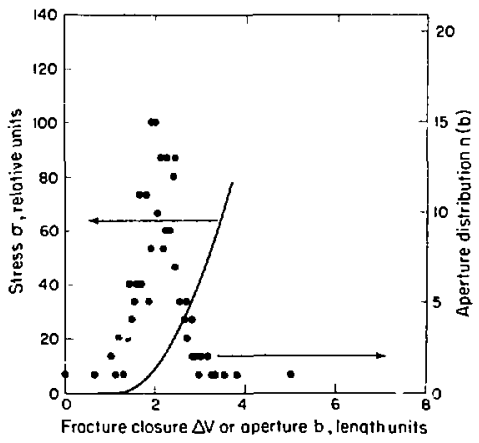

Figure 2. Fracture aperture distribution and stress fracture closure variation for a well-matched fracture. [XBL 822-1795]

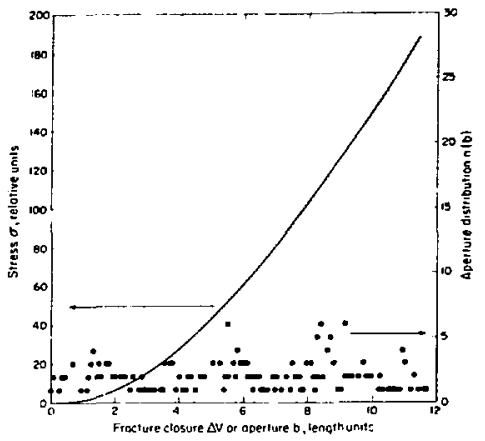

Figure 3. Fracture aperture distribution and stress fracture closure variation for an ill-matched fracture. [XBL 822-1798]

nonlinear stress-strain variation, whereas the illmatched fracture is represented by a broad and flat $n(b)$, so that the nonlinearity of the stress-strain behavior becomes less accentuated. This difference in mechanical behavior between a well-matched joint and an ill-matched joint had been seen for a granodiorite specimen (Goodman, 1976).

In this systematic study, we have arrived at the conclusion that the mechanical properties of a fracture under nornal stress can be correlated with the geometrical characteristics of the fracture. The large-scale roughness of a well-matched fracture is characterized mathematically by a narrow and peaked aperture distribution; that of an ill-matched fracturc is characterized by an aperture distribation that is broad and flat. The small-scale roughness of the fracture wall contributes to the background noise of the overall shape of the aperture distribution. Since the features in $\sigma$ vs $\Delta V$ curves have been shown to correlate with the shape of the aperture distribution, it is the large-scale roughness of the fracture walls that controls the mechanical and hydraulic behavior of the fracture. It is clear, then, that rock samples smaller than a typical large-scale undulation wavelength do not represent the fracture roughness properly, and spurious results due purely to "size" can occur when such small samples are used in stress measurements. In other words, the large-scale undulation wavelengths of the fracture wall may be a good measure of the "representative equivalent length" for the scale effect in stress measurements. Figure 1 shows that the undulation wavelengths range from about $12 \mathrm{~cm}$ for profiles numbered 1,5 , and 10 to perhaps $70 \mathrm{~cm}$ for profile 6 . The other 
profiles have wavelengths on the order of $30 \mathrm{~cm}$. If Fig. 1 is a good sampling of typical rock profiles, then our study seems to suggest that in order to obtain a data base from which laboratory experimental results may be extrapolated to field situations, rock samples much larger than those conventionally employed in laboratory stress-strain and stress-flow measurements are called for.

\section{REFERENCES}

Bandis, S., Lumisden, A.C., and Barton, N.R., 1981. Experimental studies of scaie effects on the shear behavior of rock joints. International Journal of Rock Mechanics and Mineral Science, v. 18. p. I-2I.

Goodman, R.E., 1976. Method of Geological Engineering in Discontinuous Rocks. New York, West Publishing Co., p. 170,173.

Tsang, Y.W., and Witherspoon, P.A., 1981. Hydromechanical behavior of a deformable rock fracture subject to normai stress. Joumal of Geophysical Research, v. 86, no. 1310 , p. 9287-0298.

\section{CAN WATER-INJECTION TESTS REVEAL THE POTENTIAL FOR FAULT MOVEMENTS?}

\section{J. Noorishad and P.A. Witherspoon}

The problems of induced seismicity and fractured rock deformation in response to changes in fluid pressure are intriguing. The role of fluid pressure in these events has become clear in the context of the effective stress law (Raleigh et al., 1976). Recent developments (e.g., Ayatollahi et al., 1983) in the analysis of rock mass behavior have provided the

eans for a better understanding of some of the served phenomena. Noorishad and Doe (1982) re performed a theoretical simulation of fluid jection into a horizontal fracture. Their work has demonstrated the role of the fracture deformability and the effects of the resulting permeability changes in the fractured rock. A closir look at this phenomena, in the light of the highly nonlinear material behavior of fractures, may provide an important new insight into the induced seismicity problem and the likelihood of movement in some fault situations.

The fracture response to load variations is path dependent. Therefore, this behavior may be used as a novel device to obtain important information about the state of in situ stresses. To illustrate this point, simple rheological models can be employed. In Fig. 1, the region around a horizontal fracture, shown by broken lines, is modeled by a combination of two springs with stiffnesses $K$, and $K_{f}$, representing the stiffinesses of the rock and the fracture, respectively. Initially, when there is no fluid present in the fracture, the effective stresses of the rock, $\sigma_{r}$, and of the fracture, $\sigma_{f}$, are the same and equal to the total stress $\sigma$. Assuming a sudden development of pressure, $P$, in the fracture only, the effective stress picture changes as shown in the lower right of Fig. 1. As may be seen, the effective stress in the spring representing the rock remains unchanged. However, the effective stress in the spring representing the fracture is reduced by an amount equal to the fluid pressure, thus leading to the extension (opening) of this spring by an amount $\delta U$. This quantity is inversely

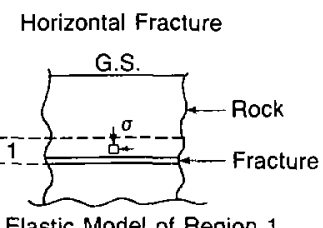

1-D Elastic Morlel of Region 1

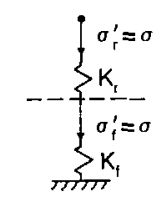

Initial Condition

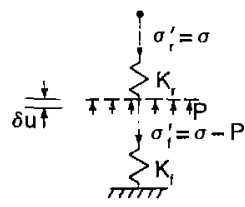

After Injection
Fracture Deformation:

$$
\delta u=\frac{P}{K_{1}}
$$

Figure 1. Static theological simulation of horizontal fracture subject to fluid injection. [XBL 8310-3366] 
proportional to the fracture stiffness, $K_{f}$. Obviously, very stiff fractures respond only to very high fluid pressures. The same modeling approach is used to represent the rocks around a vertical fracture, as siown in Fig 2. In this case, sudden development of pressure in the fracture changes the cffective stress picture in both the rock and the fracture, because the neighboring rock strains the same amount as the fracture. The amount of deformation of the fracture is inversely proportional to the sum of the stiffnesses of the rock and the fracture. Of course, the stiffer of the two elements will control the magnitude of deformation. So again, in highly stiff fractures, any measurable deformation will require very high fluid pressurization. In both of the above models, the rock is assumed to be impermeable, but permeability of the rock does not alter the principles.

In the above examples of fracture response to fluid pressurization, the stiffnesses were assumed to be a constant quantity. However, fracture stiffness is certainly a variable quantity, as can be seen in Fig. 3 . This modulus, being the tangent to the stressdisplacement graph, ranges in values from much less to much more than the adjacent rock stiffness, depending on the state of the prevailing stresses in the rock. In regions of low stress, load variations that can be achieved by pump testing will result in a noticeable fracture deformation, which will manifest

Vertical Fracture

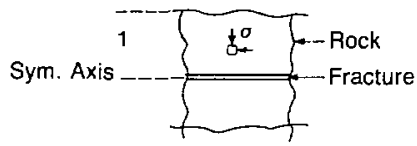

1-D Elastic Model of Region 1

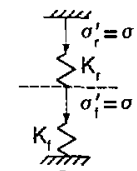

Initial Condition

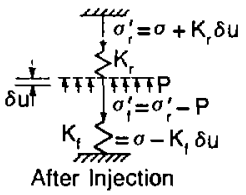

Fracture Deformation:

$$
\delta \mathrm{u}=\frac{\mathrm{P}}{\mathrm{K}_{1}+\mathrm{K}_{\mathrm{r}}}
$$

Figure 2. Static rheological simulation of a vertical fracture subject to fluid injection. [XBL 8310-3365]

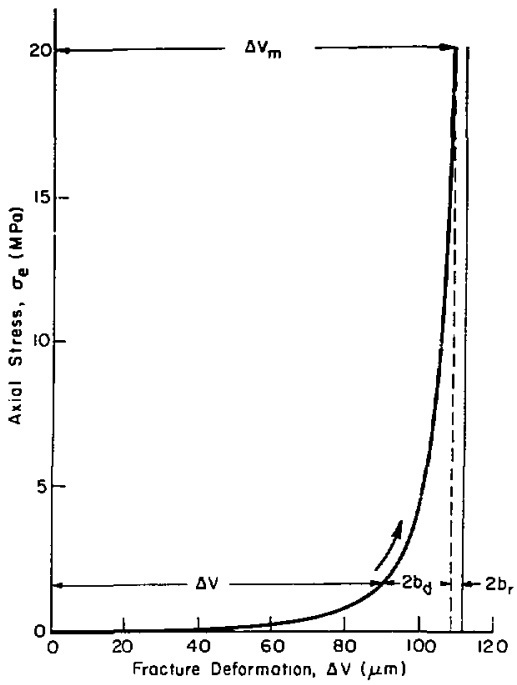

Figure 3. Mechanical properties of fracture used in determining changes in aperture with stress. [XBL 798-11132]

itself in terms of changes in the rock permeability, as observed in the Rocky Mountain Arsenal well (Hsieh and Bredehoeft, 1981). On the other hand, fracture response in regions of high in situ stresses will be slight as long as the applied pressures are not sufficient to cause fracturing or lifting. In the former case, the responses of the rock fracture system are indicative of low shear strength, and consequently there could be a problem of stability in a tectonically active region. The role of fluid pressures in triggering fault movement would need to be addressed. in the latter case, the lack of fracture response points to a higher stability for the region, and one may infer that hydroactivity-i.e., hydraulically induced fault movement-should not be a problem.

\section{REFERENCES}

Ayatollahi, M.S., Noorishad, J., and Witherspoon, P.A., 1983. Stress-fluid flow analysis in fractured rock masses. Journal of Engineering Mechanics, Division of ASCE, v. 1, p. $1-13$.

Hsieh, P.A., and Bredehoeft, J.D., 1981. A reseryoir analysis of the Denver earthquakes: $A$ case of induced seismicity. Journal of Geophysical Research, v. 86, no. B2, p. 903-920. 
Noorishad, J., and Doe, T.W., 1982. Numerical simulation of fluid injection into deformable fractures. In Proceedings, 23rd U.S. Congress on Rock Mechanics, Berkeley, California, August 15-27, p. 645-654.

\section{WELL-TEST DATA ANALYSIS FROM NATURALLY FRACTURED RESERVOIRS}

\author{
C.H. Lai, G.S. Bodvarsson, C.F. Tsang, \\ and P.A. Witherspoon
}

In the past two decades, considerable work has been devoted to the analysis of well-test data from naturally fractured reservoirs. The need for new ancirsis methods arose because of the distinct differtnces between the pressure respnnse of wells completed in homogeneous, porous-nuedia reservoirs and that of vells penetrating naturally fractured reservoirs. The approach used in developing analysis r.ethnds for well-test data of naturally fractured reservoirs is to treat the fractures and the rock matrix separately but couple their response by means of interaction terms. Thus the fractures represent high permeability for fluid transport into the well, whereas the rock matrix has a much lower permeability and provides gradual fluid drainage to the fractures. On the other hand, the fraction of the total volume occupied by the fractures (fracture porosity) is very small; consequently, the bulk of the fluid is stored in the rock matrix. This approach, currently referre ${ }^{2}$ to as the double-porosity approach, was developed by Barenblatt and Zheltov (1960), Barenblatt et al. (1960), and Warren and Root (1963). They considered the model shown in Fig. 1, in which each point in the system is assigned two pressures: one for the fractures, $p_{2}$, and the other for the rock matrix $p_{1}$. Thus, for a rigorous solution to the problem, one must solve diffusion equations for both media. However, Barenblatt and Zheltov (1960), Barenbiatt et al. (1960), and Warren and Root (1963) assumed a quasi-steady flow between the rock matrix and the fractures. This approximation simplifies the problem considerably, so that solutions for the pressures in the fractures and rock matrix can easily be obtained in the Laplace domain.

Subsequent to the studies of Barenblatt and Zheltov (1960), Barenblatt et al. (1960), and Warren
Raleigh, C.B., Healy, J.H., and Bredehoeft, J.D., 1976. An experiment in earthquake control at Rangely, Colorado. Science, v. 191, p. 12301236.

and Ront (1963), many workers have developed models that do not require the approximation of quasi-steady fluid flow between the rock matrix and the fractures. However, because of the threedimensional nature of the inodel considered by Barenblatt and others and Warren and Root (Fig 1), the treatment of transient interporosity flow is mathematically very difficult, and has been accomplished only by more or less drastic simplification of matrix block geometry. Kazemi (1969), Deruyck et al. (1982), Serra (1982), and Streltsova (1982) considered a slab model, whereas de Swaan (1976), Najurieta (1980), and Cinco-Ley and Samaniego (1982) have considered models based on spherically shaped matrix blocks.

Instead of the above transient models, we use the original model proposed by Barenblatt and Zheltov (1960), Barenblatt et al. (1960), and Warren and Root (1963) (Fig. 1). This model considers three orthogonal fracture sets separated by cubic rock matrix blocks and does not invoke further simplifications of block shapes. Fully transient fluid flow between the rock matrix and the fractures is evaluated by means of a novel approximation for spatial dependence of pressure change in the blocks (Pruess and Narasimhan, 1980).

In formulating the governing equations for the pressure in the fractures and roik matrixes, we use

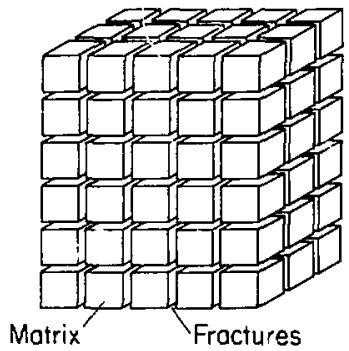

Figure 1. Idealized model of naturally fractured reservoirs. [XBL 813-2725] 
the Warrer and Root approach of lumping the fractures and the rock matrixes into two different continua. Using this approach, we can easily derive the governing equation for the pressure in the fractures, but the geometry of the rock matrix (cubic) causes some problems. For a rigorous treatment of the fluid flow in the rock matrix continuum, a threedimensional representation is necessary. However, we have developed a one-dimensional representation of the fluid flow in the rock that is quite adequate for the present problem; the results that it gives for pressure transients at a well are nearly identical to those obtained using a three-dimensional model for the rock matrix.

In addition to the approximation described above, the following assumptions are made.

1. The fluid flow from the system into the well bore is radial, and only the fractures feed the well.

2. The initial pressure, $P_{i}$, is uniform throughout the system, but at time $t>0$, a constant flow rate, $q$, is imposed at the well bore.

3. The pressure in the fractures is assumed to be equal to the pressure in the rock matrix at the contact region $(Z=D / 2)$.

4. All properties, such as permeability, porosity, and compressibility, are coustants in each cuntinuum.

In termss of dimensionless parameters, the governing equations describing the fluid flow in the fractures and the rock matrix can be expressed as

$$
\begin{aligned}
\frac{\partial^{2} P_{D 2}}{\partial r_{D}^{2}}+ & \frac{1}{r_{D}} \frac{\partial P_{D 2}}{\partial r_{D}} \\
& -\frac{\lambda}{5} \frac{\partial P_{D 1}}{\partial \eta}{ }_{\eta=1}=\omega \frac{\partial P_{D 2}}{\partial t_{D}}, \\
\frac{\partial^{2} P_{D 1}}{\partial \eta^{2}}+ & \frac{2}{\eta} \frac{\partial P_{D 1}}{\partial \eta}=\frac{15(1-\omega)}{\lambda} \frac{\partial P_{D 1}}{\partial t_{D}},
\end{aligned}
$$

where $P_{D}$ is dimensionless pressure, $t_{D}$ is dimensionless time, $r_{D}$ is dimensionless radial distance, $\eta$ is dimensionless distance in the rock matrix, $\lambda$ is the interporosity flow factor, $\omega$ is the ratio of storativity of the fracture to total storativity, and subscripts 1 and 2 refer to rock matrix and fractures, rcspectively. The reservoir systems considered include an infinite and a finite (no-flow outer boundary) system and a system with a constant-pressure outer boundary. The effects of well-bore storage and skin are illustrated.
The simulianeous solution of Eqs. (1) and (2), subjected to the given initial and boundary conditions, can be obtained using Laplace transformation techniques. Because the complex nature of the solution prohibits analytical inversion from the Laplace domain into real space, we employ the numerical inverter of Stehfest to obtain the solution in real space. To develop methods for analyzing of data from naturally fractured reservoirs, an approximate analytical solution to the pressure behavior in the well bore without well-bore storage and skin effects is expressed as

$$
\begin{gathered}
P_{D f}=-\gamma+\ln 2-\frac{1}{2} \ln \left\{\frac{\gamma}{5} \sqrt{\frac{15(1-\omega)}{e^{\gamma} \lambda t_{D}}}\right. \\
\left.\cdot \operatorname{coth}\left(\sqrt{\frac{15(1-\omega)}{e^{\gamma} \lambda t_{D}}}\right)-\frac{\lambda}{5}+\frac{\omega}{e^{\lambda} t_{D}}\right\},
\end{gathered}
$$

where $P_{D f}$ is dimensionless flowing bottomhole pressure and $\gamma$ is Euler's constant.

Equation (3) is valid for dimensionless times greater than $t_{D}=10$, which covers times of most practical interest. For this time range, Eq. (3) is generally accurate within $1 \%$; the maximum deviation from values calculated using the numerical inverter is $2 \%$. At late times, the equation is exact. Equation (3) is used as a basis in the following discussion. The pressure response of naturally fractured reservoirs is characterized by three segments, a semilog straight line at early times, a transition period, and a late-time semilog straight line. In many cases, regardless of well-bore storage effects, the initial straight line is not present. Only in cases where $(\lambda / \omega)<7 \times 10^{-7}$ can the first linear segment be observed.

The half-slope occurs around the dimensionless time winen the two last terms in Eq. (3) cancel each other:

$$
\left(t_{D}\right)_{H}=\frac{5 \omega}{e^{\gamma \lambda}}
$$

At that time, the pressure declines according to the expression

$$
P_{D f}=\frac{1}{4}\left[\ln t_{D}-\ln \lambda(1-\omega)-\ln \frac{3}{80}-3 \gamma\right]
$$

The time period over which a half-siope can be observed depends on $\omega$. For $\omega=0.001$, the half- 
siope lasts for an entire $\log$ cycle, whereas for $\omega=$ 0.01 it lasts for only half a $\log$ cycle. Where $\omega$ is larger than 0.1 , the half-slope segment cannot be easily identified.

At early times during drawdown tests, most of the fluids are produced from the fluids contained in the well bore. Obviously, during early times the pressure transients are related only to the volume of fluids stored in the well bore, so that these data cannot be used to determine any formation parameters.

Figure 2 shows the effects of rell-bore storage on the pressure-transient data for $\lambda=10^{-9}$ and $\omega$ $=0.01$. The figure shows that even for this small value of $\lambda$, well-bore storage effects will mask the initial straight line completely. The higher the wellbore storage factor $C_{D}$, the more the transition period data will be masked. However, in the case of this low value of $\lambda$, the half-slope can still be observed even though the well-bore storage factor is as large as $C_{D}=10^{4}$.

We used the data of Bourdet and Gringarten (1980) to illustrate how the present model can be used to determine important reservoir parameters. Figure 3 shows the best match obtained be:ween the observed data and the calculated values using the present model. An excellent match was obtained.

Bourdet and Gringarten analyzed the same data using the Warren and Root model and obtained values of $2 \times 10^{-6}$ and 0.25 for $\lambda$ and $\omega$, respectively. Our model gives values $2.63 \times 10^{-6}$ and 0.085 . The value of $w$ obtained using the Warren and Root model is considerably greater than our value and is unrealistically high.

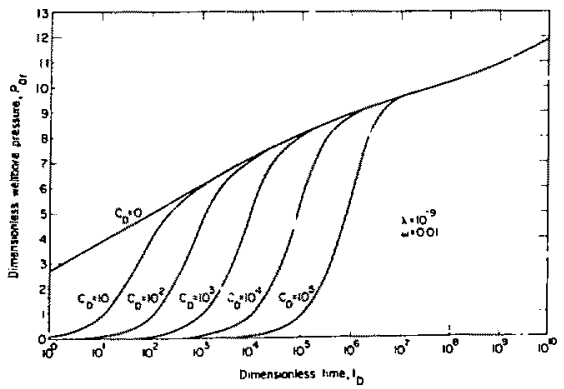

Figure 2. Effects of well-bore storage on pressure drawdown behavior. [XBL 829-4537]

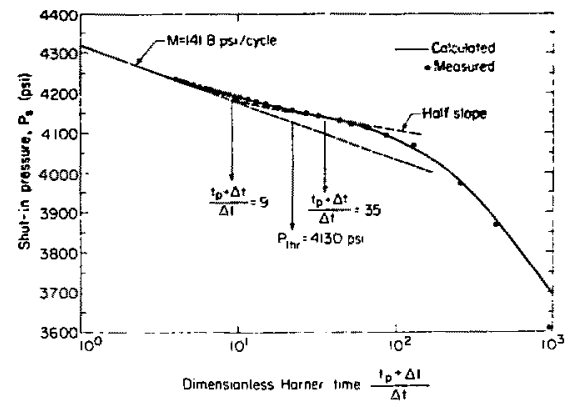

Figure 3. Pressure buildup analysis. [XBL 827-7249]

\section{REFERENCES}

Barenblatt, G.I., and Zheltov, Iu.P., 1960. On the basic flow equations of homogeneous liquids in fissured rocks. Doklady Akademii Nauk SSSR, v. 132 , no. 3 , p. 545-548.

Barenblatt, G.I., Zheitov, Iu.P., and Kochina, I.N., 1960. Basic concepts in the theory of seepage of homogeneous liquids in fissured rocks. Journal of Applied Mathematics and Mechanics, v. 24, no. 5, p. 1286-1303.

Bourdet, B., and Gringarten, $A_{n} C_{n}, 1980$. Determination of fissure volume and block size in fractured reservoirs by type curve analysis. Preserited at the 55th Annual Fall Technical Conference and Exhibition of the Society of Petroleum Engineers of AIME, Dallas, Texas, September 21-24, 1980, SPE-9293.

Cinco-Ley, H., and Fernando Samaniego, V., 1982. Pressure transient analysis for naturally fractured reservoirs. Presented at the 57th Annual Fall Technical Conference and Exhibition of the Society of Petroleum Engineers of AIME, New Orleans, Louisiana, September 26--29, 1982 , SPE-11026.

Deruyck, B.G., Bourciet, D.P., DaPrat, G., and Ramey, H.J., 1982. Interpretation of interference tests in reservoirs with duuble porosity behavior: Theory and field examples. Presented at the 57th Annual Fall Technical Conference and Exhibition of the Society of Petrolcum Engineers of AIME, New Orleans, Louisiana, September 26-29, 1982, SPE-11025.

de Swaan, A.O., 1976. Analytic solutions for determining naturally fractured reservoir properties by well testing. Society of Petroleum Engineers Journal, June, p. 117-122. 
Kazemi, H., 1969. Pressure transient analysis of naturally fractured reservoirs with uniform fracture distributions. Society of Petroleum Engineers Journal, December, p. 451-461.

Najurieta, H.L., 1980. A theory for the pressure transient analysis in naturally fractured reservoirs. Journal of Petroleum Technology, July, p. $1241-1250$.

Pruess, K, and Narasimhan, T.N., 1980. A practical method for modeling fluid and heat flow in fractured porous media. Presented at the 6 th Annual Meeting of SPE, New Orleans, Louisiana, January 31-February 2, 1980, SPE20509.
Serra, KV., Reynolds, A.C., and Raghavan, R., 1982. New pressure transient analysis methods for naturally fractured reservoirs. Presented at the SPE 1982 California Regional Meeting, San Francisco, March 24-26, 1982.

Streltsova, T.D., 1982. Well pressure behavior of a naturally fractured reservoir. Presented at the SPE 1982 California Regional Meeting, San Francisco, March 24-26, 1982. SPE-10782.

Warren, J.E., and Root, P.J., 1963. The behavior of naturally fractured reservoirs. Society of Petroleum Engineers Journal, September, p. 245-255.

\section{A NEW MECHANICAL TRANSPORT MODEL FOR NETWORKS OF FRACTURES}

\section{H.K. Endo}

A numerical model has been developed to simulate mechanical transport under steady flow in a network of fractures. Mechanical transport is caused by the movement of fluid through the conductive channels of the fracture system. The model calculates the location of streamtubes in determining the distribution of arrival times for particles traveling from one side of a flow region to another. We assume that fluid flow occurs only with planar fractures in an impermeable rock matrix and that mechanical transport is the only transport process. This discrete model is used to determine when a fracture system behaves like an equivalent porous medium and to evaluate directional mechanical transport properties of the fracture system.

The numerical approach used in this study to investigate mechanical transport in a network of fractures simulates the detailed movement of fluid within streamtubes through the fracture network. This numerical model operates in three stages: (1) generation of the fracture system, (2) calculation of flow rates in each fracture and determination of macroscopic flow properties, and (3) simulation of mechanical transport in the fracture network and determination of macroscopic mechanical transport properties.

In the first stage, a two-dimensional fracture system is created in an area called the generation region. The details of this procedure are given in Long et al. (1982). The fractures in the generation region are created one set at a time, and the number of fractures in each set is controlled by an assigned areal density. The center of each fracture in a set is randomly located in the generation region to create a statistically homogeneous system. Once a fracture has been located in the generation region, the geometric parameters necessary to construct a fracture are length, aperture, and orientation. This information may be read into the computer program directly or may be generated stochastically from probability distributions.

A flow region within the generated fracture network is selected for hydraulic and mechanical transport studies. The flow region may be oriented in any direction as long as it fits within the boundaries of the generation region. A finite-element mesh is generated for this flow region consisting of nodes, which are fracture intersections, and elements, which are fracture segments between nodes. This constitutes the first stage.

In the second stage, hydraulic boundary conditions are applied to the flow region. The hydraulic head at each node and the flow rate in each element are then calculated using a finite-element technique developed by Wilson (1970). The cubic law for laminar flow governs the flow rate in each planar fracture.

In the final stage of the program, mechanical transport is simulated for the fractures in the flow region using a streamtube model. A streamtube is a flow conduit containing a given flow rate that extends continuously across the fracture network from an inflow to an outflow boundary. As mentioned carlier, the flow rate in an element is 
governed by the cubic law for fracture flow. It can be shown that by solving the Navier-Stokes equation for laminar flow between parallel plates, an expiession for the vell-known parabolic velocity distribution across a planar element is obtained:

$$
u(\eta)=\frac{\rho g}{\mu} \frac{d \Phi}{d \xi}\left[\frac{n^{2}}{z}-\frac{b}{2} \eta\right] .
$$

The flow rate in the element is obtained by integrating $\mathrm{Eq}$. (1) over the width of the element:

$$
Q_{f}=\sum_{0}^{b} u(z) d z=-\frac{\rho g b^{3}}{12 \mu} \frac{d \Phi}{d \xi} .
$$

This is the cubic law for fracture.

The time it takes the flow in a streamtube to travel the length of an element is given by

$$
t_{S T}=\frac{L_{T}}{\frac{Q_{S T}}{\eta_{i+1}-\eta_{i}}},
$$

where $\eta_{i+1}-\eta_{i}$ is the width of a streamtube in an element. Thus, to determine $t_{S T}$, the width that a streamtube occupies in an element must be computed. Integrating Eq. (1) between $\eta_{i}$ and $\eta_{i+1}$ yields

$$
\begin{aligned}
& Q_{S T}=\sum_{n}^{n+1} u(z) d z \\
& =\frac{6 Q_{r}}{b^{3}}\left[\frac{b\left(\eta^{2}+1-\eta_{i}^{2}\right)}{2}-\frac{\left(\eta^{3}+1-\eta_{i}^{3}\right)}{3}\right] .
\end{aligned}
$$

The w: Ith occupied by the streamtube can then be determined from the flow rate in the streamtube and the starting coodinate $\eta_{i}$. For example, the node in Fig. I consists of three inflowing streamtubes labeled ST1, ST2, and ST3. Strea, ntube ST2 has a flow rate of 4 units and a starting coordinate, $\eta_{i, 2}$, equal to zero in element $E$. The ending coordinate of ST2, $\eta_{i+1,2}$, is obtained using Eq. (2). That coordinate then becomes the starting coordinate for ST3 in element $E$, from which the travel time for ST3 in element $E$ is determined.

The principle of conversion of mass and the fact that streamlines cannot cross one another in laminar flow are used to calculate the downstream location of inflow streamtubes in outflow elements at a node. Travel times within a node are considered to be negligible. The upper outflow element $D$ in Fig 1 has a flow rate of 3 units. The flow into this element must come from element $A$ because if any of the

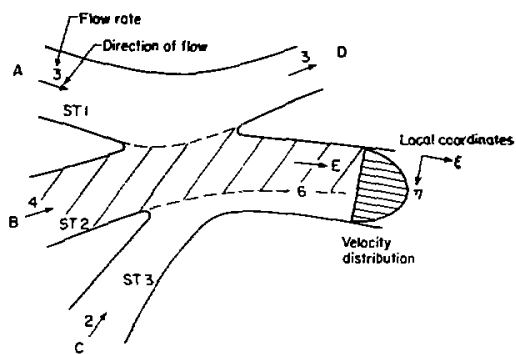

Figure 1. Redisitibution of streamtubes at a node. [XBL 829-4534]

other two streamtubes were to flow into element $D$, they would have to cross the path of STI. Using the same principle, ST2 must occupy the upper, and ST3 the lower, portion of element $E$. The order of the streamtubes and the flow rates in each streamtube are recorded for each outflow element. This information is needed to determine the travel time for the flujd in each stream tube.

The flux in an inflow streamtube can be distributed into more than one outflow element at the node, as is illustrated for ST1 in Fig. 2. When this arises, the inflow streamtube must be subdivided in such a way that a new streamtube is created for every outflow element that receives any portion of the inflow. For example, ST3 and ST4 are the result of the subdivision of the discontinued streamtube ST1. The total rravel time to this particular node for the flow in a new streamtube is determined by backtracking along the path of ST1 to its origin.

The general procedure used in tracing the location of streamtubes in the fracture network begins by assigning a streamtube to every inflow element on the boundary of the flow region. This assures that streamtubes exist in every conductive element within (a)

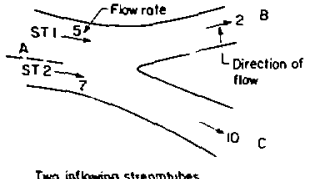

(b)

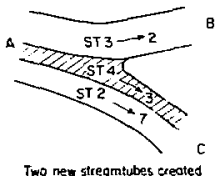

Figore 2. Creation of new streamtubes at a node. [XBL 829-4532] 
the flow region. For example, in the fracture network shown in Fig. 3, streamtubes have been iniijated in elements 1,2 , and 5 . Each assigned streamtube is given a width equal to the aperture of the element it occupies and a flow rate equal to that in the element.

The streamtube model simulates the propagation of flow from inflow to outflow boundaries of the flow region. The program proceeds in sequential nodal order to determine the outflow streamtubes at each node. The outflow streamtubes at a node can be determined only if the streamtubes are known in all inflow elements at the node. If streamtubes do not exist in an inflow element, the inflow element number and the node number are stored in memory. This situation arises when an inflow element at the node under consideration is an outflow element at a higher numbered node. The streamtubes in the inflow element at the current node can be determined only after proceeding to the higher node. In Fig. 3, node 1 is the first node examined by the computer program, and element 4 is the only outflow element at that node. The streamtubes in element 4 can be calculated only if the streamtubes are known in inflow elements $i$ and 3 . The streamtube in element 1 is known, since a streamtube was assigned to that element in the first phase of the streamtubing procedure. However, at this point, the streamtubes in element 3 are unknown. Therefore, element 3 and node 1 are stored in memory, and the program proceeds to node 2 .

The streamtuhes in the outflow elements at a node are determined when streamtubes exist in all inflow elements. After the streamtubes in all outflow elements have been determined, the program scans the elements stored in memory to remove any element that is an outflow element at the current node

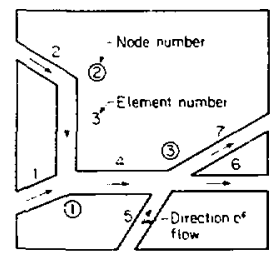

Figure 3. Frar:ure network with inflow streamtubes initiated in elements 1, 2, and 5. [XBL 833-1414] because the streamtubes are known in these elements. If an element is the only one stored for a particular node, then all the outflow streamtubes at the node are determined. Frr example, at node 2 for the fracture network in Fig. 3, the streamtube for the inflow element 2 is known. The streamtube in the outflow element 3 can therefore be computed if the streamtube in element 2 is known. The program then removes element 3 from the list of stored elements because the streamtube in element 3 has been determined. Inasmuch as element 3 is the only element stored in memory for node 1 , the streamtubes in the outflowing element 4 at node 1 can now be calculated. As the network is scanned in this fashion, the number of streamtubes increases and the width of streamtubes decreases because of the creation of new streamtubes at nodes.

The primary use of this model is to determine when a fractured rock mass may be treated as an equivalent porous medium for mechanical transport. The advantage of the porous-medium approach is that average properties are analyzed in such a way that the detailed fracture geometry and simulation of transport within each fracture are not required. In porous-media transport studies, an anisotropic medium is treated as an equivalent isotropic medium, neglecting the directional transport properties of the medium. This simplification is made because no experimental technique can fully evaluate the parameters governing dispersion for anisotropic media. Of course, other transport processes are occurring besides mechanical transport, but focusing on the fundamental mode of transport has been a great aid in developing the principles and methodology to investigate the directional nature of mechanical transport in anisotropic media. The directional characteristics of the following mechanical transport parameters are being studied: tortuosity, effective porosity, longitudinal mechanical transport coeff. cient, and linear fluid velocity.

\section{REFERENCES}

Long, J.C.S., Remer, C.R., and Witherspoon, P.A., 1982. Porous media equivalents for network of discontincus fractures. Water Resources Research, v. 18 , no. 3, p. 645-658.

Wilson, C. R, 1970. An investigation of laminar flow in fractured porous rocks (Ph.D. dissertation). Department of Civil Engineering, University of California, Berkeley, p. 77-82. 


\section{A THREE-DIMENSIONAL MODEL FOR FLUID FLOW IN NONEXTENSIVE FRACTURES}

\section{J.C.S. Long, H.M. MacLean, and P.A. Witherspoon}

Numerical models of random two-dimensional fracture systems have been used to study directional permeability (Long et al. 1982; Long, 1983). This article describes the theoretical basis for extending these techniques to three dimensions. A model is developed for three-dimensional fracture systems in which fractures are disks randomly located in space with orientation, radius, and aperture randomly assigned according to given distributions. Intersections between fractures are line segments called nodes. In each fracture, equations for flow between nodes are constructed inalytically as a function of the average head at each node. The construction of these equations empioys image theory and assumes that each node acts like a solizce of constant strength per unit line length. Once a set of mass balance equations is solved for the averaze head at each node, the flux between nodes and through the entire fracture network can be calculated.

In reality, fractures in rock are irregular, finite discontinuities. The idealization has been made that fractures can be modeled by straight line segments in two dimensions (Long et al., 1982). Likewise, we will assume that fractures are planar segments in three dimensions. We now have to make a further assumption about the shaje of the planar segments. There is suppor in the literature for elliptically shaped fractures (Baecher et al, 1978). However, the simplest and most pragmatic approach is to assume that fractures are circular. The complete threedimensional model consists of randomly located disks with distributed orientations, apertures, and radii (Fis- 1). These disks intersect to form the flow system. The intersections are line segments, whereas in the two-dimensional model the intersections are points. Thus the line segments will become the "nodes" of the three-dimensional model. Steady flow akes place in any given disk-shaped fracture from one node to another.

\section{SOLUTION OF THE FLOW EQUATION}

A general analytical solution cannoi be found for flow in large, random, three-dimensional fracture. systems; on the other hand, a purely numerical solution scheme, like that used in the two-dimensional

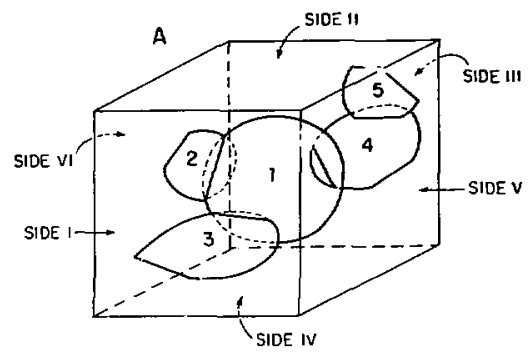

B

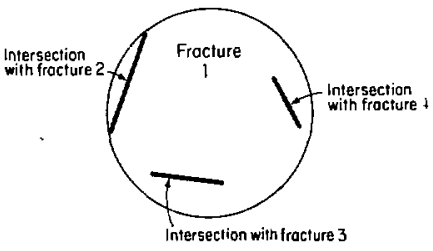

Figure 1. Three-dimensional fracture model. XBL 829-2438

problem, would require discretization of each fracture plane. Although theoretically possible, this approach is very difficult to put into practice. The solution technique proposed here is an approximate mixed numerical and analytical method. Flow in each fracture plane is handled analytically. The flux through the system is calculated using a numerical solution based on mass balance in the system.

The analytical solution in each fracture plane is based on the assumption that each fracture intersection acts like a source or sink with constant strength per unit line length. The fracture itself acts like a permeable disk with impermeahle boundaries.

\section{FLOW IN A FRACTURE DISC}

The solution for an arbitrary number of line sources and sinks within a disk with impermeable boundaries is derived from the solution for a point source within a circular flow region. Consider a circular disk that contains a point source of strength $+m$ at $B$ as shown in Fig. 2. For steady-state, onditions, Milne-Thomson (1968, p. 222) gives an image system that accounts for the impermeable boundary at $r=a$. If the source is located in the circle at $r=g$, then there is an image source of strength $+m$ at $r=a^{2} / g$ and an image sink of strength $-m$ at $r=0$. The head at any point in the fracture 


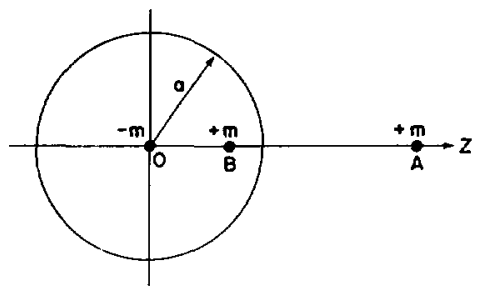

Fignre 2. Image system for a point source in a circle. [XBL 832-1692]

plane can be found by summing the head contributions of the source and the two images.

Recall that at least two fracture intersections in a fracture disk are necessary to have flow in the disk, and at least one of the intersections must act like a source and at least une must act like a sink. Furthermore, in order for the total flow into the fracture to equal the total flow out of the fracture, the total strength of all sources must be equal and opposite to the total strength of all sinks. Therefore, the total strength of all required images at $r=0$ will always be zero.

Now we allow point sources to be distributed along an arbitrary line segment in the circle such that the strength per unit line length is constant. First we must find the locus of the distributed images and the distribution of strength on the images. Then we $m$. st find the expression for the total head at any point in the circle due to the sources along the intersection and along the image. A nonradial line segment source will have an arc-shaped image sonstructed as shown in Fig. 3. A radial source will have a radial segment image.

The fundamental solution of the Laplace equation for a point source in an infinite plane is

$$
\phi=K h=\frac{-Q}{2 \pi} \ln r
$$

where $Q$ is the strength of the source, $r$ is the distance from the source, $\boldsymbol{K}$ is the permeability $\left(K=b^{2} \rho g / 12 \mu\right)$, and $h$ is the hydraulic head. Milne-Thomson (1968) shows that the potential due to sources distributed over a iine segment of length I cal the $y$ axis is given by

$$
\begin{aligned}
& \phi=K^{*} h_{i r} \\
& =\frac{Q_{0}}{2 \pi /} \int_{0}^{1} \frac{1}{2} \ln \left[x^{-2}+\left(y^{\prime}-E\right)^{2}\right] d \xi \text {. }
\end{aligned}
$$

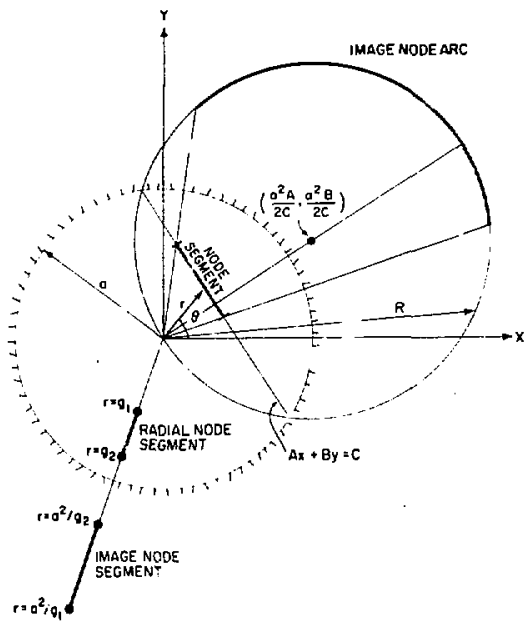

Figure 3. Construction of radial and nonradial nodal images. [XBL 832-1693]

where $Q_{i} / l$ is the strength per unit line length and $Q_{i}$ is the total strength of the line source. The subscript $i$ refers to intersection $i$, and $k$ refers to fracture $k$. Similar integrals can be derived for the images and for radial modes and images. These integrals yield equations of the form

$$
\phi_{i N}^{k}=Q_{i} F_{i}^{k},
$$

where the $F_{i}^{k}$ are shape functions for the head in the fracture plane due to sources along the intersection and its image.

\section{THE GLOBAL MASS BALANCE EQUATIONS}

The total potential in fracture $k$ is

$$
\Phi_{k}(X, Y)=\sum_{i=1}^{I} Q_{i} F_{i}^{k}(X, Y)
$$

where the $I$ are the numbers of the intersections in the fracture disk, $k$. The $F_{i}^{k}$ represent shape functions for the total head distribution over the entire fracture due to t'ie presence of the th intersection. The average potentiaj al each intersection, $i$, of fracture $k$ is 


$$
\begin{aligned}
\bar{\Phi}_{i}^{k}=\frac{1}{l_{i}}\left\{\Phi(X, Y) d l_{i}\right. & =\frac{1}{l_{i}} \int_{i} \sum_{j=1}^{l} Q_{j} F_{j}^{k} d l_{i} \\
& =\frac{1}{l_{i}} \sum_{j=1}^{l} Q_{i} \int F_{j}^{k} d l_{i} \\
& =\sum_{j=1}^{l} Q_{i} F_{j i}^{k},
\end{aligned}
$$

where $\mathscr{F}_{j i}^{k}$ is the shape function for the average head on intersection $i$ in fracture $k$ due to the intersection $j$, which is also on fracture $k$. That is,

$$
\mathscr{F}_{j i}^{k}=\frac{1}{l_{i}}\left\{_{i} F_{j}^{k} d l_{i} .\right.
$$

Changing to indicial notation, where summation over repeated subscripts is implied, we have

$$
\bar{\Phi}_{i}^{k}=Q_{j} f_{j}^{k},
$$

where $j$ takes on $I$ values and the $I$ are the numbers of the intersections on fracture $k$. By inverting Eq. (4), we have

$$
Q_{j}=\left[f_{j k}\right]^{-1} \bar{\Phi}_{i}^{k}=G_{j i}^{k} \bar{\Phi}_{i}^{k}
$$

where $\left[F_{j i}^{k}\right]^{-1}=G_{j l}^{k}$. Equation (5) is the analytical solution for the flux through intersection $j$ in terms of the average head on the $I$ intersections in fracture $k$.

Now assume that all the fracture intersections in the whole system have been numbered sequentially, 1 to $N$. In Eq. (5), $i$ and $j$ assume the intersection numbers that lie on fracture $k$. Note that the order of the subscripts on $G_{i j}$ is important. $G_{i j}$ may not be symmetric. Explation (5) can be written twice for each intersection, once for each fracture $k$ associated with intersection $i$. If frnctures $k_{1}$ and $k_{2}$ make up intersection $j$, then $Q_{j}$ for $k_{1}$ equals $-Q_{j}$ for $k_{2}$ :

$$
G_{j i_{1}}^{k_{1}} \bar{\Phi}_{i}^{k_{1}}+G_{j i_{2}}^{k_{1}} \bar{\Phi}_{i}^{k_{2}}=0,
$$

where the $i_{1}$ are the numbers of the intersections on fracture $k_{1}$ and the $i_{2}$ are the numbers of the intersections on fracture $k_{2}$. These equations are solved for $\overline{\boldsymbol{\Phi}}_{j}$. For fractures intersecting the boundaries, the $G_{j k}^{k}$ matrix is multiplied by the local $\Phi_{i}$ vector for the nodes in that fracture to obtain the fluxes through the boundary nodes. To perform the above analysis, two numerical codes have been written, FMG3D and DISCEL. The code FMG3D, a fracture mesh senerator, is described below. DISCEL calculates fluid flow through the fracture network using the mathematics and logic described above.

\section{THE FRACTURE GENERATION PROGRAM FMG3D}

\section{Primary Fracture System}

The program generates a primary fracture system consisting of one or more sets of circular fractures randomly distributed within a spherical generation region. Using a random number generator, the program generates fracture centers randomly distributed throughout the region. The orientation angles of each fracture plane in a set-i.e., the dip and the azimuth of dip-are either input or generated according to a specified statistical distribution function. The two angles determine the direction cosines of the normal to the fracture plane. The radius and aperture of each fracture in a set are also either input or generated according to specified distributions using given parameters. Any fractures lying in the same plane and overlapping are combined, and areas of fractures extending beyond the generation sphere are truncated at that boundary.

\section{Fracture System ir. the Flow Region}

The flow region, the volume to be analyzed, is a subregion of the generation sphere, and only fractures within this region are considered for input to the fluid flow model. The region is a rectangular parallelepiped centered at the origin of the sphere. Line segments of intersection between fractures and flow region boundary planes form boundary nodes. Fractures extending beyond the flow region are truncated, and those lying entirely outside the region are discarded.

\section{Fracture System Used in Flow Model}

Of the fractures in the flow region, only those that intersect other fractures or connect with boundary planes contribute to flow through the system. Intersections of fractures and boundary planes have been determined. The next step is to compare each fracture with every other fracture to determine all line segments of intersection. For a fracture to conduct flow, it must contain at least two intersections, either with other fractures or with boundary planes. 
Fraclures containing less than two intersections are identified and discarded.

\section{Input to Fluid Flow Model}

The nodal arrays to be used by the fluid flow model are assembled from boundary node and fracture intersection arrays. All nodes are optionally divided into a given number of segments in order to verify averaging assumptions made in the flow model. The nodes are sorted and renumbered to reduce the bandwidth of the global mass conservation matrix in the flow model. Beginning at a given flow region face, sorting is based on connectivity and proximity. Data for the fluid flow model, DISCEL, are written on disk, including run identification, flow region parameters, fracture data, and nodal information.

\section{A NOVEL SEVEN-POINT METHOD FOR MODELING DISPLACEMENTS WITH ADVERSE MOBILITY RATIO}

\section{K. Pruess and G.S. Bodvarsson}

In the recovery of heavy crudes, one often encounters a situation where the oil is displaced by a fluid of much higher mobility, such as water, steam, or carbon dioxide. Finite-difference simulation of such "adverse" mobility ratio displacements encounters special computational problems. In twodimensional simulations of pattern floods, the computed results depend on the orientation of the finitedifference grid relative to the lines connecting production and injection wells (Todd et al., 1972; Coats et al., 1974; Coats, 1982). The grid orientation errors increase dramatically with mobility ratio. In steam floods of highly viscous crudes, the mobility of the displacing gas phase can exceed the mobility of the hydrocarbon phase ahead of the displacement front by factors of several hundred. For this type of probsem, steam breakthrough times in five-spot floods are reported to differ by more than a factor of 3 between parallel and diagonal grids when five-point differencing is useu (Coats and Ramesh, 1982). As shown by Yanosik and McCracken (1979), grid orientation effects can be alleviated by a nine-point

\section{REFERENCES}

Baecher, G.B., and Lanney, N.A., 1978. Trace length biases in joint surveys. In Proceedings, 19th U.S. Symposium on Rock Mechanics, AIME, p. 54-65.

Long. J.C.S., 1983. Investigation of Equivalent Porous Medium Permeability in Networks of Discontinuous Fractures (Ph.D. dissertation). College of Engineering, University of Califomia, Berkeley, Lawrence Berkeley Laboratory, LBL16259.

Lorg, J.C.S., Remer, J.S., Wilson, C.R., and Witherspoon, P.A., 1982. Porous media equivalents for networks of discontinuous fractures. Water Resources Research, v. 18, no. 3, p. 645-658.

Milne-Thomson, L.M., 1968. Theoretical Hydrodynamics. New York, The Macmillan Co., p. 743.

finite-difference approximation. The nine-point scheme employs a combination of interbiock transmissibilities for "parallel" and "diagonal" rectangular grids (solid and broken lines in Fig. 1, respectively). Coats and Ramesh (1982) show that in many cases the nine-point approximation reduces grid orientation errors to acceptable levels. However, strong grid orientation effects persist in sevenspot floods and generally in problems with nonsquare grid blocks.

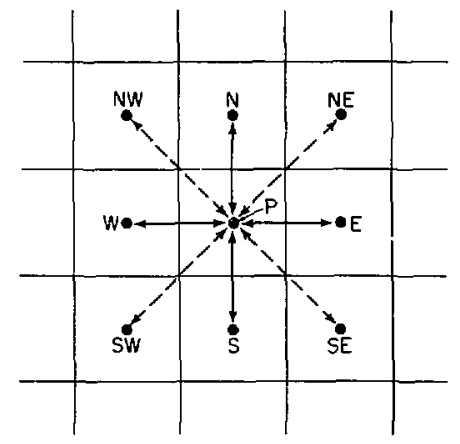

Figure 1. Five- and nine-point finite-difference approximations. [XBL 837-2134] 


\section{THE SEVEN-POINT APPROXIMATION}

We have developed a novel "seven-point" method that offers certain advantages over both fiveand nine-point approximations. In the seven-point method, a two-dimensional flow domain is partitioned into identical regular hexagons (Fig. 2). Interblock flow can occur between each nodal point and its six neighbors. For Laplace's equation, the accuracy of the seven-point method is of order $h^{4}$, where $h$ is the nodal distance. This is intermediate in comparison to accuracies of order $h^{2}$ and $h^{6}$ for fiveand nine-point methods, respectively. However, the seven-point method offers special advantages for problems with a favorable symmetry-e.g., sevenspot floods (see below). Implementation of the various higher-order differencing schemes is most easily made with an integral finite-difference method (IFD; Narasimhan and Witherspoon, 1976). Five-, seven-, and nine-point approximations are all contained within the IFD as special cases. They can be implemented simply by providing the proper geometric input parameters (grid block volumes, interface areas, nodal distances), without any programming changes. In the calculations reported below, the geometric data were generated by computer, using simple preprocessor programs ahead of the simulations.'

\section{SIMULATION OF PATTERN STEAMFLOODS}

Five-, seven-, and nine-spot steamfloods of heavy oil reservoirs were simulated with different finite-difference approximations and grid orientations, so that the accuracy of the different methods could be compared. The calculations were made with a fully implicit numerical model known as STMFLD1. ${ }^{2}$ Problem parameters were chosen that are representative of conditions encountered in steamflooding of heavy California crudes. Table 1 gives steam breakthrough times for the different cases, and Figs. 3 and 4 show oil recovery curves for seven- and nine-spot floods. The results show the expected trends. Five-point calculations have strong grid orientation effects, with more rapid steam

\footnotetext{
${ }^{1}$ We acknowledge the help of $P$. Fuller in computing the geometric
} parameters.

${ }^{2}$ STMFLDI is an improved version of a code that was jointly developed by K. Prutss, G.S. Bodvarsson, and Energy Resources Co.

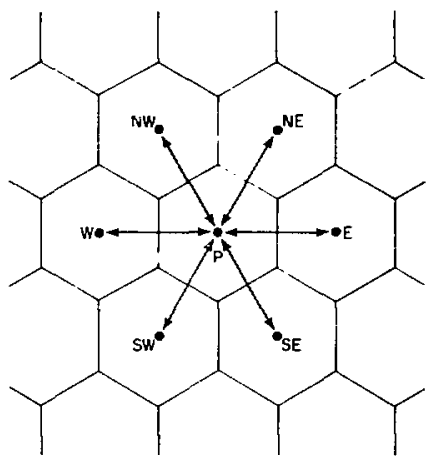

Figure 2. Computational grid of regular hexagons for seven-point finite differences. [XBL 836-1863]

breakthrough along "parallel" flow paths. In the nine-spot problem. the five-point parallel grid predicts more rapid steam breakthrough at the "far" producer $\mathbf{P}$ than at the "near" producers $\mathrm{N}$ and $\mathrm{N}^{\prime}$ (see Table 1). In the nine-point method, steam breakthrough and oil recovery depend little on grid orientation for five- and nine-spots. The seven-point method gives good performance for five- and sevenspots, but not for nine-spots, where the symmetry of the two near producers is violated. The nine-point result for the seven-spot flood is intermediate between parallel and diagonal seven-point predictions. This suggests that the nine-point method can give accurate results for seven-spot floods if square grid blocks are used. However, the minimal symmetry element of a seven-spot that can be modeled with (nearly) square grid blocks is $1 / 2$, whereas the $60^{\circ}$ symmetry of the seven-point grid makes it possible to model only $1 / 12$ of a seven-spot. In this case, therefore, the seven-point method offers substantial savings in computing work (requiring only $1 / 6$ the number of grid blocks as the nine-point method while providing comparable accuracy. 
Table 1. Steam breakthrough times (in days).

\begin{tabular}{|c|c|c|c|c|c|}
\hline \multirow[b]{3}{*}{ Mesh } & \multicolumn{5}{|c|}{ Pattern } \\
\hline & \multirow[t]{2}{*}{ Five-spot ${ }^{a}$} & \multicolumn{3}{|c|}{ Nine-spot ${ }^{b}$} & \multirow[t]{2}{*}{ Seven-spot ${ }^{2}$} \\
\hline & & $\mathbf{P}$ & $\mathbf{N}$ & $\mathbf{N}^{\prime}$ & \\
\hline Five-point parallel & 267.8 & 313.7 & 822.5 & 822.5 & \multirow{2}{*}{326.2} \\
\hline Five-point diagonal & 515.3 & 2178.0 & 153.8 & 153.8 & \\
\hline Nine-point parallel & 386.8 & 1784.5 & 317.0 & 317.0 & \multirow{2}{*}{533.0} \\
\hline Nine-point diagonal & 395.6 & 1872.7 & 312.2 & 312.2 & \\
\hline Seven-point parallel & 403.6 & 2019.8 & 289.7 & 697.1 & 512.5 \\
\hline Seven-point diagonal & & & & & 594.3 \\
\hline
\end{tabular}

${ }^{a}$ With volatile hydrocarbons.

bNo volatile hydrocarbons.

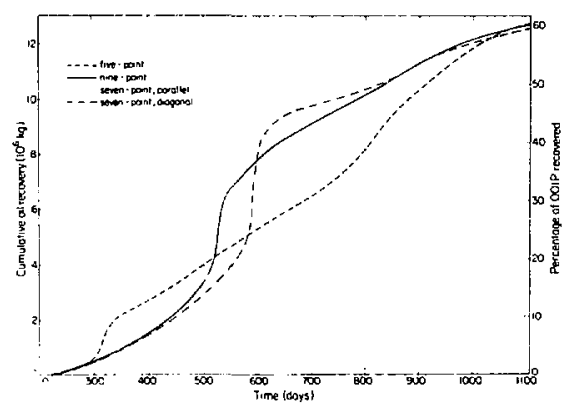

Figure 3. Cumulative oil recovery for seven-spot. [XBL $837-2144$

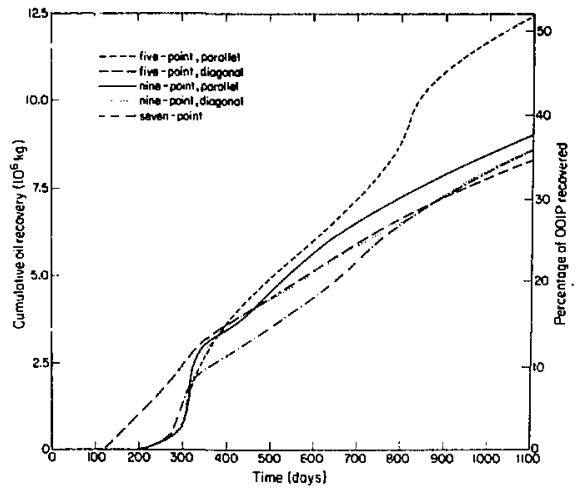

Figure 4. Cumulative oil recovery for nine-spot. [XBL 837.2143) 


\section{REFERENCES}

Conts, K.H., 1982. Reservoir simulation: State of the an. Journal of Petroleum Technology, August, p. 1633-1642.

Coats, K.H., and Ramesh, A.B., 1982. Effects of grid type and difference scheme on pattern steamflood simulation results. Presented at the 57th Annual Technical Conference and Exhibition of the Society of Petroleum Engineers of AIME, New Orleans, Louisiana, September 26-29, 1982, SPE-11079.

Coats, K.H., George, W.D., Chu, C., and Marcum, B.E., 1974. Three-dimensional simulation of steamflooding. Society of Petroleum Engineers

\section{DETAILED FIELD VALIDATION OF THE PREDICTION FOR AN ATES SYSTEM}

\section{Doughty and C.F. Tsang}

For the past several yearr, Lawrence Berkeley Laboratory (LBL) has been doing numerical modeling studies using the numerical simulator PT (Bodvarsson, 1982), developed at $\mathrm{LBL}$, to simulate the aquifer thermal energy storage (ATES) field experiments conducted by Auburn University al a site near Mobile, Alabama. Last year's annual report described the prediction of the energy recovery factor for the first two cycles (summarized in Table 1) of a recent three-cycle experiment (Tsang et al., 1983). An important result of the first-cycle prediction was the discovery of the heterogeneous nature of the
Journal, December, p. 573-592.

Narasimhan, T.N., and Witherspoon, P.A., 1976. An integrated finite difference method for analyzing fluid flow in porous media. Water Resources Research, v. 12, no. 1, p. 57-64.

Todd, M.R., O'Dell, P.M., and Hirasaki, G.J., 1972. Methods for increased accuracy in numerical reservoir simulators. Society of Petroleum Engineers Journal, December, p. 515-530.

Yanosik, J.L., and McCracken, T.A., 1979. A ninepoint, finite difference reservoir simulator for realistic prediction of adverse mobility ratio displacements. Society of Petroleum Engineers Journal, Augush, p. 253-262.

aquifer. A three-layer-aquiltr model was developed and used for further calculations. During the second cycle, large buoyancy forces dominated aquifer flow patterns and lowered the energy recovery factor substantialiy.

This year LBL has performed (1) ditailed comparisons between first- and second-cycle experimental and calculated temperature distributions, (2) a parameter study to examine the relative magnitudes and dependences of layering effects and buoyancy flow, (3) a series of design studies for the third cycle, and (4) the simulation of the actual third cycle. The results of these studies are described briefly below.

\section{COMPARISON BETWEEN FIRST- AND SECOND-CYCLE EXPERIMENTAL AND CALCULATED TEMPERATURE DISTRIBUTIONS}

Once the outcome of each cycle was preclicted, the corresponding experimental temperature data

Table 1. LBL numerical modeling of ATES field experiments at the Mubile site (reported lasi year).

\begin{tabular}{lcccccc}
\hline & $\begin{array}{c}\text { Cycle } \\
\text { durition } \\
(\mathrm{d})\end{array}$ & $\begin{array}{c}\text { Injection } \\
\text { volume } \\
\left(\mathrm{m}^{3}\right)\end{array}$ & $\begin{array}{c}\text { Injection } \\
\text { temperature } \\
\left({ }^{\circ} \mathrm{C}\right)\end{array}$ & \multicolumn{2}{c}{ Energy recovery factor } \\
\cline { 6 - 7 } & First cycle & $33-30-26$ & 25,000 & 59 & 0.55 & 0.58 \\
Second cycle & $130-34-54$ & 58,000 & 82 & 0.45 & 0.42 \\
\hline
\end{tabular}

${ }^{2}$ Injection-storage-production.

${ }^{b}$ Using a three-layer-aquifer modeI. 
were released for use. Temperatures were measured via thermisters located at 6 depths in each of 12 observation wells. The observation wells were distributed along four lines extending north, south, east, and wesi from the central injection/production well at distances of 15,30 , and $45 \mathrm{~m}$ from that well.

A variety of comparisons betwcen experimental and calculated temperatures have been made, including temperature vs radial distance ( $T$ vs $r$ ), time ( $T$ vs $f$ ), and depth ( $T$ vs $z$ ) profiles and temperature contour plots $(T(r, z))$ (Buscheck et al., 1983). Because iemperature was measured at only three values of $r$, the experimental $T$ vs $r$ and $T(r, z)$ plots could not be drawn with certainty. In contrast, for a given well, data taken from 6 depths at an average interval of $15 \mathrm{~b}$ provided ample information from which to draw $T$ vs $z$ or $T$ vs $t$ profiles.

To incorporate both depth and time variations, a new type of plot has been developed. Temperature contours are plotted as a function of depth and time for a given radial distance. As for conventional $T(r, z)$ contour plots, these $T(z, t)$ plots provide an overview of forces acting in the aquifer. Figure 1 shows $T(z, t)$ plots for three wells located $30 \mathrm{~m}$ from the injection/production well for part of the firstcycle injection period; preferental flow into the middle layer of the aquifer is clearly seen. Each experimental data plot provides information about the region of the aquifer between the injection/ production well and a particular observation well. Figure 1 als, shows results calculated using three different axisymmetric three-layer-aquifer models in

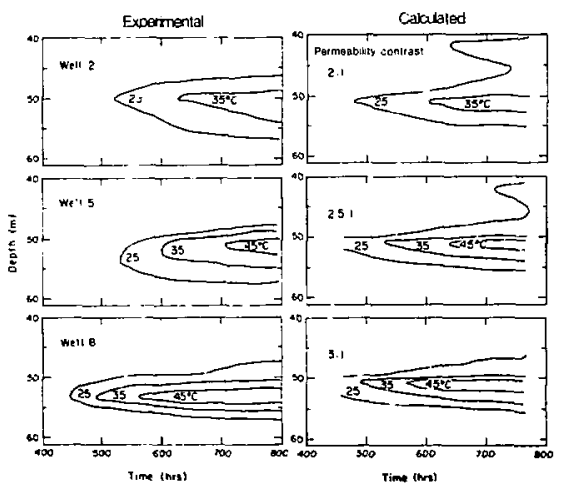

Figure 1. Experimental and calculated temperatures as a function of depth and time, $T(z, t)$, for the first cycle. [XBL 839-11400] which the permeability of the middle layer varies from 2 to 3 times that of the upper and lower layers. By comparing the experimental and calculated results, it is apparent that the permeability contrast between the layers varies throughout the aquifer and that 2.5:1 may be considered an appropriate average value for the entire aquifer.

\section{PARAMETER STUDY TO EXAMINE LAYERING EFFECTS AND BUOYANCY FLOW}

Aquifer layering and buoyancy flow are important considerations in the understanding of hot water flow in an aquifer. The following comparison of calculated first- and second-cycle recovery factors illustrates the relative importance and dependences of these effects. A simplified graphic technique (Doughty et al., 1982) that does not include buoyancy flow or layering predicts similar values for firstand second-cvcle recovery factors on the assumption that a production well open to the entire aquifer thickness is used for both cycles. To study the addition of buoyancy and layering, various calculations have been made using the numerical model PT. Table 2 summarizes the recovery factors calculated by PT for cases assuming either a one-layered or a three-layered aquifer and either little or substantial buoyancy flow. Reading acioss the table sho'ws that the effect of layering on recovery factor is small. Furthermore, it is quite similar for the two cycles and is thus temperature independent. Reading down the table shows that the increased injection temperature of the second cycle, which increases buoyancy flow, greatly decreases the recovery factor. The decrease is independent of layering in this case when the average transmissivity of the three-layer aquifer is the same as that of the one-layer aquifer. Although buoyancy flow is very sensitive to overall permeability values, the present results indicate that the detailed spatial distribution of permeabilities does not have a major influence on buoyancy flow for this particular system. The successful prediction of the first and recond cycles, with different injection temperatures, ...d hence different relative magnitudes of layering and buoyancy effects, demonstrates that we have properly accounted for both effects in our calculations.

\section{THIRD-CYCLE DESIGN STUDIES}

To assist Auburn University in planning for the third-cycle experiment, alternative injection and production schemes have been studied to maximize the recovery factor for a 3-month cycle with an injection 
Table 2. Comparison of layering and buoyancy effects on calculated recovery factor.

\begin{tabular}{lccc}
\hline & $\begin{array}{c}\text { One-layer } \\
\text { aquifer }\end{array}$ & $\begin{array}{c}\text { Three-layer } \\
\text { aquifer }\end{array}$ & Difference \\
\hline $\begin{array}{l}\text { First cycle; } \\
\text { low injection } \\
\text { temperature; } \\
\text { litis buoyancy } \\
\text { flow }\end{array}$ & 0.61 & 0.58 & $5 \%$ \\
$\begin{array}{l}\text { Second cycle; } \\
\text { high injection } \\
\text { temperature; } \\
\text { much buoyancy } \\
\text { low }\end{array}$ & 0.41 & 0.40 & $3 \%$ \\
Difference & & & \\
\hline
\end{tabular}

temperature of $82^{\circ} \mathrm{C}$. Making use of the knowledge gained from the second-cycle simulation, that buoyancy flow will be strong, three approaches have been taken.
1. Simply inject into and produce from the upper portion of the aquifer, where most of the hot water would naturally flow because of buoyancy effects, thus minimizing mixing of warm and cool waters.

2. Attempt to maintain a compact shape for the injected fluid. Buoyancy flow is counteracted by pumping from the bottom of the aquifer as hot water is injected into the top. Hot water is then extracted from the top of the acuifer.

3. Inject into the upper portion of the aquifer. Then, while producing from the upper portion, produce (and discard) colder water from the lower portion of the aquifer. In this way, the colder water will not be pulled into the upper well, where it would lower production temperature.

Table 3 summarizes the results of the numerical simulations. For a cycle consisting of 1 month each of injection, storage, and production $\left(18,300 \mathrm{~m}^{3}\right.$ injected and produced), the maximum recovery factor is about 0.52 , representing an improvement of about 0.12 over the reference case. However, if the 3-month cycle is altered so that two months of injection are followed immediately by 1 month of pro-

Table 3. Third-cycle design studies $\left(T_{1}=82^{\circ} \mathrm{C}, Q=112 \mathrm{gpm}\right)$.

I. One month each of injection, storage, production $\left(V=18,300 \mathrm{~m}^{3}\right)$

\begin{tabular}{|c|c|c|c|}
\hline \multicolumn{4}{|c|}{ Well-screen interval (\%) } \\
\hline Approach & Injection & Production & $\epsilon$ \\
\hline \multirow{2}{*}{$\begin{array}{l}\text { Reference Case } \\
\text { l }\end{array}$} & 100 & 100 & 0.404 \\
\hline & Upper 40 & Upper 40 & 0.448 \\
\hline 1 & Upper 40 & Upper 40 & 0.501 \\
\hline 2 & $\begin{array}{l}\text { Upper } 20 \\
\text { Lower } 20\end{array}$ & Upper 20 & 0.516 \\
\hline 2 & $\begin{array}{l}\text { Upper } 20 \\
\text { Lower } 20\end{array}$ & $\begin{array}{l}\text { Upper } 20 \\
\text { Lower } 20\end{array}$ & 0.487 \\
\hline 3 & Upper 40 & $\begin{array}{l}\text { Upper } 40 \\
\text { Lower } 55\end{array}$ & 0.500 \\
\hline 3 & Upper 40 & $\begin{array}{l}\text { Upper } 20 \\
\text { Lower } 55\end{array}$ & 0.521 \\
\hline \multicolumn{4}{|c|}{ II. Two months of injection, 1 month of production $\left(V=36,600 \mathrm{~m}^{3}, Q_{p}=2 Q_{j}\right)$} \\
\hline \multirow{2}{*}{$\begin{array}{l}1 \\
3\end{array}$} & Upper 40 & Upper 40 & 0.603 \\
\hline & Upper 40 & $\begin{array}{l}\text { Upper } 40 \\
\text { Lower } 55\end{array}$ & 0.629 \\
\hline 3 & Upper 40 & $\begin{array}{l}\text { Upper } 40 \\
\text { Lower } 20\end{array}$ & 0.631 \\
\hline 3 & Upper 40 & $\begin{array}{l}\text { Upper } 20 \\
\text { Lower } 20\end{array}$ & 0.661 \\
\hline
\end{tabular}


duction (at twice the injection flow rate), hence doubling the storage volume, a recovery factor of about 0.66 is possible. Thus for this short-term experiment, the volume of fluid injected is as important as experiment, the volume of fluid injected is as impor. tant as the manner in which it is injected and produced.

\section{THIRD-CYCLE SIMULATION}

A preliminary calculation based on the third cycle has been made using the axisymmetric threelayer aquifer model developed during the first-cycle simulation.

During the third cycle, $56,700 \mathrm{~m}^{3}$ of water at an average temperature of $80^{\circ} \mathrm{C}$ was injected over a period of 3 months, stored for 2 months, then produced over a period of 2 months. The injection/production-well open interval was the upper $45 \%$ of the aquifer thickness. During the production period, a rejection well located jusi $2 \mathrm{~m}$ from the injection/production well, but open over the lower $45 \%$ of the aquifer thickness, withdrew and discarded cool water from the lower region of the aquifer at an average flow rate of about $20 \%$ of the production flow rate. On the basis of the previously described studies, this rejection well was designed to minimize mixing of cool water from the lower region of the aquifer with warm water to be produced from the upper region of the aquifer.

The third-cycle calculated energy recovery factor of 0.44 agrees very well with the experimental value of 0.42. Because of the great difference in cycle duration between the design studies ( 90 days) and the actual experiment ( 223 days), the design study recovery factors arc not directly comparable with the experimental value. Figure 2 shows the experimental and calculated production and rejection temperatures versus time. The variation in calculated production temperature reveals a pattern typical of recent numerical simulations of experiments at the Mobile site: Initial overprediction of the experimental production temperature is followed by a more rapid decline than is found experimentally, leading to a final underprediction. The calculated rejection temperature consistently underpredicts the experimental value by about $5^{\circ} \mathrm{C}$. Although the overall agreement between calculated and experimental temperature distributions in the aquifer at various times throughout the cycle is good, it is apparent that the numerical model is overpredicting buoyancy flow somewhat. This provides a possible explanation for the underprediction of rejection temperature seen in Fig. 2.

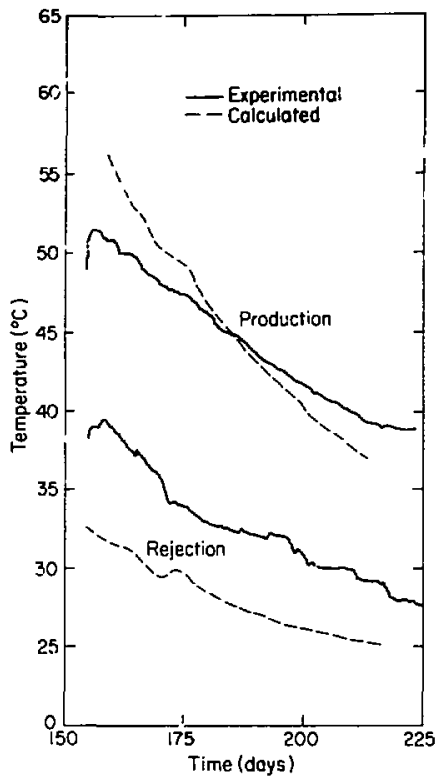

Figure 2. Experimental and calculated production and rejection temperatures for the third cycle. [XBL 834-175 ji

\section{REFERENCES}

Bodvarsson, G.S., 1982. Mathematical Modeling of the Behavior of Geothermal Systems Under Exploitation (Ph.D. dissertation). Lawrence Berkeley Laboratory, LBL-13937, p. 18-48.

Buscheck, T.A., Doughty, C., and Tsang, C.F., 1983. Prediction and analysis of a field experiment on a multilayered aquifer thermal energy storage system with strong buoyancy flow. Water Resources Research, v. 19, no. 5, p. 1307-13i5.

Dolighty, C., Hellstrom, G., Tsang, C.F., and Claesson, J., 1982. A dimensionless parameter approach to the thermal behavior of an aquifer thermal energy storage system. Water Resources Research, v. 8 , no. 3, p. $571-587$.

Tsang, C.F., Doughty, C., and Buscheck, T.A., 1983. Prediction and analysis of a field experiment on a multilayered aquifer thermal energy storage system with strong buoya $i_{2}$ y flow. In Earth Sciences Division Annual Report 1982. Lawrence Berkeley Laboratory, LBL-15500, p. 157-160. 
HEAT STORAGE IN

UNSATURATED SOILS:

INITIAL THEORETCAL

ANALYSIS OF STORAGE

DESIGN AND OPERATIONAL METHODS

\author{
C. Doughty, A. Nir, and C.F. Tsang
}

The numerical model PT (Bodvarsson, 1982) has been used to examine seasonal heat storage in shallow, unsaturated soils for semiarid climatic conditions. Heat is supplied as low-temperature warm water $\left(60-65^{\circ} \mathrm{C}\right)$ obtained from solar collectors and is transferred to the soil (initially at $24^{\circ} \mathrm{C}$ ) by pumping the water through a system of shallow horizontal ducts and deeper vertical helical ducts. The heat is used for winter warming of a greenhouse that overlies the storage medium. Heat is extracted from the deep storage region by pumping cool water $\left(20^{\circ} \mathrm{C}\right)$ through the vertical helical ducts. Heat leaves the shallow storage region by diffusion to the ground surface, where it is released into the greenhouse air. At present only conductive heat transfer is considered in the storage medium, with temperatureand saturation-independent thermal properties representative of a homogeneous mixture of $60 \%$ soil, $20 \%$ water, and $20 \%$ air. Future calculations will include unsaturated flow and the addition of phase change material to the storage medium.

A number of scenarios have been studied, involving variations in the supply and demand of energy, weather patterns, soil properties, and length and spacing of the storage ducts. The results of these calculations will aid in the design of a greenhouse storage system currently being planned ( $\mathrm{Nir}$ and Amiel, 1981; Nir et al., 1981).

For each scenario, PT calculates the evolution of the temperature distribution around a single, verticai helical duct. The helix is approximated by a cylindrical conduit; an insulated boundary at a constant radial distance from the cylinder axis represents the influence of neighboring ducts. $A$ sketch of the axisymmetric region modeled is shown in Fig. 1. Ducts located on the edge of the storage system will be studied later with a simplified three-dimensional model.

-Deser Research Institute. University of Negev, Sede Boker, Isrel.

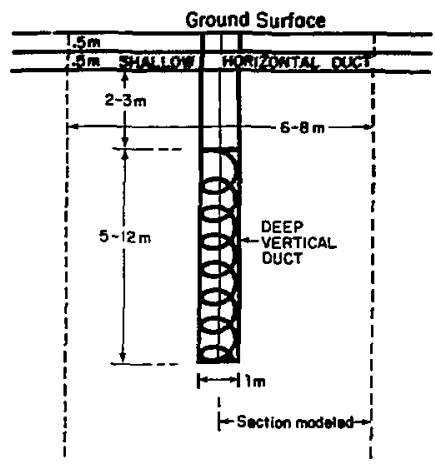

Figure 1. A sketch of the region around one vertical helical duct. The vertical broken lines are midway between adjacent ducts. [XBL 832-1716]

An example of the system's performance for a given 2-year weather sequence is shown below in Figs. 2 and 3. Seasonal climatic changes are represented by a sinusoidal ground surface temperature (Fig. 2A) and the monthly pattern of energy supply and demand (Fig. 2B). The deep storage region is charged with heat during summer and discharged during winter to provide seasonal energy storage. The shallow storage region is charged during winter to provide short-time storage between daily peak periods of energy supply (daytine) and demand (nighttime). Also shown in Fig. 2 (C and D) are the calculated flow rate through and the outlet temperature of a deep duct. So that the imposed energy supply or demand (solid line in Fig. 2B) is met, the flow rate is determined from the following equation for the energy deposited in the storage medium around the duct:

$$
E=C_{\mathrm{H}}\left(T_{\text {in }}-T_{\text {out }}\right) Q,
$$

where $E$ is the daily supply or demand of energy per duct $(\mathrm{MJ} / \mathrm{d}), C$ is the specific heat of water $(\mathrm{MJ} / \mathrm{kg}$ $\left.{ }^{\circ} \mathrm{C}\right), T_{\text {in }}$ is the duct inlet temperature $\left(60-65^{\circ} \mathrm{C}\right.$ during summer; $20^{\circ} \mathrm{C}$ during winter), $T_{\text {our }}$ is the duct outlet temperature $\left({ }^{\circ} \mathrm{C}\right)$, and $Q$ is the average daily flow rate $(\mathrm{kg} / \mathrm{d})$. The detailed fluid and heat flow through the shallow horizontal ducts is not considered; instead, a uniform heat source is defined throughout the shallow duct area, with strength given by the broken line in Fig. 2B. Figure 2E shows the heat flux through the ground surface. During summer, negative heat flux (from storage medium to air) 


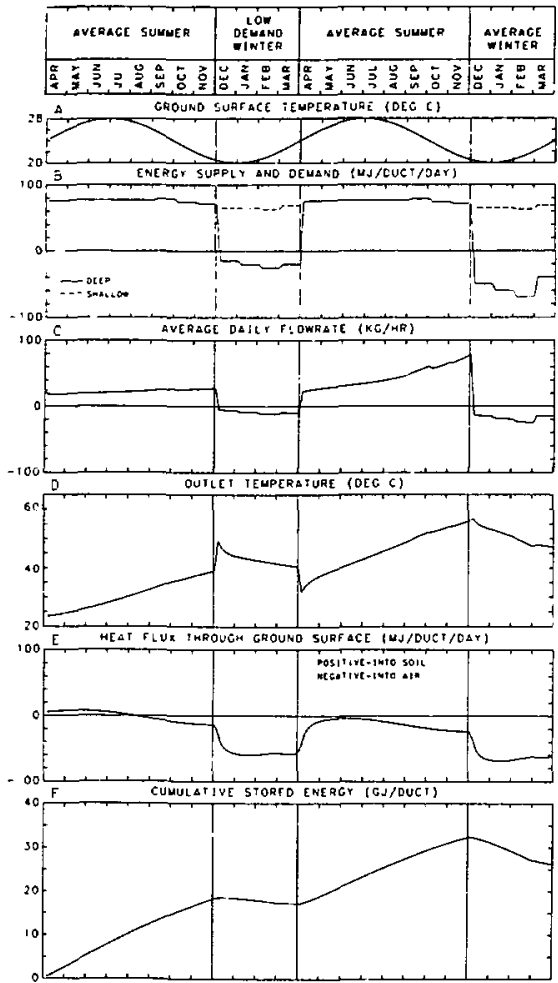

Figure 2. Boundary conditions ( $A$ and $B$ ) and calculated results (C-E) for a two-year sequence. In $B$ and $C$, positive values indicate charge, and negative values indicate discharge. [XBL 8312-2414]

is considered an energy loss; during winter, it constitutes an important part of the storage system's output. Figure $2 \mathrm{~F}$ shows the cumulative stored energy in the heat storage system, which is the sum of the curves shown in parts $B$ and $D$. The low-demand winter included in the weather sequence provides a gradual start-up period for the system, during which much more heat is stored than is extracted. This excess heat lessens conduction heat losses for future years and provides an energy reserve for especially cold ivinters. Figure 3 shows contour plets of the temperature distribution in the storage medium throughout the sequence of operation of the heat

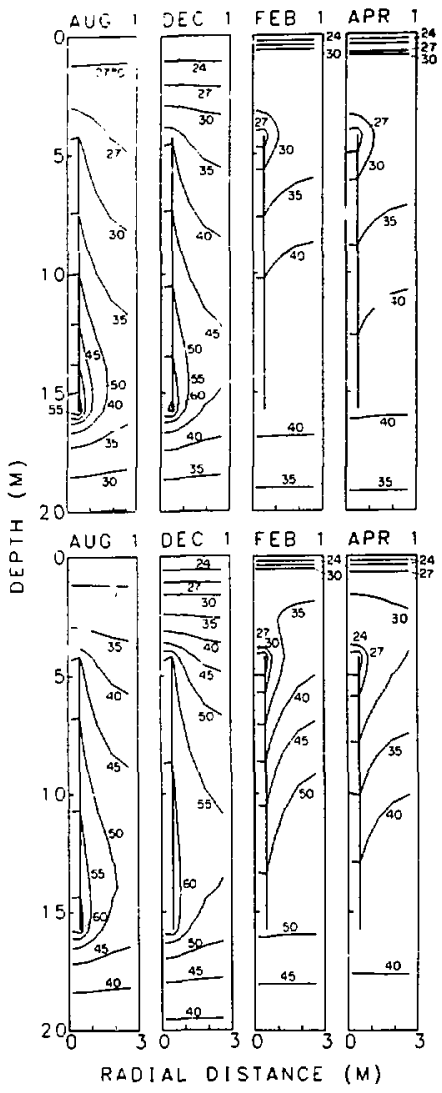

Figure 3. Calculated temperature distributions throughout the sequence. The cross section of the conduit representing the helical deep duct is shown as a heavy vertical segment. The shallow horizontal duct system lies between 0.5 and $1 \mathrm{~m}$ below the ground surface (depth 0). [XBL 8312-2413]

storage system. Note that fluid flows up the deep duct during summer and down during winter.

The vertical ducts in the heat storage system described above are $12 \mathrm{~m}$ long, start $4 \mathrm{~m}$ hlow the ground surface, and are separated laterally by $6 \mathrm{~m}$. Studies have shown that greater lateral spacing is of no benefit, because heat transfer by conduction cannot occur within the time limits imposed by the 
winter energy demand. Additionally, if the top of the vertical duct is less than $4 \mathrm{~m}$ below the ground surface, too much heat flows through the ground surface during summer. Soil parameter variation has shown that the soil must not be allowed to dry out, because the thermal conductivity of dry soil is too low to allow sufficient heat transfer into the storage medium. In addition to the sinusoidal ground surface temperature given for this case, short-term temperature variations of 5- to 10-day periods were included to simulate especially warm or cold winters. The rapidly varying surface temperature caused large surface heat fluxes, and the cold winter required much larger average daily flow rates to meet the energy demand.

\section{A MODEL FOR PARTIALLY SATURATED FLOW IN FRACTURED POROUS MEDIA}

\section{T.N. Narasimhan and J.S.Y. Wang}

The flow of water in fully saturated geologic media has received considerable attention, especially in regard to problems related to the disposal of highlevel nuclear wastes. 7 he fractures in these systems possess very high hydraulic conductivity relative to the rock blocks and act as highways for the rapid transmission of groundwater. In contrast, other systems of interest for the disposal of high-level radioactive wastes are only partially saturatrd with water. The flow of water in such systems has so far received less attention. In particular, such a system exists in the Yucca Mountain area of the Nevada Test Site. At the Yucca Mountain area, the water table lies about $500 \mathrm{~m}$ below the land surface, and the geology of the materials above the water table is characterized by prominently fractured, welded or nonwelded tuff. In order to evaluate the suitability of this site. therefore, it is essential to understand the hydrology of the partially saturated, fractured tuff.

\section{CONCEPTUAL MODEL}

A preliminary search of the literature has failed to yield any work that relates to the flow of water in a partially saturated, fractured porous medium. A first attempt was therefore made to formulate a con-

\section{REFERENCES}

Bodvarsson, G.S., 1982. Mathematical Modeling of the Behavior of Geothermal Systems Under Expluitation (Ph.D. dissertation). Lawsence Berkeley Laboratory, LBL-13937, p. 18-48.

Nir, A., and Amiel, A., 1981. Seasonal heat storage in greenhouse soil. In Proceedings, International Conference on Seasonal Thermal Energy Storage and Compressed Air Energy Storage, Seattle, Washington, October 19-21, 1981, p. $96-102$.

Nir, A., Amiel, A., Krant, 3., and Epstein, M., 1981. Solar heat supply for greenhouses with siratified soil tieat storas: : Data collection and feasibility siudy. Acta Horticulturae, v. 115.

ceptual model that stems from the basic principles of soil physics. This report is a summary of that conceptual model along with some preliminary results.

Tuff is a consolidated rock made up essentially of cemented volcanic ash. The primary pore size usually ranges from a few microns is a few tens of microns. Even at a depth of several hundred meters in such a formation, the fractures are likely to have apertures ranging from several tens to several hundreds of microns. Thus fractured tuff will have a strongly bimodal pore size distribution.

lt is well established in the field of soil physics that in partially saturated porous media the fluid pressure in the water phase is less than atmospheric and that the fluid saturation in the porous medium is a strong function of the water phase pressure. The relation between fluid pressure and saturation is governed by surface tension between the liquid and the solid phases and by the effective capillary radii of the pores. lrideed, it is well established that as the water phase pressure in the porous medium is decrensed below atmospheric pressure, the largest pores will jesaturate fizst, followed by successively smaller pores.

If one recognizes that the large pores desaturate first during the drainage process, it is easy to infer that the fractures in a fractured porous medium will tend to remain dry under conditions of partial saturation and that water will be held by capillarity in the finer pores of the matrix. Moreover, since natural fractures are characterized by rough surfaces, the aperture of a fracture is seldom constant and will be very small near asperities. Thus one would expect hat asperities will cause "islands" of water 
film to exist within the fracture plane. Within a fracture that is partially saturated in this fashion, the presence of a relatively continuous air phase will produce a nearly infinite resistance to flow in a direction parallel to the fracture. Therefore, as a fracture begins to desaturate, its effective hydraulic conductivity will decline almost abruptly by several orders of magnitude. It is reasonable to expect that the effective hydraulic conductivity of the fractures will soon become smaller than that of the porous matrix, which needs fairly large capillary pressures to initiate desaturation.

A very interesting consequence of this dramatic reduction in fracture permeability is that water will tend to flow across the fracture from one matrix block to another instead of flowing along the fracture. Thus one should expect flow lines to swing around the ary portions of the fractures (Fig. 1). The fractures will thus introduce a macroscopic tortuosity in the system. If this reasoning is sound, one may be in a position to grossly quantify the effects of the fractures in terms of an overall tortuosity factor-a task that may prove to be somewhat simpler than characterizing a saturated fractured system as an equivalent anisotropic medium.

In order to quantify the hydrology of a fractured porous medium, the reasoning presented above requires the development of three basic relations: (1) the relation between fluid pressure head (which is less than atmospheric under partial saturation) and fracture saturation, (2) the relation between fluid pressure head and fracture conductivity, and (3) the proportion of the fracture surface that remains wet-

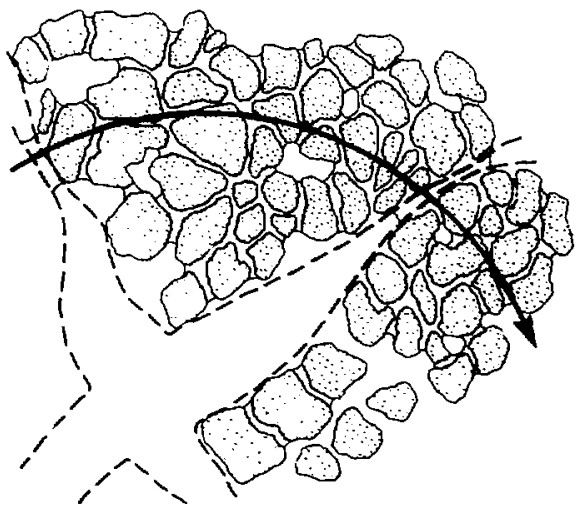

Figure 1. Flow lines in a partially saturated, fractured porous medium. [XBL 841-9580] ted. To date, no data on either category are experimentally available, especially for the Yucca Mountain rocks. To gail. nsight into the problem, one has to develop these relations on theoretical grounds, using assumed fracture roughness characteristics and surface tension characteristics. The importance of these functional relationships in regard to the transient fluid flow process lies in the fact that the roughness characteristics constituie the storage term for the fracture and the surface tension characteristics describe the time-dependent contact area for fluid flow from one matrix block to another.

\section{RESULTS}

Our statistical description of a rough-wall, variable-aperture fracture is based on averaging the aperture distribution function over the fracture plane. Capillary theory and the cubic law for fracture flow are generalized to derive theoretical formulas for the fracture saturation, conductivity, and effective fracture-flow area. These formulas are evaluated for the Yucca Mountain tuff $\iota$ sing available matrix and fracture data (matrix-saturati $j$ conductivity characteristic curve, relative permeability, fracture frequency, density, fracture surface coating, and in situ conductivity). The resuls are rotted in Figs. 2 to 4 . All parameters in the for nulas are determined by the data, and no adjustable parameters are used.

Figure 2 shows that fractures can be desaturated easily with a small suction of $-1 \mathrm{~m}$. The saturation in the matrix will remain high. With a suction of $-100 \mathrm{~m}$, the matrix will be $83 \%$ saturated. The ambient saturation at the Topopah Spring Member is $80 \%$. The hydraulic conductivit s are shown in Fig. 3. As the fractures desatur $\&$, they can no longer be transmissive to fluid flo". The decrease in matrix permeability is reduced as the pressure head becomes more negative. The hydraulic conductivities of the equivalent fracture continua will control the fluid flow near saturated conditions with a pressure head greater than $-1 \mathrm{~m}$, but the matrix will control the flow for a pressure head less than $-1 \mathrm{~m}$. For suction in the range $o-100 \mathrm{~m}$, the fracture flows are negligible and the natrix flow dominates.

The matrix flow will iso be impeded when it crosses the fractures. The matrix-fracture flow is limited by the area of fracture surface available for transmission of nuid. Figure 4 shows that the effective fracture-matrix flo: area decreases rapidly and approaches the limitir contact area fraction as the pressure head decreases. The effective fracturematrix flow area reduces the matrix flow across the matrix-fracture interiaces. 


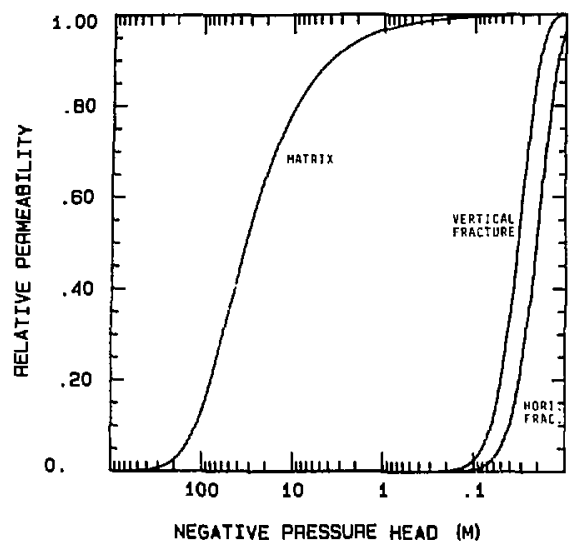

Figure 2. Saturation in the matrix blocks and in the ciscrete fractures. [XBL 841-323]

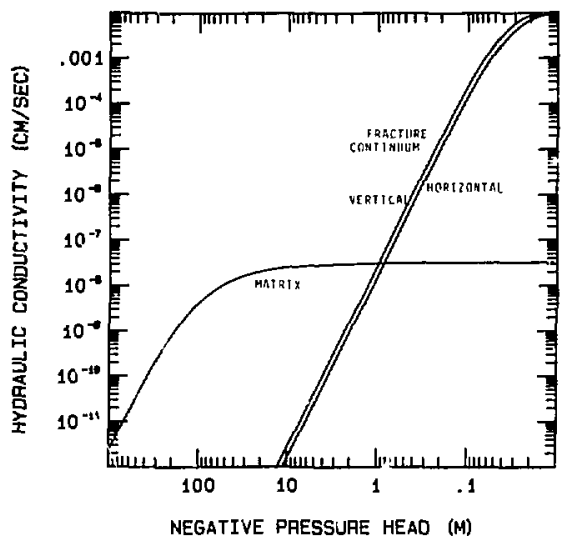

Figure 3. Hydraulic conductivities of the matrix and the equivalent fracture continuum. [XBL 841-322]

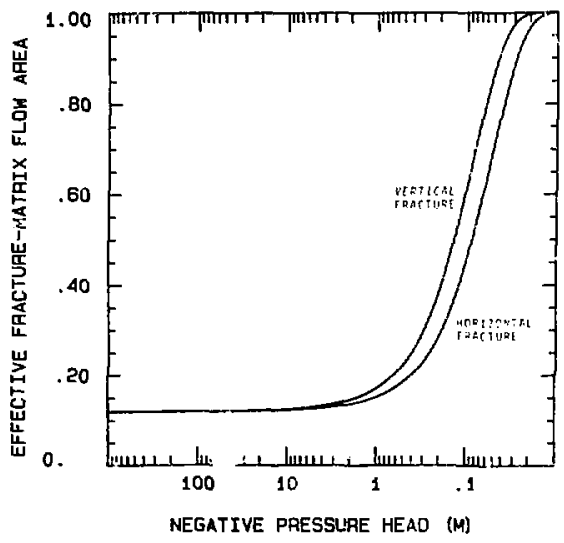

Figare 4. Effective flow area at the fracture-matrix interfaces. [XBI 841-321] 
SIMULATION OF

\section{EVAPORATION FROM THE URANIUM MILL TAILINGS PILE AT RIVERTON, WYOMING}

\section{T. Tokunaga and T.N. Narasimhan}

The now-abandoned uranium mill tailings pile at Riverton, Wyoming, lies above the shallow-watertable aquifer in the flood plains of the Wind River and the Little Wind River. The pile itself is in a state of partial saturation, with a fairly well defined downward gradient in the profile of $h ;$ draulic heads (Fig. 1). Tokunaga and Narasimhan (1982) estimate that the existing downward gradients suggest a recharge rate of $0.3-3 \mathrm{~cm} /$ year through the tailings to the shallow aquifer. To model the hydrogeologic system at Riverton and to project the bchavior of the system into the future, the essential first step is to model the observed fluid potential profile that has developed within the system over the two decades since the pile was abanched. This article summarizes the results of the $f$.for to numerirally simulaic the infiltration regine within the tailings pile at Riverton.

\section{THEORETICAI BASIS}

The hydrologic regime in the pile is characterized by variable water saturation within the tailings 'nd by the interaction of the tailings with the atmosphere at the upper surface. At the upper surface, the tailings may interact either directly with the

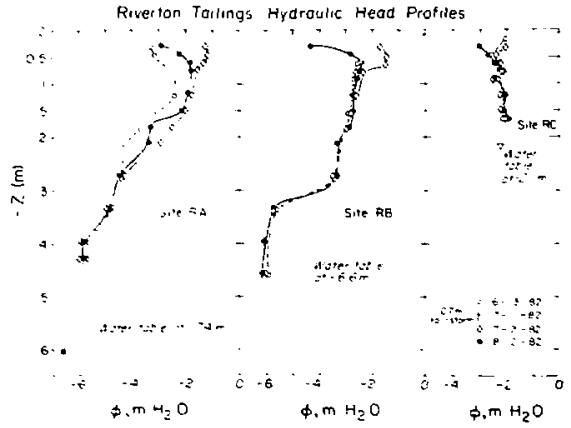

Figure 1. Hydraulic head as a function of depth at three rites on the Riverton tailings pile. [XBL 829-1151] atmosphere or through an intervenung cover. The upper boundary is characterized by recharge due to rainfall and snow melt and by discharge due to evapotranspiration. The lower boundary is characterized by a variable hydraulic head dictated by the fluctuation of the water table. Rainfall at Riverton averages about $0.25 \mathrm{~m} /$ year. The estimates of recharge made by Tokunaga and Narasimhan (198?), as well as existing perspectives on the magnitudes of evapotranspiration in semiarid regions, clearly indicate th'it the large movement of water across the upper boundary is the controlling factor in determining the fluid potential profile within the tailings. The first step in the simulation process is therefore the modeling of the hydrologic regime within the column, with careful attention paid to the upper boundary.

The Riverton tailings pile is relatively level, partially saturated, and underlain by a highly permeable shallow aquifer. Thus flow within the tailings is largely vertical, and modeling the tailings as a onedimensional column is a very useful and valid simplification for the present purpose. Within this system, the transient flow is governed by the nonlinear, parabolic partial differential equation known as Richard's equation. Field measurements have shown that the tailings column can be idealized as a heterogeneous system with three different materials: an upper san' ' $y$ unit, a middle silt ' .' sand' 'Init.

Three approaches to simulati. zporation have been investigated: (1) imposing co.. ..ant potentiai boundary conditions between precipitation events, (2) imposing potential-dependent flux boundary conditions between precipitation even 15 , and (3) prescribing flux boundary conditions. Monthly averaged climatic data from the Riverton area were used in the second and third methods to estimate evaporative flux. In all three methods. the program. TRUS] (Narasimhan et al., 1978) was used.

In the prescribed potential boundary approach, evaporation events were simulated by setting the surface node pressure head to $-6.0 \mathrm{~m} \mathrm{H}_{2} \mathrm{O}$. Rainfall events were simulated by setting the surface node pressure head to $+0.001 \mathrm{~m} \mathrm{H}_{2} \mathrm{O}$. The tailings simulation proceeded from an initial condition of full saturation through alternating periods of evaporation and rainfall at the upper surface. The lower boundary was defined by a water table fixed at $-6.0 \mathrm{~m}$ below the ipper surface. Each simulated year consisted of ten evaporation cycles interspersed with nine rainfall cycies. Rainfall durations were adjusted for consistency between simulated yearly infiltration and Riverton mean annual precipitation. By the 
tenth simulated year, quasi-steady-state hydraulic head profiles were generated within the bulk of the tailings system (Fig. 2). Significant fluctuations in the hydraulic head proifles occurred only within the upper meter of tailings, reflecting evaporation and precipitation events. These features are consistent with field observations. The steady-state recharge of the groundwater in these simulations is $0.03 \mathrm{~m} / \mathrm{year}$, consistent with the estimated upper limit for recharge in earlier studies. The principal defect of this method is that the selection of magnitudes and durations of surface potentials is rather arbitrary. The following two methods improve on this by considering effects of climate on the evaporation rates.

The second approact investigated for evaporation simulation couples climatic effects with surface soil water potential effects on surface losses. The method chosen was developed by Staple (1974). This approach essentially stbstitules surface soil water vapor pressures for saturationl vapor pressures in the Penman potential evaporation equation. Averaged monthly climatic data are used to generate upper limits on evaporation rates. The potential evaporation rates are scaled down in response to more negative surface water potentials. The potential dependent sink functions were input in tabulas form to operate on the upper surface volume element. Rainfall was concentrated into $0.0051-\mathrm{m}$ events of 2-h duration, distributed in time to nominally follow Riverton monthly precipitation patterns. The hydraulic head profiles through 3 years of simu-

R82 SIMULATIONS WITH STEP-CHANGED SURFACE POTENTIALS

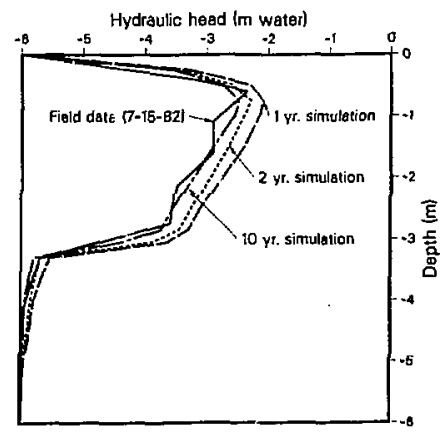

Figure 2. Simulated hydraulic head distribution using a constanl potential boundary condition at the land surface. [XCG 8311-4918] lation, again with initially saturated tailings, are summarized in Fig. 3. This model results in ne. annual losses of tailings water through the upper surface. The trends of decreasing hydraulic head and lewering of the zero-flux boundary both reflect simulated net evaporation. Alternative distributions of precipitation events did not significantly alter thesc results. Since field data clearly contradict these rest: $h$; , it is concluded that Suple's method, as usec in this study, overestimates evaporation rates. This overestimation may have resulted from our assumptions that the surface water potential is largely determined by the matric (negative pressure) potential and that the surface osmotic potential is of lesser importance.

The third method of estimating evaporation in this study is representative of the complementary relationship areal evaporation (CRAE) approach. The version discussed by Morton (1978) was used to calculate monthly average evaporation rates for the Riverton area from averages of 10 years of local climatic data. The results of the CRAE method are presented in Fig. 4; also included for comparison are the average monthly precipitation and results from calculations using Staple's method. Although the CRAE method provides much better results than Staple's method in this application, evaporation estimates are still excessive. This overestimation can be qualitatively reconciled by considering the appropriate scale for which the CRAE method was developed. The CRAE approach is suited for estimating evaporation over relatively large areas,

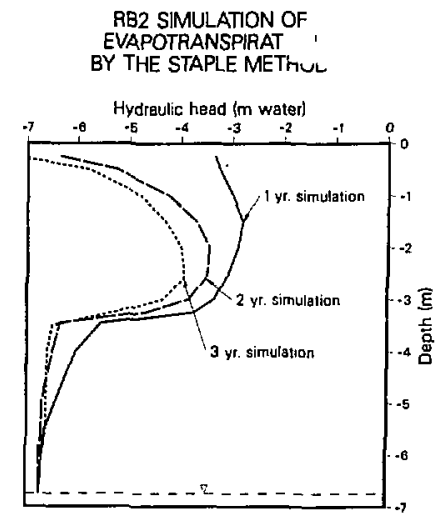

Figure 3. Simulated hydraulic head distribution using evapotranspiration estimates obtained with Staple's inethod. [XCG 8311-4919] 
RIVEFTON EVAPOTRANSPFATION BY THE CRAE METHOD

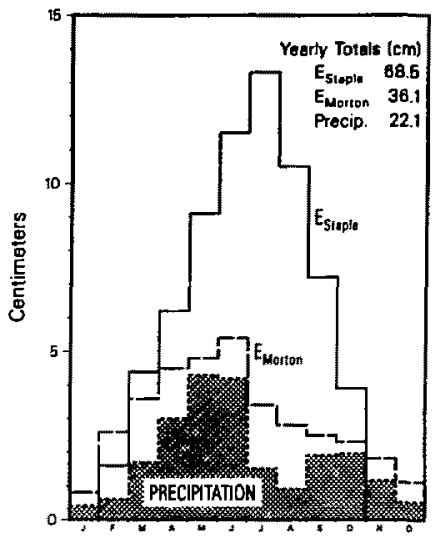

Figure 4. Comparison of evapotranspiration losses obtained using Staple's method and Morton's method. [XCG 8311-4917]

and thus our results are more representative of the Riverton area as a whole rather than ${ }^{* * \prime \prime}$ of any specific site. It seems reasonable that the sparsely vegetated cover of cobbly tauıngs would evapoiranspire at 50 to $60 \%$ of the rate of the surrounding region. A reduction in the CRAE estimates by $40 \%$ would be consistent with the observed recharge through the tailings system.

\section{REFERENCES}

Morton, F.I., 1n78. Estimation of evapotranspiration from poiential evaporation: Practicality of an inocolastic approach. Journal of Hydrology, v. 38, p. 1-32.

Narasimhan, T.N.* Witherspoon, P.A., and Edwards, A.L., 1978. Numerical method for saturatedunsaturated flow in deformable porous media, Part 2. The algorithm. Water Resources Research, v. 14, no. 2, p. 255-261.

Staple, W.J., 1974. Modified Penman equation to provide the upper boundary condition in computing evaporation from soil. Soil Science Society of America, Proceedings, v. 38, p. $837-839$.

Tokunaga, T., and Narasimhan, T.N., 1982, Recent hydrological observations from the Riverton and Maybell tailings piles, Proceedings, 5th Uranium Mill Tailings Management Symposium, Colorado State University, Ft. Collins, Colorado, December 9-10, 1982. Civil Engineering Department, Colorado State University, p، 463-474.

tion process, and hence contain highly acidic interstitial water. As this highly acidic water moves down by gravity from the tailings to the shallow-watertable aquifer below, the acidic water mixes with the neutral to slightly alkaline groundwater, which eventually leads to the neutralization of the acid and the precipitation of certain of the chemical species. This neutralization process may be augmented by the presence of particular mineral phases such as calcite in the matrix of the shallow aquifer, which will continue to maintain the alkalinity in the groundwater despite the consumption of the alkali in the neutralization process. The precipitation that occurs immediately below the tailings fixes part of the dissolved solute in the matrix and thus helps to retard the aigration of the contaminant. A quantitative understanding of precipitation-dissolution mechanisms is therefore necessary to an assessment of the potential contamination and selection of appropriate mitigative measures. 
The Uranium Mill Tailings Remedial Action Project of the U.S. Department of Energy (the UMTRA Project) is concerned with assessing the contaminant potential of the inactive uranium mill tailings pile at Riverton, Wyoming, and devising appropriate measures to ameliorate the long-term contamination of the local groundwater system. Field geochemical data (White and Delany, 1982) have indicated the existence of a prominent zone of reutralization beneath the tailings; this zone has tended to retard the migration of sulfate in the groundwater system. To simulate this observed neutralization effect, a computer program called DYNAMIX (DYNAmic MIXing) has been developed. The logical basis for this program is described below.

\section{PROGRAM DYNAMIX}

Precipitation and dissolution occur when fluids of dissimilar composition mix with each other. The chemical reactions controlling these processes are governed by $\mathrm{pH}$, redox potential, and the mineral phases that coexist with the aqueous phases. The pH and the redox potential, in turn, are governed by the chemical interactions between the many chemical species that participate in the reactions. Parkhurst et al. (1980) developed a computer program called PHREEQE for geochemical calculations at relatively low temperatures. Essentially, this program considers an electrolyte with arbitrarily many dissolved species. On the basis of an ion-pairing aqueous model, it calculates $\mathrm{pH}$ and redox potential. In addition, given two solutions with dissimilar volumes and compositions, PHREEQE can mix the two solutions in the presence of prescribed mineral species and not only compute the composition of the mixture but also indicate whether any species has been dissolved or precipitated.

Whereas the PHREEQE program is capable of simulating the mixing process, the overall groundwater transport problem requires, in addition, the transport of the dissolved species through advective, dispersive, diffusive, and decay processes, with or without adsorption. This transpon capability is available with the coniputer program TRUMP (Edwards, 1972), which analyzes the transport of a single chemical species. Inasmuch as precipitation and discolution require consideration of several chemical s;rries, program DYNAMIX was developed by extending TRUMP to handle the transport of 10 chemical species and coupling it with P.IREEQE.

The logical structure of the DYNAMIX algorithn for handling precipitation and dissolution is as follows. At the beginning of the problem, the input chemical composition of the water in each volume element in the flow region is checked for consistency and the $\mathrm{pH}$ calculated using the ion-pairing aqueous model. Next, the amount of precipitation or dissolution of each of the volume elements in the system is calculated for each time step. To achieve this, the time-averaged composition of the fluid entering an element of interest is computed from estimated time derivatives. This water is then titrated with the water present within the volume element to obtain the magnitudes of precipitation and dissolution of each species. The magnitudes are then used explicitly as sink or source terms in the multiplespecies Iranspor equation.

The preliminary version of DYNAMIX has been tested and found to reasonably simulate the dilution front migrating downward within the tailings as a result of the long-term infiltration of rain water. Further work is in progress.

\section{REFERENCES}

Edwards, A.L., 1976. TRUMP: A computer program for transient and steady-state temperature distributions in multidistributions in multidjmensional systems. Lawrence Livermore Laboratory, UCRI 14754, Rev II, 263 p.

Parkhurst, D.L., Thorstenson, D.C., and Plummer, N.L., 1980. PHREEQE-A computer program for geochemical calculations. Water Resources Investigation, U.S. Geological Survey, Report No. 80-96, 210 p.

White, A.F., and Delany, J., 1982. Chemical transport beneath a uranium mill tailings pile, Riverton, Wyoming. In Proceedings, Fifth Annual Symposium on Mill Tailings Management, Colorado State University, For Collins, Colorado, p. 295-314; Lawrence Berkeley Laboratory, LBL-15038. 
THERMOMECHANICAL RESPONSE OF SALT AND HARD ROCKS TO THERMAL LOADING BY WASTES OVER 10 YEARS OLD

J.S.Y. Wang, D.C. Mangold, and C.F. Tsang

Thermal loading is a principal consideration in the design and evaluation of a repository for geologic disposal of nuclear wastes. The duration of predisposal aging of the wastes on the surface determines the waste heat power at emplacement. The underground ventilation cooling during the repository operation and retrieval periods has the equivalent effect of surface cooling in removing a portion of the heat generated by the waste. Most previous repository thermal studies have regarded 10 years as the standard cooling period. However, the concern over thermal effects and the anticipated delay in establishing fully operational repositories require that attention should be given to older wastes.

\section{ALLOWABLE WASTE DENSITY WITH NEAR-FIELD THERMOMECHANICAL CRITERIA}

If the waste density is held fixed, the " zpository temperature will decrease with longer surface cooling periods. With lower temperature rises, the thermally induced strain in salt and stress in hard rocks will both decrease. If repository design takes advantage of the lower thermally induced impacts by emplacing waste in a more concentrated configuration, proper thermal criteria must be used to determine the optimal waste loadings.

The existing thermomechanical criteria in the Department of Energy (DOE) reports are expressed in terms of strain of room closure for salt and strength-to-stress ratios for hard rock repositories (DOE, 1980). These criteria were developed mostly by studies of 10-year-old wastes. Imposing these existing criteria on older wastes enables allowable waste densities to be determined. The analyses for salt and nonsalt are discussed in the following two subsections.

\section{Reduction of Strain for Room Convergence in} SaIt

Room convergence in salt mines depends on the temperature, pillar stress, and time. In Project Salt
Vault (Bradshaw and McClain, 1971), the results of model pillar tests of rock salt from the Lyons Mine were fitted with an analyiic formula called Lomenicl:'s formula. It has been frequently used in repository designs for salt as a plastic rock medium. In SI units the formula is

$$
E=C T^{9.5} \sigma^{3.0} t^{0.3}
$$

where $E=$ cumulative strain $(\mathrm{m} / \mathrm{m}), T=T_{\text {ambiens }}+$ $\Delta T$ (absolute temperature, $\mathrm{K}$ ), $\sigma=$ average pillar stress (Pa), $t=$ time $(\mathrm{s})$, and $C=3.4 \mathrm{E}-50$. The cumulative strain is therefore a nonlinear function of $\Delta T$. This formula was employed in the National Waste Terminal Storage (NWTS) conceptual designs for domed and bedded salt (Kaiser Engineers, 1978a,b; Stearns-Roger Engineering, 1979) and in the NWTS conceptual reference repusitory description (Bechtel Group, 1981).

The NWTS reference salt repository is assumed to contain 10-year-old wastes emplaced at $37 \mathrm{~W} / \mathrm{m}^{2}$ (150 kW/acre) at $640 \mathrm{~m}$ (2100 ft) depth with an average pillar stress of $14.5 \mathrm{MPa}(2100 \mathrm{psi})$. The waste

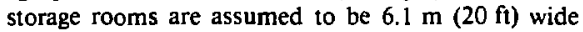
and $4.8 \mathrm{~m}$ ( $15 \mathrm{ft} 9 \mathrm{in}$.) high. After 5 years, however, the roof height decreases by $0.23 \mathrm{~m}$ ( $9 \mathrm{in}$.). Older wastes stored in the same rcom and at the same waste emplacement density have a lower average temperature risi at 5 years, thereby reducing the cumulative room convergence (Fig. 1). If $0.23 \mathrm{~m}$ of room convergence ( $5 \%$ linear strain) is acceptable for safe operations in the repository, the waste emplacement density can be increased.

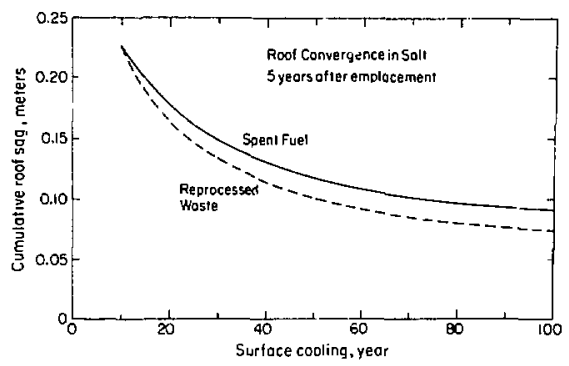

Figure 1. Roof convergence in salt as a function of surface cooling period in SF and HLW repositories. [XBL 823-2003] 


\section{Reduction of Strength-to-Stress Ratios in Granite, Basalt, and Shale}

The stress fields around a room in hard rocks such as granite. basalt, and shale depend on the temperature, the in situ stress field, and the change in load due to excavation. The thermomechanical stability limits for mined repositories in hard rock were established in the Generic Environmental Impact Statement (GEIS) study (Dames and Moore, 1978; DOE, 1979). These near-field criteria determine the repository loading density of 10 -year-old wastes.

The near-field thermomechanical criteria are expressed in terms of strength-to-stress ratios (DOE, 1979). The repositories contain 10-year-old wastes stored at a thermal power density of $47 \mathrm{~W} / \mathrm{m}^{2}(190$ $\mathrm{kW} / \mathrm{acre})$ in granite and basalt and $30 \mathrm{~W} / \mathrm{m}^{2}(120$ $\mathrm{kW} /$ acre) in shale. At 5 years after waste emplacement, the sum of the thermally induced stress and the excavation-induced stress within $1.5 \mathrm{~m}$ of the openings is half the magnitude of the rock strength for granite and basalt and equal to the rock strength for shale. Older wastes stored at the same waste emplacement density have a lower average temperature rise after 5 years, and the thermally induced stress is less (Fig. 2). The temperature rises at the end of 5 years are used to determine the stress values. If the same strength-to-stress ratio criteria can be used for older wastes to ensure mine stability, the waste emplaciment density can be increased to accommodate mort: wastes in the repository.

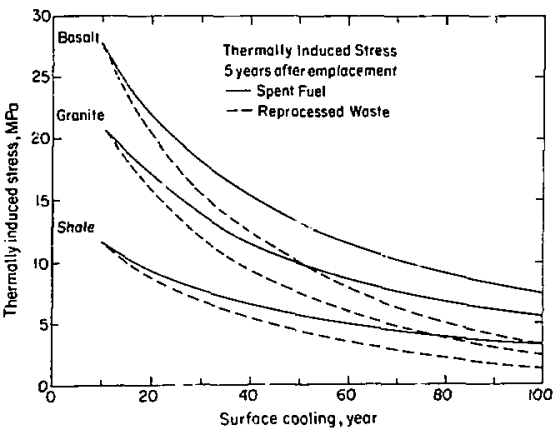

Figure 2. Thermally induced stress in granite at 47 $\mathrm{W} / \mathrm{m}^{2}$ (190 kW/acre), basalt at $47 \mathrm{~W} / \mathrm{m}^{2}$ (190 kW/acre). and shale at $30 \mathrm{~W} / \mathrm{m}^{2}(120 \mathrm{~kW} / \mathrm{acre})$ as a function of surface cooling period in SF and HLW repositories. $\mathrm{XBL}$ 823-2002

\section{Increase of Waste Emplacement Density}

The ratios of allowable waste densities of older wastes to the values of 10 -year-old wastes are illustrated in Fig. 3. The temperature dependence of the rock strength is taken into account. Figure 3 shows that older wastes could be emplaced at more concentrated densities. These results are based on the assumption that the near-field thermomechanical criteria developed for 10-year-old wastes are acceptabie independent of the surface cooling period. For reprocessed high-level waste (HLW) with a small thermal contribution from the long-lived actinides. these conclusions may be valid. However, for spent fuel repositories, the long-term, far-field effects could become the limiting consideration (see below).

Figure 3 also shows that the increase in allowable waste density is modest for salt compared to the results for hard rocks. For salt, the increase in allowable waste density grows at a slower rate for the longer surface cooling times. Thus the option of a longer surface cooling period may be less attractive for salt than for hard rock repositories. The difference in the form of the curves for salt and for hard rocks comes mainly from the different thermomechanical behaviors assumed in the analyses. For salt, the plastic creep strain is proportional to $\left(T_{a m b}+\Delta T\right)^{9.5}$, where $T_{a m b}$ is the ambient 1empera-

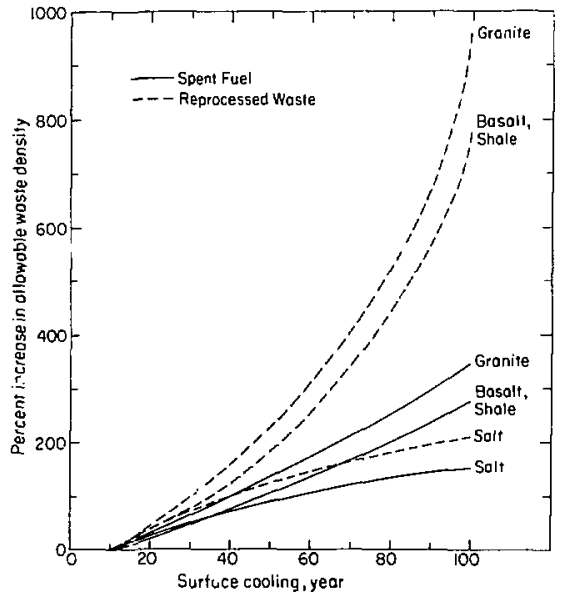

Figure 3. Percent increase in allowable waste density in four major rock types as a function of surface cooling neriod for SF and HLW repositories. (XBL 825-2211) 
ture in kelvins and $\Delta T$ is the waste-induced temperature rise (see Lomenick's formula above). For hard rocks, thermoelasticity is assumed for the stress changes, and the thermally induced stress is proportional to $\Delta T$. As longer surface cooling periods lower the temperature rise, $\Delta T$, the nonlinear temperature dependence of the creep for salt shows less sensitivity to $\Delta T$, resulting in a smaller increase in allowable waste density.

The thernoelasticity assumed for hard rocks may be oversimplified in view of the potential nonlinear contributions from the presence of fractures. Additional research is required to study the thermomechanical behavior of fractured rock masses. The temperature dependence of the elastic constants are also not taken into account in the calculations. The dependence of rock strength on temperature, however, is taken into account. Within the temperature range of interest for these calculations (below $120^{\circ} \mathrm{C}$ or $250^{\circ} \mathrm{F}$, granite exhibits a noticeable change in rock strength with temperature, whereas the basalt and shale strengths are almost temperature independent (Dames and Moore, 1978). For cooling periods of 10 to 100 years, this gain in strength with lower temperature permits an approximate increase of $20 \%$ in waste density for granite relative to its allowable limit for a fixed strength at $120^{\circ} \mathrm{C}$. Since the mechanical properties and rock strengths are highly site specific, the quantitative conclusions in these calculations should be carefully re-evaluated for any specific rock type and any potential repository site.

\section{SURFACE COOLING, CUMULATIVE HEAT, AND FAR-FIELD THERMAL EFFECTS}

The controlling quantity in assessing the far-field thermal effects is the cumulative heat released by the emplaced wastes. The waste heat will remain in the rock formation for a long period of time. Spent fuel (SF) releases more heat over a longer period of time than reprocessed HLW; extension of the surface cooling period removes only a small fraction of the cumulative heat released. On the other hand, most of the heat from reprocessed HLW is released early. The cumulative heat of reprocessed HLW is much lower than that of SF; the heat removed by surface cooling is a significant fraction of the rumulative heat. Therefore, the effect of suriace cooling is more significant for reprocessed wastes than for spent fuel in terms of long-term, far-field effects. The potentia] advantage of a 100-year cooling period for reprocessed waste is to lower the surface uplift and buoyancy flow to iess than half the magnitude of a 10 year cooling period (Wang et al., 1982a). The limitation on repository loading due to thermohydrologic considerations of buoyancy flow has been examined by Wang et al. (1982b, 1983).

\section{CONCLUSIONS}

We have extended the calculations of repository waste loading to older wastes using the existing near-field thermomechanical criteria. For reprocessed high-level wastes, the older wastes could be emplaced at more concentrated densities, especially in hard rock repositories. For reprocessed high-level wastes with small thermal rontributions from long-lived actinides, the use of near-field thermomechanical criteria alone to determine the waste densities may be valid. For spent fuel with longlived actinides, far-field criteria are also an important consideration in limiting the waste loading densities.

If the repository loading designs based on $10-$ year-old wastes are scaled for different waste ages. th: results must be carefully cvaluated for each waste type and each rock formation to avoid nonconservative conclusions. The limitations of waste loading densities of older wastes should be carefully determined by ir sing both near-field thermomechanical stability siceria and far-field thermohydrologic perturbation considerations.

\section{REFERENCES}

Bechtel Group, Inc., 198:. NWTS conceptual reference repository description (CRRD). Columbus, Ohio, Office of Nuclear' 'Naste Isolation. Battelle, ONWI-258 (Vol. 3).

Bradshaw, R.L., and McClain, W.C.. 1971. Project Sa't Vault: A demonstration of the disposal of high-activity solidified waste in underground salt mines. Oak Ridge National Laboratory, ORNL-4555, $356 \mathrm{p}$.

Dames and Moore, 1978. Technical suppor for GEIS: Radioactive waste isolation in geologic formations: Thermomechanical stress analysis and development of thermal loading guidelines. White Plains, New York, Dames and Moore, Y/OWI/TM-36/20.

Dejartment of Energy, 1979. Technology for commercial radioactive waste management. Washington, D.C., U.S. Department of Energy, DOE/ET-0028.

Department of Energy, 1980. Management of commercially generated radioactive waste. Washington, D.C., U.S. Department of Energy, DOE/EIS-0046F, $320 \mathrm{p}$.

Kaiser Engineers, 1978a. A national waste terminal storage repository in a bedded salt formation for 
spent unreprocessed fuel. Conceptual design descriptions. Oakland, California, Kaiser Engineers, KE Report No. 78-58-R.

Kaiser Engineers, 1978b. A national waste terminal storage repository in a bedded salt formation for spent unreprocessed fuel. Basis of design decisions. Oakland, California, Kaiser Engineers, KE Report No. 78-79-R.

Stearns-Roger Engineering Co., 1979. Conceptual design, NWTS repository for storing reprocessed wastes in a dome salt formation, conceptual design descriptions (Vol. 2). Denver, Colorado, Stzarns-Roger Engineering Co.

Wang, J.S.Y., Mangold, D.C., Spencer, R.K., and Tsang, C.F., 1982a. Thermal impact of waste emplacement and surface cooling associated with geologic disposal of nuclear waste. Washington, D.C., Nuclear Regulatory Commission, NUREG/CR-2910, LBL-13341, 277 p.

Wang, J.S.Y., Mangold, D.C., and Tsang, C.F., 1982. Long-term thermomechanical and thermohydrological factors controlling the optimal design of a nuclear waste repository. In S.V. Topp (ed.), Scientific Basis for Nuclear Waste Management (Vol. 6). Boston, Massachusetts, Materials Research Society, 8 p.

Wang, J.S.Y., Mangold, D.C., and Tsang, C.F., 1983. Effects of surface cooling on thermal impacts. In Waste Management ' 83 (Vol. II), Proceedings, Symposium on Waste Management, Tucson, Arizona, February 27-March 3, 1983, p. 243-247. 


\section{RESERVOIR ENGINEERING AND HYDROGEOLOGY}

The research effort of the Reservoir Engineering and Hydrogeology group is concerned primarily with the movement of mass and energy through rocks. One commonly finds that rock masses are fractured or faulted, and thus it is necessary to analyze the flow phenomena within both the fractures and the matrix. More recently, it has become clear that we must also address the problems of the complex coupling between aspects of the thermal, hydraulic, mechanical, and geochemical behavior of rocks.

The topics that are summarized in this section present the results of research in a number of related areas within the broad fields of reservoir engineering and hydrogeology. Flow has been investigated in fractured porous media, in single fractures. and in networks of fractures under isothermal and nonisothermal conditions. Systerns that are saturated/unsaturated and that involve the complexities of multiphase, multicomponent flows must be considered to enable a realistic handling of practical field situations.

A significant amount of this work is concerned with theoretical studies. but various examples of results from field studies are also included to demonstrate applicability. These studies have revealed the importance of expanding the overall research program to include certain experimental investigations on twophase flow in permeable rocks. 


\section{GEOMECHANICS}

Research topics in Geomechanics covered in these reports for fiscal 1983 include studies associated with the properties of a columnar-jointed rock mass around an underground openini, predicting the in situ state of stress in sait. advances in water-jet-assisted rock cutting, longwall ventilation in U.S. coal mines, and the analysis of laboratory studies of elastic wave propagation in permafrost and granite. The disturbed rock zone around an underground opening mined in basalt has been investigated in situ with a cross-hols acoustic technique, and the extent of the zone and its hydrologic properties are discussed in 'wo of a series of three articles concerned with properties of a columnar-jointed rock mass. The third in the series evaluates the technology a vailable for detecting geologic anomalies ahead of a tunnel driven in basalt. In the first of a series of three articles concerned with laboratory programs, the efficacy of hydraulic fracturing for determining the in situ state of stress in massive salt is discussed in light of the results of a program devoted to small-scale hydraulic fracturing experiments in salt. Two further articies in the series describe a model for elastic wave propagation in permafrost, discuss the influence of claysized particles on permafrost seismic velocity, and assess the influence of water saturation on elastic wave propagation in granite. The last two articles cover aspects of mining engineeririg. In the first, technological advances in water-jetassisted rock-cutting systems are described, including the ability to predict the optinum water jet power for a mining machine and methods to improve water economy. The second discusses results of a series of experiments performed in a longwall district of a Colorado coal mine and describes the modeling necessary to improve ventilation of the longwall face.

These investigations have utilized experimental, analytical, and compuiational facilities both at Lawrence Berkeley Laboratory (LBL) and on the University of California campus, in particular, laboratories associated with the Civil, Mechanical, and Materiais Sciences and Mineral Engineering Departments. The research effort has been shared by LBL staff, campus faculty, and Uriversity graduate siudents. 


\section{EXTENT AND HYDROLOGIC PROPERTIES OF THE DISTURBED ROCK ZONE AROUND IINDERGROUND
OPENINGS IN BASALT}

L.R. Myer

Excavation of shafts and entries for a nuclear waste repository will alter the hydrologic properties of the rock in a zone adjacent to the opening. This zone is referred to as the disturbed rock zone (DRZ). Changes in the hydrologic properties of the DRZ must be evaluated to determine if the rate of radionuclide release through the zone is significant to the performance of the repository. Then, if necessary, remedial methods can be applied to reduce the rate and quantity of radionuclide transport through the DRZ.

Because of the complexity of the phenomena affecting rock mass hydromechanical properties, field testing will be required to make a definitive assessment of the hydrologic properties of the DRZ. Theoretical studies can, however, provide scoping estimates of possible behavior and help define the parameters that must ultimately be measured in situ.

In this study, the hydrologic properties of the DRZ around openings at repositery depth at the site of the Basalt Waste Isolation Project (BWIP) were assessed. This site is located in the Pasco Basin within the Columbia River basalts, near Richland, Washingten.

The DRZ consists of two principal subzones. Nearest to the opening, a zone of increased permeability referred to as the blast damage zone will be created by the energy imparted to the rock mass by the excavation procedure. Farther from the opening is a zone of stress redistribution and displacement induced by creation of the opening regardless of the excavation technique; this is the stress induced $z$ one.

Calculation of flow through the DRZ requires estimates of the extent of each of these subzones and distribution of permeability within them.

\section{EXTEIVT AND FROPERTIES OF THE STRESS INDUCED ZONE}

An important factor affecting the extent and permeability of the stress induced zone at repository depth is the rock mass strength. When the stresses around an opening exceed tie rock mass strength, the rock yields and a "yiastic" zone of nonelastic deformation develops. Since an elastic zone is always present, a plastic zone can significanuly increase the area of the stress induced zone. The nonelastic deformations can also result in subsiantially greater permeabilities in the plastic zone than in the elastic zone.

A repository at the BWIP site would be constructed in the entablature portion of a basalt flow. From field observations and inspection of cores, the entablature rock mass at repository depth is characterized as unweathered but intensely fractured rock with a joint spacing of $0.15 \mathrm{~m}$ to $0.23 \mathrm{~m}$ in all directions and very little weak, fracture-infilling material.

Although it is well known that the in situ strength of a fractured rock mass is less than that of small, intact pieces, quantification of the difference remains largely a matter of engineering judgement. Under unconfined conditions, the strength of an intensely fractured rock mass will be very low. However, as indicated by laboratory tests of block assemblages (Einstein and Hirshfielc, 1973) and intensely fractured marble (Rosengren and Jaeger, 1968), addition of moderate confining pressure to a tightly interlocked rock mass will result in rapidly increasing peak strength. A similar effect of confining pressure might also be expected in the post-peak, or residual, strength behavior.

Assuming the rock mass in the entablature of a basalt flow to be a tightly interlocked rock mass that woulci behave as described above, peak and residual strength criteria were developed as shown in Fig. 1. The reduced strength values compared with those neasured for intact laboratory samples were scaled according to the results of tests performed by Rosengren and Jaeger (1968).

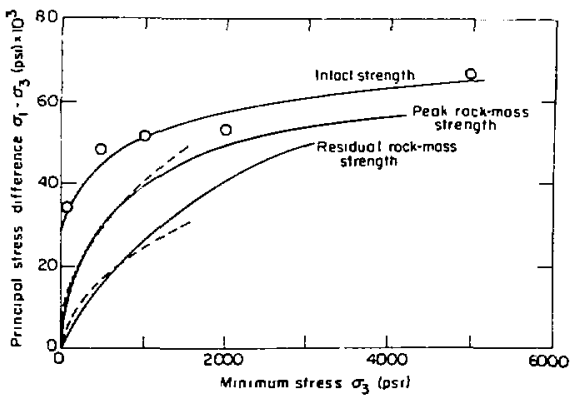

Figure 1. Estimated rock strength for the dsinse interior of a basa'i flow. [XBL 834-1577] 
As proposed by Hoek and Brown (1980), the failure criterion for the rock mass was assumed to be

$$
\sigma_{1}=\sigma_{3}+\sqrt{m \sigma_{c} \sigma_{3}+s \sigma_{c}^{2}}
$$

where $\sigma_{1}$ is the major principal stuess, $\sigma_{3}$ is the minor principal stress, $\sigma_{c}$ is the consputed unconfined compressive strength of the intact basalt, and $m$ and $s$ are material constants. Values of $m$ and $s$ were computed from data for the peak and residual rock mass strength; graphs of Eq. (1) incorporating these constants are shown as broken lines in Fig. 1 .

A plane-strain elastoplastic stress analysis was performed to evaluate the extent of rock mass failure arouno an opening at repository depth. Assuming an isotropic in situ stress of $67 \mathrm{MPa}$ (Haimson and Kim, 1982), a very small plastic zone extending a distance of 0.03 radii (os $90 \mathrm{~mm}$ in a $6-\mathrm{m}$-diameter excavation) was predicted. Though the actual in situ stress state is anisotropic, analysis indicated that this would not appreciably increase the extent of the predicted plastic zone.

When the plastic zone is limited to a very small volume of rock on the periphery of the opening, the effects of nonelastic deformations would be indistinguishable from the effects of disturbances in the blast damage zone. Thus changes in the permeability of the stress induced zone of the DRZ were assumed to be a function only of the elastic principal stresses around the opening. Principal stresses were calculated from a linear elastic stress analysis incorporating observed anisotropy in the in situ stresses at repository depth.

Changes in permeability were assessed in the radial direction $\left(K_{r}\right)$, and in the direction parallel to the axis of the opening $\left(K_{z}\right)$ (see Fig. 2). Relating $K_{r}$ and $K_{2}$ to calculated principal stresses required a number of assumptions and idealizations regarding the flow regime in the dense interior of a basalt flow. It was assumed that flow through the natural fracture system could be represented by flow through equivalent averaged fractures, as shown in Fig. 2. Further, it was assumed that all flow was confined to the equivalent average fractures, which were ubiquitous and oriented perpendicular to the principal stress directions. It was also assumes that the net changes in $K_{z}$ and $K_{r}$ were due only to changes in normal stress across fractures perpendicular to the minimum $\left(\sigma_{3}\right)$ and maximum $\left(\sigma_{1}\right)$ principal stresses, respectively.

The results of Iwai (1976), who measured the change in hydraulic conductivity of basalt fractures as a function of normal stress across the fracture. were used to estimate the changes in permeability of

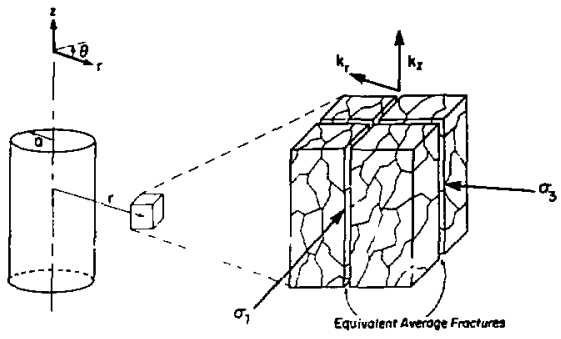

Figure 2. Conceptual model of flow through an element of rock mass in the stress induced zone around an opening in the dense interior of a basalt flow. [XBL 834-1757]

the equivalent average fractures. Our analysis predicted a maximum increase in $K_{z}$ in the stress induced zone of about an order of magnitude. In addition, the analysis indicated that the extent of significant change in $K_{z}$ is small. For example, at repository depth, the region in which $K_{z}$ would be 1.3 or more times the undisturbed value would extend only about $0.6 \mathrm{~m}$ beyond the outer boundary of the blast damage zone of a $6-\mathrm{m}$ diameter opening. Because of the high in situ stress levels, $K_{r}$, the permeability in the radial direction would change very little.

The importance of the assumptions of rock mass strength can be seen by comparing the results of our analysis with those of a similar analysis performed by Kelsall et al. (1982). Using the empirical guidelines of Hoek and Brown (1980), Kelsall assumed a much lower rock mass strength. He therefore predicted a plastic zone of significant size and, consequently, a much larger stress induced zone. Because of the large area of the stress induced zone and the high permeability of the plastic zone, predictions of the total flow through the stress induced zone were more than 60 times greater than those of our analysis.

\section{EXTENT AND PROPERTIES OF THE BLAST DAMAGE ZONE}

Energy imparted to the rock by the excavation procedurc will cause disturbances in a zone of rock adjacent to the opening. Though no satisfactory analytic techniques are available for evaluating the extent of the blast damage zone, studies incorporating geophysical techniques such as "petite sismique" and cross-hole seismic have indicated that blast damage around openings in hard rock may extend from $0.5 \mathrm{~m}$ to $1.5 \mathrm{n}$ into the rock mass. A cross-hole 
seismic study recently performed by Lawrence Berkeley Labriatory (King et al., 1983) in the Near Surface Test Facility at the BWIP site has shown the extent of the blast damage zone at that location to be $1.0-1.5 \mathrm{~m}$. The most severe damage (as indicated by acoustic wave velocities) was confined to about the first $0.5 \mathrm{~m}$ of depth.

Detonation of a charge will create new fractures in intact material and propagate existing ones. Interblock rotation and shear will cause a zone of loosening in blocky material. All these phenomena will cause an increase in permeability as well as a decrease in rock mass strength. Under the high in situ stress at repcsitory depth, the reduced rock mass strength will result in failure in the blast damage zone, inducing further deformations and higher permeabilities in an already loosened zone.

The influence of the blast damage zone on the quantity of flow through the disturbed zone may be significant. For example, consider a 7-m-diameter opening with a 0.5 -m-wide blast damage zone and a stress induced zone with properties as predicted in the analysis discussed above. If the permeability of the blast damage zone were 1000 times that of the undisturbed rock mass, the total groundwater flux through the blast damage zone would be 100 times the total flux through the stress induced zone.

Estimates of permeability in the blast damage zone of 1000 times the undisturbed values do not seem unreasonable, However, the complexity of the deformations associated with blasting, particularly close to an excavation, preclude the use of analytic methods to assess the permeability changes in the blast damage zone, and very few applicable field $\mathrm{or}$ laboratory data are available. Thus the uncertainty associated with estimates of properties of this zone are large. This uncertainty will not be resolved until site-specific in situ testing is performed in openings excavated by the same methods that will be used in repository construction.

\section{SUMMARY}

The total groundwater flux through the DRZ will consist of flow through the blast damage zone and flow through the siress induced zone. If the rock in the repository horizon behaves substantively as postulated in our analysis, increases in permeability in the DRZ would be limited to a region within 2 or $3 \mathrm{~m}$ of the opening wall (assuming an opening of $5-8 \mathrm{~m}$ in diameter). The area of this region would be approximately evenly divided between the stress induced zone and ine blast damage zone. Within the stress induced zone, the maximum permeability increase parallel to the opening axis was found to be about an order of magnitude. The potential for groundwater leakage through the DRZ would therefore be dominated by the blast damage zone.

\section{REFERENCES}

Einstein, H.H., and Hirshfield, R.C., 1973. Model studies on mechanics of jointed rock. Journal of the Soil Mechanics and Foundations Division. Proceedings of the American Society of Civil Engineers, v. 99, no. SM3, p. 229-248.

Haimson, B.C., and Kim, K., 1982. Deep hole hydrofracturing stress measurement in the Columbia Basin at the Hanford Site. Transactions, American Geophysical Union, v. 63, no. 45 , p. 1102.

Hoek, E., and Brown, E.T., 1980. Underground Excavation in Rock. London, The Institution of Mining and Metallurgy, p. 130-255.

Iwai, K., i976. Fundamental Studies of Fluid Flow Through a Single Fracture (Ph.D. dissertation). Department of Civil Engineering, University of California, Berkeley.

Kelsall, P., Case, J., Chabannes, C., 1982. A preliminary evaluation of the rock mass disturbance resulting from shaft, tunnel, $o_{\star}$ borehole excavation. ONWI Topical Report, prepared by D’Appolonia Consulting Engineers, Project No. NM79-137.

King, M.S., Myer, L.R., and Rezowalli, J., 1983. Cross-hole acoustic measurements in basalt. Earth Sciences Division Annual Report 1983 (this volume). Lawrence Berkeley Laboratory, LBL-16920.

Rosengren, K.J., and Jaeger, J.C., 1968. The mechanical properties of an interlocked lowporosity aggregate. Geotechnique, v. 18, n. 3, p. 316-326. 


$$
\begin{aligned}
& E(n)=\sum_{0=0}^{\infty} n \frac{\mu^{n} e^{-\mu}}{n !} \\
& =\mathrm{e}^{-\mu} \mu \sum_{n=1}^{\infty} \frac{\mu^{(n-1)}}{(n-1) !}=\mathrm{e}^{-\mu} \mu \sum_{s=0} \frac{\mu^{s}}{s !}, s=n-1 \\
& \uparrow \uparrow \\
& \text { Note the changes in the } \\
& \text { limits of summation. } \\
& =\mu \text {. }
\end{aligned}
$$

In q similar fashion, we can establish (exercise) that $V(n)=\mu$. It is the same as the mean.

We have already shown (Chapter 2) that if $X$ and $Y$ are Poisson, then

$$
g(x+y)=\frac{\left(\mu_{x}+\mu_{y}\right)^{x+y} e^{-\mu_{x}-\mu_{y}}}{(x+y) !},
$$

which is $\mathrm{P}_{\mu_{n}+\mu_{9}}(\mathrm{X}+\mathrm{Y})$, and therefore the sum of two Poisson r.v.'s is also Poisson, and the Poisson possesses the - Reproductive Property.

This means that if we observe signal $\mathrm{X}$ and background $\mathrm{Y}$ in an experiment, each of which is an independent Poisson, then the sum is also Poisson. This has important applications for background subtraction, in which we must be able to estimate errors.

It can be shown (exercise) that the interval size $\mathrm{s}$ is distributed as $\mathrm{f}(\mathrm{s})=\lambda \mathrm{e}^{-\lambda s}$, a distribution known as the exponential, which will be covered shortly. This is the interval in time "s" from one event to the very next, or its analogue if the parameter 5 represents a space dimension. The derivation does not actually depend upon starting at the previous event-we could have started anywhere, and just timed to the first event after starting.

Here, we could substitute distance for time, and look for the distribution of e.g., single scattering collisions of angle greater than "something" along a track. The use of the Poisson there, of course, assumes that no process (e.g., slowing down) changes the scattering probability appreciably, since the probability must be the same in each small interval.

\section{Poisson Approximation to a Binomial Problem}

Consider the case of a collection of $n$ radioactive atoms. In any particular time interval, $T$, some of them will decay and others not. Therefore we will have a binomial distribution of the number " $r$ " which decay:

$$
P(r)=B(r ; n, p)=\frac{n !}{r !(n-r) !} p^{r} q^{n-r}
$$

$p=$ some probability for one atom which depends, of course, on $T$. The difference between this case and the Poisson is the limit " $n$ " to the number of atoms: as more and more decay, there are less and less left to decay. Thereforc the Poisson proportionality $\lambda$ depends on $T$, and so the number of decays per unit time interval, or in time interval $T$, is not Poisson. But if there are a lot of atoms, and pn $\ll n$, then this depletion is not noticed over the time interval of a given experiment. Then $r<<$ $\mathrm{n}$ with high probability, and 
will probably not have a significant impact on stability unless oriented unfavorably with respect to the tunnel axis.

Local variations in the character and intensity of jointing may also precipitate structural instability or water inflows. These variations may be reflections of the natural spatial variability in fracturing or of specific structures, such as the inverted fan iointing illustrated in Fig. 1. In outcrop, these structures are characterized by a fan-shaped pattern of joints radiating from a depression in the contact between flow top and dense ir. erior. Though the permeability of these structures has not been evaluated, the welldeveloped subvertical jointing may establish a highpermeability link between the dense interior and the flow top. In addition, the flow top depressions associated with these structures are a hazard if they extend to the level of excavation.

\section{ANOMALY DETECTION METHODS}

Pertinent data for the primary methods considered for anomaly detection are summirized in Table 1. For each of the methods, an evaluation was made of the ability of currently available instrumentation to detect the types of anomalies of concern at the BWIP si:

By far the most common technique for probing ahead of an advancing tunnel face is a single, smalldiameter, percussively drilled borehole. In many civil projects, if excessive gas or water inflows are possible, the drill hole is often kept between 3 and 30 $\mathrm{m}$ ahead of the face.

General information derived from percussively drilled holes, with simple instrumentation installed at the collar, is limited to water inflow rate and pressure as well as a very qualitative indication of rock mass strength deduced from drilling rate information. Though all this information is extremely important, it was felt that additionai data on the character of rock mass fracturing and the location of geologic structures will be required for adequate virinition of anomalies during repository excavation. Coring the boreholes would provide much of the additional data, but that process would be too time consuming for use at an advancing face. In addition, use of horizontal drill holes would not provide adequate warning of anomalies lying parallel or subparallel to the tunnel. The jeterious effect ci flow top renetration on the hysi-s ogic containment capability of the derse interir may preclude the use of inclined boreholes despite their advantage in locating anomalies outside the boundaries of the excavation.

Indirect or geophysical methods were therefore investigated $\because \because$ a means of providing additional data required for definition of tory excavation in basalt $t_{1}$ ires during reposithough the field of applied geophysics encompiseses a large number of techniques, most are either inapplicable or require very extensive development for use in anomaly detection. The indirect methods with the greatest potential were found to be seismic methods, including surface reflection; cross-hole reflection. velocity, and attenuation studies; and the nonseismic methods of radar and conventional borehole logging.

Seismic reflection surveys could be performed from the surface of the tunnel walls behind the face or from boreholes drilled ahead of the face. Information on the location of flow tops and bottoms and breccia zones abtained behind the face could be extrapolated to the region ahead of the face. Reflection surveys from boreholes would provide information on structure between the boreholes and might be extended to provide information on the location of flow tops or bottoms not intersecting the boreholes.

Because of the lack of experience in use of seismic reflection techniqucs underground in 'asalt, additional study and development will be required in several areas. Detection of discontinuities less than $1 \mathrm{~m}$ wide (such as breccia zones) will require source frequencies of at least $1 \mathrm{kHz}$, but no equipment is available to conrict systematic multichannel (greater thas 48 ) surveys at sampling rates of $1-10 \mathrm{kHz}$. There are also problems of carrying out surface surveys across uneven mine faces and in working in a hot, humid environment with sophisticated electronics. Three-dimensional location of structures that do not lie between boreholes will require development of referencing techniques. Cross-hole seismic surveys utilizing the "direct wave" rather than secondary or reflected arrivals can be c..rried out simultaneously with cross-hole reflection surveys, thus aiding in interpretation of structure between the boreholes. Direct cross-hole surveys can also be carried out indepe: dently. By using high frequencies $(60-100 \mathrm{kHz})$, changes in the fracture deusity can be detected. Thus breccia or fault zones intersecting tie boreholes and other regions of incompetent rock may be located ahead of the face. A study investigating the use of the direct cross-hole technique for characterizing the fracturing in basalt is currently underway (see King et al., 1983).

Though direct cross-hole seismic surveys are more commonly performed than cross-hole reflection surveys, in. sield processing and data collection tech. niques and equipment are not sufficiently developed for routine use in underground workings. If full waveform analysis is desired, data storage and handling become problems. Instrument survival in the 
Table 1. Summary of anomaly detection capabilities.

\begin{tabular}{|c|c|c|c|c|c|c|c|}
\hline \multirow{2}{*}{\multicolumn{2}{|c|}{ Method }} & \multirow{2}{*}{$\begin{array}{l}\text { Parnmeter } \\
\text { measured }\end{array}$} & \multirow{2}{*}{$\begin{array}{l}\text { Resolution } \\
\text { of method }\end{array}$} & \multicolumn{2}{|c|}{ Current anomaly detection capability } & \multirow{2}{*}{$\begin{array}{c}\text { Ciner } \\
\text { advantages }\end{array}$} & \multirow{2}{*}{$\begin{array}{c}\text { Other } \\
\text { disadvantoges }\end{array}$} \\
\hline & & & & Can be detected & Cannot be detected & & \\
\hline \multirow[t]{2}{*}{ I. } & Perewsively Drilled Hole & & & & & & \\
\hline & A, Horizontal & $\begin{array}{l}\text { Penetration rate, } \\
\text { water i.flow, } \\
\text { water pressure }\end{array}$ & $\begin{array}{l}\text { Features greatcr } \\
\text { than } 2 \text { ft across, } \\
\text { water inflow and } \\
\text { pressure to } \pm 1 \%\end{array}$ & $\begin{array}{l}\text { High permeability anom- } \\
\text { alies, i.e., tectonic } \\
\text { brectia zones, inverted } \\
\text { fan jointing, sudden low } \\
\text { top depression, other } \\
\text { weak zones (wide tectonic } \\
\text { brecciss or fault zones) }\end{array}$ & $\begin{array}{l}\text { Anomalies outside exea- } \\
\text { vation boundary (now } \\
\text { top, jointing irregul } \\
\text { larities, fault zones). } \\
\text { Thin, "dry" tectonic } \\
\text { breccias or fault zones }\end{array}$ & $\begin{array}{l}\text { Most ofen used. } \\
\text { Little interference } \\
\text { with excavation }\end{array}$ & $\begin{array}{l}\text { Poor resolutiow of } \\
\text { location and ezient of } \\
\text { anomaly; litte infor- } \\
\text { mation as to c'ass of } \\
\text { anomaly }\end{array}$ \\
\hline \multirow[t]{3}{*}{ II. } & Active Seismic & & & & & & \\
\hline & $\begin{array}{l}\text { A. Surfuce } \\
\text { reflection }\end{array}$ & $\begin{array}{l}\text { Amplitude and } \\
\text { arrival time of } \\
\text { reflected wave } \\
\text { (usullly P-wave) }\end{array}$ & $\begin{array}{l}\text { Discontinuties } \\
\sim 1 / 8 \text { wavelensth } \\
\text { (function of } \\
\text { frequency and } \\
\text { attenuation) }\end{array}$ & $\begin{array}{l}\text { Location of flow top, } \\
\text { tectonic breccia zones, } \\
\text { fault zones behind face } \\
\text { and not intersecting } \\
\text { tunnet (assuming sharp } \\
\text { changes in acoustic } \\
\text { impedance) }\end{array}$ & $\begin{array}{l}\text { Subtle changes in } \\
\text { jointing, e.g- "platy" } \\
\text { zone or inverted fan } \\
\text { jointing, } 2 \text { : other } \\
\text { anc malies at large } \\
\text { angles to wave }\end{array}$ & $\begin{array}{l}\text { Ability to map } \\
\text { location of fow } \\
\text { top without pene. } \\
\text { tration }\end{array}$ & $\begin{array}{l}\text { Lack of experience in } \\
\text { use in basalt; jenetra- } \\
\text { tion depth in basalt } \\
\text { unknown. Significant } \\
\text { interference with } \\
\text { operation if applied } \\
\text { at face. Equipment } \\
\text { data processing tech- } \\
\text { niques not adspted to } \\
\text { underground use; } \\
S \text {-wave techniques } \\
\text { relatively undeveloped }\end{array}$ \\
\hline & $\begin{array}{l}\text { B. Borehole } \\
\text { reflection }\end{array}$ & Same as above & Same as aisove & $\begin{array}{l}\text { Anomalies betwcen } \\
\text { boreholes, c.\&., fault } \\
\text { zones, tectonic breccio, } \\
\text { now top depression } \\
\text { (assuming sharp change } \\
\text { in acoustic impedance) }\end{array}$ & $\begin{array}{l}\text { Suble ch nges in } \\
\text { jointing, t. B., "platy" } \\
\text { zone or inverted fan } \\
\text { jointing; or } 0 \text {. iser anom- } \\
\text { alies at large angles to } \\
\text { wave or outside of exca- } \\
\text { vation boundary }\end{array}$ & $\begin{array}{l}\text { Potential for devei- } \\
\text { opment to detect } \\
\text { anomalies outside } \\
\text { excavation boundary; } \\
\text { can be done simul- } \\
\text { taneously with } \\
\text { direct cross-hole. } \\
\text { Minimum interfer- } \\
\text { ence at face }\end{array}$ & $\begin{array}{l}\text { Techniques for data } \\
\text { collection and process- } \\
\text { ing not adapted to } \\
\text { underground use. Lack } \\
\text { of experience in use } \\
\text { in basalt. } S \text {-wave } \\
\text { techniques undeveloped }\end{array}$ \\
\hline
\end{tabular}


Table 1. Summary of anomaly detection capabilities (continued).

\begin{tabular}{|c|c|c|c|c|c|c|c|}
\hline \multirow{2}{*}{\multicolumn{2}{|c|}{ Method }} & \multirow{2}{*}{$\begin{array}{l}\text { Purameter } \\
\text { measured }\end{array}$} & \multirow{2}{*}{$\begin{array}{l}\text { Resolution } \\
\text { of method }\end{array}$} & \multicolumn{2}{|c|}{ Current anomaly detection capability } & \multirow{2}{*}{$\begin{array}{c}\text { Other } \\
\text { aduaniages }\end{array}$} & \multirow{2}{*}{$\begin{array}{c}\text { Ouher } \\
\text { disadvantanes }\end{array}$} \\
\hline & & & & Cin be detected & Cannot be detected & & \\
\hline & $\begin{array}{l}\text { C. Diret } \\
\text { erosebole }\end{array}$ & $\begin{array}{l}\text { Arrival time of } \\
P \cdot, S \text {-waves; } \\
\text { atsenuation of } P_{-}, \\
S \text {-waves }\end{array}$ & $\begin{array}{l}\text { Discontinuties } \\
\sim 1 / 10 \text { wrvelenth } \\
\text { (function of timines } \\
\text { also of number } \\
\text { of wave paths for } \\
\text { tomosephy) }\end{array}$ & $\begin{array}{l}\text { Anomalies between bore- } \\
\text { holes; e.e, fault zones, } \\
\text { tectonic breccin, fow } \\
\text { top depression, changes } \\
\text { in frecture density such } \\
\text { as "platy" zone or in- } \\
\text { veried fan jointing if } \\
\text { sufficient contrust in } \\
\text { fracture frequency }\end{array}$ & $\begin{array}{l}\text { Aromalies outside exa- } \\
\text { vation bmundary (Aow } \\
\text { top, breoc1a zones, } \\
\text { jointing irretularities) }\end{array}$ & $\begin{array}{l}\text { Can be used simul- } \\
\text { taneously with bore } \\
\text { reflection. Minimum } \\
\text { interference at face }\end{array}$ & $\begin{array}{l}\text { Techniques for comptete } \\
\text { in-field deta procest } \\
\text { ins not developed for } \\
\text { underground use. Leck } \\
\text { of experience in use } \\
\text { in basult }\end{array}$ \\
\hline \multirow[t]{5}{*}{ HI. $N$} & Nonsetsmic & & & & & & \\
\hline & $\begin{array}{l}\text { A. Conventioses } \\
\text { borebole loerins } \\
\text { Dentity }\end{array}$ & $\begin{array}{l}\text { Rudiontive } \\
\text { absorplion } \\
\text { Induction or } \\
\text { eelf-potentiv }\end{array}$ & $\begin{array}{l}\text { Depends on } \\
\text { contrast in } \\
\text { properties } \\
\text { between anomaly } \\
\text { and adjacent } \\
\text { rock mass }\end{array}$ & $\begin{array}{l}\text { Low-density, high-. } \\
\text { permeability enomalies } \\
\text { that intersect borehole, } \\
\text { e.e, tectonic breccias } \\
\text { fault zones, flow lop } \\
\text { depressien, or inverted } \\
\text { fan jointins of sufficient } \\
\text { density or perme- } \\
\text { ability contrat }\end{array}$ & $\begin{array}{l}\text { Anomalies that do nor } \\
\text { intessect borebole (flow } \\
\text { lop, fault zones, or } \\
\text { tectonic brecciss, } \\
\text { "platy" zones) }\end{array}$ & $\begin{array}{l}\text { Greal deal of } \\
\text { experience, some in } \\
\text { basalt: quickly } \\
\text { performed with } \\
\text { minimum interfer- } \\
\text { ence }\end{array}$ & $\begin{array}{l}\text { Poor resolution of } \\
\text { thape of anomaly; } \\
\text { depth of penetration } \\
\text { very small (approx. } \\
\text { a centimeter) }\end{array}$ \\
\hline & $\begin{array}{l}\text { Requitivity } \\
\text { Sonic }\end{array}$ & $\begin{array}{l}\text { Electrical } \\
\text { risinnot } \\
\text { Acoustic } \\
\text { velocity }\end{array}$ & & & & & \\
\hline & $\begin{array}{l}\text { Menetic } \\
\text { Cellpes } \\
\text { visual (TV) }\end{array}$ & $\begin{array}{l}\text { Mapnetic } \\
\text { susceptibility }\end{array}$ & & & & & \\
\hline & D. Redier & $\begin{array}{l}\text { Reflected EM } \\
\text { pulse }\end{array}$ & $\begin{array}{l}\text { Several centi- } \\
\text { melen dependins } \\
\text { on wavelength }\end{array}$ & 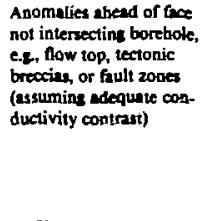 & $\begin{array}{l}\text { Subde chanjes in frat- } \\
\text { ture density }\end{array}$ & $\begin{array}{l}\text { Yotential for direc- } \\
\text { tional location of } \\
\text { anomalics outside } \\
\text { boundarict of exca- } \\
\text { vation; performed } \\
\text { at ines in sinde } \\
\text { hole with minimum of } \\
\text { inverference lo } \\
\text { operation of field } \\
\text { lechniques }\end{array}$ & $\begin{array}{l}\text { Leck of experience in } \\
\text { basalt: proper } \\
\text { frequency mane, } \\
\text { penet - tion untrown }\end{array}$ \\
\hline
\end{tabular}


harsh environment at repository depth is also a problem.

The technology of conventional borehole logging is highly developed, and considerable experience has been gained in its use in vertical drillholes at the BWIP site. Further work is needed, however, to correlate conventional geophysical Ings with properties of specific anomalies.

Radar methods are analogous to seismic reflection methods; conceptually, the cnly difference is that the frequency of the source energy of radar is much higher. It is not known how radar will perform in basalt. However, several potential advantages warrant further investigation of the method, Use of radar is potentially cost effective because equipment and techniques for performing downhole surveys are currently available. In addition, in the frequency range of $100-500 \mathrm{MHz}$, resolution of discontinuities on the order of several centimeters in size should be pos'.: Moreover, the directional properties of the $\mathrm{m}$ may make it possible to locate features that do is.. . .tersect the probe holes. As indicated above, one of the protlcms in interpreting seismic reflection data obtained in boreholes is the ambiguity in the direction of the reflected wave. Radar methors would not have this problem because of the directionality of the transmitters and receivers.

\section{SUMMARY}

We have concluded that the principal elements of a system ior detection of geologic anomalies ahead

\section{CROSS-HOLE ACOUSTIC MEASUREMENTS IN BASALT}

\author{
M.S. King, L.R. Myer, and J. Rezowalli
}

A series of cross-hole acoustic measurements has been performed in a rock mass around an underground opening mined by the drill-and-blast method at a depth of $46 \mathrm{~m}$, well above the water rable. The rock mass at this depth is characterized as a basalt flow entablature with a $0.15-0.35 \mathrm{~m}$ thick vertical columnar jointing structure cut by low-angle cross jointing. The purposes of the test program were

1. To evaluate the rock mass characteristins around the opening. of a turi: drilled probe holes augmented by geophysical methods such as seismic reflection and direct crosshole methods, conventional borehole logging, and radar. Areas requiring further development were outlined for each of the geophysical methods; in general, develsimment of improved in-field processing techniques will require the major emphasis. Because of the lack of experience with the geophysical methods in basalt, an important first step in the development process will be field tests at a site in basalt to provide baseline data on performance of the techniques. It is probable that not all of the geophysical methods discussed above will be required. The optimum combination of methods will evolve as further knowledge of instrument performance and excavation and construction details is acquired.

\section{REFERENCES}

King, M.S., Myer, L.R., and Rezowalli, J., 1983. Cross-hole acoustic measurements in basalt. Earth Sciences Division Annual Report $198 \mathfrak{j}$ (this volume). Lawrence Berkeley Laboratory, ILEL-16920.

Myers, C.W., and Price, S.M., 1981. Subsurface geology of the Cold Creek Syncline. Rockwell Hanford Operations, Richland, Washinglon, RHO-BWI-ST-14.

2. To determine the zone of blast damage around the opening.

3. To evaluate seismic methods for anomaly detection ahead of mining in this type of rock.

The cross-hole measurements were made between four $76-\mathrm{mm}$-diameter horizontal boreholes diamond drilled $12 \mathrm{~m}$ into the wall of the underground opening, as indicated in Fig. 1. The toreholes were each surveyed over the whole length. Some 550 acoustic measurements were made between each of the six pairs of the four boreholes in planes parallel to the wall at different distances down the borcholes. A typical plane of six measurements is indicated in Fig. I.

The field system used is shown in block form in Fig. 2. It is based essentially on that used in a sim!- 


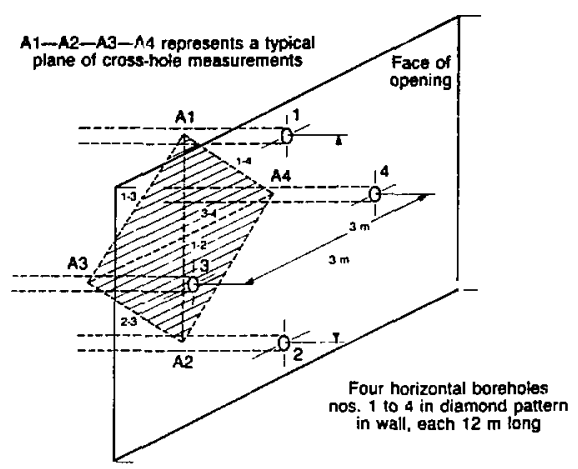

Figure 1. Layout of boreholes. [XBL B31 ]-7326|

lar research program in a granitic rock mass in Sweden (Paulsson and King, 1980). Repetitive pulses of compressional $(P)$ and shear $(S)$ waves in the frequency range $1-100 \mathrm{kHz}$ are propagated from the transmitter sonde through the rock mass to the receiver sonde. The $P$ - and $S$-wave transmitter and receiver transducers are broadband ceramic steel sandwiches with a center frequency of approximately $80 \mathrm{kHz}$. The sondes are clamped hydraulically to

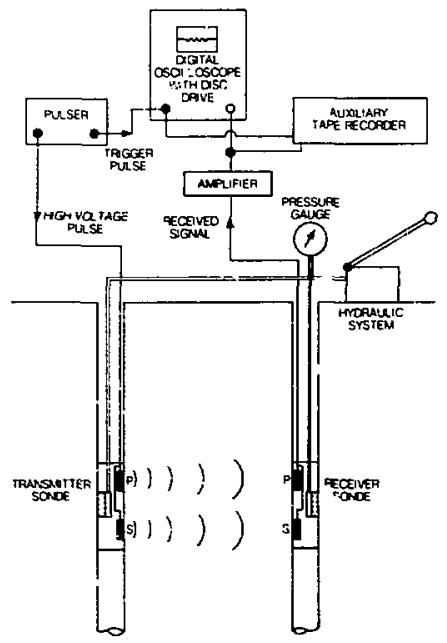

Fine 2. Block diagram of experimental setup. |XBL $337-434$ the borehole wall to ensure good acoustic contact. The received $P$ - and $S$-wave signals are preamplified in the sonde and transmitted to the surface, where they are further amplified and bandpass filtered in the frequency rarige $500-100 \mathrm{kHz}$. The complete $P$ and $S$ waveforms are digitized by a digital oscilloscope with a $2-\mathrm{MHz}$ sampling rate and stored on floppy disks. An auxiliary analog tape recorder with a $62-\mathrm{kHz}$ bandwidth may be employed where the signals are of such poor quality that signal enhancement by stacking is required.

The digitized $P$-and $S$-wave records vere later analyzed to determine the arrival times of $P$ - and $S$ wave pulses, so that the velocities $V_{p}$ and $V_{s}$ could be determined using the distances between the pairs of boreholes calculated from the survey data. The delay times for the transducer holders themselves were first determined by clamping the sondes in an aluminum calibration block, and the arrival times were corrected for them. The digitized records were also subjected to Fast Fourier Transforms (FFTs), and their amplitude spectra in the frequency domain were studied.

Preliminary results of the test program are shown in Figs. 3, 4, and 5. In Fig. 3 are shown the $P$-wave velocities measured between boreholes along paths in vertical and horizontal directions as a func-

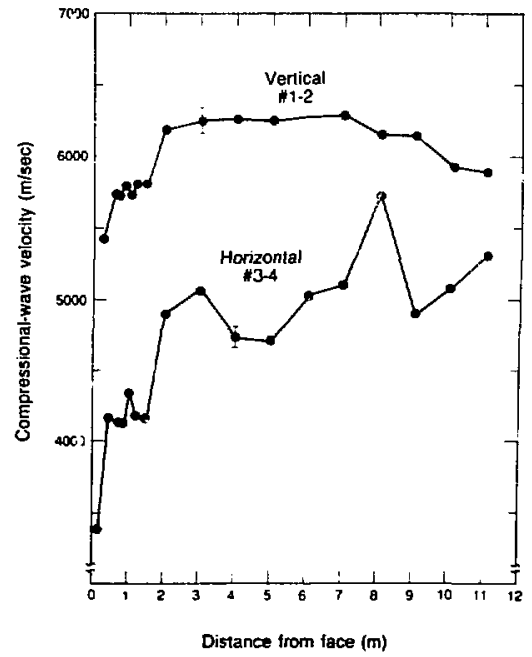

Fisure 3. Compressional wave velocity between borehotes in vertical and horizontal directions. [XBL $83[1-7325]$ 
tion of distance of the plane of measurement from the face. Figure 4 shows the $S$-wave velocities measured in the same manner. Experimental errors ensuing from possible errors in the arrival times and survey data are indicated by error bars. Figure 5 shows the elastic modulus and Poisson's ratio calculated from the velocity data using the classical theory of elasticity and an average density of $2848 \mathrm{~kg} / \mathrm{m}^{3}$ measured for the basalt. Acoustic velocities and elastic properties for the remaining four diagonal paths between the boreholes tend to lie between the limits established by measurements made in the vertical and horizontal directions.

Results of the FFT analyses indicate that there is a considerable difference in frequency content of the received $P$. and $S$-wave signals between those propagating horizontally and those vertically and between those measured in planes lying close to the face and those in planes well behind the face. Near the face, both $P$-and $S$-wave amplitude spectra tend to peak at approximately $5 \mathrm{kHz}$ or less. Farther away from the face, at distances greater than approximately $2 \mathrm{~m}$, the amplitude spectra for $P_{-}$and $S$ waves propagating vertically tend to peak at $20 \mathrm{kHz}$ or more, and those horizontally at $5 \mathrm{kHz}$ or less.

Figures 3,4, and 5 show that there are considerable reductions in $P$ - and $S$-wave velocities at distances less than $2 \mathrm{~m}$ from the face: up to $55-65 \%$ in magnitude. Clearly these low values are associated with blast damage. Beyond $2 \mathrm{~m}$, the velocities in a

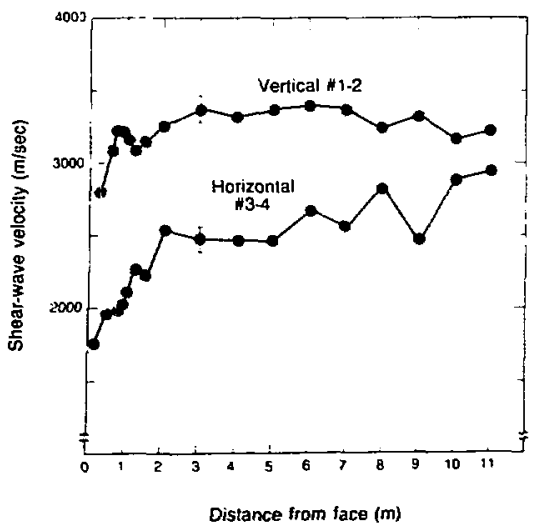

Fhare 4. Shear wave velocity between boreholes in vertical and horizontal directions. [XBL 8311-7323]

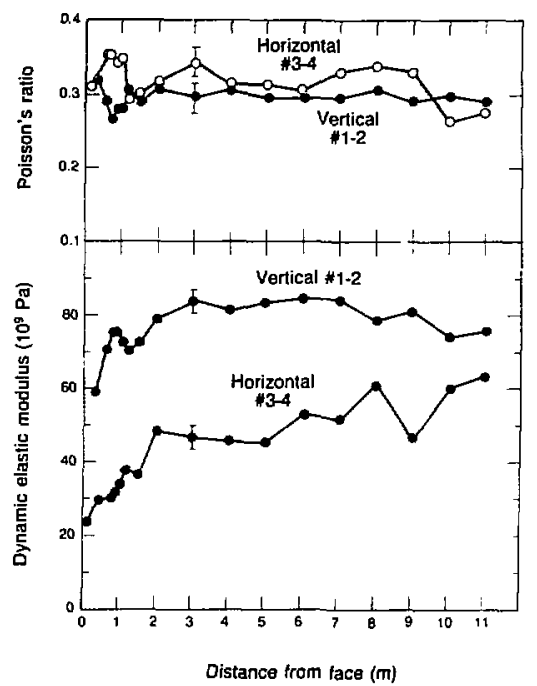

Figure 5. Dynamic elastic modulus and Poisson's ratio in vertical and horizontal directions. [XBL 8311-7324]

vertical direction indicate almost constant values, with a tendency for a slight decrease at distances greater than $7 \mathrm{~m}$. This may well be due to a vertical stress concentration present around the opening. The velocities in the horizontal direction beyond $2 \mathrm{~m}$ appear erratic, but show a general tendency to increase as a function of distance from the face. They remain, however, some $15 \%$ lower in value than the corresponding velocities in the vertical direction. Near the face, the differences in $P$ - and $S$ wave velocities arc considerably greater, with horizontal velocities approximately $30 \%$ lower in value than the vertical. The velocity and frequency data obtained correspond to a model of a jointed rock in which the joints intersected in the vertical direction are fewer and tighter than those intersected in the horizontal direction. The nature of the columnarjointed rock mass in which the test program was conducted supports this model. Furtner analyses of the velocity and frequency data-in conjunction with studies of core logs and ultrasonic measurements performed on specimens of core recovered from the boreholes, which are currently underway-are expected to form the basis for a quantitative model of the rock mass. 


\section{REFERENCE}

Paulsson, B.N.P., and King, M.S., 1980. Betweenhole acoustic surveying and monitoring of a granitic rock mass. International Journal of Rock Mechanics and Mining Sciences, v. 17, p. 371-376.

\section{LABORATORY HYDRAULIC FRACTURING STRESS MEASUREMENTS IN SALT}

\section{T.W. Doe and G. Boyce}

Determination of the state of stress is a key to the design of radioactive waste repositories in salt. Most conventional stress measurement techniques, such as overcoring and hydraulic fracturing, are based on the theory of elasticity, which may not be applicable in salt, which is well known for its nonelastic behavior. To determine the effects of nonelastic behavior on hydraulic fracturing stress measurements, we have performed a series of laboratory fracturing tests in salt under controlled stress conditions.

The determination of the maximum horizontal stress by hydraulic fracturing is based on the premise that the breakdown pressure is equal to the minimum tangential stress concentration in the borehole wall plus a tensile st:ength. For elastic materials, thc minimum tangentia stress is

$$
\sigma_{\mathrm{tan}}=3 \sigma_{H \min }-\sigma_{H \max },
$$

where $\sigma_{\text {un }}$ is the minimum tangential stress, $\sigma_{H \min }$ is the minimum horizontal stress, and $\sigma_{H \max }$ is the maximum horizontal stress. Goodman (1980) gives the expressions for closure of a borehole in a linear viscoelastic material, noting that the stress distribution around the hole is not a function of time. On the other hand, in nonlinear viscoelastic materials, the stress distribution is time dependent, and the tangential stress may be less than that predicted by elastic theory (Goodall and Chubb, 1970; Hata, 1975). Under such conditions, the tangential stress varies with time and has the effect of lowering the breakdown pressure. The use of elasticity assumptions when the stress distribution varies with time may result in significant errors in the stress calculations.

\section{LABORATORY TESTING PROGKAM AND RESULTS}

The laboratory testing program used both salt cores and prismatic blocks, which were loaded under hydrostatic and nonhydrostatic conditions, respectively. The salt samples were obtained from the A very Island salt dome in Louisiana. The cores for the hydrostatic tests were $15 \mathrm{~cm}$ in diameter and 22 $\mathrm{cm}$ long. The radial loads were supplied by a USBM biaxial cell, and the axial loads were provided by a hydraulic press. The hydrostatic tests were run to investigate the effects of (1) hydrostatic stress magnitude, (2) time delay between application of load and hydraulic fracturing, (3) flow rate of the fracturing fluid, (4) borehole diameter, and (5) use of inflatable packers.

For hydrostatic pressures of up to $13.8 \mathrm{MPa}$, we have found that the breakdown pressures generally correspond with those predicted by elastic theory (i.e., about twice the hydrostatic pressure), although the breakdown pressures fall somewhat too low at higher pressures (Fig. 1). The breakdown pressures do not vary between times of load application of 15 min to $64 \mathrm{~h}$ (Fig. 1), which is at variance with predictions based on steady creep formulations of the tangential stress relaxation with time. The breakdown pressure is a function of flow rate but not of borehole diameter or the presence or absence of inflatable packers. Shut-in pressures aie generally consistent with the magnitude of the horizontal stress.

The nonhydrostatic stress tests used prismatic blocks that were $30 \mathrm{~cm} \times 30 \mathrm{~cm} \times 46 \mathrm{~cm}$ in size and loaded using flatjacks in a polyaxial loading frame. A constant time delay of $2 \mathrm{~h}$ was used between the application of the load and the hydraulic fracturing. As shown in Fig. 2, the breakdown pressures remain constant with increasing horizontal stress ratio. This result is inconsistent with elastic theory, which would predict a decrease in breakdown pressure with incieased stress ratio for a given minimum horizontal stress; the predictions of breakdown pressure with horizontal stress ratio are shown 


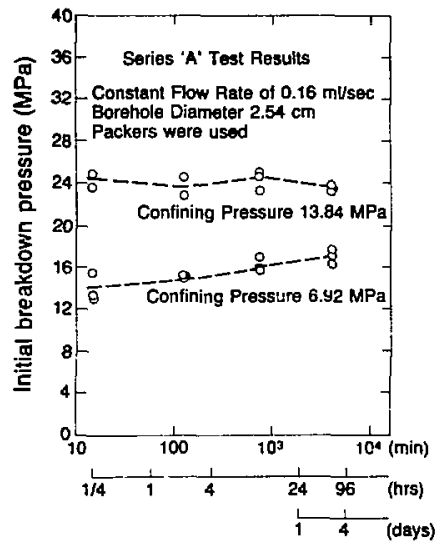

Time (log scale)

Figure 1. Variation of breakdown pressure as a function of confining pressure and time for hydrostatic tests on cylindrical samples. [XBL-8310-3372]

in Fig. 2. Shut-in pressures are generally higher than the minimum horizontal stress. The hydraulic fractures themselves are not single ruptures, but appear to sccupy a diffuse zone that is aligned normal to the minimum principal stress.

\section{CONCLUSIONS}

Eceakdown pressures under hydrostatic conditions do not vary with times of load application between $15 \mathrm{~min}$ and $64 \mathrm{~h}$. Evidence from borehole deformation measurements and observations of packers becoming caught in the borehole by closure suggest that the borehole deformation and accompanying stress readjustment occur very quickly after the application of the load.

Breakdown and shut-in pressures accurately reflect horizontal stress values urder hydrostatic but not nonhydrostatic stress conditions. Using conventional interpretation techniques, it may be possible to determine only the minimum horizontal stress magnitude and its orientation. As the breakdown

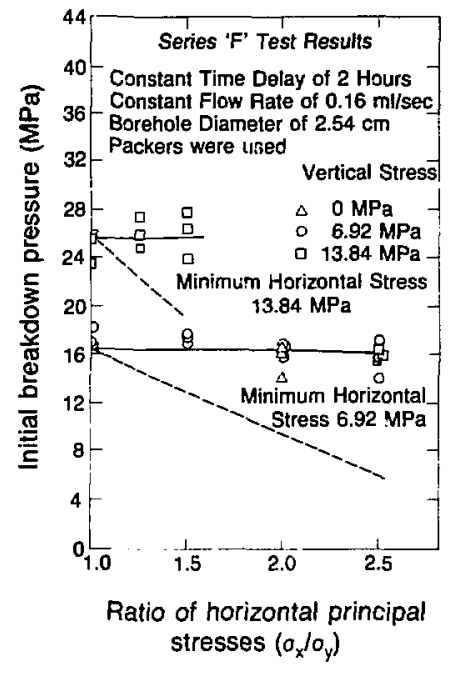

Figure 2. Variation of breakdown pressure as a function of vertical st-'ss and horizontal stress ratio for minimum horizontal stress values of 6.9 and $13.8 \mathrm{MPa}$. [XBL 8310-3374]

pressure is not dependent on horizontal stress ratio, determinations of maximum horizontal stress from hydraulic fracturing stress measurements in salt may not be valid, regardless of the time elapsed between drilling the borehole and performing the test.

\section{REFERENCES}

Goodall, I.W., and E.J. Chubb, 1970. Creep of large thin plates with central circular holes subjected to biaxial edge tractions. Nuclear Engineering and Design, v. 12, p. 89.

Goodman, R.E., 1980. Introduction to Rock Mechanics. New York, John Wiley \& Sons, Inc., $478 \mathrm{p}$.

Hata, T., 1975. A transient creep solution for uniaxial tension rectangular thin plates with central circular holes. Nuclear Engineering and Design, v. 32, p. 325 . 


\section{ELASTIC WAVE VELOCTTIES IN QUARTZ MONZONITE AT DIFFERENT LEVELS OF WATER SATURATION}

\author{
M.S. King
}

During a comprehensive rock mechanics and geophysics research program (Witherspoon et al,, 1979) involving large-scale heater tests at a depth of $340 \mathrm{~m}$ in an abandoned iron ore mine in central Sweden, it became evident that the interpretation of cross-hole acoustic surveys requires knowledge of compressional $\left(V_{p}\right)$ and shear wave $\left(V_{s}\right)$ velocities in the granitic rock under different conditions of stress and water saturation. Nur and Simmons (1964) have reported significant increases in $V_{p}$ at low stress levels when dry rocks containing porosity predominantly in the form of cracks were saturated with water, However, these workers also reported little change in $V_{s}$ for rocks of this type with changes in water saturation. Nur and Simmons (1964) and King (1983) have discussed the importance of knowing the actual degrec of water saturation of nominally "dry" rock samples in interpreting acoustic measurements, particularly at low stress levels.

Paulsson and King (1980a,b) have described the high-frequency acoustic monitoring of the heated rock mass between four vertical boreholes in the vicinity of a vertical cylindrical heater embedded in the rock. The monitoring tests fell into two categories: (1) between-hole surveys and monitoring as a function of depth in the boreholes, and (2) computer-aided reconstruction of the acoustic velocity and attenuation fields between a pair of boreholes.

The results of laboratory ultrasonic velocity measurements made on quartz monzonite core specimens recovered from two of the verical boreholes surrounding the heater have been reported by King (1984). The specimens were tested first fully saturated with water and then after being oven dried. The dry specimens were then stored in an atmosphere of $100 \%$ relative humidity and tested periodically over a period of 3-1/2 months, by which time they had become almost fully saturated again.

\section{EXPERIMENTAL PROCEDURES}

The three quartz monzonite specimens tested were prepared from 45 -mm-diameter core, with their plane surfaces ground parallel to a length of approxi- mately $75 \mathrm{~mm}$. The specimens were saturated fully with distilled water, first under a varuum and then under a hydrostatic pressure of $10 \mathrm{MPa}$. They were then weighed (to $0.01 \mathrm{~g}$ ) and tested. During testing, the specimens were surrounded with a rubber membrane to prevent loss of moisture.

The specimens were dried for $24 \mathrm{~h}$ in an oven maintained at $105^{\circ} \mathrm{C} \pm 2^{\circ}$ and then for $24 \mathrm{~h}$ in a vacuum oven maintained at the same temperature. They were weighed in the dry state (within $15 \mathrm{~s}$ of removal from the cooled vacuum oven) and tested ; ith a rubber membrane surrounding each of them. The effective (interconnected) porosity was calculated from the differences in the weight and dimensions of water-saturated and dry specimens.

Upon completion of these iests, the dry specimens were placed above the water level in a sagl ..t glass vessel containing distilled water. At intervals of time over the next 3-1/2 months, they were removed, quickly weighed (within $15 \mathrm{~s}$ ), enclosed in a rubber membrane, tested, and finally returned to the sealed glass vessel.

Ultrasonic velocity measurements were made by the pulse time-of-flight method for sequentially measuring $V_{p}$ and $V_{s}$, as described by King (1983). Each assemblage of rock specimen and transducer holders was placed in a laboratory press, and the velocity measurements were made as the axial stress on the specimen was increased from 2.5 to $30 \mathrm{MPa}$.

\section{RESULTS AND DISCUSSION}

The mean effective porosity of the three specimens was 0.0041 ; bulk densities of $\mathrm{dry}$ and watersotirated specimens were 2603.7 and $2607.8 \mathrm{~kg} / \mathrm{m}^{3}$, respectively. The results for the absorption of moisture when the dry specimens were stored in a relative humidity of $100 \%$ are shown in Fig. 1, in which the water saturation measured as a fraction of effec-

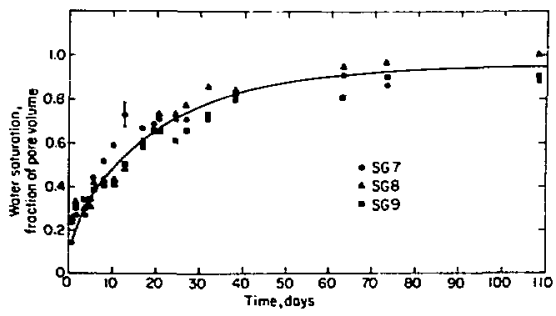

Figre 1. Absorption of water by rock specimens as a funclion of lime. [XBL 8210-2563] 
tive pore volume is plotted as a function of time in days. Note that after approximately $50 \mathrm{~d}$, the specimens bad absorbed sufficient water to fill most of the interconnected pore space.

The compressional and shear wave velocities $V_{p}$ and $V_{s}$, for the three specimens in both the fully saturated and the dry state are shown in Fig. 2 and 3 as a function of axial stress in the range 2.5-30 MPa. Figures 4 and 5 show the increases in $V_{p}$ and $V_{s}$ as the dry specimens absorbed moisture over a period of 3-1/2 months; the increases are expressed as a function of the fraction of water-filled pore space for specimens subjected to an axial stress of $10 \mathrm{MPa}$.

The compressional and shear wave velocities and porosity for the dry specimens have been averaged to calculate a spectrum of pore and crack aspect ratios and their volume concentrations following the theory developed by Kuster and Toksöz (1974) and an inversion scheme for this theory based on one proposed by Cheng and Toksöz (1979). Kuster and Toksöz assumed that the pores and cracks were all oblate spheroidal in shape. Though it is rare in rocks to find inhomogeneities of such regular shape, the assumption of oblate spheroids is-in contrast with other models in which the cracks have shapes more truly representative of those found in natureamenable to analysis and results in a unique solution. Despite its drawbacks, it does provide an intuitive feel for the sizes and shapes of the flaws. The results of the analysis are presented in Table 1.

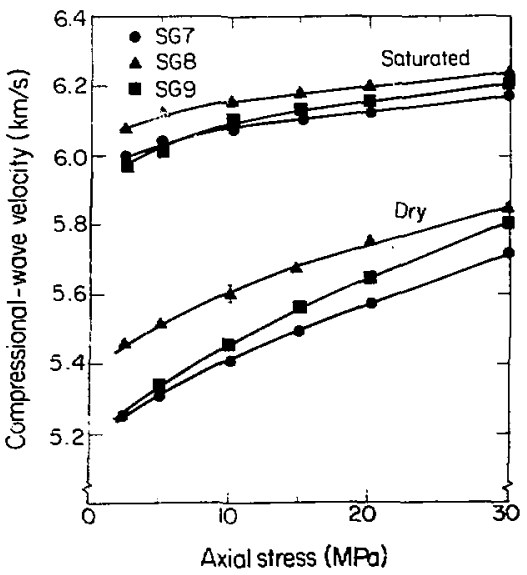

Figre 2. Compressional wave velocity for watersaturated and iry specimens as a function of axial stress. [XBL 833-1395]

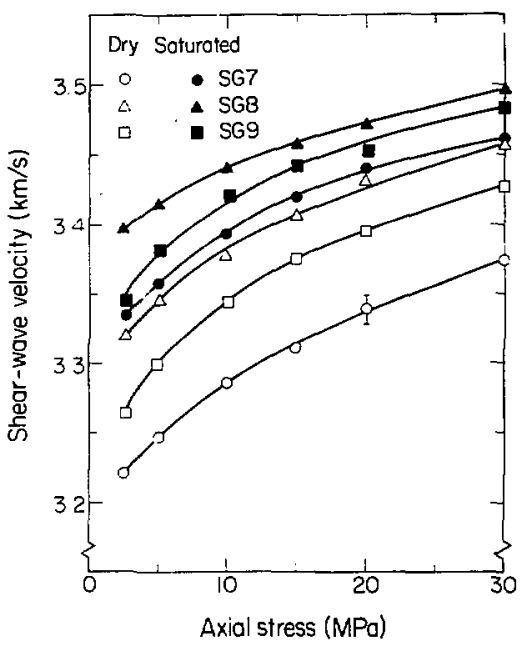

Figure 3. Shear wave velocity for water-saturated and dry specimens as a function of axial stress. [XBL 8331396]

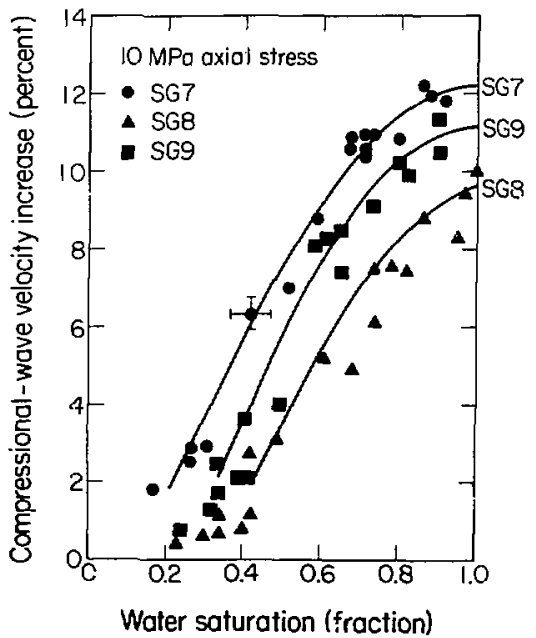

Fy 4 re Increase in compressional wave velocity at $10 \mathrm{MP}$ axial stress as a function of water saturation. [XBL 833-1398] 


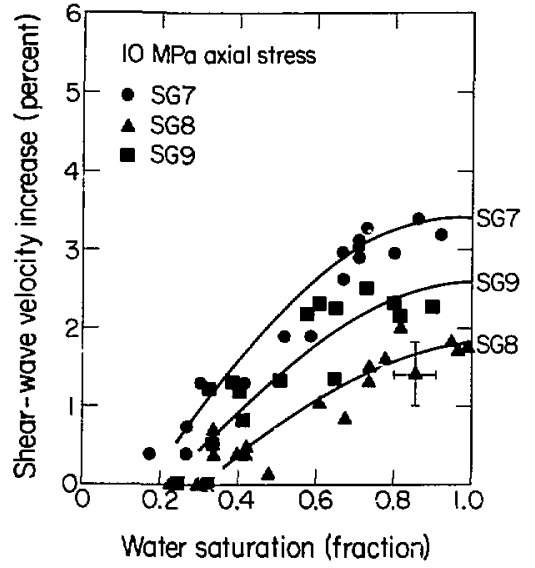

Figure S. Increase in shear wave velocity at $10 \mathrm{MPa}$ axial stress as a function of water saturation. [XBL 8331403

The Kuster and Toksöz (1974) theory has been empioyed to calculate the increases in average compressional and shear wave-velocities from the dry to the fully saturated state as water absorbed by the rock first fills the cracks of smallest aspect ratio and then those of progressively larger aspect ratio. This sequence of crack saturation described here is consistent with the capillary forces acting in 2 quartz-rich rock in the presence of water. The results are presented in Table 1 for different levels of axial stress.

Comparison of the calculated crack aspect ratios with the data for Westerly Granite presented by Cheng and Toksöz (1979) in their Table 1 shows approximately the same distribution of aspect ratios for the cracks but larger volume concentrations than for the quartz monzonite in our study. The agreement is good, however, when the difference in porosity is taken into account: Westerly Granite, $0.9 \%$; quartz monzonite, $0.4 \%$.

The velocity increases reported in Table 1 indicate that small amounts of water absorbed by cracks of low aspect ratio result in large increases in $V_{D}$ and $V_{s}$. These increases are much more pronounced than those measured experimentally and shown in Figs. 4 and 5 . The reason for the difference between the measured values and those predicted by theory is explained as follows. The pulses of compressional and shear waves used to measure $V_{p}$ and $V_{s}$ travel in comparatively narrow beams concentrated along the axis of the cylindrical specimen. It is this region of the specimen that is lower in saturation than the specimen mean water saturation, because water is absorbed first through the cylindrical and flat external surfaces of the specimen. The saturation gradient will be particularly pronounced during the initial stages of water absorption.

gradient will be particularly pronounced during the initial stages of water absorption.

Table 1. Spectrum of pore aspect ratios and velocity increase for different water saturations.

\begin{tabular}{ccccc}
\hline Aspect ratio & Concentration & $\begin{array}{c}\text { Water saturation } \\
\text { with cracks filled }(\%)\end{array}$ & $\begin{array}{c}\text { Velocity increase } \\
V_{p}\end{array}$ & $V_{s}$ \\
\hline $10^{-4}$ & 0.00001 & - & - & - \\
$3 \times 10^{-4}$ & 0.00005 & 1.6 & 3.8 & 1.1 \\
$10^{-3}$ & 0.00014 & 5.0 & 7.2 & 2.0 \\
$3 \times 10^{-3}$ & 0.00032 & 12.7 & 9.8 & 2.6 \\
$10^{-2}$ & 0.0009 & 34.6 & 11.8 & 3.1 \\
$10^{-1}$ & 0.0027 & 100 & 11.9 & 3.1 \\
\hline
\end{tabular}


The increases in mean $V_{p}$ and $V_{s}$ calculated from the Kuster and Toksöz (1974) theory for full saturation, indicated in Table 1 , agree well with those measured experimentally and shown in Figs. 4 and 5 .

\section{CONCLUSIONS}

1. Rocks containing porosity predominately in the form of cracks and maintained in an environment of $100 \%$ relative humidity for months at a time can become more than $90 \%$ water saturated.

2. Small increases in moisture content of dry rocks containing appreciable crack porosity result in substantial increases in $V_{p}$ and $V_{s}$.

3. The Kuster and ${ }^{p}$ Toksöz model provides a convenient framework within which to study the variation of elastic wave velocities it partly saturated and saturated low-porosity rocks.

\section{REFERENCES}

Cheng, C.H., and Toksöz, M,N., 1979. Inversion of seismic velocities for the pore aspect ratio spectrum of a rock. Journal of Geophysical Research, v. 84, p. 7533-7543.

King, M.S., 1983. Static and dynamic elastic properties of rocks from the Canadian Shield. International Journal of Rock Mechanics and Mining Sciences, v. 20, p. 237-241.

\section{THE INFLUENCE OF CLAY- SIZED PARTICLES ON SEISMIC VELOCITY IN PERMAFROST}

\author{
M.S. King
}

Over the past two decades, considerable interest has resulted in the exploration for and exploitation of the large mineral resources to be found in the Far North. It is therefore necessary to study the effects of permafrost on the interpretation of geophysical surveys performed in that region. Interpretation of seismic reflection data, an important technique in exploration: geophysics, depends upon seismic velocity control, particularly in near-surface sediments. It is these sediments that often are in the permanently frozen state in the Far North.

A number of studies have demonstrated that when water in the pore spaces of sediments becomes
King, M.S., 1984. Elastic-wave velocities in quartz monzonite at different levels of water saturation. International Journal of Rock Mechanics and Mining Sciences, v. 21, in press.

Kuster, G.T., and Toksöz, M.N., 1984. Velocity and attenuation of seismic waves in two-phase media, Part I-Theoretical formulations. Geophysics, v. 39 , p. 587-606.

Nur, A., and Simmons, G., 1964. The effect of saturation on velocity in low porosity rocks. Earth and Planetary Science Letters, v. 7, p. 183-193.

Paulsson, B.N.P., and King, M.S., 1980a. Betweenhole acoustic surveying and monitoring of a granitic rock mass. International Journal of Rock Mechanics and Mining Sciences, v. 17, p. 371-376.

Paulsson, B.N.P., and King, M.S, 1980b. A crosshole investigation of a rock mass subjected to heating. Proceedings, Rockstore '80: Special Session on Nuclear Waste Disposal, Stockholm (Vol. 2), p. 969-976.

Witherspoon, P.A., Gale, J., Nelson, P., Doe, T., Thorpe, R., Forster, C., and Paulsson, B., 1979. Rock mass characterization for storage of nuclear waste in granite. Proceedings 4th Congress, International Society for Rock Mechanics, Montreux (Vol. 2), p. ?11-718.

frozen, large increases in seismic velocity can result. Besides ground temperature, other factors influencing the fraction of ice formed in the pore spaces of sediments are the moisture content, the pore sizes and shapes, the pore-water chemistry, and the states of stress in the sediment and pore water. Theoretical aspects of these points have been discussed in considerable detail in a review prepared by Anderson and Morgenstem (1973).

From his studies of elastic wave propagation in a number of water-saturated sedimentary rocks at permafrost temperatures, Timur (1968) concluded that as the temperature is reduced below $0^{\circ} \mathrm{C}$ in these rocks, ice forms first in the larger pore spaces and then in progressively smaller ones as the temperature is reduced still further. He ascribed this behavior to the progressively increasing interfacial forces associated with larger specific surface areas as the pore sizes become smaller, coupled with the salinity of the interstitial water. Behavior confirming Tir.sur's hypothesis has been reported by a numi er of 
researchers during measurements of elastic wave velocities, complex electrical resistivity, and thermal conductivity in samples of natural permafrost and other water-saturated porous rocks at temperatures below $0^{\circ} \mathrm{C}$

The results of a study to determine the effects of clay-sized particles on elastic wave velocities in unconsolidated permafrost have been presented by King (1984) and are summarized here.

\section{THEORY}

An expression often used to calculate the fraction of ice contained in permafrost pore space is the three-phase time-average relationship. This equation, however, applies to consolidated porous rocks and is inapplicable to unconsolidated permafrost sediments unless an artificially low value of matrix velocity for unconsolidated material is assumed.

The relationship proposed here, which is shown to fit the data obtained for frozen unconsolidated sediments, is based on the Kuster and Toksöz (1974a) two-phase model, which has been modified to account for the three phases found in permafrost: ice, water, and solid matrix material. The first stage in developing the model is to consider an ice matrix in which spherical water inclusions form. The elastic properties are calculated for a complete spectrum of ice/water ratios. The elastic constants for this ice/water mixture are then employed in a second model of a matrix of varying ice/water content with quartz inclusions to obtain the elastic properties for the three-phase system.

Kuster and Toksöz (1974b) have demonstrated the validity of their model for elastic wave velocities in suspensions of solid particles in liquids over a wide range of concentrations. Toksöz et al. (1976) have demonstrated its validity for determining the velocities in liquid-saturated porous rocks. The results of the analysis described are shown in Fig. 1, where $P$-wave velocity, $V_{p}$, is plotted as a function of permafrost porosity for a complete range of pore space fractional ice cuntents.

\section{TEST SPECIMENS ANL FXPERIMENTAL PROCEDURES}

Thirty-seven permafrost samples from shallow boreholes along the Mackenzie River, from boreholes beneath the Beaufort Sea, and from shallow bortholes in the Canadian Arctic Islands were recovered and maintained in their natural, frozen state. Test specimens were prepared in their frozen state following the procedures described by King (1977). The test procedures employed were as

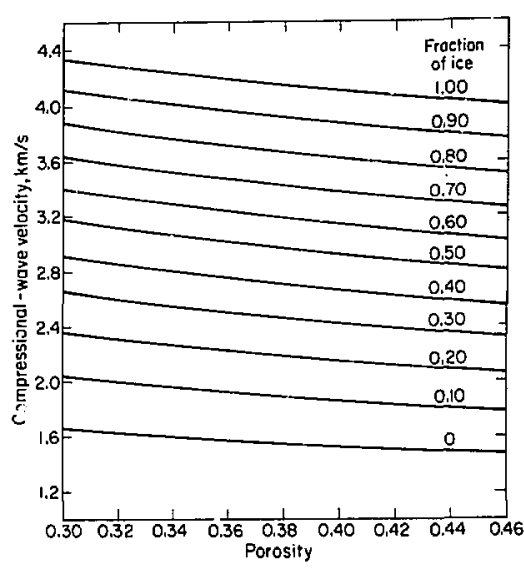

Figure 1. $P$-wave velocity for unconsolidated permafrost plotted versus porosity for different ice contents. |XBL 832-1677|

described by King, except that the specimens here were subjected to a hydrostatic confining stress of only $0.35 \mathrm{MPa}$ (50 psi) under drained conditiuns. This is representative of the effective stress experienced by the permafrost samples in their natural state.

$P$-wave velocitips were measured by a first-pulse arrival technique at ascen.ting temperatures in the range -16 to $+5^{\circ} \mathrm{C}$, except for those specimens recovered from the Beaufort Sea, for which the temperature range was -10 to $-1^{\circ} \mathrm{C}$. $S$-wave velocities were measured sequentially along with the $P$-wave velocities, but it generally proved difficult to identıfy $S$-wave arrivals unequivocally ai the low confining stress employed.

The bulk density, porosity, water conteni, and grain size distribution were measured by stardard procedures on small samples taken from the samples used to prepare the test specimens. Standard $x$-ray diffraction analyses were performed on representative samples to identify the clay minera's resent. Kaolinite, illite, and chlorite were found in fairly constant props:rtions of $3: 1: 1$, respectively, for all samples analyzed.

\section{EXPERIMENTAL RESULTS AND DISCUSSION}

The $P$-wave velocities for the permafrost specimetis are plotted in Figs. 2 and 3 as a function of 


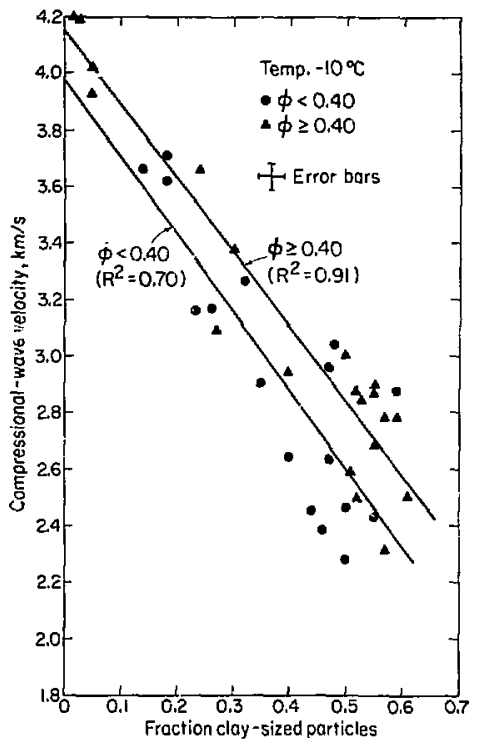

Figure 2. Measured $P$-wave velocity for permafrost versus fraction of clay-sized particles at a temperature of $-10^{\circ} \mathrm{C}$. [XBL 832-1680]

fractional clay content, $F_{c}$, for temperatures of -10 and $-5^{\circ} \mathrm{C}$, respectively. Linear regressions for porosities $\phi<0.40$ and $\phi \geqslant 0.40$ are shown in each figure.

The fraction $F_{i}$ of ice contained in the pore space has been calculated for each specimen at temperatures of $-10,-5$, and $-2^{\circ} \mathrm{C}$ from Fig. 1 on the basis of the theory discussed earlier. $V_{p}$ measurements for all specimens are plotted in Fig. 4 at tempeiatures of $-10,-5$, and $-2^{\circ} \mathrm{C}$ as a function of water-filled porosity, $\phi\left(1-F_{i}\right)$. A linear regression of the data is shown in the figure.

When the $V_{D}$ measurements are plotted as a function of fraction of clay-sized particles for a given temperature below $0^{\circ} \mathrm{C}$ in Figs. 2 and 3 , it is sesn that an increase of clay-sized particles $F_{c}$ in perinafrost results in a lower measured $V_{p}$ at a given temperature in the frozen state. Linear regressions for porosities $\phi<0.40$ and $\phi \geqslant 0.40$ indicate that an increase in porosity at a given clay content results in a significantly higher measured $V$. It is interesting to note that the $V_{n}$ measurements for specimens containing low fractions of clay-sized particles are

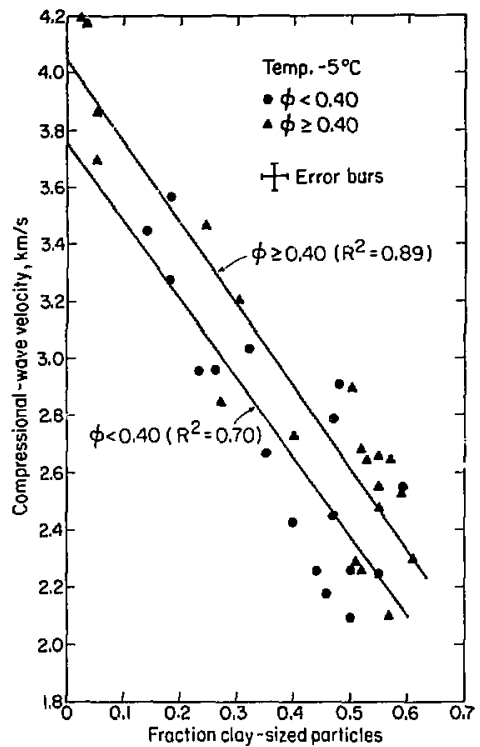

Figure 3. Measured $P$-wave velocity for permafrost versus fraction of clay-sized particles at a temperature of $-5^{\circ} \mathrm{C}$. [XBL 832-1679]

close to $V_{p}$ values predicted from the theory plotted in Fig. 1 for fractional ice contents $F_{i}$ close to 1.0.

Figure 4 shows the $P$-wave velocity $V_{D}$ plotted as a function of water-filled porosity $\phi\left(1-F_{i}\right)$. The linear relationship $V_{p}=4.14-6.23 \phi\left(1-F_{i}\right)$ fits the data very well, particularly over the range of values of $\phi\left(1-F_{i}\right)$ from 0.00 to 0.20 , despite the fact that the theory does not predict a unique dependence of $V_{p}$ on $\phi\left(1-F_{j}\right)$. There appears to be no statistically significant difference between the data for temperatures of $-2,-5$, or $-10^{\circ} \mathrm{C}$.

\section{CONCLUSIONS}

It is concluded that the $P$-wave velocity for unconsolidated permafrost from the Arctic correlates well with the water-filled porosity $\phi\left(1-F_{j}\right)$, irrespective of the original porosity, fraction of claysized particles, or temperature when $F_{i}$ is calculated from the Kuster and Toksöz theory. This correlation remains to be confirmed by actual measurements of the fractional ice content by an experimental technique such as nuclear magnetic resonance. Such a study is currently underway. 


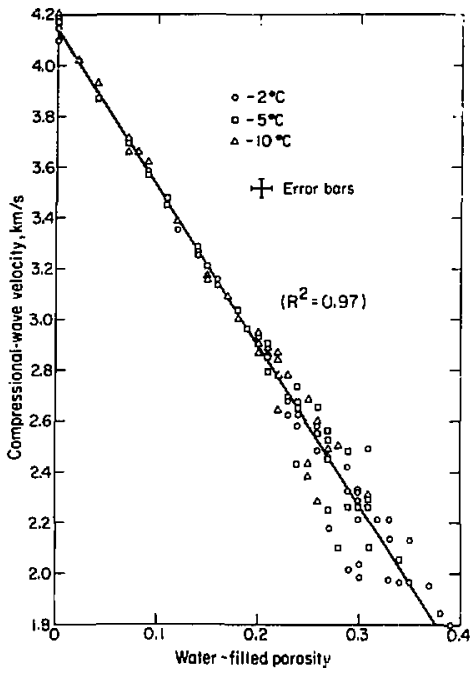

Figure 4. Measured $P$-wave velocity for permafrost versus function of water-ílled porosity. [XBL 832-1673]

\section{REFERENCES}

Anderson, D.M., and Morgenstern, N.R., 1973. Physic', chemistry and mechanics of frozen ground: A review. In Permafrost-The North American contribution to the Second International Conference, Yakutsk. Washington, D.C., National Academy of Sciences.

King, M.S., 1977. Acoustic velocities and electrical properties of frozen sandstones and shales: Canadian Journal of Earth Sciences, v. 14, p. 1004-1013.

King, M.S., 1984. The influence of clay-sized particles on seismic velocities for Canadian arctic permafrost: Canadian Journal of Earth Sciences, v. 21, p. 19-24.

Kuster, G.T., and Toksöz, iM.N., 1974a. Velocity and attenuation of seismic waves in two-phase media, Part I., Theoretical formulations. Geophysics, v. 39, p. $587-606$.

Kuster, G.T., and Toksöz, M.N., 1974b. Velocity and attenuation of seismic waves in two-phase media, Part Il., Experimental results. Geophysics, v. 39 , p. $607-618$.

Timur, A, 1968. Velocity of compressional waves in porous media at permafrost temperatures. Geophysics, v. 33, p. 584-595.

Toksöz, M.N., Cheng, C.H., and Timur, A., 1976. Velocities of seismic waves in porous rocks. Gecphysics, v. 41, p. 62I-645.

appears to be a lack of general understanding of the infiuence of the water jets on the rock-breakage process. Although the researchers who have investigated this hybrid cutting system are in general agreement that substantial benefits are derived when water jets are used, it is apparent that the magnitude of these effects is dependent on a number of factors, including rock type, jet pressure, jet flow rate, jet position, bit velocity, and depth of cut. The relative importance of these parameters is not known. Arother reason for hesitation by industry in commercializing this technology is a fear that another level of complexity will need to be added to already complicated mining and tunneling machines. This article addresses these two issues. First, attention is paid toward advancing the rate of knowledge of the rock-breakage process ahead of a drag bit when water jets are used to assist this process. Second, a patent disclosure is described that attempts to resolve some of the engineering problems associated with the 
incorporation of a water-jet-assist system on a mining machine.

A series of laboratory experiments was conducted that focused on the influence of the jet parameters in reducing bit forces. The position of the jet with respect to the bit was found to be of crucial importance in this regard. The optimum jet position with the V-face chisel bit used in these tests was a single jet aimed parallel to and about $1 \mathrm{~mm}$ ahead of the leading face of the bit. Jet power also influenced the results, and it appeared that a threshold jet power level had to be exceeded to achieve satisfactory results. However, if the jet power was increased beyond this threshold value, no further benefit was observed in terms of a continued decrease in the bit forces. On the contrary, for reasons that are not yet well understood, if the jet power was increased substantially beyond the threshold value, the bit forces were observed to inerease. This phenomenon is illustrated in Fig. 1. The magnitude of the threshold value for jet power is likely to be a function of bit velocity, depth of cut, and perhaps rock type. A jet power of $3 \mathrm{~kW}$ was measured while taking $15-\mathrm{mm}$-deep,cuts in Indiana Limestone at a bit cutting speed of $0.06 \mathrm{~m} / \mathrm{s}$.

The influence of bit velocity was examined in so far as it was possible to investigate this parameter within the constraints provided by the laboratory apparatus. It was found that an increase in the bit velocity by a factor of 4 , from 0.06 to $0.25 \mathrm{~m} / \mathrm{s}$, resulted in a decrease in the force reduction achieved with water jets from 50 to $44 \%$. This result indicates that the influence of bit velocity on bit force reductions is small. These limited data are used to specu-

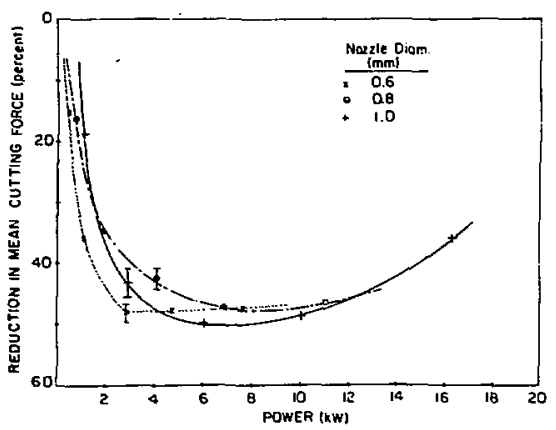

Fisme 1. Force reductions for single relieved cuts as a function of jet power with three different nozzles. [XBL $843-967$ late about the likely requirements for the total installed jet power on a mining machine such as a continuous miner. It is estimated that, at realistic bit velocities on a mining machine, about $15 \mathrm{~kW}$ of jet power per bit may be needed to overcome the threshold value to achieve substantial bit force reductions (Figs. 2 and 3). If it is assumed that 40 bits may be in contact with the rock at any one time, then the total power to the jets will need to be 600 $\mathrm{kW}$. This is of the same order as the installed mechanical power on a machine. It should be recognized, however, that this increase in the total machine power is accompanied by an increase in the rate of excavation; that is, because the bit forces are reduced by a factor of about 2 , the machine now can mine at twice the rate. Thus the specific energy of the rock-breaking operation is, at worst, the same as for present machinery; if the bit forces are reduced by more than a factor of 2 , then the specific energy is less than for present systems.

Experiments were conducted to investigate the mechanisms of the fracture process when jets are used. Results from these tests indicate that an important-and perhaps the most importantinfluence of the jets is to remove the rock fragments, particularly the fine fragments, from ahead of the bit -very quickly after these particles are formed. The findings show that when jets are not used, the bit travels in the groove, pushing a pile of rock particles ahead of its leading face and riding on top of a cushion of finely crushed material. The jets seems to

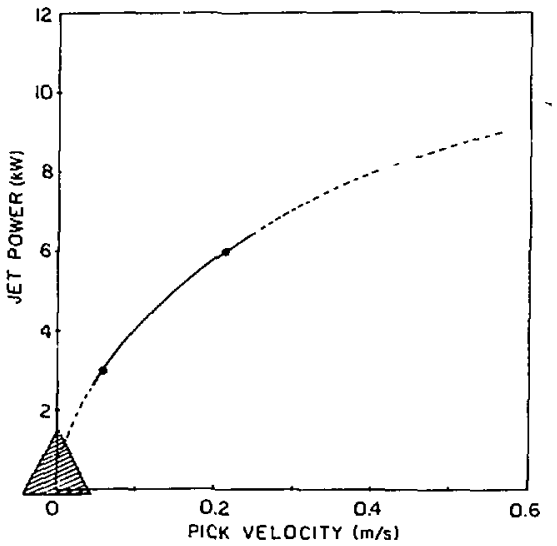

Figure 2. Speculative plot of jet power as a function of bit velocity. [XBL 843-968] 


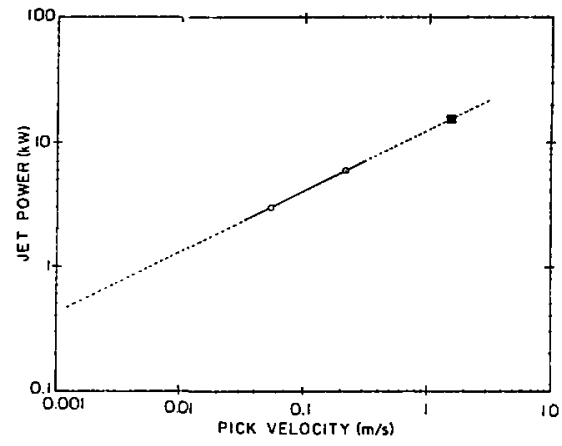

Figure 3. Speculative log-log plot of jet power as a function of bit velocity. [XBL 843-969]

act to clear all of these fragments from around the bit and thereby enable it to make more direct contact with the rock to generate more effectively the stresses required to cause failure.

In terms of progress toward the second objective of overcoming some of the engineering difficulties associated with the incorporation of a water-jet-assist system on a mining machine, a patent application has been filed in which a number of key features are described. First, a method is outlined for phasing the jets on a rotating cutter head so that a jet servicing an individual bit is activated only when that bit is in contact with the rocix. This method calls for a mechanically activated check valve to be located on the surface of the cutter head beneath the bit. When force is applied to the bit while it is cutting, the valve opens and permits water to flow into the bit body. Second, a technique is described for sealing the interface between this valve and the drum. This seal consists of a simple nylon insert housed in the bit body. Third, a method is outlined for channeling the water through the bit body and housing the jet nozzle in this body.

\section{REFERENCES}

Dubugnon, O., 1981. An experimental study of water assisted drag bit cutting of rocks. Proceedings of the First U.S. Water Jet Symposium, Golden, Colorado, April 7-9, 1981, p. II4.1-II-4.11.

Hood, M., 1976. Cutting strong rock with a drag bit assisted by high pressure water jets. Journal of the South African Institution of Mining and Metallurgy, v. 77, no. 4, p. 79-90.

Hood, M., 1977. Phenomena related to the failure of strong rock adjacent to an indenter. Journal of the South African Institution of Mining and Metallurgy, v. 78 , no. 5 , p. 113.

Hood, M., 1978. A Study of Methods to Improve the Performance of Drag Bits Used to Cut Hard Rock (Ph.D. dissertation). Department of Mining Engineering, Untversity of the Witwatersrand, Republic of South Africa.

Ropchan, D., Wang, F.D., and Wolgamott, J., 1980. Application of water jet assisted drag bit and pick cutter for the cutting of coal measure rocks. Final Technical Report submitted to the U.S. Department of Energy.

Tomlin, M., 1982. Field Trials with 10,000 psi prototype system. Proceedings of Seminar on Water Jet Assisted Roadheaders for Rock Excavation. Sponsored by the U.S. Department of Energy and the U.K. National Coal Board, Pittsburg, Pennsylvania, May 26-27, 1982, p. C1-C11.

Tutluoglu, L., Hood, M., and Barton, C., 1983. An investigation of the mechanisms of water jet assistance on the rock cutting process. Proceedings, 24th Symposium on Rock Mechanics, State College Texas, June 20-22, 1983, p. 743-749. 


\section{A VENTHLATION STUDY OF A LONGWALL DISTRICT IN A COAL MINE}

\author{
M.J. McPherson
}

The predominant method of mining in U.S. underground coal mines is the room-and-pillar method, in which the coal is won from the solid seam by driving a series of orthogonal entries (rooms). The remaining pillars of coal, perhaps 5 to $15 \mathrm{~m}$ square, are usually left unmined to provide support for the superincumbent strata. Although simple in concept, the method has several drawbacks. As mines become deeper, the pillars must be greater in areal extent to support the increased load. Hence the percentage of coal extracted may be reduced to unacceptable levels. Furthermore, even when mechanized, this method cannot attain truly continuous extraction.

A mining layout that overcomes these drawbacks is the longwall system, the major method used throughout Europe and China. In this technique, the coal seam is exposed by driving a narrow opening some $100-150 \mathrm{~m}$ in length between two sets of preconstructed airways. This "longwall face" is then advanced through the seam by taking strips of coal $0.5-1.0 \mathrm{~m}$ in thickness. The face is supported for a distance of about $3 \mathrm{~m}$ back from the solid coal, beyond which the strata are allowed to collapse into the "waste" or "gob" zone.

The complete mining operation is fully mechanized. The coal is broken from the solid seam by a heavy-duty shearing machine that moves backward and forward along the face. The broken coal is transported through the face by an armored flexibic chain conveyor that articulates forward after passage of the shearer. The self-advancing supports are powerful hydraulic chocks that control the rate of convergence of roof and floor. As the conveyor snakes forward, each set of chocks, in turn, lowers its cantilever roof bars, advances to a new position, and resets its roof bars.

The enhanced productivity potential of the longwall system is persuading increasing numbers of U.S. mine operators to adopt the method. However, it also suffers from some disadvantages, not the least of which is the difficulty of maintaining acceptable environmental conditions at the face. The very success of the longwall system in producing coal at a high rate from a single location also exacerbates problems of dust, methane gas, heat, and humidity.
This article outlines four experiments that were carried out on the ventilation system of a longwall district in a mine owned by the Snowmass Coal Mining Company of Carbondale, Colorado, during 1982-1983.

\section{THE DISTRIBUTION OF AIRFLOW ALONG A LONGWALL FACE}

The type of longwalling practiced in the United States involves the use of "bleeder return" airways. These are employed intentionally to draw air from the face, through the caved area from which the coal has been extracted, and into the return airways. This practice helps to limit the amount of gas that moves from the waste zone toward the face. However, the reduction in airflow along the face may have unfortunate consequences on environmental conditions toward the return end of the face.

Field observations consisted of taking 14-16 air velocity measurements on a grid covering each of 6 locations along the face. Velocity contours were plotted on scale drawings of each cross section.

The data analysis included an examination of (1) the variaticn in airflow along and across the longwall and (2) the role of the hleecier airways in producing the pressure differentiais that cause such variation. Figure 1 illustrates the changes that occurred in air volume flow rate along the length of the face. Note that the airilow actually increased along the first half of the faceline, the flow being diverted from the caved zone onto the face. The increase was due to a smali fault encountered at about the middle of the face, which caused enhanced fragmentation and consolidation of the caved material and interfered with

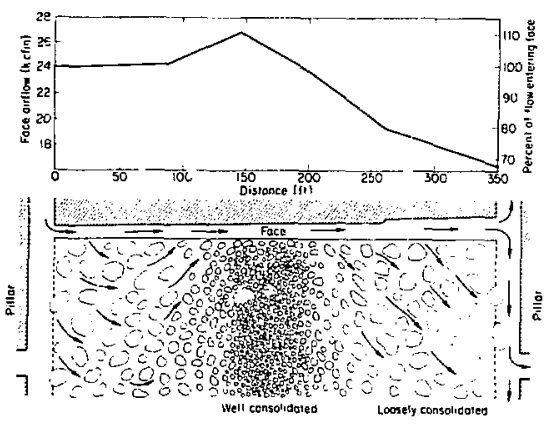

Figure 1. Variation in air flow along the face. $\mathrm{XBL}$ 843-96851 
the normal migration paths of air passing through the gob.

A further analysis was carried out on the distribution of airflow across the face, i.e., (1) close to the coal front, (2) in the conveyor track, (3) in the traveling track, and (4) between the chock legs. The results provided valuable information relating to the control of methane and dust during shiaring operdtions.

\section{THE DETERMINATION OF LONGWALL FACE RESISTANCE}

Within the ventilation network of a mine that emplcys the longwall method of working, the branches that offer the highest resistance to airflow along the main ventilation routes are usually the longwall faces themselves. Unfortunately, very few data are available in the literature to assist the mine ventilation engineer in predicting the resistance of a planned longwall and, hence, the fan power required.

During the field study, detailed measurements were made of the frictional pressure drops and corresponding airflows across the face ends, shearer, and increments of length along the face. The pressure differentials were measured by sensitive diaphragm gauges connected by tubing between pitot tubes, and the airflows were determined by spot measurements on a grid of points covering the cross section of each measuring station. These observations allowed the variation in resistance (per meter length) to be established along the faceline, across the shearer, and at the face ends. The results are illustrated in Fig. 2. The unit of resistance, P.U. (practical unit), is defincd by $R=p / Q^{2}$, where frictional pressure drop, $p$, is in milli-inches of water gauge and aifflow, $Q$, is in thousands of cubic feet per minute (kcfm).

An analysis of the data produced a range of friction factors ( $k$ values) applicable to mechanized longwall faces equipped with powered supports. These were incorporated into nomograms for the rapid estimation of faceline resistances.

A theoretical examination of shock losses at face ends and at the shearer was combined with experimental data to facilitate determinations of the additional equivalent resistances of those areas.

The overall result of this investigation was the development of an improved procedure for mining engineers to use in assigning values of airway resistance to longwall faces during the planning and design of mine ventilation systems.

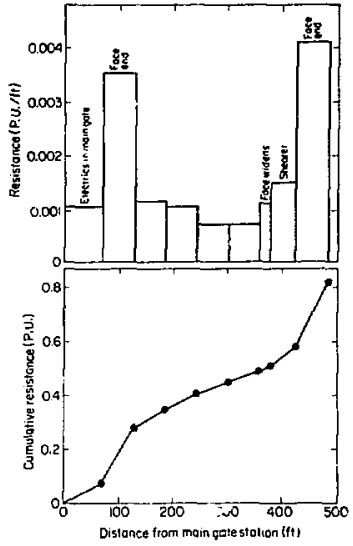

Figure 2. (a) Variation in resistance along the face. (b) Cumulative resistance along the face. [XBL 843-4686]

\section{THE LAW OF AIRFLOW FOR A LONG'NALL FACE}

The relationship between $p$ and $Q$ in mine openings yaries from a linear dependence for the laminar flow that may occur in very large excavations or in sealed areas to a logarithmic law, $p=R Q^{\prime}$ for varying degrees of turbulence. The logarithmic index, $n$, normally remains close to the theoretical value of 2 for fully developed turbulence. This has been verified on a number of occasions for airways in which the turbulence is exacerbated by wall roughness.

In recent years, a number of mining engineers have questioned the validity of the iormaliy accepted "square law," $p=R Q^{2}$, when applied to the highly constricted corridor of a longwall face, where much of the resistance is caused by the aerodynamic drag of hydraulic roof supports. To determine the index $n$, it is necessary to vary the airtlow by means external to the airway under investigation and to observe the corresponding effect on frictional pressure drop. Unfortunately, this is difficult to accomplish safely on an operating longwall face. The availability of a standing, but fully equipped longwall at Snowmass offered a rare opportunity to carry out the test.

Following a comprenensive theoretical investigation into the possible causes of deviations from the 
square law, a field experiment was carried out in the Colorado mine. A pressire tube was suspended along the full length of a longwall face with a sensitive pressure gauge connected in line. The airflow was adjusted in increments between the maximum attainable and the minimum compatible with safety. Throughout this experiment, one of the team members patrolled the bleeder return airways to ensure that methane concentrations remained below mandatory limits. The variation in airflow was achieved by adjusting ventilation control d hors and regulators and by constructing temporary brattice cloths in airways slose but external to the longwall face.

The results of this test are shown graphically in Fig. 3, which reveals that a consistent logarithmic relation exists between frictional pressure drop and airflow over the range of airflows measured. Furthermore, the slope of the line for $\ln p$ vs $\ln Q$ is 1.987 , confirming that the relation between pressure drop and airflow does, indeed, adhere very closely to the theoretical square law.

\section{MODELING THE LEAKAGE OF AIR THROUGH THE CAVED WASTE BEHIND A LONGWAL.L FACE}

A number of computer simulation programs have been developed for the analysis of mine venti-

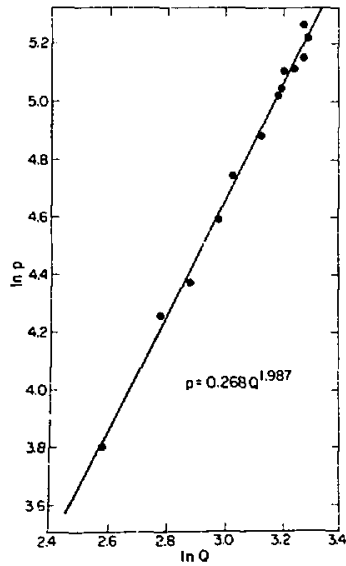

Figure 3. Pressure drop versus airflow at the longwall face. [XBL 843-9687] lation networks. These play an important role in the design and planning of mine ventilation systems. Unfortunately, much of the air that enters a mine does not reach the operating faces but pa;ses from intake to retum airways through leakage paths. In the case of a longwall district, air migrates through the caved zone. This can, if properly arranged, assist in maintaining control of gas emitted into the caved area. ". he simulation modcls currently available do not represent adequately the leakage airflows through longwall wastes but merely include such air migration as a few "equivalent resistances." Data have not hitherto been available to produce a more accurate mathematical representation.

A detailed pressure volume survey was carried out throughout a complete longwall district at Snowmass. This included all four boundaries of the caved area. Measurements of airflow were made by low-velocity anemometry or smoke tubes in ali crosscuts connecting the bleeder airways to the caved zone. The results were employed during a comprehensive investigation to develop mathematial simulations of leakage through a longwall waste. These varied from finite-element models to networks of equivalent resistance flow paths. The most practicable of the models divided the waste zone into areal elements with resistance values determined by element size and position, taking into account the dynamic stress pattern that exists over a longwall waste. This model was also sufficiently efficient in computer time to be incorporated into an existing ventilation-network-analysis package modified to allow a mixture of laminar and turbulent flow paths.

\section{CONCLUSIONS}

The combined experiments at the Snowmass mine represent one of the most thorough investigations to be conducted on longwall ventilations systems in recent years. The results have not only been analyzed theoretically but have also led to improved procedures for the planning and control of ventilation in current and future nines employing the longwall system.

\section{REFERENCE}

McPherson, M.J., and Brunner, D.J., 1983. An investigation into the ventilation characteristics of a longwall district in a coal mine. Report prepared for the U.S. Department of Energy, September 1983, A 751520. 


\section{SEISMOLOGY}

\section{CENTER FOR COMPUTATIONAL SEISMOLOGY}

\author{
T.V. McEvilly and E.L. Majer
}

Seismology has traditionally been a dataintensive, multidisciplinary science with consequent problems in the reduction and analysis of large volumes of data on the one hand and in the effective handling, analysis, and presentation of results on the other. To be fully effective in seismology, a modern research laboratory requires data manipulation and storage capabilities beyond those of most computational facilities, along with a sophisticated flexibility in graphics and interactive operations.

Massive amounts of digital and analog seismographic data reside in the variuus archives and seismologic research centers working with regional and global earthquakes. Add the tremendous data collection rates of operational modern global networks (RSTN, AIDS, WWSSN, IDA, NDSS) and arrays (NORSAR, ALPA, etc.), and the scale of the problem becomes cleal. On a more limited scale, consider the some 50 regional microearthquake networks (in the U.S. alone) operating some 1600 individual stations in a continuous monitoring mode. Finally, increasing use is being made of seismic reflection profiling and more general deep seismic sounding (DSS) methods in basic geophysical research. For example, the Consortium for Continental Reflection Profiling (COCORP) operates one field crew full time in data acquisiition for basic crustal structure studies.

The modern research group in seismology usually includes users of all these types. Unfortunately, an enormous variety of software is required to manipulate these data, not to mention the codes necessary for the interpretation aspects of the research (i.e., the "forward" and "inverse" calculations). Although the physics of most seismologic problems is relatively straightforward, the seismologist is frequently not equipped with the best computational tools for solving a particular problem. As a consequence, there is a tendency for the seismologist to apply an approach that often involves the "wha: works first," or "brute force," method. Results may lack valuable information and analyses of experimental sensitivity, errors, or uniqueness. Decisions on such things as the proper statistical analysis, stability of solution, convergence criteria, or appropriate matrix manipulation algorithms can have major impacts on results. A related problem is the presentation of risults in a form that is effective and efficient for the scientist. Often a number of competing numerical methods and techniques must be evaluated in some interactive way. The presence of an adequate computational facility that offers the opportunity for interaction between seismologists and computational experts is a fundamental requirement for an effective and dynamic program in basic research.

It became apparent that existing personnel, equipmen:, and mutual interests at UC Berkeley (UCB) and Lawrence Berkeley Laboratory (LBL) provided a unique opportunity to establish the Center for Computational Seismology (CCS) with minimal personne! and equipment. The combined expertise in computer science, hardware development, data file management and manipulation, numerical analysis, computer graphics, and seismology offers a powerful center capability.

The basic $L B L$ resources available to support CCS are the Computer Center and the Computer Science and Mathematics Department (CSAM). These resources can compensate for the hardware and software lirnitations discussed at the outset. The LBL Computer Center provides the basic computational equipment. This has the advantage of drawing upon the continuing hardware and software developments of a langer facility, thus minimizing the risk of obsolescence. We have added to thêse facilities the hardware necessary to run the imaging software and to provide the CCS user with terminal and graphics service. That is, we have established within a larger computational complex a specially equipped and staffed computational facility to support and advance the wide-ranging program of seismologic research and education within the $\mathrm{UCB} / \mathrm{LBL}$ community.

The natural first step in implementation was the acquisition of the imaging hardware and software in late fiscal 1982. The most attractive and highly developed of these commercial packages was available from Digicon Inc and runs on the VAX 11/780 computer. The rationale for implementing the imaging software and associated hardware as soon as pos- 
sible is to expose CCS quickly to a wide variety of seismologic applications. The advantages inherent in having CCS reside within LBL's active Computer Center become clear in the context of retaining state-of-the-art capabilities.

Funding began with LBL seed money, bringing $\mathrm{CCS}$ to an initial computational capability with space and a management structure in the Summer of 1982. Full capability was reached in fiscal 1983 with funds from the Department of Energy, Oflice of Basic Energy Sciences (DOE/OBES). Creation of CCS within the existing LBL structure, using Computer Center hardware and support systems, offered major economical advantages. Duplication of such a facility, independent of the complement of research scientists at Berkeley, would cost many times the amount invested to date.

As CCS develops, there should emerge an unmatched effort in the broadest development of new applications and approaches to computation in seismology. The secret lies in the mix of applied and theoretical seismologists working at UCB/LBL and in the promise of cooperation with other institutions and with visiting scientists attracted to $\mathrm{CCS}$. The potential exists for a research facility that could surpass in breadth of contributions anything existing today.

The first year of operation has been devoted mainly to software development and utilization of the imaging package. The principal areas of research with our specific application are

1. Deep reflection profiling techniques

San Andreas Fault

Charleston fault zone

2. Refection profiling in thermal regions

Basin and Range (northern Nevada)

California Coast Range (The Geysers)

Salton Trough (Cerro Prieto)

3. Source mechanism studies

Long Valley microearthquake activity

The Geysers seismic activity

Coalinga earthquake sequence

Acoustic emission studies of thermally disturbed zones

Characterization of underground nuclear explosions

4. Waye propagation

Seismic tomography

Cross-nole seismic studies in basalt
Scattering and attenuation of seismic waves

Seismic polarization and signal enhancement

Surface wave studies across the Tibetan Plateau

5. Data base studies

Satellite data center for the DARPA (Defense Advanced Research and Projects Administration) Center for Seismic Studies

Regional data center for USGS Office of Global Seismology

6. Special studies

Time series analysis of Long Valley gravity data

Ground motion studies for LBL's proposed Center for Advanced Materials (CAM) and for the Stanford Linear Accelerator (SLAC) projects

In addition to the above research areas, CCS is interacting with Lawrence Livermore National Laboratory (LLNL) to provide facilities for reflection profiling processing for data acquired at the Nevada Test Site (NTS) and to offer CCS as a host for the development of a VAX version of the LLNL seismic analysis code (SAC). CCS also became a member of the California Consortium for Crustal Studies (CALCRUST) initiative to the National Science Foundation for the processing, analysis, and archiving of reflection data in active western tectonic regions. In total, there is routine usage by seven graduate students, two postdoctoral research scientists, four faculty/LBL staff scientists and five undergraduates in geophysics or computer sciences. Visiting scientists came from LLNL(3), USGS, the State Seismological Bureau of the People's Republic of China, University of Washington, Penn State, and Cal State, Northridge. The average length of visit was 3 months.

Overall, CCS has become a viable research center with constantly improving hardware and software facilities. Major new projects inc'ude a comprehensive research program for use in modern seismic techniques to study the hydraulic fracturing in boreholes with the goal of defining the fracture extent and characterizing the mechanism of hydrofracturing itself. Support for this hydraulic fracturing research is coming from Oak Ridge National Laboratory, the Gas Research Institute, the Office of Nuclear Waste lsolation, the USGS, and the AEC of Canada. The program includes field measurement, laboratory stress measurement, and, of course, data analysis and processing. 
ACOUSTIC EMISSION AND WAVE PROPAGATION MONITORING AT THE SPENT FUEL TEST-CLIMAX

\author{
E.L. Majer and T.V. MCEvilly
}

Since 1978, the U.S. Department of Energy has been conducting tests under the technical direction of Lawrence Livermore National Laboratory (LLNL) to demonstrate the feasibility of storage and retrieval of spent nuclear fuel from a deep geologic environment. Of the many objectives of the test, one was to consider several technical issues relating to the geologic characterization of granite as a medium of storage. In April and May of 1980, spent fuel canisters and heaters were emplaced in the Climax Stock quartz monzonite unit. The purpose of using heaters as well as spent fuel was to compare the effects of heat and heat plus radiation on the granite. The Spent Fuel Test-Climax (SFT-C) offered a unique ofportunity to study in situ repository conditions. In addition to the experiment described here, concurrent experiments in thermal, stress, displacement, and hydrologic characterization were also being carried out. At the conclusion of the 3-year storage period, the fuel was removed, heaters turned off, and an extensive post-test drilling program initiated to determine rock properties and stress levels (Ballou et al., 1982). For a detailed description of the (SFT-C), the reader is referred to Ramspott et al. (1979). Reported here are the results and conclusions of over $3-1 / 2$ years of continuous monitoring of acoustic emission and wave propagation characteristics $(P$. and $S$-waves) before, during, and after the storage of the spent fuel. Although the experimental procedures will be briefly discussed, a detailed description and conceptual design with preliminary results can be found in Majer et al. (1988!, 1982) and Ramspott et al. (1979).

Figure 1 is a layout of the experimental facility, showing the location of the spent fuel assemblies and heaters some $420 \mathrm{~m}$ below the surface in quartz monzonite. The center drift is the storage area for a linear array of 11 spent fuel assemblies and 6 heaters. The experiment provides simulation within a 15- by $15-\mathrm{m}$ area of the first 5 years of operation of a large panel of a full-scale repository. The thermal output of the waste canisters and heaters in the center drift started at $1.5 \mathrm{~kW}$ (2.5-year-old spent fuel assemblies). The two side drifts eath contain 10 smaller heaters on 6-meter cenlers. Rock tempera- ture, stresses, and displacement are monitored continuously with 430 thermocouples, 18 (vibrating wire) stress meters, 116 extensometers, 34 convergence wire extensometers, and 21 fracture monitors.

\section{RESULTS}

\section{Acoustic Emission Monitoring}

Continuous monitoring or" acoustic emission/ microseismic (AE/MS) activity began on January 11, 1980, and continued until August 10, 1983. The summary of occurrence rates is shown in Fig. 2 vs temperature at several points within the rock mass. Figure 1 shows the location of the highest quality events $( \pm 0.5 \mathrm{~m})$ in plan view and in cross section. These events were relocated using the raw data output from the automated seismic processor (ASP) and using corrections obtained from "calibration hits" at various points within the array. As can be seen in Fig. 2, several peaks of activity are superimposed upon a background level of 2-3 events per week. Cultural noise, such as construction, canister handling, and drilling, would produce false events. These events would of course not be included as "real" events, and could be identificd as unreal events by their location and wave shape (six channels were monitored with a strip chart recorder) and time of occurrence.

The peaks of activity during the heating phase can be divided into two different types of events. The first type of event is one that has characteristics similar to what one would observe in a microearthquake: clear $P$ - and $S$-wave arrivals with impulsive onsets and b-values near 1. The second type is one that has a poorly defined $S$-wave and an emergent onset of the $P$-wave and occurs in swarms over a restricted magnitude range. Although one may infer that attenuation may be parly responsible for the difference between these two wave types, the type 2 events are in general of larger magnilude and of Jower frequency content, with travel path distances equal to those of type 1 events. Each peak in activity can be correlated with a physical phenomenon.

Examination of the overall AE activity leaves no doubt that the heating and cooling affect the rate of activity. It may also be correct to say that the region of AE aclivity may map changes in the stress field to some extent. The peak temperature at a distance of $36 \mathrm{~cm}$ within the rock was only $65-70^{\circ} \mathrm{C}$. Most laboratory experiments indicate that $\mathrm{AE}$ activity does not occur until at least $70^{\circ} \mathrm{C}$ (Yong and Wang, 1980). 

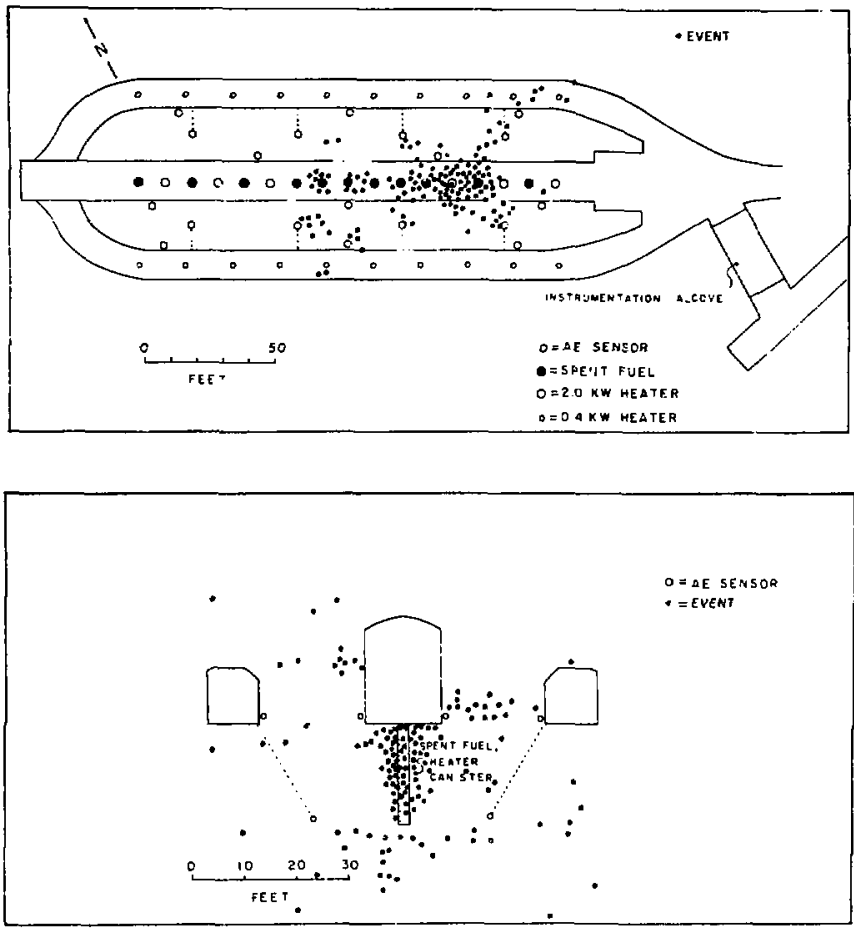

Figure 1. Experimental layout of the Climax $A E$ monitoring facilities and the location of the signific:nt AE events $( \pm 0.5 \mathrm{~m})$ in plan and cross section; each is a composite drawing. The thermal outputs of the heaters are adjusted to the thermal outputs of the spent fuel. The dotted lines on the AE sensors indicate the "deep" sensors. [Top, XBL 831]-2330; Bottom, XBL 8311-2331]

Sowever, the extra stress from the thermal load may be enough to produce $A E$ activity in an area that is alreedy affected by tectonic and excavation-induced stresses. The water saturation (or lack of it) would suggest that there is little possibility that increased pore pressure will induce fracturing. It appears that the AE activity occurs on planes of pre-existing weakness or fracturing. There were periods of relatively little or no activity near the middle of the experiment, when the temperature in the rock had peaked and reached a state of relative equilibrium. tcivity began to increase when cool-down started (i.e. when the peak temperature was reached within the rock and the temperature started to decreas., even though the canisters and heaters were still emplaced). When the heaters were turned off and the spent fuel removed, a significant increase in the activity occurred, mainly in the eastern half of the test region, but basically there was little difference in the spatial distribution of events between the heat-up and cool-down phases. The stress drops also followed the same patterns luring the heat-up and ccol-down periods.

\section{Wave Propagation}

On Day 293, 1980, a piezoelectric pulser was installed in the bottom of hole AE13. This transducer was pulsed daily with a $1.6-\mathrm{kV}, 3-\mu \mathrm{s}$ rise time power source to produce a "calibration" source for 


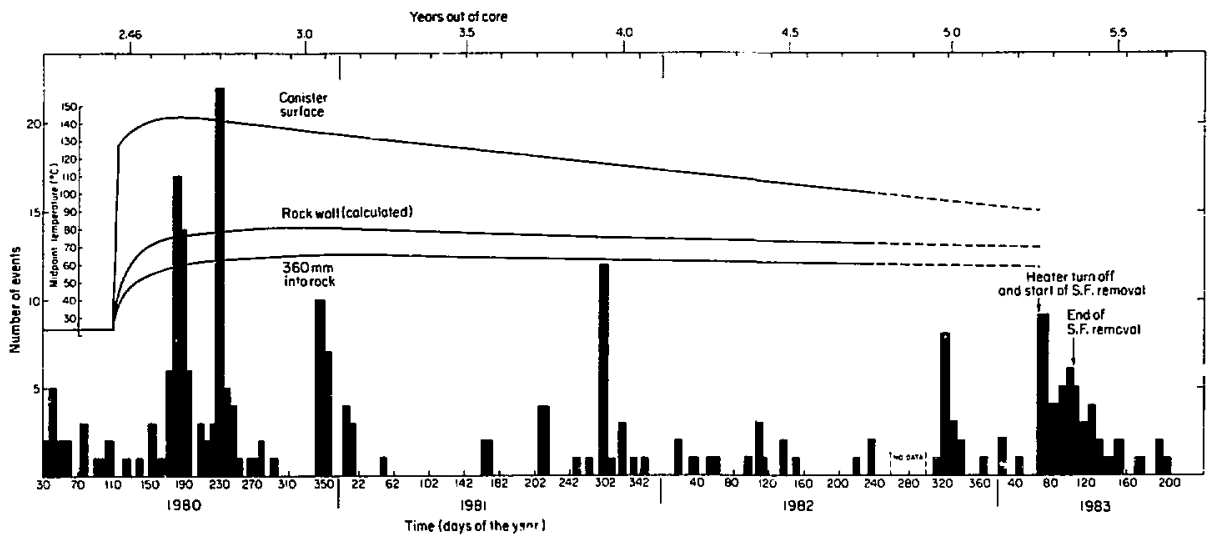

Figure 2. Number of events per week ys time. Also shown is the temperature at various points on the rock vs time. [XBL 8310-2254]

monitoring the amplitudes and arrival times at the various $A E$ sensors throughout the repository.

Shown in Fig. 3 are the results of the amplitude hanges over time of the $P$ - and $S$-waves monitored at several sites throughout the repository. Cnly the beginning and end of the experiment are shown; there was little change in 1982 . Because little change was noted on a daily basis, measurements were made weekly.

As can be seen in Fig. 3, there was little systematic change in the $P$-wave amplitude relative to : refererce value over the length of the experiment. Because of recording variations and possible sourcereceiver coupling changes, it was felt that a ratio would give a more reliable measure of change than the absolute amplitude. Hole AEI 9 was selected as the reference station because of its proximity to the source and its position relative to the heated zone. It would have been optimal to place the reference path completely outside of the heated zone, but since the heated zone was relatively large and the paths desired went througin the canister region as well as the heater regions, to do so would have required large path lengths. As it was, the path lengths being used were almost maximum for the frequencies involved $(5-10 \mathrm{kHz})$, and the use of lower frequencies would have meant forfeiting the resolution necessary for the experiment. Although it was not known at the beginning of the experiment, the fracture content of the rock mass around the experiment varies to a large exterit, so that the use of large path lengths would have irtrodiced stiil another variable to contend with. If the $P$-wave attenuation had changed throughout time, then the change musi have been uniform at all st:ations, which is unlikely, or so small that it could not be reliably measured with the system. Travel paths $\mathrm{AE} 13$ to $\mathrm{AE} 5, \mathrm{AE} 13$ to $\mathrm{AE2}$, and $A E 13$ to AF2 experienced the greatest temperature change, whereas $A E 13$ to $A E 19$ and $A E 13$ to AE1 2 experienced the least amount of change. There does not, however, seem to be any significant difference in $P$-wave amplitude.

To determina the effect of a sudden temperature change at heater turn-off and waste retrieval, another sensor wes placed approximately $6 \mathrm{ft}$ below the surface of the canister drift floor inside CEH09 to monitor near-field effects of AE activity and to monitor wave amplitudes and arrival times. In Fig. 3, the trace marked "CD" (lowermost trace for 1983) is the result of $P$-wave amplitude monitoring during the cool-down. As can be seen, no effect was noted during the cool-down, which lends further support to the suspicion that $P$-wave amplitude monitoring is insensitive at these temperatures and frequencies. It should also be noted that there was no change in the velocity along this path $( \pm 10 \mu \mathrm{s})$.

Also measured were the $S$-wave amplitudes at a few selected stations where the $S$-wave arrivals were very good. Ratios of $S$-wave amplitude to $P$-wave amplitude were measured at these stations to elim- 

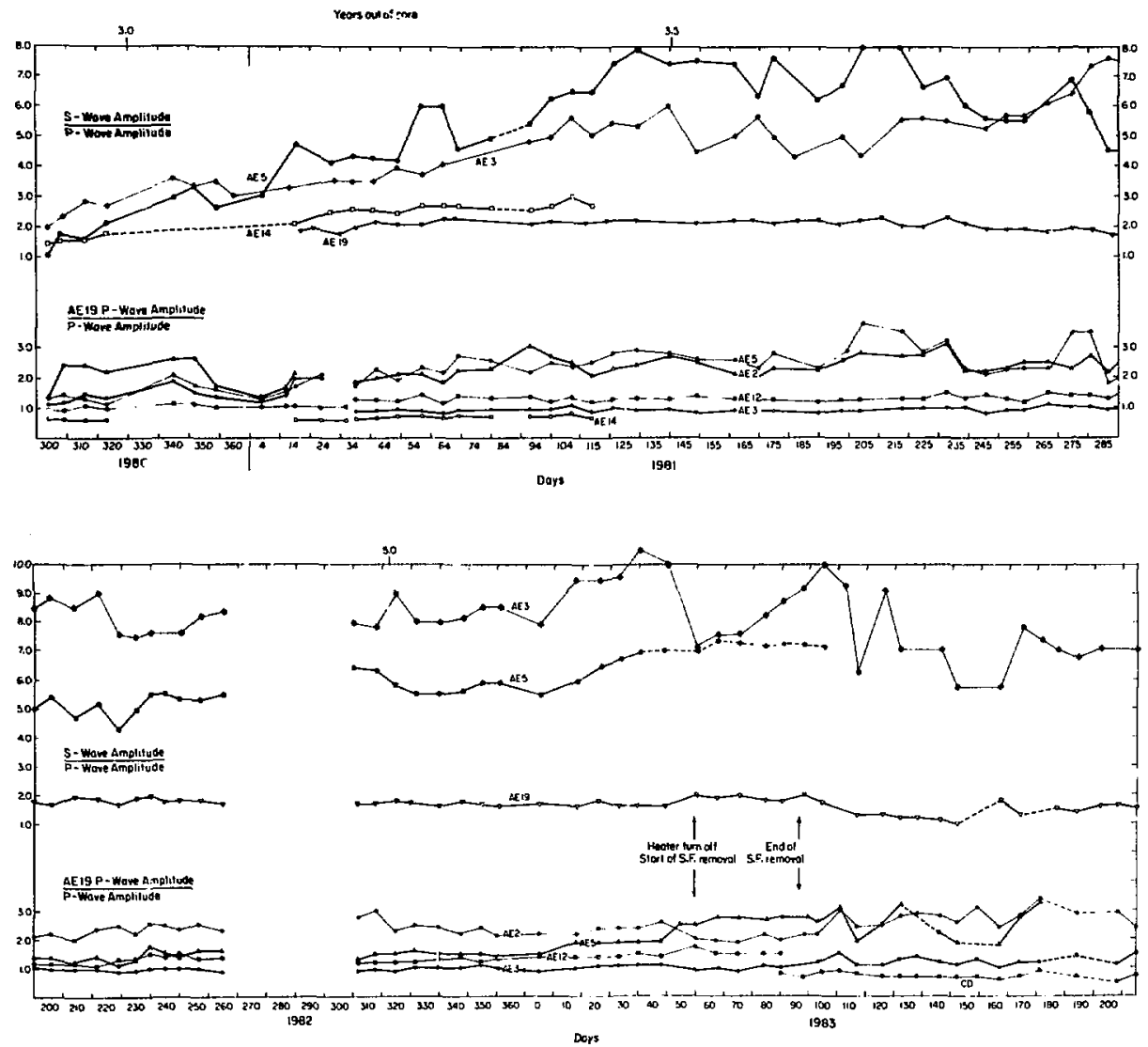

Figure 3. $P$-and $S / P$ wave amplitude versus time for various wave paths during the experiment. [Top, XBL 816-3120A; Bottom, XBL 831-1638]

inate source and receiver effects. It was felt that, over time, such ratios would provide a more reliable measure of wave amplitude change than ratios between stations. As can be seen from Fig. 3, there was a more consistent urend to the data. For wave paths through the more heated areas, AES and AE3, there was a significant change in $S$-wave amplitude relative to the $P$-wave amplitude compared with AE19. As the experiment progressed, the amplitudes tended to stabilize. Cool-down resulted in a signifi- cant change in the ratio of $S$-wave to $P$-wave at AE3 but not at AE5. It should be noted that by this time the P-wave amplitude at AE5 from the piezoelectric pulser had deteriorated to such an extent that it could not be considered reliable. Also of note is the apparent permanent change in the $P$ - and $S$-wave transmitting properties of the rock; the $S$ - to $P$-wave ratios have not returnted to their oripinal values, probably because the rock is still above is original temperature. On the other hand, it seems reasonable 
that the rock has undergone sc ne small-scale permanent changes in the eastern half of the canister drift, especially where the AE activity was high (i.e., the area through which the majority of travel paths passed). On the western side of the mine, where $A E$ activity was low, it was very difficult to transmit energy thro - gh the rock at any time in the experiment. Obviousily this area is more fractured (Wilder and Yow, 1981), accounting for its absorbent nature, and not subject to discrete energy release through AE.

In addition, the arrival times and amplitudes were record. $d$. The rate of digitization was 100,000 samples $/ \mathrm{s}$, or $10 \mu \mathrm{s}$. The total travel time for the largest path was over $3 \mathrm{~ms}$. Thus we could resolve velocity changes to better than $1 \%$. No charges were observed in either the $P$ - or $S$-wave velocities at any time during the total monitoring period.

\section{CONCLUSIONS AND \\ RECOMMENDATIONS}

When correlated with the available stress, temperature, and displacement data, acoustic emission data indicate that even within a small area there is a large variation in rock strength and ability to deform under the thermal load. In general, $A E$ activit: seems to indicate that some zones have higher stress concentrations because of their greater over all rock strength. Moreover, $P$ - and $S$-waves are less attenuated in these zones than in "aseismic" areas that are under the same thermal load.

Monitoring of $P$ - and $S$-waves revealed that at the scales and temperatures involved (several centimeters in wavelength), there is no variation in wave velocity. However, amplitude monitoring did indicate measureable changes in the $S$ - to $P$-wave amplitude ratios due to crack closure, dewatering of the rock, or both. If future studies are undertak $u$, it is recommended that

1. Monitoring be done before, during, and after any thermal disturbances.

2. Stations be spacec several meters apart.

3. Resolution be about $I \mu s$ if velocity variation is monitored.

4. Total processing be carried out, since the event count or occurrence rate is not adequate at the scales used (fault plane solutions, moment tensor analysis, and source mechanism should be related to the available stress and displacement measurements). Such analysis was attempted, but too few events occurred at the scales used (tens of meters) to obtain any conclusive results.
5. A smaller-scale array be emplaced once zones of $\dot{A E}$ have been determined so that information can be collected for comprehensive data analysis.

6. A larger number of sources be used for controlled velocity and amplitude monitoring.

In general, seismic measurements can provide useful information on the overall stability and integrity of a rock mass subjected to stress changes from either mining activities or thermal loads. In the subject experimen:, the changes in rock properties were small enough not to cause measureable anomalies in $P$ - or $S$-wave propagation velocities or $P$-wave amplitudes. Changes were noted in $S / P$ wave amplitude ratios, indicating that rock properties did change to some extent. The AE data also indicate very small scale failure or slip, source dimensions of several $\mathrm{cm}$ with displacements of $0.01-0.05 \mathrm{~mm} / \mathrm{event}$, but no damaging or catastrophic failure. At this time, it is not known if the areas of $\mathrm{AE}$ and waveform anomalies are characterized by increased permeability. The methods employed at the Climax experiment are useful for monitoring potential failure or detecting potential zones of increased permeability due to increased fracturing or crack opening, but not for fine-scale crack delineation.

\section{REFERENCES}

Ballou, L.B., Patrick, W.C., Montan, D.N., and Butkovich, T.R., 1982. Test completion plan for spent fuel test-Climax, Nevada Test Site. Lawrence Livermore National Laboratory, UCRL-53367.

Majer, E.L., McE.illy, T.V., and King. M.S., 1981. Monitoring an underground repository with modern seismological methods. International Jourral of Rock Mechanics and Mining Science, v. 18, p. 517-527.

Majer, E.L., King, M.S., anỏ McEvilly, T.V., 1982. Monitoring acoustic emissions and wave propagation characteristics at the Climax Stock. In Proceedings, Third Conference on Acoustic Emission/Microseismic Activity in Geologic Structures and Material. Clausthal-Zellerbach, Clausthal, West Germany, Transtech Publicativns.

Ramspott, L.D., Ballou, L.B., Carison, R.C., Montan, D.N., Butkovich, T.R., Duncan, J.E., Patric, W.C., Wilder, D.G., Brough, W.G., and Mayr, M.C., 1979. Technical concept for a test for geologic storage of spent reactor fuel in the Climax graniti. Nevada Test Site. Lawrence Livermore National Laboratory. UCRL-52796. 
Wilder, D.G., and Yow, J.L., Jr., 1981. Fracture mapping at thie Spent Fuel Test-Climax. Lawrence Livermore National Laboratory, UCRL-53201.

\section{MONITORING \\ HYDROFRACTURES USING SEISMIC TECHNIQUES}

\author{
E. L. Majer
}

An important problem in reservoir stimulation or in situ stress measurement is the determination of the direction and extent of the fractures generated during hydrofracture operations. The petroleum industry lacks reliable ieal-time information on the success of the hydrofracture "treatment"; i.e., how much propant penetrates the formation and by what path. It is often assumed that the fluid carrying the propant (be it a gel or a liquid) actually follows the fracture. However, we know that the propant does not always follow the "carrier." Often the formation is so tight that the propant is left behind in the larger fractures while the carrier follows unknown paths.

Another area where an understanding of the hydrofracture process is necessary is in the disposal of hazardous wastes. If these waste products, whether they be nuclear or toxic, are to be disposed of in underground environments, then it is necessary to understand the state of stress. Hydrofracturing has been proposed to measure the direction and amount of the principal stresses. Despite the wide use of the hydrofracturing technique for this purpose, several aspects critical to the geometrical interpretation of results have remained unresolved. Two of the most apparent of these are the questions of (1) the vertical and horizontal extent of the fracture, and (2) the analysis of the test when the borehole is oblique to the principal stress directions.

Surface techniques for remote monitoring of fractures are usually adversely affected by noise or attenuation of signal. Second-order effects such as tilt or the change in the magnetic field (due to the use of a propant) can be monitored only in situations where the fracture is close to the surface. In-hole fracture location methods include either impression packers or televiewing equipment, which are limited because they detect the fracture only at the walls of the well.
Yong, C., and Wang, C., 1980. Acoustic emission in thermal cracking processes of Westerly Granite. Unpublished repor, University of California, Berkeley.

Seismic methods offer a more direct approach. For years earthquake seismologists have been concemed with characterizing fractures in rock. The goal has been to specify the dynamic source properties: fracture orientation, dimensions, history, and stress distribution. No assumptions are made on the orientation or type of source. In the case of an earthquake, the "fracture" is a fault.

The frequency content and amplitude of the seismic signals given off by a fracture depend upon the source dimensions, nature and rate of stress release, amount of displacement, and rock properties. Theoretically, all of the information necessary to determine the static properties of the individual fractures (dimensions and orientation) is contained in a wide-band recording of the seismic waves made by a single three-component (one vertical and two hiorizontal) seismometer. Such factors as attenuation and the imperfection of velocity models, however, make it necessary that additional data be obtained at varying azimuths and distances. That is, given the variation of ground displacement (radiation pattern) produced by a seismic source and a reasonable estimate of the propagation effects, the source of the seismic disturbance can be decomposed into components such as shear and tension.

Using seismic methods to detect a hydrofracture is not a new idea. Because the seismic signals that radiate from fractures are first-order effects, it seems reasonable to monitor those signals. Most efforts in the past have been to place single sensors either on the surface or in a nearby well to detect the $P$ and/or $S$-waves produced as the fractures form. In some instances, sensors were placed at the top of the well or on the casing. The results of these experiments were mixed at best. Problems with sensors (inadequate bandwidth or wrong natural frequency), large amounts of noise from pumping operations, and severely attenuated signals have caused most investigators to abandon this technique. More sophisticated seismic techniques have been tried. Power et al. (1976) described an experiment in which a large array of instruments was placed around a well that was being fractured. The results were quite encouraging, considering the depth of fracture $(9000$ ft). Such features as azimuth, length, and symmetry of fracture were inferred. 
Our interest is to measure the seismic waves created by the hydrofracture with an array of instruments in order to locate the individual fractures or seismic sources (whose sum makes up the entire hydrofracture) and trace their growth with time. In addition to the standard data reduction techniques employed in hydrofracture measurements, the seismic results will be correlated with time and pressure records to provide a better understanding of the actual source mechanisms (shear, tensile) involved at various times within the process. The data are analyzed for different types of events. Previous experience has shown us that the shear events do not necessarily occur as a result of the same processes as the tensional events, nor do they have the same seismic signature. Moreover, it may be possible that the fracture is acting as a continuous emitter of seismic energy, thus allowing utilization of the large body of analysis techniques available in seismic reflection technology.

For the past several years, Lawrence Berkeley Laboratory ( $\mathrm{LBL}$ ) has made various attempts to characterize and detect hydrofractures using seismic methods at many different scales. Our first attempt was made in 1980 during a massive hydrofracture at the East Mesa geothermal field. Four digital tape recorders were set out around the hydrofracture, each with a single $4.5-\mathrm{Hz}$ geophone attached. Nothing was detected. It was clear that more sophisticated attempts to detect the fracture were necessary.

The second attempt was at a smaller scale. The experiment was carried out in the Stripa granite. To answer several basic questions, an array of accelerometers was placed in pre-existing holes in the vicinity of the hydrofracture (Majer and McEvilly, 1982). Sought were the answers to such questions as these:

1. Are detectable acoustic emissions ( $A E$ ) associated with the hydrofracturing process?

2. If so, how large are they, what is the frequency content of the events, and when do they occur relative to pressurization, breakdown, and future propagation?

3. Does the AE activity occur in individual discrete events or in inseparable swarms?

Given that these questions were answered in the affirmative, the next question to ask is whether the signal-to-noise ratio is sufficient to apply standard seismological techniques to the processing of the data? Although the Stripa experiment was not optimally designed and equipment problems prevented adequate data recording, several significant results should be noted:
1. Detectable, discrete events were recorded awring the hydrofracture process.

2. All events recorded were similar in nature, i.e., impulsive, with clearly defined $P$ - and $S$-waves, implying shear failure, although the equipment problems prevented a fair assessment of the ratio of shear events to tensile events.

3. The detectable AE activity occurred during the fracture-driving process rather than before or during breakdown, although this apparent lack of activity may have been the result of detection problems due to the use of a faulty tape recorder.

4. The events were separated far enough in time to allow each one to be treated individually, so that standard seismic techniques for determining the location, orientation, and dimension of the "fault plane," as well as source parameter determination, could be applied.

5. To within a reasonable doubt, the hydrofracture generated was not symmetric, but its azimuth did correspond to impression packer results.

As a next step toward understanding the fracture process, several hydrofractures in a salt block were monitored in the lab with an array of AE sensors to determine source mechanisms, rate of activity, and location relative to principal stress directions. We found that all events are tensile, that the crack follows the direction one would expect from the maximum and minimum stress directions, and that the rate of activity is a function of pumping rate.

Ideally, what is needed is a seismic discriminant that would determine the mechanism that is generating the seismic wave. Depending on the partitioning of energy from the hydrofracture process, and how much of this energy is spent in breaking the rock, the rate and manner of the energy release will be reflected in the type of seismic waves generated. Such factors as rock strength, permeability, porosity, pressure gradients, fluid compressibility, and volume will all affect the rate of energy release and the form of seismic activity. How these factors all interact to form the hydrofracture, and to what extent they are reflected in the seismic activity, is the subject of these invertigations.

Assuming passive monitoring, there are two basic approaches to detecting the hydrofracture. The first and most straightforward is utilizing the discrete events associated with the hydrofracture process. If conventional earthquake analysis techniques were used, these events could then be treated as "nanoearthquakes," with each one being processed for such parameters as location, orientation, and dimensions of the "fault plane" and principal stress 
directions. The locus of these results would then define the path of the hydrofracture in space and time. The second approach is to treat the hydrofracture as a continuous generator of seismic energy (such as a vibrator in seismic reflection surveys) and to utilize imaging techniques to trace the growth of the hydrofracture.

To address the question of detectable seismic activity, the following experinents were designed to be carried out during two separate 1000 -ft-depth hydrofractures in an actual field environment.

In the first experiment, designed for use in a tight gas sand in ccoperation with The Gas Research Institute (GRI), arrays of sensors were deployed on the strface and downhole in monitor wells drilled symmetrically around the hydrofracture hole at distances and depths of about $500 \mathrm{ft}$. Groups of geophones were used for maximum surface noise cancellation. The most economical and efficient method for data collection was to utilize high-resolution seismic reflection methods. Thus the data set was gathered with standard formats and with state-ofthe-art electronics. Having one crew collect all the data minimized the logistical and coordination problems, provided quality control, and avoided timeconsuming squipment development. It also provided a convenient format for all the imaging software available at CCS.

The purpose of the second experiment was to determine the path and characteristics of hydrofractures in tight shale formations. These shale experiments, performed in collaboration with Oak Ridge National Laboratory, are very similar to GRI's in that the objective is to gain sufficient understanding of the hydrofracturing process to make the technique applicable to other rock types and relate the fracturing processes to such factors as pumping rates and fluid viscosity. In brief, the hydrofractures will be carried out in a $1000-\mathrm{ft}$ well over a period of $1-3 \mathrm{~d}$. Approximately several hundred thousand gallons of fluid will be used. The fluid is a grout that carries low-level nuclear waste. The hydrofractures will be monitored with tilumeters and seismic arrays. LBL is responsible for designing and carrying out the seismic monitoring and relating the seismic activity (be it tensional or shear events or some combination of the two) to the physical processes involved. In addition to these geophysical studies, there will be leveling studies, complete hydrologic, lithologic, stratigraphic, structural and rock mechanic, petrologic and geochemical, and grout interaction and stability studies. The program duration is $4-5$ years. In short, the work involves detailed monitoring during a series of injections over the next several years, the comprehensive characterization of the disposal site, an assessment of the physical processes that control the fracturing, an evaluation of various grout mixtures, and the application of the results to other sites for the disposal of hazardous wastes (chemical as well as nuclear).

\section{REFERENCES}

Majer, E.L., and McEvilly, T.V., 1982. The Stripa acoustic emission experiment. Proceedings of the Workshop on hydraulic Fracturing for Stress Measurements. JSGS Open File Report 821075 , p. 569-582.

Paulsson, B.N.P., 1983. Seism: Velocities and Attenuation in a Heated Underground Repository (Ph.D. dissertation). Department of Materials Science and Mineral Engineering, University of California, Berkeley.

Power, D.V., Shuster, C.L., Hay, R., and Twombly, J., 1976. Detection of hydraulic fracture orientation and dimensions in cased wells. Journal of Petroleum Technology, p. 1116-1124.

Smith, M.B., Holman, G.B., Fast, C.R., and Covlin, R.J., 1978. The azimuth of deep, penetrating fractures in the Wattenberg field. Journal of Petroleum Technology, p. 185-193. 
DETAILED

MICROEARTHQUAKE STUDIES

AT LONG VALLEY CALDERA, CALIFORNIA

\section{J.E. Peterson, E. L. Majer, and T. V. McEvilly}

Intense seismicity and substantial uplift have been recorded since 1978 in the Long Valley caldera, near the iown of Mammoth Lakes, California. This renewai of activity has prompted an unprecedented amount of field work in the area, principally because of the history of violent volcanic eruptions there, including the ejection of an estimated $600 \mathrm{~km}^{3}$ of magma some 700,000 years ago (Savage and Clark, 1982). Several of the earthquakes in the sequence recorded since 1978 have exceeded magnitude 6 , and events greater than magnitude 1 have at times been recorded at rates of about 100 per day. Uplift of about $40 \mathrm{~cm}$ has been measured in the caldera in the past 5 years. Seismicity in the area has generally decreased since the major events of 1978, although occasional bursts of swarm activity are associated with larger earthquakes in the sequence. The rate of decrease, however, predicts that activity should be substantially above normal for decades.

The concentrated source zune, the high rate of seismicity, and the possible link to magma injection make Mammoth Lakes an ideal place to apply the Automated Seismic Processor (ASP), a portable system developed at Lawrence Berkeley Laboratory and UC Berkeley (McEvilly and Majer, 1982) for realtime, in-field processing of microearthquake data. Capable of operating while unattended, the ASP processes an event for location and fault characteristics, completing a full 15 -station analysis within $40 \mathrm{~s}$. Source parameters are determined automatically by the ASP using the Fourier-transformed $P$ - and $S$ waves. The technique follows Brune $(1970,1971)$ in estimating stress drop, fault radius, and amount of slip from the corner frequency and low-frequency level of the far-field displacement spectra. The ASP then performs a linear inversion for the moment tensor components (Stump and Johnson, 1977), using as data the sign of the first motion times the normalized moments of the $P$-wave. The solution is not constrained to a double-couple source, so that any components of the source, such as tensile failure (Julian, 1983) or radial expansion, will be estimated along with the conventional double-couple parameters. The ASP generates the principal stress directions from the eigenvectors of the moment ten- sor, and these can be quite revealing of source processes in complex regions.

A reconnaissance study in the summer of 1982 prompted a more detailed investigation in the summer of 1983 in which a 12- to 15-station network was deployed with much closer spacing than is usually used in permanent monitoring networks. All stations were placed within a zone $10 \mathrm{~km}$ in diameter in 1982 and within $5-\mathrm{km}$ zones in two successive deployments in 1983, concentrating on known areas of high activity within and outside of the Long Valley caldera. The goal was the elimination of $1-$ to $3-\mathrm{km}$ bias in calculated hypocenter positions commonly seen with more sparse networks, so that seismic activity could be associated more accurately with the complex geologic structures of the caldera.

During August $10-19,1982$, the 13-station network shown as triangles in Fig. I detected and processed approximately 450 microearthquakes. Magnitudes of processed events range from -2.0 to 2.5 for the 9-day deployment period. Also shown in Fig. 1 are those locations with the lowest standard errors in time ( $\leqslant 0.5 \mathrm{~s})$, in epicenter location $(\leqslant 0.02 \mathrm{~km})$, and in focal depth $(\leqslant 2.5 \mathrm{~km}$ ); size of symbols is proportional to seismic noment, ranging from $10^{16}$ dyne-cm $\left(M_{L} \sim-1.5\right)$ to $10^{19}$ dyne-cm $\left(M_{L} \sim 2.0\right)$. Three loose clusters of activity are apparent, two within the caldera and one outside to the south. In the 4-week 1983 study, some 1400 events were located.

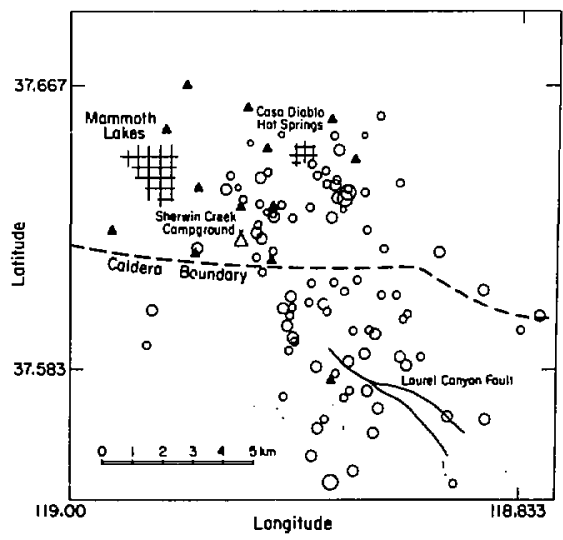

Figure 1. Earthquake locations for 1982 study. Symbol sizes are proportional to seismic moments from $10^{16}$ to 10 ${ }^{19}$. [XBL 841-9513] 
Previous analysis of Long Valley seismicity by others pointed to an ominous shallowing of earthquakes with time, indicating a possibility of rising magma. A major purpose of the 1982-1983 study was to investigate carefully the depth distribution of the earthquakes in the area in order to test the hypothesis that location bias and uncertainty-aiong with a real difference in depth among earthquakes in the various clusters of activity in and outside - could combine through a time variation in the spatial concentration of seismicity to give an apparent vertical migration of hypocenters. Examination of the 198? data indicated that this might be so. In Fig. 2 we compare $\mathrm{N}-\mathrm{S}$ cross sections showing 1982 hypocenters in the cluster south of the caldera and in the westernmost cluster within the caldera. Indeed, the two populations seem to have clearly different depth distributions. Admittedly, the precision in depths for events south of the caldera in the 1982 study was less than optimal, since most of the network was to the north, but the indicated difference is unlikely to be completely an artifact of depth bias.

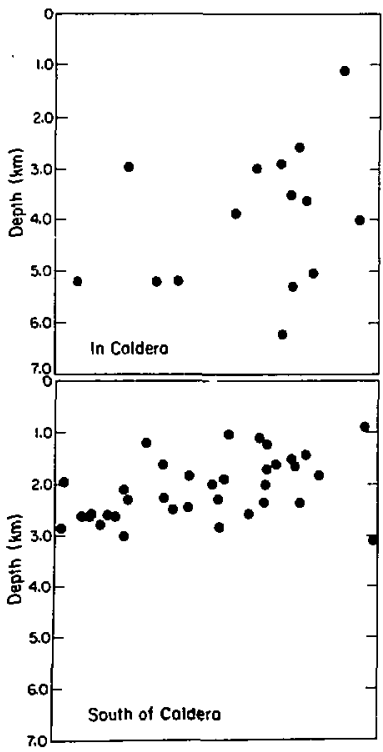

Figure 2. Projections of 1982 hypocenters onto roughly $\mathrm{N}-\mathrm{S}$ cross sections in subsets of events within the caldera (top) and south of the caldera (bottom). [XBL 841-9508]
The 1983 study was designed specifically to clarify these apparent substantial differences in source mechanisms and depth distributions inside and outside the caldera. A lowered magnitude threshold and an increased hypocenter resolution were sought to allow the investigation of possible magmatic processes related to the earthquakes. Improved accuracy also is needed in the evaluation of any prospective deep drilling site to be proposed for this area.

The 1983 experiment was done in two successive 10-day deployments (Fig. 3) of 15 and 10 stations, respectively. The first network detected and processed more than 900 events in the 1982 study area. The second network, set up to monitor activity south of the caldera, detected and processed 500 events. Difficult terrain precluded the coverage of the main activity west of the Laurel Canyon Fault, so that none of the larger events occurred within the network.

Of the events detected during the first 1983 deployment, 500 were located inside the network, and 120 of these were high-quality locations, shown in Fig. 4. During the same period, the more conventionally deployed network of the USGS and the University of Nevada, Reno (UNR), with an operating magnitude threshold of 0.8 , located 20 events within the ASP network boundaries. The ASP network has thus effectively lowered the magnitude threshold to about zero for high-quality locations and to about -0.8 for all locations. Furthermore, for the 20 USGS-UNR events, the ASP locations form a tighter cluster toward the center of the network,

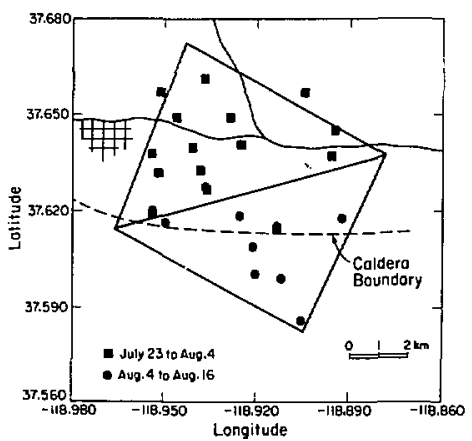

Figure 3. The two retworks used during the 1983 study. The network-enclosing triangles are used for scale in Fig. 4. [XBL 841-9510] 


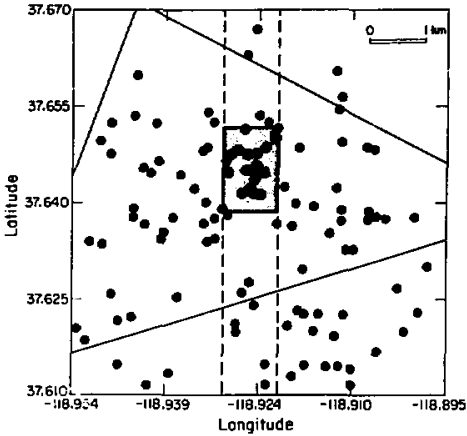

Figure 4. Quality ASP locations recorded within the caldera during the first deployment of the 1983 study (July 23-August 4). Broken lines indicate zone of cross section shown in Fig. 5; shaded rectangle encloses the cluster. Slanted lines are the triangular network boundaries shown in Fig. 3. [XBL 841-951]]

differing from USGS epicenters as much as $2 \mathrm{~km}$ (about $800 \mathrm{~m}$ on the average). For detailed studies, this difference can be very important $w$ ! in the area of interest must be pinpointed accurately for subsequent investigations (such as drilling).

The area of clustering - situated just west of Casa Diablo Hot Springs and about $1 \mathrm{~km}$ north of the clustering seen around Sherwin Creek Campground in the 1982 study-is indicated by the shaded rectangle ir Fig. 4. Figure 5, a N-S cross section through the area of clustering, shows the events within the 1$\mathrm{km}$-wide zone indicated by the broken lines in Fig. 4. The pattern in the section suggests a zone of quiescence bounded by the clustering of events to the north and at the caldera boundary. The depths gradually shallow between these bounds from about 5 $\mathrm{km}$ to $1 \mathrm{~km}$ atop the nonseismic area. The absence of seismic activity in this area may indicate that material is flowing under stress rather than fracturing. It is tempting to attribute the absence of activity to high temperatures.

The horizontal projections of the tension axes for the better quality solutions from the 1982 study show a pattern of NW-SE tension within the caldera, contrasting with $\mathrm{E}-\mathrm{W}$ or $\mathrm{NE}-\mathrm{SW}$ tension south of the caldera, which is more clearly representative of the regional tectonic stress field. For the 1983 data, the intermediate stress axes are oriented largely normal to the aseismic zone, indicating that the rock is fracturing radially away from this zone. The pressure axes are generally parallel to the quies-

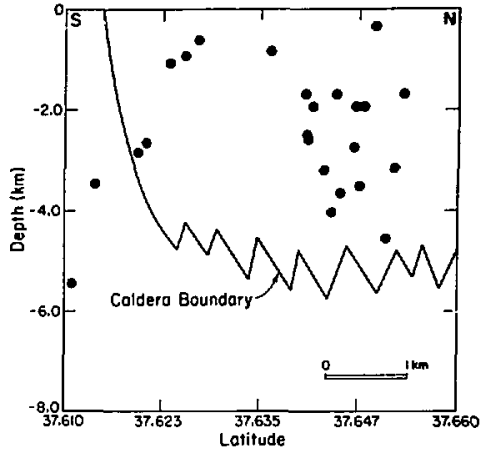

Figure 5. Cross section of 1983 events within the caldera and bounded by the broken lines in Fig. 4. [XBL 8419512]

cent zone, and the tension axes are aligned more nearly $E-W$, corresponding to the regional tension. This is consistent with the expansion of the aseismic zone, aithough the data are still sparse. One to two months of monitoring should sharpen the picture substantially at this level of detection.

There are two advantages to conducting an investigation of the kind described here. First, only one person is required to manage the entire opera. tion of a 15-station seismic network, incliding the detection of hundreds of events per day, discriminating against noise and poorer quality arrivals, selecting the best events, and processing them with sophisticated computations that would normally be used by seismologists in a laboratory environment. Second, the analysis can be done in real time. All results are available in less than $40 \mathrm{~s}$ after the first $P$-wave detection of an event, so that a truly real-time monitoring system for a significant earthquake series is available. This can be particularly significant when the monitoring program is addressing a problem of substantial geologic hazard and action may be required on relatively short warning. All of the parameter data, arrival times, polarities, amplitudes, qualities, and Fourier spectral data are written to tape cartridge (about 500 events per cartridge) for later review and reanalysis, as desired. In addition, the operator in the field can play back and review the full data set from cartridge, if desired, although the salient location and moment data are printed out in very abbreviated form during real-time operation.

The 1983 study shows that a real-time seismic processor may lower the magnitude threshold to $M_{L}$ 
$<0$ using a dense network with $1-\mathrm{km}$ spacing. Taken with the improved resolution of locating hypocenters, the ASP proves a useful tool in detailed

The Mammoth Lakes hypocenters show an area of quiescence surrounded by rather high seismicity. The source parameters of these events have not yet been fully analyzed, but are generally consistent with an intruding body that may' flow when stressed. Of course, other models may fit the data.

Future studies should utilize the ASP system for a longer period to determine any temporal migration of the hypocenters and to better determine the stress field in the region of high seismic activity.

\section{REFERENCES}

Brune, J.N., 1970. Tectonic stress and the spectra of seismic shear waves from earthquakes. Journal studies of seismically active regions.

of Geophysical Research, v. 75, p. 4997-5009.

Brune, J.N., 1971. Correction (to Brune, 1970). Journal of Geophysical Research, v. 76, p. 5002.

Julian, B., 1983. Evidence for dike intrusion earthquake mechanisms near Long Valley caldera, California. Nature, v. 303, p. 323.

McEvilly, T.V., and Majer, E.L., 1982. ASP: An automated seismic processor for microearthquake networks. Bulletin of the Seismological Society of America, v. 72, p. 303-325.

Savage, J.C., and Clark, M.M., 1982. Magmatic resurgence in Long Valley caldera, California. Science, v. 217, p. 531-532.

Stump, B., and Johnson, L.R., 1977. The determination of source properties by the linear inversion of seismograms. Bulletin of the Seismological Society of America, v. $6 z$, p. $1489-1502$.

genic zonss and magmatic belts, platforms, and (2) Precambrian shields and platforms. All six types are used to classify the epicenter, station, and turning points of a ray path.

Figure 1 shows a sample of the raw data consisting of a travel-time curve for the distance interval $10-30 \mathrm{deg}$, reduced by a slowness of $8 \mathrm{~s} / \mathrm{deg}$, for rays that bottom below the continental tectonic region

Tau confidence intervals were calculated from International Seismological Centre (ISC) $F$-wave travel-time data, with epicenter, station, and turning point of the ray paths classified according to the global tectonic regionalization of Jordan (1981). The tau method of analyzing travel-time data has the potential for providing a statistical characterization of lateral variations in the velocity structure of the earth. Significant differences in the tau data can be directly inverted to yield velocity differences as a function of depth.

A total of 62,500 paths for source depths less than $70 \mathrm{~km}$ was used for the period February 1971 through January 1972. Travel time and distance were corrected for ellipticity and source focal depth.

The global tectonic regionalization of Jordan (1981) consists of three types of oceanic and three types of continental regions. The oceanic regions are defined by equal increments in the square root of crustal age (0-25 m.y., 25-100 m.y., and $<100$ m.y.). The regionalization of the continents is based on the generalized tectonic behavior of the continental crust during the Phanerozic. The three types of continental regivins recognized are (1) oro-

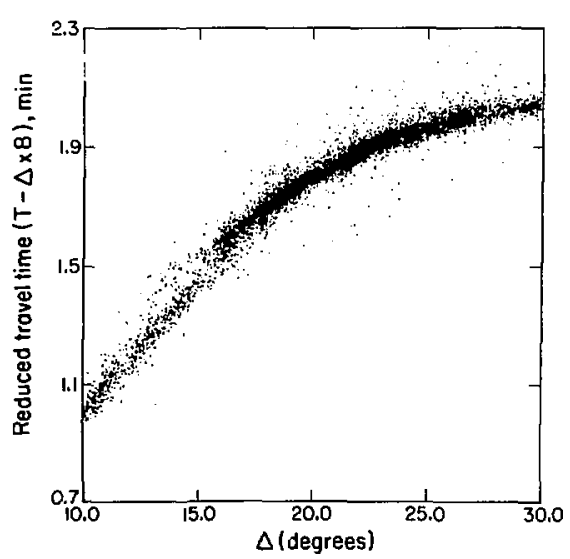

Figare 1. Reduced travel-time curve for ray paths bottoming below youngest continental tectonic regions. [XBL 841.9571] 
that corresponds to orogenic zones and magmatic belts and which covers $22 \%$ of the earth's surface area. Shown in the figure are 9163 points with a standard deviation of a couple of seconds. The distance range $15-25 \mathrm{deg}$, where there is a higher density of readings, is where most standard models of the upper mantle have triplications. However, since ISC gives only first arrivals, one cannot get an entire tau curve for the upper mantle.

The need to determine the depth at which the variations appear led to the initial classification of the ray paths according to their turning point. This was achieved by projecting the turning-point coordinate pair onto the surface of the earth and simply assigning to it the corresponding tectonic region. This admittedly pushes the applicability of the global regionalization, but is an initial step in the classification of the ray paths while providing for six independent data sets. It also addresses the question of thc maximum extent in depth of the tectonic regions. Furthermore, to allow comparison of the six sets of tau confidence intervals, to constrain erratic behavior, and to ensure a unifors: sampling, weighting according to the fractional surface area represented by the regions of the epicenter and sta-

\section{SOURCE PARAMETERS OF COALINGA AFTERSHOCKS FROM A UC BERKELEY TEMPORARY DIGITAL ARRAY}

\section{D.R. U'Connell and P.E. Murtha*}

The Coalinga earthquake $\left(M_{L}=6.7\right.$, UCB) of May 2, 1983, marks the beginning of a sequence of earthquakes that occurred along at least two faults in the vicinity of Coalinga, California. Fault rupture associated with the June 11, 1983, earthquake $\left(M_{L}=5.1, \mathrm{UCB}\right)$ was observed approximately 15 $\mathrm{km}$ west of the epicenter of the main shock (McJunkin and Hart, 1983). surface expressions indicate that faulting resulted from reverse motion on a steeply east dipping fault. No surface expression of rupture has been found for the main shock (Clark et al., 1983). In this article, we discuss the type of faulting

* Seismographic Station, Department of Geology and Geophysics, University of Califomia. Berkeley (UCB). tion was undertaken.

Using such a weighting procedure, tau confidence intervals were calculated at the $99.9 \%$ level. From the six independent calculations, a weighted mean is obtained and residuals determined. The 29 lower mantle $P$-delta intervals are taken from the work of Lee (1981), and work is continuing to cevelop intervals for the upper mantle for each of the six regions.

Finally, the approach adopted here will detect lateral variations only if they are systematic and spread over large areas. While current work indicates interesting problems, no preliminary results are available at this time.

\section{REFERENCES}

Jordan, T.H., 1981. Global tectonic regionalization for seismological data analysis. Bulletin of the Seismological Society of America, v. 71, no. 4, p. 1131-1141.

Lee, R.C., 1981. Constraints on Seismic Velocity in the Earth's Mantle (Ph.D. dissertation). Department of Geology and Geophysics, University of California, Berkeley.

of the aftershocks and their spectral source parameters. The sequence provides an excellent opportunity to study earthquake sources using near-field recordin: : of strong ground motion.

Eleven strong-motion stations were occupied from 15 hours UTC May 3, 1983, to 05 hours UTC May 8, 1983, each consisting of a three-component force-balance accelerometer recording on a 12-bit digital event recorder. Station locations are shown as triangles in Fig. 2(a,d,g).

On May 18, 1983, the same sites were reoccupied to record four USGS explosions along an eastwest refraction line near Coalinga. Velocity transducers consisting of a three-component package of 4.5-Hz geophones were used instead of accelerometers to provide a better signal-to-noise ratio for these smaller events. Forty-three earthquakes ranging in magnitude from $M_{L} \sim 1$ to $M_{L}=4.8$ were recorded at four or more stations during the two recording periods.

\section{VELOCITY MODEL}

The geologic setting of the Coalinga earthquakes suggests the presence of a layer of sediments overlying higher-velocity materials, both of which have 
undergone folding and faulting. Lateral velocity gradients would be expected along structural features as well as distinct changes in velocity across boundaries of geologic provinces. The array straddled Anticline Ridge, which is located between the Coast Range Province and the Great Valley Province.

A piecewise continuous $P$-wave velocity model was constructed to fit travel-time data from three USGS refraction shots recorded by the array and a COCORP interval velocity model (Fielding et al., 1983) near Coalinga. The $V_{P} / V_{S}$ ratio derived from Wadati diagrams for 15 earthquakes is 1.9. This value is used to derive the $S$-wave velocity model. Both models are plotted in Fig. 1.

\section{EARTHQUAKE LOCATIONS}

First motions were read for each of the earthquakes, and $P$-wave and $S$-wave arrival times were used to determine locations. Duning experimentation with five different velocity models ( $V_{P} / V_{S}=1.9$ for all models), absolute locations changed no more than $1 \mathrm{kın}$ for almost all the earthquakes. The earthquakes are all located near the edge or within the array (Fig. 2a,d,g) and usually have both $P$-wave and $S$-wave arrival imes at several stations. Thus the latitude, longitude, and depth of most earthquakes are well constrained by the array, regardless of which velocity model is used. The earthquakes are well located relative to each other for any reasonable velocity model.

\section{FOCAL MECHANISMS AND FAULT PLANE SOLUTIONS}

The earthquakes were divided into three groups on the basis of relative spatial and temporal locations. The eleven earthquakes recorded by the acılerometers have magnitudes $3.0 \leqslant M_{L} \leqslant 4.8$

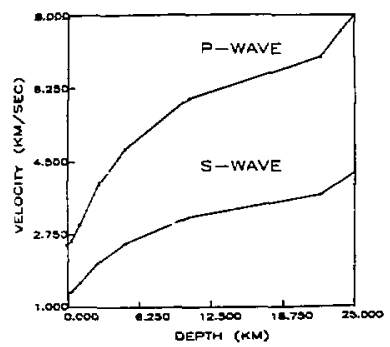

Figure 1. Velocity model used to locate the earthquakes. [XBL 843-1238] and plot primarily northwest of the array (Fig 2a). The composite focal mechenism (Fig. 2b) has one notal plane oriented $\mathrm{N} 20^{\circ} \mathrm{W}, 19^{\circ} \mathrm{SW}$ and the other nodal plane oriented $\mathrm{N} 20^{\circ} \mathrm{W}, 71^{\circ} \mathrm{NE}$. $A$ cross section drawn N61'E (Fig. 2c, shown as a broken line in Fig. 2a) shows the earthquakes lying in a shallow, southwest-dipping pattern. A least-squares fit of a plane to the hypocenters of the acceleration earthquakes strikes $\mathrm{N} 29.0^{\circ} \mathrm{W} \pm 19.6^{\circ}$ and $\operatorname{dips} 13.2^{\circ} \mathrm{SW} \pm$ $5.0^{\circ}$. The composite focal mechanism, cross section, and least-squares fit are all consistent with the existence of thrust faulting during the $5 \mathrm{~d}$ immediately following the May 2 main shock.

Group $A$ is made up of eight earthquakes located northeast of the array and recorded $16 \mathrm{~d}$ after the main shock on May 18 and May 19 (Fig. 2d). In contrast to the acceleration earthquakes, the composite focal mechanism for these earthquakes shows reverse faulting (Fig. 2e). The cross section (Fig. 2f), oriented $\mathrm{N} 45^{\circ} \mathrm{E}$ (shown as a broken line in Fig. 2d), suggests that faulting occurred on northeast-dipping planes.

The eleven earthquakes of Group B, also recorded $16 \mathrm{~d}$ after the mainshock, plot inside the array (Fig. $2 \mathrm{~g}$ ). The cross section, oriented $\mathrm{N} 60^{\circ} \mathrm{E}$ (Fig. 2i, shown as a broken line on Fig. 2g), does not clearly define either nodal plane of the composite focal mechanism (Fig. 2h) as a fault plane. Instead, the distribution of earthquakes in Fig. $2 b$ suggests that thrust faulting and reverse faulting occurred in this region.

\section{SPECTRAL ANALYSIS OF SH-WAVES}

$S H$-wave spectra were computed to determine the seismic moments, source radii, and stress drops of 39 earthquakes using the Brune $(1970,1971)$ model. Spectra were corrected for the instrument response. No corrections were made for complex wave propagation effects or attenuation. The product of the free surface correction and the radiation pattern correction was assumed to be unity. Source parameters were computed from two or more stations using the methods outlined in Archuleta et al. (1982). This approach provides a rough estimate of source parameters, which allows us to make an internal comparison of these earthquakes.

The momenis range from a high of $2.6 \times 10^{22}$ dyne-cm $\left(M_{L}=4.8\right)$ to a low of $3.1 \times 10^{17}$ dynecm. UCB Richter magnitudes are not available for earthquakes smaller than $M_{L} \sim 3$. Stress drops range from 0.061 to 56 bars. and source radii range from 80 to $979 \mathrm{~m}$.

The small-magnitude earthquakes $\left(1<M_{L}<2\right)$ have stress drops that are one to two orders of mag- 


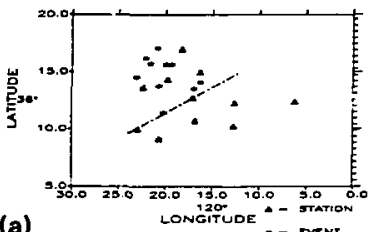

(a)

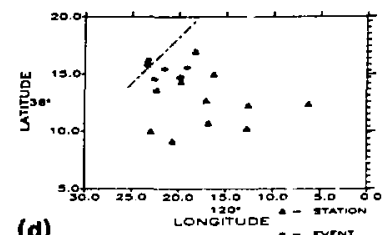

(d)

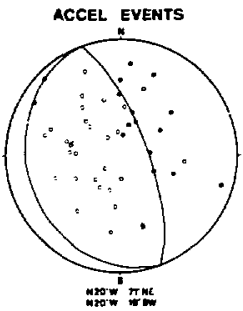

(b)

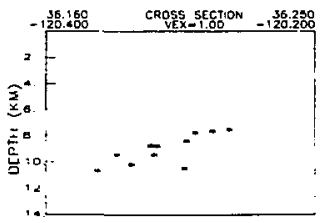

(c)

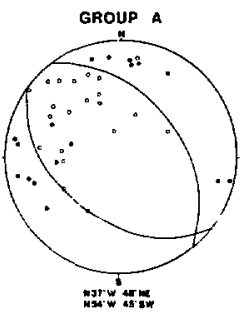

(e)

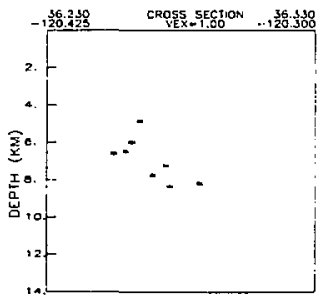

(1)

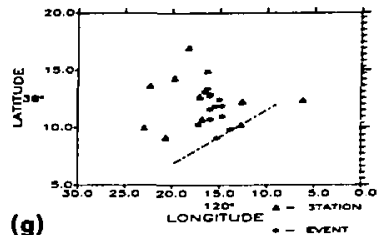

(h)
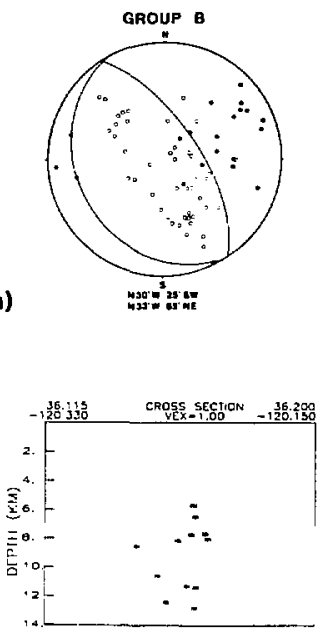

(i)

Figure 2. Epicenter locations, composite focal mechanisms, and cross sections for groups of aftershocks. Composite focal mechanisms are shown on !ower hemisphere projections. Open circles are compressions and solid circles dilatations. [XBL 843-1241]

nitude smaller than earthquakes with magnitudes greater than $M_{L}=3.0$. Average source radii of the smaller-magnitude earthquakes are only a factor of 2-3 smaller than the average source radius of the larger-magnitude events. Corner frequencies range from 0.86 to $26 \mathrm{~Hz}$; corner frequencies for the smaller earthquakes range from 4 to $26 \mathrm{~Hz}$. There is no clear correlation of corner frequency with hypocentral distance. Lack of correlation of corner frequency with recording stations shows that sutiondependent site effects are not significant.

To test whether low whole-path $Q$ had biased the corner frequencies of the small-moment earthquakes, several spectra of an $M \sim 1.8$ earthquake were corrected for $Q$. Whole-path $Q$ values of the order of
50-70 are required to produce significant shifts in the corner frequencies for all but the smallest four earthquakes. Such $Q$ values seem lower than would be expected for average sedimentary rocks. Morever, observed corner frequencies increase with decreasing moment within the smaller-moment earthquakes. These results indicate that the corner frequencies we observe for smaller-moment earthquakes are the true source corner frequencies, although attenuation may downwardly bias the corner frequencies of some of the smallest four earthquakes.

Figure 3 shows that similarity (constant stress drop) holds for $M_{0}>5.0 \times 10^{20}$ dyne-cm and nearly holds for $M_{0}<2.6 \times 10^{19}$ dyne-cm, but not for all the earthquakes combined. Similarity breaks 


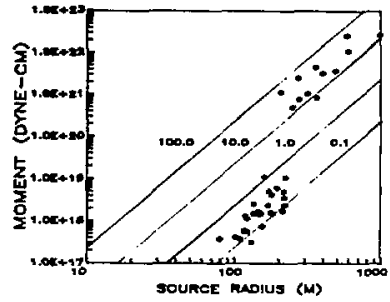

Figure 3. Moment versus source radius for 39 earthquakes. Lires of constant stress drop are shown with values (in bars) to the left of the line. [XBL 843-1239]

down between $M_{0} \sim 5.0 \times 10^{20}$ dyne-cm and $M_{0} \sim 2.0 \times 10^{19}$ dyne-cm. The nature of the transition of stress drop and source radius between these moments cannot be determined from this data set because earthquakes are lacking in this moment range. Tucker and Brune (1973), Bakun et al. (1976), Fletcher (1980), and Archuleta ct al. (1982) have observed a breakdown of similarity for earthquakes with $M_{0}<1.0 \times 10^{20}$ dyne-cm. As observed in these studies, there is a difference in the slope of moment vs source radius (Fig. 3 ) between the smaller-moment earthquakes and the larger-moment earthquakes. However, the slope difference between larger-moment earthquakes and smaller-moment earthquakes is much less pronounced in our study. At the position on Fig. 3 where similarity is violated, the source radii have values of $200-250 \mathrm{~m}$. In the studies mentioned above, similarity is violated where source radii have values of $100-300 \mathrm{~m}$.

An explanation of the observed variations of stress drop and source radius with moment is that the assumptions implicit in the Brune-type spectral source model are not valid throughout the range of magnitudes observed in this study. For instance, corner frequencies of the smaller-magnitude earthquakes could be proportion:] to the source rise time and not to the source dimension. This would occur when the source rise time is much longer than the nupture time. As discussed in Archuleta et al. (1982), this might occur if the source dimension of the smaller-magnitude earthquakes were less than some critical fracture length needed for a fracture to propagate. In that case the stress drops of the smaller-magnituje earthquakes could be underestimated or meaningless.

\section{REFERENCES}

Archuleta, R.J., Cranswick, E., Mueller, C., and Spudich, P.K.P., 1982. Source parameters of the 1980 Mammotk. Lakes, California earthquake sequence. Journal of Geophysical Research, v. 87 , p. $4595-4607$.

Bakun, W.H., Bufe, C.G., and Stewart, R.M., 1976. Body-wave spectra of central California earthquakes. Bulletin of the Seismological Society of America, v. 66, p. 363-384.

Brune, J.N., 1970. Tectonic stress and the spectra of seismic shear waves from earthquakes. Journal of Geophysical Research, v. 75, p. 4997-5009.

Brune, J.N., 1971. Correction. Journal of Geophysical Research, v. 76, p. 5002.

Clark, M.M., Harms, K.K., Lienkaemper, J.J., Perkins, J.A., Rymer, M.J., and Sharp, R.V., 1983. The May 2, 1983 earthquake at Coalinga, Caljfornia: The search for surface faulting. USGS Open-File Report 83-511, p. 8-19.

Fielding, E., Barazangi, M., Brown, L., Oliver, J., and Kaufman, S., 1983. COCORP seismic reflection profiles near the 1983 Codinga earthquake sequence; deep structures. California Division of Mines and Geology Special Publication 66 .

Fletcher, J.B., 1980. Spectra from high-dynamic range digital recordings of Oroville, California aftershocks and their source parameters. Bulletin of the Seismological Society of America, v. 70 , p. $735-756$.

McJunkin, R.D., and Hart, E.W., 1983. Ground rupture, Coalinga earthquake of 10 June 1983. California Geology, v. 8, p. 182-184.

Tucker, B.E., and Brune, J.N., 1973. Seismograms, S-wave spectra, and source parameters for aftershocks of San Fernando earthquake. In San Fernando, California, earthquake of February 9, 1971 (Vol. 3, Geological and geophysical studies). Washington, D.C., U.S. Government Printing Office, p. 69-121. 


\section{SEISMIC ATTENUATION AND CRUSTAL STRUCTURE NEAR THE SAN ANDREAS FAULT ZONE FROM REFLECTION PROFILING}

\section{J.E. Scheiner}

Characterization of crustal structure and composition, especially in tectonically active regions, is sought as a means of understanding crustal evolution as well as delineating subsurface features for energy development purposes. Of particular importance here is the nature of the San Andreas fault zone in central California. Fault zone structure and constitution are studied to enhance understanding of longterm physical processes (tectonic evolution, plate motions) and short-term physical processes (temporal and spatial characteristics of strain energy accumulation and release-earthquake processes). Furthermore, given the wealth of high-resolution seismic reflection data and the relatively limited applications to date, there is both the opportunity and the necessity to develop new techniques for analyzing the attenuation and scattering properties of the earth's crust.

There have been several innovative approaches to the problem of determining the crustal attenuation and scattering properties using earthquake sources. Surprisingly large fluctuations in amplitude and slowness anomalies across the LASA and NORSAR arrays from teleseismic sources motivated a number of statistical investigauons of the crust as a random elastic medium (Aki, 1973; Capon, 1974; Berteussen et al. 1975). In these studies, based on the work of Chernov (1960), the crust and upper mantle were characterized by a single velocity with a standard deviation representing the random perturbation. Studies designed to correlate anplitude and phase information between neighboring subarrays and stations led to relatively crude and poorly constrained results; the parameters of interest were the mean fractional velocity perturbation and the correlation or scale size of inhomogeneity.

Using data from earthquake sources in Japan and central California, Aki and Chouet (1975) devised a very different approach in which the coda decay was modeled as a diffusion process with a loss term included. The coda was interpreted as the result of scattering of primary waves by the numerous inhomogeneitics of the crust. (This type of model has been successfully applied to lunar "seismograms" by Dainty and Toksöz (1977).) The decay profile gave a measure of the intrinsic attenuation, and the diffusivity characterized the heterogeneity of the ruedium. However, the measured $Q$ values undoubtedly included some unknown amount of nonintrinsic scattering losses; furthermore, there is some confusion about the physical interpretation of he diffusivity.

In a similar study, Sato $(1977,1978)$ used local earthquake data from the Kanto district of Japan in an attempt to determine the attenuation and scattering properies of the medium from the decay of coda power. Using a model based on weak single scattering, Sato interpreted the decaying envelope of coda amplitude to determine the mean free path and $Q$ of $S$-waves.

In many important ways, seismic reflection data are superior for such studies. The relativeiy small aperture allows finer resolution and may even permit the determination of the depth deperdence of the relevant parameters. The spectral characteristics of the source are more easily determined, and source timing and location are precisely known. Perhaps the greatest advantage is due to the stacking process: To a good approximation, the stacked reflection seismogram or vertically propagating coda represents the impulse response to a point source at the observation point. In particular, we are quite fortunate to have a unique and fascinating data set to work with. A 16-km profile done in 1978 using Vibroseis with 24-fold coverage over a frequency sweep from $\theta$ to $24 \mathrm{~Hz}$ crosses the San Andreas Fault about 25 miles south of Hollister in central California. The Gabilan Granite to the west is juxtaposed with the Franciscan Formation of the Diablo Range to the east. The contrast in crustal reflectivity is dramatic, as seen in the original stacked section (Fig. 1). Preliminary results using the diffusion model have been carried out. Over the bandwidths $6-12 \mathrm{~Hz}$ and $12-24 \mathrm{~Hz}$, $Q$ was found to have a general decrease eastward, with high values in the fault zone itself. $Q$ values for the 12-24 Hz band were generally higher than those for the lower-frequency band; $Q$ ranged between 80 and 500 , in rough agreement with values of other investigations in the same area (including that of Aki and Chouet (1975)). In addition, some preliminary work involving the autocorrelation of averaged CDP traces over a j-s window has yielded interesting results. Generally, the autocorrelations are broader in the Franciscan data than those for the granitic CDPs. Furthermore, there is a tendency on some CDPs in the western section for the autocorrelation 


\section{Bickmore Canyon: True Amplitude Seismic Section}

CDP numbers

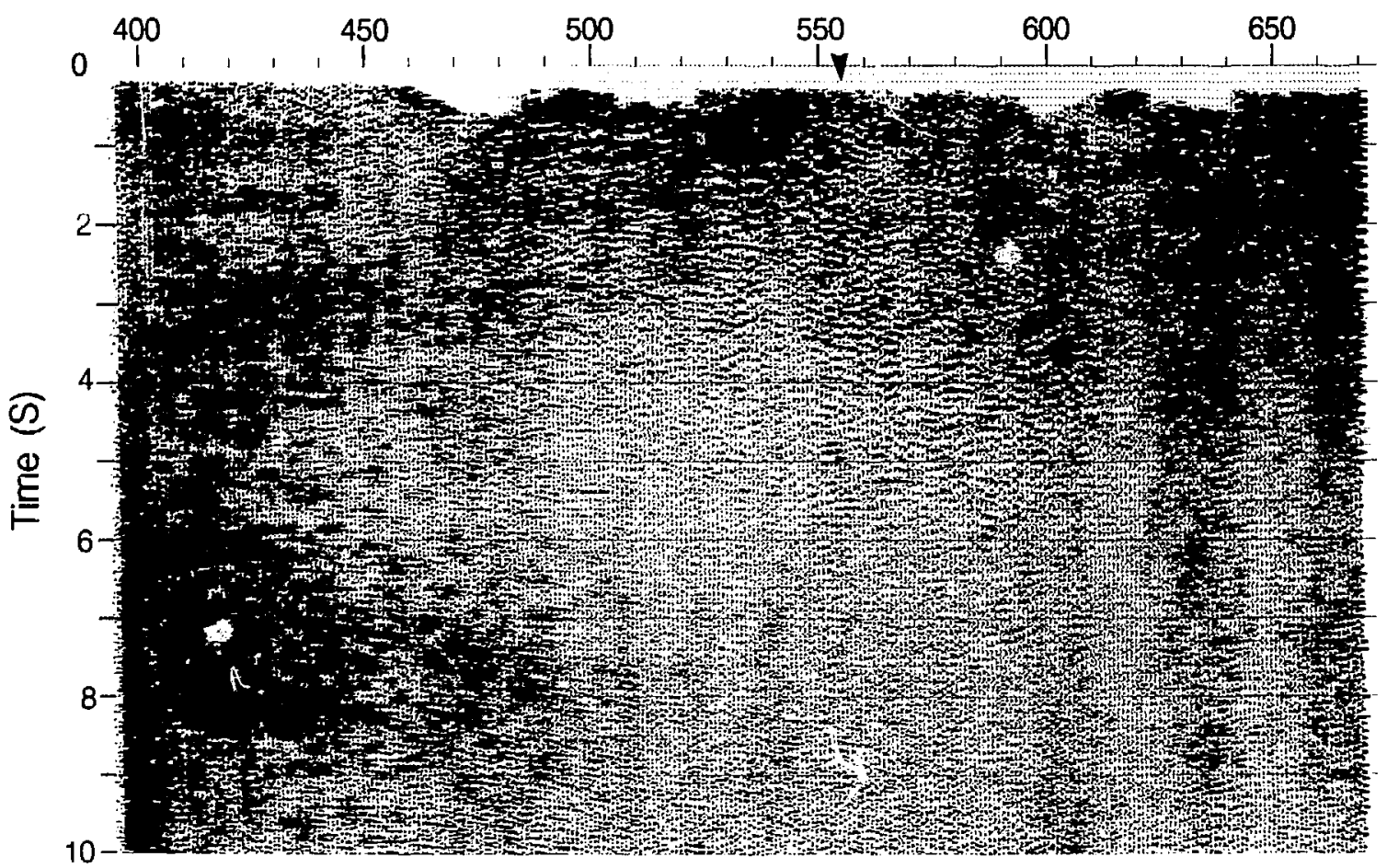

Figure 1. Cross section of the earth's crust through the San Andreas Fault (arrow near CDP 550). Horizontal exaggeration is about 6:1. The Moho reflections appear at about 7-8 s; note the clarity of these and other reflectors on the western (granitic) side vs the general lack of reflectivity on the eastern (Franciscan) side. This section shows true amplitude except for the application of a simple spherical divergence correction. [XBL 846-8476] 
to show peaks at lag times corresponding to strong reflections in the data, as expected.

Until recently, standard data processing was done by a private company in Denver; the acquisition of Digicon's reflection data-processing software package (DISCO) has enabled in-house analyses using standard techniques as well as nonstandard creative approaches. Thus far, standard processing at the Center for Computational Seismology has included extensive editing of poor quality data, detailed geometry definition for crooked line processing, preliminary and residual statics corrections, and advanced velocity analyses. The critical dependence of any structural interpretation on the velocity model is acknowledged, and we are rapidly converging on several viable models; of particular interest is the refined model of Feng \& McEvilly (1983). Evidence for strong lateral velocity gradients suggests the ueed for pre-stack migration of the data; this is being accomplished by means of a finite-difference migration algorithm provided in DISCO.

It is necessary to look more closely with filtered data at the envelope of energy rather than at the amplitudes themselves. This is entirely possible with the advanced processing capabilities of the DISCO system. Furthermore, it is important to look at other time windows to study any depth variations that may exist. Another interesting possibility involves correlation studies of lateral variations in acoustic impedance.

All of the above approaches can and should be applied over several frequency bands, as the frequency dependence of the results is of great interest. Moreover, it is critical to test these results with a forward modeling scheme; unfortunately, no viable procedure has yet been devised.

The San Andreas Fault in the Hollister region has been extensively studied in terms of many different parameterizations; it will be quite illuminating

\section{THE IDEAL BODY METHOD FOR STATIC EARTH DISPLACEMENTS}

\author{
D.W. Vasco
}

This study extends Parker's (1974) method of ideal bodies to the area of static earth displacement. to compare the results of this analysis with the large body of existing dat2.

\section{REFERENCES}

Aki, K., 1973. Scattering of $P$ waves under the Montana LASA. Journal of Geophysical Research, v. 78 no. 8, p. 1334-1346.

Aki, K., and Chouet, B., 1975. Origin of coda waves: Source, attenuation, and scattering effects, Journal of Geophysical Research, v. 80, no. 23 , p. 3322-3342.

Berteussen, K.A., Christoffersson, A., Husebye, E.S., and Dahle, A., 1975. Wave scattering theory in analysis of $P$-wave anomalies at NORSAR and LASA. Geophysical Journal of the Royal Astronomical Soriety, v. 42, p. 403-417.

Capon, J., 1974. Characterization of crust and upper mantle structure under LASA as a random medium, Bulletin of the Seismological Society of America, v. 64, no. 1, p. 235-236.

Chernov, L.A. 1960. Wave Propagation in a Random Medium (trans. R. Silverman), New York, McGraw-Hill.

Dainty, A.M., and Toksöz, 1977. Elastic wave propagation in a highly' scattering medium-A diffusion approach. Journal of Geophysics, v. 43, p. $375-388$.

Feng, R., and McEvilly, T.V., 1983. Interpretation of seismic reflection profiling data for the structure of the San Andreas fault zone. Bulletin of the Seismological Society of America, v. 73, p. $1701-1720$.

Sato, H., 1977. Energy propagation including scattering effects: Single isotropic scattering approximation. Journal of Phrsics of the Earh, v. 25, p. $27-41$.

Sato, H., 1978. Mean free path of $S$-waves under the Kai to District of Japan. Journal of Physics of the Earth, v. 26, p. 185-198.

The sinallest fractional volume change that would produce a given surface displacement is sought, and a least upper bound on the depth of the anomalous body is examined. The resulting algorithm is used to estimate the least upper bound on the depth of a proposed magma body at Mammoth Lakes, California. There are important reasons for producing these estimates: Surface displacement, like gravity, cannot in general be inverted to yield a unique sinurce. Even when a homogeneous body force is 
specified, the source shape is still not uniquely determined. An excellent illustration of this was produced by the finite-element models of Dieterich and Decker (1975). These authors note that source depths for a given anomaly varied by a factor of 3.5 for the models considered, depending on source shape. With such nonuniqueness present it is desirable to derive, if possible, some properties common to all possible sources. Fortunately, Parker (1974) has developed a method for extracting such properties from potential field anomalies. For example, given bounds on density, one may place bounds on source depth; conversely, given bounds on source depth, one may place bounds on density. As shown below, this technique may be extended to the problem of static earth displacements caused by a volume source at depth. The above technique might prove useful in areas of anomalous uplift and deformation in which a fluid body is believed to be the perturbing source.

\section{THE METHOD OF IDEAL BODIES}

Parker examined the general linear problem in which a scalar model property $\Delta \theta(\mathrm{r})$ is considered. $N$ observations of displacement are assumed to have been made. Their connection with the model property is given by

$$
u_{i}=\iiint_{V} \Delta \theta(\mathbf{r}) K_{i}(\mathbf{r}) d V, i=1,2,3, \ldots, N .
$$

He then showed that, if the anomalous property is assumed to be of only one sign, certain parameters may be found that will describe "a body of least $\Delta \theta(\mathbf{r})$ that fits the original data set." It was asserted that a sufficient condition for the existence of a positive lower bound on the largest value of $\Delta \theta(\mathbf{r})$ is the existence of constants

$$
\theta, \alpha_{i} \quad i=1,2,3, \ldots, N
$$

such that the function

$$
\Delta \theta=\left\{\begin{array}{lll}
\theta & & \sum \alpha_{j} K_{i}(\mathrm{r})>0 \\
& \text { where } & \\
0 & \sum \alpha_{i} K_{i}(\mathbf{r})<0
\end{array}\right.
$$

satisfies Eq. (1). It is further stated that the volumes $V_{+}$and $V_{-}$in which the above linear combination of the kemels is positive or negative are uniquely determined under one condition, i.e., if the set of points where

$$
F(\mathbf{r})=\Sigma \alpha_{i} K_{i}(\mathbf{r})=0
$$

bas zero volume. The theorem is very general and may be used in many applications, provided that the property of interest is related to observations by an equation of the above form. One possible use would be in the study of static earth displacements, such as those caused by faulting or the expansion of magma bodies. Here the surface displacements $u_{m}(q)$ are related to a dislocation distribution on a surface by the Volterra integral,

$$
u_{m}(\mathbf{q})=\iint_{\Sigma} \Delta u_{k}(\mathbf{p}) W /(\mathbf{p}, \mathbf{q}) d \Sigma,
$$

where $\mathbf{q}=\left(x_{1}, x_{2}, x_{3}\right)$ is any point in the half-space other than the dislocation surface itself, $\mathbf{p}=\left(\xi_{1}, \xi_{2}, \xi_{3}\right)$ is a point on the dislocation surface, $\Delta u_{k}(\mathbf{p})=$ $u_{k}^{+}-u_{k}^{-}, u_{k}^{+}$denotes the displacement vector for a point $p^{+}$, originally situated at $p$ on $\Sigma$ but now on $\Sigma^{+}$, and $u_{k}^{-} W_{k}(p, q)$ is the Green's function relating the dislocation $\Delta u_{k}$ (p) to the surface displacement component $u_{m}(\mathbf{q})$. In the case of a purely dilatational volume source, the above surface integral can be put into the form needed to make use of the ideal body theorem, as shown in the next section. In this case,

$$
\Delta e_{11}=\Delta e_{22}=\Delta e_{33}=\frac{\Delta \theta}{3}(\mathrm{r}),
$$

and

$$
K_{i}(\mathbf{r})=W h(\mathbf{p}, \mathbf{q})
$$

\section{THE STATIC-EARTH DISPLACEMENT PROBLEM}

For a displacement due to a purely dilatational source, one may convert the Volterra integral (2) into the form necessary for the application of Parker's theorem. Using the divergence theorem on (2) gives

$$
u_{m}(\mathbf{q})=\iiint_{V}\left\{\Delta u_{k}(\mathbf{p}) W M(\mathbf{p}, \mathbf{q})\right\}, 1 d V(\xi)
$$

Differentiating yields

$$
\begin{aligned}
u_{m}(\mathbf{q})=\iiint_{V}\left\{\Delta u_{k, l}(p) \boldsymbol{W} k(\mathbf{p}, \mathbf{q})\right. \\
\\
\left.+\Delta u_{k}(\mathbf{p}) W W_{l, l}(\mathbf{p}, \mathbf{q})\right\} d V(\xi) .
\end{aligned}
$$


One may consider $W g_{f,(p, q)}$ to be the $k \mathrm{tth}$ component of the stress tensor at point $q$ due to a unit body force in the $m$ direction at the point $p$ (Maruyama, 1964). Hence it satisfies the equation of equilibrium

$$
W\left[l,(\mathbf{p}, \mathbf{q})+f_{k}^{m}(\mathbf{p})=0,\right.
$$

where $f_{k}^{\prime \prime}(\mathrm{p})$ denotes the $k$ th component of the unit body force in the $m \mathrm{th}$ direction, $\delta_{m}^{k} \delta(x-\xi)$. Using the above equation in the volume integral changes the second term to

$$
\iiint_{V} \Delta u_{k}(\xi) \delta_{m}^{k} \delta(\mathbf{x}-\xi) d V(\xi)=\Delta u_{m}(\mathbf{x}) .
$$

But since there is no dislocation discontinuity at the surface, $\Delta u_{m}(\mathbf{x})$ vanishes. Considering only a volume dilatational source (i.e., $k l=11,22,33$ ) and deformation observed at the surface $m=3$, one obtains

$$
u_{s}(\mathbf{x})=\iiint_{V} \Delta u_{k, k}(\xi) W_{k k}^{Z}(\mathbf{x}-\xi) d V(\xi),
$$

where

$$
\Delta u_{k, k}(\xi)=\Delta e_{k k}(\xi) .
$$

For a fluid source volume undergoing a transformational strain $\Delta e_{i j}$,

$$
\Delta e_{11}=\Delta e_{22}=\Delta e_{33}=\Delta \theta / 3 .
$$

By defining $K_{i}(\xi)$ as

$$
K_{i}(\xi)=W_{k k}^{3}\left(\mathbf{x}_{i}, \xi\right)
$$

one changes the form of Eq. (3):

$$
u^{3}\left(\mathrm{x}_{i}\right)=\iiint_{V} \Delta \theta(\xi) K_{i}(\xi) d V(\xi) .
$$

This is of the form necessary for the use of Parker's theorem. The kernel $W_{k k}^{3}(\mathbf{p}, \mathbf{q})$ in Eq. (4) has been derived by extension of Maruyama's (1964) study of the response of a homogeneous half-space to point forces and couples.

\section{APPLICATIONS: THE TWO-DATUM PROBLEM}

For $N$ observations at points $\mathbf{x}_{i}$, Parker's theorem states that the equation

$$
F(\xi)=\Sigma \alpha_{i} W_{k k}^{3}\left(\mathbf{x}_{i, \xi}\right)=0
$$

defines a surface separating $V_{+}$and $V_{-}$, i.c., a surface bounding the anomalous body. In general, this equation is very difficult to solve for $N$ observations (Parker 1975), hence we consider the simplest possible case, $N=2$, which happens to yield a third-order equation that defines the surface:

$$
\tau_{1}^{3} i-\beta \tau_{2}^{3}=0,
$$

where $\tau_{2}=\cos \phi_{2}$ ( $\phi_{2}$ being the angle between the vertical (positive upward) and the line from the observation at station 2 to a point on the surface of the perturbing body), and $\beta$ is the ratio $-\alpha_{2} / \alpha_{1}\left(\alpha_{1}, \alpha_{2}\right.$ being the constants that appear in Eq. (5)). Basically, the above equation may be solved for $\phi_{2}$ given a value of $\phi_{1}$. The intersection of lines leaving the two stations at the respective angles $\phi, \phi_{2}$ then defines a point on the surface of the "ideal body." The idea is to vary $\phi_{1}$ from 0 to $x$ radians and calculate $\phi_{2}$ over this range for a given fixed value of $\beta$.

Consider an even simpler problem: that of a two-dimensional voiume source, infinite in extent along one axis. Integration yields a kernel of the form

$$
K_{i}(\xi)=\frac{2}{3 \pi}(\Delta+1) \xi_{3} / S^{2},
$$

where $S=\sqrt{\left(x_{1}-\xi_{1}\right)^{2}+\left(x_{2}-\xi_{2}\right)^{2}-\xi_{3}^{2}}$. Parker's theorem for this two-dimensional, two-datum problem results in a quadratic equation in $\tau_{1}, \tau_{2}$, and $\beta$. Hence $\beta$ is a parameter that defines the form (shape, size, etc.) of the ideal body. It was found that only values of $\beta$ between 0 and 1 result in meaningful roots. The ideal bodies resulting from the solution of the quadratic equation are shown in Fig. 1 for values of $0.01 \leqslant \beta \leqslant 0.99$ and a Poisson's ratio of 0.25 . The uplifts associated with these bodies for a $1 \%$ volume change and at a depth of 0.2 station spacings are shown in Fig. 2.

Having aerived the ideal bodies and the uplifts associated with them, one may now attack the inverse problem of determining the greatest lower bound on the fractional volune change or a least upper bound on the depth. These are complementary problems, in that to find one extremum the other property must be bounded. For example, to bound the depth, one must place a lower bound on the fractional volume change. One calculates $u_{1}$ and $u_{2}$, the uplift at stations 1 and 2, for all $\beta$ in the interval $(0,1)$, keeping the fractional volume change $\Delta \theta$, and the depth of burial, $D$, fixed. As $\beta$ varies, a curve will be traced out that relates these two parameters. Such curves are shown in Fig. 3. From these curves, one may determine a unique upper bound on 


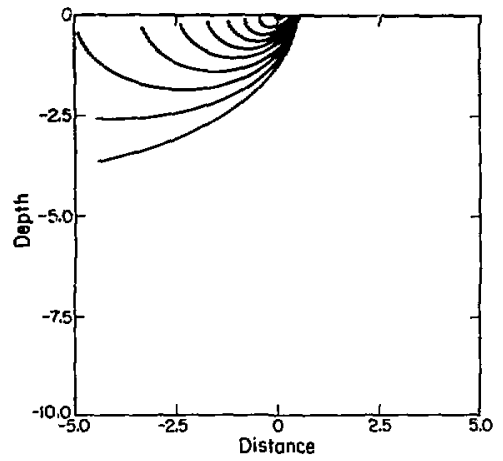

Figure 1. Ideal body forms obtained as $\beta$ varies from 0.01 (smallest body) to 0.99 (largest body) in increments of 0.10. [XBL 841-9566]

the fractional volume change or, conversely, estimate a lower bound on the depth. In the absencc of any estimates, one may take the most pessimistic estimate possible: an infinite fractional volume change or an infinitely deep body. As stated previously, when three or more measurements are considered, the calculations become complex. In such a case, the most expedient course is to consider various pairs of anomaly measurements. The pair that gives an extremum in $\Delta \theta$ or $D$ is then used. Unfortunately, this is not quite as good an estimate as the full $N$ datum treatment.

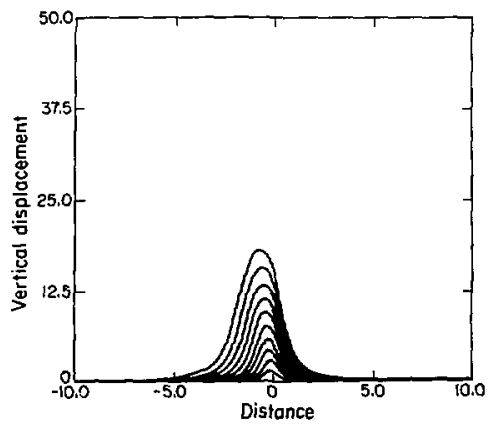

Figure 2. Uplint associated with the ideal bodies in Fig. 1 for a $1 \%$ volume change and a depth of burial of 0.2 . [XBL 841-9567]

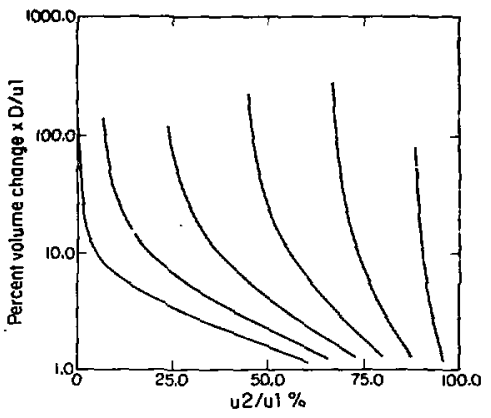

Figure 3. Fractional volume change bounds as a furction of the ratio of the uplifts at station 2 and station 1 and for depths of burial $h=0$ (lowest), $0.2,0.5,1.0,2.0,5.0$ (highest). [XBL 841-9568\}

\section{FUTURE CONSIDERATIONS}

It is hoped that this method may be applied to the uplift data from the Mammoth Lakes region. A least-squares estimate of the depth to a main perturbing body has been made. It would be interesting to derive a least-upper-bound depth estimate. It might also be possible to extend the method using the idea of positivity constraints (Sabatier, 1977), as Safon et al. (1977) have done for the inverse gravity problem.

\section{REFERENCES}

Dieterich, J.H, and Decker, R.W., 1975. Finite element modeling of surface deformation associated with volcanism. Journal of Geophysical Research, v. 8, p. 4094.

Maruyama, T., 1964. Statical elastic dislocations in an infinite and semi-infinite medium. Bulletir of the Earthquake Research Institute, Tokyo Universily, v. 42, p. 289.

Parker, R.L., 1974. Best bounds on density and depth from gravity data. Geophysics, v. 39, p. 644.

Parker, R.L., 1975. The theory of ideal bodies for gravity interpretation. Geophysical Journal of the Royal Astronomical Society, v. 42, p. 315.

Sabatier, P.C., 1977. Positivity constraints in linear inverse problems: 1. General Theory. Geophysical Journal of the Royal Astronomical Society, v. 48 , p. 415.

Safon, C., Vasseur, G., Cuer, M., 1977. Some applications of linear programming to the inverse gravity prcblem. Geophysics, v. 42, p. 1215. 
DETAILED SEISMIC REFLECTION STUDIES OF LATERALLY HETEROGENEOUS MEDIA: CERRO PRIETO

\section{S. Blakeslee}

During 1983, Lawrence Berkeley Laboratory (LBL) significantly expanded its seismic processing and interpretation capabilities with the acquisition of DISCO, a state-of-the-art software package for seismic reflection processing. For the first time, LBL has the opportunity to investigate directly the seismic reflection data gathered over the past 5 years by the Comision Federal de Electricidad (CFE) at the Cerro Prieto geothermal field, Baja California. This is important because the data set is extraordinarily dense and comprehensive. Over $400 \mathrm{~km}$ of line was shot with a coverage of up to 160 -fold (Fig. 1). Many of the lines intersect each other and pass over

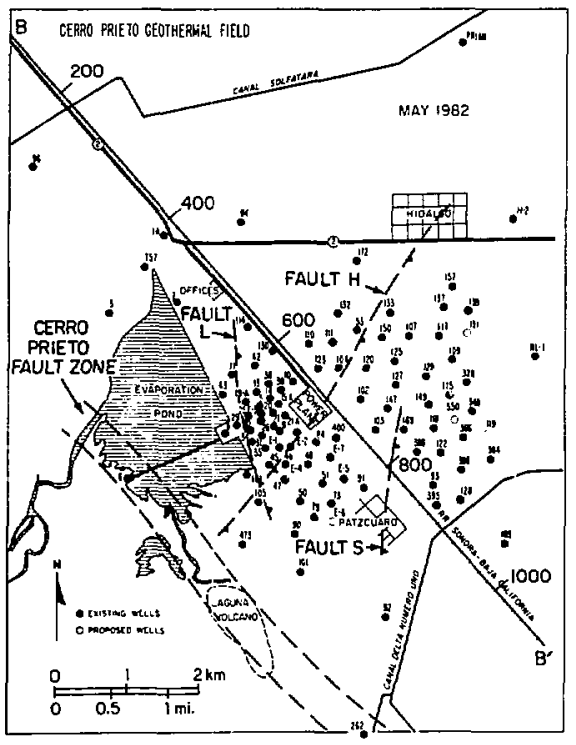

Figure 1. Production zone with common depth point numbers (CDPs) on line $B-B^{\prime}$. The faults are located at depth from well $\log$ data. [XBL 827-2320A] the zone of current production. Because of the high level of resolution available in the reflection data, the subsurface structure and characteristics of the geothermal reservoir may be mappable.

A valuable first cut at processing the data was done by a commercial processor. Although the cursory processing carried out was not sufficient to obtain the detail required for fine discrimination between lithofacies in the subsurface, it did ca!l attention to the potential of the data set. The goals of this project are twofold: (1) to use the processing capabilities available to optimize the imaging of the seismic data and (2) to develop and apply techniques to idcntify the seismic signature associated with regions of intense hydrothermal alteration.

\section{PROCESSING}

Upon careful inspection of the raw, unstacked sections, it became evident that the 256-channel sign bil data were contaminated by several major sources of noise. One of the contaminants correlated well with the seismic source, and the other was related to the receivers. The noise associated with the seismic source was analyzed in the wavenumber-frequency domain, and appropriate filters were designed and applied. The noise associated with the receivers was dealt with on an individual basis. Since there are 60,000 seismic traces for the one line (line B) being processed, finding the noisy traces proved to be time consuming. However, once they were eliminated, a significant enhancement of the signal-to-noise ratio was achieved, aiding in the resolution of deeper reflections that had been ambiguous, at best, before the noise reactions.

Perhaps the most important step in processing multichannel seismic data is the accurate determination of the parameters required for stacking, or summing the data. This is particularly important in regions such as Cerro Prieto, where the subsurface is sufficiently heterogeneouls that a poor parameterization results in signal degradation rather than enhancement. Consequently, a great deal of effort was spent obtaining optimal root-mean-squarevelocity travel-time pairs. This was done using a variety of techniques: Velocity spectra (Fig. 2), trial stacking velocities, and well-log velocities were used to oblain an ultimate vellocity profile. The number of velocity-travel picks was greater in number by a factor of 7 than the number used by the commercial processing company. In addition, the final velocity profile reveals a much greater degree of lateral heterogeneity.

Although topographic variations along the line were small and static corrections had already been 


\section{Velocity Coherence (CDP numbers 925-930)}

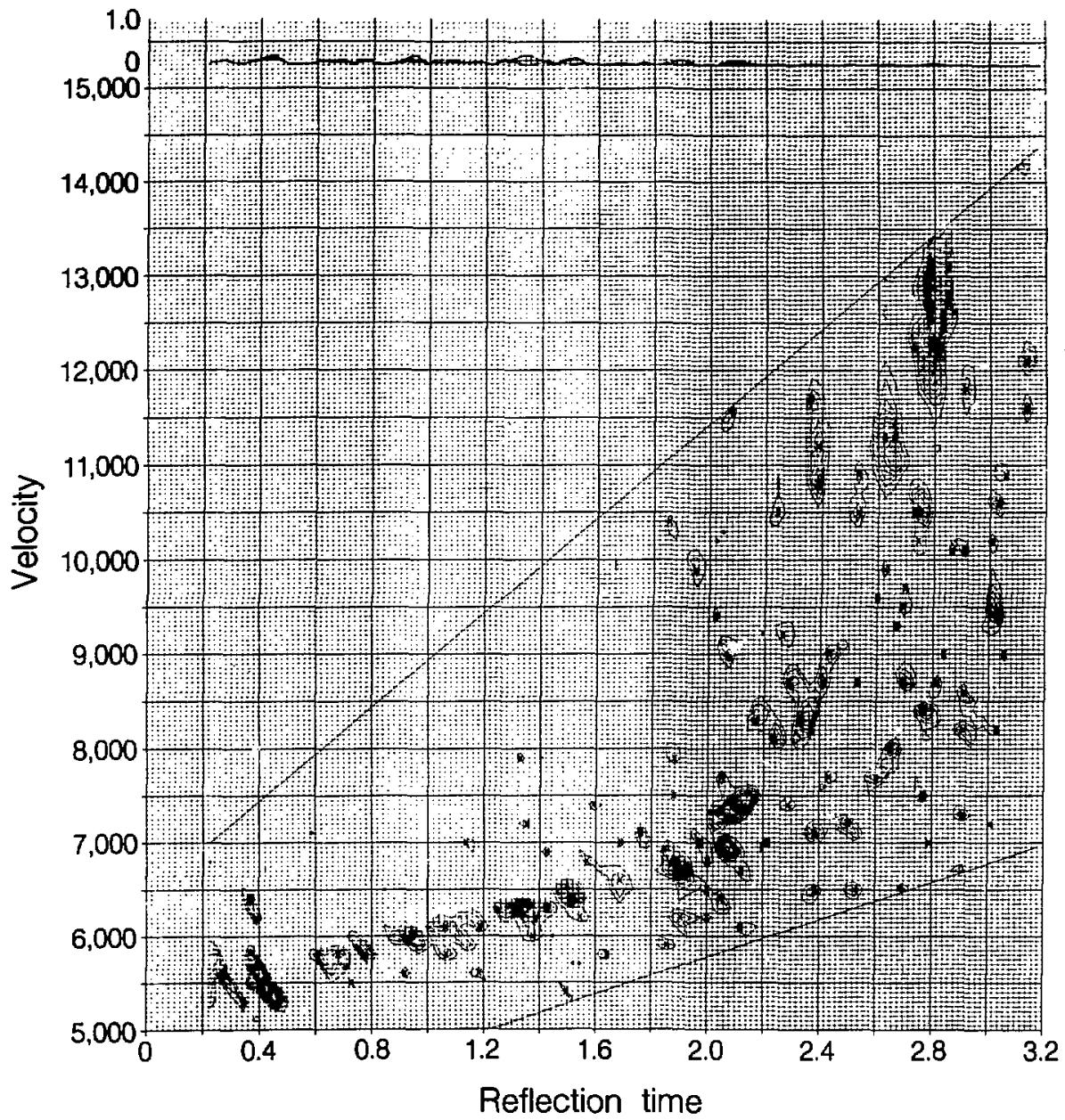

Figure 2. Example of velocity spectra (for CDP 925-930 stacked). [XBL 843-1240]

applied, residual statics were computed. After a number of iterations, the residuals converged and the corrections were applied. This tended to improve continuity of the reflectors.
The dipping reflectors wamanted migration of the data. This was performed using a finitedifference algorithm that allowed the input of the heterogeneous velocity profile (Fig. 3a). Although 


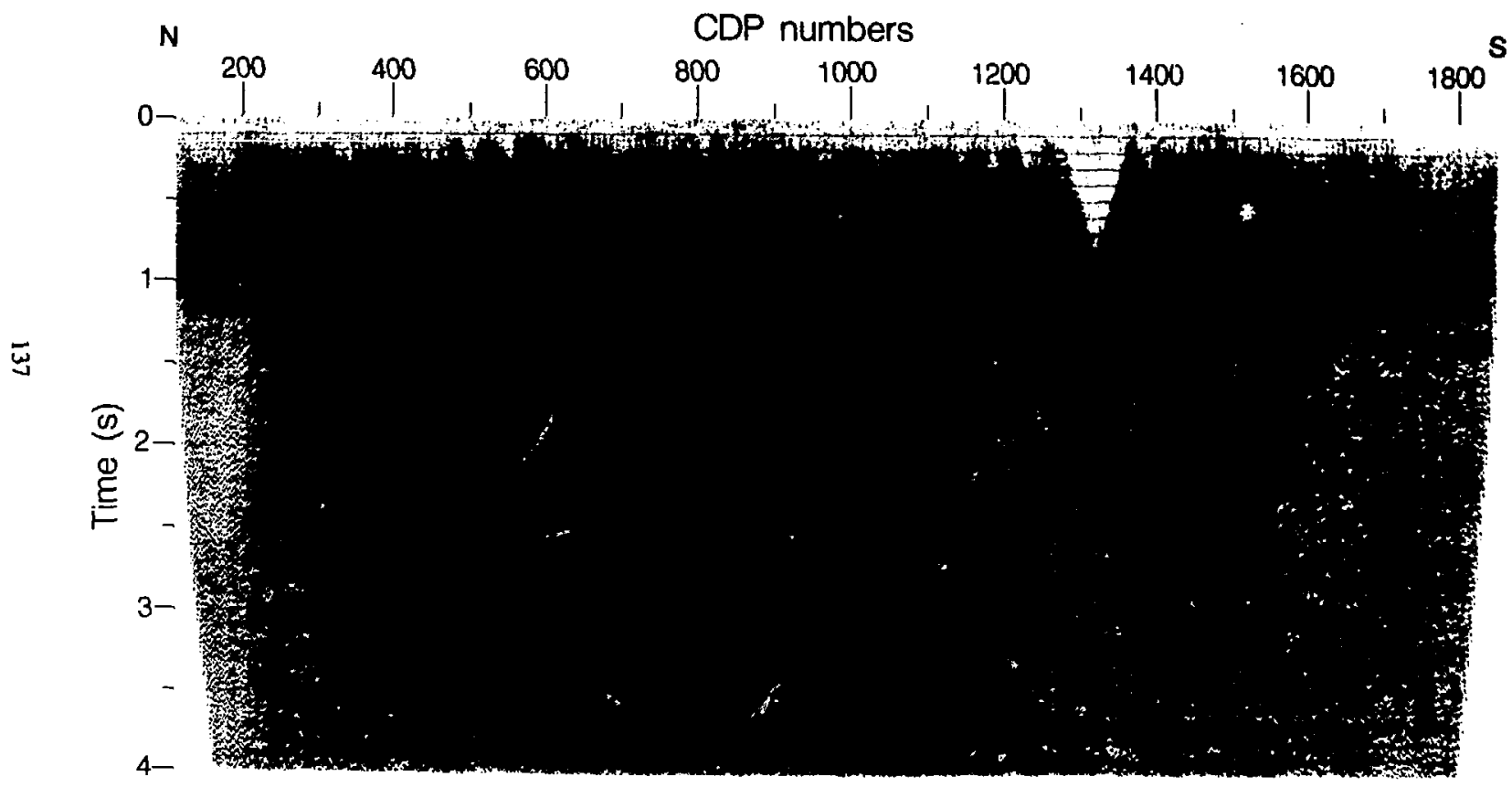

(a)

Figure 3. Reprocessed line $B$ (common depth point numbers). (a) Reprocessed with laterally heterogeneous velocity profiles. [XBL 846-2464] 


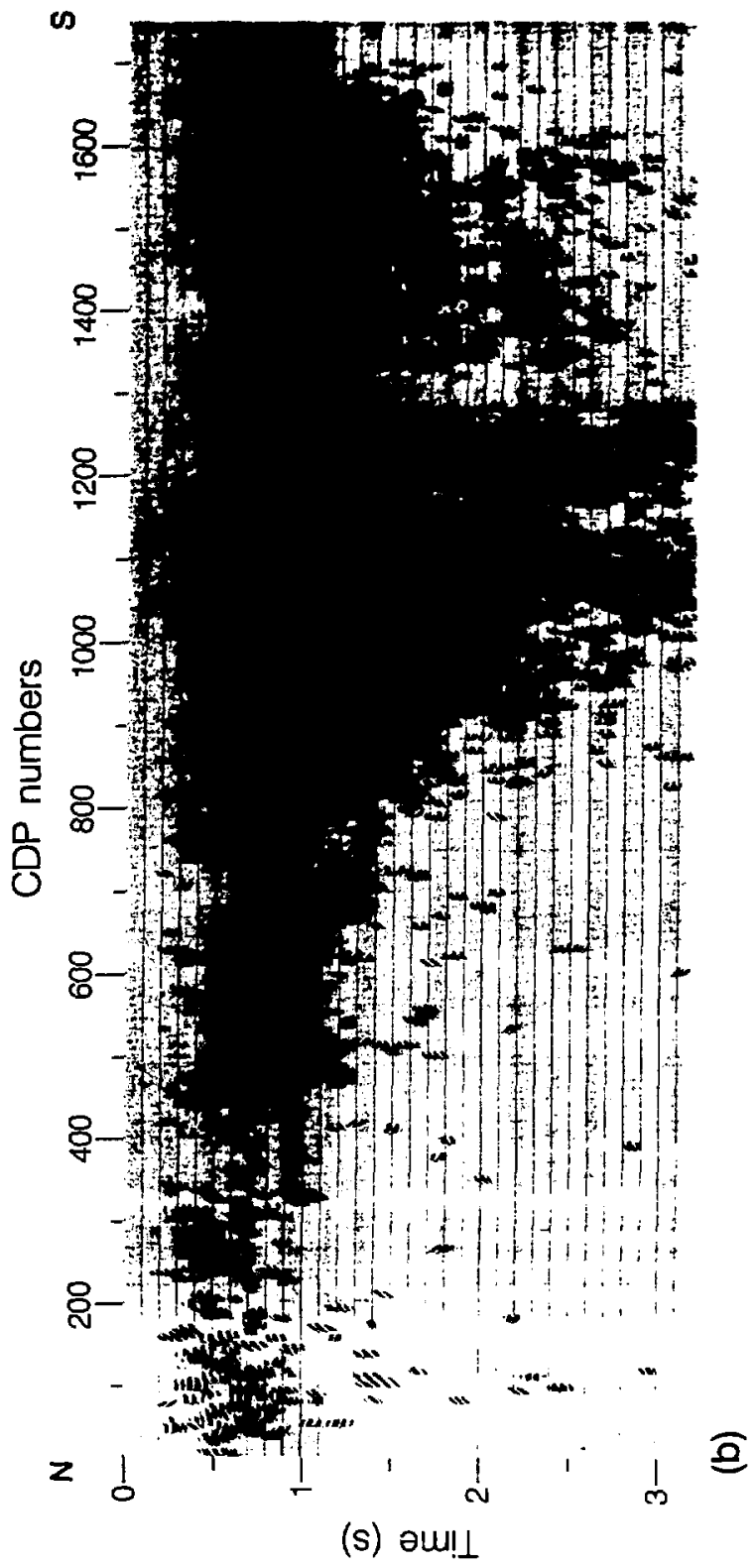


the results are still being studied, a preliminary analysis reveals that migration has aided our understanding of fault geometries.

\section{RESULTS}

Although the processing capabilities provided by the DISCO package have only recently been applied to seismic data over a geothermal field and much of the time has been spent learning the new system, the results are very encouraging.

The first of the goals - enhancement of subsurface imaging-is clearly attainable. The commercial processing provided overall trends in the reflectors but was not of sufficient quality to quantify impedence ratios, correlate reflectors with seismic log data, or identify faults. The correct location, orientation, extent, and character (tied up in the waveforms themselves) of the subsurface reflectors have been enhanced by the reprocessing. Though extensive work with the well log data is required to correlate the observed lithofacies with the known geology, there is every reason to believe that this can be achieved.

Of critical importance is the identification of the several known faults in the area (Fig. 1 in Halfman et al., 1984). Learning how they interact with the region of geothermal activity may provide important data relating to the history of the field. A seismic section was generated that consists solely of reflectors that demonstrate a prescribed level of eoherency (Fig. 3b). That section has aided in confirming several known or postulated faults.

The second of the goals-identification of discriminants associated with the geothermal fieldis still in the research phase. Other researchers (Fonseca and Razo, 1979) have noted that the zone of production exhibits a high level of correlation with regions of reflection attenuation. After reprocessing the data, we believe that this phenomenon is not simply an artifact of poor parameterization in the processing. The phenomenon is real and will be

\section{CCS/DARPA SEISMIC DATA BASE DEVELOPMENT}

\section{Scherrer}

One of the primary goals of the Center for Computational Seismology (CCS), a joint research facility the focus of the next level of analysis. The upcoming study will include an extensive investigation into the statistical properties of the wave field (Sinyhal and Khattri, 1983), application of the techniques of complex trace analysis (Morlet et al., 1982o, 1982b), and a first-order mapping of $Q$.

Ultimately, the bulk of the available data will be processed to provide a resolution of subsurface stratigraphy heretofore unavailable. Finally, using the results from the discriminant analysis, it is hoped that the geothermal reservoir region can be mapped and parameterized with a high level of confidence.

\section{REFERENCES}

Fonseca L., H.L., and Razo M., A., 1979. Gravity, magnetics and seismic reflection studies at the Cerro Prieto geothermal field. In Proceedings, Second symposium on the Cerro Prieto Geothermal Field, Baja California, Mexico, October 17-19, 1979. Mexicali, Comisión Federal de Electricidad, p. 303-323.

Halfman, S.E., Lippmann, M.J., Zelwer, R., and Howard, J.H., 1984. A geologic interpretation of geothermal fluid movement in the Cerro Prieto field, Baja California, Mexico. Bulletin of the Amcrican Association of Petroleum Geologists, in press.

Morlet, J., Arens, G., Fourgeau, E., and Giard, D., 1982a. Wave propagation and sampling theory-Part I: Complex signal and scattering in multilayered media. Geophysics, v. 47, no. 2, p. 202-221.

Morlet, J., Arens, G., Fourgeau, E., and Giard, D., 1982b. Wave propagation and sampling theory-Part 2: Sampling theory and complex waves. Geophysics, v. 47, no. 2, p. 222-236.

Sinyhal, A., and Khattri, K., 1983. Application of seismic reflection data to discriminate subsurface lithostratigraphy. Geophysics, v. 48 , no. 11 , p. $1498-1513$.

of Lawrence Berkeley Laboratory and UC Berkeley, is to develop and provide access to an organized and managed digital seismic data base. The DARPAfunded Center for Seismic Studies (the Center), located in Arlington, Virginia, has similar objectives: to collect, manage, aud analyze digital data to support data exchange provisions for future test-ban treaties. One of the valuable features of both the Center and CCS is their role as host to visiting scien- 
tists. This is particularly important, since each site serves as a central data repository for many large and unique data sets and analysis programs. However, each site has independently genernted its own structures and procedures for maintaining data archives, making exchange of data difficult. In addition, each facility essentially requires that the seismologist be on site to use its archives, a costly and inconvenient allocation of time. Thus both the Center and CCS could make larger contributions to the research community if the data archives and other data retrieval capabilities of each facility were available to scientists in the normal conduct of research wherever they work.

To address these problems, CCS entered into a cooperative effort with the Center and with LBL's Computer Science and Mathematics Department, which could provide the necessary computer expertise, to set up mechanisms for remote access and data exchange between the two sites. The uniform handling of data is the key to providing researchers with a mechanism for exchange of data with the Center. Moreover, with data treated in a uniform, standard fashion, transfer of technology and tools between CCS, the Center, and the research community would be feasible.

\section{APPROACH}

The approach chosen by CCS was to establish a prototype off-site user's project that would provide a model for developing the minimal set of data management tools needed to handle data from both the Center and researchers at other locations. Specifically, necessary tools and procedures were to be provided that would allow uploading of unique data sets between CCS and the Center and make existing Center data available to researchers. Since the Center and CCS use similar machines (VAX 11/780), but different operating systems (UNIX (tm) and VMS), the primary requirements were to select those Center utilities and procedures necessary to generate and maintain archival data sets, isolate the systemdependent portions of the software, and reimplement those sections in as system-independent a manner as possible. Additional tools would be developed as needed to assist in the transformation of data in local format to the Center's standardized structure.

\section{PROGRESS}

A compaible data management system was acquired and installed. The Center uses the Ingres relational data management system on their UNIX system. CCS was able to purchase a conmpatible ver- sion of Ingres to use on its VMS system. Data structures used by the Center were duplicated on the CCS system via a set of load mactos provided by the Center.

The Center receives a large amount of information each day (about 285 megabytes), and this information is handled by inserting it into an elaborate tape archiving system. A minimal required set of Center tape archiving utilities was identified, moved to the local site, and reimplemented on the local operating system.

Portions of locally available NTS near-field data sets were then identified for use as a model set to be uploaded to the Center. These data sets resided on a variety of media (cards, tape, cassettes) and in several formats. Programs were written to access the various media and to convert the data into the standard format used by the Center. The data seis were then installed in the Center-style local data base and tape archive. Interface procedures were developed to allow efficient (human) inclusion of parameter data not available in machine-readable format. These data sets were then shipped to the Center both over the MILNET network and on standard Centerformat tapes.

Documentation was prepared for those utilities not part of the Center library, and Center documentation was adjusted for the local site. A User's Manual was developed that includes information on extracting both wav sform and parameter data from either site and shipping it over the network or via magnetic tape.

\section{DATA MANAGEMENT}

The data management environment developed at the Center and reimplemented at CCS is somewhat unique. Seismic applications exhibit many characteristics typical of other scientific and statistical data base applications, and these are not easily handled by conventional data management systems. A high degree of flexibiity and data independence is necessary, coupled with a need for retrieval based on user-unique combinations of aspects of the data. The Center's choice of Ingres, one of the newly developeci relational systems, provides the user with a high degree of data independence coupled with powerful query facilities for data definition, retrieval, update, access control, support of individual views, and integrity verification. This relational system allows data to be indexed and accessed by a wide variety of seismological attributes.

The Center uses the data management system iil two ways: (1) to maintain indices to waveform data stored on disk or in archivil form on tapes; and 
(2) to maintain parameter (textual) data both directly and indirectly related to the waveform data. Though Ingres provides the primary data management capability, the envitonment exploits the features of the UNIX hierarchical file system (also available on VMS) for organizing and temporarily maintaining both waveform and parameter data. Thus desired portions of information can easily be extracted from the data management system and placed on external files in standardized formats for use by regular utilities or special-purpose programs. Likewise, waveform data, which is generally maintained on magnetic tape in a standard archive format, can be selectively extracted and stored on disk files. Figures 1 and 2 depict the control flow for preparing, archiving, and dearchiving waveform data.

This relational system also allows for a clean and logical organization of parameter data. A relational data management system maintains data in the conceptual form of tables or lists. Entries in tables are associated with other tables through the values of particular entries. Figure 3 gives a simplified view of the parameter data organization used by the Center and CCS. As waveforms are collected, information about them and pointers to their locations are stored in the "wftape" or "wfdisc" tables. Analysis of the waveforms produces a set of specific arrivals, kept in the "arrivals" table. The seismologist can then analyze events by looking at st'ts of arrivals, collected and grouped into possible origins via the "assoc"

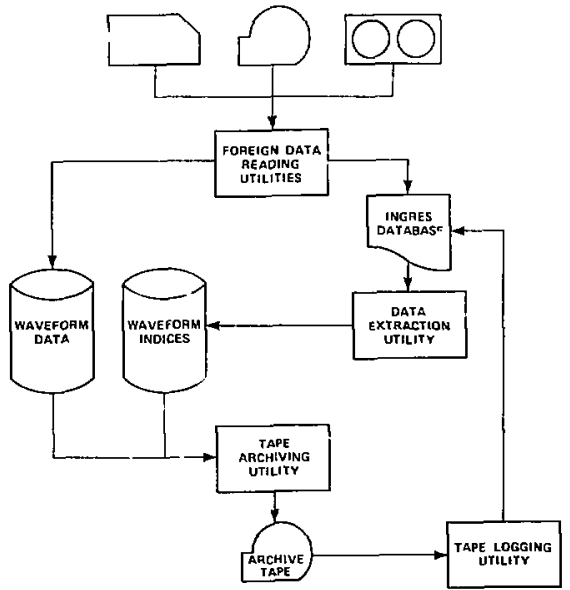

Figure 1. Archiving data. [XBL 841-9576]

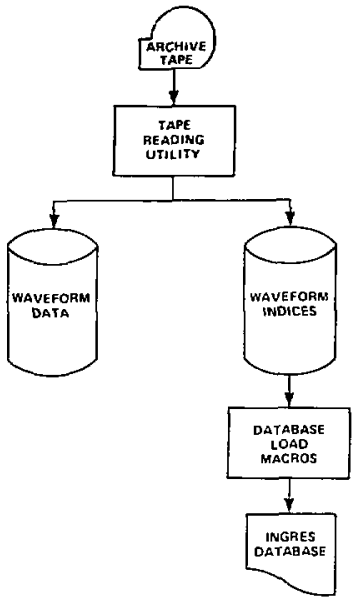

Figure 2. Extracting archived data. [XBL 841-9575]

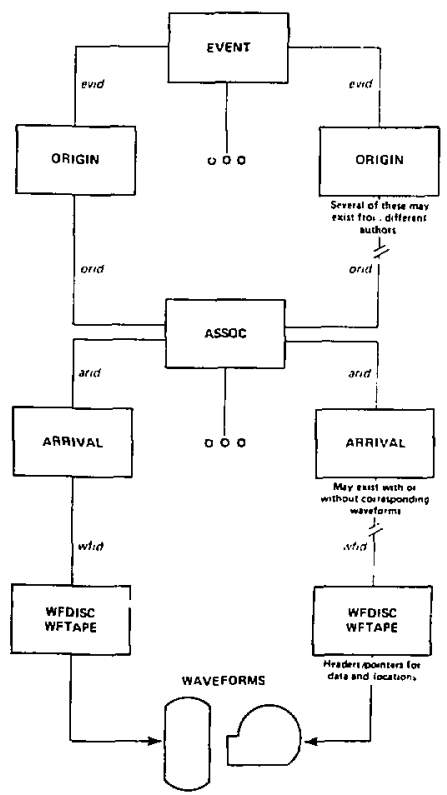

Figure 3. Data associations within data base. [XBL 841-9577) 
("association") table. This conceptually straightforward data organization frees the seismologist from details about data retrieval and storage and allows him to invest his energies in data analysis.

\section{ONGOING AND FUTURE EFFORTS}

Primary efforts during the past year have emphasized creating a standardized data handling mechanism at both sites. Now, with the data treated in a uniform fashion and data exchange between the two sites begun, emphasis can shift to providing new procedures and methodologies for seismic data research and the creation of an effective computing environment for the seismic researcher. Methods for interfacing the standardized data sets to locally available seismological packages are being developed. These analysis packages include the commercially developed DISCO system nd the SAC system, created at Lawrence Livermore Laboratory and recently installed at CCS. In addition, the Center uses a large and powerful Megatek color plotting device for graphically depicting waveforms. A similar device will be installed at CCS shortly, thus allowing for the codevelonment of graphics interfaces.

The design of an effective seismic analysis environment requires more than standardized data handling and graphics utilities. The seismic researcher will need to be isolated from the idiosyncrasies of the host computer operating system. He will also need mechanisms for incorporating his own data sets into the system and for developing his own analysis techniques on the basis of general capabilities already provided. Finally, to operate in this joint project, the environment will have to provide a common interface to the two distinctly different operating systems in use. The computer science expertise necessary to design and develop such an environment is being provided by the Computer Science and Mathematics Department of the Laboratory.

The sharing of common data handling structures and procedures along with a similar graphics environment provides $\mathrm{CCS}$ and the Center with a unique opportunity to proceed in parallel with each other, taking advantage of each other's efforts yet maintaining the individuality required for successful seismological research.

\section{ELECTRICAL AND ELECTROMAGNETIC TECHNIQUES}

\section{ELECTROMAGNETIC SOUNDINGS IN THE LONG VAILEY CALDERA, CALIFORNIA}

\author{
N.E. Goldstein, H.F. Morrison, M.J. Wilt, \\ and $J$. Turnross
}

Forty-six frequency-domain, controlled-source electromagnetic soundings (CSEMi) and five magnetotelluric (MT) soundings were made in the Long Valley caldera to determine subsurface resistivities to depths of several kilometers. The purpose of this work, done by Lawrence Berkeley Laboratory (LBL) under the Continental Scientific Drilling Program, was to gain indirect information on the location of possible heat sources within the caldera, particularly in the south moat area, where earthquake activity has been extremely high since 1980 .

\section{CSEM SOUNDINGS}

To perform the CSEM soundings, a strong primary elcctromagnetic field is created by impressing a low-frequency current (typically 0.1 to $30 \mathrm{~Hz}$ ) into a large, multiturn loop laid out on the surface. Figure 1 is a schematic diagram of the LBL controlledsource system, which is driven by a $60-\mathrm{kW}$ motor generator (Morrison et al., 1978; Goldstein et al., 1982; Wilt et al., 1983). Transmitter loops ate varied in diameter from $100 \mathrm{~m}$ for shallow exploration to over $1 \mathrm{~km}$ for greater depths of investigation. Depth of investigation is also strongly dependent on the separation between loop and receivers. Figure 2 shows the distribution of transmitter loops and receiver stations employed in Long Valley. By using larger loops, we achieve larger dipole moments, and this allows us to detect signals $10 \mathrm{~km}$ or more from the loop. Depending on subsurface resistivities, depth of investigation varies approximately from 0.5 to 1.0 times the loop-receiver separation. 

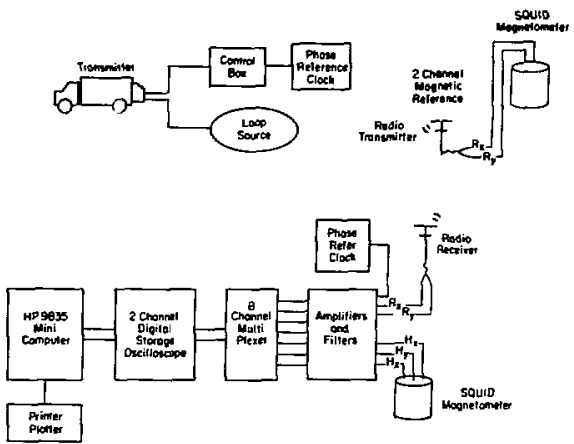

Figure 1. Schematic diagram of the EM-60 CSEM system. The loop source is typically a square 100 to $1000 \mathrm{~m}$ on a side, and the SQUID magnetometer/receiver scan is 0.5-10 km away. A distant SQUID magnetometer reference is used for noise cancellation. [XBL 818-3383]

Fields were detected using a three-component S2UID (Superconducting Quantun Interference Device) magnetometer. After bandpass filtering to reject low frequencies and eliminate aliasing, the signals are notch filtered to remove 60 - and $180-\mathrm{Hz}$ powerline noise, and segments are then stacked. Several stacks of each band per station are processed in the field, and the results are stored on tape for additional post-field processing. During data collection, the observed signals are monitored by the operator, who chooses whether to accept or reject

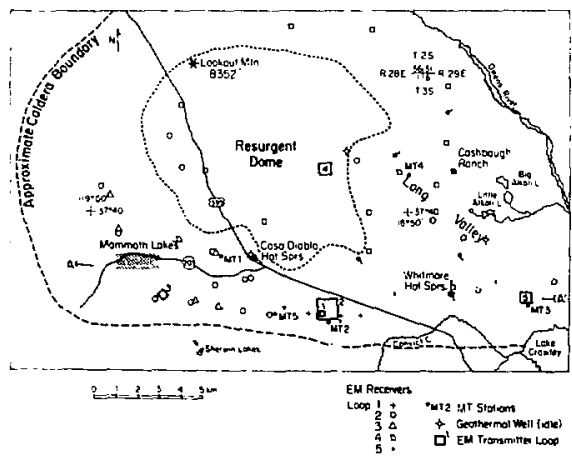

Figure 2. Location of the transmitter loops, receiver stations, and MT sounding sites occupied in Long Valley. [XBL 832-1712A] any time series. During the observations we also employ a second, distant reference magnetometer for additional noise rejection at the lower frequencies. The horizontal geomagnetic field signals at the reference are telemetered to the recording site, where they are used to cancel natural geomagnetic noise in the local station signal prior to recording.

After corrections are made for system amplitude and phase characteristics, the frequency spectra of the averaged field parameters, such as (1) normalized vertical field $\left(\mathrm{H}_{z}\right)$ amplitude and phase, (2) normalized radial field $\left(H_{r}\right)$ amplitude and phase, (3) ellipticity of $H_{2}, H_{r}$, and (4) wavetilt amplitude and phase, are fitted independently or jointly to a layered (onedimensional) earth model by means of a leastsquares inveision. The inversion procedure accounts for elevation differences between transmitter and receiver and effects of a tilted (nonhorizontal) transmitter. Figure 3 shows how well independent fits to $H_{z}$ and $H_{r}$ amplitudes agree at one of the Long Valley stations.

If the earth were truly one-dimensional, there should be no tangential magnetic field, $H_{\theta}$, except for a small noise component. The fact that a significant $H_{\theta} / H_{r}$ ratio is observed at several stations, and is not due to sensor misorientation, is a clear indication that the primary fields are being distorted by two- and three-dimensional inhomogeneities. Although the source of these inhomogeneities has not been confirmed by numerical modeling, we suspect that much of the observed effect is due to the highly variable thickness and resistivity of the surface layer encountered in the caldera. The impact of inhomogeneous surface conditions on onedimensional interpretations is to bias layer thicknesses and introduce errors into layer resistivities.

\section{SHALLOW RESISTIVITY DISTRIBUTION}

To illustrate the inhomogeneous nature of the surface layer, we plot in Fig. 4 the electrical resistivity based on one-dimensional inversions of CSEM data. Values (in $\Omega \cdot \mathrm{m}$ ) correspond to resistivities of the surface layer; thicknesses of the first layer vary from 100 to $500 \mathrm{~m}$. This picture is similar to resistivity maps reported by earlier workers who used audio-frequency magnetotellurics (AMT) (Hoover et al., 1976) and bipole-dipole dc resistivity (Stanley et al., 1976). . Some of the EM features are laterally displaced from those shown by Hoover et al. (1976) and Stanley et al. (1976)-a result of differences in station locations, primary field characteristics, a.d plotting conventions. Note that we plot CSEM data midway between transmitter and receiver. 

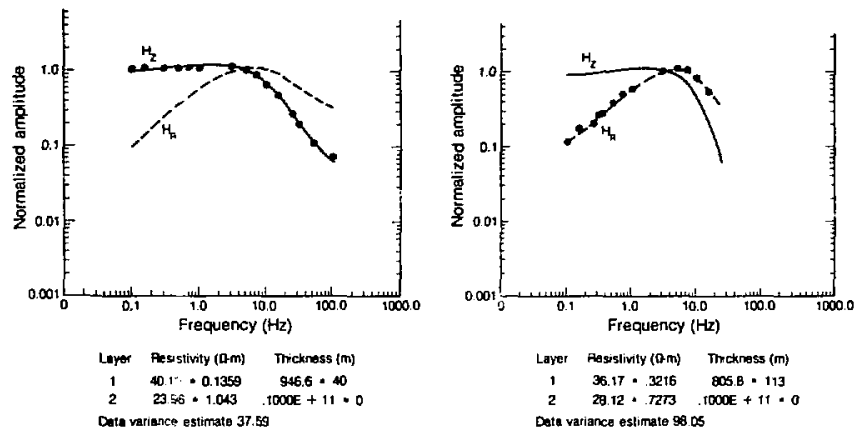

Figure 3. Examples of $c$ e-dimensional inversion fits to the normalized and corrected vertical magnetic field $H_{z}$ and radial magne ic field $H_{r}$ for one receiver site. [XBL 8312-2419]

Resistivity lows detected by the three methods are located around Casa Diablo Hot Springs (extending eastward toward Whitmore Hot Springs) and east of the resurgent dome. Resist; ity highs are related to specific post-caldera volcanic units (e.g., the Hot Springs Rhyolite near Whitmore Hot Springs) and to the area of glacial debris along the south rim.

The cause of the resistivity ows is believed to be due mainly to porous volcanics and lake sediments saturated, in places, with warm water; e.g., Sorey et al. (1978) recorded $70^{\circ} \mathrm{C}$ at $100^{+} \mathrm{m}$ in shallow wells east of the resurgent dome.

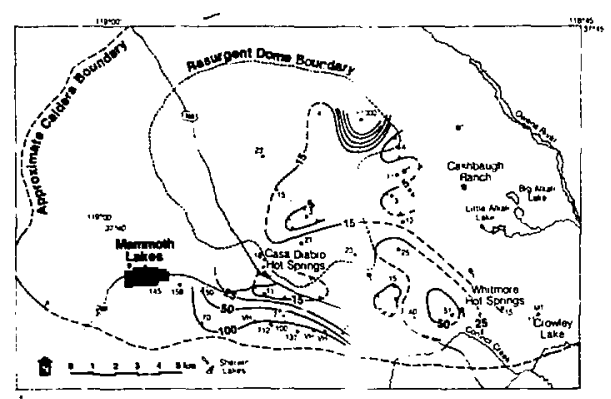

Figere 4. Firsi layer resistivities $(\Omega \cdot \mathrm{m})$ based on onedimensional inversions. The first layer thickness varies from about 100 to $500 \mathrm{~m}$. [XBL 843-9667]

\section{DEEP RESISTIYITY ANOMALIES}

At some of the MT stations and some of the large-separation EM stations, intrabasement conductors were discerned. Figure 5 shows the approximate locations of two apparently separaie and distinct intrabasement conductors, $\mathrm{C} 1$ and $\mathrm{C} 2$. Both are within $3 \mathrm{~km}$ of the surface at their apex, but depths may be somewhat greater because of errors introduced by surface inhomogeneities. Only the conductor tops can be resolved.

Conductor $\mathrm{Cl}$ is located in the south moat area from Casa Diablo Hot Springs eastward toward

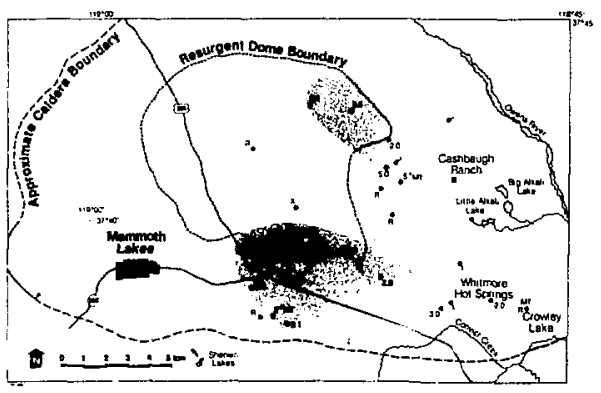

Figure 5. Approximate locations of two conductive zones at depths of $+25 \mathrm{~km}$ discerned from a combination of EM and MT soundings. $R$ indicates where only a resistive basement was found. [XBL 843-9668] 
Crowley Lake. The conductor correlates in part with the area of earthquake epicenters recorded since 1980. The Cl boundary is open to the south, and may extend southward into the Sierra block. Although the source of $\mathrm{Cl}$ is not known, one possible explanation is a region of hydrothermally altered and fractured rock above a hypabyssal heat source. Whether a geologic relationship exists between $\mathrm{Cl}$ and the recent intense earthquake activity in the period December 1982 to January 1983 is a critical point, but one that cannot be answered at this time.

Conductor $\mathrm{C} 2$, near the northeast corner of the resurgent dome. is less well defined laterally than $\mathrm{Cl}$ and seems to plunge to the southeast. Although there is no present seismic activity near $\mathrm{C2}$, this conductor correlates well with the dominant aeromagnetic high observed within the caldera. This has raised the speculation that $\mathrm{C} 2$ is related to a mafic intrusive, possibry a post-caldera pluton as proposed by Pakiser et al. (1964) and Kane et al. (1976).

\section{RELATIONSHIP OF THE INTRABASEMENT CONDUCTORS TO THE AEROMAGNETIC DATA}

Aeromagnetic data, both high and low level (13,000 ft and $9000 \mathrm{ft}$ above sea level), show a pronounced, elongate, northwest-trending high located between the resurgent dome and the Owens River (Kane et al., 1976). The magnetic source seems to be a large, deep body with at least two shallow projections. The more northerly of the two apparently comes to within $1 \mathrm{~km}$ of the surface on the basis of its gradient and correlates very well with conductor $\mathrm{C} 2$ in location (Fig. 6). The magnetic high also correlates reasonably wcll in location with a gravity high (Sorey et al., 1978).

A magnetic low occurs in the vicinity of conductor $\mathrm{Cl}$, and this is probably the result of nonmagnetic metasediments. A roof pendant of Paleozoic rocks was intersected at $1400 \mathrm{~m}$ beneath the Bishop Tuff in Union Oil's Mammoth No. I well near Casa Diablo Hot Springs and exposed in the Sierra block to the south of the caldera.

\section{CONCLUSIONS}

Although a rigorous multidimensional interpretation of the CSEM data has not yet been done, the one-dimensional interpretation indicates that at least two conductors exist beneath the Bishop Tuff within the raldera. The causes of the conductors and their relationship to subsurface temperature and heat sources are not known. However, aeromagnetic and seismic data suggest that conductor $\mathrm{Cl}$ in the south

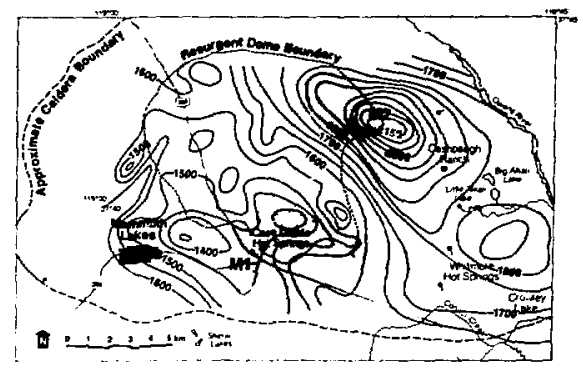

Figure 6. Spatial relationships between basement conductors $\mathrm{Cl}$ and $\mathrm{C} 2$ and the aeromagnetic survey data; flight altitute $9000 \mathrm{ft}$ above sea level. [XBL 843-9668A]

moat could be fractured granitic and metasedimentary bascment rock whose low resistivity results from a combination of temperature-related effects, such as hydrothermal alteration, high fracture porosity, and inherently low resistivity of the metasediments. Conductor $\mathrm{C} 2$ may be related to a zone of shallow, post-caldera mafic intrusives that were unable to breach the Bishop Tuff, A sheeted dike comrlex might produce the low resistivities observed.

\section{REFERENCES}

Goldstein, N.E., Mozley, E., and Wilt, M. 1982. Interpretation of shallow electrical features from electromagnetic and magnetotelluric surveys at Mount Hood, Oregon. Journal of Geophysical Research, v. 8/, no. B4, p. 2815-2828.

Hoover, D.B., Frischknecht, F.C., and Tippens, C.L., 1976. Audiomagnetotelluric sounding as a reconnaissance exploration technique in Long Valley, California. Journal of Geophysical Reseach, v. 81, p. $801-809$.

Kane, M.F., Mabey, D.R., and Brace, R.L., 1976. A gravity and magnetic investigation of the Long Valley caldera, Mono County, California. Journal of Geophysıcal Research, v. 81, no. 5, p. 754-762.

Morrison, H.F., Goldstein, N.E., Hoversten, M.. Oppliger, G., and Riveros, C.A., 1978. Description, field test, and data analysis of a controlled source EM system (EM-60). Lawrence Berkeley Laboratory, LBL-7088.

Pakiser, L.C., Kane, M.F., and Jackson, W.H., 1964. Structural geology and volcanism of Owens $\mathrm{Val}$ ley region, California-A geophysical study. USGS Professional Paper 438. 
Sorey, M.L., Lewis, R.E., and Olmsted, F.H., 1978. The hydrothermal system of Long Valley calJera, Califomia. USGS Professional Paper 1044-a.

Stanley, W.D., Jackson, D.B., and Zohdy, A.A.R., 1976. Deep electrical investigations in the Long Valley geothermal area, California. Joumal of

\section{GEOTHERMAL INJECTION MONITORING WITH de RESISTIVITY METHODS}

\author{
M.J. Wilt, K. Pruess, G.S. Bodvarsson, \\ and N.E. Goldstein
}

The temperature and salinity differences between injected and in situ fluids can result in a significant difference in their electrical resistivities, and that difference may be manifested by changes in subsurface apparent resistivities. In this article, we exam ine the possibility of mapping thermal and chemical injection plumes using surface and downhole electrical resistivity methods. We use computer codes to simulate injection experiments and calculate apparent resistivity for the model before and after each simulation.

\section{METHODOLOGY}

To ealculate the extent of thermaily and chemically swept regions, we use a simple model for porous-medium-type reservoirs (Fig. 1). Assuming piston-like fluid displacement, Bodvarsson (1972) has calculated the locations of the chemical and thermal frorits. In all cases, the injected wate: is at $100^{\circ} \mathrm{C}$, and the reservoir is initially at $300^{\circ} \mathrm{C}$.

We consider injection of a "small" and a "large" amount of fluid, corresponding to injection rates of $25 \mathrm{~kg} / \mathrm{s}$ and $250 \mathrm{~kg} / \mathrm{s}$, respectively, for a 3-year period. For both cases, we use a reservoir thic'sness of $400 \mathrm{~m}$ and a porosity of $15 \%$. The thermal and chemical fronts will have advanced 57 and $128 \mathrm{~m}$, respectively, for the small injected mass and 180 and $404 \mathrm{~m}$, respectively, for the large injected mass.

To determine how changes in reservoir temperature and salinity affect the bulk resistivity that might be observed in practice, we have carried out resistivity calculations using a three-dimensional finitedifference computer code RESIS3D (Dey and Morrison, 1979). The modeling parameters and ir.i-
Geophysical Research, v. 81, no. 5, p. 810-820. vilu, M., Goldstein, N.E., Stark, M., Haught, J.K., and Morrison, H.F., 1983. Experience with the EM-60 electromagnetic system for geothermal exploration in Nevada. Geophysics, v. 48, no. 8, p. 1090-1101.

tial resistivity distribution are given in Table 1 and in cross section in Fig. 1. The reservoir region is represented by a rectangular prism $1.6 \mathrm{~km} \times 1.6 \mathrm{~km}$ and $0.4 \mathrm{~km}$ thick within a uniform half-space. To add an element of realism to the model and make it similar to conditions at the Cerro Prieto geothermal field, Baja California, we introduce a conductive (5 $\Omega \cdot \mathrm{m}$ ) surface layer (Wilt and Goldstein, 1981). The parts of the model affected by injection are designated as region I (thermal region), region II (swept region), and region III (nonswept region).

The resistivities of the different regions in Fig. 1 are calculated from Archie's law and from expressions relating the resistivity to the temperature and salinity of pore fluids (Ersaghi et al., 1981). We use an initial reservoir temperature of $300^{\circ} \mathrm{C}$ and an initial in situ reservoir water salinity of $10,000 \mathrm{ppm}$. For the background region, the temperature is $100^{\circ} \mathrm{C}$ and the salinity $1000 \mathrm{ppm}$. Model resistivities for regions I, II, and III were adjusted after 3 years of injection to correspond to the new subsurface fluid and temperature distribution.

Two resistivity arrays were used in these calculations: (1) a dipole-dipole array and (2) a downhole surface array. We have considered six cases for this study; the parameters are summarized in Table 1.

\section{RESULTS}

\section{Dipole-Dipole Array}

Dipole-dipole resistivity calculations were made for the initial conditions and two injection cases. The injection cases correspond to cold fresh-water injection for 3 years at a low rate $(25 \mathrm{~kg} / \mathrm{s})$ and a high rate $(250 \mathrm{~kg} / \mathrm{s})$. For these cases, percent difference psuedosections were prepared that correspond to the spatial distribution of observed apparent resistivity change. In both cases, the maximum anomaly appears at the edges of the pseudosection. This is a typical anomaly pattern for a dipole-dipole measurement, an artifact of the way the data are plotted. After 3 years, the percent difference pseudosection 
Table 1. Summary of injection and resistivity modeling parameters.

\begin{tabular}{|c|c|c|c|c|c|c|}
\hline \multirow{3}{*}{ Case } & \multirow{2}{*}{\multicolumn{2}{|c|}{ Injection }} & \multirow{3}{*}{$\begin{array}{l}\text { Resist vity } \\
\text { array }\end{array}$} & \multicolumn{3}{|c|}{$\begin{array}{l}\text { Rock resistivities of } \\
\text { the three regions }\end{array}$} \\
\hline & & & & & & \\
\hline & Rate & Type & & & & \\
\hline $\begin{array}{l}\text { Base } \\
\text { case }\end{array}$ & 0 & $\begin{array}{l}\text { No injection } \\
300^{\circ} \mathrm{C} \\
10,000 \mathrm{ppm}\end{array}$ & Dipole-dipole & 2.15 & 2.15 & 2.15 \\
\hline 1 & $25 \mathrm{~kg} / \mathrm{s}$ & $\begin{array}{l}100^{\circ} \mathrm{C} \\
1000 \text { ppm } \\
\text { (cold fresh } \\
\text { water) }\end{array}$ & Dipole-dipole & 15.6 & 10.75 & 2.15 \\
\hline 2 & $250 \mathrm{~kg} / \mathrm{s}$ & $\begin{array}{l}100^{\circ} \mathrm{C} \\
1000 \mathrm{ppm} \\
\text { (cold fresh } \\
\text { water) }\end{array}$ & Dipole-dipole & 15.6 & 10.75 & 2.15 \\
\hline 3 & $250 \mathrm{~kg} / \mathrm{s}$ & $\begin{array}{l}100^{\circ} \mathrm{C} \\
1000 \mathrm{ppm} \\
\text { (cold fresh } \\
\text { water) }\end{array}$ & $\begin{array}{l}\text { Downhole surface } \\
\text { electrode in } \\
\text { injection well }\end{array}$ & 15.6 & 10.75 & 2.15 \\
\hline 4 & $250 \mathrm{~kg} / \mathrm{s}$ & $\begin{array}{l}100^{\circ} \mathrm{C} \\
10,000 \mathrm{ppm} \\
\text { (isochemical) }\end{array}$ & $\begin{array}{l}\text { Downhole surface } \\
\text { electrode in } \\
\text { injection well }\end{array}$ & 15.6 & 10.75 & 2.15 \\
\hline 5 & $250 \mathrm{~kg} / \mathrm{s}$ & $\begin{array}{l}100^{\circ} \mathrm{C} \\
10,000 \mathrm{ppm} \\
\text { (isochemical) }\end{array}$ & $\begin{array}{l}\text { Downhole surface } \\
\text { electrode in } \\
\text { injection well }\end{array}$ & 4.0 & 2.15 & 2.15 \\
\hline 6 & $250 \mathrm{~kg} / \mathrm{s}$ & $\begin{array}{l}100^{\circ} \mathrm{C} \\
15,000 \mathrm{ppm} \\
\text { (cold saline } \\
\text { water) }\end{array}$ & $\begin{array}{l}\text { Downhole surface } \\
\text { electrode in } \\
\text { injection well }\end{array}$ & 1.90 & 1.07 & 2.15 \\
\hline
\end{tabular}

for the lower injection rate shows a maximum change of about $1 \%$, which is comparable with the accuracy attainable in field measurements. For the higher injection rate, a maximum apparent resistivity change of about $3 \%$ is observed. The main reason for the insensitivity of dipole-dipole measurements is that a relatively small volume of ock is affected by the injection compared to the volıme of rock sampled by the measurements.

\section{Downhole Surface Array}

For downhole surface measurements, a current electrode is placed in the injection well at a depth of
$900 \mathrm{~m}$ (central case) or in another well outside the injection plume at the same depth (offset case). Voltage measurements are made along a profile between closely spaced surface dipoles.

Figure 2 shows apparent resistivity changes after 3 years of injecting fresh cold water at the high rate. Note the marked, bell-shaped anomaly where the maximum change is more than $70 \%$. The anomaly is due almost entirely to the salinity rather than the temperature contrast. The approximate position of the chemical front may be estimated by a "halfwidth" calculation, which in this case corresponds to a distance of $4.50 \mathrm{~m}$ from the well, where the actual position is $400 \mathrm{~m}$. 


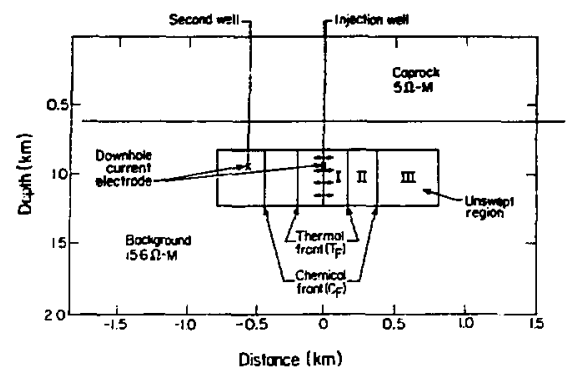

Figure 1. Cross section of the resistivity distribution for injection simulation. The actual reservoir region is a rectangular prism $1.6 \mathrm{~km}^{2}$ and $0.4 \mathrm{~km}$ thick. Regions I, II, and III represent the thermally swepl region, the chemically swepl region, and undisturbed parts of the reservoir, respectively. [XBL 836-2643]

\section{Offset Downhole Electrode}

For this case, the current electrode was placed $1066 \mathrm{~m}$ from the injection well at a depth of $900 \mathrm{~m}$. Figure 3 is a plot of the results after 3 years of highrate injection. An anomaly shows clearly in the region where fluid is injected, but the magnitude of the anomaly is smaller than that observed in the previous case. The anomaly also has an asymmetric shape and is not centered over the injection well. The asymmetric anomaly pattern is the result of subsurface current redistribution around the zone of

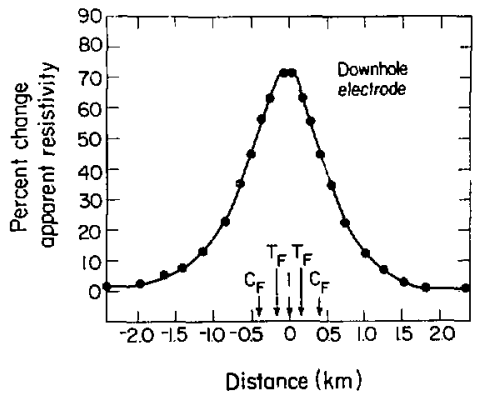

Figure 2. Percent difference plot for central downhole electrode tase after? years of high-raie injection. I is the surface position of the current elecirode, $T$ is the surface position of the thermal front, and $C$ is the surface position of the chemical (salinity) front. [XBL 836-2654]

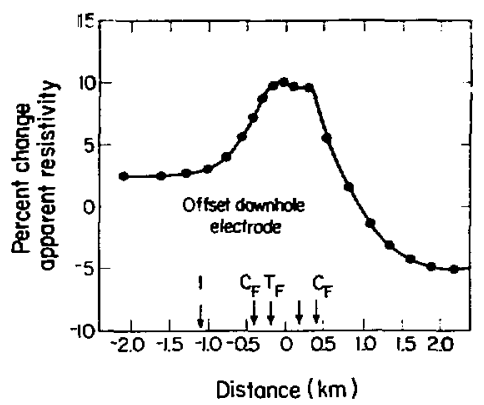

Figure 3. Percent difference plot for offset downhole injection case afier 3 years of high-rate injection. [XBL 836-2653]

increased resistivity due to injection. Currents tend to gather at the closer chemical front boundary and disperse at the far boundary.

For the offset case, a half-width calculation indicates a chemical front $440 \mathrm{~m}$ from the injection well.

\section{Isochemical Injection}

To determine that portion of the magnitude of the resistivity anomaly due solely to thermal effects, we have considered a case in which the injected water has the same salinity as the in situ water. We consider high-rate injection and a central downhole electrode.

Figure 4 shows the percent apparent resistivity change for the isochemical injection case. The bell-

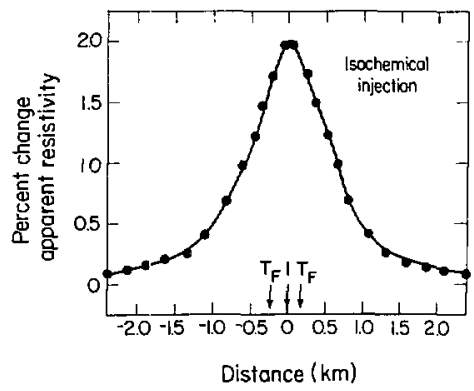

Figure 4. Percent difference plot for the isochemical downhole injection case after 3 years of high-rate injection. [XBL 836-2648] 
shaped anomaly has a maximum amplitude of only about $2 \%$ and a half-width of about $200 \mathrm{~m}$, in good agreement with the radius, $R t=180 \mathrm{~m}$, of the thermally swept refion. The thermal effects seem minor compared with chemical effects for two reasons; first, because heat is exchanged between the injected fluid and the rock, the thermally affected region is considerably smaller than the swept region; second, the variation of resistivity with temperature is much smaller than its variation with fluid salinity.

\section{Saline Water Injection}

In the final case considered, the injected water hs a temperature of $100^{\circ} \mathrm{C}$ and is $50 \%$ more saline an in situ water. A central downhole current electrode is used with high-rate injection.

Figure 5 reveals a characteristic bell-shaped curve with a half-width of $450 \mathrm{~m}$. The anomily is negative, corresponding to a decrease in resistivity in

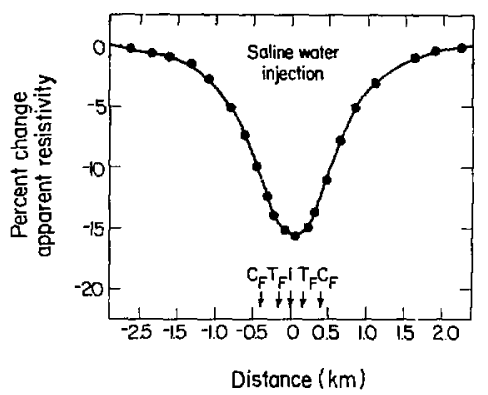

Figure 5. Percent difference plot for the high-salinity downhole injection case after 3 years of high-rate injection. [XBL 8312-4790] the injected region. Although the resistivity in the swept region decreased only by a factor of about 2 , the maximum anomaly is almost $20 \%$.

\section{CONCLUSIONS}

The major conclusions reached by this study are:

1. It is possible to locate the position of injection plumes if the salinity of the injected water differs significantly from tivat of the in situ water and a relatively large mass of water is injected.

2. Downhole surface resistivity zrrays are better for detecting injection plumes than surface measurements.

3. The change in apparent resistivity due to the thermal plume is typically only 0.1 that of the chemical plume and may be difficult to detect.

4. Resistivity measurements are more sensitive when injected water is more saline than wien it is less saline than the in situ water.

\section{REFERENCES}

Bodvarsson, G., 1972. Thermal problems in the siting of reinjection wells. Geothermics, v. 1, no. 2.

Dey, A., and Morrison, H.F., 1979. Resistivity modeling for arbitrarily shaped threedimensional structures. Geophysics, v. 44, no. 4.

Ershaghi, I., Dougherty, E.E., and Handy, L.L., 1981. Formation evaluation in liquid dominated geothermal reservoirs. Report to Department of Energy, D0E/ET/28384-T1.

Wilt, M., and Goldstein, N.E., 1981. Results from two years of resistivity monitoring at Cerro Prieto. In Proceedings, Third Symposium on the Cerro Prieto Geothermal Field, Baja California, Mexico, March 24-26, 1981. Lawrence Berkeley Laboratory, LBL-11967, p. 372-379. 


\section{RECENT RESULTS OF DIPOLE- DIPOLE RESISTIVITY MONITORING AT THE CERRO PRIETO GEOTHERMAL FIELD, MEXICO}

\section{M.J. Wilt and N.E. Goldstein}

In the Spring of 1983, the fifth in a series of anrual repetitive dipole-dipole resistivity measurements was made on line E-E' at Cerro Prieto (Fig. 1). In addition, measurements were also made along a new line ( $F-F^{\prime}$ ) established over the field.

The purpose of the dipole-dipole measurements is to indirectly monitor reservoir changes related to large-scale fluid production. Measurements on $\mathbf{E}-\mathbf{E}^{\prime}$ have already yielded significant information on movement of water within the producing zone at Cerro Prieto (Wjit and Goldstein, 1982). It was hoped that by having two monitoring lines crossing over the field, we would be in a better position to track large-scale movements of subsurface fluids. In

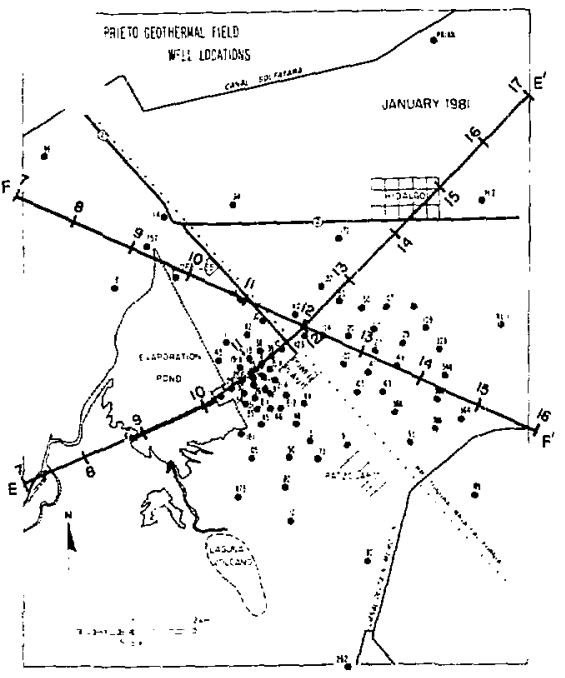

Figure 1. Stalion location map for dipole-dipole lines $E-E^{\prime}$ and $F-F^{\prime}$ in relation to the wellfield. [XBL 81]2532D addition, line F-F crosses an area of wells that will supply steam to a new electrical generating plant (Cerro Prieto II), scheduled to start up in 1984. Future measurements on this line may indicate how the reservoir is responding to massive changes in fluid withdrawal and recharge.

\section{RECENT RESULTS}

In Figs, 2 and 3, percent difference pseudosections are shown for line E-E'; these correspond, respectively, to observed 4-year and 18-month changes in apparent resistivity. In Fig. 2, the overall pattern indicates declining resistivity, particularly between stations 11 and 17 , during the 4-year period. Between stations $1 i$ and 17 , the section indicates an average apparent resistivity decrease of greater than $10 \%$; for some $\mathrm{p}$ ints, the apparent resistivity has decreased more than $30 \%$. Although this part of the pr sfile has consistently shown declining resistivity since measurements began, the rate of decrease has intensified during the past year (Wilt and Goldstein, 1982). On the other hand, we observe a region of significant apparent resistivity increase between stations 7 and 11 . This region, which corresponds to the present production zone at Cerro Prieto, has consistently indicated a higher resistivity than the baseline measurements, but the average rate of increase has declined from $10 \%$ in 1982 to about $5 \%$ in 1983. Figure 3 shows apparent resistivity changes during the past i 8 months on line E-E'. The pseudosection indicates an overall apparent resistivity decrease of about 5\%; between stations 7 and 11 , the decrease is more than $10 \%$.

The results shown in Figs. 2 and 3 suggest that significant changes in groundwater conditions have occurred at Cerro Prieto within the past several years. Within the present production zone, a 30 month pattern of increasing resistivity has been reversed over the past 18 months. The increasing resistivity was attributed to the influx of fresher, cooler water into the shallow $(\alpha)$ reservoir from above and from the sides (Grant et al., 1981). The reversal of this pattern suggests that some significant changes are occurring in the $\alpha$ reservoir. Alhough recent reports from the field operators at Cerro Prieto indicate that most of the brine produced there still comes from the shallow $(\alpha)$ reservoir, some of the wells that tap the $\alpha$ reservoir have been shut in as newer wells tapping the deeper, highertemperature, higher-salinity $(\beta)$ reservoir have been put into production. Recent chemical anajyses of brines produced from the shallow system show a significant increase in chloride concentration from specific wells, but it is not known whether there has 


\section{Percent Difference $Q_{A}$ \\ Spring 1983 Compared to Spring 1979}

W

Kilometers

$\mathbf{E}$

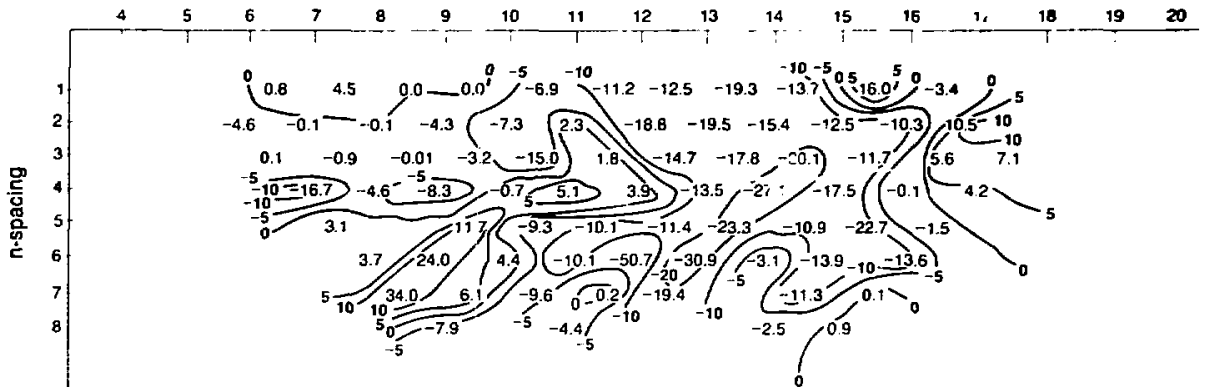

Figure 2. Pseudosection plot of apparent resistivity differences between Spring 1983 and Spring 1979.

[XBL 8312-6711]

\section{Percent Difference $\varrho_{A}$ Spring 1983 Compared to Fall 1981}

W

Kilometers

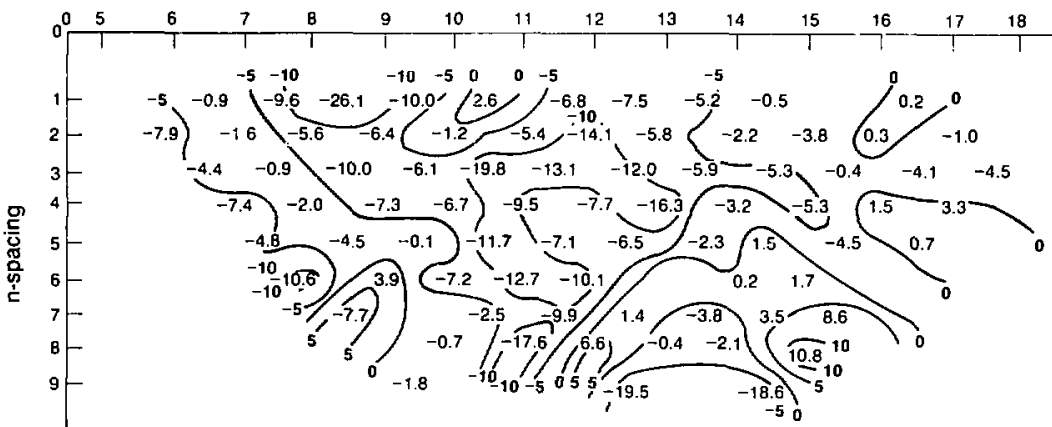

Figure 3. Pseudosection plot of apparent resistivity differences between Spring 1983 and Fall 1981.

[XBL 8312-6722] 
been an overall increase in chloride. The water levels in observation wells $M-6$ and $M-34$ are both rising, and the level in M-34 is up more than $100 \mathrm{~m}$. The dipole-dipole data suggest that pore fluid pressure and salinity are increasing in the $\alpha$ reservoir, but the data are not yet conclusive.

The overall decrease in apparent resistivity for the region below stations 11 to 17 is consistent with the concept of saline water intrusion into the system. However, as few wells are presently producing fluid in that part of the field, it is not possible to compare apparent resistivity changes with changes in water chemistry. One significant change that has occurred in this area is the halt in farming and irrigation caused by construction of the Cerro Prieto II power plant. The land in this region has not been irrigated for more than 2 years, and the shall sw groundwater has probably become warmer and more saline. Both of these factors cause a decrease in rock resistivity and could explain the observed resistivity decrease in the shallow part of the system. However, to explain resistivity decreases at depths greater than a few hundred meters, other mechanisms are needed. Halfman et al. (1982) reported that hot saline fluid enters the system at depth in the region and gradually moves upward and westward into the $\alpha$ aquifer. The decreasing resistivity may be the result of an increase in the rate of hot water inflow due to lower pressures in the shallow pan of the system. Altematively, the decrease may reflect water-rock interactions that produce mineralogic changes, such as the formation of zeolites.

Line $F-F^{\prime}$ is $20 \mathrm{~km}$ long and was surveyed using a dipole spacing of $1 \mathrm{~km}$ (Fig. I). Emplacement of the permanent electrodes and initial measurements were made in the Spring of 1983; we hope to make additional measuremerts after the start-up of the Cerro Prieto II power plant. Measurements were made with $n$-spacings from $/$ to 9 , which translates to a maximum depth of investigation of about $3 \mathrm{~km}$. The average standard error of these data is about $3 \%$.

The apparent resistivity pseudosection for line $\mathbf{F}-\mathbf{F}^{\prime}$ is given in Fig. 4. Although two-dimensional modeling has yet to be done, there are some overall similarities with line E- $E^{\prime}$ (which was modeled) that allow us to derive a qualitative model for the resistivity distribution. Between stations 1 and 4 , the data suggest that a zone of relatively high resistivity exists at a depth of about $1 \mathrm{~km}$. The high resistivity probably represents hydrothermal metamorphism within shales and sandstones in the reservoir (Elders et al., 1981). The deep section $(<1 \mathrm{~km})$ betwe $\cdot \mathrm{n}$ stations 11 and 15 is associated with a low-resistivity zone. This area correlates with a zone of high thermal gradients and a clay-rich cap rock (Halfman et al., 1982). As fluid for Cerro Prieto II will be pro-

\section{F-F' Apparent Resistivity}

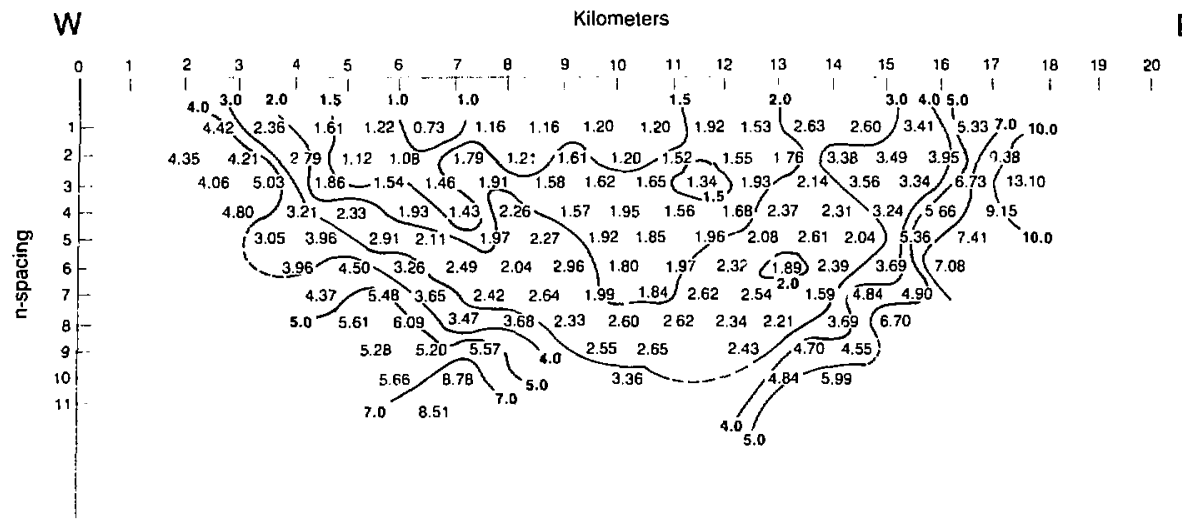

Figure 4. Apparent resistivity pseudosection for dipole-dipole line $F-F^{\prime}$. |XBL 8312-6723] 
duced in this region at these depths, future dipoiedipole measurements in this area are important for understanding groundwater changes due to production. The pseudosection also shows evidence of a sharp resistivity boundary near station 17. East of this point the resistivity is substantially higher to great depth. Exploration wells drilled in the area of higher resistivity have encountered a large thickness of sands containing fresh and cooler fluids. There is also an ausence of any significant shale layers that tend to be more conductive than sandstones. The resistivity boundary, which had also been earlier noted in magnetotelluric sounding data, may therefore mark the eastern boundary of the geothermal field.

\section{REFERENCES}

Elders, W.A., Williams, A.E., and Hoagland, J.R., 1981. An integrated modes for the natural flow regime in the Cerro Pricto geothermal field based upon petrological and isotope geochemical criteria. In Prozeedings, Third Symposium on the Cerro Prieto Geothermal Field, Baja Califor-

\section{A STUDY OF THE FINITE- ELEMENT SOLUTION OF A 2-1/2 DIMENSIONAL ELECTROMAGNETIC PROBLEM}

\author{
K.H. Lee and H.F. Morrison
}

An important element in the successful use of controlled-source electromagnetic (EM) techniques is the ability to interpret data taken in areas where the geologic structures do not safely permit a layeredearth assumption. For this reason a numerical solution for the electromagnetic scattering by an arbitrary two-dimensional earth has been developed (Lee, 1978). Using a Fourier transformation, we can represent, approximately, the frequency-domain EM variational integral by a sum of two-dimensional integrals in harmonic space. Each two-dimensional variational integral is then cvaluated on a finiteelement mesh and, according to the variational principle, is finally reduced to a system of simultaneous equations. The solution is obtained in terms of the nia, Mexico. March 24-26, 1981. Lawrence Berkeley Laboratory, LBL-11967, p. 102-110.

Grant, M.A., Truesdell, A.H., and Mañón, M., 1981. Production induced boiling and cold water entry in the Cerro Prieto geothermal reservoir indicated by chemical and physical measurements. In Proceedings, Third Symposium on the Cerro Prieto Geothermal Field, Baja California, Mexico, March 24-26, 1981. Lawrence Berkeley Laboratory, LBL-11967, p. 221-238.

Halfman, S.E., Lippmann, M.J., Zelwer, R., and Howard, J.H., 1982. Fluid flow model of the Cerro Prieto field based on well log interpretation. In Proceedings, Fourth Symposium on the Cerro Prieto Geothermal Field, Guadalajara, Mexico, August 10-12, $1982 . \quad$ Mexicali, Comisión Federal de Electricidad, in prepara. tion.

Wilt, M.J., and Goldstein, N.E., 1982. Interpretation of dipole-dipole resistivity monitoring data at Cerro Prieto. In Proceedings, Fourth Symposium on the Cerro Prieto Geothermal Field, Guadalajara, Mexico, August 10-12, 1982. Mexicali, Comisión Federal de Electricidad, in preparation. secondary electric field, from which the secondary magnetic field is numerically obtained through $\nabla X E$ operation. It is in this last numerical step where we have detected a systematic numerical error, especially for the real part of the magnetic field. To understand the problem encountered, we performed a simple numerical analysis relative to a uniform half-space. In this case, the magnetic field, say $H_{x}$, can be calculated analytically in harmonic space. For comparison, the same magnetic field may be computed numerically. To do the numerical analysis, we first calculate the electric fields at four corners of a rectangle. Then the numerical version of the magnetic field is derived from these fields using the relation

$$
H_{x}=\frac{i}{\omega \mu}\left(i k_{y} E_{z}-\frac{\partial E_{y}}{\partial z}\right) .
$$

where $k_{y}$ is the harmonic wave number in the strike direction.

In the problem studied, a half-space of $100 \Omega \cdot \mathrm{m}$ was selected. A horizontal magnetic dipole with unit moment and frequency of $30 \mathrm{~Hz}$ is located at $x=0$, 
$20 \mathrm{~m}$ above the surface of the earth. For a harmonic wave number of $k_{y}=0.000$ :. these fields are computed at the four corner nodes of a rectangle defined by $(x, z)=(18,0),(24,0),(24,-10),(18,-10)$. The $z$ axis is positive downward. The magnetic field given at the center of the rectangle, $(x, z)=(22,-5)$, is analytically computed and shown in Fig. 1. Assuming that the electri- field behaves linearly within the rectangle, we can numerically compute the magnetic field as $H_{x}=(-4.851,-i 25.88) \times 10^{-8}$, and the result is remarkably close to the one analytically computed. As we increase the harmonic wave number, however, the similarity between results disappears. The field diagram for the same rectangle is shown in Fig. 2 for $k_{y}=0.0625$. As shown at the center of the rectangle, the real part of $H_{x}$ is negligible. However, from the numerical derivatives of electric fields, the horizontal component of the magnetic field is found to be $H_{x}=\left(1.560^{-} \times 10^{-6}\right.$, $-i 5.101 \times 10^{-10}$ ). This is entirely difierent from the one analytically obtained, especially the real part.

There is no imaginary part of $E_{2}$; therefore, the imaginary part of the numerical $H_{x}$ comes from the vertical derivative of the real part of the electric field $E_{y}$. For $k_{y} \gg$ ' $k$ ', where $k$ is the propagation constant, the field in harmonic space behaves as $e^{-k_{r} \rho}$. The cylindrical distance $\rho$ is defined on the $x z$ plane, perpendicular to the strike. Over the vertical distance $(z)$ of $10 \mathrm{~m}$, the electric field amplitude would decrease by approximately $50 \%\left(=e^{-0.625}\right)$ away from the surface of the earth. Consequently, the numerical derivative of the electric field itself generated considerable error. In our analysis for $k_{y}$ $=0.0625$, the imaginary part of the numerical $H_{x}$ is about $20 \%$ larger than the analytical one. The real

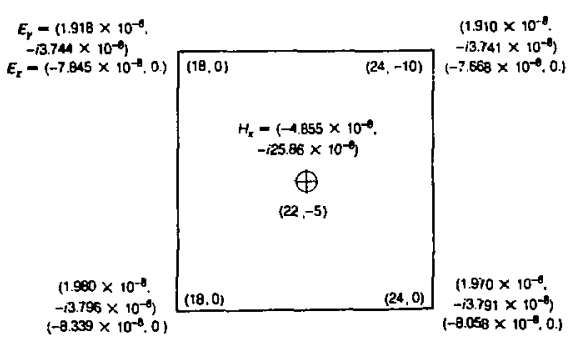

Figure 1. Analytically computed electric and magnetic fields for $k_{y}=0.0005$. [XBL 844-9735]

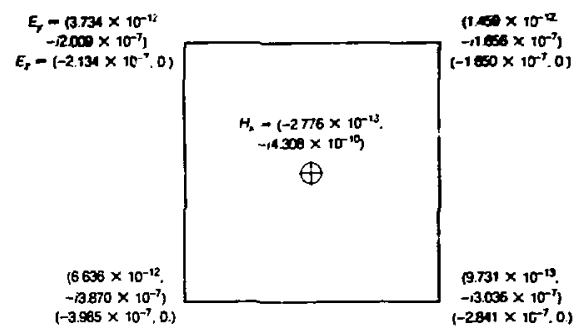

Figare 2. Analyticaily computed electric and magnetic fields for $k_{y}=0.0625$. [XBL 844-9736]

part of $H_{x}$ comes from the difference between the cross derivatives of the electric fields $E_{y}$ and $E_{z}$. With a $20 \%$ numerical error associated with each of the derivatives, the error contained in the difference would be cumulative. Therefore, the real part of the numerica! $H_{x}$ consists entirely of this enhanced error itself, because the true solution has a negligible real part for the larger $k_{y}$ vaiue.

Although the analysis has been made for the scattered field from a uniform half-space, a similar degree of numerical error would be expected for the numerical derivatives of the scattered electric field (and their differences) from a lateral inhomogeneity.

One way of obtaining the magnetic field with relatively less error is to use integrals rather than derivatives. Assuming that the electrically inhomogeneous body is finite in extent, the secondary magnetic field may be obtained from

$\bar{H}^{s}\left(x, k_{y}, z\right)=\iint_{s} \bar{G}^{H J}\left(x, x^{\prime}, k_{y}, z, z^{\prime}\right)$

$$
\cdot \bar{J}_{S}\left(x^{\prime}, k_{y}, z^{\prime}\right) d x^{\prime} d z^{\prime}
$$

where $\bar{G}^{H J}$ is the dyadic Green's function for the magnetic field and the "scattering current" $\overline{7}_{s}$ is given (Harrington, 1961) as

$$
\bar{J}_{S}=\Delta \sigma \vec{E} .
$$

where $\Delta \sigma$ is the difference in conductivity between the inhomogeneity and the host rock and $\bar{E}$ is the electric field derived from the finite-element solution. In this case, the scattering current $J_{S}$ is nonzero only at inhomogeneous areas. 


\section{REFERENCES}

Harrington, R.F., 1961. Time-Harmonic Electromagnetic Fields. New York, McGraw-Hill, p. 124.

THE ACCURACY OF TWO LINE SOURCES FOR

\section{APPROXIMATING THE FIELDS OF A LARGE RECTANGULAR LOOP: FREQUENCY DOMAIN}

\section{Mackiewicz and H.F. Morrison}

Large rectangular loops of insulated cábic are commonly used for transmitting antennas in electromagnetic exploration and depth soundings. Quantitative in:erpretation of the detected fields over the two-dimensional geologic models is possible with some numerical models, but the computation costs can be extremely high, even on the fastest machines. In an attempt to ameliorate this problem, we have evaluated an approximate interpretation method using two parallel, infinite wires, the solutions for which are orders of magnitude faster, and hence cheaper, than using a rectangular loop source. The parallel lines are not a good approximation to the rectangular loop unless the length of the loop is more than 10 times its width and unless the receiver is located at least two widths away from the nearest line.

\section{APPROACH}

\section{Layered Medium}

To obtain the large rectangular loop response for the layered earth, we use the method of reciprocity described by Poddar (1982). To calculate the $H_{z}$ component for our source at a certain point $P$, we calculate the mutual inductance, $M$, between the source loop and an infinitesimal loop representing a vertical magnetic point dipole at point $P$. The relationship hetween $H_{z}$ and $M$ is given by the expressions

$$
\int \bar{E}_{\theta} \cdot \overline{d l}=-M i \omega I_{p},
$$

Lee, K.H., 1978. Electromagnetic Scattering by a Two-Dimensional Inhomogeneity Due to an Oscillating Magnetic Dipole (Ph.D. dissertation). Department of Engineering Geosciences, University of California, Berkeiey.

$$
H_{z}=\frac{M I_{s}}{\mu_{o} s_{p}}=\frac{-I_{s} \int \bar{E}_{\theta} \cdot \overline{d l}}{i \omega m_{p} \mu_{o}},
$$

where $I_{s}$ is the current in the large loop, $m_{p}$ is the magnetic dipole moment of the point dipole, $I_{p}$ is the current in the point dipole, $s_{p}$ is the area of the point dipole, $E_{\theta}$ is the field component of the point dipole evaluated along the circumference of the large loop, $\mu_{o}$ is the permeability, and $i$ is $\sqrt{-1}$.

In our study, we compare the $H_{z}$ response from two kinds of sources: (1) two parallel lines separated by $100 \mathrm{~m}$ and (2) a square loop with shorter sides $100 \mathrm{~m}$ in length and variable longer sides 300,600 , 1200 , and $3000 \mathrm{~m}$ in length. The medium is a $1-\Omega \cdot \mathrm{m}$ layer $30 \mathrm{~m}$ thick overlying a $100-\Omega \cdot \mathrm{m}$ half-space.

Figure 1 shows the geometry where a twodimensional conductive body (considered later) is also included. Figure 2 presents the results in terms of percent differences in the secondary $H_{z}$ response of the two parallel lines and the rectangular loops of different lengths. The results are calculated along the

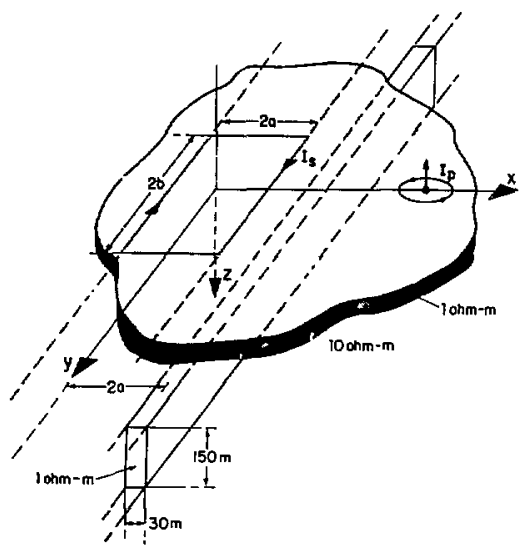

Figure 1. Model geometry. |XBL 843-9650| 


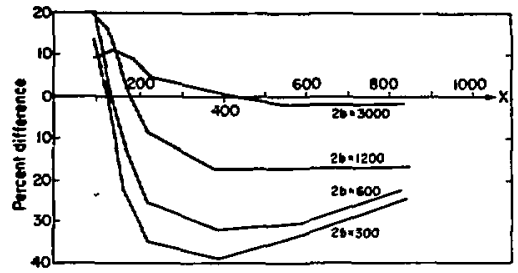

Figure 2. Percent difference in the secondary $H_{z}$ component between two parallel lines and large rectangular locps of different lengths over the layered earth shown in Fig. 1. Here $x$ is the distance from the center of the rectangular loop, and $2 b$ is the long leg of the loop, both measured in meters. [XBL 841-9572]

symmetry axis of the long side of the loop and at a frequency of $10 \mathrm{~Hz}$.

Only for the largest loop is a two-line source approximation valid within $10 \%$. Contrary to intuition, we do not necessarily get a better approximation at points closes to the source. The short sides of the loop seem to have a pronounced effect on fields until the separation is more than 10 times its width.

\section{CONCEALED VERTICAL CONDUCTOR}

To obtain the response of a two-dimensional medium for a large rectangular loop, we modified a program written by Lee (1978) for a magnetic dipole suurce. We initially approximated the loop of current by a sum of magnetic dipoles, following the suggestion of G.M. Hoverston (personal communication, 1983). We use the sinc function only in the $y$ direction because of the way the original program was set up. In the $x$ direction, the source is approximated by summing a finite number of dipoles. The following expressions should clarify our approach:

$$
\begin{aligned}
& m(k y)=\lim _{\substack{N \rightarrow \infty \\
\Delta y \rightarrow \infty}} \sum_{n}^{2 N} \Delta m_{n}\left(k_{y}\right)=2 I_{s} \Delta x b \frac{\sin \left(k_{y} b\right)}{k_{y} b}, \\
& \Delta m_{n}\left(k_{y}\right)= \\
& I_{s} \Delta x \Delta y \int_{-\infty}^{\infty} \delta\left(y \pm \frac{\Delta y}{2}(2 n-1)\right) e^{-i k_{y} y} d k_{y} \\
&=I_{s} \Delta x \Delta y e^{ \pm i k_{y}(2 n-1) \Delta y / 2},
\end{aligned}
$$

where $k_{y}$ is the transform variable, $m\left(k_{y}\right)$ is the total magnetic dipole moment of a strip of length $2 b$ in $k_{y}$ space, $\Delta m_{n}\left(k_{y}\right)$ is the $n$th dipole moment in $k_{y}$ space, $\Delta x, \Delta y$ are the dimensions of the $n$th dipole, $2 a, 2 b$ are the width and length of the large loop, and $2 N$ is the number of $\Delta m_{n}\left(k_{y}\right)$ dipoles in a strip of length $2 b$ and width $\Delta x$.

To calculate the response from the twodimensional conductor, we use the same sources previously described. The anomalous body is a vertical slab $30 \mathrm{~m}$ thick, $150 \mathrm{~m}$ in depth extent, $1 \Omega \cdot \mathrm{m}$ in resistivity, and is located $30 \mathrm{~m}$ below the surface (Fig. 1).

Figure 3 presents the results for the anomalous $H_{z}$ component, where the convention used is the same as in the one-dimensional case. For this particular configuration, two parallel lines provide a better approximation for loop results over the buried conductor than over the layered half-space.

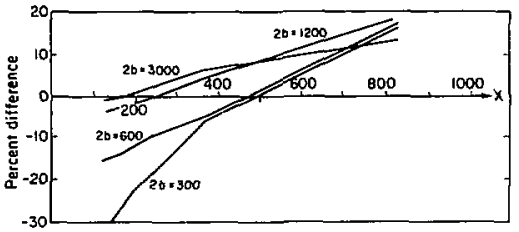

Figure 3. Percent difference in the anomalous $H_{z}$ component between two parallel lines and large rectangular loops of different lengths over the layered earth shown in Fig. 3. Dimensions are the same as for Fig. 2. [XBL 8419573:

\section{CONCLUSIONS}

Although the approximation of a rectangular loop by two parallel lines is not always accurate, it is a good tool for preliminary interpretation. It is inexpensive to use on the LBL CDC 7600 computer and describes the behavior of measured fields quite accurately. If a detailed interpretation is needed, the model response should be calculated for the actual source.

\section{REFERENCES}

Lee, K.H., 1978. Electromagnetic Scattering by a Two-Dimensional Inhomogeneity Due to an Oscillating Magnetic Dipole (Ph.D. dissertation). Department of Engineering Geosciences, University of California, Berkeley.

Poddar, M., 1982. A rectangular loop source of current on a two-layered earth. Geophysical Prospecting, v. 30 , p. 101-114. 


\section{ELECTROMAGNETIC MAPPING OF SEDIMENTARY SECTIONS BENEATH BASALT FLOWS}

\section{H.F. Morrison and J. Brzeski}

The principal goal of electromagnetic sounding is to resolve the conductivity distribution as a function of depth. Almost all electromagnetic sounding interpretations reported to date have assumed that, to a first approximation, the earth is horizontally layered. In some applications (such as mineral and geothermal exploration), the goal of electromagnetic surveying is to locate conductivity inhomogeneities, and these by their nature preclude the use of onedimensional (layered-earth) interpretations. Even in simpler geologic problems, many sounding results are not truly one dimensional, and a point is reached where one is forced to recognize that a numerical model with a higher degree of dimensionality is needed to interpret the sounding results.

We have begun an analysis of the validity of one-dimensional interpretations using a horizontal loop soundisg system and a model representing a sedimentary section (resistivity of $1 \Omega \cdot m$ ) buried beneath basalts $(50 \Omega \cdot \mathrm{m})$. This is a model of current interest for petroleum exploration in the states of Washington and Oregon (Fig. 1).

The electromagnetic response for the model was calculated using a finite-element code described by Lee (1983). A vertical magnetic dipole source was assumed to be located at $2-\mathrm{km}$ intervals along the surface, and the magnetic fields (amplitude and phase of the vertical and horizontal secondary fields) were calculated at distances of 2 and $4 \mathrm{~km}$ from the source. The responses were calculated at discrete frequencies; the major limitation of the study is that numerical limitations precluded the use of frequencies above $1 \mathrm{~Hz}$.

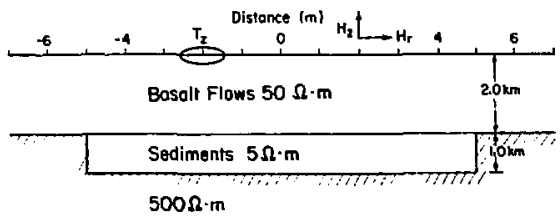

Figure 1. A simplified model for the sedimentary section in the resistive half-space overlain by basalt fows. [XBL 8312-2429]
The fields at five frequencies were calculated at successive positions of the transmitter and receiver as the pair was traversed across the model in 2-km increments. For each position, the data were given arbitrary $1.0 \%$ noise levels and then inverted using a standard ieast-squares inversion program. Two- and three-layer first guesses were tried, and the best fit was judged on the basis of the minimum currulative squared differences between the given data and the data from the inversion process.

Figure 2 shows a comparison of how well the vertical magnetic field $\left(H_{z}\right)$, the radial magnetic field $\left(H_{r}\right)$, and the ellipticity $(\varepsilon)$, each inverted separately, resolve the two-dimensional structure using a threelayer model. Although all data sets indicate the presence of the conductive sediments, none accurately resolve the geometry and resistivity of the sediments. Of the three parameters, ellipticity seems to come closest in estimating the actual depth and thickness of the sediments. It is interesting to note that $H_{t}$ inversions yield interpretations that fit the data better than $H_{r}$ and $\epsilon$ inversions, as evidenced by the smaller cumulative squared differences shown by the numbers in parenthesis, but that the $H_{z}$ inversions quite incorrectly show the sediments to bow upward into an anticlinal structure.

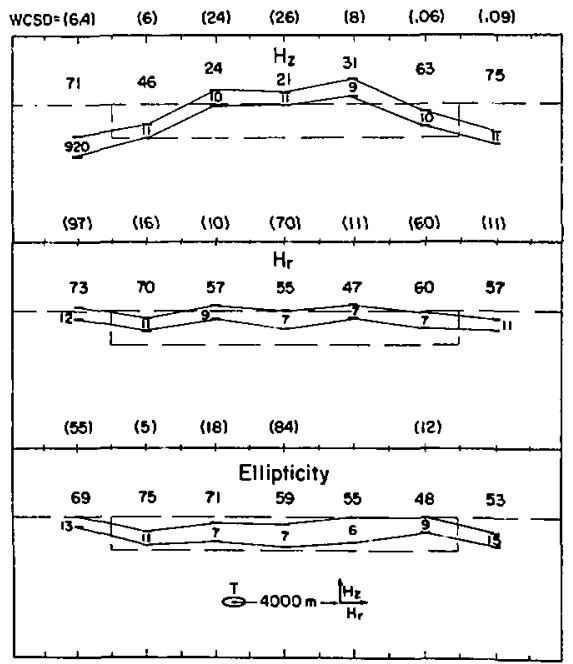

Figure 2. Comparison of 'nversion resolutions using $H_{z}$, $H$, , and $\epsilon$, respectively. for the two-dimensionc: structure using a three-layer model. [XBL 8312-2435] 
The finite-element mesh used in this study did not allow the transmitter-receiver pair to move far enough away from the boundaries of the sedimentary layer to determine when the three-layer model would cease fitting the data. A separate study has shown, however, that these edges are well resolved from the shape of the anomaly as the transmitter-receiver pair is traversed across the section.

For the model studied, the results indicate that one-dimensional inversions, particularly those using the ellipticity parameter, are useful for preliminary interpretation of controlled-source EM data.

\section{REFERENCES}

Lee, K.H., 1983. A numerical solution for the electromagnetic scattering by a two-dimensional inhomogeneity. To be submitted to Geophysics.

Finally, it has long been known that gravity and leveling data are interdependent when both elevation and mass changes occur (Whitcomb, 1976), but no separation of mass and elevation effects had ever been carried out on real data. Results of repetitive gravity measurements made in 1983 are reported here and interpreted in terms of subsurface mass changes.

\section{REPETITION OF GRAVITY SURVEY IN 1983}

The entire gravity network was repeated in early 1983. The same techniques were used as in previous surveys, with two main differences. First, a new D model LaCoste and Romberg meter was used in place of the $\mathrm{G}$ model, which had 'secome unavailable. To maintain continuity, the $\mathrm{D}$ meter was calibrated on a previously established calibration line (Grannell, 1982). Each station was looped in three times, with two readings taken each time. The newness of the meter was responsible for frequent tares; additional replications were performed as needed to offset this problem. Second, approximately $25 \%$ of the previously existing stations had been destroyed by construction activities between 1981 and 1983; secondary stations on permanent cultural features, such as concrete well pads, were established to offset this loss, although continuity from 1981 to 1983 was obviously interrupted. Similarly, field interpretation of the data suggested a shift of the gravity changes tcward the east, and new stations along the eastern periphery of the field (north, souih, and east of Nuevo León) were established for future monitoring or this area.

Values of observed gravity differences relative to the Cerro Prieto volcano basc were compared with the 1981 differences. Changes in these differences are shown in Fig. 1. The major pattern is cumplex, reaching a maximum amplitude of $+47 \mu$ gals in the eastern part of the field. Compared with previous

- Deparment of Geological Sciences, California State University, 

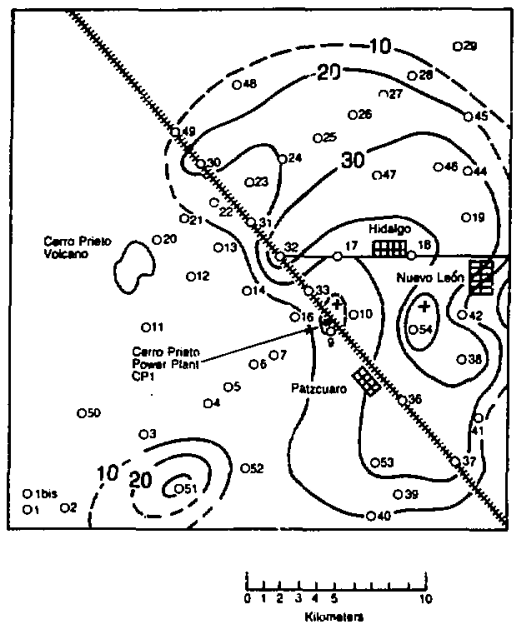

Figure 1. Significant gravity changes from 1981 to 1983. Contour interval is $10 \mu \mathrm{gals}$. [XBL 844-10317]

patterns of gravity changes (Figs. 2 and 3), the disturbance has migrated eastward and has expanded in size. The amplitude is smaller than for the interval 1980-1981, when the Victoria earthquake caused gravity increases in excess of $80 \mu$ gals, but larger than changes from 1978 to 1980 , when power production was $75 \mathrm{MW}$ rather than the current $180 \mathrm{MW}$. Gravity changes during all three intervals is positive, suggesting net subsidence and/or mass increase.

The gravity change noted at station 51 appears to be aberrant, and is probably unrelated to geothermal production. This same station has changed in other years but with no discerniblc pattem; cultural or meteoric changes may be responsible.

\section{SEPARATION OF GEOMETRIC ELEVATIONS FROM ORTHOMETRIC ELEVATIONS}

The interrelationship between gravity and leveling causes both data sets to be affected when both elevaticn and mass (density) changes occur. Leveling, which is based on an equipotential surface, can be in error when the equipotential surface is distorted over time by mass changes in the subsirface. Thus apparent changes in elevation can occur even though the ground sirface remains uncharsed. To determine the urue s. Jmeuric elevation chanzes from
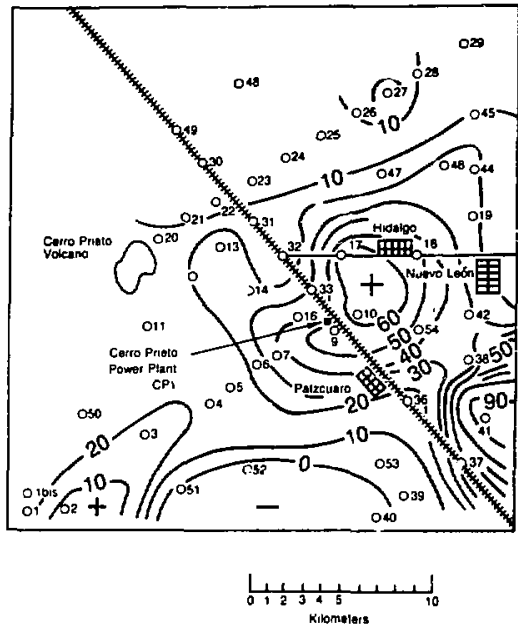

Figure 2. Sigiilicant gravity changes from 1980 to 1981 . Contour interval is $10 \mu \mathrm{gals}$. [XBL 844-10312|

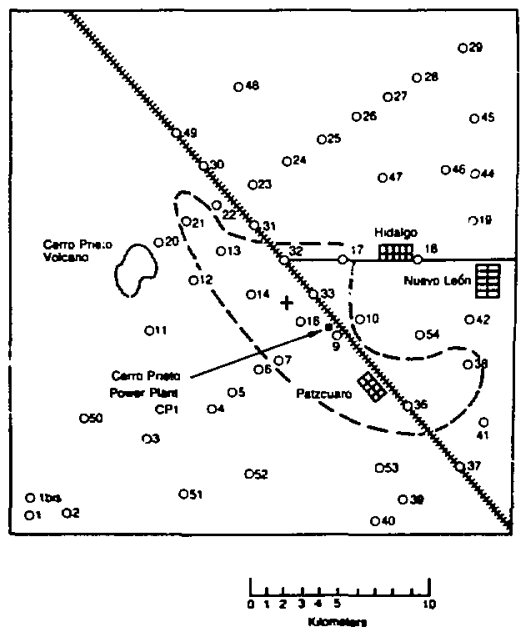

Figure 3. Significant gravity changes from 1978 to 1980 . The dotted lines is not a contour interval, but rather encloses the area in which positive values exceed $15 \mu$ gals. to a maximum of 31 нgals. [XBL 844-:0313] 
the orthometric elevations found from leveling, we apply a mathematical separation based or potential tieory. The operative equation (Whitcomb, 1976) is

$$
\text { geometric elevation }=\frac{e^{\prime} \alpha / a+\Delta G}{\alpha / a-\beta},
$$

where $e^{\prime}$ is the orthometric elevation change, $\Delta \mathrm{G}$ is the gravity change, $a$ is the radius of the disk used as the model of the changing volume, $\alpha$ is the free air gradient of the potential $\left(981 \mathrm{~cm} / \mathrm{s}^{2}\right)$, and $\beta$ is the free air gradient of gravity $\left(3.08 \times 10^{-6} / \mathrm{s}\right)$.

We calculated geometric changes in elevation from the aravity changes and leveling changes, assuming a dizk of radius $4 \mathrm{~km}$ (approximately the dimensiors of changes seen in the field). The resulting geometric changes, referred, like the gravity values, to Cerro Prieto volcano, show true subsidence in the field but with a different areal pattern than either gravity or leveling values. These are shown as Figs. 4, 5, and 6. Changes in elevation from 1978 to 1980 were relatively small but in excess of $20 \mathrm{~mm}$ in many areas; changes in subsequent measurement intervals exceeded $200 \mathrm{~mm}$ during 1980-1981 (associated with the Victoria earthquake) and $100 \mathrm{~mm}$ during 1981-1983. The changes, aside from those due to the Victoria earthquake, are mostly spatially associated with the fie!d, although
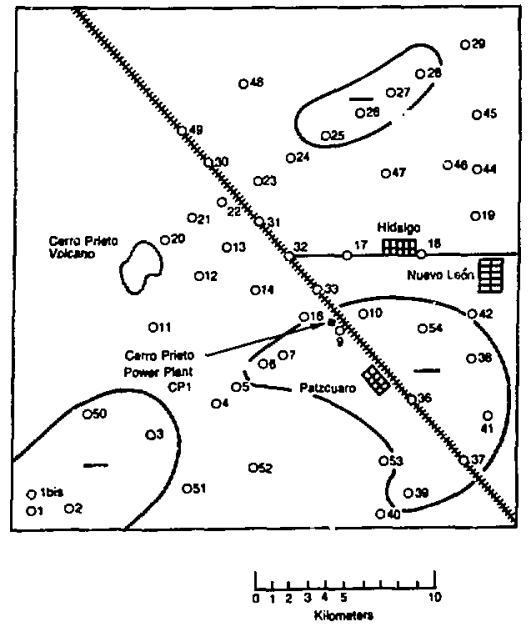

Figure 4. Geometric elevation changes for 1978-1980. Contours enclose areas approaching $20 \mathrm{~mm}$ or greater of subsidence. [XBL 844-10315]

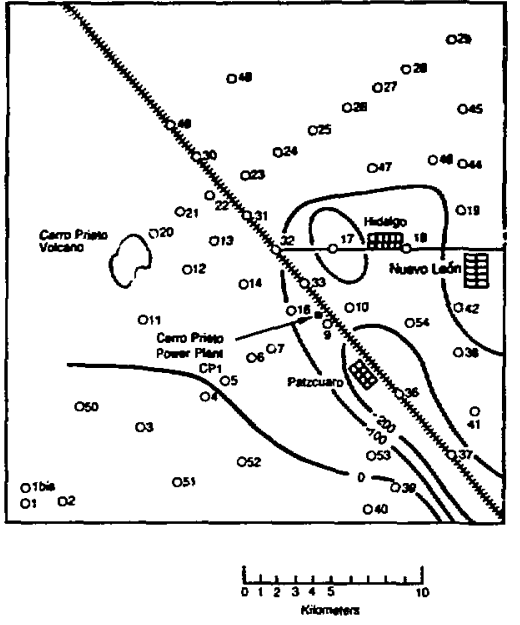

Figure 5. Geometric elevation changes for 1980-1981. Contour interval is $100 \mathrm{~mm}$. [XBL 844-10316]
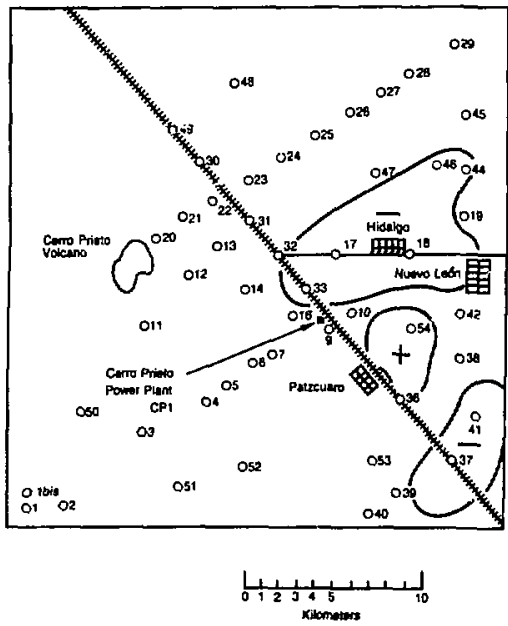

Figure 6. Geometric elevation changes for $1981-1983$. Contour interval is $100 \mathrm{~mm}$. [XBL 844-10314] 
changes from the Sierra Cucapa to the Cerro Prieto volcano in the interval 1978-1980 may indicate widespread minor uplift of the Mexicali Valley, with superimposed geothermally induced subsidence.

The results presented here allow two conclusions. (1) Net subsidence requires that natural recharge be incomplete, suggesting that some net fluid withdrawal is occurring. (2) The discrepancies between orthometric and geometric values indicate net mass changes. These could result from one or a combination of several factors: densification from thermal contraction (Zelwer and Granncll, 1982): influx of more saline waters (Wilt and Goldstein, 1984); and compaction of sediments during subsidence.

We wish to thank the following individuals and organizations for their assistance:

1. The personnel of the Comision Federal de Electridad (CFE) at the Cerro Prieto geothermal field, who provided leveling data and logistical support and who sought out missing gravity stations.

2. The Department of Energy and Lawrence Berkeley Laboratory (LBL) for partial financing of the research work. Personnel from LBL were also instrumental in providing well logs and for interfacing with the CFE in arranging for the work.

\section{REFERENCES}

Chase, D.Ś., Clover, R.C., Grannell, R.B., and Leggewie, R.M., 1978. Precision gravity studies a1 Cerro Prieto. In Proceedings, First Symposium on the Cerro Prieto Geothermal Field, Baja California, Mexico, September 20-22, 1978. Lawrence Berkeley Laboratory, LBL-7098, p. 249-256.

QUANTITATIVE

INTERPRETATION OF THE BOUGUER ANOMALY OVER THE CERRO PRIETO GEOTHERMAL FIELD, MEXICO

\section{R.B. Grannell * G. Rardale,*H. Zhou,* and J.K. Phibbs*}

Even though precise gravity measurements have been made over the Cerro Prieto geothermal field

*Deparment of Geological Sciences, Falifomia State University, Long Beach. Collaborators in the Cerro Prieto research program.
Grannell, R.B., 1982. Repetitive precision gravity studies of the Cerro Prieto and Heber geothermal fields. Lawrence Berkeley Laboratory, LBL-15073, $95 \mathrm{p}$.

Grannell, R.B., Tarman, D.W., Clover, R.C., Leggewie, R.M., Aronstam, P.S., Kroll, R.C., and Eppink, J., 1980. Precision gravity studies at Cerro Prieto the second year. Lawrence Berkeley Laboratory, LBL-9551, 3 p.

Grannell, R.B., Kroll, R.C., Wyman, R.M., and Aronstam, P.S., 1982a. Precision gravity studies at Cerro Prieto: A progress report. In Proceedings, Third Symposium on the Cerro Prieto Geothermal Field, Baja California, Mexico, March 24-26, 1981. Lawrence Berkeley Laboratory, LBL-11967, p. 329-333.

Grannell, R.B., Wyman, R.M. Leggewie, R.M., and Roudall, G.A., 1982b. Subsidence detection at the Cerro Prieto geothermal field. In Proceedings, Fourth Symposium on the Cerro Prieto Geothermal field, Baja California, Mexico, August 10-12, 1982. Mexicali, Comisión Federal de Electricidad (preliminary volume), p. 61-62.

Whitcomb, J.H., 1976. New vertical geodesy. Journal of Geophysical Research, v. 81, no. 26, p. 4937-4944.

Wilt, M.J., and Goldstein, N.E., 1984. Interpretation of dipole-dipole resistivity monitoring data at Cerro Prieto. Geothermics, v. 13, no. 1/2, p. 13-26.

Zelwer, R., and Grannell, R.B., 1982. Correlation between precision gravity and subsidence measurements at Cerro Prieto. Lawrence Berkeley Laboratory, LBL-14894, 7 p.

since 1978 , only primitive interpretations have been made to help explain resistivity anomalies (Wilt et al., 1980) and seismic refraction results (Majer et al., 1980). Gravity data obtained in the early part of the study (Chase et al., 1978) have been quantitatively modeled as both two- and three-dimensioral density distributions. The densities for the models were obtained by integrating published density information (Lyons and van de Kamp, 1979; Prian, 1979, 1981; Howard et al., 1981; Seamount et al., 1981) with gamma-gamma density logs for 10 wells in and adjacent to the producing field. The models consist of either partial infinite slabs (third dimension infinite) or rectangular prisms. Their gravitational attraction was solved at the same locations as the measured gravity values so that the calculated and meas- 
ured values could be directly compared. Refinements of these two-dimensional models were made until they agreed with the measured values within 1 mal or less (average $0.5 \mathrm{mgal}$ ) and the threedimensionai model within 2 mgals (average $1 \mathrm{mgal}$ ).

Figures 1 and 2 show the gravity curves and modeled cross section through the centes of the field in a southwest-northeast direction, intersecing through wells M-50, M-127, and M-117. This line passes midway between the power plant $\left(\mathrm{CP}^{2} 1\right)$ and the village of Patzcuaro and is nearly zarallel to resistivity line E-E'. The main part of the field lies between 10.7 and $16.8 \mathrm{~km}$, within which interval we find a densified dome of sediments coming to within $300 \mathrm{~m}$ of the surface. Roughly between the Cerro Prieto and Imperial Faults, we show a deep zone $(2.7+\mathrm{km}$ depth) of denser rocks that may be due to the mafic dikes encountered in some of the deeper wells and ascribed to magma intrusion into the pullapart basin that has formed between those faults (Goldstein et al., 1984). Our gravity interpretation is preliminary and has to be checked against other geophysical and well log daza. We also have to reinterpret the resijual Bouguer gravity after regional effects have been removed.

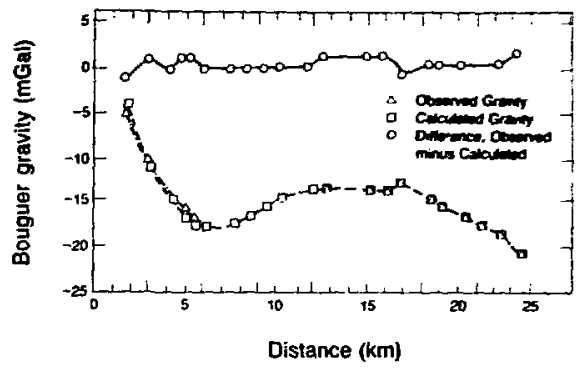

Figure 1. Comparison of the Bouguer gravity observed over the Cerro Prieto geothermal field and the calculated gravity due to the two-dimensional model shown in Fig. 2. [XBL 844-10311]

We wish to thank the following individuals and organizations for their assistance:

1. Robert M. Leggewie for writing the software (in the APL language) that made the gravity reduction and interpretation possible.

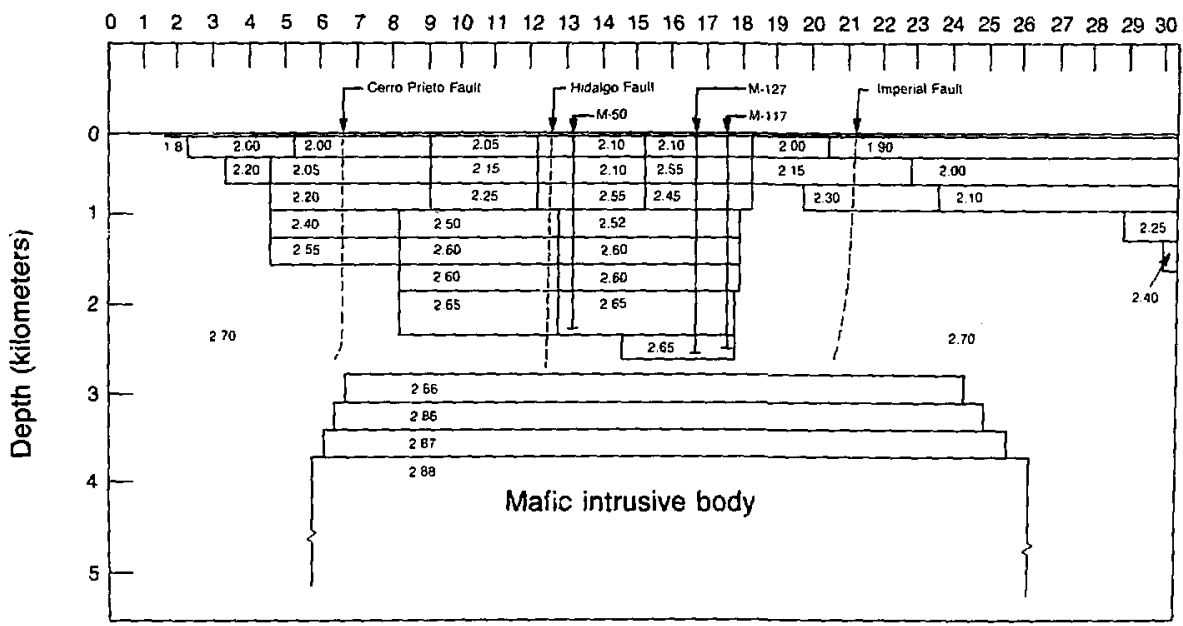

Figure 2. Two-dimensional density model for the Cento Prieto gers thermal field. Numbers in blocks are densities in grams per cubic meter. [XBL 844-10310] 
2. The Department of Energy and Lawrence Berkeley Laboratory (LBL) for partial financing of the research work. Personnel from LBL were also instrumental in providing well logs and for interfacing with the Comision Federal de Electricidad in arranging for the work.

\section{REFERENCES}

Chase, D.S., Clover, R.C., Grannell, R.B., and Leggewie, R.M., 1978. Precision gravity studies at Cerro Prieto. In Proceedings, First Symposium on the Cerro Prieto Geothermal Field, Baja California, Mexico, September 20-22, 1978. Lawrence Berkeley Laboratory, LBL-7098, p. 249-256.

Goldstein, N.E., Wilt, M.J., and Corrigan, D.J., 1984. Analysis of the Nuevo León magnetic anomaly and its possible relationship to the Cerro Prieto magnetic-hydrothermal system. Geothermics, v. 13 , no. $1 / 2$, p. 3-12.

Howard, J.H., Halfman, S.E., and Vonder Haar, S.P.. 1981. Evaluation of geological characteristics at Cerro Prieto. In Proceedings, Third Symposium on the Cerro Prieto Geothermal Field, Baja California, Mexico, March 24-26, 1981. Lawrence Berkeley Laboratory, LBL-11967, p. 62-71.

Lyons, D.J., and van de Kamp, P.C., 1979. Subsurface geological and geophysical study of the Cerro Prieto geothermal field. In Proceedings,
Second Symposium on the Cerro Pricto Geothermal Field, Baja California, Mexico, Ociober 17-19, 1979. Mexicali, Comisión Federal de Electricidad, p. 173-199.

Majer, E.L., McEvilly, T.V., Albores, A., and Diaz, C.S., 1980. Seismological studies at Cerro Prieto. Geothermics, v. 9, no. 1/2, p. 79-88.

Prian C., R., 1979. Development possibilities at the Cerro Prieto geothermal area, Baja California Norte. Second Symposium on the Cerro Prieto Geothermal Field, Baja California, Mexico, October 17-19, 1979. Mexicali, Comisión Federal de Electricidad, p. 146-162.

Prian C., R., 1981. Drilling rate for the Cerro Prieto stratigraphic sequence. In Proceedings, Third Symposium on the Cerro Prieto Geothermal Field, Baja California, Mexico, March 24-26, 1979. Lawrence Berkeley Laboratory, LBL11967 , p. 77-85.

Seamount, D.T., and Elders, W.A., 1981. Use of wireline logs at Cerro Prieto in the identification of the distribution of hydrothermally altered zones and dyke locations, and their correlation with reservoir temperatures. In Proceedings, Third Symposium on the Cerro Prieto Geothermal Field, Baja California, Mexico, March 24-26, 1981. Lawrence Berkeley Laboratory, LBL-11967.

Wilt, M.J., Goldstein, N.E., and Razo M., A., 1980. LBL resistivity studies at Cerro Prieto. Geothermics, v. 9, n. 1/2, p. 15-26. 


\section{GEOPHYSICS}

The geophysical program at Lawrence Berkeley Laboratory is strongly applied, having its origins in the Geothermal Exploration Technology Development Program that was started under the Atomic Energy Commission and the Energy Research and Development Administration. For this reason, the geophysical program has an orientation toward techniques for resource definition and the monitoring of subsurface processes. Research efforts cuncentrate on developing better field instrumentation and techniques and on interpretation of seismic and electromagnetic data. The success of the geophysical program has been due to the effective collaboration between LBL staff scientists and engineers and the UC Berkeley faculty associates and graduate students. Many students from the Department of Materials Science and Mineral Engineering (College of Engineering) and from the Department of Geology and Geophysics (College of Letters and Science) have completed or are currently doing their graduate research in support of LBL projects.

As evidenced by the geophysical research summaries that follow, most of the geophysical projects fall into the categories of seismology or electromagnetics. Since the creation of the Center for Computational Seismology (CCS) in 1982. the number and diversity of seismological projects have increased; these projects range in scope from earthquake mechanisms and elastic waye propagation to mapping faults and hydrofractures and thermally induced stresses. CCS also has a supporting role in developing a seismic data base for the Defense Advanced Research and Projects Administration (DARPA).

In electromagnetic studies, the main emphasis is on the collectivis and interpretation of electromagnetic sounding data for resource definition and for basic crustal investigations coupled to the Continental Scientific Drilling Program. We are also continuing dc resistivity and gravity monitoring of the Cerro Prieto geothermal field, Baja California, Mexico, to determine how that reservoir is responding to production. 
THERMODYNAMIC

PROPERTIES OF SILICATE MATERIAIS

\section{I.S.E. Carmichael, F.C. Bishop, B. Lange, X. Mo. M.L. Rivers, and J.F. Stebbins}

Calorimetric measurement of multicomponent silicate liquids and glasses continued in 1983 . From the existing experimental data, it is possible to calculate the heat capacity of any glass (composed of the nine most geologically abundant oxides) as a function of temperature and composition to within a precision of about $0.6 \%$. For the corresponding silicate liquids, this precision decreases to about $3 \%$, partly because of experimental error and partly because of the inherent properties of the liquids.

Molar volumes of silicate liquids can be calculated as a function of composition and temperature to within 1-3\%, but thermal expansions can be uncertain by as much as $40 \%$. Interlaboratory differences in methods and techniques can account for many of the discrepancies in these properties.

With th 'se problems in mind, we have begun to evaluate ano eliminate interlaboratory disagreement by selectively amassing critical data so that precision can be reliably estimated. The derivative properties are particularly significant but have the greatest errors. Our understanding of the way that simple oxides mix to form multicomponent silicate liquids can be much improved by refining experimental techniques and increasing precision.

\section{PHASE EQUILIBRIUM EXPERIMENTS ON NATURAL LAYA COMPOSITIONS}

Basic lavas erupted along the continental margins typically have a higher oxygen fugacity than those erupted along the mid-ocean ridges. The ferric-ferrous ratio of the magma is a function of oxygen fugacity and temperature. The compositions of the ferromagnesian solids that precipitate as the liquid cools are sensitive to changes in the ratio of ferric iron to magnesium in the liquid and thus are in part controlled by any reaction of $\mathrm{Fe}^{2+}$ to form $\mathrm{Fe}^{3+}$ in the liquid (Kilinc et al., 1983).

A series of experiments on three different lava compositions was undertaken to attempt to duplicate the crystal-liquid assemblages found in a series of lavas erupted during 1759-1774 in Jorullo, Mexico, and to study the effects of oxygen fugacity on the cooling path of the liquids. The results show that the natural assemblages could not be duplicated at atmospheric pressure. Partial crystallization at elevated pressure, possibly combined with a small amount of dissolved water, was thus necessary in the evolution of the lava series (Mo and Carmichael, 1982).

\section{ULTRASONIC MEASUREMENTS}

The velocity and attenuation of ultrasound have been measured in about 25 silicate liquids (Rivers and Carmichael, 1982a,b). Data obtained using a single-transducer interferometric system have been collected over a temperature range of $1000-1600^{\circ} \mathrm{C}$ and a frequency range of $2-10 \mathrm{MHz}$. Compositions studied include binary silicates of $\mathrm{Li}, \mathrm{Na}, \mathrm{K}, \mathrm{Rb}, \mathrm{Cs}$, $\mathrm{Mg}, \mathrm{Ca}, \mathrm{Sr}$, and $\mathrm{Ba}$ and five natural lavas. For most compositions, data from at least the low-frequency or high-temperature regions allow the estimation of zero-frequency moduli and therefore the isothermal compressibilities. These results are essential to the calculation of densities of magmas at high pressures and thus have a wide range of geochemical and geophysical applications.

In addition, the more $\checkmark$ :scous melts show dispersion, or an increase in velocity, at higher frequencies. Here, structural relaxation times in the liquid are similar to the period of the ultrasound (100-500 ns). Such information can be used in the calculation of such properties as volumetric viscosity and may provide insight into the molecular structure of the liquids.

Our data have been combined with an equal number of results from the literature to derive a simple model to calculate velocities and compressibilities for complex, multicomponent liquids. Velocities are fitted to within about $\pm 2 \%$. These "partial molar sound speeds" for the oxide components confirm what was seen in the original data: Larger, lower-charged cations make a liquid more compressible than smaller. nigher-charged cations.

\section{HIGH-TEMPERATURE ENTHALPIES AND HEAT CAPACITIES}

Measurements of the heat capacities of liquid $\mathrm{BaSi}_{2} \mathrm{O}_{5}, \mathrm{Rb}_{2} \mathrm{Si}_{2} \mathrm{O}_{5}$, and $\mathrm{Li}_{2} \mathrm{SiO}_{3}$ have been made to extend the range of cation field strength (cation charge divided by the square of the cation-oxygen distance) (Stebbins and Carmichael, 1983). Calculated constant-volume heat capacities $\left(C_{p}\right)$ for both the pure compounds and the oxide components are systematically higher for high-field-strength cations than for low-field-strength cations (Fig. 1). As values of $C_{p}$ (per gram atom) for most silicate liquids are 


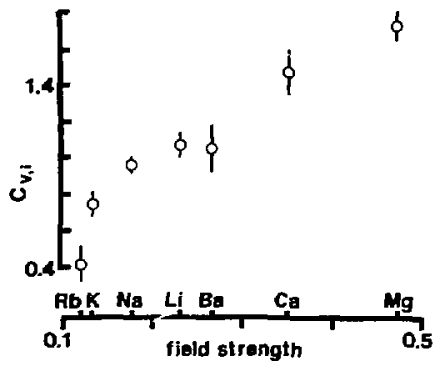

Figure 1. Partial molar constant volume heat capacities for oxide components in silicate liquids, divided by $3 R$ per gram atom. Cation field strength is defined in text. [XBL 3310-12161]

considerably more than 3 times the gas constant, $R$, an important structural or configurational contribution must be present. High-field-strength cations thus raise $C_{y}$ by increasing the relative mobility of the molecular units of silicate liquids, allowing a greater increase with $T$ in the number of available structural configurations (Carmichael and Stebbins, 1982; Stebbins et al., 1983c).

This effect probably contributes to the observed trend toward higher entropies of fusion in highfield-strength caticn liquids within a group of the same stoichiomeiry (Table 1 and Stebbins et al., 1983b). Materials with higher ratios of networkmodifying to network-forming cations also have higher entropies of fusion, as is expected from their lower state of polymerization.

A new, high precision, very high temperature $\left(2400^{\circ} \mathrm{C}\right)$ drop calorimeter has been designed by Leif Hansen and Bruce Dudak of the Engineering and Technical Services Division, and is currently under construction. The instrument incorporates a number of new design features that shouid provide an accuracy at least an order of magnitude better than that obtainable with existing devices. This will allow us to extend our measurements to the very refractory materials (such as $\mathrm{Mg}_{2} \mathrm{SiO}_{4}$ ) that make up most of the earth's mantle and to determine in detail the melting properties of many other components of natural and synthetic systems.

\section{NEW PROJECTS}

A study of the thermodynamics of the $\alpha-\beta$ transitions in leucite $\left(\mathrm{KAlSi}_{2} \mathrm{O}_{6}\right)$ and iron leucite $\left(\mathrm{KFeSi}_{2} \mathrm{O}_{6}\right)$ has been begun in order to quantify the
Table 1. Entropies of fusion of silicates at their melting points.

\begin{tabular}{|c|c|c|}
\hline & $\begin{array}{c}T_{f} \\
(\mathrm{~K})\end{array}$ & $\underset{\mathrm{jK}^{-1} \mathrm{~g} \text { atom }}{\left.\stackrel{\Delta S_{f} T_{f}}{-1}\right)}$ \\
\hline $\mathrm{Fe}_{2} \mathrm{SiO}_{4}^{\mathrm{a}}$ & $1490 \mathrm{~m}^{b}$ & $8.56 \pm 0.11$ \\
\hline $\mathrm{Mn}_{2} \mathrm{SiO}_{4}$ & 1620 & $7.91 \pm 0.05$ \\
\hline $\mathrm{MgSiO}_{3}{ }^{\mathrm{a}}$ & $1840 \mathrm{~m}$ & 8.4 \\
\hline $\mathrm{CaMgSi}_{2} \mathrm{O}_{6}{ }^{\mathrm{a}}$ & 1665 & $(7.14) \pm 0.15$ \\
\hline $\mathrm{CaSiO}_{3}$ & 1817 & $6.3 \pm 0.3$ \\
\hline $\mathrm{Li}_{2} \mathrm{SiO}_{3}^{\mathrm{a}}$ & 1474 & $8.3 \pm 0.2$ \\
\hline $\mathrm{Na}_{2} \mathrm{SiO}_{3}$ & 1361 & $6.39 \pm 0.12$ \\
\hline $\mathrm{Li}_{2} \mathrm{Si}_{2} \mathrm{O}_{5}$ & 1306 & $5.2 \pm 0.4$ \\
\hline $\mathrm{Na}_{2} \mathrm{Si}_{2} \mathrm{O}_{5}$ & 1147 & $4.3 \pm 0.4$ \\
\hline $\mathrm{K}_{2} \mathrm{Si}_{2} \mathrm{O}_{5}$ & 1309 & $2.7 \pm 0.4$ \\
\hline $\mathrm{CaAl}_{2} \mathrm{Si}_{2} \mathrm{O}_{8}{ }^{\mathrm{a}}$ & 1830 & $5.70 \pm 0.15$ \\
\hline $\mathrm{NaAlSiO}_{4}^{\mathrm{a}}$ & $1750 \mathrm{~m}$ & $4.00 \pm 0.2$ \\
\hline $\mathrm{NaAlSi}{ }_{3} \mathrm{O}_{8}{ }^{a}$ & 1373 & $3.52 \pm 0.12$ \\
\hline $\mathrm{KAISi}_{3} \mathrm{O}_{8}^{\mathrm{a}}$ & $1473 \mathrm{~m}$ & $3.02 \pm 0.15$ \\
\hline $\mathrm{SiO}_{2}$ & 1999 & $1.49 \pm 0.15$ \\
\hline $\mathrm{KMg}_{3} \mathrm{AlSi}_{3} \mathrm{O}_{10} \mathrm{~F}_{2}$ & 1670 & $9.24 \pm 0.05$ \\
\hline $\mathrm{CaTiSiO}_{5}$ & 1670 & $9.27 \pm 0.05$ \\
\hline
\end{tabular}

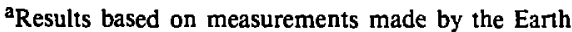
Science Division Geochemistry group.

${ }^{b} \mathrm{~m}$ indicates a metastable melting point.

effects of substituting $\mathrm{Fe}^{3+}$ for $\mathrm{Al}^{3+}$ in minerals. Measurements of heat capacity and enthalpy by differential scanning calorimetry indicate that variations in stoichiometry and perhaps in ordering state affect both the temperature and the magnitude of the transitions.

In collaboration with Professor F.C. Bishop (on Jeave from Northwestern University), we have been measuring sulfur solubility in silicate liquids (Stebbins et al., 1983a); results obtained so far indicate that high-field-strength cation liquids have lower $\mathrm{SO}_{3}$ solubilities than low-field-strength liquids, as would be expected if tha gas reacts with nonbridging oxygens to form sulfate species in the melt. Interestingly, data from the literature indicate that, as for $\mathrm{H}_{2} \mathrm{O}$, the activity of $\mathrm{SO}_{3}$ in the liquid is proportional to the square of its mole fraction. 


\section{REFERENCES}

Carmichael, I.S.E., and Stebbins, J.F, 1982. Silicate liquid heat capacities: New data on partial molar quantities and $\Delta C_{R}$ at the glass transition. EOS, Transactions, American Geophysical Union, v. 63, p. 1137.

Kilinc. A.1., Carmichael, I.S.E., Rivers, M.L., and Sack. R.O., 1983. The ferric-ferrous ratio of natural silicate liquids equilibrated in air. Contributions to Mineralogy and Petrology, v. 83, p. 136-140.

Mo, X., and Carmichael, I.S.E., 1982. Phase equilibrium experiments on Jorullo lavas (1759-1774 A.D.), Mexico. EOS, Transactions, American Geophysical Union, v. 63, p. 1142.

Rivers, M.L., and Carmichael, I.S.E., 1982a. Ultrasonic velocity and attenuation of liquids in the system $\mathrm{NaAlSi}_{3} \mathrm{O}_{8}-\mathrm{CaAl}_{2} \mathrm{Si}_{2} \mathrm{O}_{8}-\mathrm{CaMgSi}_{2} \mathrm{O}_{6}$. EOS, Transactions, American Geophysical Uniun, v. 63, p. 1136.

Rivers, M.L., and Carmichael, I.S.E., 1982b. The

\section{THERMODYNAMICS OF THE SYSTEM $\mathrm{NaCl}-\mathrm{H}_{2} \mathrm{O}$ TO $823 \mathrm{~K}$ WITH ESTIMATES TO $3900 \mathrm{~K}$}

\section{K.S. Pitzer, Yi-gui Li, J.C. Peiper, R. Phutela, and} J.M. Simonson

In view of the dominance of $\mathrm{NaCl}$ in most natural brines, a thorough and precise knowledge of the properties of the system $\mathrm{NaCl}-\mathrm{H}_{2} \mathrm{O}$ is extremely important. It is also desirable that this knowledge be represented in a form that is most useful for systems containing other components. With the completion of a very comprehensive and accurate treatment to $573 \mathrm{~K}$ and of exploratory investigations of the region above $573 \mathrm{~K}$, it seems appropriate to review the status of knowledge for $\mathrm{NaCl}-\mathrm{H}_{2} \mathrm{O}$. This will be discussed in terms of three ranges of temperature: 273-573 K, 423-823 K, and 823-3900 K.

In the range to $573 \mathrm{~K}$, there is now a comprehensive array of accurate experimental measurements of the volume, the vapor pressure or activity of $\mathrm{H}_{2} \mathrm{O}$, and the enthalpy. These data provide the basis for a model with the same degree of detail and precision as is used for properties near room temperature. This is the ion-interaction or virial-series model, ultrasonic velocity and attenuation of silicate melts. Geological Socicty of America, Abstrecis with Programs, v. 14, p. 600.

Stebbirs, J.F., and Carmichael, I.S.E, 1983. Entropies of fusion, heat capacities, and melt structure: The alkali and alkaline earth silicates. Geological Society of America, Abstracts with Programs, v. 15, p. 695.

Stebbins, J.F., Bishop, F.C., and Carmichael, I.S.E., 1983a. Solubility of sulfur in silicate liquids at high $f_{o_{r}}$ EOS, Transactions, American Geophysical Union, v. 64, p. 874.

Stebbins, J.F., Carmichael, I.S.E., and Weill, D.F., 1983b. The high temperature liquid and glass heat contents and the heats of fusion of diopside, albite, sanidine, and nepheline. American Mineralogist, v. 68, p. 717-730.

Stebbins, J.F., Carmichaei, I.S.E., and Moret, L.K. Heat capacities and entropies of silicate liquids and glasses, 1983c. Contributions to Mineralogy and Petrology, in press.

which includes a Debye-Hückel term that is immediately applicable to mixed brines of unlimited complexity. The composition dependence is accurately described by the second and third virial coefficients, each of which is pressure and temperature dependent.

The volumetric properties, which give the pressure dependence of other thermodynamic quantities, were treated earlier (Rogers and Pitzer, 1982) for the range to $573 \mathrm{~K}$. The activity of water in this range was carefully measured by Liu and Lindsay (1972). Enthalpy and other thermal data include the very accurate heat of dilution measurements of Busey et al. (1984), as well as several sets of measurements of Wood and Associates (including Smith-Magowan and Wood, 1981; and White and Wood, 1982). These measurements, made at various pressures, were converted to a single pressure for fitting of the temperature dependence. The result is a comprehensive equation of state for all thermodynamic properties of $\mathrm{NaCl}-\mathrm{H}_{2} \mathrm{O}$ to $573 \mathrm{i}$ and $1 \mathrm{kbar}$ (Pitzer et al., 1984). In addition to extensive tables, equations are provided for the engineering properties of specific volume, entropy, and enthalpy as well as for the chemically interesting activity and osmotic coefficients and the thermal properties per mole of $\mathrm{NaCl}$. The uncertainties increase somewhat with increase in temperature. For example, with in $\gamma_{ \pm}$, 
the estimated uncertainty at $1 \mathrm{~mol} / \mathrm{kg}$ and $300 \mathrm{~K}$ is 0.002 at low pressure and 0.006 at $1 \mathrm{kbar}$. These values increase slowly to 0.005 and 0.013 at $473 \mathrm{~K}$ and then more rapidly to 0.015 and 0.05 at $573 \mathrm{~K}$. In addition, the $\mathrm{Na}^{+}, \mathrm{Cl}^{-}$virial coefficients are given for use in calculations for brines with other components. Recent research of Holmes and Mesmer (1983a,b), as well as that of Rogers and Pitzer (1981), provides parameters for several other components of geochemical interest at elevated temperatures.

Above $573 \mathrm{~K}$, the experimental data are both less accurate and less complete; hence a simpler modeling equation is appropriate. It is found that an equation developed for aqueous systems continuous to a fused salt (Pitzer, 1980, 1981) is successful for $\mathrm{NaCl}-\mathrm{H}_{2} \mathrm{O}$ from $373 \mathrm{~K}$ to $823 \mathrm{~K}$, which is the upper limit of data covering a wide range of composition. At the highest temperature, there are vapor pressure and density measurements, primarily by Urusova (1974, 1975). In this connection it was necessary to develop a new equation for the dielectric constant of water at very high temperature and pressure. An equation was obtained (Pitzer, 1983) with a sound theoretical form such that extrapolation above the range of experimental dielectric data should be as reliable as possible. The vapor pressure data were fitted within an uncertainty of about $3 \%$, which implies a similar uncertainty for the activity coefficient of either component for the range 0-1 kbar and $373-823 \mathrm{~K}$. Figure 1 compares the experimental and calculated activity coefficients at 723 and $823 \mathrm{~K}$. The papers reporting this research (Pitzer and $\mathrm{Li}$,

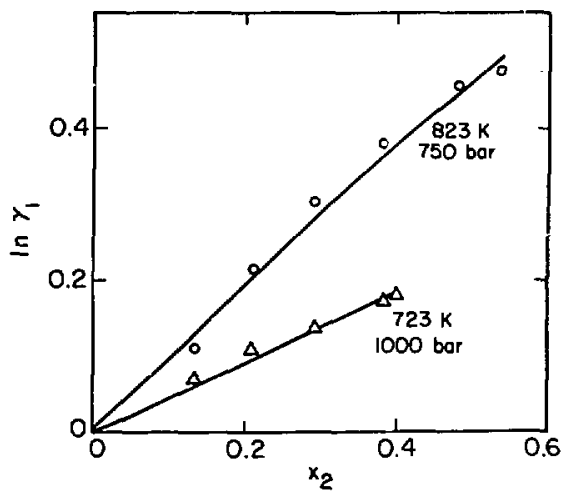

Figure 1. Comparison of calculated curves for the activity coefficient of water with measured values. [XBL 841-3201
1983, 1984) include calculations by temperature difference of the heat of dilution that agree reasonably with the measurements of Busey et al. (1984) at $673 \mathrm{~K}$. The equation applies up to saturation with solid $\mathrm{NaCl}$, which is at about 70 mass \% at $823 \mathrm{~K}$.

In the range above $823 \mathrm{~K}$, the critical pressure and composition are known (Sourirajan and Kennedy, 1962) to $973 \mathrm{~K}$ for aqueous sodium chloride. Kirshenbaum et al. (1962) made measurements on pure $\mathrm{NaCl}$ and estimated critical properties by extrapolation. Recent theoretical advances and spectroscopic measurements allow a considerably improved extrapolation (Pitzer, 1984) yielding $T_{c}=3900 \mathrm{~K}, V_{c}$ $=530 \mathrm{~cm}^{3}, p_{c}=258$ bars for pure $\mathrm{NaCl}$. These values are, of course, subject to considerable uncertainty. It was found that a very simple model based on the properties of pure $\mathrm{NaCl}$ was useful for the aqueous system. Specifically, it is assumed that the interionic forces are attenuated by the dielectric constant of pure steam at the temperature and pressure of interest. This model fits quite well the known critical properties from 723 to $973 \mathrm{~K}$. In particular, the calculated critical volume at $823 \mathrm{~K}$ is 490 $\mathrm{cm}^{3} / \mathrm{mol}$, which is fortuitously close to the observed $480 \mathrm{~cm}^{3} / \mathrm{mol}$ of $\mathrm{NaCl}$ (Urusova, 1975). The model then gives a preliminary estimate for the critical curve for $\mathrm{NaCl}-\mathrm{H}_{2} \mathrm{O}$ from 973 to $3900 \mathrm{~K}$, as shown in Fig. 2. This model is being tested with respect to other properties such as the solubility of solid $\mathrm{NaCl}$. Modifications or refinements may be required to yield a comprehensive theory for the region above $823 \mathrm{~K}$

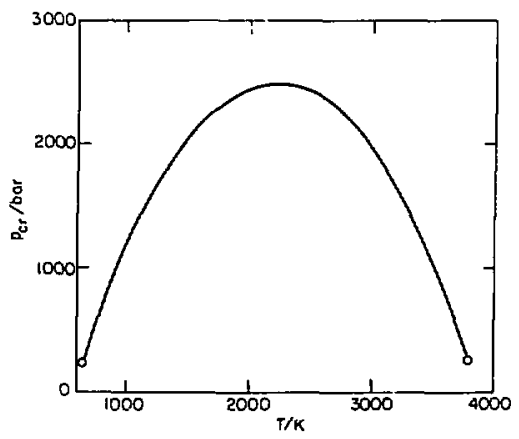

Figure 2. The critical curve for aqueous $\mathrm{NaCl}$. $\mathrm{XBL}$ 8310-6548] 


\section{REFERENCES}

Busey, R.H., Holmes, H.F., and Mesmer, R.E., 1984. The enthalpy of dilution of aqueous sodium chloride to $673 \mathrm{~K}$ using a new heat and liquid flow caiorimeter. Excess thermodynamic properties and their pressure coefficients. Journal of Chemical Thermodynamics, in press.

Holmes, H.F., and Mesmer, R.E., 1983a. Thermodynamic properies of aqueous solutions of the alkali metal chlorides to $250^{\circ} \mathrm{C}$. Journal of Physical Chemistry, v. 87, p. $1242-1255$.

Holmes, H.F., and Mesmer, R.E., 1983b. Isopiestic studies of aqueous solutions at elevated temperatures VII $\mathrm{MgSO}_{4}$ and $\mathrm{NiSO}_{4}$. Journal of Chemical Thermodynamics, v. 15, p. 709-719.

Kirshenbaum, A.D., Cahill, J.A., McGonigal, P.J., and Grosse, A.V., 1962. The density of liquid $\mathrm{NaCl}$ and $\mathrm{KCl}$ and an estimate of their critical constants together with those of other alkali halides. Journal of Inorganic and Nuclear Chemistry, v. 24, p. 1287-1296.

Liu, C.-1., and Lindsay, W. T., Jr., 1972. Thermodynamics of sodium chloride solutions at high temperatures. Joun,al of Solution Chemistry, v. 1, p. $45-69$.

Pitzer, K.S., 1980. Electrolytes: From dilute solutions to fused salts. Journal of the American Chemical Society, v. 102, p. 2902-2906.

Pitzer, K.S., 1981. The treatment of ionic solutions over the entire miscibility range. Berichte der Bunsengesellschaft fuer Physikalische Chemie, v. 85, p. 952-959.

Pitzer, K.S., 1983. Dielectric constant of water at very high temperature and pressure. Proceedings of the National Academy of Sciences USA, v. 80 , p. $4575-4576$.

Pitzer, K.S., 1984. Critical point and vapor pressure of ionic fluids including $\mathrm{NaCl}$ and $\mathrm{KCl}$. Chemical Physics Letters, in press.

Pitzer, K.S., and Li, Yi-gui, 1983. Thermodynamics of aqueous sodium chloride to $823 \mathrm{~K}$ and 1 kbar. Proceedings of the National Academy of
Sciences USA, v. 80, p. 7689-7693.

Pitzer, K.S., and Li, Yi-gui, 1984. Critical phenomena and thermodynamics of dilute aqueous sodium chloride. Proceedings of the National Academy of Sciences USA, v. 81, p. 1268-1271.

Pitzer, K.S., Peiper, J.C., and Busey, R.H., 1984. Thermodynamic properties of aqueous sodium chloride solutions. Journal of Physical and Chemical Reference Data, in press.

Rogers, P.S.Z., and Pitzer, K.S., 1981. Hightemperature thermodynamic properties of aqueous sodium sulfate solutions. Journal of Physical Chemistry, v. 85, p. 2886-2895. (See also v. 86, p. 2110.)

Rogers, P.S.Z., and Pitzer, K.S., 1982. Volumetric properties of aqueous sodium chloride solutions. Journal of Physical and Chemical Reference Data, v. 11, p. 15-81.

Smith-Magowan, D., and Wood, R.H., 1981. Heat capacity of aqueous sodium chloride from 320 to $600 \mathrm{~K}$ measured with a new flow calorimeter. Journal of Chemical Thermodynamics, v. 13, p. 1047-1073.

Sourirajan, S., and Kennedy, G.C., 1962. The system $\mathrm{H}_{2} \mathrm{O}-\mathrm{NaCl}$ at elevated temperatures and pressures. American Journal of Science, v. 260, p. 115-141.

Urusova, M.A., 1974. Phase equilibria in the sodium hydroxide-water and sodium chloride-water systems at $350-550^{\circ} \mathrm{C}$. Russian Journal of Inorganic Chemistry, v. 19, p. 450-454.

Urusova, M.A., 1975. Volume properties of aqueous solutions of sodium chloride at elevated temperatures and pressures. Russian Journal of Inorganic Chemistry, v. 20, p. 1717-1721.

White, D.E., and Wood, R.H., 1982. Absolute calibration of flow calorimeters used for measuring differences in heat capacities. A chemical standard for temperatures between 325 and $600 \mathrm{~K}$. Journal of Solution Chemistry, v. 11, p. 223-236. 


\section{HYDROTHERMAL ALTERATION OF HOST ROCKS NEA R BURIED HIGH-LEVEL RADIOACTIVE WASTE}

\author{
J.A. Apps
}

During fiscal 1983, a project was initiated at the request of the Nuclear Regulatory Commission to study the alteration of basalt under hydrothermal conditions, with the goal of resolving questions pertaining to radionuclide containment in the thermally affected region surrounding a stored waste canister. Progress during 1983 included planning and preliminary research for a series of experiments designed to meet this goal. Objectives of the experiments are to determine

1. How fast and in what way the host rock will alter between pre-storage temperatures and $350^{\circ} \mathrm{C}$. Research will include identification of secondary mineral assemblages and the mechanisms leading to their formation.

2. How alteration will affect porosity and permeability of the host rock.

3. The chemical composition, $\mathrm{pH}$, and oxidation state of the coexisting fluid phase.

These objectives should support the development of mathematical models simulating alteration in the near field, where the duration and spatial dimensions of a repository greatly cxceed those attainable in the laboratory.

I will briefly summarize the findings of the literature review conducted to date on basalt alteration and discuss the implications they have on the design of the experiments planned to meet the experimental objectives.

When a basalt is exposed tc water at elevated temperature in the field, any mesostasis glass, if present, and microcrystalline phases in the mesostasis are initially altered to smectite. Primary mineral phenocrysts-i.e., olivine, pyroxene, and plagioclase-are more slowly attacked. In their place are formed secondary minerals whose makeup is dependent both on the temperature and duration of exposure to hydrothermal conditions. Smectites and chlorite are dominant, but zeolites, feldspars, silica, calc-aluminosilicates, calcite, iron oxides, and iron sulfides are frequently observed.

A comparison of the secondary mineral assemblages in basalts in lceland and elsewhere with those observed from laboratory experiments shows that only smec'ite, illite, anhydrite, iron oxides, silica, and analcime form sufficiently rapidly in the laboratory below $300^{\circ} \mathrm{C}$ to be identified by conventional diagnostic methods. Theoretical calculations of mineral stabilities in coexisting geothermal groundwaters (Palmason et al., 1979; Gunnlaugsson and Amorsson, 1982; Amorsson et al., 1983) indicate that many of the observed minerals have more extensive stability fields than suggested by field occurrences or that $t$ :ey are metastable. I conclude that aiteration mineral assemblages surrounding a waste repository can be predicted on the basis of available field and laboratory evidence but that quantification of mineral growth rates as a function of temperature will be needed for precise estimates.

The bulk chemical composition of the rock and the secondary mineralogy can be affected by the introduction or loss of chemical components from the system by groundwater transport. However, the total volume of fluid passing through the rock has to be very large, i.e., greater than 50-100 times the rock mass in the case of sea water (Mottl and Seyfried, 1980 ) before the secondary mineralogy is significantly affected. In a repository in basalt, the water/rock ratio is unlikely to exceed 10 , and the concentrations of constituents dissolved in the water will normally be low. The impact of groundwatertransported components on the secondary mineral assemblages surrounding a repository may therefore be neglected in most situations. For laboratory experiments, the water/rock ratio is not critical and can range from 0 to 20 .

In designing a repository, we also need to know how fast alteration will proceed during the thermal period following repository closure. This necessitates identification and quantification of basalt alteration rates. Basalt alters through

1. Hydration and devitrification of the glass mesostasis through solid-state diffusion.

2. Surface dissolution.

3. Aqueous diffusion of reactants and products through pores.

4. Surface diffusion of reactants and products along intergranular boundaries.

5 Precipitation of secondary minerals.

I have reviewed these processes and summarized some of my findings in a sopical report for the Nuclear Regulatory Commission (Apps, 1984). From the limited data available, it appears that basalt glass hydrates similarly to obsidian at temperatures above $200^{\circ} \mathrm{C}$ with a similar activation energy but with a solid-state diffusion coefficient 3 times faster. Below $200^{\circ} \mathrm{C}$, however, alteration 
appears to be accelerated by some as-yet-unidentified mechanism in relation to rates predicted by extrapolation from higher temperatures. Surface dissolution rates of basalts and basaltic glasses follow zero-order kinetics and are similar to those for the dissolution of silicate minerals (Wood and Walther, 1983), but they are about four orders of magnitude slower than for rhyolitic glasses. Further experiments will be required to explain this significant difference.

I have found little information that would help establish the rate of surface or intergranular diffusion of reactants or products through basalt, nor can I find sufficient information to predict surface precipitation reactions controlling the growth of secondary minerals. Further study of relevant precipitation reactions is certainly required.

Nothing appears to be known about how rock alteration affects the permeability and porosity of basalt. Measurements of basait permeability and porosity have been reported in the literature and are summarized by Hume and Desai (1982), but these are inadequate for the purpose of predicting repository behavior during hydrothermal alteration. Clearly, further study is required ty reference to field material and through laboratory experiments.

We are in a much better position regarding the prediction of groundwater $\mathrm{pH}$, oxidation state, and composition. Arnorsson et al. (1983) show that Icelandic geothermal waters display smooth trends of the variation of chemical potentials of all major rock-forming components with temperature and that the only parameters required to define the composition of the groundwater are ionic strength and temperature. Gunnlaugsson and Arnorsson (1982) also noted that all Icelandic geothermal waters contain sulfide species in equilibrium with sulfate ion and with either pyrite, pyrrhotite, or marcasite. The Eh of the system appears to be controlled by equiljbrium between these species, and therefore the Eh can also be uniquely determined as a function of temperature and ionic strength.

The chemical composition of the water in Icelandic basalts is largely controlled by the rock, and the system behavior is said to be "rock dominated." Similar conditions are expected in a waste repository and in laboratory experiments where the water/rock ratio is less than 50 .

Experiments to measure conditions anticipated in a repository environment must be quantified and reconciled with published findings of field and laboratory observations. This can be done only if the host rock petrofabric is retained and alteration processes can to monitored as a function of time and temperature. Traditional leaching experiments with pulverized rock will not yield the information needed. Specially sized rock wafers whose surface area, porosity, and permeability are known should be leached with water at temperatures ranging from 150 to $350^{\circ} \mathrm{C}$ for periods up to 3 months while monitoring the coexisting solution compositions. Pre- and post-experiment mineralogical cxaminations and water surface area, porosity, and permeability determinations will contribute to the elucidation and quantification of rock alteration rates.

Further details outlining the planned experiments are given in Apps (1984).

\section{REFERENCES}

Apps, J.A., 1984. Hydrothermal evolutic: : repository groundwaters. Washington, D.C., U.S. Nuclear Regulatory Commission, NUREG/CP0052.

Arnorsson, S., Gunnlaugsson, E., and Sv² arsson, H. 1983. The chemistry of geothermal waters in Iceland. II. Mineral equilibria and independen: variables controlling water sompositions. Geochimica et Cosmochimica Actia, 47, p. 547-566.

Gunnlaugsson, E., and Arnorsson, S., 1982. The chemistry of iron in geothermal systems in Iceland. Journal of Volcanolog' and Geothermal Research, v, 14, p. 281-299.

Hume, H.R.. and Desai, P.D. 1982. Mechanical properties of basalt. In L 1. Gevantman (ed.), Physical Properties Data for Basalt. Washington, D.C., National Bureau of Standards Information Report, NBSIR 82-2587, p. 427-502.

Mottl, M.J., and Seyfried, W.E., 1980. Sub-seafloor hydrothermal systems, rock- vs. seawaterdominated. In P.A. Rona and R.P. Lowell (eds.), Seaflonr Sprer ding Center Hydrothermal Systems. Dowden Hutchinson and Ross, Benchmark Papers .n Geology, p. 66-82.

Palmason, G., Arnorsson, S., Fridleifsson, I.B., Kristmannsdottir, H., Saemundsson, K., Stefansson, V., Steingrimssc ?, B., and Tomasson, J., 1979. The Jceland Crist: Evidence from drillhole data on structure and processes. In Deep Drilling Results in the Atlantic Ocean: Ocean Crust. Washingtol, L.C., The American Geophysical Union, p. 43-65.

Wood, B.J., and Walther, J.V., 1983. Rates of hydrothernal reactions. Science, v. 222, p. 413-415 


\section{GEOCHEMISTRY RESEARCH PLANNING FOR UNDERGROUND REPOSITORIES}

\author{
J.A. Apps
}

In 1980 the Nuclear Regulatory Commission (NRC) asked for a plan for research on unresolved geochemical problems pertaining to underground isolation of nigh-level radioactive waste. The plan was to identify projects that could resolve present uncertainties and contribute to an acceptable technology for waste disposal.

The response to this jequest is given in two reports (Apps et al., 1982; Apps, 1984). The approach adopted is summarized as a flow chart in Fig. 1 . In this article, I discuss the component steps taken and give some findings resulting from their execution.

The objectives used to guide planning were those of the Interagency Review Group on Nuclear Waste Management (1979), who defined the objectives for

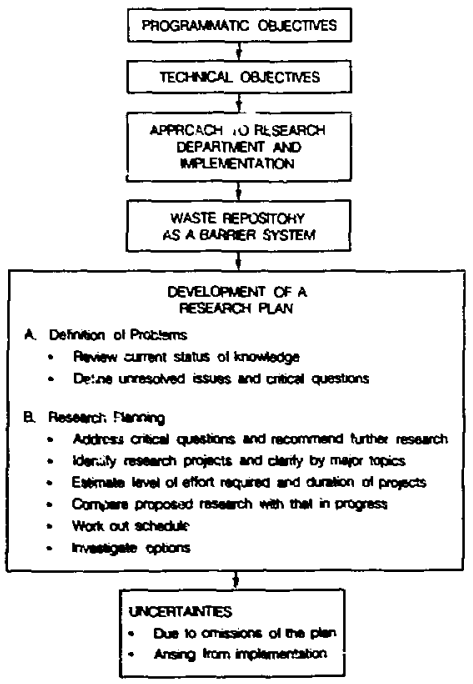

Fizure 1. Appraach to geochemistry tesern planning for the underground storage of high-level n-mlear waste. [XBL 843-9733] disposal of nuclear waste from military and civilian activities. Research and development needs for an underground repository are much more elaborate than for conventional engineerir. design and construction. Radionuclides must be contained for many thousands of years. Yet laboratory and fieid testing to verify containment can, at most, extend only for a few years before answers are found and a decision made to start repository construction. To overcome this problem, predictive models of repository performance are needed that can reconcile short-term experiments with analogous natural processes that have operated for periods curresponding to required containment tumes. A logic diagram that incorporates this approach is laid out in Fig. 2.

A repository is a system of engineered and natural barriers to radionuclide migration. The engineered barriers should be made of materials similar to those that persist naturally. Otherwise, there would be no means of reconciling their predicted performance with known natural processes.

The engineered barriers include the waste form. container, overpack, and backfill. These in turn are surrounded by near. and far-field hosi rocks, the natural barriers to radionuclide migration. The repository host rock will be selected from one or more of the following rock types: salt (either dome or bedded), basalt, tuff, and possibly granite. The choice will affect the selection and design of the engineered barriers. The barriers, each designed to fulfill one or more discrete functions, constitute the "system" or framework for planning a logical sequence of research activities.

The systems approach to the geologic repository was used to correlate the materials and barrior parameters with critical seochemical questions or issues concerning their functions. The issues were also correlated with present sections from the technical rules given in 10 CFR Part 60 (NRC, 1981). Tasks for clarifying the issues were initiated through review of the current status of knowledge pertaining to those issues. Each issue was then examined and evaluated by means of preliminary heuristic calculations and by modeling when time and resources pern.itted. This approach differed from that used in earlier reviews in that it was designed to resolve or at least clarify the issue rather than merely determine the current status of research progress relating to it. Exhaustive literature reviews were de-emphasized in favor of identifying the principal hindrances to solution of the issues. Even though most issues could not be resolved with the resources available, conclusions were reached and recommend?:ions made for further research. 


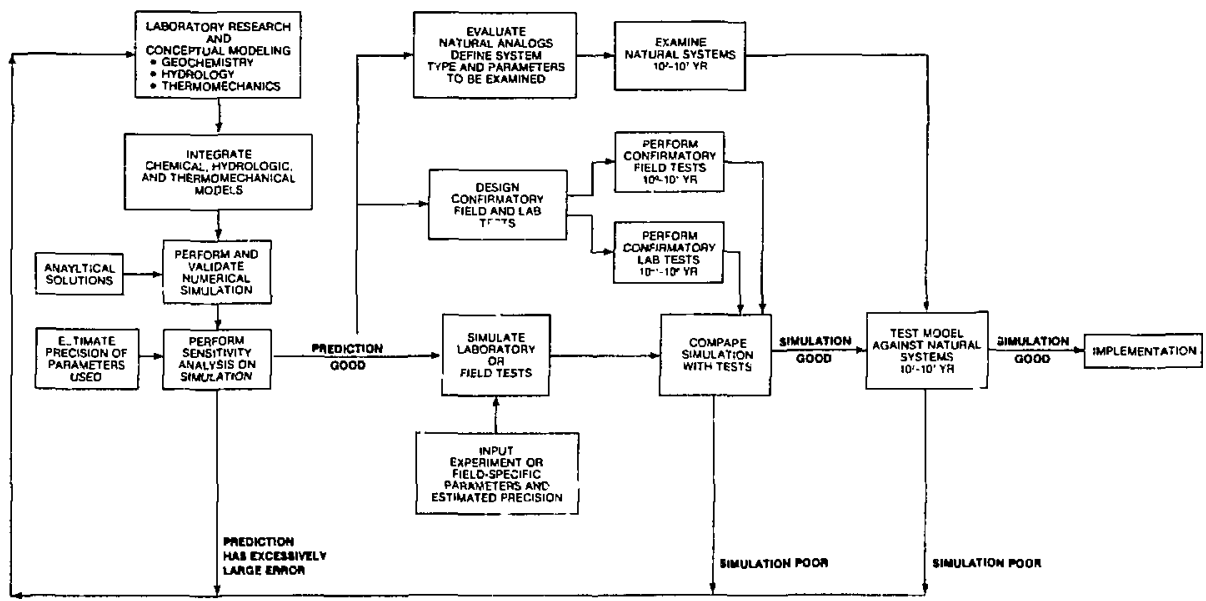

Figure 2. Logic chart for developing predictions of radioactive waste containment by an $i$, snd repository, [XBL 822-1871]

The issues were divided into three categories:

1. Bounding geochemical conditions and radionuclide compositions expected to spend reactor fuel and high-level waste at various times after 1000 years. The purpose was to set limits on the scope of subsequent evaluations by restricting conditions or radionuclides to those relevant to waste :-spository containment. Among the conditions discussed were pressure, temperature, host rock mineralogy, groundwater composition, and hot rock physical parameters such as porosity, permeability, and effective surface area. All potentially toxic radionuclides were considered.

2. Problems relating to radionuclide migration. Problems relating to the transport of radionuclides through repository barriers fail into three subcategories: the forms in which radionuclides are transported, recardation mechanisms, and transport models incorporating chemical $r$. actions.

3. Specific problems relating to barriers. These include backfill physical properties that affect radionuclide migration, radionuclide transport through backfill (with and without sorption), criticality potential, the effect of waste emplacement on the near-fieli environment, and groundwater dating in the far field.
The selection of lasks for evaluating each issue resulted in a series of prioritized recommendations that led to the specification of 62 research proposals covering a wide range of theoretical, laboratory, and field studies. The proposed research was classified inte seven scientific or technical areas: (1) bounding conditions, (2) transported radionuclide forms, (3) radionuclide transport mechanisms, (4) retardation mechanisms, (5) physical/chemical properies of barriers, (6) chemical iransport algorithms, and (7) field evaluation. This classification reflects the logic given in Fig. 2 but is now specified in terms of research projects.

The review of issues, listing of recommendations, and descriptions of proposed research projects are given in Apps et al. (1982). Research planning is outlined in Apps (1984), where the projects described in Apps et al. (1982) are used to develop a research plan. This requires an estimation of the required level of effort and duration of each project. In addiuon, the linking of projects is needed-i.e., certain projects must be done sequentially because output from one or more projects may be required as input for another. On the basis of this additional input, 16-year program schedule was produced using CPMG, a computer code to facilitate the planning 
and orzanization of complex projects. CPMG also graphs manpower distribution during the course of a project. In addition to the 16-year schedule, an alternative "minimum effort" schedule and manpower. distribution was also computed in which intermediate research results lead to the elimination of some projects.

Schedule and manpower charts are valuable because they identify projects on the critical path and uneven distributions of manpower in the program, and they highlignt the uncertainties that remain and pinpoint the options for overcoming them. Projects on the critical path are given in Table 1.

The plan also brings into focus the relationship between risk of repository malfunction and the research costs affecting that risk. For example, the repository size might possibly be decreased if the maximum temperature tolerated in the repository could be raised by $100^{\circ} \mathrm{C}$. Estimates of the additional research required to allow the design of a repository with the same integrity can be made, and the additional cost and expected delay in repository commissioning can also be estinated. Some options could have large payoffs in relation to the research funds expended.

Sunport presently provided by the DOE :- insufficient to resolve many of the issues raise. This does not mean that an underground repost. y cannot be built; rather, greater uncertainty will attend its functioning as designed. Whether this uncertainty will prove acceptable to the public at large will be learned within the coming decade.

\section{REFERENCES}

Apps, J., 1984. Geochemistry research planning for the underground storage of high-level nuclear waste. Lawrence Berkeley Laboratory, LBL17745.

Apps, J.A., Camahan, C.L., Lichtner, P.C., Michel, M.C., Perry, D., Silva, R.J., Weres, O., and White, A.F., 1982. Status of geochemical problems relating to the burial of high-level radioactive waste, 1982 . Lawrence Berkeley Laboratory, LBL-15103 (NUREG/CR-3062), p. 365.

Table 1. Projecis on the critical path to the geochemistry program.

\begin{tabular}{|c|c|}
\hline Description & $\begin{array}{r}\text { Duratio } \\
\text { (years) }\end{array}$ \\
\hline $\begin{array}{l}\text { Groundwater composition in the backfill and near } \\
\text { field to } 300^{\circ} \mathrm{C}\end{array}$ & 3 \\
\hline Complexes of actinides in groundwater to $175^{\circ} \mathrm{C}$ & 3 \\
\hline $\begin{array}{l}\text { Radioelement adsorption on backfill and host rocks } \\
\text { to } 175^{\circ} \mathrm{C}\end{array}$ & 3 \\
\hline Sorption of radioelements on specific minerals & \\
\hline $\begin{array}{l}\text { Incorporating radionuclide adsorption to } 175^{\circ} \mathrm{C} \text { on } \\
\text { appropriate mineral surfaces in a chemical solution } \\
\text { algorithm }\end{array}$ & $l$ \\
\hline $\begin{array}{l}\text { Devclopment of transport algorithm incorporating a } \\
\text { relistic description of the barrier medium }\end{array}$ & 2 \\
\hline $\begin{array}{l}\text { Laboratory verification of transport models } \\
\text { Field verification of transport models }\end{array}$ & 3 \\
\hline Interpretation of field data & 1 \\
\hline & 16 \\
\hline
\end{tabular}


Interagency Review Group of Nuclear Waste Management, 1979. Report to the President by the Interagency Review Group on Nuclear Vaste Management, TID-29442, p. 140.

\section{EFFECT OF A SECOND-ORDER} RATE OF INTERPHASE MASS TRANSFER ON

\section{ADVECTIVE/DISPERSIVE SOLUTE TRANSPORT IN POROUS MEDIA}

\section{J.S. Remer and C.L. Carnahan}

The computer program NONEQ is being used to extend our earlier theoretical studies of sorption during advective/dispersive solute transport in a threedimensional, infinite porous medium. Previously, we derived analytical solutions to the problem of solute transport for two different types of sorptive behavior: equilibrium between the solute concentration in the fluid and solid phases and mass transfer between the fluid and solid phases governed by a reversible, first-order rate of interphase mass transfer (Carnahan and Remer, 1981). NONEQ numerically solves the solute transport problem when the sorption is governed by a reversible, second-order rate law. The second-order rate law accounts for a finite sorptive capacity of the solid phase. The first-order rate law is an approximation made by assuming that the surficial concentration of the sorbed phase is very small relative to the sorptive capacity. The second-order rate law is regarded as nore physically realistic than the first-order rate law, but the resulting system of equations is more difficult to solve.

We completed development of NONEQ early in fiscal 1983, having presented preliminary results from our work with the code at the 1982 Fall Meeting of the American Geophysical Union (Remer and Carnahan, 1982). During the remainder of the fiscal year, we ran many numerical simulations with NONEQ to determine under what tonditions the concentration distributions predicted by the secondorder rate law will differ significantly from those predicted by the first-order rate law.
U.S. Nuclear Regulatory Commission, 1981. Disposal of high-level radioactive wasles in eeologic repositories. Federal Register, v. 46, 37 and 130 , p. 1397-13987 and 35280-35296.

\section{EQUATIONS OF TRANSPORT AND INTERPHASE MASS TRANSFER}

To simplify the transport equation, we have made the following assumptions: The medium is isotropic and homogeneous, the principal axes of the dispersion tensor are parallel to those of a Cartesian coordinate sustem, and the fluid velocity is steady and uniform in the direction of the $z$ axis. After changing to cylindrical coordinates, the governing transport equation may be written

$$
\begin{aligned}
\frac{\partial C}{\partial t}=D_{T} & \left(\frac{\partial^{2} C}{\partial r^{2}}+\frac{1}{r} \frac{\partial C}{\partial r}\right) \\
& +D_{L} \frac{\partial^{2} C}{\partial z^{2}}-v \frac{\partial C}{\partial z}-\lambda C-\left(\frac{1-\epsilon}{\epsilon}\right) S
\end{aligned}
$$

where $C$ is the concentration in the fluid phase, $S$ is the rate of interphase mass transfer, $r$ is the radial distance, $z$ is the longitudinal distance, $t$ is the time, $v$ is the average, steady fluid velocity in the $z$ direction, $D_{L}$ is the coefficient of longitudinal dispersion, $D_{T}$ is the coefficient of transverse dispersion, $\epsilon$ is the porosity, and $\lambda$ is the radioactive decay constant of the solute. The governing equation for the solid phase concentration, $Q$, is

$$
\frac{\partial Q}{\partial t}=-\lambda Q+S
$$

The rate of interphase mass transfer expresses the rate at which the solute moves from the fluid to the solid phase. The rate law for Langmuir adsorption assumes a finite sorptive capacity:

$$
S=k_{1}{ }^{\prime}\left(Q_{S}-Q\right) C-k_{2}{ }^{\prime} Q,
$$

where $k_{1}{ }^{\prime}$ is the forward rate constant, $k_{2}{ }^{\prime}$ is the backward rate constant, and $Q_{S}$ is the sorptive capacity of the solid phase. If we assume that the sorp- 
live capacity of the sciid phase is very iarge compared to the solid concentration, then (3) may be reduced to a first-order rate law:

$$
S=k_{1} C-k_{2} \mathbf{Q},
$$

which is the expression for $S$ used to obtain the analytical solutions described in the preceding section.

As initial condition and two boundary conditions complete the problem formulation. Initially, the fluid and solid phase concentrations are zero:

$$
C(r, z, 0)=0, Q(r, z, 0)=0 .
$$

At infinity, the solute in both phases is zero:

$$
\lim _{r, z \rightarrow \infty} C(r, z, t)=0, \lim _{r, z \rightarrow \infty} Q(r, z, t)=0 .
$$

The second boundary condition is a statement of conservation of mass, $M(t)$, in the system:

$$
\begin{aligned}
2 \pi \int_{-i n f}^{+\infty} \int_{0}^{+\infty}[\epsilon C(r, z, t) \\
+(1-\epsilon) Q(r, z, t) \mid r d r d z=M(t) .
\end{aligned}
$$

The mechanism for introducing mass into the system is a point source located at the origin of the coordinate system. Three types of mass release have been incorporated into $\mathrm{NONEQ}$; an instantaneous release of $m_{o}$ moles; a continuous release of $m_{o}^{\prime}$ $\exp (-\lambda t)$ moles per unit time, where $m_{0}{ }^{\prime}$ is the injtial rate of release and $\lambda$ is the decay constant; and a continuous rate of release equal to $m_{o}^{\prime} \exp (-\lambda l)$ moles per unit time, which ceases at time $t_{f}$.

\section{METHOD OF SOLUT'ION}

Before solving the governing equation for $C$ numerically, the equation is transformed using a coordinate transformation that maps the infinite problem space onto a finite space. This is done to avoid approximating the boundary condition at infinity by a boundary condition at a finite distance from the origin. Transforming the partial differential equation introduces variable coefficients into the finite-difference equation, but because the new coefficients depend only on the space variables. they have to be calcuiated only once.
Several numerical techniques have been combined to solve the system of Eqs. (1), (2) and (3). The alternating-direction-implicit method has been used to solve (1) for $C$. This method was chosen because it is consistent and unconditionally stable; in addition, it yields a tridiagonal system of equations that computationally is easy to solve (Douglas, 1961: Douglas and Gunn, 1964). A simpler finitedifference scheme is used to solve (2) for $Q$.

Because of the nonlinear term $C Q$ in (3), a halftime step projection method followed by an iteration scheme must be used to calculate $S$ (von Rosenberg, 1969). At the beginning of the time step, $S$ at the half-time step is approximated by a trincated Taylor series that involves time derivatives of $C$ and $Q$ at the previous time step. The time derivatives of $C$ and $Q$ in the expression for $S$ are replaced by finitedifference approximations. This procedure gives an initial estimate for $S$ at the half-time step, which is used in the finite-difference equations for $C$ and $Q$. After $C$ and $Q$ have been calculated at the end of the time step, the value of $S$ at the end of the time step is calculated from the rate law expression, (3). Thereafter, the average of the value of $S$ at the previous time step and its new vaiue at the end of the current time step is used to estimate $S$ at the halftime step for the next iteration. The iterative process continues until the difference between the old and new estimates of $S$ is less than a specified tolerance.

The equation of mass conservation, (7), has been approximated by an integration formula that combines three methods of numerical integration. A five-point integration formula is used in a small region surrounding the origin, the trapezoidal rule is used at the outer boundary, and Simpson's formula is used in the intermediate region (Abramswitz and Stegun, 1965; Dahlquist and Björck, 1974). The final form of the equation is a weighted sum. In the case of an instantaneous release of mais, this form is used to check the agreement between the computed and actual mass in the system at the end of each time step. If the release of mass is continuous, the approximation replaces the finite-difference equation for $C$ at the origin.

\section{RESUITS}

The difference between the second-order and first-order rate laws, (3) and (4), is the term $k_{1}{ }^{\prime} C Q$. Therefore, it is not surprising that the concentration fistributions that result from using the second-order rate law differ sigrificantly $f_{i} \mathrm{am}$ those of the firstorder rate law when a large value of the forward rate 
constant is used. For small values of $k_{1}{ }^{\prime}$, the fluid phase concentrations for the two rate laws are barely distinguishable at early times. At later times, over a range of values of $k_{2}^{\prime}$ and $Q_{s}$, the relative difference between the fluid phase concentrations for the firstorder and second-order rate laws differ by a few percent. For large values of $k_{1}$, the fluid phase concentrations for the two rate laws differ significantly, in terms of both magnitude and shape of profile.

Having determined a lower limit on the value of $k_{1}^{\prime}$ that would show a difference in the fluid phase concentrations predicted by the first-order and second-order rate laws, we investigated the effects of varying $k_{2}^{\prime}$ and $Q_{5}$. The difference between the fluid phase concentrations for the two rate laws increases with time for small values of $Q_{x}$ and decreases in time for large values. Initially, however, there is a larger relative difference between the fluid phase concentrations for the first-order and second-order rate laws for large values of $Q_{5}$. The profile of the fluid phase concentration for the second-order rate law everywhere exceeds that for the first-order rate law for small values of $Q_{s}$. Initially, that is also the case for large values of $Q_{s}$, but at later times the profile for the first-order rate law exceeds that for the second-order rate law near the origin.

Varying $k_{2}^{\prime}$ has a larger effect on the itid phase concentration for the first-order rate law than on that for the second-order rate law over the range of values investigated. At early times, the profiles for the first-order rate law differ in magnitude and in shape. The profile for a relatively small value of $k_{2}^{\prime}$ peaks near the origin, whereas the profile for a larger value of $k_{2}^{\prime}$ steadily decreases with distancc away from the origin. At the same early time, the fluid phase concentrations nearly soincide for the secondorder rate law over the range of values of $k_{2}{ }^{\prime}$ considered. At later times and in a region near the origin, the profile for the second-order rate law with a large value of $k_{2}^{\prime}$ exceeds the profile for a small value of $k_{2}^{\prime}$ by a difference that increases with time; the same statement also applies to the profiles for the first-order rate law at later times.

The solid phase concentrations for the first-order and second-order rate law always differ by many orders of magnitude near the origin, regardless of the value of $k_{1}{ }^{\prime}$. The reason for this is that using a firstorder rate law is equivalent to assuming an infinite sorptive capacity. In the case of an instantaneous release of mass, the analytical solution for the solid phase concentration derived from the first-order rate law is actually infinite at the origin (Carnahan and Remer, 1981).
If the amount of mass released into the system is sufficient to cause saturation of the solid phase, the solute concentration in the solid phase for the second-order rate law is approximately equal to $Q_{\text {s }}$ at the origin. Near its leading edge, the solid phase concentration profile for the second-order rate law coincides with or exceeds by a f-w percent the profile for the first-order rate law.

\section{CONCLUSION}

Our motivation for developing the combuter code NONEQ has been to compare solute distributions (during advective/dispersive transport) resulting from first-order and second-order rates of interphase mass transfer. If a first-order rate law is assumed, then the resulting system of equations can be solved analytically. The second-order rate law, however, includes a nonlinear term, the product of the fluid and solid phase concentrations. The system of equations is no longer amenable to analytical solution; NONEQ solves the system numerically.

We are particularly interested in the concentration of solute in the fluid phase. Our work with NONEQ this year has shown us that for small values of the forward rate constant, the same fluid phase concentration results whether a first-order or second-order rate law is used. If the forward rate constant is large enough, the profile of the fluid phase concentration for the first-order rate law differs significantly in magnitude and shape from the profile for the second-order rate law. The backward rate constant and the sorptive capacity in the second-order rate law also affect the differences in magnitude and shape between the profiles.

\section{REFERENCES}

Abramowitz, M., and Stegun, I.A., 1965. Handbook of Mathematical Functions, New York, Dover Publications, p. 891.

Carnahan, C.L., and Remer, J.S., 1981. Nonequilibrium and equilibrium sorption with a linear isotherm during mass transport through an infinite, porous medium: Some analytical solutions. Lawrence Berkeley Laboratory, LBL13005.

Dahlquist, G., and Björck, A.. 1974. Numerical Methods. Englewood Cliffs, New Jersey, Prentice-Hall, p. 154, 166, 167, 266, 267.

Douglas, J., 1961. A survey of numerical methods for parabolic differential equations. In F.L. Alt (ed.), Advances in Computers. New York, Academic Press, p. 1-54. 
Douglas, J., and Gunn, J.E, 1964. A general formulation of altemating direction methods. Part $\mathrm{I}$. Parabolic and hyperbolic problems. Numerische Mathematik, v. 6, p. 428-454.

Remer. J.S., and Camahan, C.L., 1982. Advective/dispersive solute transport through a infinite porous medium with a second-order rate of inte.phase mass transfer. Presented at the 1982 Fall Meeting of the American Geophysical Union, San Francisco, California, December $7-15,1982$.

von Rosenberg, D.U., 1969. Methods for the Numerical Solution of Parial Differential Equations. New York, Elsevier, p. 113.
THE GALENA/DICHROMATE SOLUTION INTERACTION AND THE NATURE OF THE RESULTING CHROMIUM(III) SPECIES: AN IMPORTANT REACTION SYSTEM IN THE FROTH FLOTATION

\section{PROCESSING OF GALENA}

\section{D.L. Peiry and L. Tsao}

The reaction of aqueous sodium dichromatc, $\mathrm{Na}_{2} \mathrm{Cr}_{2} \mathrm{O}_{7}$, with galena (PbS) is one of the most commonly observed reactions in the froth flotation separation of galena from other metal suifide ores, the sodium dichromate acting as a modifier in the process. Surface studies (Clifford et al., 1975; Nefedov et al., 1980) have shown that the resulting chemical species on the galena include both the chromium(VI) species and the reduced chromium(IiI) species. While the $x$-ray photoelectron data regarding the chromium(VI) species in these studies were consistent with $\mathrm{PbCrO}_{4}$, the assignment of the chromium(III) species was not so unequivocal. One team of researchers (Clifford et al., 1975) suggested that the $\mathrm{Cr}$ (III) probably was some type of oxidation product formed on the surface; another team of investigators (Netedov et al., 1980) speculated that it was $\mathrm{PbCr}_{2} \mathrm{O}_{4}$ (a combination of $\mathrm{Pb}(\mathrm{OH})_{2}$ and $\left.\mathrm{Cr}_{2} \mathrm{O}_{3}\right)$ on the basis of binding energy data alone. This laboratory has reinvestigated this reaction system, making detailed studies of the x-ray photoelectron spectra (XPS) of the reacted galena surfaces and comparing them with those of model chromium(11l) compounds.

The galena samples were reacted with aqueous $\mathrm{Na}_{2} \mathrm{Cr}_{2} \mathrm{O}_{7}$ solutions in a manner almost identical to methods previously used (Clifford et al., 1975;
Nefedov ei al., 1980). Instead of using an aqueous solution of $\mathrm{SO}_{2}\left(\mathrm{H}_{2} \mathrm{SO}_{3}\right.$, or sulfurous acid) to remove any oxidation products on the surfaces of the galena samples, boiling water was used. The resulting samples yielded spectra that show only the sulfide species; no traces of oxidation products such as sulfur or sulfate can be detected. Variations in the ratio of $\mathrm{PbS}: \mathrm{Cr}_{2} \mathrm{O}_{7}{ }^{2-}$ in the reaction solution yielded spectra that are virtually identical; this is in agreement with results previously reported.

\section{RESULTS AND DISCUSSION}

Figure 1 shows the chromium $2 p_{3 / 2,1 / 2}$ spin-orbit doublet spectrum of the reacted galena. Each of the two photoelectron lines consists of obvious doublets. one line in each doublet representing chromiun(III) and the other line representing chromium(VI). Binding energies and spin-orbit splittings (Table 1 ) for the

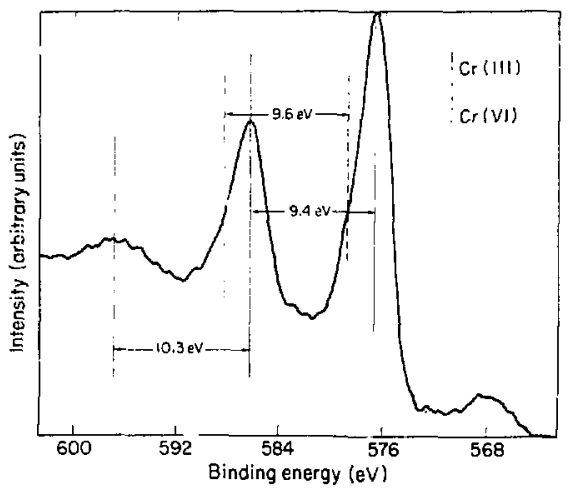

Figure 1. The chromium $2 p_{3 / 2, / 2}$ photoelectron spectrum of galena that has been reacted with an aqueous solution of $\mathrm{Na}_{2} \mathrm{Cr}_{2} \mathrm{O}_{7}$ using the reaction conditions given in Clifford et al. (1975) and Nefedov et al. (1980). [XBL 839-2218] 
Table 1. X-ray photoelectron data for the galena/ $\mathrm{Cr}_{2} \mathrm{O}_{7}{ }^{2-}$ reaction and related $\mathrm{Cr}(\mathrm{IIJ})$ compounds. ${ }^{2 . b}$

\begin{tabular}{|c|c|c|c|c|c|c|c|}
\hline Sample & $\mathrm{C}=2 p_{3 / 2}$ & $\operatorname{Cr} 2 p_{1 / 2}$ & $0 ! s$ & $\mathrm{C} 15$ & $\operatorname{Cr}\left(2 p_{3 / 2}-2 p_{3 / 2}\right)$ & Cr 3s spliting & $C: \Sigma P_{1 / 2}$ satclitie ${ }^{d}$ \\
\hline \multirow[t]{2}{*}{ Galena $/ \mathrm{C}_{2} \mathrm{O}_{7}{ }^{2-}$} & $577.0-\operatorname{Cr}(\mathrm{III})$ & $586.4 \mathrm{Cr}(\mathrm{III})$ & 530.9 & 288.0 & 9.4 & $4.1-4.3$ & 10.3 \\
\hline & $578.8-\mathrm{Cr}(\mathrm{VI})$ & $588.4-\mathrm{Cr}(\mathrm{VI})$ & & & 9.6 & - & - \\
\hline $\mathrm{Cr}_{2} \mathrm{O}_{3}$ & 576.3 & 586.1 & 529.9 & - & 9.8 & 4.3 & $i 0.3$ \\
\hline $\mathrm{Cr}(\mathrm{OH})_{3}{ }^{e}$ & 576.6 & 586.4 & 530.8 & 288.0 & 9.8 & 4.1 & 10.3 \\
\hline $\mathrm{Cr}_{2}\left(\mathrm{CO}_{3}\right)_{3} \cdot n \mathrm{H}_{2} \mathrm{O}^{\mathrm{f}}$ & 577.0 & 587.1 & 531.2 & 288.0 & 10.1 & 4.1 & 10.3 \\
\hline
\end{tabular}

'All values in eleciron volts, $\mathrm{eV}$.

bAdventitious carton $i s=284.6 \mathrm{eV}$.

'Carbon line attributable to the carbonate species.

dDistance (10 the high-bindirg-energy side) from the main $2 p_{1 / 2}$ line.

-Also formulated as $\mathrm{Cr}_{2} \mathrm{O}_{3} \cdot n \mathrm{H}_{2} \mathrm{O} \cdot \mathrm{COO}_{2}$.

fAlso formulated as $\mathrm{Cr}_{2} \mathrm{O}_{3} \cdot n \mathrm{H}_{2} \mathrm{O} \cdot x \mathrm{CO}_{2}$.

chromium(VI) lines are in good agreement with an assignme.1t of $\mathrm{PbCrO}_{4}$, as previously reported.

The chromium(III) portion of the spectrum, however, represents a much more complex situation, since chromium(III), with its $3 d^{3}$ electronic paramagnetic configuration [as opposed to the diamagnetic $3 d^{0}$ state of chromium(VI) $\mid$ exhibits a broader $2 p$ core line, associated "shake-up" satellite lines to the high-binding-energy side of the main photoelectron lines, and multiplet splitting of the $3 s$ core levels by the $3 d$ valence electrons (Vernon et al., 1976). Additionally, spectral characteristics and parameters resulting from these effects can be altered by such factors as sample hydration.

The two chromium(III) lines shown in Fig. I have binding energies of 577.0 and $586.4 \mathrm{eV}$, respectively, for the $2 p_{3 / 2}$ and $2 p_{1 / 2}$ lines. These values are very similar to those exhibited by $\mathrm{Cr}(\mathrm{OH})_{3}$ and hydrated $\mathrm{Cr}_{2}\left(\mathrm{CO}_{3}\right)_{3}$. shown ial $\mathrm{I}$.ble 1 . as well as $\mathrm{tc}$ those previously reported for the natural mineral $\mathrm{CrOOH}$ (Ikemoto et al., 1976), a hydrated chromium(III) oxide. The spin-orbit splitting between the $\mathrm{Cr} 2 p_{3 / 2}$ and $2 p_{1 / 2}$ lines is $9.4 \mathrm{eV}$ within experimental error, also quite close to the splitting of $9.8 \mathrm{eV}$ exhibited by the hydroxide and carbonate chromium(1II) models in Table 1 . The seeming discrepancy of $0.4 \mathrm{eV}$ between the two values can probably be attributed to the inability to locate the centroids of the chromium(III) peaks exactly. Whue these splitings also compare favorably with that of 9.7 eV, previously reported by Allen et al. (1973) for
$\mathrm{Cr}_{2} \mathrm{O}_{3}$, it is highly unlikely that any $\mathrm{Cr}_{2} \mathrm{O}_{3}$ formed in an aqueous reaction medium would be anhydrous.

If one examines the region of the spectrum on the high-binding-energy side of the chromium $2 p_{l / 2}$ peak, the similarities between the spectra of the dichromate-treated galena and the $\mathrm{Cr}(\mathrm{OH})_{3}$ and $\mathrm{Cr}_{2}\left(\mathrm{CO}_{3}\right)_{3} \cdot n \mathrm{H}_{2} \mathrm{O}$ compounds ase even more striking. As a result of elcctronic configuration interactions (Vernon et al., 1976), which are most pronounced in paramagnetic jons such as chromium(III). the "shake-up" satellites of each spectrum are identical, with a value of $10.3 \mathrm{eV}$ to the high-binding-energy side of the main $2 p_{1 / 2}$ photoelectron line. Indeed. the chromium $2 p$ spectra (and associated "shake-up" satellites) of the dichromate-treated galena and these two model compounds exhibit profiles that are virtually identical; with the exception of the small differences in binding energies, the spectra are superimposable. The profile of the chromium $2 p$ spectrum of the other model compound in Table $1-\mathrm{Cr}_{2} \mathrm{O}_{3}$-is also identical to that of the dichromate-rreated galena surface. The line width (FWHM, or full width at half maximum) of the chromium $2 p$ lines for each of these compounds is approximately $3.1 \mathrm{eV}$, virtually identical to that reported $(3.0 \mathrm{eV})$ for $\mathrm{Cr}_{2} \mathrm{O}_{3}$ (Allen et al.. 1973). The ratio of the intensity of the satellite (at $10.3 \mathrm{eV}$ to the high-bindingenergy side of the $\mathrm{Cr}_{\mathrm{r}} 2 p_{1 / 2}$ line) to that of the main line is 0.18 ; this, 100 , is close to the value of 0.16 reported for $\mathrm{Cr}_{2} \mathrm{O}_{3}$ (Verriun et al., 1976), strongly indicating that all of the model compounds and the 
chromium(III) complex on the dichromate-treated galena surface are related to $\mathrm{Cr}_{2} \mathrm{O}_{3}$.

The oxygen $1 s$ binding energies reported in Table 1 give further evidence that the chromium(III) species may be derived from some form of hydrated chromium(III) oxide such as $\mathrm{Cr}(\mathrm{OH})_{3}$. The binding energies for this photoelectron line are 530.9, 530.8, and $531.2 \mathrm{eV}$ for dichromate-treated galena, $\mathrm{Cr}(\mathrm{OH})_{3}$, and $\mathrm{Cr}_{2}\left(\mathrm{CO}_{3}\right)_{3}-n \mathrm{H}_{2} \mathrm{O}$, respectively. This represents a range of only $0.4 \mathrm{eV}$ for the three sam. ples, which are in fairly close agreement with one another. Those three values, however, are a full volt higher than that for $\mathrm{Cr}_{2} \mathrm{O}_{3}$, further indicating that the chromium(III) species on the galena surface cannot be the simple, anhydrous $\mathrm{Cr}_{2} \mathrm{O}_{3}$. Since the degree of hydration of metal oxide has been shown by other workers (Auen et al., 1973; Perry and Taylor. 1983; Perry et al., 1984) to strongly influence the oxygen $1 s$ binding energies, it is not surprising that the binding energy here for the $\mathrm{O} l s$ line is this high. Allen et al., (1973) have shown tha: hydrating chromium oxides can increase the binding energy to $2 \mathrm{eV}$. This would be consistent with the present observations if one assumes that the chromium(III) species on the galena surface is some type of hydrated $\mathrm{Cr}_{2} \mathrm{O}_{3}$ or is derived from hydrated $\mathrm{Cr}_{2} \mathrm{O}_{3}$.

The chromium $3 s$ multiplet splitting (Vernon et al., 1976) exhibited by the dichromate-treated galena is approximately $4.1 \mathrm{eV}$ for all but one of the samples examined, the multiplet splitting in that sample being $4.3 \mathrm{eV}$. Again, this is in excellent agreement with the value of $4.1 \mathrm{eV}$ reported in Table 1 for $\mathrm{Cr}_{2}\left(\mathrm{CO}_{3}\right)_{3} \cdot n \mathrm{H}_{2} \mathrm{O}$ and $\mathrm{Cr}(\mathrm{OH})_{3}$; the lower end of the range of values is also extremely close to the value of $3.9 \mathrm{eV}$ reporied for $\mathrm{CrOOH}$ (lkemoto et al, 1976). A small range of $0.3 \mathrm{eV}$ in the splitting values for different galena samples is not surprising in light of still other recent results from an invest ${ }^{-}$ation of hydrated iron(III) oxides; the $3 \mathrm{~s}$ multiplet spliting has been shown to vary almost $2 \mathrm{eV}$ because of the extensive hydration of the oxides (Perry and Taylor, 1983).

An examinatiois of the carbon 15 line reveals not only the adventitious carbon line at $284.6 \mathrm{cV}$ but also a line at $288.0 \mathrm{eV}$ for the dichromate-treated galena sample, $\mathrm{Cr}(\mathrm{OH})_{3}$, and $\mathrm{Cr}_{2}\left(\mathrm{CO}_{3}\right)_{3} \cdot n \mathrm{H}_{2} \mathrm{O}$. This line indicates the presence of the carbonate species, which undoubledly results from the chemisorption of $\mathrm{CO}_{2}$ from the reaction solution and its subsequent reaction with the hydrated chromium oxide. This reaction, forming a mixed hydrated oxide/carbonate complex, has been documented for several other metal oxide (and "hydiroside") systems, including lead (Taylor and Perry, i984), uranium (Perry et al.,
1984), and plu:onium (Toth and Friedrnan, 1978). While one cannot assign the carbonate species to the chromium(III) exclusively, such an association is reasonable in light of the chemisorption of $\mathrm{CO}_{2}$ by all the anhydrous $\mathrm{Cr}_{2} \mathrm{O}_{3}$ samples prepared and studied in this investigation. Previous workers have indicated that $\mathrm{Cr}_{2} \mathrm{O}_{3}$ otten has a coating of $\mathrm{Cr}(\mathrm{OH})_{3}$, or $\mathrm{CrOOH}$, on its surface that acts as a reaction substrate for $\mathrm{CO}_{2}$; moreover, Allen et al. (1973) have shown the effects on the XPS spectra of aging $\mathrm{Cr}_{2} \mathrm{O}_{3}$ in open air. The extreme similarivies in the XPS spectral parameters of $\mathrm{Cr}_{2} \mathrm{O}_{3}$ and $\mathrm{CrOOH}$ have also been compared previously (Ikemoto it al., 1976). Strong evidence has been observed for tive presence of the analogous lead(II) hydroxide/carbonate complex (Taylor and Perry, 1984) on the galena surface on the basis of the lead core photoelectron lines.

While not totally obvious initially, the model compounds $\mathrm{Cr}(\mathrm{OH})_{3}$ and $\mathrm{Cr}_{2}\left(\mathrm{CO}_{3}\right)_{3} \cdot n \mathrm{H}_{2} \mathrm{O}$ are indeed very much related chemically. $\mathrm{Cr}(\mathrm{OH})_{3}$ probably is not a true hydroxide but rather a hydrated chromium(III) oxide of the type $\mathrm{Cr}_{2} \mathrm{O}_{3} \cdot n \mathrm{H}_{2} \mathrm{O}$ (Rollinson, 1973). Similarly, $\mathrm{Cr}_{2}\left(\mathrm{CO}_{3}\right)_{3}^{2} \cdot n \mathrm{H}_{2} \mathrm{O}$ cannot be considered a true carbonate but rather hydrated $\mathrm{Cr}_{2} \mathrm{O}_{3}$ with a chemisorbed layer of $\mathrm{CO}_{2}$ (Udy, 1956). This can best be generally formulated as $\mathrm{Cr}_{2} \mathrm{O}_{3} \cdot n \mathrm{H}_{2} \mathrm{O} \cdot x \mathrm{CO}_{2}$, a mixture of both chromium(III) oxide and carbonate. Both compounds are thus essentially chemical modifications of $\mathrm{Cr}_{2} \mathrm{O}_{3}$, with their exact chemical composition varying as a function of the degree of hydration and carbonation.

On the basis of the present $x$-ray photoelectron data, the reaction between galena and an aqueous solution of sodium dichromate yields both chromium(IlI) and chromium(VI) species. The chromium(III) complex is actually hy Irated chromium(III) oxide, $\mathrm{Cr}_{2} \mathrm{O}_{3} \cdot n \mathrm{H}_{2} \mathrm{O}$, with a layer of chemisorbed $\mathrm{CO}$, on the surface, thus forming a mixed complex of the type $\mathrm{Cr}_{2} \mathrm{O}_{3} \cdot n \mathrm{H}_{2} \mathrm{O} \cdot x \mathrm{CO}_{2}$. This product is a result of the hydration of chromium(III) oxide, which in turn adsorbs (and subsequently reacts with) $\mathrm{CO}_{2}$. There is, however, no way of determining the amount of carbon dicxide adsorbed from the air during handling.

\section{REFERENCES}

Allen, G.C., Curtis, M.T., Hooper, A.J., and Tucker, P.M., 1973. X-ray photoelectron spectroscopy of chromium-oxygen systems. Journal of the Chemical Society, Dalton Transactions, p. i675-1683. 
Clifford, R.K., Purdy, K.L., and Miller, J.D., 1975. Characterization of sulfide mineral surfaces in froth flotation systems using electron spectroscopy for chemical analysis. AlChE Symposium Series, v. 71 , no. 150 , p. 138-147.

Ikemoto, I., Ishii, K., Kinoshita, S., Kuroda, H., Franco, M.A.A., and Thomas, J.M., 1976. Xray photoelectron spectroscopic studies of $\mathrm{CrO}_{2}$ and some related chromium compounds. Journal of Solid State Chemistry, v. 17, p. 425-430.

Nefedov, V.I., Salyn, Y.V., Solozhenkin, P.M., and Gulatov, G.Y., 1980. X-ray photoelectron study of surface compounds formed during flotation of minerals. Surface and Interface Analysis, v. 2, p. 170-172.

Perry, D.L., and Taylor, J.A., 1983. X-ray photoelectron studies of beta-FeOOH. Abstracts, 185th National Meeting of the American Chemical Society, Seattle, Abst. INOR 107.

Perry, D.L.. Tsao, L., and Brittain, H.G., 1984. Xray photoelectron and luminescence studies of

\section{THORIUM SPECIES ON BASALT SURFACES}

\section{D.L. Perry and L. Tsao}

One of the most important areas of research used in determining the suitability of a nuclear waste repository site and its potential for retaining the waste is that of determining the chemical spicies involved in the interaction of the nuclear waste with the geologic material of the repository and subsequent interaction and migration by means of groundwater. The various radionuclide species will exhibit different chemistries and solubilities; therefore, these radionuclides will migrate in a variety of chemical forms (such as colloids). Furthermore, the solubilities of the radionuclide species will affect their concentrations in the groundwater and also the amounts of the radionuclides that will chemisorb/precipitate onto ite surrounding geologic media: These geochemical conditions must be ardressed and evaluated if there is to be a thorough understanding of the effects they have on the movement of radionuclides in the ground.

In a typical experiment, thorium(IV) was reacted with Hanford basalt at $\mathrm{pH}$ values of $10-12$; the surface of the basalt and accompanying precipitates hydrated uranium oxides. Inorganic Chemistry, in press.

Rollinson, C.L., 1973. Chromium. In A.F. Trotman-Dickenson (exec. ed.), Comprehensive Inorganic Chemistry. (Vol. 3). New York, Pergamon Press, p. 666-667.

Taylor, J.A., and Perry, D.L., I984. An x-ray photoelectron (XPS) and electron energy loss (EELS) study of the oxidation of lead. Journal of Vacuum Science Technology, in press.

Toth, L.M., and Friedman, H.A., 1978. The infrared spectrum of Pu(IV) polymer. Journal of Inorganic and Nuclear Chemistry, v. 40, p. 807-810.

Udy, M.J., 1956. Chromium. In American Chemical Society Monograph Series, (Vol. 1). New York, Reinhold Publishing Company, p. 210.

Vernon, G.A., Stucky, G., and Carlson, 1976. Comprehensive study of satellite structure in the photoelectron spectra of transition metal compounds. Inorganic Chemistry, v. 15. p. 278-284.

were then studied by $x$-ray phototlectron, infrared. and other techniques. Figure 1 shows a survey $(0-1000 \mathrm{eV}) \mathrm{x}$-ray photoelectron spectrum of thorium that has been chemisorbed onto (and subsequently reacted with) Hanford basalt. The different

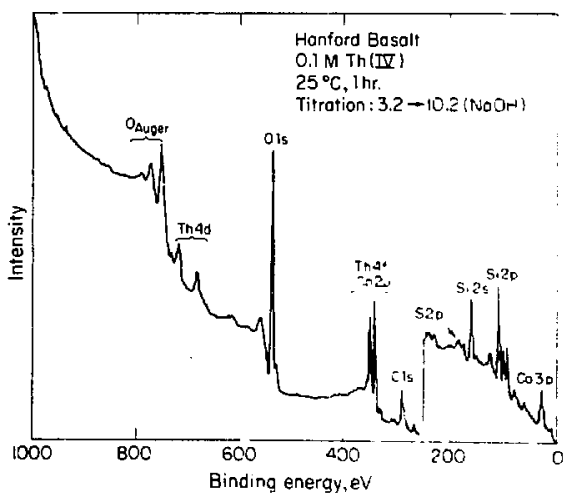

Figure 1. The $x$-ray photoclectron survey $(0-1000 \mathrm{eV}$ ) spectrum of the surface of a Hanford basali sample that has been exposed to an aqueous solution of thorium(IV). XBL 837-2148 
photoelectron lines such as the $\mathrm{Th} 4 f, \mathrm{Ca} 2 p$, and Si $2 p$ reflect both the thorium species and the mineralogical composition of the rock surface. Reaction times longer than those used in this work $(1 \mathrm{~h})$ produced spectra identical to those resulting from the shorter-term exposure of the basalt to thorium.

Several features of the basalt surface chemistry were observed after a detailed study of the lines of several of the elements. Figure 2 shows highresolution oxygen Is spectra of the same sample, the binding energy ("averaged," charge referenced against the carbon $\mathrm{Is}=284.6 \mathrm{eV}$ line) being $531.4 \mathrm{eV}$ for the original "as reacted" surface. This is a normal value for the $\mathrm{OH}^{-}$(and $\mathrm{CO}_{3}{ }^{2-}$ ) species (Perry et al., 1977) on a surface and is not unexpected for a basalt surface at high pH. Additionally, asymmetry was also observed on both the high and low binding energy sides of the peak, possibly indicating more than one oxygen species. Indeed, when the peak was deconvoluted, peaks were also observed that are indicative of surface water and lattice oxides that are inberent in the rock.

Figure 3, however, depicts the carbon is spectrum of the same Hanford basalt sample. The principal peak at $284.6 \mathrm{eV}$ is due to the "adventitious" carbon peak that is used to compensate for the surface charge in all of the x-ray photoelectron lines.

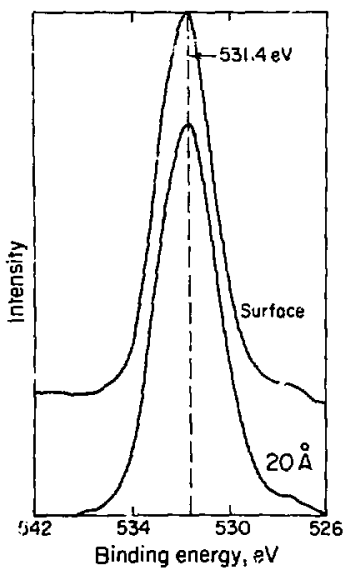

Figure 2. The oxygen lis photoelectron spectra of the surface of the original sample of Hanford basalt, which was exposed to aqueous thorium(IV), and the resulting surface of the same sample after about $20 \mathrm{~A}$ (relative to a standard $\mathrm{Ta}_{2} \mathrm{O}_{5}$ reference material) has been removed. [XBL 837. 2]46|

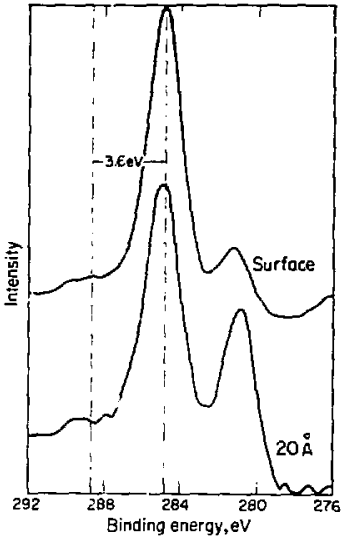

Figure 3. The carbon is photoelectron spectra of the surface of the original sample of Hanford basalt, which was exposed to aqueous thorium(IV), and the resulting surface of the same sample after about $20 \mathrm{~A}$ (relative to a standard $\mathrm{Ta}_{2} \mathrm{O}_{5}$ reference material) has been removed. [XBL 8372149]

The smaller peak, however, at a binciing energy $3.6 \mathrm{eV}$ higher, is indicative of the $\mathrm{CO}_{3}{ }^{2-}$ functional group and supports the inference of such a species frort the oxygen ls spectrum.

During the process of removing about $20 \mathrm{~A}$ (relative to a $\mathrm{Ta}_{2} \mathrm{O}_{5}$ standard) of the basalt surface by ion sputtering, the concentration of thorium remained unchanged at 2-4\% (atomic concentration) of the surface being examired, thus indicating that the thorium species was not merely lightly chemisorbed but had instead penetrated into the rock bulk. Indeed, the thorium and carbon spectra in Figs. 2 and 3 show virtually no chanze between the surfice layer and the layer remaining after $20 \mathrm{~A}$ had been removed. Variable take-off angle $x$-ray photoelectron spectra (Ebel and Wernisch, 1981) recorded for this sample surface also indicate significant penetration into the sample bulk. These data are consistent with a process involving the chemisorption of $\mathrm{CO}_{2}$ onto (and subsequent reaction with) a hydrated thorium oxide $\left(\mathrm{ThO}_{2} \cdot \mathrm{xH}_{2} \mathrm{O} \text {, or "Th(OH) }\right)_{4}$ ", thus forming a mixed oxide/hydroxide-carbonate. This reaction phenomenon has been repored previously for plutonium (Toth and Friedman, 1978).

Because of the basicity of the thorium hydrolysis prod. ... studied here, chemisorption of carbon dioxide $f$." the atmosphere by the samples and subse- 
quent complexation as a thorium carbonate cannot be precluded. As mentioned above, other researchers have observed the absorption of $\mathrm{CO}_{2}$ by other basic actinide complex surfaces such as plutonium(IV) polymers formed by the $\mathrm{NaOH}$ effected hydrolysis of plutonium(IV) salts in aqueous solutions (Toth and Friedman, 1978); this in effect forms Pu(IV) carbonate complexes as surface layer complexes with oxide/hydroxide species, and the same reaction occurs here to some extent.

Indeed, there is additional infrared evidence in this study to support such a phenomenon with the present thorium surface products. Small infrared bands or inflections at 890 and $1350 \mathrm{~cm}^{-1}$ that appear in the spectra of the $\mathrm{Pu}(\mathrm{IV})$ polymers (Toth and Friedman, 1978) also appear in the infrared spectra of the basalt/thorium samples studied here. A reaction of this type should not be unexpected for the basic thorium-reacted basalt samples studied here, especially in light of the similarity to the Pu(IV) polymers. Moreover, many other metal hydroxides, such as $\mathrm{Pb}(\mathrm{OH})_{2}$, also exhibit carbonate layers in their $x$-ray photoelectron spectra (Perry and Taylor, 1984); this, too, results from ine same chemisorption/reaction of $\mathrm{CO}_{2}$ with the initial metal hydroxide.

Data such as these are exitemely important, since a thorough knowledge of the radionuclide species is important in dissolution experiments of actinide and radionuclide species that have been experimentally shown actually to be formed on basalt. Modeling of precipitation/dissolution

\section{ANALYTICAL PERFORMANCE MODELS FOR GEOLOGIC REPOSITORIES CONTAINING RADIOACTIVE WASTE}

T.H. Pigford, P.L. Chambré, R. Kobayashi, C.L. Kim, H.C. Lung. Y. Takagi, W.J. Williams, and S.J. Zavoshy

This research is con-erned with the development of analytical models to predict the long-term migration and release of radioactive waste in geologic repositories. The work reported here deals with the following topics: (1) time-dependent dissolutioin of solid waste as limited by diffusive-convective mass processes using only a single species such as anhydrous $\mathrm{ThO}_{2}$, for example, would not be correct. In the course of this research, we have also shown that the chemical characteristics of any thorium hydrolysis polymers generated at high $\mathrm{pH}$ values typical of those found in groundwater will change rather dramatically with respect to their thermal and chemical history (Perry et al., 1983).

\section{REFERENCES}

Ebel, M.F., and Wernisch, U.J., 1981, Shading at different take-off angles in $x$-ray photoelectron spectroscopy. Surface and Interface Analysis, v. 3, p. 191-193.

Perry, D.L., and Taylor, J.A. 1984. An x-ray photoelectron (XPS) and electron energy loss (EELS) study of the oxidation of lead. Journal of Vacuum Science and Technology, in press.

Perry, D.L., Bonnell, D.W., Parks, G.D., and Margrave, J.L , 1977. Spectroscopic studies of hightemperature materials. I. The use of $x$-ray photoelectron spectroscopy (XPS) to study the surface chemistry of copper, cobalt, and nickel ferites. High Temperature Science, v. 9, p. 85-98.

Perry, D.L., Brittain, H.G., and Tsao, L., 1983. Juminescence of the hydrolysis products of Th(IV). Journal of Luminescence, v. 28, p. 257-265.

Toth, L.M., and Friedman, H.A., 1978. The infrared spectrum of $\mathrm{Pu}(\mathrm{IV})$ polymer. Journal of Incrganic and Nuclear Chemistry, y, 40, p. $807-810$.

transfer into groundwater, (2) steady-state mass transfer from solid waste through backfill and into rock, (3) mass transfer through backfill with nonlinear sorption, and (4) time-temperature-dependent mass transfer from heat-generating solid waste. Additional results during fisciai year 1983 are reported elsewhere (Chambré and Pigford, 1983; Kobayashi et al., 1983; Pigford, 1983).

\section{TIME-DEPENDENT MASS TRANSFER} FROM WASTE INTO GROUNDWATER

In an earlier report (Chambré et al., 1982) we presented Chambré's analytical space-timedependent solution for the concentration field of radionuclides disso'ved from a waste solid into groundwater and the solution for the mass-transfer rate from the waste solid, subject to the boundary 
condition that the concentration in the liquid at the waste surface is at the maximum concentration given by the solubility limit for the dissolving species. Our previous summary report (Pigford et al., 1983a) concentrated on the rates of steady-state mass transfer from a waste solid in a repository environment and developed a means of predicting the long-term dissolution source term for repository performance analysis. During the past year the applications of Chambre's theory have been extended to unsteadystate dissolution rates and the effect of radioactive decay.

From Chambrê's general solution for the timedependent mass transfer of dccaying species from a long cylinder (of radius $R$ and length $L$ ) into groundwater moving at pore velocity $U$ in a surrourding porous medium of porosity $\epsilon$, the equation for the time-dependent fractional release rate for a Peclet number $(P e)$ greater than $4(P e=U R / D, D$ = diffusion coefficient in the pore liquid) is

$$
\begin{aligned}
\dot{f}_{j}= & \frac{8 N_{j \mathrm{k}}^{*}(D U)^{1 / 2}(1+R / L)}{(\pi R)^{3 / 2} n_{j}}\left\{\frac{e^{-\lambda /} E\left[m^{2}(\tau)\right]}{m(\tau)}\right. \\
& \left.+D a \int_{0}^{\tau} e^{-D_{a} r^{*}} \frac{E\left[m^{2}\left(\tau^{\prime}\right)\right]}{m\left(\tau^{\prime}\right)} d \tau^{\prime}\right\}, \frac{U R}{D} \text { large }
\end{aligned}
$$

where $D a$ is the Damköhler number, a dimensionless group defined as

$$
D a \equiv K \lambda R / U,
$$

$K$ is the retardation coefficient in the surrounding rock, $E[x]$ is the complete elliptic integral of the second kind, and

$$
\begin{aligned}
m(\tau) & \equiv[1-\exp (-4 \tau)]^{1 / 2}, \\
\tau & \equiv \frac{U_{l}}{K R} .
\end{aligned}
$$

Iypical results are shown in Fig. 1, where the normalized fractional dissolution rate $\dot{f} n_{j} / N_{j}^{*}$ is plotted against the time since the waste is first exposed to groundwater in the surrounding porous rock for $R$ $=0.15 \mathrm{~m}$ and $R / L=0.062$. A sorption retardation constant of 10 for the rock is assumed. If the waste solia can react with groundwater rapidly enough to maintain the saturation in groundwater at the waste surface, the early rate of mass transfer will be high.

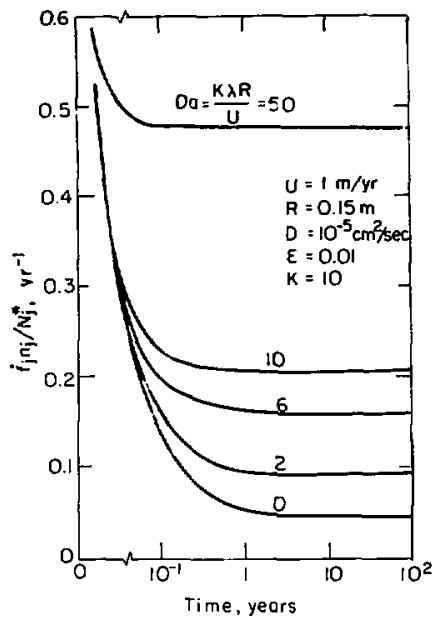

Figure 1. Normalized mass transfer rate as a function of time and Damkóhler number; flow around a waste cylinder. |XBL 8311-6584|

and it will decrease as the concentration profile penetrates farther from the waste surface. With no decay, and for the parameters chosen for Fig. 1, steady state is reached in about 1 year.

Radioactive decay can increase the rate of mass transfer by steepening the concentration gradient near the waste surface. This is shown in Fig. $i$ by curves for various values of the Damköhler number. Increasing Damköhler number from zero, for no decay, to $D a=10$ causes a more than fourfold increase in the steady-state dissolution rate, and it decreases the time to reach steady state. For the parameters in Fig. 1, a Damköhler number of 10 and a retardation constant of 10 correspond to a half-life of 0.1 year, too short to be of any consequence in geologic disposal. If the radionuclide were strongly sorbing, with a retardation constant of $10^{4}$, then the decay correction would be important for half-lives of about 1000 years or less. For a mixture of stable and unstable isotopes of a given element, the appropriate half-life is the effective half-life of the isotopic mixture at the time the half-life is the effective half-life of the isotopic mixture at the time the decay correction is to be applied. Decay corrections are more important if the mass transfer is controlled by diffusion, when the pore velocity is so low that convection does not affect dissolution. 
For the waste-form parameters of Fig. 1, the normalized fractional dissolution $\dot{f} n_{j} / N_{j}^{*}$ from E. plotted in Fig. 2 against time since the beginning of exposure to water for various values of the retardation coefficient $K$ and for nondecaying species. Increasing sorption in the rock increases the time to steady state, and it increases the transient dissolution rate because sorption steepens the transient concentration gradient. For a retardation constant of 1000 , about 100 years would be required to reach steady state with no decay. At steady state, in the absence of decay, the effect of sorption disappears.

For diffusion-controlled mass transfer from a sphere of radius $R$, Chambré has derived the equation for the time for the mass transfer of a nondecaying species to equal $(1+\nu)$ times the steady-state value:

$$
t=\frac{K R^{2}}{\pi D v^{2}}, U=0
$$

For $R=44 \mathrm{~cm}$, corresponding to a sphere of surface area equal to the cylindrical waste form of Fig. 1, and assuming a retardation constant of 10 , the time for the dissolution rate to be no more than $1 \%$ greater than the steady-state rate is $1.9 \times 10^{5}$ years, as compared with 1.8 years estimated for a pore velocity of $1 \mathrm{~m} /$ year about a cylindrical waste form.

Using the solutions by Chambre for the transient dissolution rate from a waste sphere $c_{i}$ constant radius, we obtain the normalized dissolution rate $\dot{f} n_{j} / N_{j}^{*}$ as a function of time shown in Fig. 3 for varicus values of the retardation constant of the rock. The results are qualitatively similar to those in Fig. 1 with convection, but the times to steady state

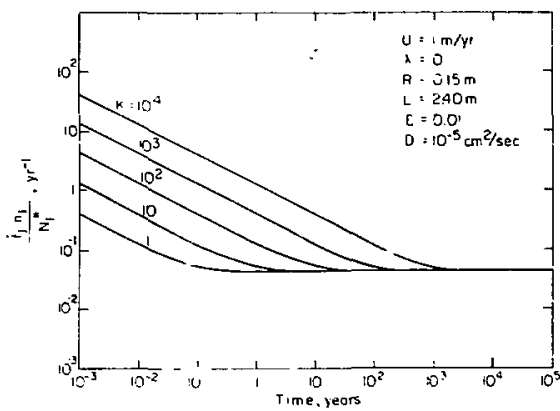

Figure 2. Normalized mass-transfer rate as a function of time and retardation coefficient $(K)$; flow around a waste cylinder. [XBL 843-996]

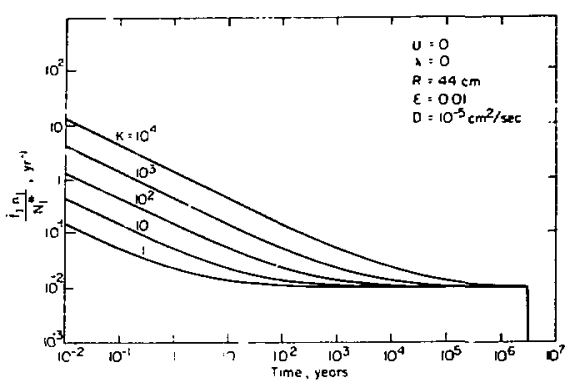

Figure 3. Normalized mass-transfer rate as a function of time and retardation coefficient $(K)$; diffusion from spherical waste form. [XBL 843-995]

are longer. Effects of backfill on times to reach steady state are considered later.

\section{STEADY-STATE MASS TRANSFER THROUGH BACKFILL INTO GROUNDWATER}

For a waste canister surrounded by backfill material of thickness $L$, a solution for the steadystate mass transfer rate into groundwater in the surrounding porous rock has been chtained by Chambré et al. (1983a) by approximating the waste cylinder as a slender prolate spheroid surrounded by backfill with the same focal distance (Fig. 4) and with a semimajor axis $a_{l}$ at the backfill-rock interface. The prolate spheroidal coordinate is $\alpha$, in which $\alpha=\alpha$ s describes the backfill's inner surface and $\alpha=\alpha$, the interface between the backfill and the exterior porous medium. The backfill is assumed to be sufficiently impermeable that liquid in backfill pores is stagnant. Groundwater is assumed to flow in the porous rock with an approach pore velocity $U$. Radioactive decay is neglected for this steady-state solution.

The boundary conditions to be satisfied are

$$
N_{b}\left(\alpha_{S}\right)=N^{*}, N_{b}\left(\alpha_{J}\right)=N_{l},
$$

where $N^{*}$ is the saturation concentration and $N /$ is the yet unknown average concentration at the backfill-rock interface. Neglecting nearby waste sources, the cotcentration in the exterior medium approaches zero at a large distance from the waste.

As in our previous analyses, we solve for the space-dependent co centration in backfill and exterior medium and integrate the local mass flux over the outer surface of the backfill to obtain the mass 


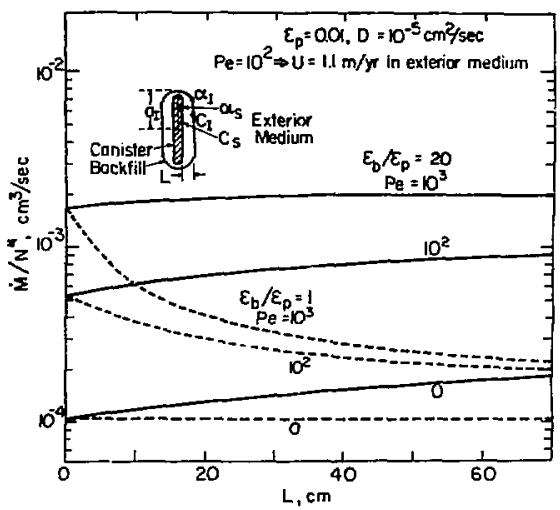

Figure 4. Normalized mass-transfer rate as a function of backfill thickness $L$, porosity ratio $\epsilon_{b} / \epsilon_{p}$, and Peclet number $P e . \quad$ |XBL 831-5049]

transfer rate $\dot{M}$ (mass/time) from the waste forminto the porous rock:

$$
\dot{M}=\frac{4 \pi N^{*}{ }_{c_{p}} D_{a_{l}}}{\frac{c_{p}}{\epsilon_{b}}\left[Q_{0}\left(\alpha_{s}\right)-Q_{0}\left(\alpha_{l}\right)\right] \cosh \left(\alpha_{l}\right)+[S h(P e)]^{-1}},
$$

where

$$
Q_{o}(\alpha)=\ln \left(\operatorname{coth} \frac{\alpha}{2}\right)
$$

and $\epsilon_{p} / \epsilon_{l}$ is the rock-to-backfill porosity ratio. The mass-transfer resistance in the exterior medium is given in Eq. (8) by the reciprocal of the Sherwood number, $S h$, which depends on the Peclet number $\left(P e=U a_{l} / D, U=\right.$ pore veiccity in the exterior medium) as follows:

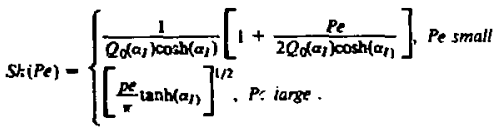

Moreover, an equation is developed for the concentration $N_{d}$ at the backfill-rock interface:

$$
N_{I}=\frac{N^{*}}{\left.\left(\frac{e_{p}}{e_{b}}\right) \mid Q_{0}\left(\alpha_{s}\right)-C_{(}\left(\alpha_{1}\right)\right) \mid \cosh \left(\alpha_{1}\right) \operatorname{Sh}(P e)+1} \text {. }
$$

Figure $\mathbf{4}$ shows the mass-transport rate as a functivn of backfill thickness, $L$; the backfill-to-rock porosity ratio, $\epsilon_{b} / \epsilon_{p}$; and $P e$. For equal porosities of backfill and rock, backfill reduces the mass-transfer rate because of the assumed zero flow in the backfill. For a given backfill thickness, decreasing the backfill porosity decreases the mass-transfer rate. A decrease in $\epsilon_{b} / \epsilon_{p}$ from 20 (solid curver) to 1 (broken curves) causes much of the exterior-medium resistance to shift to that of the backfill. For $\epsilon_{b} / \epsilon_{p}=20$, the backfill is sufficiently porous that increasing $L$ causes the rate of mass transfer into the rock to increase. Increasing the Peclet number from zero for pure diffusive transport to $\mathrm{Pe}=1000$ shows an expected increase in the mass-transfer rate.

Figure 5 shows the interface concentration ratio $N_{I} / N^{*}$ as a function of the parameters. The ratio $N_{l} / N^{*}$ decreases with increasing Peclet number. It decreases with decreasing $\epsilon_{b} / k_{p}$, showing that as this parameter decreases, the backfill resistance increases and becomes more important than the exterior medium resistance.

The steady-state nondecay mass-transfer rate is not affected by sorption in backfill or rock. Unless the backfill can be made far less porous than the rock, large reductions in the steady-state rate of release of jadionuclides into the rock cannot be expected.

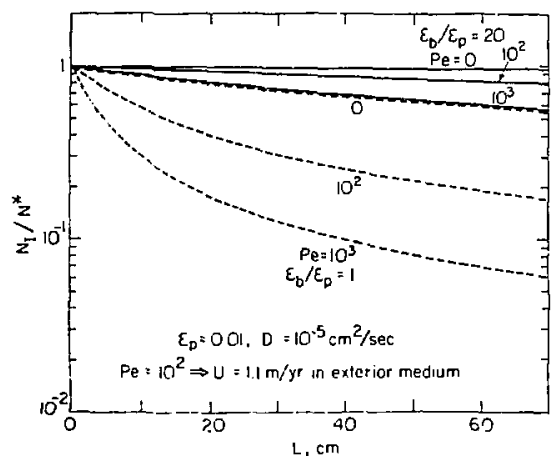

Figure 5. Normalized backfili-rock interface concentration as a function or backfill thickness $L$, porosity ratio $\epsilon_{b} / \epsilon_{f}$, and Peclet number $P e$. |XBL 83i-5050| 


\section{MASS TRANSFER THROUGH BACKFILL WITH NONLINEAR SORPTION}

In the previous analyses, we have assur.ed linear sorption in backfill, as expressed by a retardation constant independent of concentration. Some data show nonlinear sorption in bentonite, with a tendency toward saturation. Here we analyze the timedependent diffusion of radionuclides through backfill material that can reach local sorption saturation (Lung et al., 1983). Local equilibrium is assumed for the sorbing species in the solid and liquid phases, described by a Langmuir sorption isotherm (Fig. 6) of the form

$$
K_{d^{\prime}}\left(N_{f}\right)=\frac{N_{s}}{N_{f}},
$$

where $N_{s f}$ are the nuclide concentrations in the solid and liquid, respectively. The retardation coefficient $K$ is then defined as

$$
K\left(N_{f}\right)=i+\frac{1-\epsilon}{\epsilon} K_{d}\left(N_{f}\right),
$$

where $\epsilon$ is the backfill porosity. Assuming diffusive transport in the liquid phase and none in the solid, the governing equation for one-dimensional transport of the nuclide is

$$
\begin{aligned}
\frac{\partial}{\partial t}\left|K\left(N_{f}\right) N_{f}\right|=D \frac{\partial^{2} N_{f}}{\partial x^{2}} \\
\quad-\lambda K\left(N_{f}\right) N_{f}, x>0, t>0 .
\end{aligned}
$$

An analytical solution in the absence of decay is obtaiscis by approximating the isotherrn by two straight line segments, as shown in Fig. 6a. Here $Q$ is the saturation concentration of the nuclide in the

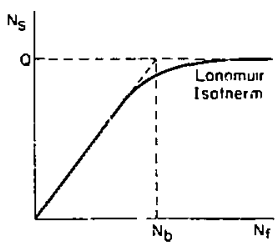

(a)

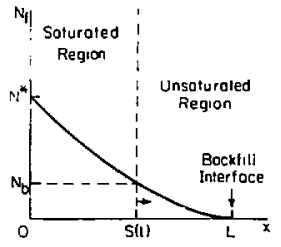

(b)
Figure 6. Nonlinear sorption isotherm and concentration profile. ;XbL 843-997| solid and $N_{b}$ is the concentration in the liquid at the onset of saturation. The following side conditions for Eq. (13) are assumed:

$$
\begin{gathered}
N_{f}=0 \text { at } t=0, x>0, \\
N_{f}=N^{*}>N_{b} \text { at } x=0, t>0 .
\end{gathered}
$$

with $N_{f} \rightarrow O$ as $x \rightarrow \infty$ for $t>0$. Equation (14b) implies a release from the waste form beginning at $t=0$, with a constant concentration at the inner surface of the backfill $(x=0)$ given by a solubility limit $N^{*}$ for $t>0$.

The above describes a backfill divided into parts, as shown in Fig. 6b: (1) an inner saturated region inside which the liquid concentration is greater than $N_{b}$ and (2) an outer unsaturated region of lower concentration. Saturation will begin at the inner surface $(x=0)$, and the interface between saturated and unsaturated regions will move outward along the trajectory $S=S(t)$. The solution to Eqs. (13) and (14) shows, when $\lambda=0$, that the interface moves according :o

$$
S(t)=k\left(\frac{N_{b}}{N^{*}}, D, K\right) \sqrt{t} .
$$

Neglecting radioactive decay and assuming the semi-infinite medium are justified a posteriori. The interface position is an indicator of backfill performance because it shows how quickl". saturation takes place with a resulting loss of nuclide retardation.

Figure 7 shows $k$ as a function of $\left(N_{b} / N^{*}\right)$ with $K$ as a parameter. As $K$ for the unsaturated region increases, $k$ decrease $\varsigma$ and slows the interface motion. Rctardation by the backfill disappears when the saturation interface penetrates a distanze $L$ equal to the backfill thickness. The breakthrough time $T_{b}$ for such penetration is given by $(L / k)^{2}$ and is shown in Fig. 7 as a function of the same parameters.

The importance of saturation can be secn by comparing these results with those for no saturation. Assuming a linear isotherm with $K=4000$ and the same diffusion coefficient, Nowak (1979) showed that it wnuld take 1000 years to raise the concentration at $x=30 \mathrm{~cm}$ to $1 \%$ of $N^{*}$. If saturation can occur with $N_{b}=0.01 N^{*}$, the breakthrough time is reduced to 60 years, only $6 \%$ of the time for nonsaturation. Hence saturation in the backfill can greatly reduce the breakthrough time.

To apply the solution for semi-infinite geometry and a backfill of finite thickness, we havc limited the time span for Fig. 7 to a concentration ratio of 


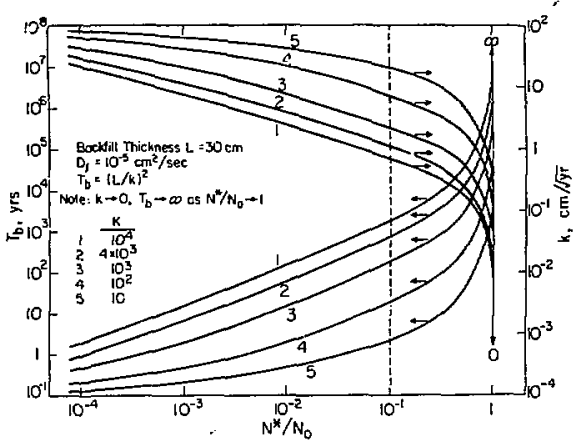

Figure 7. Rate constant $k$ for saturated-unsaturated interface and breakthrough time $T_{b}$ as functions of $N_{b} / N^{*}$ and retardation coefficient $K$. [XBL 831-5048]

$N_{b} / N^{*}=0.1$ at the backfill-rock interface. Because $T_{b}$ is less than 2000 years for $K<0.1$, nuclides with half-lives greater than 5000 years can be treated as nondecaying for this analysis.

\section{MASS TRANSFER DURING REPOSITORY HEATING}

The theory for control of dissoilition rate by mass transfer can be extended to predict the timedependent mass transfer for a waste solid exposed to groundwater when the repository is heated by radioactive decay. When the tempera'ure is higher than ambient, dissolution rates can increase because of the increased solubilities and diffusion coefficients and because the increased groundwater velocities from thermal convection can decrease the thickness of the concentration boundary layer. Here we assume a repository with pore velocities low enough, even during repository heating, that the mass transfer is mainly by diffusion (Chambré et al., 1982). We also assume that the waste solid is directly in contact with porous rock. For a repository resaturated with groundwater, the temperature at the waste-rock interface is the appropriate temperature for determining the solubility $N^{*}$ boundary condition. For a time-dependent maximum rock temperature prescribed from heat-transfer calculations, and given the temperature dependence on solubility, e.g., as for amorphous silica (Foumier and Power, 1977), the time-dependent boundary concentration $N^{*}(t)$ can be expressed as

$$
N^{*}(t)=N_{o}^{*} f(t)
$$

The diffusion coefficient in groundwater adiac nt to the waste solid will be greater at the waste-Ter.. interface than in the cooler rock, but we will conservatively choose a time-dependent diffusion coefficient evaluated, using the data in Table 1 , at the timedependent temperature of the waste-rock interface. The time-dependent diffusion coefficient can then be expressed as

$$
D(t)=D_{o} g(t) .
$$

The resulting analysis by Chambré for the timedependent mass-transfer rate $\dot{M}(t)$ from a spherical waste of radius $R$ for a time-independent retardation coefficient, yields

$$
\begin{aligned}
& \dot{M}(t)-4 \pi R D_{0} N_{a^{*}}^{*} \frac{g(t)}{X} e^{-\lambda t} \\
& \cdot\left\{\bar{f}(\tau(t)) \quad \frac{:}{\sqrt{\pi}}\left[\frac{\bar{f}(0+)}{\sqrt{r}(t)}+\int_{0}^{\pi(t)} \frac{\left.\overline{\tau^{\prime}(r(\eta)}-\eta\right)}{\sqrt{\pi}} d \pi\right]\right\},
\end{aligned}
$$

where

$$
\bar{f}(\tau) \equiv f(t(\tau)) e^{\lambda(\tau)}
$$

and

\begin{tabular}{|c|c|c|}
\hline $\begin{array}{c}\text { Temperature } \\
\left({ }^{\circ} \mathrm{C}\right) \\
\end{array}$ & $\begin{array}{c}\text { Solubiliwita } \\
\left(\mathrm{g} / \mathrm{cm}^{3}\right)^{\mathrm{a}}\end{array}$ & $\begin{array}{c}\text { Diffusion } \\
\text { coefficient }^{b} \\
\left(\mathrm{~cm}^{2} / \mathrm{s}\right)\end{array}$ \\
\hline 20 & $5.0 \times 10^{-5}$ & $1 \times 10^{-5}$ \\
\hline 50 & $8.8 \times 10^{-5}$ & $2.0 \times 10^{-5}$ \\
\hline 100 & $1.1 \times 10^{-4}$ & $4.5 \times 10^{-5}$ \\
\hline 150 & $2.6 \times 10^{-4}$ & $7.9 \times 10^{-5}$ \\
\hline 200 & $4.2 \times 10^{-4}$ & $1.2 \times 10^{-4}$ \\
\hline 250 & $5.8 \times 10^{-4}$ & $1.6 \times 10^{-4}$ \\
\hline
\end{tabular}

$$
\tau(t) \equiv \frac{D_{o}}{K R^{2}} \int_{0}^{t} g\left(t^{\prime}\right) d t^{\prime} .
$$

Table 1. Effect of ternperature on the solubility and liquid diffusion coefficient for silica. 
To illustrate, we adopt data (Altenhofen, 1981; Pigford et al., 1983b) from the basalt waste-isolation project for the time-dependent temperature of rock at the inner surface of emplacement holes (Fig. 8). The early rise from ambient temperature is neglected in these calculations. From these data and the data on temperature-dependent solubilities and diffusion coefficients (Chambré ct al., 1983b), we predict the time-dependent mass-transfer rates of silica from borosilicate glass waste in basalt for retardation coefficients of 1 and 100 . Nomalizing to the masstransfer rate $M_{0}$ that would occur at steady state and at the basalt ambient temperature of $58^{\circ} \mathrm{C}$ yields the results in Fig. 8. The mass-transfer rate at 1 year and $K=100$ is 154 times the steady-state ambient rate because of the temperature-increased solubility and diffusion coefficient and because of the steeper concentration gradient at the waste surface near the beginning of dissolution. The transient concentration gradient and dissolution rate are reduced in the absence of sorption $\left(K={ }^{1}\right)$.

Also shown is the cumulative dissolution for $K$ -1 , normalized to that predicted for steady state at ambient temperature. This ratio is 5.0 at 1000 years and 1.9 at 10,000 years. The cumulative dissolution of silica over 10,000 years is $1.5 \%$ of the initial silica.

Equation (18) applies also to a glass constituent that dissolves at a fractional rate lower than the silica matrix, such as neptunium 237. Assuming equal heats of solution for silica and neptunium and a nep-

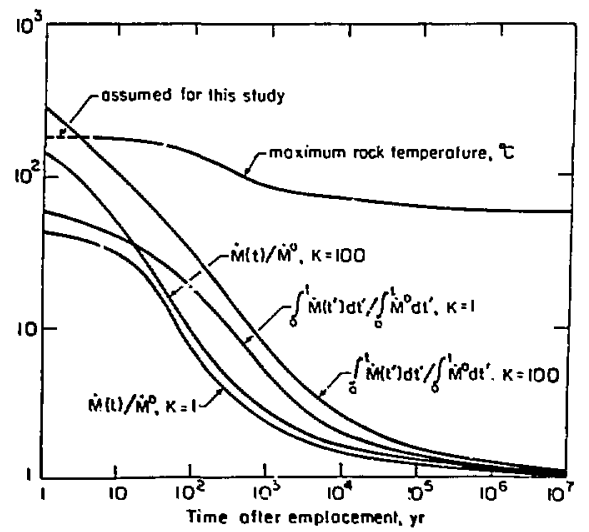

Fyure 8. Basalt temperature at waste hole and normalized-transfer rates as functions of time and retardation coefficient; diffusion from a waste sphere. [XBL $8310-6514$ ] tunium retardation coefficient of 100 (Pigford et al., 1983b), the normalized dissolution rates of Fig. 9 for $K=100$ also apply for neptunium 237 .

The effect of accelerated dissolution ciuring repository heating on the far-field concentration of dissclved radionu lides can be calculated from the general solution (Harada et al., 1980) for onedimensional advective transport for an arbitrary time-dependent boundary concentration. The resulting concentration $N(z, t)$, normalized to th: boundary concentration $N_{o}$ predicted for steas -state ambient-temperature dissolution, is shown in ig. 9 for neptunium 237 at $100 \mathrm{~m}$ from the plane of waste emplacement for various values of dispersion ccefficient.

With no dispersion in groundwater transport, the dissolution rate at 1 year results in a 140-fold increase in the local far-field concentration above that for ambient steady state. This concentration spike rapidly dissapears, because later arrivals reflec. lower-temperature dissolution and lower concentration gradients at the waste surface.

Because the time span of the early spike in the dissolution rate and in the boundary concentration is only a few hundred years, dispersion in groundwater transport easily broadens and attenuates this spike. Increasing dispersion causes earlier arrival of the contaminant, destroys the far-field concentration spike, and results in far-field concentrations only slightly above those predicted for steady-state dissolution at ambient temperatures. This suggests that exposing high-level waste to groundwater during the thermal period may result in only small increases in the far-field concentration above those predicted for

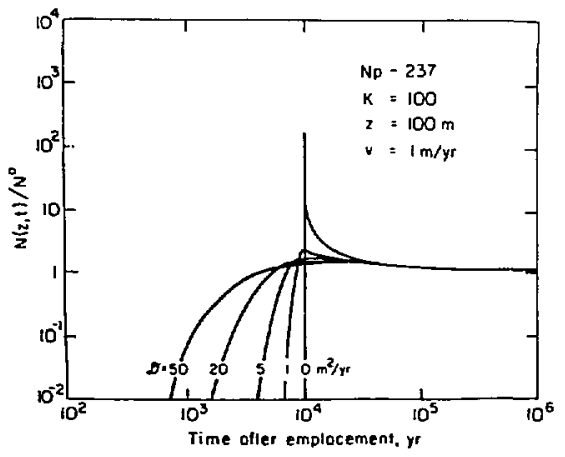

Figure 9. Normalized concentration at $100 \mathrm{~m}$ from waste as a function of time and dispersion coefficienl; diffusion from a waste sphere. [XBL 8310-6513] 
the later steady-state dissolution at ambient temperature.

\section{REFERENCES}

Altenhofen, M.K., 1981. Waste package heattransfer analysis: Model deveiopment and temperature estimates for waste packages in a repository located in basait. Richland, Washington, Rockwell Hanford Operations, RHO-BWI-ST18.

Chambre, P.L, and Pigford, T.H., 1983. Prediction of waste performance in a geologic repository. In G. McVay (ed.), The Scientific Basis for Nuclear Waste (Vol. 8). New York, Elsevier.

Chambrè, P.L., Pigjord, T.H., Fujita, A., Kanki, T., Kobayashi, R., Lung, H., Ting, D., Sato, Y., and Zavoshy, S.J., 1982. Analytical performance models for geologic repositories. Lawrence Berkeley Laboratory, LBL-14842.

Chambrè, P.L., Lung, İ.C., Pigford, T.H., 1983a. Mass transport from a waste enplaced in backfill and rock. Transactions of the American Nuclear Society, v. 44, p. 112.

Chambré, P.L., Williams, W.J., Kim, C.L., Pigford, T.H., 1983b. Time-temperature dissolution and radionclide transport. University of California (Berkeley) report UCB-NE-4033.

Foumier, R.O., and Power, J.J., 1977. American Mineralogist, v. 62, p. 1052-1056.

Harada, M., Chambré, P.L., Foglia, M., Higashi, K., Iwamoto, F., Leung, D., Pigford, T.H., and Ting. D., 1980. Migration of radionuclides through

\section{THE BEHAVIOR OF}

\section{AMERICIUM IN AQUEOUS CARBONATE SYSTEMS}

\section{R.J. Silva}

An experimental program has been initiated at LBL to investigate key compounds and solution species of high-level waste radionuclides that could be important to the prediction of solution concentrations and migration rates in geologic settings associated with underground waste storage facilities. In the event that the canister and waste form fail .o contain the stored radioactive waste materials, soibing media: Analytical solutions I. Lawrence Berkeley Laboratory, LBL-10500.

Kobayashi, R., Sato, Y., Kanki, T., Chambré, P.L., and Pigford, T.H., 1983. Solubility-limited transport of radionuclides through fractured rock. Transactions of the American Nuclear Society, v. 44, p. 113.

Lung, H.C., Chambré, P.L., and Pigford, T.H., 1983. Nuclide migration in backfill with a nonlinear sorption isotherm. Transactions of the American Nuclear Society, v. 45, p. 107.

Nowak, E.J., 1979. The backfill barrier as a component in a multiple barrier nuclear waste isolation system, Alberqerque, New Mexico, Sandia National Laboratories, SAND 79-1109.

Pigford, T.H., 1983. Geologic disposal of radioactive waste 1983. Presented at the American Institute of Chemical Engineers 75th Anniversary Meeting, Washington, D.C., October 5-November 4, 1983, LBL-16795.

Pigford, T.H., Chambré, P.L., Fujita, A., Kanki, T., Lung, H., Sato, Y., Ting, D.K., and Zavoshy, S.J., 1983a. Analytical performance models for geologic repositories containing radioactive waste, Earth Sciences Division. Annual Report 1982, Lawrence Berkeley Laboratory, LBL15500 .

Pigford, T.H., Blomeke, J.O., Brekke, T.L., Cowan, G.A., Falconer, W.E., Grant, N.J., Johnson, J.R., Matusek, J.M., Parizek, R.R., Pigford, R.L., and White, D.E., 1983b. A study of the isolation system for geologic disposal of radioactive wastes. Washington, D.C., National Academy Press.

radionuclides will enter the local groundwater system. The radionuclides will react with various components of the groundwater, with dissolved waste form materials, and with the host rock to form insoluble compounds and solution complexes that can control concentrations and migration rates of the waste radionuclides. Since the time scale being considered is 1000 years or longer, predictions based on realistic modeling studies provide the main avenue of assessment. Thus reliable data on the nature and solubilities of compounds, as well as on the nature and formation constants of complexes of the waste radionuclides that form in natural systems, are neesed as a first step in the prediction of the amounts and rates of release of radionuclides from a proposed underground repository. 
Computer calculations show that the actinides $U$ to $\mathrm{Cm}$ are major contributors to the radioactivity of the waste for storage times of 1000 years or greater (Little, 1977; Barney and Wood, 1980). Although a number of inorganic components present in groundwaters can form insoluble compounds and solution complexes with the actinides, hydroxide and carbonate are common to all groundwaters and are expected to play a dominant role in determining the speciation and solubilities of the important actinides (Allard, 1982; Moody, 1982). Data on trivalent lanthanide carbonates, good analogs for trivalent actinides, suggest that the carbonates of the latter should be quite insoluble. These compounds could be important ir. the control of actinide solution concentrations, but no daia have been reported. The object of the work described here was to investigate the solubility of a trivalent actinide, americium, iit an aqueous carbonate system.

\section{THE SOLUBILITY OF AmOHCO}

The solubility of crysıalline $A \mathrm{mOHCO}_{3}$ was measured at $25 \pm 1^{\circ} \mathrm{C}$ and 1 atm in aqueous solutions of $0.1 \mathrm{M} \mathrm{NaClO}_{4}$ and $2.08 \pm 0.09 \times 10^{-4} \mathrm{M}$ $\mathrm{HCO}_{3}{ }^{-}$. Initial experiments indicated that this compound, rather than $\mathrm{Am}_{2}\left(\mathrm{CO}_{3}\right)_{3}$, was the stable solid phase in dilute aquecus solutions of bicarbondte. The measurements were conducted at a fixed $\mathrm{pH}, 6.12 \pm 0.03$. The $\mathrm{pH}$ and $\mathrm{HCO}_{3}{ }^{-}$conceniration were sufficiently low to avoid significant hydrolysis and carbonate complexation of the $\mathrm{Am}^{3+}$. The $\mathrm{pH}$ was controlled with a potentiostat and the bicarbonate fixed by contacting the solution with an atmosphere of $0.792 \% \mathrm{CO}_{2}$ and $99.2 \% \mathrm{Ar}$.

The solubility studies were conducted in two parts. The first involved following to steady state the solution concentration of Am over a period of $30 \mathrm{~d}$ in a solution initially free of the element but which had been placed in contact with the crystalline solid. The second part involved following to steady state the solution concentiation of Am over a period of $51 \mathrm{~d}$ in a solution initially surerseturated in Am with respect to the precipitation of a solid phase but with no solid initially piesent. At the beginning and end of part $I$ and the end of par 2, $x-r_{4} y$ powder diffraction patterns were obtained from the solids, and the three patterns were found to be the same. There are no x-ray diffraction data on trivalent actinide hydroxycarbonates. but, the pc sder patterns obtained were nearly identical to th:at reponed for $\mathrm{NdOHCO}_{3}$ (Dexpert and Caro, 1974). From the molar concentrations of $\mathrm{Am}^{3+}, \mathrm{HCO}_{3}{ }^{-}$and $\mathrm{H}^{+}$, a solubility product quotient was calculated. The reaction and the quotient. obtained from averaging the results of parts 1 and 2 , are giv^n in Tr jle 1. A more detailed description of these studies is given elsewhere (Silva, 1982).

\section{MODELING CALCULATIONS}

To test the effect of the presence of carbonate on the solubility of $\mathrm{Am}^{3+}$, a series of speciation calculations was performed for several $\mathrm{pH}$ values and carbonate concentrations. The reactions and constants used in the calculations are given in Table 1 . Since this involves the solution of a number of coupled equations simultaneously. the calculation of the concentration of solution species and solubilities from the thermodynamic data were made using a comculet code called MINEQL (Westall, et al., 1976).

Figure la shows a plot of the logarithm of the calculated concentrations of the various Am solution species (broken curves) and the sum of the concentrations of the solution species (solid curve), i.e., the solubility line, in the absence of casbonate using the Am $(\mathrm{OH})_{3}$ solubility and hydrolysis quotients in Tablc 1. The solid curve is labeled with the stable solid phase. Figure $1 \mathrm{~b}$ shows a plot for a fixed partial $\mathrm{CO}_{2}$ pressure of $10^{-3.5} \mathrm{~atm}$, i.e.. normal concentration in air. Figure lc shows a plot for a constant total carbonate concentration of $2 \times 10^{-3} \mathrm{M}$, or about 120 ppm.

Finally, a MINEQL calculation was made for a simulated groundwater with a composition similar to that reported $\mathrm{f}_{\mathrm{i}}$ a Hanford Basalt groundwater with a $\mathrm{pH}$ of about 9.5 (NRC, 1983). In addition to hydrolysis and carbonate complexation, fluoride, sulfate and chloride complexations were included. The reactions and quotients for $0.1 \mathrm{M}$ ionic strengtr (Phillips, 1982) are given in Table 1. The solution composition was taken to be $42 \mathrm{ppm} \mathrm{F}^{-}, 199 \mathrm{ppm}$ $\mathrm{SO}_{4}{ }^{2-}, 297 \mathrm{ppm} \mathrm{Cl}^{-}$and $157 \mathrm{ppm}$ total carbonate. The results of these calculations are shown in Fig. ld.

\section{CONCLUSIONS}

The results of the measurements and the MINEQL calculations lead to the following conclusions:

1. The presence of carbonate at normal groundwate - concentrations can have a substantial effect on the nature and solubility of $\mathrm{Am}^{3+}$ compounds as well as solution species. Since actinides in the same valence state tend to exhibit similar properties (Katz and Seaborg, 1957), this result should be true for other actinides in the trivalent state as well.

2. The solid phase $\mathrm{AmOHCO}_{3}$ is predicted to be more stable than $\mathrm{Am}(\mathrm{OH})_{3}$ over the $\mathrm{pH}$ range 
Table 1. Thermodynamic data used in MINEQL calculations $\left(25^{\circ} \mathrm{C}, 0.1 \mathrm{M}\right.$ ionic strength).

\begin{tabular}{|c|c|c|}
\hline Reaction & $\log Q$ & Reference \\
\hline $\mathrm{Am}^{3+}+\mathrm{H}_{2} \mathrm{O}=\mathrm{AmOH}^{2+}+\mathrm{H}^{+}$ & $-7.7 \pm .3$ & Edelstein, 1982 \\
\hline $\mathrm{Am}^{3+}+2 \mathrm{H}_{2} \mathrm{O}=\mathrm{Am}(\mathrm{OH})_{2}^{+}+2 \mathrm{H}^{+}$ & $-16.6 \pm .5$ & Silva, 1982 \\
\hline $\mathrm{Am}^{3+}+3 \mathrm{H}_{2} \mathrm{O}=\mathrm{Am}(\mathrm{OH})_{3}+3 \mathrm{H}^{+}$ & $-24.8 \pm .2$ & Silva, 1982 \\
\hline $\mathrm{Am}^{3+}+4 \mathrm{H}_{2} \mathrm{O}=\mathrm{Am}(\mathrm{OH})_{4}^{-}+4 \mathrm{H}^{+}$ & $<-35$ & Silva, 1982 \\
\hline $\mathrm{Am}^{3+}+\mathrm{CO}_{3}^{2-}=\mathrm{AmCO}_{3}^{+}$ & 6.1 & Lundqvist, 1982 \\
\hline $\mathrm{Am}^{3+}+2 \mathrm{CO}_{3}{ }^{2-}=\mathrm{Am}\left(\mathrm{CO}_{3}\right)_{2}^{-}$ & 10.1 & Lundqvist, 1982 \\
\hline $\mathrm{Am}(\mathrm{OH})_{3}(\mathrm{c})+3 \mathrm{H}^{+}-\mathrm{Am}^{3+}+3 \mathrm{H}_{2} \mathrm{O}$ & $16.5 \pm .2$ & Silva, 1982 \\
\hline $\mathrm{AmO}^{\prime} \mathrm{HCO}_{3}(\mathrm{c})+2 \mathrm{H}^{+}-\mathrm{Am}^{3+}+\mathrm{HCO}_{3}^{-}+\mathrm{H}_{2} \mathrm{O}$ & $2.74 \pm .17$ & Silva and Nitsche, 1983 \\
\hline $\mathrm{Am}^{3+}+\mathrm{F}=\mathrm{AmF}^{2+}$ & 3.9 & Phillips, 1982 \\
\hline $\mathrm{Am}^{3+}+2 \mathrm{~F}=\mathrm{AmF}_{2}^{+}$ & 6.4 & Phillips, 1982 \\
\hline$A m^{3+}+3 F=A m F_{3}$ & 9.3 & Phillips, 1982 \\
\hline $\mathrm{Am}^{3+}+\mathrm{SO}_{4}^{2-}=\mathrm{AmSO}_{4}^{+}$ & 2.6 & Phillips, 1982 \\
\hline $\mathrm{Am}^{3+}+\mathrm{SO}_{4}^{2-}=\mathrm{AmSO}_{4}^{+}$ & 2.6 & Phillips, 1982 \\
\hline $\mathrm{Am}^{3+}+2 \mathrm{SO}_{4}^{2-}=\mathrm{Am}\left(\mathrm{SO}_{4}\right)_{2}$ & 3.7 & Phillips, 1982 \\
\hline $\mathrm{Am}^{3+}+\mathrm{Cl}^{-}=\mathrm{AmCl}^{2+}$ & 0.5 & Phillips, 1982 \\
\hline $\mathrm{Am}^{3+}+2 \mathrm{Cl}=\mathrm{AmCl}_{2}^{+}$ & -0.1 & Phillips, 1982 \\
\hline
\end{tabular}

6-9.5. It is expected to be more insoluble than $\mathrm{Am}(\mathrm{OH})_{3}$ by factors of $10-10^{4}$, dipending on the $\mathrm{pH}$ and carbonate concentrations in dilute carbonate waters.
3. The carbonate complexes of $\mathrm{Am}, \mathrm{AmCO}_{3}{ }^{+}$ and $\mathrm{Am}\left(\mathrm{CO}_{3}\right)_{2}{ }^{-}$, are predicted to be major solution species for pH values of about 7 and higher for low dissolved solid groundwaters. 

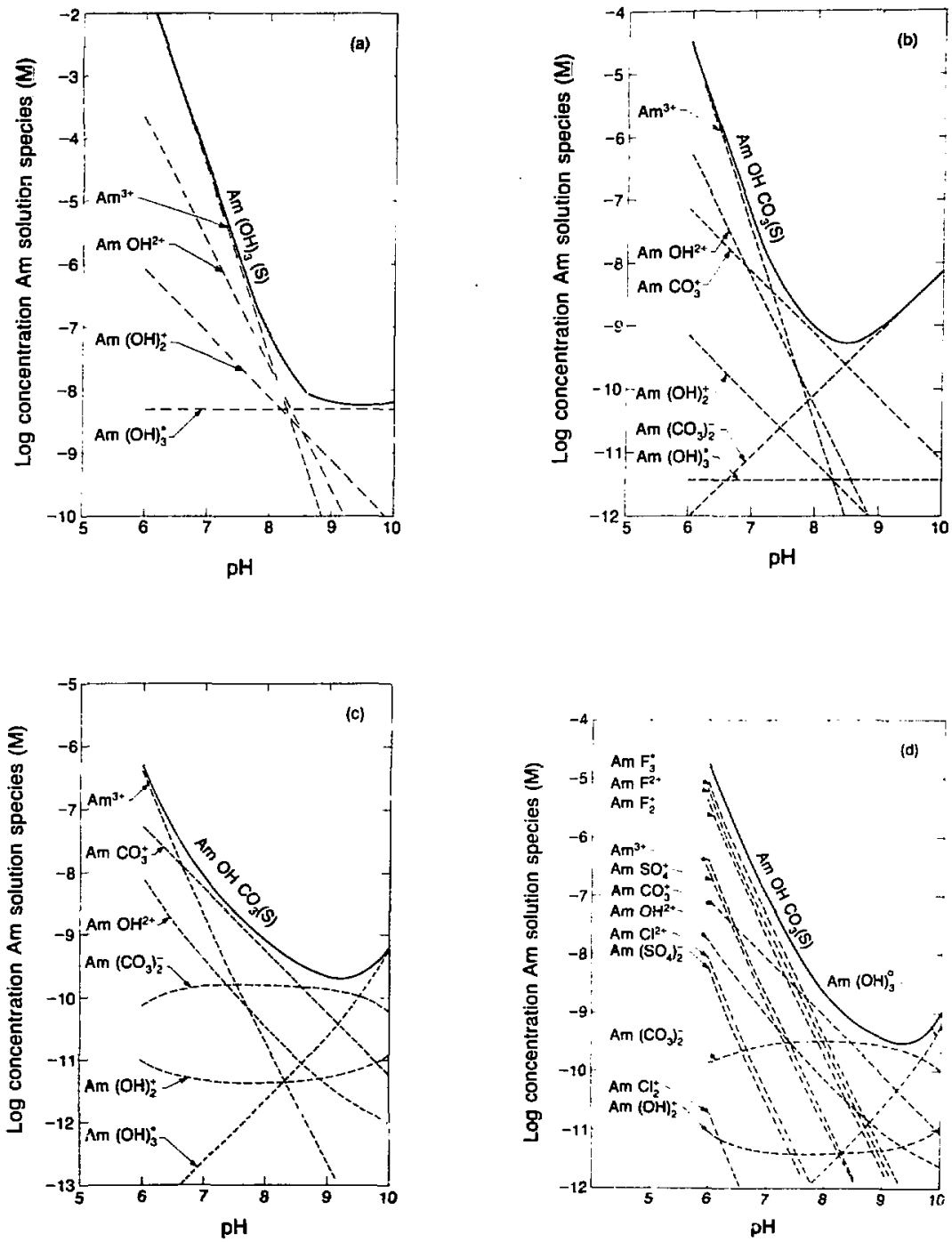

Figure 1. Calculated concentrations of Am solution species (broken curves, labeled with species) and their sums (solid curves, labeled with the controlling solid phase) for $0.1 M$ ionic strength as a function of pH. (a) $P_{\left(\mathrm{CO}_{2}\right)}=0 \mathrm{~atm} ;(b) P_{\left(\mathrm{CO}_{1}\right)}=10^{-3.5} \mathrm{~atm}$; (c) total $\mathrm{CO}_{3}=2 \times 10^{-3} \mathrm{M}$; (d) simulated groundwater of low dissolved solids: $\mathrm{C}^{-}=8.4 \times 10^{-3} \mathrm{M}, \mathrm{SO}_{4}^{2-}=2.1 \times 10^{-3} \mathrm{M}, \mathrm{F}^{-}=2.2 \times 10^{-3} \mathrm{M}$, total $\mathrm{CO}_{3}$ $=2.6 \times 10^{-3} \mathrm{M}$. [XBL 839-3273A] 


\section{REFERENCES}

Allard, B., 1982. Solubilities of actinides in neutral or basic solutions. In N. Edelstein (ed.), Actinides in Perspective. New York, Pergamon Press, p. 533-580.

Barney, G.S., and Wood, B.J., 1980. Identification of key radionuclides in a nuclear waste repository in basalt. Richland, Washington, Rockwell Hanford Operations, RHO-BWI-ST-98, p. 8.

Dexpert, H., and Caro, P., 1974. Determination de la structure crystalline de la variete a des hydroxycarbonates de terres rares $\mathrm{LnOHCO}_{3}$. Materials Research Bulletin, v. 9, p. 1577-1586.

Edelstein, N., Bucher, J., Silva, R, and Nitsche, H., 1982. Thermodynamic properties of chemical species in nuclear waste. (Topical Report for the Office of Nuclear Waste Isolation.) Lawrence Berkeley Laboratory, LBL-14235, p. 50.

Katz, J.J., and Seaborg, G.T., 1957. The Chemistry of the Actinide Elements. New York, John Wiley \& Sons, p. 406-475.

Little, A.D., 1977. Technical support standards for high-level radioactive waste management. Washington, D.C., U.S. Environmental Protection Agency, EPA-520/4-79-007A.

Lundqvist, R., 1982. Hydrophilic Compleces of the actinides. I. Carbonates of trivalent americium and europium. Acta Chemica Scandinavia, v. A36, p. $741-750$.

Moody, J.B., 1982. Radionuclide migration retardation. Columbus, Ohio, Office of Nuclear Waste Isolation, ONWI-321, p. 6.

NRC, 1983. Draft site characterization analysis of the site characterization report for the basalt waste isolation project. Washington, D.C., U.S. Nuclear Regulatory Commission, NUREG-0960, p. U-15.

Phillips, S.L., 1982. Hydrolysis and formation Constants at $25^{\circ} \mathrm{C}$. Lawrence Berkeley Laboratory, LBL-1 4313.

Silva, R.J., 1982. The solubilities of crystalline neodynium and americium trihydroxides. (Topical Report for the Office of Nuclear Waste Isolation.) Lawrence Berkeley Laboratory, LBL15055.

Silva, R.J., and Nitsche, H., 1983. Thermodynamic properties of chemical species of waste radionuclides. (Topical Report for the U.S. Nuclear Regulatory Commission.) Lawrence Berkeley Laboratory, LBL-16696.

Westall, J.C., Zachary, J.C., and Morel, F.N.M., 1976. MINEQL, A computer program for the calculation of chemical equilibrium composition of aqueous systems. (Department of Civil Engineering Technical Report, Massachusetts Institute of Technology) Cambridge, Massachusetts, Technical Note 18.

occurs during initial dewatering of the tailings, downward infiltration of precipitation, and groundwater intrusion into the base of the tailings pile.

\section{SITE HYDROLOGY}

Snallow groundwater is contained in 4-8 $\mathrm{m}$ of coarse gravel and sand of the Wind River flood plain. The water table in this alluvium is within $1 \mathrm{~m}$ of the base of the tailings pile, which in turn is as much as $1.5 \mathrm{~m}$ below grade relative to the natural land suiface. The hydraulic gracient is toward the Little Wind River to the southeast (Fig. 1).

Deeper aquifers are contained in coarse-grained sandstones of the underlying Wind River Formation of Eocene age. Radiogenic tritium (half-life $=12$ years) in the shallow aquifer is high, ranging between 65 and 95 tritium units ( $1 \mathrm{TU}=3.2 \rho C_{l}^{-1}$ ) and is indicative of modern recharge (Gat, 1980). Tritium concentrations in domestic wells completed in the Wind River aquifer are low, indicating negligible 


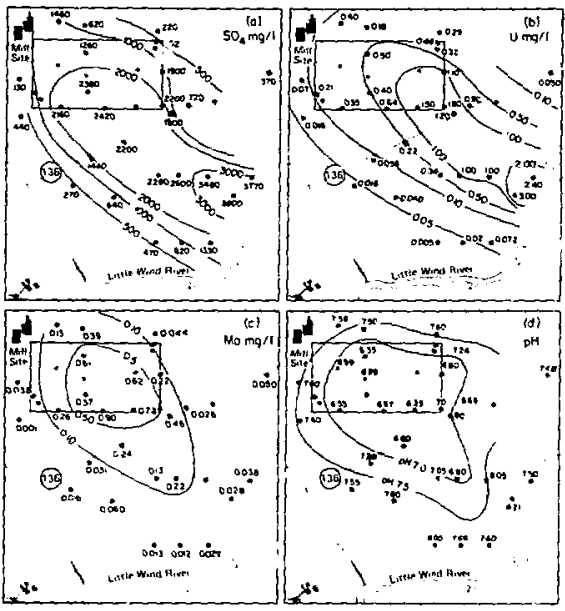

Figure 1. Contaminant distributions for groundwater in the shallow alluvial aquifer. XBL 8311-7392B]

recent recharge. This age difference implies a lack of aquifer interconnection and a low potential for conramination of the Wind River aquifer.

\section{PORE WATER CHEMISTRY}

The tailings pile is currently $50-100 \%$ saturated. Vertical chemical profiles of pore waters in the pile can be constructed using data collected from the nested suction water samples. Profiles of major and selected trace elements are shown in Fig. 2. As indicated, maximum chemical concentrations occur at intermediate depths within the pile. Clearly these high concentrations, particularly those of iron and aluminum sulfate, are associated with very low $\mathrm{pH}$. This chemistry is indicative of residual process water containing concentrated $\mathrm{H}_{2} \mathrm{SO}_{4}$ used to leach. uranium during milling.

In the upper $1.5 \mathrm{~m}$ of the tailings pile, pore water pH is less acidic (Fig. 2), Relatively rapid infiltralion rates $\left(3-5 \times 10^{-6} \mathrm{~m} / \mathrm{s}\right)$, measured in artificial recharge tests coupled with heavy precipitation events such as summer thunderstorms, suggest periodic recharge events. Dilution and vertical displacement of the low $\mathrm{pH}$ pore water by recharge results in the loss of acid-soluble iron and aluminum salts.

The lower third of the tailings pile contains even more dilute pore waters (Fig. 2) with the $\mathrm{pH}$
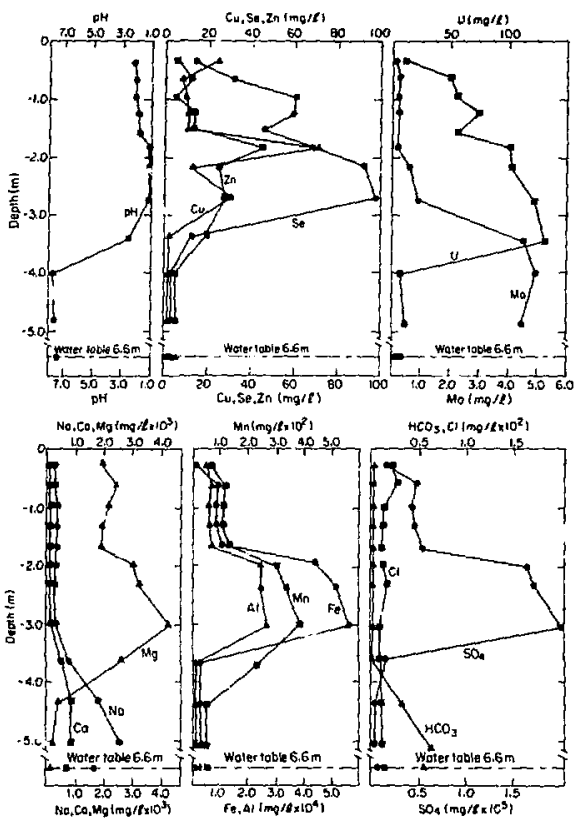

Figure 2. Verniral chemical distribution of pore waters in the tailings pile. |XBL 8311-2367)

approaching neutrality. This results from intrusion of the shallow groundwater into the base of the tailings.

Groundwater dilution also results in nearbackground concentrations of iron, aluminum, and trace metals in the pore waters at the base of the tailings. As indicated in Fig. 2, the major exception to this trend is molybdenum, which exhibits significant increases. The dominant molybdenum species at neutral $\mathrm{pH}$ is the soluble $\mathrm{MoO}_{4}{ }^{-2}$ anion (Baes and Messmer, 1976), which is apparently mobilized by groundwater intrusion.

\section{CONTAMINATION OF THE SHALLOW AQUIFER}

Elevated concentrations of major dissolved species, including $\mathrm{Na}, \mathrm{Ca}$, and $\mathrm{SO}_{4}$, occur in the shallow groundwater in the alluvium. As shown in Fig. Ia for the sulfate data, the contaminant plume parallels the hydraulic gradient. The lack of signifi- 
cant lateral dispersion suggests channeling in the river-deposited alluvium.

An interesting feature of the plume, again indicated by the sulfate data, is that maximum chemical concentrations occur downgradient near the Little Wind River. This concentration offset from directly beneath the tailings pile suggests that accelerated dewatering of the pile probably occurred in the past during deposition of a tailings slurry.

The lateral uranium distribution in the shallow aquifer (Fig. lb) closely parallels the sulfate distribution, again indicating a past episode of maximum contamination. Aside from ${ }^{238} \mathrm{U}$, no elevated radionuclide activities were detected in the shallow aquifer. The contaminant plume for molybdenum (Fig. 1c) shows a different configuration from that for sulfate or uranium, with maximum concentrations $(0.9 \mathrm{mg} / \mathrm{l})$ directly beneath the pile and decreasing concentrations downgradient. These elevated groundwater concentrations correlate with high molybdenum values in the base of the tailings (Fig. 2) and appear to be related to later groundwater intrusion into the pile.

\section{MODEL FOR CONTAMINANT MIXING}

In both the tailings pore water and the groundwater, $\mathrm{pH}$ is the prime variable in controlling contaminant speciation and concentration. As indicated by Fig. 1d, the pH of contaminated groundwater beneath the pile is only slightly lower (pH 6.35-6.99) than that of uncontaminated groundwater upgradient from the pile ( $\mathrm{pH} 7.50-7.60$ ). This $\mathrm{pH}$ buffering is indicative of acid neutralization by carbonate minerals in the soil. At low $\mathrm{pH}$, these reactions are

$\mathrm{CaCO}_{3 \text { soil }}+2 \mathrm{H}_{\text {tillines }} \rightarrow \mathrm{Ca}^{2+}+\mathrm{CO}_{2}+\mathrm{H}_{2} \mathrm{O}$

and

$\mathrm{HCO}_{3}^{-}$groundwater $+\mathrm{H}_{\text {Lilines }}^{+} \rightarrow \mathrm{CO}_{2}+\mathrm{H}_{2} \mathrm{O}$

The saturation state of the groundwater relative to calcite (Eq. 1) was calculated by the PHREEQE code (Parkhurst et al., 1980). Results indicate that the calcite buffer has not been consumed through acid reaction with tailings water.

In addition to calcite saturation, groundwater contaminated by significant amounts of tailings water is saturated with gypsum. The effect of gypsum precipitation on $\mathrm{pH}$ is defined by the reaction
$\mathrm{CaCO}_{3}$ soil $+\mathrm{H}_{2} \mathrm{SO}_{4}$ tailings

$$
+\mathrm{H}_{2} \mathrm{O} \rightarrow \mathrm{CaSO}_{4} \cdot 2 \mathrm{H}_{2} \mathrm{O}+\mathrm{CO}_{2}
$$

and the subsequent equilibration between $\mathrm{CO}_{2}$ and dissolved bicarbonate (Eq. 2).

Additional important precipitation reactions during contaminant mixing involve high concentrations of dissolved metals in the tailings pore waters, principally iron and aluminum. Assuming oxidizing conditions within the tailings (on the basis of measurable $\mathrm{O}_{2}$ partial pressures), the precipitation reactions at neutral $\mathrm{pH}$ are represented as

$$
\mathrm{Fe}^{3+}+3 \mathrm{H}_{2} \mathrm{O} \rightarrow \mathrm{Fe}(\mathrm{OH})_{3}+3 \mathrm{H}^{+}
$$

and

$$
\mathrm{Al}^{3+}+3 \mathrm{H}_{2} \mathrm{O} \rightarrow \mathrm{Al}(\mathrm{OH})_{3}+3 \mathrm{H}^{+}
$$

Using the PHREEQE code, reactions (1) to ( 5 ) can Jefine $\mathrm{pH}$ changes as a function of mixing between initially uncontaminated shallow groundwater and pore water contained in the tailings. Constraints on groundwater mixing included continual equilibration with $\mathrm{Fe}(\mathrm{OH})_{3}$ and $\mathrm{Al}(\mathrm{OH})_{3}$ (Eqs. 4 and 5) and equilibrium with gypsum after saturation has been achieved (Eq. 3). The parial pressuse of $\mathrm{CO}_{2}$ was fixed at 0.1 atm, which is the average partial pressure for the gas data. The Eh was assumed to be oxidizing $(0.4 \mathrm{~V})$ and controlled by $\mathrm{Fe}^{2+} / \mathrm{Fe}^{3+}$ equilibrium.

Calculated changes in groundwater $\mathrm{pH}$ as a function of the volume mixing fraction of tailings pore waters is shown in Fig. 3a. Two scenarios shown are for groundwater equilibrated and unequilibrated with calcite. Calcite equilihrit:m, which is the current mixing condition based $r$ saturation data, results in strong buffering in the $\mathrm{pH}$ range 6.5-6.3. The lack of carionate equilibrium, which corresponds to a buffering loss due to complete removal of calcite from the aquifer, results in a rapid decrease in $\mathrm{pH}$.

The volume fraction of tailings water mixed with the groundwater beneath the tailings is estimated from the range of $\mathrm{pH}$ values shown in the crosshatched area of Fig. 3a, which correspond to the contaminated groundwater samples. As indicated, the mixing fraction is relatively small, between 0.28 and $0.56 \%$ of the total groundwater volume.

An independent check on the mixing fraction can be made by also considering the volume of tail- 

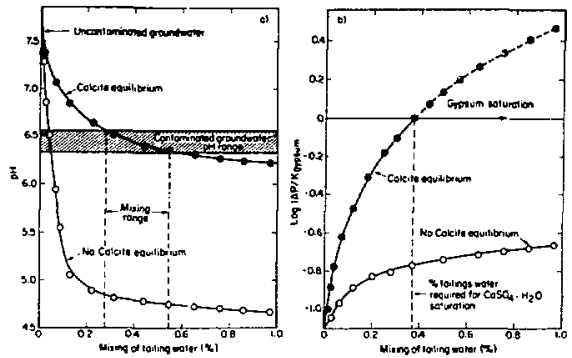

Figure 3. Changes in groundwater $\mathrm{pH}$ and gypsum sauration as a function of mixing with tailings water assuming equilibrium and nonequilibrium with calcite. Broken vertical lines define the mixing range required to produce the observed $\mathrm{pH}(a)$ and minimum mixing required to achieve gypsum satuartion (b). [XBL 831]2366A

ings water required to produce gypsum saturation in the groundwater, as was documented for contaminated groundwater. The logarithm of the $I A P / K_{s}$

\section{INVESTIGATION OF NATURAL ANALOGS OF NUCLEAR WASTE REPOSITORY CONDITIONS IN COLUMBIA RIVER BASALT}

\author{
H.A. Wollenberg, D.G. Brookins, S. Flexser, \\ and $M$. Murphy*
}

Among the natural analog studies conducted at Lawrence Berkeley Laboratory (Wollenberg et al., 1983), investigations in Columbia River basalt were emphasized in fiscal 1983. They comprised a detailed geochemical study of the contact zone between a rhyodacite dike and the Wanapum Basalt, and a study of strontium isotope ratios in fracturefilling minerals in the Grande Rondc Basalt. These studies are the subjects of more detuiled papers by Bropkins et al. (1983a,b).

-Department of Geology. Universily of New Mexico. Albuquerque. ratio for $\mathrm{CaSO}_{4} \cdot 2 \mathrm{H}_{2} \mathrm{O}$ is plotted in Fig. 3b agains: the mixing fraction of pore water. As indicated, the groundwater, saturated with calcite but initially unsaturated with gypsum, reaches gypsum saturation $\left(I A P / K_{s}=0\right)$ after mixing with approximately $0.4 \%$ tailings water. This volume percent is within the range predicted from the $\mathrm{pH}$ mixing model and indicates low current rates of recharge through the tailings pile and subsequent groundwater contamination.

\section{REFERENCES}

Baes, D.F. and Messmer, R.E., 1976. The Hydrolysis of Cations. New York, Wiley Interscience.

Gat, J.R., 1980. The isotopes of hydrogen and oxygen in precipitation. In P. Fritz and $\mathrm{J}$. Ch. Fontes (ed.), Handbook of Environmental Isotopes in Geochemistry. Amsterdam, Elsevier, p. $21-44$.

Parkhurst, D.L., Thorstensen, D.C., and Plummer, L.N., 1980. PHREEQE-A computer program for geochemical calculations. USGS Investigation, 80-96, 209 p.

\section{THE RHYODACITE DIKE/WANAPUM BASALT OCCURRENCE}

This contact zone, exposed in a quarry on the Hood River, Oregon, is considered to be an appropriate analog, tecause chemical gradients between the dike and the basalt are pronounced, permitting assessment of element migration during intrusion of the dike as well as during and after its cooling. In this study, radioelement contents and $\mathrm{Sr}$ isotope ratios were determined from a sampling traverse encompassing the dike and extending several meters into the basalt. If chemical and/or isotopic exchange has occurred between such contrasting rock types, mixing should be apparent in analyses of these samples.

The distributions of radioelement contents and Sr isotope ratios are plotted in Fig. 1. The sharp contrast betiveen the uranium and thorium contents of the rhyodacite and the basalt is evident, as is the strong contrast in ${ }^{87} \mathrm{Sr} /{ }^{86} \mathrm{Sr}$. Uranium in the rhyodacite averages $4.3 \mathrm{ppm}$; thorium, $13.2 \mathrm{ppm}$; potassium, 3.1\%; and ${ }^{87} \mathrm{Sr}{ }^{86} \mathrm{Sr}, 0.7041$. Corresponding average values for basalt art: $U, 1.05 \mathrm{ppm}$; Th, 3.95 $\mathrm{ppm} ; \mathrm{K}, 0.9 \%$; and ${ }^{87} \mathrm{Sr} /{ }^{86} \mathrm{Sr}, 0.7052$. These data 


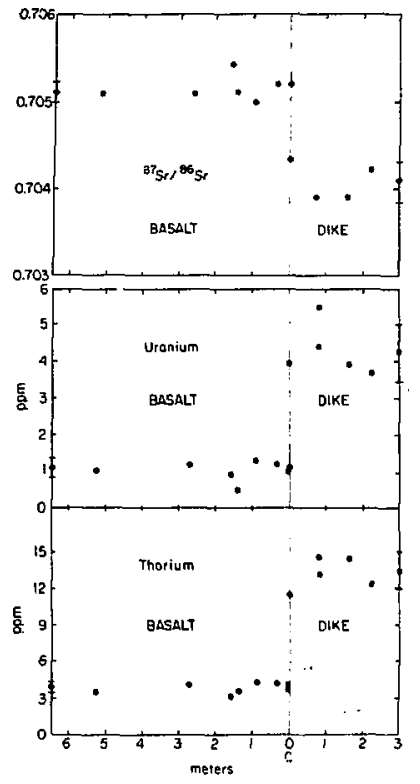

Figure 1. Variation in $\mathrm{U}, \mathrm{Th}$, and ${ }^{87} \mathrm{Sr} /{ }^{86} \mathrm{Sr}$ in a rhyodacite dike and the surrounding basalt, East Fork, Hood River, Oregon. [XBL 828-2328]

argue against any transfer of radioelements or $\mathrm{Sr}$ from one rock into the other, either during intrusion of the dike or through fractures formed in the basalt after the dike had cooled.

It is concluded from this occurrence that

1. The strontium isotopic characteristics of both the intrusive and intruded rocks are preserved. There is no evidence for $\mathbf{S r}$ isotopic disturbance or redistribution due to the emplaceinent of the rhyodacite dike in the Wanapum Basalt.

2. The distribution of radioelements, with pronounced gradients in $\mathrm{U}, \mathrm{Th}$, and $\mathrm{K}$ between the rhyodacite and basalt, shows that no radioelements have been transferred across the contact.

3. Consideration of the rhyodacite as a heat engine, and therefore as an analog for buried radioactive waste in baselt, indicates that radionuclide migration into the host rock is unlikely under the conditions of dike intrusion.

\section{STRONTIUM ISOTOPES AND TRACE ELEMENTS IN THE FRACTURE FILLINGS OF THE GRANDE RONDE BASALT}

Of concern is whether waters can percolate vertically through the rocks at the Basalt Waste Isolation Project site at the Hanford Reservation, Washington. Flow in well-defined horizontal interbed units is well known, but vertical flow has not been fully investigated. Since verical fractures are common, it is possible that some waters could penetrate the basalts and move normal to the horizontal flow layers. To investigate this, we have examined the chemistry and isotopics of minerals found in the fractures. These minerals may have originated earlier in the basalt history, in which case their chemistry and isotopic composition should reflect that of the basalt. Alternatively, they may have formed late in the basalt's history, in which case their chemistry may be a reflection of material deposited from percolating waters or they may represent a mixing of the basalt and groundwater reservoirs. To examine this important problem, we measured the strontium isotopic composition of the various reservoirs, and compared those measurements with the results of other chemical studies.

Samples were selected of core (in the LBL collection) from hole DC- 6 on the Hanford Reservation, spanning the depth range from 740 to $1153 \mathrm{~m}$. Most of the fracture-filling material consists of a mixture of zeolite, primarily clinoptilolite, with quartz, although some samples contain phillipsite and cristobalite. Illite and erionite were identified in only two samples.

The trace-element data for basalt, fracture fillings, and stream water are listed in Table 1 . It is apparent that the data for fracture-filling trace elements are much more consistent with those for basalt than with those for stream water, especially when elemental ratios are considered. The strontium isotopic data (Table 2) also support the lack of a major stream water component in the fracturefilling minerals. There is only a very small difference in $\mathrm{Sr}$ isotope ratios between individual fracture-filling pairs, while there are variations in isotopic ratios with depth in the basalt.

Waters from surface streams and groundwater of the Hanford region have not yet been made available for this study. As a result, we used $\mathrm{Sr}$ data for several western U.S. streams (Brass, 1973) to apply a mixing model (Faure, 1977). Assuming values of $60 \mathrm{ppb} \mathrm{Sr}$ for average streams and a ${ }^{87} \mathrm{Sr} /{ }^{86} \mathrm{Sr}$ ratio of 0.709 , we find that the data for fracture fillings are compatible with derivation from a large amount 
Table 1. Comparison of basalt, stream water, and fracture filling materials.

\begin{tabular}{lcccc}
\hline Element & $\begin{array}{c}\text { Basalt } \\
(\mathrm{ppm})^{\mathrm{a}}\end{array}$ & $\begin{array}{c}\text { Stream } \\
\text { waters } \\
(\mathrm{ppb})^{b}\end{array}$ & $\begin{array}{c}\text { Hanford } \\
\text { groundwater }^{(\mathrm{ppb})^{\mathrm{c}}}\end{array}$ & $\begin{array}{c}\text { Fracture/Fillings } \\
(\mathrm{ppm})^{\mathrm{a}}\end{array}$ \\
\hline $\mathrm{Sc}$ & 30 & 0.004 & - & 12.5 \\
$\mathrm{Ti}$ & 10,000 & 10 & - & 8800 \\
$\mathrm{Cr}$ & 170 & 1 & 30 & 41 \\
$\mathrm{Mn}$ & 1500 & 8 & 50 & 618 \\
$\mathrm{Fe}$ & major & 40 & 50 & 53,000 \\
$\mathrm{Co}$ & 48 & 0.2 & 5 & 19.6 \\
$\mathrm{Ba}$ & 330 & 50 & 30 & 718 \\
$\mathrm{Th}$ & 2.7 & 0.1 & - & 1.8 \\
$\mathrm{U}$ & 1 & 0.1 & - & 0.55 \\
$\mathrm{Rb}$ & 130 & 1 & - & 42 \\
$\mathrm{Sr}$ & 465 & 60 & 60 & 240 \\
$\mathrm{~K} / \mathrm{Rb}$ & 255 & $(1000 \pm)$ & - & 217 \\
$\mathrm{Th} / \mathrm{U}$ & 2.7 & 1 & - & 3.3 \\
$\mathrm{Rb} / \mathrm{Sr}$ & 0.28 & 0.016 & - & 0.18 \\
\hline
\end{tabular}

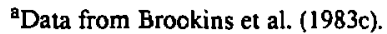

bata from Drever (1982).

${ }^{c}$ Data from DOE (1982).

of basalt (95\%) and no more than $5 \%$ water. Further, the supporting trace element data argue that the actual surface water component is probably near zero, although specific waters must be tested to verify this. sions:

These investigations lead to the following conclu+

1. Strontium isotopic signatures of fracturefilling minerals are essentially identical to those of their host basalt.

2. The trace-element data indicate that the fracture-filling minerals reflect the chemistry of their basalt source.

3. If water flowing vertically through the basalt had caused the presipitation of the scondary minerals noted, the chemistry of the minerals would reflect that origin. This is not the case. 
Table 2. Strontium isotopic data-basalt and fracture fillings.

\begin{tabular}{lcc}
\hline & \multicolumn{2}{c}{$\left.{ }^{87} \mathrm{Sr}\right)^{86} \mathrm{Sr}$} \\
\cline { 2 - 3 } Sample & Basalt & $\begin{array}{c}\text { Fracture } \\
\text { fillings }\end{array}$ \\
\hline 2427 & 0.7053 & 0.7060 \\
2933 & 0.7050 & 0.7055 \\
3006 & - & 0.7054 \\
3089 & 0.7054 & 0.7056 \\
3275 & 0.7050 & 0.7052 \\
3337 & 0.7060 & 0.7059 \\
3340 & 7.7058 & 0.7057 \\
3436 & 0.7057 & 0.7089 \\
3541.7 & 0.7067 & 0.7059 \\
3542 & 0.7060 & 0.7063 \\
3572 & 0.7056 & - \\
3636 & 0.7060 & 0.7048 \\
3666.2 & - & 0.7056 \\
3688 & - & 0.7056 \\
\hline
\end{tabular}

The sample numbers are the depths of samples from drill hole DC-6.

\section{REFERENCES}

Brass, G.W., 1973. The sources of marine strontium and the ${ }^{87} \mathrm{Sr} /{ }^{86} \mathrm{Sr}$ ratio in the sea throughout

\section{THERMODYNAMIC COUPLING OF TRANSPORT PROCESSES IN NEAR.FIELD REGIONS OF NUCLEAR WASTE REPOSITORIES}

\section{C.L. Carnahan}

Processes of heat flow, fluid flow, and solute transport are expected to occur simultaneously in the vicinity of a nuclear waste repository, and efforts to
Phanerozoic time (Ph.D. dissertation). Yale University, $160 \mathrm{p}$.

Brookins, D.G., Murphy, M.T., Wollenberg, H.A., and Flexser, S., 1983a. Geochemical studies of Columbia River basalts. In G, McVay (ed.), Scientific Basis for Nuclear Waste Management (Vol. 8). New York, Elsevier.

Brcokins, D.G., Murphy, M.T., and Wollenberg, H.A., 1983b. Strontium isotopic study of fracture filling minerals in the Grande Ronde Basalt, Washington. In G. McVay (ed.), Scientific Basis for Nuclear Waste Management (Vol 8). New York, Elsevier.

Department of Energy, 1982. Site characterization report for the Basalt Waste Isolation Project. Wasnington, D.C., Department of Energy, DOE/RL 82-3 (Vol. 1).

Brookins, D.G., Murphy, M.T., Wollenburg, H.A., and Flexser, S., 1983c. Geochemical and strontium isotropic studies of Columbin River basalts. Report to the U.S. Nuclear Regulator: Commission as part of a summary document on geochemical research.

Drever, J.I., 1982. The Geochemistry of Natural Waters. Englewood Cliffs, New Jersey, Prentice-Hall, 388 p.

Faure, G., j977. Principles of Isotope Geology. New York, Wiley-Interscience, $460 \mathrm{p}$.

Wollenberg, H.A., Brookins, D.G., Cohen, L.H., Flexser, S., Abashian. M., Murphy, M. and Williams, A.E., 1983. Uranium, thorium and trace elements in geologic occurrences as analogues of nuclear waste repository conditions. Report (LBL-17638) to the U.S. Nuclear Regulatory Commission as part of a summary document on geochemical research.

simulate these processes numerically are receiving increasing attention. In the near-field region, large gradients of temperature, pressure, and composition can give rise to thermodynamically coupled processes in which flows of heat and matter are driven by seemingly unrelated forces. Such processes include thermal osmosis, thermal diffusion, ultrafiltration, and chemical osmosis.

\section{PHENOMENOLOGICAL EQUATIONS FOR MATTER FLOWS}

The thermodynamics of inteversible processes is particularly adaptable to the description of transport 
processes in multicomponent systems acted on by a variety of driving forces. For the purpose of the discussion to follow, we consider a simple twocomponent system-water (index o) and a single solute (index $s$ )-that forms a dilute, ideal solution in a saturated, porous or semipermeable medium acted on by gravity and gradients of temperature $(T)$, pressure $(P)$, and composition. It can be shown (Carnahan, 1983) that the vector flows of volume $\left(j_{v}\right)$, water $\left(j_{o}\right)$, and solute $\left(j_{s}\right)$, are given by the equations

$$
\begin{gathered}
j_{v}=-L_{v q} \frac{\nabla T}{T}-L_{v v} \nabla h-L_{v s} \frac{R T}{M_{s}} \frac{\nabla \rho_{s}}{\rho_{s}} \\
J_{o} \approx-\rho_{o}\left(L_{v q} \frac{\nabla T}{T}+L_{v v} \nabla h+L_{v s} \frac{R T}{M_{s}} \frac{\nabla \rho_{s}}{\rho_{s}}\right), \\
j_{s} \approx-\left(\rho_{s} L_{v q}+L_{s q}\right) \frac{\nabla T}{T} \\
-\left(\rho_{s} L_{v v}+L_{s v}\right) \nabla h-\left(\rho_{s} L_{v s}+L_{s s}\right) \frac{R T}{M_{s}} \frac{\nabla \rho_{s}}{\rho_{s}},
\end{gathered}
$$

where $\nabla$ is the vector gradient operator, $R$ is the gas constant, $M_{s}$ is the molecular weight of the solute, and $p_{o}$ and $\rho_{s}$ are the partial mass densities of water and solute, respectively. The vector force $\nabla h$ is given by

$$
\nabla h=\nabla P+\rho f g \nabla z
$$

where $\rho_{J}$ is the total mass density of the fluid, $g$ is the acceleration of gravity, and $z$ is the height above an arbitrary datum. The volume flow is defined by

$$
j_{v}=\bar{V}_{o} j_{o}+\bar{V}_{s} j_{s},
$$

where $\bar{V}_{0}$ and $\bar{V}_{s}$ are the partial specific volumes of water and solute, respectively. The flows are current densities, i.e., quantities of volume or mass per unit area per unit time. The Onsager reciprocal relations require equality of the phenomenological coefficients $L_{s v}$ and $L_{v s^{*}}$

We identify various processes by reference to the phenomenologicai coefficients associated with them. The direct processes are advection $\left(L_{v y}\right.$ and diffusion $\left(L_{s s}\right)$, described by Darcy's law and Fick's law, respectively. The thermodynamically coupled processes are thermai usmosis $\left(L_{v q}\right)$, thermal diffusion $\left(L_{s q}\right)$, chemical osmosis $\left(L_{v s}\right)$, and ultrafiltration $\left(L_{s v}\right)$.

We use (1), (2), and (3) to compare flows of fluid and solute arising from thermodynamically coupled processes to the nows that would be predicted by the laws of Darcy and Fick.

\section{APPLICATION TO A HYPOTHETICAL REPOSITORY ENVIRONMENT}

To estimate possible magnitudes of thermodynamically coupled effects relative to direct effects, we assume conditions previously hypothesized for the near-field region of a repository sited in basalt. Values of phenomenological coefficients are taken from experimental data reported in the literature. Although a considerable literature exists on thermodynamically coupled processes in entirely fluid systems, data relevant to porous and semipermeable natural materials are relatively scarce. Thus we use data on thermal osmosis in kaolinite, even though we recognize that kaolinite may not be a principal candidate for a backfill material. However, the results obtained should be approximately represeniative of clay backfills, in general.

\section{Repository Conditions}

We assume that the repository is sited in basalt and that the near-field environment is saturated by groundwater flowing down a regional hydraulic gradient equal to $10^{-3} \mathrm{~m} / \mathrm{m}\left(\nabla h \approx 10 \mathrm{~J} / \mathrm{m}^{4}\right)$. To estimate the thermal effects, we adopt calculations reported (Hodges, 1980) for a hypothetical basalt repository which indicate that at 50 years after closure the temperature a few tens of meters from the repository will be approximately $420 \mathrm{~K}$ and the temperature gradient will be approximately $2 \mathrm{~K} / \mathrm{m}$. The groundwater characteristics of this basalt has a dissolved solids content equal to a solute partial mass density $\left(\rho_{\mathrm{s}}\right)$ of $0.4 \mathrm{~kg} / \mathrm{m}^{3}$. The molecular weight of the solute is assumed to $\mathrm{be} 0.1 \mathrm{~kg} / \mathrm{mol}$.

\section{Thermal Osmosis in Kaolinite}

Experiments on thermal osmosis of pure water through kaolinite (Srivastava and Avasthi, 1975) provide the following values of $L_{y y}$ and $L_{v q}$ corresponding to the experimental conditions:

$$
\begin{gathered}
L_{v v} \approx 5 \times 10^{-14} \mathrm{~m}^{5} /(\mathrm{J} \cdot \mathrm{s}), \\
L_{v q} \approx 8 \times 10^{-8} \mathrm{~m}^{2} / \mathrm{s} .
\end{gathered}
$$


We assume that these values can be used to provide approximate resulis under our assumed repository conditions; then using (1) with gradient $\rho_{s}$ equal to zero, we calculate the following contributions to $\dot{j}_{v}$ from thermal osmosis and Darcy's law:

$$
\begin{gathered}
j_{v}(\text { thermal oxmosis }) \approx 4 \times 10^{-10} \mathrm{~m} / \mathrm{s}, \\
j_{v}(\text { Darcy }) \approx 5 \times 10^{-13} \mathrm{~m} / \mathrm{s} .
\end{gathered}
$$

Thermal osmosis in this material, under the assumed temperature gradient, produces a volume flow (specific discharge) 800 times as large as the Darcian flow. It is clear that the kaolinite acts as a semipermeable membrane with an extremely small Darcian permeability.

A hydraulic gradient of about $0.8 \mathrm{~m} / \mathrm{m}$ $\left(\nabla h \approx 8000 \mathrm{~J} / \mathrm{m}^{4}\right)$ would be required to produce a Darcian flow equal to the thermal osmotic flow estimated in this example.

Chemical Osmosis, Ultrafiltration, and Diffusion in Bentonite

Results of isothermal experiments with Wyoming bentonite (Letey and Kemper, 1969) provide the following estimates of $L_{s w} L_{v w}$ and $L_{s s}$ :

$$
\begin{gathered}
L_{s v} \approx-0.8 \times 10^{-16} \mathrm{~kg} \cdot \mathrm{m}^{2} /(\mathrm{J} \cdot \mathrm{s}), \\
L_{v v} \approx 2.4 \times 10^{-16} \mathrm{~m}^{5} /(\mathrm{J} \cdot \mathrm{s}), \\
\left.L_{s s} \approx 6.8 \times 10^{-17} \mathrm{~kg}^{2} / \mathrm{m} \cdot \mathrm{J} \cdot \mathrm{s}\right) .
\end{gathered}
$$

We assume that these values are valid under the assumed repository conditions and that the relative concentration gradient of the solute $\left(\nabla \rho_{s} / \rho_{s}\right)$ is $0.1 / \mathrm{m}$. Then we use (2) and (3) with $\nabla T$ equal to zero to estimate contributions to flows of water and solute form processes driven by gradients of hydraulic potential and solute concentration.

From (2), the contributions to water flow from chemical osmosis and from Darcy's law are

$$
\begin{gathered}
\left.j_{o}(\text { chemical osmosis }) \approx-2.9 \times 10^{-10} \mathrm{~kg} / \mathrm{m}^{2} \cdot \mathrm{s}\right), \\
j_{o}(\text { Darcy }) \approx 2.3 \times 10^{-12} \mathrm{~kg} /\left(\mathrm{m}^{2} \cdot \mathrm{s}\right) .
\end{gathered}
$$

Here the flow due to chemical osmosis is about 125 times larger than the Darcian flow and is directed against the gradient of solute concentration.
If each partial flow of solute in (3) is regarded as a vector quantity, it is seen that the flow from ultrafilitration is directed against the advective flow and that the chemical osmotic flow is directed against the diffusive flow. The various contributions to the total flow of solute are

$$
\begin{gathered}
j_{s}(\text { advection }) \approx 9.3 \times 10^{-16} \mathrm{~kg} /\left(\mathrm{m}^{2} \cdot \mathrm{s}\right), \\
j_{s}(\text { ultrafitiation }) \approx-8.2 \times 10^{-16} \mathrm{~kg} /\left(\mathrm{m}^{2} \cdot \mathrm{s}\right), \\
j_{s}(\text { total along } \nabla h) \approx 1.1 \times 10^{-16} \mathrm{~kg} /\left(\mathrm{m}^{2} \cdot \mathrm{s}\right),
\end{gathered}
$$

and

$$
\begin{gathered}
j_{s}(\text { chemical osmosis }) \approx-1.2 \times 10^{-13} \mathrm{~kg} /\left(\mathrm{m}^{2} \cdot \mathrm{s}\right), \\
j_{s}(\text { diffuion }) \approx 2.4 \times 10^{-13} \mathrm{~kg} /\left(\mathrm{m}^{2} \cdot \mathrm{s}\right) \\
j_{s}\left(\text { total along } \nabla \rho_{s}\right)
\end{gathered}
$$

The bentonite used in this example is semipermeable and has characteristically low Darcian permeability and mass diffusivity; thus the thermodynamically coupled processes, chemical osmosis and ultrafiltration, are significant contributors to flows of water and solute. In the case of solute transport ultrafiltration reduces flow along the hydraulic gradient by about an order of magnitude relative to the value that would be calculated from Darcy's law alone, and chemical osmosis greatly reduces flow along the concentration gradient $r$-lative to the value that would be calculated from Fic: : law alone.

Thermal and Fickian Diffusion in Permeable Material

In granular, noncohesive materials that are permeable to solutes, the coefficients $L_{v g}$ and $L_{v s}$ may be vanishingly small relative to other coeffivients in the phenomenological equations, leaving thermal diffusion as the only (potentially) significant thermodynamically coupled transport process. If a hydraulic gradient is absent in such a permeable material, (3) can be written as

$$
j_{s} \approx-D_{s s}\left(\rho_{s} s_{s} \nabla T+\nabla \rho_{s}\right),
$$

where $D_{s s}$ the "diffusion coefficient," and $s_{s}$, the "Sorêt coefficient," are defined by 


$$
D_{s s}=\frac{L_{s s}}{\rho_{s}} \frac{R T}{M_{s}} \text { and } s_{s}=\frac{L_{s q}}{L_{s s}} \frac{M_{s}}{R T^{2}}
$$

From (4), the ratio of the magnitude of solute flow produced by thermal diffusion to that produced by Fickian diffucion is

$$
\frac{\left.j_{s} \text { (chermal diffusion }\right)}{\left.j_{s} \text { (Fickian diffusion }\right)}=\frac{s_{s}|\nabla T|}{\left|\nabla \rho_{s} / \rho_{s}\right|} .
$$

Recent measurements of thermal diffusion of solutes in a system containing saturated, $3-\mu \mathrm{m}$ alumina have provided values of $s$ of about $4 \times$ $10^{-3} / \mathrm{K}$ (Thornton and Seyfried, 1933). Using our assumed repository conditions and the reported value of $s_{s}$, the ratio given by (5) is 0.08 .

\section{CONCLUSIONS}

The thermodynamics of irreversible processes provides phenomenological equations that encompass a broader range of physical phenomena than is accessible through consileration of simultaneous, direct processes (Fourier's law, Darcy's law, Fick's law) alone.

The approximate calculations presented here indicate that thermodynamically coupled transport processes can contribute to the mass flows in nea-field regions of nuclear waste repositories. Backfills containing large proportions of clay can act as semipermeable membranes and produce mass flows by thermal osmosis, chemical osmosis, and ultrafiltration that are significant relative to Darcian and Fickian flows. Predictions of water and solute flows through semipermeable materials based only on

\section{RADON-222 IN GROUNDWATER OF THE LONG VALLEY CALDERA, CALIFORNIA}

\author{
H.A. Wollenberg, S. Flexser, A.R. Smith, \\ and D.F. Mositi
}

Continuing seismic activity, together with measurable uplif, (Savage and Clark, 1982) and the appearance of new fumaroles suggest that magma may be circulating at depths as shallow as $5 \mathrm{~km}$ beneath the Long Valley caldera. It is possible that the contents of elements dissolved in hot and cold
Darcy's law and Fick's law could be seriously in error in magnitude and possibly also in direction, the latter depending on the relative alignments of driving forces. Thermal diffusion can be active also in such backfills, but would be the only significant coupled process expected in permeable backfills and in porous or fractured geologic media.

\section{REFERENCES}

Carnahan, C.L., 1983. Thermodynamic coupling of heat and matter flows in near-field regions of. nuclear waste repositories. Presented at Annual Meeting, Materials Research Society, Symposium D: Scientific Basis for Nuclear Waste Management, Boston, November 14-17, 1983.

Hodges, F.N., 1980. Repository conditions. In M.J. Smith (principal author), Engineered Barrier Development for a Nuclear Waste Repository in Basalt: An Integration of Current Knowledge. Richland, Washington, Rockwell Hanford Operations, RHO-BWI-ST-7, p. 2-105-2-133.

Letey, J., and Kemper, W.D., 1969. Movement of water and salt through a clay-water system: Experimental verification of Onsager reciprocal relation. Soil Science Society of America Proceedings, v. 33, p. 25-39.

Srivastava, R.C., and Avasthi, P.K., 1975. Nonequilibrium thermodynamics of thermo-osmosis of water through kaolinite. Journal of Hydrology, v. 24, p. $111-120$.

Thornton, E.C., and Seyfried, W.E., 1983. Thermodiffusional transport in pelagic clay: Implications for nuclear waste disposal in geological media. Science, v. 220, p. 1156-1158.

springs in and near the caldera may reflect variations in the subsurface thermal-hydrologic regime as magma is injected, and they may also reflect the resulting structural changes in the earth's crust. The content of the radioactive gas ${ }^{222} \mathrm{Rn}$ dissolved in the water has been demonstrated to vary as stresses in a region change in advance of or in response to seismic activity (Smith et al., 1976; King, 1978). Changes in other chemical constituents of groundwater have also been interpreted as possible seismic precursors. For these reasons, samples from hot, warm, and cold springs are being collected periodically in the Long Valley area to furnish a baseline of data on water chemistry for comparison with results of future resamplings. A continuous monitoring sys- 
tem has been installed to measure the radon contents of groundwater.

The water sources sampled include many of those sampled and analyzed over the past decade by members of the USGS (Sorey et al., 1978). Sampling was done at orifices where boiling is occurring as well as at those of intermediate and cold temperatures (the spring locations are shown in Fig. 1). Specific conductance, temperature, $\mathrm{pH}$, and radioactivity were measured at the time of sampling. Samples for laboratory gamma counting for ${ }^{222} \mathrm{Rn}$ were obtained by filling two $500-\mathrm{ml}$ thick-walled Nalgene bottles, then capping them and taping them tightly. Samples were also collected for analyses of major and trace elements by filtering water into two polyethylene bottles at each site, one acidified to preserve the dissolved silica contents in solution. Unfiltered samples were also taken in small glass bottles for oxygen and hydrogen isotope analyses.

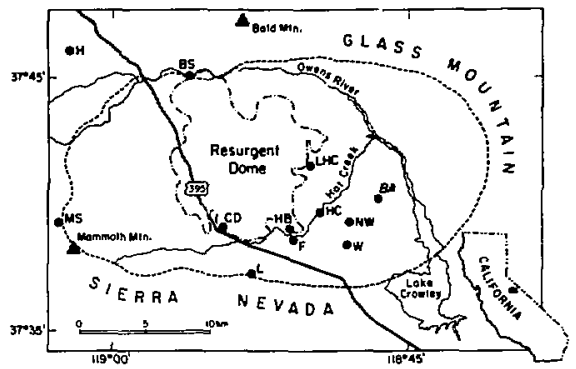

Figure 1. Outline map of the Long Valley caldera (after Sorey et al., 1978), showing locations of the springs sampled. The broken line represents the border of the caldera; the dash-dot line outlines the outcrops of the resurgent dome. Letter symbols are keyed to Table 1. [XBL 8439683]

Table 1. Radon contents and other parameters of spring wat: $r$.

\begin{tabular}{|c|c|c|c|c|c|c|c|}
\hline Location & $\begin{array}{l}\text { Rock } \\
\text { type }^{\mathrm{a}}\end{array}$ & Name & $\mathrm{pCi} / \mathrm{L}$ & $\begin{array}{l}\text { No. of } \\
\text { analyses }\end{array}$ & $\begin{array}{l}\text { Specific cond. } \\
(\mu \mathrm{ohms} / \mathrm{cm})\end{array}$ & $\mathrm{pH}$ & $\begin{array}{c}\text { Temp. } \\
\left({ }^{\circ} \mathrm{C}\right)\end{array}$ \\
\hline BA & al & Big Alkali Lake & 225 & 1 & $1700-1750$ & $6.3-6.5$ & 59 \\
\hline BS & $\mathrm{b}$ & Big Spring & $601 \pm 67$ & 4 & $175-180$ & $6.5-6.7$ & 10 \\
\hline $\mathrm{CD}$ & $\mathbf{r}$ & Casa Diablo & 23 & 1 & $1400-1425$ & $7.6-7.8$ & 94 \\
\hline $\mathbf{F}$ & $\mathrm{b}$ & $\begin{array}{l}\text { Fish Hatchery } \\
\text { "CD" pool } \\
\text { "H-2\&3" pool }\end{array}$ & $\begin{array}{l}789 \pm 170 \\
664 \pm 50\end{array}$ & $\begin{array}{l}4 \\
3\end{array}$ & $210-220$ & $6.6-6.7$ & 13 \\
\hline $\mathbf{H}$ & g & Hartley Spring & 2490 & 1 & $40-60$ & $6.5-6.7$ & 2 \\
\hline HB & $\mathbf{r}$ & Hot Bubbling Pool & 42 & 1 & $1800-1850$ & $7.5-7.7$ & 63 \\
\hline $\mathbf{H C}$ & $\mathbf{r}$ & Hot Creek George & 16 & 2 & $1700-1750$ & $8.1-8.2$ & 90 \\
\hline $\mathbf{L}$ & g & Laurel Spring & $2428 \pm 135$ & 20 & $100-110$ & $8.5-8.6$ & 11 \\
\hline LHC & r,l & Little Hot Creek & 319 & 2 & & & \\
\hline MS & m & Minaret Summit & 1430 & 1 & $210-220$ & $6.6-6.7$ & 3 \\
\hline NW & $\mathbf{r}, \mathbf{1}$ & North of Whitmore & 200 & 1 & $1400-1450$ & $7.4-7.6$ & 53 \\
\hline $\mathbf{w}$ & $r, a l$ & Whitmore & 395 & 1 & $625-650$ & $7.0-7.2$ & 51 \\
\hline
\end{tabular}

${ }^{2}$ Rock types encompassing spring systems: $a l=$ alluvium, $b=$ basalt, $\mathrm{g}=$ granitic rock, 1 = lake bed deposits, $\boldsymbol{m}=$ metavolcanic rock, $\mathrm{I}=$ rhyolite. 
Fieid measurement data and results of laboratory measurements of the ${ }^{222} \mathrm{Rn}$ content of the samples are listed in Table 1.

Examination of Table 1 indicates a wide range of radon contents, generally corresponding inversely to the temperatures and specific conductances measured at the springs. Gamma-ray spectral analyses of rock samples indicate that radon contents of spring water also correlate roughly with the uranium content ${ }^{\frac{1}{5}}$ of the encompassing rocks. The highest radon contents are in the dilute cold springs, Hartley and Laurel (from granite) and Minaret Summit (from metavolcanic rock), while the waters sampled at the hottest springs, Casa Diablo, Hot Creek, and Hot Bubbling Pool, arc very low in radon. Springs of intermediate temperature in Long Valley proper, Big Alkali Lake, Whitmore, and north of Whitmore, have easily measureable radon contents, as do the cool springs emanating from basalt at the fish hatchery and Big Spring.

A continuous monitoring system was installed in one of the springs emanating from a basalt flow in the south moat area to provide hourly records of $R \mathbf{n}$ content. A NaI(Tl) detector is submerged in a pool so that the water surrounding the detector serves as a shield against gamma rays, except those originating in the water. We have observed that the gamma radioactivity measured in this manner is due almost exclusively to the $\mathrm{Rn}$ content of the water. Initial operation of this system in the late summmer of 1983 shows diumal variations that correspond to earth tidal fiuctuations, as illustrated in Fig. 2. This correspondence is also illustrated by the frequency distribution diagram (Fig. 3), which shows the 12and 24-hour periodicities characteristic of earth tides.

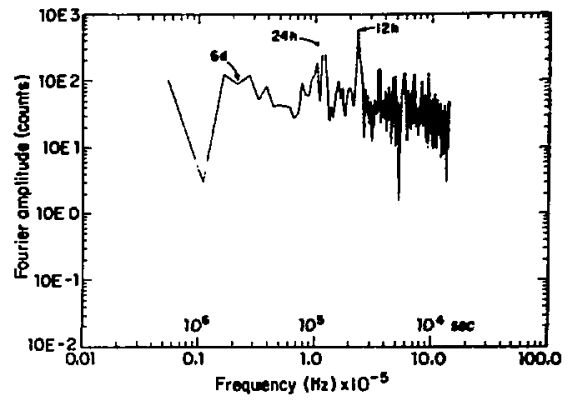

Figure 3. Frequency distribution of radon in spring water. |XBL-8312-2409|

The concordance with the earth tidal response of the rocks encompassing the hydrologic system feeding the basalt spring indicates that radon variations are sensitive indicators of crustal stress and that this tidal response makes up a large part of the background upon which the effects of magma injection and seismicity will be superimposed.

These, and more recent results are the subject of a paper by Wollenberg et al., (1984).

\section{REFERENCES}

King, C.-Y., 1978. Radon emanation in tectonically active areas. In T. Gesell and W. Lowder (eds.), Natural Radiation Environment III. Washington, D.C., Department of Energy, CONF. 780422 , p. $175-183$.

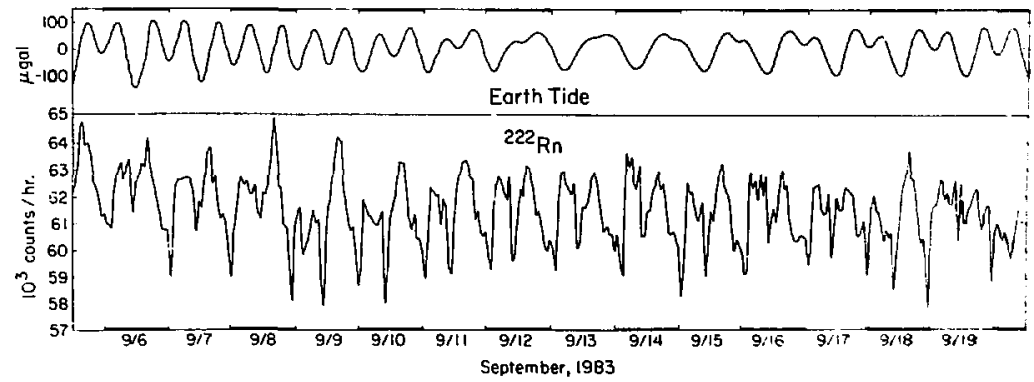

Figure 2. Variation of gamma radioactivity with time from continuous monitoring of the fish halchery spring water. Earth tidal variations also plotled are calculated for Long Vallev's position and altitude and are expressed in gravitational visits. $|X B L-8312-2410|$ 
Savage, J.C., and Clark, M.M., 1982. Magmatic resurgence in Long Valley caldera, California: Possible cause of the 1980 Mammoth Iakes earthquakes. Science, v. 217, p. 531-533.

Smith, A.R., Bowman, H.R., Mosier, D.F., Asaro, F., Wollenberg, H.A., and King, C.-Y., 1976. Investigation of radon-222 in subsurface waters as an earthquake predictor. IEEE Transactions on Nuclear Science, v. NS-23, no. 1, p. 694-698.

\section{ROCK-FLUID REACTIONS IN ENHANCED OIL RECOVERY}

\section{W.H. Somerton}

Cores from a number of California oil-producing formations, that are potential candidates for enhanced oil recovery (EOR) opcrations have been tested, to evaluate the effects of disturbing fluid/rock equilibrium by injecting EOR fluids. The fluid-flow capacity of reservoir rocks may be severely affected by introduction of ioreign fluids. In addition, loss of injected chemicals to the rock by adsorption, ion exchange, mineral dissolution, and reactions with formation brines may minimize the effectiveness of the EOR fluid injection.

Many of the cores tested did show serious reduction in fluid-flow capacity upon changing the ionic content or concentration of the injected fluid. This reduction is attributed to mobilization of and subsequent plugging by formation fines. Ultrafine mineral particles have been noted in the effluent from fluidflow tests. Some cores from two southern San Joaquin Valley fields (Kern Front and MidwaySunset) showed anomalous behavior in this regard. These cores showed a reduction of the effluent $\mathrm{pH}$ to as low as 4.0 when neutral $\mathrm{NaCl}$ solution was injected. This $\mathrm{pH}$ reduction, which iasts for many pore volumes (PV) of injection, is attributed to $\mathrm{H}^{+} / \mathrm{Na}^{+}$exchange, releasing $\mathrm{H}^{+}$into the flowing fluid. These cores, although mineratogically similar to other cores from the same formation and, in one case, from the same well, show no reduction in permeability regardless of the nature of the injected fluid.

Screening tests have been developed to identify those cores that do not show permeability reduction to freshwater injection. Similar tests have also been developed to demonstrate the effectiveness of stabil-
Sorey, M.L., Lewis, R.E., and Olmsted, F.H., 1978. The hydrothermal system of Long Valley caldera, Californiz. USGS T:ofessiorid Paper 1044-A.

Wollenberg, H.A., Smith, A.R., Mosier, D.F., Flexser, S., and Clark, M., 1984. Radon-222 in groundwater of the Long Valley caldera, Californ i. Lawrence Berke]cy Laboratory, LBL-17636.

izing agents (dilute $\mathrm{AlCl}_{3}$ solution in this work) in reducing the susceptibility of cores to permeability reduction.

\section{FLUID FLOW TESTS}

Results of fluid flow tests on Midway-Sunset cores are shown in Figs. 1 to 4 . Figure 1 shows large and irreversible reduction in permeability when the core is contacted by deionized water. Effluent analyses for this core show sharp spikes in the $\mathrm{Si}$ and $\mathrm{Al}$ concentrations just one PV after injection of deionized water (Fig. 2). These spikes are due to the passage of ultrafine mineral particles through the core, the larger of which plugged the core and caused a serious loss in permeability. The initial loss in permeability is caused by core stabilization and probably some clay swelling due to cistionic exchange of $\mathrm{Ca}^{2+}$ for $\mathrm{Na}^{+}$.

Figure 3 shows results of tests on a MidwaySunset core from the same producing formation. In this case there was no significant loss in permeability upon introduction of deionized water. Figure 4 shows no spikes in the $\mathrm{Si}$ and $\mathrm{Al}$ concentrations of

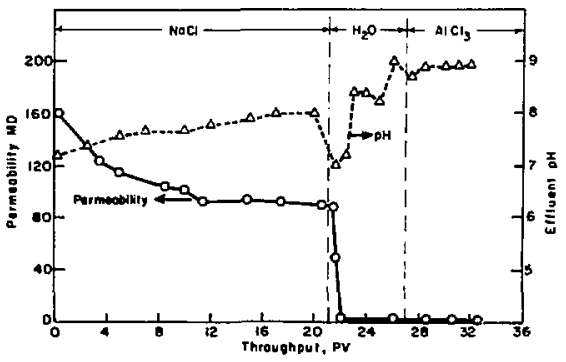

Figure 1. Results of now tests on Midway-Sunset core MS1-2. [XBL 841-319] 


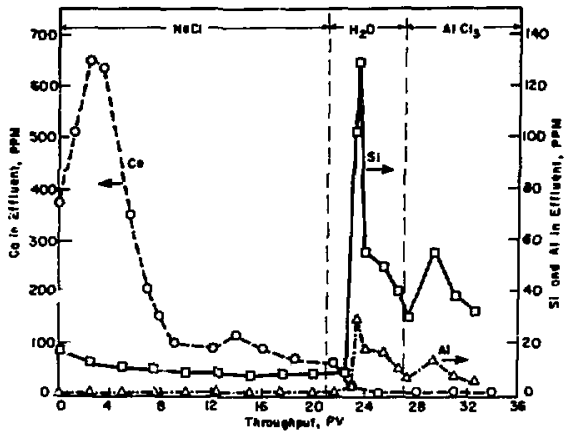

Figure 2. Effluent analysis for Midway-Sunset core MS1-2. [XBL841-318]

the effluent. indicating no transport of fines through the core. These two findings are consistent. An unusual feature of this core is the low $\mathrm{pH}$ of the effluent during $\mathrm{NaCl}$ injection. This is attributed to cationic exchange of $\mathrm{Na}^{+}$for $\mathrm{H}^{+}$, releasing $\mathrm{H}^{+}$to the flowing fluid and causing reduction in $\mathrm{pH}$ of the efflueni.

\section{SCREENING TESTS}

Flow behavior of Midway-Sunset cores noted above could have been predicted by simple jar tests. An amount of the core material is placed in a flask containing dilute $\mathrm{NaCl}$ solution. The $\mathrm{pH}$ of the solu-

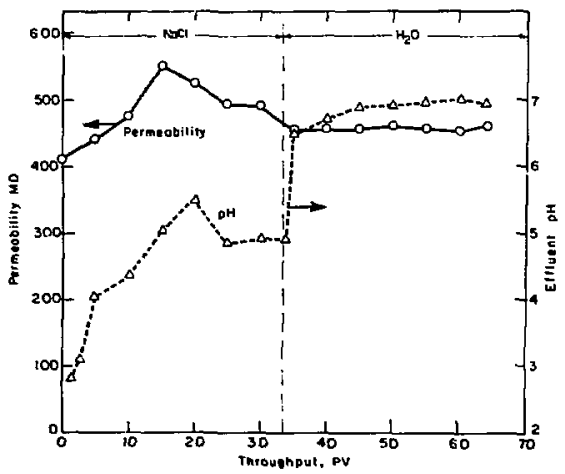

Figure 3. Results of flow tests on Midway-Sunset core MS2-2. [XBL 841-317]

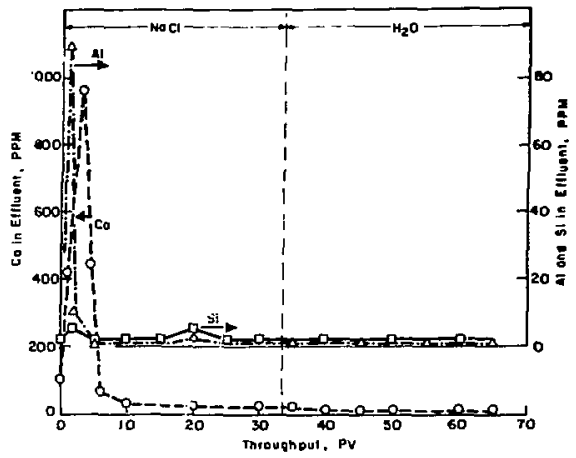

Figure 4. Effluent analysis for Midway-Sunset core MS2-2. |XBL 841-316]

tion was measured at various times, yielding the results in Table 1. The MS1 core showed no $\mathrm{pH}$ response, as was found in the flow test, but the MS2 core showed significant $\mathrm{pH}$ lowering, indicating again that cationic exchange was occurring.

The above behavior has been noted in other southern San Joaquin Valley cores. Kern Front cores from the same formation show the same two types of behavior.

\section{CONCLUSIONS}

From the present work, some general conclusions can be reached that are not necessarily unique but do confirm previous findings. Further work is needed to test the validity of some of the screening tests presented here.

Tabie 1. pH values from jar tests, Midway-Sunset cores. .

\begin{tabular}{rll}
$\begin{array}{c}\text { Time } \\
\text { (hours) }\end{array}$ & MS1 & MS2 \\
\hline 0 & 7.0 & 6.0 \\
20 & 6.9 & 5.1 \\
44 & 7.2 & 4.8 \\
68 & 7.3 & 4.2 \\
92 & 7.3 & 4.2
\end{tabular}


1. Many California oil-producing formations show serious reduction in fluid-flow capacity whęn the ionic content or concentration of the flowing fluid is changed. This is particularly true when fresh water is injected into these formations.

2. Loss of fluid-flow capacity is due primarily to the mobilization and subsequent deposition of mineral fines in pore necks. This is partly confirmed by the temporary restoration of part of the flow capacity upon reversal of flow direction. Moreover, ultrafine mineral particles in the effluent have been detected by atomic adsorption spectroscopy (AAS) analyses as spikes appearing about one PV after injection of fresh water. From the relative concentrations of $\mathrm{Si}$ and $\mathrm{Al}$ detected, it may be concluded that both finely divided aluminum silicates and quartz are being transported through the core, the larger particles of which cause the plugging and attendant loss in flow capacity.

3. Some southern San Joaquin Valley cores show no loss in flow capacity upon changing the injection fluid to fresh water. These cores are characterized by unexpected behavior in that when contacted by dilute $\mathrm{NaCl}$ solutions, the $\mathrm{pH}$ of the solution quickly drops to values below 4.0. This is attributed to $\mathrm{Na}^{+} / \mathrm{H}^{+}$exchange, releasing $\mathrm{H}^{+}$to the solution and reducing its $\mathrm{pH}$ value. The relationship of this $\mathrm{pH}$ response to inhibiting the loss of fluidflow capacity has not yet been established. However, jar tests may be used to identify cores that show pH response, and presumably these cores will not suffer permeability damage by freshwater injection.

\section{REFERENCE}

Somerton, W.H., Chen, S.P., Schuh, M.J., and Yuen, J.P., 1983. Screening tests to evaluate formation damage in EOR operations. Presented at the Sixth Symposium on Formation Damage Control, February 13-14, 1984. Bakersfield, California. SPE- 12500 .

\section{FIGH-RESOLUTION MAGIC- ANGLE SPINNING NMR SPECTROSCOPY OF ALUMINOSILICATE MINERALS
AND GLASSES}

\section{J.B. Murdock, J.F. Stebbins, I.S.E. Carmichael, and A. Pines}

Nuclear magnetic resonance (NMR) is a radiofrequency spectroscopic technique in which a nucleus with nonzero spin is used as a sensitive probe of its local electronic environment. The most useful parameter obtained is the chemical shielding (or chennical shift), which characterizes the degree to whicl: nearby electrons shield the probe nucleus from a large external magnetic field. Nuclei in different bonding sites or environments are shielded differently and hence absorb energy at different frequencies.

In a polycrystalline solid, however, spectral features are broadened by the orientational anisotropy of chemical shielding and by interactions between nuclei. By rapidly spinning a powdered sample at the inagic angle, $54.7^{\circ}$, relative to the externat magnetic field, this broadening averages to zero. One can obtain well-resolved spectra of isotropic chemical shifts, similar to NMR spectra commonly obtained from liquids. As such, magic-anglespinning (MAS) NMR is a powerful new means for studying structure and short-range order in minerals and glasses.

The magnetically active nuclei we have investigated are sodium-23 and aluminum-27 (both $100 \%$ isotopically abundant) and silicon-29 (4.7\% abundant). Silicon is thus harder to detect than aluminum or sodium, but offers two advantages: Its spectra are intrinsically better resolved and are more easily interpretable. A large number of crystalline silicates have been analyzed in the past 4 years, and a good correlation has been found between silicon chemical shifts (measured in ppm relative to tetramethylsilane) and the degree of silicate polymerization ranging from isolated $\mathrm{SiO}_{4}{ }^{4-}$ units to threedimensional framework structures (Lippmaa et al., 1980). The silicon chemical shift is also affected by the number of adjacent aluminate tetrahedra, becoming less negative as the number of next-nearestneighbor aluminums increases from zero to four (Klinowski et al., 1981; Lippmaa et al., 1981). These shift ranges are reasonably well separated, often providing an unambiguous structural assignment.

Silicon shifts have also been correlated with average bond lengths (Higgins and Woessner, 1982), 
bond angles (Smith and Blackwell, 1983), and bond strengths (Smith et al., 1982). These empirical relationships, determined using well-characterized сгystalline samples, can then be used in the study of disordered or glassy materials.

Our own research in the past year has focused on two areas: the nature of silicon-aluminum ordering in feldspars and the extent of silicate polymerization in glasses, particularly as a function of the cations present.

\section{SILICON-ALUMINUM ORDERING IN ALBITE}

Albite $\left(\mathrm{NaAlSi}_{3} \mathrm{O}_{8}\right.$ ) is a triclinic alkali feldspar with four crystallographically distinct tetrahedral sites. In low albite, the most common naturally occurring form, silicons occupy three of these sitcs and aluminum exclusively occupies the fourth. Prolonged heating of albite close to its melting point of $1100^{\circ} \mathrm{C}$ is known to cause disordering of the tetrahedral cations; from $\mathrm{x}$-ray analysis, it is believed that about a month of heating will distribute the aluminum cations nearly equally among the four sites (Winter et al., 1979).

Using silicon-29 MAS NMR, we have been able for the first time to monitor the extent of short-range order during this process. Samples of a very pure Franciscan vein albite were heated at $1080^{\circ} \mathrm{C}$ for various lengths of time from 1 to $56 \mathrm{~d}$. Four of the resulting NMR spectra are shown in Fig, 1, each scaled to the same overall height. Initially one sees three sharp peaks of roughly equal intensity corresponding to the three distinct silicon sites. These peaks remain (and slightly broaden) as the albite is heated, contributing approximately $40 \%$ of the total ${ }^{29} \mathrm{Si}$ spectral intensity even after $56 \mathrm{~d}$. This suggests that the thermal disordering process occurs heterogeneously. Small additional features in the broad background associated with disordered regions of the 56-d sample can be assigned to silicons with zero to three aluminate neighbors, but the relative intensity of these peaks differs from the pattern expected for a purely random distribution of silicons and aluminums. In particular, the measured intensities are consistent with Loewenstein's rule (Loewenstein, 1954), which predicts an absence of Al-O-AI linkages. Such details of local ordering can contribute to a better understanding of mineral thermodynamics. Relaxation properties of the ordered and disordered albite phases differ as well: ${ }^{29} \mathrm{Si}$ nuclei in a disordered environment return to equilibrium more rapidly after the application of a radio frequency pulse.

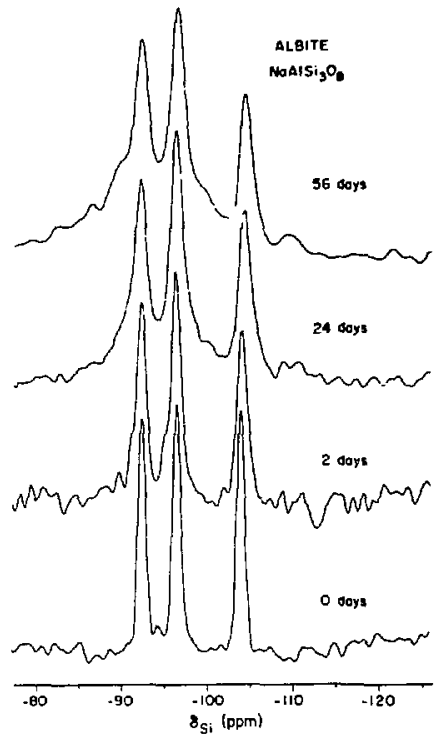

Figure 1. Silicon-29 MAS NMR spectra of albite samples heated at $1080^{\circ} \mathrm{C}$ for various lengths of time. The spinning rate was approximately $3 \mathrm{kHz}$. [XBL $83 / 1-4485$ ]

As noted earlier, one can also use ${ }^{23} \mathrm{Na}$ and ${ }^{27} \mathrm{Al}$ NMR to investigate feldspar structure. Unlike ${ }^{29} \mathrm{Si}$, these nuclei are nonspherical and hence interact with local electric field gradients. In a powdered or polycrystalline sample, this interaction gives rise to a characteristic broadening that cannot be removed by magic-angle spinning. Some representative ${ }^{23} \mathrm{Na}$ spectra are shown in Fig. 2. The line shape in low Franciscan vein albite is consistent with electric field gradient (EFG) parameters determined from singlecrystal NMR measurements (Brun et al., 1960). |A new technique, Fourier transform nuclear quadrupole resonance by pulsed field cycling (Bielecki et al., 1984), can also be used to obtain EFG values in polycrystalline minerals.] The MAS spectrum of a disordered Amelia albite has the same chemical shift but is narrower, suggesting that either a greater degree of sodium motion or a more symmetric distribution of surrounding silicons and aluminums has reduced the average electric field gradients experienced by the sodiums. The same is true in albite glass. 


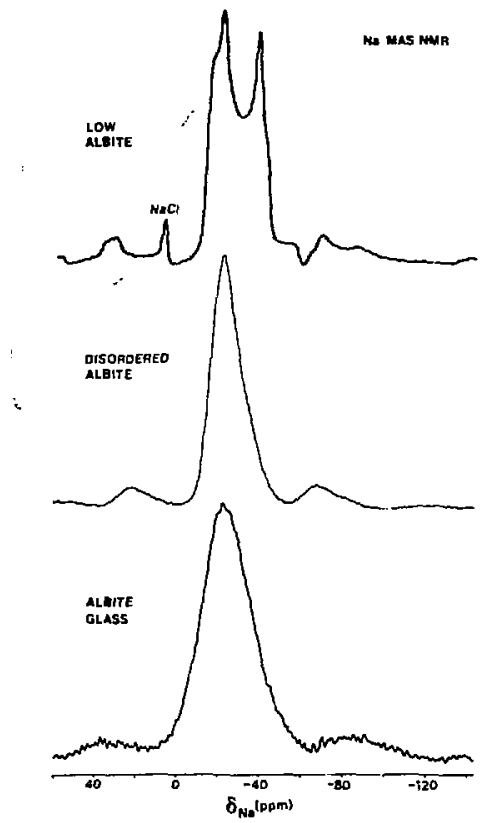

Figure 2. Sodium-23 MAS NMR spectra of ordered and disordered crystalline albite and albite glass, measured in $\mathrm{ppm}$ relative to aqueous $\mathrm{NaCl}$. The small peak in the top spectrum is due to a few grains of solid $\mathrm{NaCl}$ added as an intemal frequency standard. The small features flanking each of the center peaks are spinning sidebands, which appear when the chemical shift anisotropy expressed in $\mathrm{Hz}$ is greater than the spinning frequency. [XBL 8311-4484]

\section{STRUCTURE OF SILICATE GLASSES}

The structure of glasses is of interest in that they are a frozen approximation of silicate liquids, for which a detailed knowledge of silicate speciation is needed to better understand magmatic processes. A typical ${ }^{29} \mathrm{Si}$ MAS spectrum, that of albite glass, is featured in Fig. 3. The broad peak reflects a wide range of silicon sites, characterized in part by both longer and shorter $\mathrm{Si}-\mathrm{O}$ bond lengths than those found in crystalline albite. (The line width for the glass is $19.2 \mathrm{ppm}$ versus $1.4 \mathrm{ppm}$ for each of the three crystalline peaks.) The spectrum of albite glass is nonetheless quite distinct from that of nepheline glass (NaAlSiO $)$. In albite glass, with a 3:1 siliconto-aluminum ratio, each silicon most likely has one

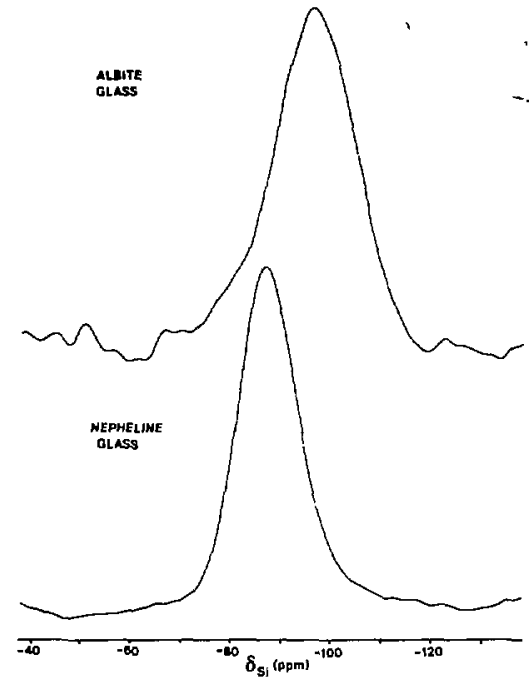

Figure 3. Silicon-29 MAS NMR spectra of albite $\left(\mathrm{NaAlSi}_{3} \mathrm{O}_{8}\right)$ anis nepheline $\left(\mathrm{NaAlSiO}_{4}\right)$ glasses. Full widths at has. height are 19.2 and $13.9 \mathrm{ppm}$, respectively. [XBL 835-9908]

or two aluminate neighbors. In nepheline glass, with a 1:1 silicon-to-aluminum ratio, each silicon is most likely surrounded by four aluminate tetrahedra.

We have recently determined the range of silicun environments in a series of disilicate glasses with various network-modifying cations present $\left(\mathrm{K}^{+}, \mathrm{Na}^{+}\right.$, $\mathrm{Li}^{+}, \mathrm{Sr}^{2+}$, and $\mathrm{Ba}^{2+}$ ). For these glasses, the following equilibrium has been proposed. (Virgo et al., 1980):

$$
2 \mathrm{Si}_{2} \mathrm{O}_{5}^{2-} \rightarrow \mathrm{SiO}_{3}^{2-}+\mathrm{SiO}_{2},
$$

where $\mathrm{Si}_{2} \mathrm{O}_{5}{ }^{2-}, \mathrm{SiO}_{3}{ }^{2-}$, and $\mathrm{SiO}_{2}$ refer to structural units in sheet-like, chain-like, and three-dimensional framework environments, respectively. More generally, one can write

$$
2 \mathrm{Q}_{3} \rightarrow \mathrm{Q}_{2}+\mathrm{Q}_{4} \text {, }
$$

where $Q_{n}$ refers to a silicate tetrahedron with $n$ bridging oxygens (Lippmaa et al., 1980).

Intuitively, one would expect that an increase in the polarizing power of the charge-balancing cations (defined as the ionic charge divided by the ionic radius) would tend to disrupt the silicate network, 
shifting these equilibria to the right. Our NMR results support this simple hypothesis. Silicon-29 MA.S line widths, which reflent the range of silicate environments, increase as follows:

$$
\mathrm{K} \simeq \mathrm{Na}<\mathrm{Li} \simeq \mathrm{Ba}<\mathrm{Sr},
$$

matching the increase in cation polarizing power. We have observed a similar relationship for the metasilicate glasses $\mathrm{CaSiO}_{3}, \mathrm{CaMgSi}_{2} \mathrm{O}_{6}$, and $\mathrm{MgSiO}_{3}$, for $\because$ hir.h an increase in cation polarizing power would be expected to shift an equilibrium such as

$$
2 Q_{2} \rightarrow Q_{1}+Q_{3}
$$

to the right. These findings are in general agreement with results obtained by $\operatorname{SiK} \beta$ x-ray emission spectroscopy (de Jong et al., 1981) and Raman spectroscopy (Matson et al., 1983).

We have also explored the effect of quenching at high pressure on glass structure. Because highpressure quenched meits are prepared in small amounts, we must use ${ }^{23} \mathrm{Na}$ or ${ }^{27} \mathrm{Al} \mathrm{NMR}$, nuclei which provide better sensitivity than ${ }^{29} \mathrm{Si}$. The sodium NMR spectra of two albite glasses-one quenched at 1 bar, the other quenched at $30 \mathrm{kbar}-$ are essentially the same, suggesting that at least the sodium environments are similar in the two glasses.

Finally, we have used ${ }^{29} \mathrm{Si}$ MAS NMR to examine a series of iron-pour silitic lava glasses as a function of silica content and to compare several sodium gallosilicate glasses with the corresponding aluminosilicates.

\section{REFERENCES}

Bielecki, A., Murdoch, J.B., Weitekamp, D.P., Zax. D.B., Zilm, K.W., Zimmermann, H., and Pines, A., 1984. Fourier transform pure nuclear quadrupo: resonance by pulsed field cycling. Journal of Chenical Physics, v. 80, p. 2232-2234.

Brun, E., Hafner, S., and Hartmann, P., 1960. Elektrische quadrupolwechselwirkungen in einigen feldspaten. Helvetica Physica Acta, v. 33, p. $495-496$.

de Jong, B.H.W.S., Keefer, K.D., Brown, G.E., and Taylor, C.M., 1981. Polymerization of silicate and aluminate tetrahedra in glasses. melts, and aqueous solutions. III. Local silicon environments and internal nucleation in silicate glasses. Geochimica et Cosmochimica Acta, r. 45, p. 1291-1308.

Higgine, J.B., and Woessner. D.E., $1982 .{ }^{29} \mathrm{Si},{ }^{27} \mathrm{Al}$, and ${ }^{23} \mathrm{Na}$ NMR spectra of framework silicates. EOS, Transactions of the American Geophysicai Union, v. 63, p. 1139.

Klinowski, J., Thomas, J.M., Fyfe, C.A., and Hartman, J.S., 1981. Applications of magic-anglespinning silicon-29 nuclear magnetic resonance. Evidence for two different kinds of siliconaluminum ordering in zeolitic structures. Journal of Physical Chemistry, v. 85. p. 2590-2594.

Lippmaa, E., Magi, M., Samoson, A., Engelhardt, G., and Grimmer, A.-R., 1980. Structural studies of silicates by solid-state high-resolution ${ }^{29} \mathrm{Si}$ NMR. Journal of the American Chemical Society, v. 102, p. 4889-4893.

Lippmaa, E., Magi, M., Samoso1, A., Tarmak, M., and Engelhardt, G., 198L. Investigation of the structure of zeolites by solid-state highresolution ${ }^{29} \mathrm{Si}$ NMR spectroscopy. Journal of the American Chemical Society, v. 103. p. $4992-4996$.

Loewenstein, W., 1954. The distribution of aluminum in the tetrahedra of silicates and aluminates. American Mineralogist, v. 39, p. 92-96.

Matson, D.W., Sharma, S.K., and Philpotts, J.A., 1983. The structure of high-silica alkali-silicate glasses. A Raman spectroseopic investigation. Journal of Non-Crystalline Solids, v. 58, p. 323-352.

Smith, J.V., and Blackwell, C.S., 1983. Nuclear magnetic resonance of silica polymorphs. Nature, $v$. 303, p. 223-225.

Smith, K.A., Kinsey, R.A., Oldfield, E., Kirkpatrick, R.J., and Hower, J., 1982. Characterization of silicates and aluminosilicates by ${ }^{29}$ silicon NMR. EOS, Transactions of the American Geophysical Union, v. 63, p. 1139-1140.

Virgo, D., Mysen, B.O. and Kushiro, I., 1980. Anionic constitution of 1-atmosphere silicate melts: Implications for the structure of igneous melts. Science, v. 208, p. 137/-1373.

Winter, J.K., Okamura, F.P., and Ghose, S., 1979. A high-temperature structural study of high albite, monalbite, and the analbite $\rightarrow$ monalbite phase transition. American Mineralogist, v, 64, p. 409-423. 


\section{GEOCHEMISTRY}

Much of the geochemical research summarized here focuses upon the behavior of subsurface aqueous fluids at high temperatures and pressures. Such fluits are capable of dissolving and transporting considerable quantities of materiat and of interacting physically with the rocks through which they pass.

Concern about radioactive waste disposa!-and the security of the waste both chemically and physically-has led to extensive modeling of the repository environment and to the analysis of ion migration and the chemical interaction of fluids flowing through rocks. In addition, natural analogs of a radionuclide repository have been studied, as well as the movement of meteoric water through old mill tailings dumps containing uranium. Such studies also involve maintaining a data base on aqueous radionuclide species and on the surface chemistry of minerals likely to be used in repository bartiers.

Experimental results obtained at low-temperatures have allowed predictions of solid properties to made for regions that are presently experimentally inaccessible. Another research group has continued to contribute data on the macroscopic thermodynamic properties of silicate liquids and glasses while investigating some of their structural properties. 


\section{APPENDIXES}

\section{APPENDIX A: ABSTRACTS OF JOURNAL ARTICLES}

Ayatoliahi, M.S., Noorisinad, J., and Witherspoon, P.A., 1983

Siress-fuid fon analysis of fractured rocks

Journal of Engineering Mechanics, v. 109, no. 1 (LBL-1 1430)

A variational principle is used in conjunction with the finite-element method to sol- - the nonlinear coupled field enuations of an initial boundary value privien for flow in deformable fraclured rock masses. This results in a powerful method for modeling coupled stress and fluid now behavior of rocks. Stress and deformation history for both solid and lıquid phases, for arbitrary boundary conditions, and within complex geomeirical configuration, can be determined. Direct application can be made to fluid flow problems in hydrauiically fractured resirvoirs and naturally fractured rocks.

Benson, S.M., and Bodvarsson, G.S., 1983

Analysis of nonisothermal injection and fallofr rests

Society of Petroleum En; neers Joumal, in press (LBL-14270)

Injection tests are commonly performed in geothermal wells to obtain reservoir and well data. Most of the tests are analyzed assuming that either the injected fluid is the same temperature as the reservoir fluid or that a slationary boundary separates the reservoir regions of Jifferent Ruid properties. In general, neither of these assumptions is appropriate for the analysis of nonisothermal injection tests. Pressure transients in response to nonisothermal injection are controlled, to a great exicnt by the temperaturedependent fluid properties, viscosity and density. In this study, numerically simulated pressure transients during anjection and falloff tests are analyzed to develop methods for oblaining the conret: oermeability-tr ickness of the reservoir and the skin factor for the well.

The results show that to correclly analyze pressure transients governed by a moving thermal front the values used for the fluid properties must correspond to the temperature of the injected fluid. On the other hand, for pressure falloff tests and for injection tests conducted in a well cooled by previous injection or drilling the physical properties of the in situ reservoir huids must be used. It is also shown that the application of conventional isothermal methods for calsulating skin values from injection and falloff data will give eroneaus results. A new method is presented for calculating skin values from injection and falloff data that accuratcly corrects for nonisothermal effects. A number of detrited examples are given that illustraic the suggested method of analysis. The tech1.; ue is applied to the analysis of injection test dita from a well lucated in the East Mesa gcol' - mal field in southem Californin.

Bodvarsson, G.S., Benson, S.M.. Sigurdsson, O., Stefansson, V., and Eliasson, E. T., 1983

The Krafla geothermal ficld. Iceland: I. Analysis of well test data

Water Resources Research, in press (LBL-16203)

Extensive modeling studies of the Kralla geothermal field in leeland an presented in a series of four papers. This first paper describes the geological settings of the field and the ansiysis of well tes: tata

The geothermal system at Kafla is yery complex. with a single-phase liquid resen vit overlying a two-phase reservoir. The reserveir rocks are voleantc with sequences of basalt flous, hylcilastics, and intrusions. The fluid now in the reservoir is fracture-dominated.

Considerable pressure transient dala from injection tests have been gathered from the Krafla wells. These data are analyzed to yield the transmissivity distribution in the reservoir system. As the data are complicated by various factors (nelibore effects, nonisothermal effects, tho-phase now, and fractured rocks) the applicability of conventional well test analyxis methods is questionable. We have developed a methodolozy to analyze injection lests for such systems. The ssults obtained show that the transmissivity of the Krafla reservoir is low, averaging 2 Darcy-meters (D. m). The average trensmissivity of most commercially suocessful colhermal fields is an order of magnitude higher.
Bodvarsson, G.D., Pruess, K., Stefansson, V.., and Eliassun, E.T., 1983

The Krafla geothermal field, Iceland: 2 . The natural slatc of the system Water Resources Research, in press (LBL-16204)

A model of the natural state of the Krafla reservoir system in leeland has been devrloped. The model consists of a vertical cross section which includes reservoirs in both old and new well fields. The physical processes considered inciude mass transport, conductive and convective heat transfer and boiling, and condensation. Natural heat losses to surface manifestations (springs) are also included. The model matches very well all relevant data from the Krana field. The natural fow of hor fuids through the reservoirs is estimated as approximately $20 \mathrm{~kg} / \mathrm{s}$. Stcam escaping to surface springs constitules the bulk of the heat losses in the area modeled. Conduclive heat losses through the caprock are approximalely $1.0 \mathrm{~W} / \mathrm{m}^{2}$, and heat

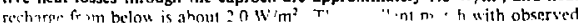
data gives confidence in the iransmissivity batule infered from the injeclion Iest data.

Bodvarsson, G.S., Prucss, K., Stelansson, V., and Elizsson, E.T., 1983

The Krafla Geothermal Field. Iceland: 3. The' generating capacity of the field

Water Resources Research, in press (1.BL-16205)

This paper presents analyticai and numericas ztudies of the gencrating capacity of the Krafla field. A lumped-parameter model is developed. which tan be used to oblain rough estimates of the generating capacily of a geothermal field based on the size of the wellfield, the average formation porosity, and the amount of recharge to the system. The model is apnlied. to the olo wellficld at Krafla. More sophisticated calculations of the gencrating capacity of thic Krafla field are performed using distributedparameler models. Two-dimensional areal medels of the different reservoir regions at Krafle are developed and their generating capacitie: in $\mathrm{MW}$. years evaluated. The results obtained indicate that the old weilfield can sustain steam production of $30 \mathrm{MW}$, for 30 years. years. The estimated power potential of the new wellfield is $20 \mathrm{MW}$, years. To obtair the required steam production scveral additional wells may be drilled in the old and new wellfields.

Bowman, H., Stross, F.H., Asaro, F., Hay, R.L., Heiztr. R.F., and Michel, H.V. 1983

The northern Colossus of Menton: Vew slonts

Archacomeiry, in press (LBL-15633)

Chemical and petrographic studies of the two 720-10n "Colossi of Meinnon" located near Luxor in Upper EGYpt, and of quartzite quarries (near Cairo, Aswan. Silsila, and Silwa (EI Massaic)), indicate that the rear pedesal blocks of the northern statue (as well as the reconstructed upper torso) were quarricd at Aswan. about $210 \mathrm{~km}$ south of Luxor. The large front pedestal block of this statue, like its lower torso and the southem stalue and pedeski: were quaried it Cairo sbout $676 \mathrm{~km}$ north of Luxor. These studies suggest that the rear pedestal blocks of the norhem statue were part of the same reconstruction projecl which was undertaken by the Roman cmperor Septimius Severus around 200 A.D.

The statues are tilted toward each other, a feature that at leust to some degree had already been observed in antiquity. The tilting of the front par of the norhem pedestal at present is considerably more pronounced than that of the rear pedestal blocks. Our studies, including an analysis of measurements of the angles of tilc, furnher suggest that the rear par of the lower torso of the northem statue was moved when the statue was reconstrucled. Then a foundation was buill of quarzite blocks from Aswan, and the lower rear torso placed on the new foundation and aligned with the front torso. The upper part of the statue was also Isconstructed with blocks from Aswan, and the added weight was centered roughly over the new quartzite foundation blocks. This study suggests that a substantial part of the present-day tilting of the nonhern statue oxcurred prior to its reconsinuction. 
Bune, AL., and Radke, CJ., 1983

Divalent ion exchange with alkali

Society of Petroleum Engineers Joumal, v. 23, A ugust (LBL-17723)

Exchane of hardness ions is important in EOR with chemical additivities. In both micellor/polymer and coustic flooding processes, multivalent ions released from rock surkaces san interect wilh anionic suffactants, rendering them preferentially oil soluble and/or insolubte in water. Because hurdness cations are speringly soluble and precipitate in alkaline solutions. such solutions may be more efticient as surfactant-flood preflushes than are softened brines. Muhivalent ion precipitotion may also occur in alkaline waterflooding To permit design of such processes, this paper presents a chromatossaphic theory for simulaneous ion exchange with precipitation of divalent ions.

Theoretical effluent histories and concentration profiles are presented for the cases of finite pulses and continuous injection of hydroxide ions into linear cores. Complete enpture of the insoluble sait particles is assumed. Results are given for the case of insiantaneous equilibration of the solution with the precipitate, as well as for the case of complete nonequilibrium, in which the solid precipitate does not redissolve. These two physical extremes predict field performance and laboratory resuits, respectively. Data for Berea sandstore and an argillaceous sand compare favorably with the proposed theory.

Tire efficiency of alkaline preflushing is shown to depend on the exchange isotherm, initial divalent loading of the rock, injected $\mathrm{pH}$ and salinity, the solubility product of the precipitated salt, and pulse size. The effect of pulse size on complete equilibrium removal of hardness jons is reduced efficiency with increasing size untis a critical volume approximating continuous injection is reached. Increasing injected pH and salinity pro. vides a more favorable response.

The theoretical model, when applied to field conditions, predicts redis. solution zones that have not been previously recognized because solution residence times in laboratory columns are too short. Calculations show that precipitate redissolution by the low-pH solutions following alkaline pulses may introduce high concentrations of calcium behind the preflush where interference with micellar or poiymer solutions is likely. These results sug. gest that reservoir preflush design from laboratory tests, while possible, must be made carefully.

\section{Buscheck, T.A., Doughty, C., and Tsang, C.F., 1983}

Prediction and analysis of a field experiment on a multilayered aquifer thermal energy slorage system with sirong buovancy fow

Water Resources Rescarch, v. 19, no. 5, p. 1307-1315 (LBL-15037)

The results of the first two cycles of the seasonal aquifer thermal energy storage field experinient conducted by Auburn University near Mobile, Alabama, in $1981-1982$ (injection temperatures $59^{\circ} \mathrm{C}$ and $82^{\circ} \mathrm{C}$ ) were predicted by numerical modeling before their conclusion with good accuracy. Subsequent comparison of experimental and calculated results provided important insight into areas of model improvement and alternative experimental designs. Key factors influencing energy recovery appear to be aquifer heterogeneity (layering) ar i strong buoyancy flow in the aquifer. An optimization study based on second-cycle conditions calculated a series of scenarios, each using a different injection and production scheme, to study possible ways to improve energy recovery. The results of this optimization study were used by fubum University in the design of the third-cycle experiment.

\section{Camahan, C.L, and Remer, J.S., 1983}

Nonequilibrium and equilibrium sorption with a linear sorption isorherm during mass transport rhrough an infinite, porous medium: Some analytical solutions

Journal of Hydrology, in press (LBL-1 300S)

Analyjical solutions have been developed for the three-dimensional, axisymmetric problem of solute transpon in a steady field of groundwater now with nonequilibrium mass transfer of a radioactive :jpecies between fluid and solid phases and with uneņual longitudinal and tateral hydrodymomic dispersion. Interphase mass transfer is described by a first-order rate expression. Solutions are presented also for the case of equilibrium disivitution of solute between fluid and solid phases. Three types of release from a point source were considered: instantaneous release of a finite mass of solute, continuous release at an exponentially decaying rate, and release for a finite period of time. Computational results for point-source solutions show the expected variation of sorptive retardation effects progressing from the case of no sorption, through cases of nonequilibrium sorption, to the case of equilibrium sopption. The point-source solvtions can be isteesied over finite regions of space to provide analytical solutions for rctions of solute release having finite spatial extents and various exometrical siapes. thus considerably extending the utility of the point-source solutions.

Chambrí, P.L, Lung, H.C., and Piglord. T.H., 1983

Mass Iransport from waste emplaced in backfill and rock

Transactions of the American Nuclear Society, v. 44, p. 1[2-[13 (LBL16414)

Previous studies of radionuclide transpon through backfilt have considered only delays for dissolved radionuclides to penetrate into infinite backfill. However, a steady-state rate of transpon into surroundine mock can result if concentrations at the inner surface of the backfill are governed by soluhility, as is considered in the present paper. Eartier publications have presented analytical solutions for the rate of dissolution of radionuclide species from solid waste emplaced in porous rock, as limited by solubility at the waste surface and by diffusion and convection into the groundwater. Here we extend those analyses to include the effect of a linite backfill layer between the waste and rock.

Chan, T., Hood, M., and Board, M., 1982

Rock properties ond their effect on thermally induced displacements and stresses

Journal of Energy Resources Technolosy, v. 104, p. 384-388 (LBL16428)

A discussion is given of the importance of material properties in the finite-element calculations for thermally induced displacements and stresses resultirg from a heating experiment in an in-situ granitic rock, at Stripa, Sweden. Comparisons are made between field measurements and finite element method calculations using (i) temperature independent, (ii) temperature dependent thermal and thermomcchanical properties, and (iii) in-situ and laboratory measurements for Young's modulus. The cilculations of rock displacements are influenced predominantly by the temperature dependence of the thermal expansion coefficient, whereas the dominant factor affecting predictions or rock stress is the in-situ modulus.

Clarke, J., Gamble, T.D., Goubau, W.M., Koch, R.H., and Miracky, R.F., 1983

Remole-reference magnetolellurics: Equipment and procedures

Geophysical Prospecting, v. 31, p. $149-170$ (LBL-1 3559)

During the past 3 years, major advances in the magnetotelluric technique have improved the quality of magnetotelturic data to the point where random errors in the impedance 1ensor and tipper are gencrally smaller than the uncerainty in their interpretation. The major factor in this improvement has been the introduction of the remote-reierence technique, although the use of ultrasensitive magnetometers and minicomputers for in-ficld data processing has alsc been important. Afier a review of the remote-reference technique, this paper describes the equipment and procedures used for remote-reference magnetotellurics by the authors. Magnetometers using d.c. Superconducting Quantum Interference Devices typically have - sensitivity of $10^{-14} \mathrm{~T} \mathrm{~Hz}^{-1 / 2}$, a dynamic ange of $10^{7}$ in a $1 \mathrm{~Hz}$ band width, and a slewing rate of $3 \times 10^{-5} \mathrm{~T} \mathrm{~s}^{-1}$ at $10 \mathrm{kHz}$. The electric field measurements use conventional Cu-CuSO, elcctrodes. The remote magnetic reference signals are transmitted to the base station using FM analos telemetry. The data are collected and processed by a minicomputer based on an LSI-1I microprosessor; the essential results-for example, the apparent resistivities and the tipper components, with their probable errors-are available in the field. Practical details are given of the handling of supereonducting devices, low temperature cryostats and liquid helium in the field. Various spurious noise souress are mentioned, and techniques for minimizing their eflects are described.

deLima, M.C.P., and Pitzer, K.S., 1983

Thermodyratizites of saturated aqueous solutions including mixiures of $\mathrm{NaCl} . \mathrm{KCl}$. and $\mathrm{CsCl}$

Joumal of Solution Chemisıry, v. 12, p. 171-186 (LEL-15301)

The activity coefficients for saturated aqueous $\mathrm{KCl}, \mathrm{CsCl}$ and mixtures of $\mathrm{NaCl}$ with each of these electrolytes are calculated from solution properties using the ion interaction model as well as from the solubility. The akreernent between the two sets of results for both single and mixed electrolyles is, in general, good when it is considered that the saturated solution molalities are oflen much higher than those whose properties were used in 
the evaluation of the ion inveraction parameters. Also, for pure $\mathrm{KCT}(* \mathrm{q})$ the a teemenl is eood up to $300^{\circ} \mathrm{C}$, an extrapolation $50^{\circ} \mathrm{C}$ above the range of dath on which the equations were based.

delimu, M.C.P, and Pitzer, K.S., 1983

Thermodynamics of saturated electrolyre mixtures of $\mathrm{NaCl}$ with $\mathrm{Na}$ SO. and wish $\mathrm{MgCl}$

Joumal of Solution Chemistry, v. 12, no. 3, p. 187-199 (LBL-15323)

The ion-interaction equation is used to alculate the mean activity coef ficients for the saturaled aqueous mixtures, $\mathrm{NaCl}+\mathrm{Na}, \mathrm{SO}$, and $\mathrm{NaCl}+$ $\mathrm{M}_{\mathrm{E}} \mathrm{C}_{2}$ A comparison between these values and those obtained from solubility shows a tood aereement over a wide temperature range as well as at high ionic strengths for both mixed systems.

Feng. R., and McEvilly, T.V. 1983

Interpretation of seismic reflection profiling data for the structure of the San Andreas faut zone

Bulletin of the Seismological Society of America, v. 73, no. 6, p. $1710-1720$ (LBL-16563)

A seismic reflection profile crossing the San Andreas fault zone in central Califomia was conducted in 1978. Resulis are complicated by the extreme lateral heterogeneity and low velocities in the fault zone. Othe evidence for severe lateral velocity change across the faul zone lies in hypocenter bias and nodal plane distortion for earthquakes on the fault. Conventional interpretation and processing methods for reflection data are hard-pressed in this situation. Using the inverse raw method of May and Covey (1981), with an initial model derived from a variety of data and the impedance contrasts inferred from the preserved amplitude stacked section, an iterative inversion process yields a velocity model which, while clearly nonunique, is consistent with the various lines of evidence on the fault zone structure.

Frink, D, and Sundaram, P.N., 1983

Regression analysis of experimental dala using desktop computers Geotcehnical Tining Joumal, in press (LBL-14485)

This paper describes regression analysis of certain types of experimental dats obzained from geotechnical testing. By suitable transformation, nonlinear equations may be converted into linear equations if appropriate weighting factors are applied to the data before performing the regression analysis. Sample problems in BASIC which can be used with desktop computers are described. Typical examples from soil mechanics and rock mechanics are included.

Ghiorso, M.S, Carmichael, I.S.E., Rivers, M.L., and Sack, R.O., 1983

The Gibbs free energy of mixing of natural sillcate liquids; an expanded regular solution opproximation for the calculation of magmatic intensive yariables

Contributions to Mineralogy and Petrology, v. 84, p. 107-145 (LBL17257)

The compositions of liquids coexisting with experimentally grown crystals of olivine, plagioclase, clinopyronene, orthopyroxene, leucite, spinel, rbombohedral oxide, melilite and potassium feldspar are used to define, throuth mass action expressions of liquid/solid equilibrium, compositional derivatives of the Gibbs free energy of mixing of naturally occurring silicate liquids as a function of temperature pressure and the fugacily of oxygen. The available experimentai data describe these derivatives over a range of compositions which indudes basic magmas. Therefore, for silicate liquids in this composition rage, the topolony of the Gibbs free energy of mixing can be approximated trom experimental determinations of its derivatives. The majority of the existing thermodynamic data on the liquid phase is consistent with the application of retular solution theory to model the free eneryy of mixing. Suriclly symmetric, temperature and pressure indepen. dent, repular solution intenction parameters are calibrated from this phase equilibrium data using regression techniques which have their basis in inverse theory. These rectniques enerate numerically stable interaction parameters which incorporate inter-variabie correlation and account for experimental uncertainty. The reguly solution model fils the available data on anhydrous silicate liquids to within the accuacy of the thermodynamic datubase ( \pm 550 cals). Extensions to refular solution theory allow water solubility in more silica rich liquids to be modeled somewhat less accuralely $( \pm 750$ cals $)$
The topoloty of the excess free energy of mixing surfuce is strondy asymmetric, possessing a single multicomponent suddk point which defines a spinodal lorus. Given this prediction of a multicomponent spinode a mathematical procedure based upon minimisation of Gibbs free enery of mixine is developed for the calculation of the compositions of ecexistin: immiscible liquids. Predieted binodal compositions substantially aeree with elemental liquid/liquid partitioning trends observed in lavas. Calculations surest that an immiscible domr, in temperature-composi?: on spece, intersects the liquidus field of the magma type tholeiite. Immiscible phenomena are predieted at sub-liquids temperatures for the bulk compositions of more basic or alkatic lavas, but are absem in more siliceous rock types for temperatures of the metasiable liquid down to $900 \mathrm{~K}$.

The regular sulution model is used in four petrological appliations The first concerns a prediction of the binary olivine-liquid phase diagram. The calculated geometry exhibits a minimum near $\mathrm{Fa}_{2}$, which though not in accord with experimental resulis on the pseudobinary system, compares quite favorsbly with olivine-liquid phase equilihria interpreted from rhyolites, namely that the olivise phenocrysts of rhyoljtes are more iron rich than their coexisting liquids. The second petrological exariple concerns estimating the depth of the suurce regions of several basic lavas whose compositions cover a range from ugandite to basaltic andesite. The third application is a calculation of the saluration temperatures and compositions of plagioclase and olivine in four experimental basalic liquids and a prediction of the liquidus temperatures and first phenocryst compositions of the Thingmuli lava series of Eastern Iceland. Lastly, enthalpies of fusion are computed for a variety of stoichiometric compounds of geologic interesi. These demonstrate good agreement with calorimetrically measured quantities.

Goldstein, N.E., Wilt, M.J., and Corrigan, F.J., 1984

Analysis of the Nuevo Ledn magnetic anomaly and its possible relation to the Cerro Prieto magmatic-hydrothermat system

Geothermics, v. 13, no. 1/2, p. 3-1/ (LBL-14900)

The broad dipolar magnetic anomaly whose positive peak is centered near Ejido Nuevo León, some $5 \mathrm{~km}$ east of the Cerro Prieto I power plant, has long been suspected to have a genetic relationship to the thermal source of the Cerro Prieto geothermal system. This suspicion was reinforted after several deep geothermal wells, drilled to depths of $3-3.5 \mathrm{~km}$ over the anomaly, intersected an apparent dike-sill complex consisting mainly of diabase but with minor rhyodacite. A delailed fit of the observed magnetic field to a compuler model indicates that the source may be approximated by a tabular block $4 \times 6 \mathrm{~km}$ in area, $3.7 \mathrm{~km}$ in depth, $2.3 \mathrm{~km}$ thick, and dipping slightly to the north. Mafic dike chips from one well, NL-1, were analyzed by means of electron microprobe analyses which showed them to contain a titanomagenetite that is paramagnetic at in situ temperature conditions. As the dike mineralugy does not account for the magnetic anomaly, the magnetic source is believed to be a deeper, magnetite-rich assemblage of peridotite-gabbro plutons. The suite of igneous rocks was probably emplaced at a shallow depth in response to crystal extension and thinning brought on by an echelon strike-slip faulting. The bottom of the masnetic source body, ai an estimated depth of $6 \mathrm{~km}$, is presumed to be at or near that of the Curie isotherm $\left(575^{\circ} \mathrm{C}\right)$ for magnetite, the principal ferromag. netic mineral in periodotitic-geophysical data. In particular, earhquake data suggest dike injection is oceurring at depths of $6-11 \mathrm{~km}$ in an area bereath the magnetic souree. Thus, it is possible that heat for the geothermal field is being maintained by continuing crystal and magnetic aclivity.

Goubau, W.M., Maxion, F.M., Koch, R.H., and Clarke J., 1983

Noise correlation lengths in remote reference magnetotellurics

Geophysics, in press (LBL-15484)

In remote reference magnetotellurics one uses a reference magretometer, located typically several kilometers from the magnetotelluric site, to abtsin estimates of the jmpedance tensor that are unbiased by random nojse. Measurements have been made of the correlation length of this noise by using a third SQUID magnetometer as a local reference. The impedance tensor was determined as a function of the separation between this magnetorneter and the magnetorelluric site, and compared with the tensor obtuined simulaneously using the remote reference. This study yielded the surprising result that a separation of as litte as $200 \mathrm{~m}$ was sufficient 10 obtuin an unbiased estimate of the impedance tensor. The magnitude of the magnetic noise was determined with two difftrent techniques, one involving the impedance tensor, and the other involving a magnetic unsfer tensor. The second method produced a subsiantially lower estimate of the 
magnetic noive at periods above about 1 second. It is concluded that a component of the noise arises from the non-plane wave nature of the masnetic and electric fields.

Huimson, B., and Doe, T.W., 1983

Sioue of strets, permeability and fractures in the Precambrian of Northern Illinois

Journal of Geophysical Research, v. 8B, no. B9, p. 7355-7371 (LBL 16463)

In situ fracture loaxing. permeability teats, and stress measurements have been conducled in UPH 3, a 1600-m-deep hole drilled into the Precambrian enanitic basement of northern Illinois Two major fracture zones are revealed, which cannot be discemed in UPH 2 a similarly deep hole about $1 \mathrm{~km}$ away. The segments of the UPH 3 core that were oriented indicated the existence of three sets of subvenical joints stibing at $N 55^{\circ} \mathrm{E}$. $\mathrm{N} 40^{\circ} \mathrm{W}$ and $\mathrm{E}-\mathrm{W}$. These sets correspond to surface and shallow borehole joint directions in the Precambrian and Paleozoic rock of southern Wisconsin as well as cther areas of the Midwest. The permeability values in UPH 3 display an overal! reduction with depth from about $10^{-1}$ darcy at $700 \mathrm{~m}$ to $10^{-1}-10^{-9}$ darcy at $1600 \mathrm{~m}$. Permeability is highest in the zones of greatest fracturing, one of which occurs near the top of the granite and is probably related to fractures which were formed when the granite was at the surface in lace Paleozoic times. Permeability reduction with measurements in UPH 3 reveal a compressional stress field with the largest stress horizontal and oriented at $\mathrm{N}^{4} \mathrm{8}^{\circ} \mathrm{E}\left( \pm 30^{\circ}\right)$. Based on linear regression of 13 test results in the depth range of 686- $1449 \mathrm{~m}$, the greatest horizontal stress has a maznitude of $[20.5+(0.023 \times$ depth $(\mathrm{m})]] \mathrm{MPa}$ The least horizontal compression has a value of $[8.7+(0.019 \times$ depth $(m))] \mathrm{MPa}$. The vertical stress, based on density measuremenis, is given by $\mid-1.3+(0.026 \times$ depth (m))| MPa. Both magniludes and directions support previous results in the tectonically stable Great Lakes refion of the midcontinent. However, a $m_{t}-4.4$ earthquake did oceur in 1972 some $90 \mathrm{~km}$ south of UPH 3, at a depth of $13 \mathrm{~km}$. The focal mechanism solution revealed strike slip motion with the pressure axis horizontal and trending northeast, in accord with our measured stress directions and relative magnitudes but not predicted from a frictional sliding criterion based on Byerlee's law.

Hajnal, Z, Stauffer, M.R., King, M.S., Wallis, P.F., Wang, H.F., and Jones, L.E.A., 1983

Seismic characteristics of a Precambrian pluton and ins adjacemt racks Geophysics, v. 48, no. 5, p. 569-581 (LBL-1 7662)

Surface, borchole, and jaboratory acoustic measurements all confim the existence of a near-surface low-velocity zone in metavoleanic, metasedimentary, and plutonic rocks of the Flin Flon tegion of Canada. This zone is caused by a high frequency of open fractures and extends from the surface to depths of between 5 and $44 \mathrm{~m}$, although occasional open fractures exiend to at least $60 \mathrm{~m}$.

There is a linear decrease in sonic velocity with increasing frequency of large fractures; the details, however, vary for different sites, depending upon several geologic features including rock type and nonfracture porosity. Laboratory sonic data indicate very low microcrack densities in the volcanic and plutonic rocks.

Synthetic seismograms derived from sonic log information from the center of the granitic pluton have been compared with a nearby multifold seismic profite. This shows that the near-surface low-velocity zone attenuates most of the high-frequency seismic energy. However, the remaining low-frequency portion of the seismic spectrum can be used to map some fentures of the pluton.

Halfman, S.E, Lippmann, M. J., Zelwer, R., and Howad, J.H., 1984

Geologic interpontotion of geothermal fuid movement in Cerro Prieto Field, Baja California Mexico

American Association of Petroleum Geologists Bulletin, v. 68, no. 1, p. 18-30 (LBL-15201)

A zeologic madel of the liquid-dominated Cerro Prieto geothermal Field was developed on the brsis of geophysical and lithologic well loes. The direction of subsurface gothermal fluid flow before exploitation, and the seologic features controlling this movement were determined by integratiog well completion and downhole temperature data with the geologic model.

The data show that fluid (possibly heated by intrusive dikes found in wells ofilled in the eastern area of the field) enters the system from une eas: at depths $>10,000 \mathrm{ft}(>3,050 \mathrm{~m})$. The fluid moves westwand through sandrione beds and rises to shallow depths through fault zones and permeable sandy paps in the overlying shale layers. The shale lavers provide local cap rocks. Some of the hot fluid reaches the suriace west of the field. in an area characterized by numerous geothermal manifestations. The rey of the fuid mixes with colder ground walers west of the geolherma! resource.

Javandel, l., and Witherspoon, P.A., 1983

Analytical solution of a partially penetrating well in a mo-lajer aquifer Water Resources Rescarch, v. 19, no. 2 p. 567-568 (LBL-9479)

The behavior of a layered aquifer under the influence of a pumping well is a problem of interest in the fields of tydrogeolozy. zeothermal engineering, and petroleum engineering in this paper we shall present an analytic solution to the problem of transient flow to a parially penearating well that is open in either layer of finite thickness in a two-layered system. Crossflow is permitted at the inierface between the two layers. Closed form solutions have been obtained which can exsily be evaluated numerically. Simplified forms of the solutions for small and large values of time have been developed from the main solution. It has siso been shown that the solution reduces to the case of single layer partial penetration once we allow the permeability of the nonperforated layer to vanish. The approach here is to stant with the problem when the pumping well is open only is the top layer. A second solution is also developed when the well is partially penetrating only in the lower layer. A numerical evaluation of these solutions and the application of the results to the interpretation of field problems will be presented in a subsequent paper.

\section{Kanehiro, B.Y., 1983}

Reply to "Comment" on 'A note on the meaning of storage coefficjent' by J.D. Bredehoeft and R.L. Cooley

Water Resources Research, v. 19, no. 6, p. 1635 (LBL-17519)

In thcir comment on our paper (Narasimhan and Kanehiro, 1980), Bredehoef and Cooley slate that "Jacob [1950] demonstrated that the iransient flow equation is quite general and does indeed appiy to what Narasimhan and Kanehiro describe as undrained conditions." In general, undrained conditions refer to conditions where fluid is neniner introduced nor removed from the system. Under such consirainis, changes in pore pressure can only result from changes in the total stress on the system. The form of the transient flow equation that is commonly cited in the groundwater literaiure does not include consideration of changes in total stress. While there may be some latitude in the interpretation of the transient flow equation and an element of judgment may be involved, it would seem that the suggestion of Bredehoef and Cooley that such a term is implicitly included in the flow equation places a considerable burden on the reader. Indeed, it would appear that the derivation of their equation (12), which considers changes in total stress, involves an extension of the commonly cited fonn of the equation. Thus, for the purposes of our original paper, there appears to be reasonable justification for concluding that the commonly cited form of the transient flow equation does not explicitly apply to undrained conditious because it does not explicitly consider changes in total stress.

The transient flow equation presented by Bredehoef and Cooley as their equation (12) appears to be applicable to drained as well as undrained conditions. In particular, for constant total stress, as assumed in Jacob's derivation for drained conditions, the equation simplifies to the standard transient how equation. For undrained conditjons, where the divengence term goes to zero, the equation simplifies to a commonly accepted expression for the change in pressure with respect to change in total stress.

Keely, J.F., and Tseng, C.F., 1983

Velocily plots and caplure zones of pumping centers for ground water investigations

Ground Water, v. 21, no. 6, p. 701-714 (LBL-16101)

Nonpumping monitoring wells are commonly installed and sampled to delineate the extenl of a contaminant plume and its chemical character. Samples from municipal and private pumping wells are frequently collected during ground water contamination investigations as well. Pumping wells are also employed for remedial actions.

To properly interpret sampling data from monitoring and pumping wells and to estimate their potential elfectiveness in remedial actions, it is important 10 clearly define the geometry of that portion of the aquifer con- 
tributine wher to the well (the capiure zons). Velocity distribution plots by manul and compuletized methods are illusinied and shown to be simple and of reasonable accuracy.

Kjlinc, A, Carmichael, L.S.E, Rivers, M.L, and Sack, R.O., 1983

The ferric-ferrous ratio of natural silicate liquids equilibrated in air Contributions to Mineralogy and Petrolony, v. B3, p. 136-140

Resulis of chemical analyes of alesses produced in 46 meltins experiments in air at $1,350^{\circ} \mathrm{C}$ and $1,450^{\circ} \mathrm{C}$ on rocks ranging in composition from nephelinite to thyolite have been combined with other published data to obtain an empirical equation relating $\ln \left(X / \mathrm{m}_{0} / X\right.$ fo $)$ to $T$, In $f_{0}$ and buik composition. The whole set of experimental dela naze over $1,200-1,450^{\circ} \mathrm{C}$ and oxyen fusacities of $10^{-\rightarrow \infty}$ to $10^{-0, n}$ bars, respectively. The standard errors of temperature and $\log _{10} f_{0}$ predictions from this equation are $52^{\circ} \mathrm{C}$ and 0.5 units, respectively, for 186 experiments.

\section{King. M.S. 1983}

Static and dynamic elastic properties of igneous and metamorphic rocks from the Canadian Shield

Intercational Joumal of Rock Mechanics and Mining Sciences and Geomechanics Abstracts, v. 20, p. 237-241 (LBL-1 5823)

Techniques involving the propagation of acoustic or seismic waves are becoming of increasing importance in the characterization of rock masses in mineral exploration, mining operations, site investigations and other engineering applications.

As part of a number of research studies in the Canadian Shield associated with the stability of underground mine openings (King et al., 1978), seismic reflection surveys (Hajnal et al., 1983), and the proposed use of a tunnel-boring machine (TBM) for developing mine headings, a long-term laboratory rock mechanies program has been conducted to determine the static and dynamic elastic propertics of samples of igneous and metamorphic rocks from the Canadian Shield. This paper reports the results of 174 measurements of static elastic modulus $(E)$ and 152 measurements of uniaxial compressive strength $(C)$ for these rocks as a function of dynamic elastic modulus $\left(E_{0}\right)$.

\section{King, M.S., 1984}

Elastic-wave velocities in quartz monzonile at different levels of woter saturation

International Joumal of Rock Mechanics and Mining Sciences and Geomechanics Abstracts, v. 21, in press (LBL-1 6665)

During a comprehensive rock mechenics and geophysics research programme associated with large-scale heater tests at a subsurface depth of 340 $m$ in an abandoned iron-ore mine in central Sweden, it became evident that the interpretation of cross-hole acoustic surveys required a knowledge of compressional $(V)$ and shear-wave $(V)$ velocities in the granitic rock under different conditions of stress and water saturation. A number of workers have reponed significant increases in $V$ at low stress levels when dry rocks containing porosity predominanty in the form of cracks were salurated with water. However, they also reponed litule change in $V$, for rocks of this type with changes in water saturation.

Repored here are the results of laboratory ultrasonic velocity measurements made on quarz monzonite core specimens recovered from two of the vertical boreholes surrounding one of the heaters referred to above. The specimens were tested first in their fully water-saturated sare and then oven-dried. The dry specimens were then stored in an atmosphere of $100 \%$ relative humidity and tested periodically over a period of 3-1/2 months, by which time they had reached almost full saturation.

It is concluded that rocks containing porosity predominately in the form of cracks and maintained in an environment of $100 \%$ relative humidity for periods of time of the order of months can become more than $90 \%$ water saturated. Small inereases in moisture content of dry rocks containing appreciable crack porosity result in substantial increases in $V$ and $V$. The Kuster and Toksoz model provides a convenient framework within which to study the variation of elastic wave velocities in partly and fully watersaturated low porosily rocks.
Kine MS. 1984

The influence of claysized panicles in seismic velocity for Canodian Arctic permafrost

Canadian Joumal of Earth Sciences, v. 21, p. 19-24 (LBL-16174)

Seismic wave velocities have been measured on 37 unconsolidated permafrost sumples as a function of kemperature in the ranec $-16^{\circ}$ to $+5^{\circ} \mathrm{C}$. The smples, tuken from a number of locations in the Canadian Anctic Islands, the Beaufor Sex and the Mackenzie River, were tightly sealed immediately upon recovery in several layers of polyethylene film and mainbined in their frozen state during storates specimen preparation, and until they were lested under controlled-environmental conditions. Durine testine the specimens were subjected to a conslant hydrostatic confinine stress of $0.35 \mathrm{MP}$ (50 psi) under drained conditions. At no stage was a devirtoric stress applied to the permafrost specimens. The fraction of clay-sized paricles in the test specimens varied from almost zero to approximately $65 \%$. At temperatures above $0^{\circ} \mathrm{C}$ the compressional-wave velocity was observed to be a function only of porosity, with virtually no dependence upon the fraction of chay-sized perticles. Calculation of the fractional ice content of the permafrost pore space from the Kuster and Toksonz theory showed that for a given fraction of clay-sized particles the ice content increases with an increase in porosity. It is concluded that the compressional-wave velocity for unconsolidated permafrost from the Canadien Arctic is a function of the water-filled porosity, irrespective of the original porosity, clay content, or temperature.

Kobayashi, R., Pigford, T.H., and Chambré, P.L., 1983

Solubility-limited dispersive transport through porous media

Transactions of the American Nuclear Society, Y. 45, p. 108-109 (LBL16988)

Although increasing the dissolution rate of a radionuclide in a geologic repository increases the near-field concentration, we have shown elsewhere that with suitably large transport time and dispersion, the maximum farfield concentration is not affected by dissolution rate. Also, we have shown that similar effects occir in fracture-nlow transport due to pore diffusion, even when hydrodynanic dispersion is neglected. Here we extend that analysis to examine the effect of different solubilities on the maximum farficld concentration in a porous medium with dispersion.

Lippmann, M.J., 1983

Overview of Cerro Prieto studies

Geothermics, v. 12, no.4, p. 265-289 (LBL-1 5664)

The studies performed on the Cerro Prieto geothermal field, Mexico, since the late 1950's are summarized. Emphasis is given to those activities leading to the identification of the sources of heat and mass, the fluid flow paths, and the phenomena occurring in the field in its natural stale and under exploitation.

Lippmann, MJ., and Bodvarsson, G.S., 1983

Numerical studies of the heat and mass transport in the Cerro Prieto geothermal field

Water Resources Research, v. 19, no. 3, p. 753-767 (LBL-15509)

Numerical simulation techniques are employed in studies of the natural flow of heat and mass through the Cerro Ptieto reservoir, Mexico, and of the effects of exploitation on the field's behavior. The reservoir medel is a two-dimensional vertical east to west-southwest cross section, which is based on a recent hydrogeologic mode: of this geothermal system. The numerical code MULKOM is used in the simulation studies.

The steady-state pressure and temierature distributions are computed and compared againsi observed preproduction pressures and temperatures: a reasonable match is obtained. A natural hot water recharge rate of about $1 \times 10^{-2} \mathrm{~kg} / \mathrm{s}$ per meter of field length (measured in a north-south direction) is obtained.

The model is then used to simulate the behavior of the field during the 1973-1978 production period. The response of the model to fluid extraction aerees to what has been observed in the field or postulated by other authors. There is a decrease in temperatures and pressures in the produced 
Tejion; so exiensive-two-phase zone develops in the reservoir because of the stron fluid rechery. Mast of the fluid recharging the system comes from colder rejions locaind above and west of the produced reservoir.

\section{Luet HC., Chambrt, P.L, and Piarord, T.H., 1983}

Nuclide mistarion in backfill with a nonlinear sorption isotherm

Transactions of the Amerian Nuclear Society, v. 45, p. 197-108 (LBL 16987)

A function of beckfill material between waste form and rock is to retand the migration of nuclides released from the waste packaze. Here we analyze the time-dependent diffusion of radionuclides through backfill material that can rach local sorption saturation. This is an extension beyond previous analyses, which assume a linear sorption isotherm.

\section{Nansimhar, T.N., Kanehiro, B.Y., and Witherspoon, P.A., 1984 \\ Interpretation of earth tide response of three deep confined aquifer \\ - Journal of Geophysical Research, in press (LBL-12093)}

The response of a confined, areally inftnite aquifer to extermal loads imposed by earth tides is examined. Because the gravilational influence of celestial objects occurs over large areas of the earth, the confined aquifer is assumed to respond in an undrained fashion. Since undrained response is controlled by water compressibility, earh-tide response can be directly used only to evalunte porous medium compressibility, if porosity is known. Morecver, since speciffic storage, $S$, quantifies a drajned bebavior of the porous medium, one cannol directly estimate $S$, from earth tide response. Except for the fact that barometric changes act both on the water surface in the well and on the aquifer as a whole, while stress changes associaled with earth tides act only in the aquifer, the two phenomena jniluence the confined aquifer in much the same way. In other words, barometric response contains only as much information on the elastic properties of the aquifer as the earth tide response does. Factors such as wellbore storage, aquifer transmissivity, and storane coefficient contribute to time-lag and damping of the aquifer response as observed in the well. Anjlysis shows that the observation of nuid pressure changes alone, without concurrent measurement of external stress changes, is insufficient to uniquely interpret earthtide response. In the present work, change in extemal stress is estimated from dilatation by assuming a reasonable value for bulk modulus. Earthtide response of geothermal aquifers from Marysville, Montana; Eası Mesa, California; and Raft River Valley, Idaho were analyzed and the ratio of $S$ to porosity was estimated. Comparison of these estimates with independent pumping lests shows reasonablc agreement.

Perry, D.L. and Taylor, J.A., 1984

An X-ray photoelectron (XPS) and electron energy loss study of the oxidation of lead

Joumal of Vacuum Stience and Tec'inology, in press (LBL-17515)

Lead-oxygen compounds, the lead-oxygen minerals massicot and lithare, and the exposures of clean polyctystalline $\mathrm{Pb}^{\circ}$ to $\mathrm{O}, \mathrm{H}_{2} \mathrm{O}$, and air at various temperatures have been studied with $x$-ray photoeleciron (XPS) and electron energy loss (EELS) spectroscopies. Results indicate that the shape of the Auger O KVV lines and EELS are suficiently differen1 to distinguisb $\mathrm{PbO}, \mathrm{PbO}, \mathrm{Pb} \mathrm{O}$. and carbonate-hydroxide. Differences in the EELS spectra indicate that orthorhombic $\mathbf{P b O}$ is formed one clean $\mathrm{Pb}^{*}$ exposed to dry $\mathrm{O}$, at cemperatures below the melting point of $\mathrm{Fb}^{\circ}$ and tetragonal Pbo is formed at or above its melting point.

Perry, D.L, Tseo, L., and Britlain, H.G., 19BA

Euminescence studies of thorium hydrolysis products

Joumal of Luminescence, in press (LBL-15974)

Raising the $\mathrm{pH}$ of an aqueous solution of thorium nitrate results in the precipitation of a hydrated thorium oxide, rather than in the generation of a hydroxide species. At room temperature, this material does not exhibit any emissive properties but upon cooling to $7 \mathrm{H} \mathrm{K}$ a strong green luminescence an be observed. The emission spectrum is fairly broad and is character ized by an emission lifetime of 125 usec. Emission from a thorium hydroJysis product has not hithero been reported in the literature. Calcination of this material as $800^{\circ} \mathrm{C}$ for three hours produces thorium dioxide afler dehydntion of the hydrolysis produch and this material does no: exhibit any luminescence properties at any temperature.
The rature of the luminescence associnted with the thorium hydrolysis product was further investignted by exuminine the emission of a series of mixed-hydrolysis products. It was found that the costins of bydrelyzed thorium onto silica resulted in the production of the emission. but that orecipiution from a mixed Th/Le solution yielded hydrolysis products which only exhibited luminescence at low La concenisitions. Precipitation from mixed'Th/Gd solutions yielded material which could emit over much wider ranges of Th concentration. Finally, production of the mixed Th/Eu product enabled the demonstration that excitation energy conld be uransferred to the Eu ion, resulting in enhanced emission from this species. These observations lead one to conclude that the ereen Themission is due to luminescence associated with an inorganic eximer. Seppration of the Th centers (by bulky $\mathrm{La}$ ions, or less bulky Gd ions) eliminates the lumines. cence in a manner not linear with concentration, and the emissiop lifetime associated with the green emission also does not vary in a lines manner.

Perry, D.L, Tsao, L., and Brittain, H.G., 1984

Photophysical studies of uranyl complexes. 4. X-ray photoelectron and luminescence studies of hydrolyzed urany/ salts

Inorganic Chemistry, in press (LBL-16975)

The solid state hydrolysis products of the uranyl ion, $\mathrm{NO}^{2+}$, have been studied using $x$-ray photoelectron spectroscopy (XPS) and luminescence spectroscopy. The hydrolysis products consisted of uranium oxides and various forms of uranyl hydroxides, two of the most important classes of uranium species involved in the geologic transpon of uranium. Evidence for carbon dioxide chemisorption by the complexes from the aumosphere. leading 10 mixed oxide/hydroxide/carbonate complexes, is discussed.

Perry, D.L., Tsao, L., and Brittain, H.G., 1984

Photophysical studies of uranyl complexes. 5. Luminescence spectrum of $\mathrm{K}, \mathrm{VO}(\mathrm{CO})$

Joumal of Luminescence, in press (LBL-17516)

The photoluminescence spectrum of the potassium salt of the $\mathrm{UO}_{3}\left(\mathrm{CO}_{3}\right)_{3}^{4-}$ ion, one of the most important chensical species of uranium in geologic and oceanographic environments, has been studied under conditions of high resolution at cryogenic temperatures. The bonding parameters of this compound are imporant, since they control the chemicai reactions of the species involved in geologic migration. Additionally, they are responsible for the close association of uranium with coal and peat deposits.

Perry, D.L., Tsao, L, and Taylor, J.A., 1984

The galena/dichromate solution interaction and the nature of the resulting chromium(III) species

Inorganica Chimica Acta, v. 85, p. L75 (LBL-17517)

$X$-ray photoelectron spectroscopy has been used to study the surface species on galent after its reaction with aqueous sodium dichromate, a reaction that occurs in the froth folation processing of galena. Data indicate the chromium(III) species resulting from reduction on the surface to be a mixed hydrated chromium(11I) oxide/carbonate complex formed by the chemisorption (and subsequent reaction) of carbon dicxide onto hydrated chromium(III) oxide. This compound can best be formulated as $\mathrm{Cr}_{2} \mathrm{O}_{3}, n \mathrm{H}_{2} \mathrm{O} \cdot \mathrm{CO}_{2}$.

Pigford, T.H., Chambrè, P.L, and Zavoshy, S.J., 1983

Effect of repositary heating on dissclustion of glass waste

Iransactions of the American Nuclear Society, v. 45 (LBL-16416)

Here we analyse the effects of reposilory heating on the dissolution rate of borosilicale glass waste, using the equations derived by Chambre for the steady-state dissolution of low-solubility species, limited by diffusion and convection in the surrounding groundwater.

To illustrate, we adopt calculations for a repository in Hanford basait that show basalt temperatures as high as $230^{\circ} \mathrm{C}$ diring the thermal period. Higher temperatures increase dissolution rates by increasing both the solubility and the diffusion coefficient in the groundwater. Also, thermally induced flow can decrease the boundary layer thickness and iscrease the dissolution rate. 
Pitzer, K.S., 1983

Dielectic constant of water at very high temperatures and pressure Proceedings of the National Academy of Sriences USA. v. 80 , p. $4575-4576$ (LBL-1594t)

Perinem staistical mechanical theory is combined with the available measurements of the dielectric constent of water al high semperature and pressure to predict that properny at sill higher temperature. The dielectric constant is needed in connection with studies of electrolytes such as $\mathrm{NaCl} / \mathrm{H}_{2} \mathrm{O}$ al very high temperature.

\section{Pilzer, K.S., and Li, Yi-zui, 1983}

Thermadynamies of aqueous sadium chloride $10823 \mathrm{~K}$ and I kilobar Procedings of the National Academy of Sciences LSA, v. 80, p 7689-7693 (LBL-16561)

It is shown thal a very simple semi-empirical question represents quite accurately the thermodynamic properties of aqueous sodium chloride from $373 \mathrm{~K}$ to $823 \mathrm{~K}$. The equation comprises one Masgules term and a DebyeHückel termi Just the one Margules parameter is freely adjustable since the Debye-Húckel parameter is determined by the properties of water. The equation is valid from the saturation composition down to infinite dilution for solvent densily above $0.75 \mathrm{~g} \mathrm{~cm}^{-3}$ but at lower density only above a solvent mole fraction of about 0.1 on an ionized basis. Both solute and solvent activit coefficients are fitted from the lowest pressure of solution existence up to 1 kbar. Derivation of enthalpy and other related functions is discussed.

Pizer, KS., and Li, Yi-gui, 1984

Critical phenomena and thermodynamics of diture aqueous sodium chloride to $823 \mathrm{~K}$

Proceedings of the National Academy of Sciences USA, v. 81, p. 1268-1271 (LBL-16831)

Semi-empirical equations are developed that represent the behavior of dilute solutions of $\mathrm{NaCl}$ in water (steam) in the range ${ }^{\top} 23-323 \mathrm{~K}$ where ion paiting is extensive. This supplements the equations given eartier for more concentrated solutions. In this temperature range the system $\mathrm{NaCl} / \mathrm{H}, \mathrm{O}$ shows critical behavior with iwo phases below the critical pressure. The equations fir the dilute solutions yield critical behavior. Though the equations for concentrated solutions do not yield critical behavior al the critieal pressure, only a very small interpolation function is required to connect smoothly the two equations. The jon-pairing equilibrium constants are reported as well as the Gibbs energies of hydration for both ions and ion pairs.

\section{Pitzer, K.S., and Simonson, J.M., 1983}

lon patring in a system continuously miscible from the fused sall to dilute solution

Journal of the American Chemical Society, in press (LBL-16562)

Electrostatic ion pairing is well-known for highly charged ionic systems in water or for 1-1 electrolytes in solvents of low Jielectric constant. Davies first presented equations for the conductance of such systems in which the solute fraction of the ion pairs reached a maximum and then decreased with further increase in concentration. This apparent "redissociation" phenomenon is investigated by experimental measurements, theory, and model calculations. The solvent activity is measured at $373 \mathrm{~K}$ for the system tetra-n-butyl-ammenium picratc in n-butanol for which the conductance and viscosity are known. Over the measured range from solute mole fraction 0.08 10 0.94 the activity data can be fitted without ion pairing using a simple equation including a Debye-Hückel lerm and a van Laar term. But conductance data demonstrate jon pairing in more dilute solutions, and both sets of data can be fitted with a model including ion pairing. The ion distribution implied by this model is calculated. In the "redissaciation" range the fraction of defined "ion pairs" does diminish, but the total probability of finding unlike ions near one anothe- steadily increases with increasing concentration. Thus there is redissociation only in a formal sense in terns of a particular model.

In brozdening the understanding of concentrated electrolyzes, systems continuously miscible from a fused salt to dilute solution in polar solvent are of particular interest. Since the pure salt is clearly ionic, any ion pairing effects at lower concentration must arise primarily from electrostatic effects. Most systems for which data are available over the full composition range are aqueous, near $373 \mathrm{~K}$, and show no significant ion pairine Bet with lower dielectric constant one expects ion paring and this is known to occus in many hiphiy but not fully miscibte systems. In water. ion pairing is imponant for higher valence salts at moderate temperature or for I-I sals at very high temperalure. Thus a careful study of a fully miscible system showing ion paing is of broad interest.

Seward measured buth conductance and viscosity for the system tetra$n$-butylammonium picrate-n-butanol at $91^{\circ} \mathrm{C}$ which is miscible over the full range. The conductance indicates substantial ion pairing in the range 0.0001 to 0.01 molar but the conduclance-viscosity product for more concentrated solutions is similar to that for fully ionized systems. The pure fused pierate has properties typicat of fully ionized insed sals. Thus it seemed especially interesting to obtain activity data for this same picratebutanol system over the full range of composition. Measurements of the vapor pressure of butanol are reported and the solvent activity calculated therefrom. These activity data are fitted to the equations ccrresponding to several models or theories, with and without simultaneous consideration of the conductance data, and the results are discussed with respect both to the structural implications and to the practical representation of thermodynamic properies.

\section{Pitzer, K.S., Peiper, J.C., and Busey, R.H., 1983}

Thermodynamic properties of aqueous sodium chloride solutions

Journal of Physies and Chemical Referenge Data, in press (LBL-15512)

Experimental measurements of the osmotic and activity coefficients, the enthalpy, and the heat capacity were used to derive a semi-empirical equation for the thermodynamic properties of $\mathrm{NaCl}(\mathrm{aq})$ at constani pressure. This equation may be combined with the previous paper on the volumetric properties to yield a complete equation of state valid in the region $273 \mathrm{~K} \leq$ $\mathrm{T}<573 \mathrm{~K}$, saturation pressure $<\mathrm{p} \leq \mathrm{I} \mathrm{kbar}, 0 \leq \mathrm{m}<6.0 \mathrm{~mol} \mathrm{~kg}{ }^{-1}$. It is shown that this equation may be extrapolated to higher solute molalities at lower pressures, An estimation of uncertainties in various quantities is given. Tables of values for various thermodynamic properties are presented in the appendix.

\section{Pruess, K., $1+\overline{8} j$}

Heat transfer in fractured geothermal resenoirs with boiling

Water Resources Research, v. 19, no. 1, p. 201-208 (LBL-13615)

Analytical and numerical techniques are used to study nonisolhermal flow of water and steam in idealized fractured porous media. We find that heat conduction in the rock matrix can substantially alter the flowing enthalpy in the fractures. Effects of matrix permeability and fracture spacing are demonstrated for production from and injection into vapordominated and liquid-dominated geothermal reservoirs.

\section{Pruess, K., and Narasimban, T.N., 1982}

On fluid reserves and the production of superheated steam from frat. tured, vapor-dominated geothermal resenvoirs

Journal of Geophysical Research, v. 87. nc BI I, p. $9329-9339$ (LBL12921).

Vapor-dominared geothermat reservoirs produce salumated or superheated steam, and venical pressure gradients are close 10 vapor static. These observations have been generally accepted as providing conclusive evidence that the liquid saturation musi be rather small ( $<50 \%$ ) in order that liquid may be nearly immobile. This conclusion ignores the crucial role of conduclive heat transfer mechanisms in fractured reservoirs for vaporizing liquid flowing under two-phase conditions. We have developed a multiple intera,cting continuum method (MINC) for numerically simulating two-phase now of a homogeneous fuid in a fractured porous medium. Application of this method to reservoir conditions representative of The Gieysers, Califomia, and results from an analytical approximation show that, for matrix permeability less than a critical value $(\approx 2.5$ to 5 microdar cies), the mass flux of water from the metrix to the fractures will be con. tinuously vaporized by heat transported due to conduction. This gives rise to production of superhealed steam even when the matrix has nearly full liquid saluration. Simple estimates also show that heat-driven steam/water counterlow an mainain a gearly yapor static venical pressure profile in the presence of mobile liquid water in a reservoir with low vertical matrix permeability. The implication of these findings is that the fluid reserves of vapor-dominated geothermal reservoirs may be langer by a facior of abous 2 than has generally been believed in the past. 
Fruex, K., Bodvarseon, G.S., Stefinswon, V., and Elinseon, E.T., 1983 The Krafta seorhermal field Iceland: 4. Well performance and reservoir depietion

Water Resourcet Research, in press (LBL-16206)

A detailed distributed-parameter model, in which all wells are represented individually, is reported for the Krafla seothermal system. The model is based on a synthesis of seolopiol, peophysical, seochemical, and recrvoir enpineerin data from the field. Numerical simulations achieve an approximate match for production rates and flowing enthaipies for ten wells during the period 1976-1982. Predictions of future field performance on a well-by-well basis are presented for altemative frold development plans, including additional production wells, and reinjection of waste flujds.

Pruess, K, Weres, O, and Schroeder, R.C., 1983

Distributed purameter modeling of a producing rapor-dominated geathermal reservoir: Serrazzano, Italy

Water Resources Research, v. 12, no. 4, p. 1219-1230 (LBL-11235)

The sinulator SHAFT79 of Lawrence Berikeley Laboratory has been applied 10 a field-wide distributed parameter simulation of the vapordominated zeothermal reservoir at Serrazzano, Italy. Using a threedimensional geologically aceurate mesh and detailed flow rate data from 19 producing weils, a period of 15.5 years (from 1959 to 1975) has been simulated. The reservoir model used is based on field measurements of temperatures and pressures, laboratory data for core samples, and available geological and hydrological information. The main parameters determined (adjusted) during development of the simulation are permeabilities and much of the initial conditions. Simulated patterns of pressure decline show semiquantiutive agreement with field observations. Field pressures decline overall somewhat more rapidly than predicted in the simulation. It is concluded that (1) the interace between overlying steam cap and deeper boiling aquifer remains stationary during exploitation and (2) the aquifer boils approximately uniformly throughout in response to production. Furthermore, the simulation suggests that some steam flowing to the main well field originates from deep fractures rather than from boiling in the twophase zones modeled. Effects of cold recharge, incomplete thermal equilibration between rock and fluid, and different assumptions regarding the depih of the steam/1wo-phase interface are investigated. The reservoir model is used to extrapolate (forecast) production rates on a well-by-well basis through 1990. Injection of spent condensate is briefly examined, and negligible impact on field performance is predicted. Simulation methodo!agy and ambiguity of parameter determination are discussed.

Pruess, K., Wilt, M., Judvarsson, G.S., and Goldstein, N.E., 1983

Simulation and resistivity modeling of geothermal reservoir with waters of different salinity

Geothermics, v. 12, no. 4, p. 291-306 (LBL-14652)

Apparent resistivities measured by mzans of repetitive dipole-dipole surveys show significant changes within the Cerro Ptieto reservoir. The cbanges are attributed to production and natural recharge. To understand better the observed yeophysical phenomena, we performed a simple reservoir simulation study combined with the appropriate DC resistivity calculations to determine the expected magnitude of apparent resistivity change. We consider production from a liquid dominated reservoir with dimensions and parameters of the Cerro Prieto ' $A$ ' reservoir and assume lateral and vertical recharge of colder and less saline waters. Based on rather schematic one-nd two-dimensional reservoir simulations, we calculate changes in formation resistivily which we then tranform into chonges in apparent resistivity that would be observed at the surface. Simulated chanzes in apparent resistivities over the production zane show jncreases of 10 to $20 \%$ over a 3 year period at the current rate of luid extraction. Changes of this magmllude are nor only within our ability to discern using proper field techniques, but are consistent in magnitude with some of the observed effects. However, the patterns of apparent resistivity charges in the simulated dipoiedipole pseudosection only partially resemble the obsered field data. This is explained by the fact that the actual nuid recharge into the ' $A$ ' reservoir is more complicated than assumed in our simple, schematic recharge models. DC resistivity monitoring appears capable of providing indirect information on fluid flow processes in a producins geothemal reservoir. Such information is extremely valuable for the development of quantitative predictions of future reservoir performance.
Rezowalli, J.J., King M.S., and Myer. L_R., 1984

Cross-hole acoustic surveying in basalt

International Journal of Rock Mechanics and Minins Sciences and

Geomechanics Abstracts, in press (LBL-17314)

The in situ assessment of pomechanica: characteristics of rock masus is an essential prerequisite to the desien and analysis of structures, both $\mathrm{cn}$ the surfwee and underyound. A particular in situ investigative technique that continues to show promise for this purpose is the cross-hole higherfrequency acoustic method.

The purpose of this technical note is to present preliminary results of a series of cross-hole acoustic measurement performed in a tunnel situated in a basaltic rock mass. The tunnel, at a subsurface depth of $46 \mathrm{~m}$, was excavated by conventional drill-and-blast techniques. Located well above the water table, the rock mass is characterized as dense basalt with a juinting structure of 0.15 to $0.36 \mathrm{~m}$ thick vertical columns cut by low-2nele cross joints.

The objectives of the test program were: first to evaluate in situ dynamic elastic properties, and to ascess their spatial variation around the opening: second, to evaluate the extent of blast damage around the opening and third, to assess the spatial variation of jointing and frocturing around the opening Analysis of the data included an evaluation of the velocities and frequency spectra of compressional and shear waves transmiled through the rock.

It is concluded that the acoustic velocity and attenuation data are clearly indicative of an anisotropic, jointed rock mass, with a preater intensity of jointing in the horizontal than the verical direction. Low acoustic velocities are indicative of blast damage, and of zones of interse jointing or fractures. The same trend is seen also in the values of dynamic elastic modulus. The dynamic Poisson's ratio, however, appears to be relatively insensitive to the degree of jointing or fracturing.

\section{Roy, R.N., Gibbons, J.J., Peiper. J.C., and Pilzer, K.S., 1983}

Thermodynamics of the unsymmelrical mixed electrolyte $\mathrm{HCl} \cdot \mathrm{LaCl}$

Journal of Physical Chemistry, v. 87, p. 2365-2369 (LBL-15319)

The contribution of higher order electrostatic terms (beyond the DebyeHūckel approximation) has been investigated for the system $\mathrm{H}^{*}-\mathrm{La}^{3 *}-\mathrm{Cl}$ $\mathrm{H}_{3} \mathrm{O}$. Emf measurements were carried out on solutions at temperatures from 288.15 to $318.15 \mathrm{~K}$, and a1 jonje strengibs from 0.1 to $5.0 \mathrm{~mol} \mathrm{~kg}^{-1}$. by using hydrogen and silver-silver chloride clectrodes. From these measurements it is possible to determine the Pilzer mixing coefficients $\mathrm{H}_{,} \mathrm{La}^{*}$ and $\psi \mathrm{H}, \mathrm{La}, \mathrm{C} \varepsilon \mathrm{s}$ a function of temperature. They are well represented by linear equations yielding temperature-invariant estimates of $\mathrm{d}^{\mathrm{O}} \mathrm{H}, \mathrm{La} / \mathrm{dT}$. These estimates may be used to credict the relative apparent molal enthalpy for aquenus solutions containing $\mathrm{H}^{+}, \mathrm{La}^{3+}$, and $\mathrm{Cl}^{-}$with reasonable confidence. $A$ bnef lable of the enthalpy and the activity coeflicients is included.

Roy, R.N., Gibbons, J.J., Williams, R., Godwin, L., Baker, G., Simonson, J.M., and Pilzer, K.S., 1983

The thermodynamics of equeous carbonale solutions including mixtures of potarsium carbonate. bicarbonate, and chloride

Journal of Chemical Thermodynamies, in press (LBL-16317)

Electromotive force data for the cell without liquid junction $\mathrm{P}, \mathrm{H}, / \mathrm{K}, \mathrm{CO}_{3}\left(\mathrm{~m}_{1}\right), \mathrm{KHCO}(\mathrm{m}), \mathrm{KCl}\left(\mathrm{m}_{1}\right) / \mathrm{AgCl}, \mathrm{Ag}$ have been obrained over a brosd range of solute concentratinn at 298.15, 298.15, 310.15 and $318.15 \mathrm{~K}$ These data have been used in conjusiction wjth previously available electrochernical cell data and isopiestic dala to calculate activity and osmotic coefficients of aqueous $\mathrm{K} \mathrm{CO}$, and $\mathrm{KHCO}_{1}$ using the ion-inieraction equations of Pizer for mixed electrolyte systems.

Roy, R.N., Gibbons, J.J., Wood, M.D., Williams, R.W., Peiper, J.C., and Pitzer, K.S., 1983

The first ionization of carbonic acid in aqueous solutions of potassium chloride including the activity coeffitients of potossium bicarbonate

Journal of Chemical Thermodynamics, v. 15, p. 37-47 (LBL-13482)

The electrochemical cell without liquid junction $\mathrm{P}_{1} \mathrm{H}_{\mathrm{J}} / \mathrm{KHCO}\left(\mathrm{m}_{1}\right)$. $\mathrm{KCl}\left(\mathrm{m}_{2}\right), \mathrm{CO}_{2}\left(\mathrm{~m}_{3}\right) / \mathrm{AgCl}, \mathrm{Ag}$ has teen used to determine the first ionization constant of carbonic acid and the activity coefficient of $\mathrm{KHCO}$, in potas- 
sium chloride solutions and in water at 278.15, 298.15, and $318.15 \mathrm{~K}$. The

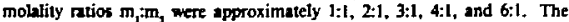

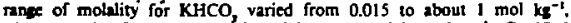
wheress at that for $\mathrm{KCl}$ ranged from 0.01 to about $0.34 \mathrm{~mol} \mathrm{~kg}^{-1}$. Certified primary grade gas mixtures ( $\mathrm{H}_{2}$ and $\mathrm{CO}$ ) were used. The average value of pK for all difterent ratios of $\mathrm{m}^{2} / \mathrm{m}$, at $298.15 \mathrm{~K}$ is 6.360 , which is the sume as the previous result of 6.360 for the $\mathrm{NaHCO}_{1}+\mathrm{NaCl}+\mathrm{H}_{3} \mathrm{O}$ system. The data were also treated by fitting to the Pitzer equations for mixed electrolyies. All paramelers reliably and accurately known from other systems were adopted leaving only the $\mathrm{KHCO}$, parameters to be determined. From these results, values are calcalated for activity and osmotic coeficients of

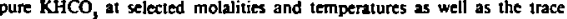
activity coefticient of $\mathrm{KHCO}_{3}$ in $\mathrm{KCl}$.

Sato, Y., Fujita, A, Chambré, P.L., and Pigford, T.H., 1982

Effect of solubility-limited dissolution on the migration of radionuclide chain

Transactions of the Ametican Nuclear Society v. 43, p. 64-66 (LBL14731)

Pigford et al. have presented the analytical solution for transport of a parent nuclide, such as plutonium, uranium, and neptunium, with limited solubility in groundwater. It was pointed out that neglect of the effect of solubility limits leads to an overestimate of the maximum concentration of the radionuclides. In Ref. 2, the solubility-limited migration of the daughter nuclide was studied, and it was shown that the solubility limit decreases its maximum concentration comparable to that of the mother nuclide. In the following we generalize the analysis to the space-timedependent concentrations of the daughter nuclides in a multimember decay chain in groundwater, with the mother nuclide exhibiting solubility-limited dissolution.

Schmidt. D.P., Soo, H., and Radke, C.J., 1983

Lincar oil displacement by the emulsion entrapinen pracess

Society of Petroleum Engineers Journal, in press (LBL-14926)

Lack of mobility control is one of the major impediments to successful enhanced oil recovery, especially for high viscosity oils. This work presents experimental and theoretical results for continuous, linear, secondary oil displacement using dilute, stable suspensions of oil drops. The major hypothesis is that the $\mathrm{O} / \mathrm{W}$ emulsion provides microscopic mobility control through entrapment or local permeability reduction, not through viscosityratio improvement. In order to describe the displacement process, previous emulsion filtration theory is extended to longer cores and to two-phase flow. Agreement between theory and experiment is satisfactory for continuous secondary oil displacement with 1 to $2 \mu \mathrm{m}$ diameter drops of volume concentrations up to 5 percent in unconsolidated sandpacks with parmeabilities ranging from 1 to $3 \mathrm{\mu m}^{2}$.

Son, H., and Radke, C.J., 1983

The fow mechanism of dilute, stable enulsions in porous media

Industrial and Engineering Chemicals, Fundamentals, in press (LEL17474)

This work establishes the flow mechanism of dilute, stable emulsions in fine grained porous media. Oil-in-water emulsions of mean drop sizes ranging from 1 to $10 \mu \mathrm{m}$ are studies in sandpacks of 0.57 and $1.15-\mu \mathrm{m}^{2}$ permeability at a superficial velocity of $0.07 \mathrm{~mm} / \mathrm{s}$. Low viscosity oil drops causc permeability reductions of up to $80 \%$, with 4 to $5-\mu \mathrm{m}$ size drops being the most effective. By examining drop sizes and pore sizes. as well as transient effluent emulsion concentration and transient pressure data, we find that permeability reductions during emulsion flow are caused by droplet capture mechanisms similar to those found for solid particles in deep-bed filiration. The proposed filtration mechan' is verified by a nicromodel study.

Stebbins, J.S., and Carmichael, I S.E., 1983

The heat of fusion of fayalite

American Mineralogist, in press (L BL-16237)

The relative enthalpies $\left(H_{\mathrm{T}}-H_{\mathrm{xon}}\right)$ of crystalline fayalite $(\Leftrightarrow \mathrm{Fe}$.SiO, and of the liquids resulting from the melting of fayalite in platinum and iron-plated capsules have been measured from 985 to $1705 \mathrm{~K}$ by drop calorimelry. Analyses of the samples quenched from the liquid show that because of incongruent melving and disproportionation of $\mathrm{FeO}$ during cooling. a mixture of phases was produced. possibly including the mineral laihunite $\left(\Leftrightarrow \mathrm{Fe},\left(\mathrm{SiO}_{4}\right)_{2}\right.$. Measured enthalpies have been corrected for these effects, resulting in an enthatpy of squilibrium, incongruent melting at $1490 \mathrm{~K}$ of $88.4 \pm 1.1 \mathrm{~kJ} \mathrm{~mol}^{-1}$ and an enthalpy of hypothetical coneruent meltung of $89.3 \pm 1 . \mathrm{i} \mathrm{k} \mathrm{mol}^{-1}$.

Stebbins, J.F., Bishop, F.C., and Carmichael, 1.S.E. 1983

Solubility of sulfur in silicate liquids al high $f_{O}$

Iransactions of the American Geophysical Union, v. 64, p. 874 (LBL17174)

The oxurrence of CaSO, phenocrysts in the 1982 pumice enuption of $\mathrm{E}$ Chichon has stimulated an experimental study of sulfur-axyen pes solubilities in silicate liquids. The CaSO, phenocrysis have the following composition (in ppm) in contrast to the residual glass:

$\begin{array}{lrrrrrrrrrr} & \text { La } & \text { Ce } & \text { Nd } & \text { Yb } & \text { Th } & \text { U } & \text {.Ta } & \text { Hf } & \text { Ba } & \text { S } \\ \text { phero. } & 159 & 258 & 77 & 2.0 & 2.4 & 1.1 & .15 & <0.5 & 8 & - \\ \text { glass } & 34 & 59 & 21 & 1.9 & 19.1 & 5.8 & 1.2 & 5.4 & 1320 & 2800\end{array}$

and are taken to represent equilibrium. Thus, in high $f_{O}$ magmas ( $>$ NNO), the reaction:

$\mathrm{Na}_{9} \mathrm{Al}_{6} \mathrm{Si}_{6} \mathrm{O}_{26} \mathrm{SO}_{2}+\mathrm{CaAl}_{2} \mathrm{Si}_{2} \mathrm{O}_{3}+16 \mathrm{SiO}_{2}=8 \mathrm{NaAlSi}_{3} \mathrm{O}_{8}+\mathrm{CaSO}_{4}$

demonstrates that anhydrite plays a role in siliceous magmas that 15 similato that of noscan in mafic melts. The presence of pyrthotite phenoctzist is the Chichon samples suggests that some of the sulfur in the glass is sutfide and the balance more oxidized species.

Results of others indicate that high sulfur contents ( $S_{2}$ ) ean be $\bar{x}$ duced in synthetic melts at high $f_{\mathrm{SO}}$, We have made experiments is $=12$ cuated silica tubes using the $\mathrm{SiO}_{2}-\mathrm{CaSiO},-\mathrm{CaSO}$, buffer at $12 \mathrm{SJ}^{\circ} \mathrm{C}$ a-c $f_{\mathrm{SO}_{1}}=0.029 \mathrm{~b}$. Preliminary results indicate that $\mathrm{S}_{\mathrm{tat}}$ is greater in $\mathrm{L}_{\mathrm{S}} \mathrm{S}_{1}, \mathrm{O}$, and $\mathrm{K}, \mathrm{Si}, \mathrm{O}$, than in a $58 \% \mathrm{SiO}$, andesite in $24 \mathrm{hr}$ runs. No $\mathrm{S} 1<100$ Dras was detected in an albite melt under the same conditions. Longer exper:-

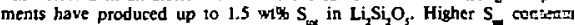
after longer run times and concentration gradients indicate that these turnples have not reached equilibrium, Further experiments in gas niu-is apparatus are underway, and sulfur speciation determinations by wet ciersical techniques are being made.

Stebbins, J.F., Carmichael, I.S.E., and Weill, D.F., 1983

The high temperature liquid and glass heal contenis and the bastr it fusion of diopside, albite, sanidine, and nepheline

imerican Mineralogist, v. 68, p. 717-730 (LBL-16238)

surate values of the heats of fusion of minerals are required is is variety of problems in igneous petrology, including the modeling of ecurt: budgets of cooling magmas and the definition of standard states for the components of more complex silicate liquid and solid solutions.

We have recently reported on the heal of fusion ( $L / H$ ) of secrthte

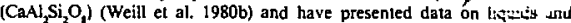
lasses of plagioclase composition (Stebbins et al. 1982). Here we $25-{ }^{i} u t=:$ new data to define hetter the hests of fusion of disorderet ilnte

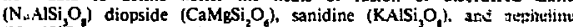

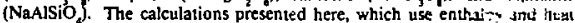
capacity results for the stable liquids, should produce much ecos ribuint

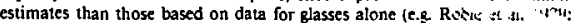
Yoder 1976).

It has been suggested (Boettcher et al. 1980) that altet: lkitut williti : produced by reheating of the glass above its liquidus teanersture :nar rot

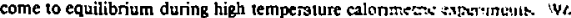

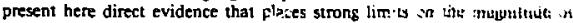
such an effect on the measured themal properuts

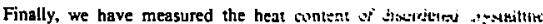
albite near its melting point.

Stebbins, J.F., Carmichael, I.S.E., and MIorst. L.K, 1.4k,

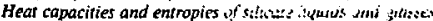

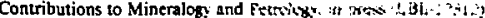

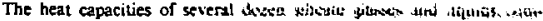

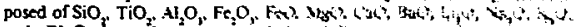

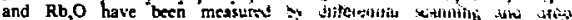

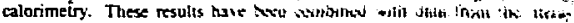


ture to fit $C$ as a function of composition. A model awuming ideal mixin (linzar combination) of partial molar heat capecities (independent of composition), reproduces the glass date within error. The assumption of constancy of $C$ is less sccurate for the liquids, but date ste not sufficient to adequakly constrain a more complex model. For liquids containing alkali metal and alkaline earth oxides, heat capacitics are sysiemuticaly erenter in liquids with high "field strengh" network modifying cations. Entropies of fusion (pes s-alom) and changes with configurational entropy with temperature, are similarly affected by composition. Both smaller cation size and greater churge are thercfore inferted to lead to greater development of new structural confizurations with increasing temperature in siliate liquids.

\section{Weres, O., 1983}

The partitioning of hydrogen sulphide in the condenser of Gevers Unit 15 Grothermics, v. 12, no. 1, p. 1-15 (LBL-12791)

The innsport and partitionins of hydrogen sulphide and other gases within the surface condenser of Geysers Unit 15 has been numerically modelled It was concluded that the venting of gas-rich vapor from the tubbing bundles in the main condenser was very uneven. This contributed to the poor hydrogen sulphide partitioning observed with this Unji. It was recommended that the condenser be physically modified to eliminate this problem, and these modifications were implemented. After the modifications, the hydroger sulphide partitioning performance of the Unit was approximately as had been predicted by the modellinis work.

Weres, O., 1983

Numerical evaluation of surface condensers for geothermal powerplants Geothermics, in press (LBL-15047)

The transport and partitioning of gases in four surface condensers for geothermal power plants has been modelled numerically. A vent condenser between the main condenser and the first stage gas ejectors improves hydrogen sulphide partitioning, particularly if the condensate from it, and from the interand after condensers, is recireulated to the main condenser tub bundles Rezardless of steam composition, hydrogen sulphide emissions may be largely eliminated by a Stretford Unit combined with a suitable surface cordenser. However, if the steam contains ammonia it may be necessary to add sulphur dioxide to neutralize pan of the ammonia. In no case is hydrogen peroxide needed to largely eliminate hydrogen sulphide air pollution.

Weres, O., 1983

Numerical evaluation of contact and hybrid condensers for geotherma: power plants

Geothermics, in press (LBL-15048)

The transport and partitioning of gases in two contact condensers in use at The Geyers has been modelled numerically. Improvements on these designs have been investigated. Adding a surface type vent condenser between the main condenser and first slage gas ejectors improves hydrogen sulphide partitioning dramatically. This "hybrid condenser" can match the performance of a surface condenser. Adding a contact type gas cooler altows $90 \%$ partitioning to be attained with stearm that contains little ammonia. (This has been demonstrated in practice by Clover and Han.)

White, A.F., 1983

Surface chemistry and dissolurion kinetics of glessy rocks at $25^{\circ} \mathrm{C}$

Geochimica et Cosmochimica Acla, v. 7. p. 805-815 (LBl-17577)

The weathering rates and mechanisms of three types of glassy rocks were investigated experimentully at $25^{\circ} \mathrm{C}$, pH 1.0106 .2 , and reaction times to as much to 3 months. Changes in major element chemistry were moni. tored concurently as a function of time in the aqueous solution and within the near-surface region of the elass. Leach profiles, obtained by a HF leaching technique, displayed near-surface zones depleted in major cations. These zones increased in depth with increasing time and decreasing $\mathrm{pH}$ of reactions. Release rates into the aqueous solution were parabolic for $\mathrm{Na}$ and $\mathrm{K}$ and linear for $\mathrm{Si}$ and $\mathrm{Al}$. A coupled weathering moder, involving surface dissolution with concurrent diffusion of $\mathrm{Na}, \mathrm{K}$, and $\mathrm{Al}$, produced a mass balunce between the aqueous and glass phoses. Steady-siate conditions are reached at pH 1.0 after approximately 3 weeks of reaction. Steady sute is not reached even after 3 months at $\mathrm{pH} 6.2$.
An intendiffusion model describes observed chanes in $\mathrm{Na}$ diffusion profiles for perlice at $\mathrm{pH}$ 1.0. The calcr lated $\mathrm{Na}_{2}$ sejf-diffusion coefficient of $5 \times 10^{-11}=\mathrm{m}^{2} \cdot \mathrm{s}^{-1}$ at $25^{\circ} \mathrm{C}$ approximates coefficients extrapolated from previowsly resorted hish temperature dut in obsidian. The self-diftusion coefficient for $\mathrm{H}, \mathrm{O}^{+}, 1.2 \times 10^{-14} \mathrm{~cm}^{2}-\mathrm{s}^{-1}$, is similar to measured rate of whter diflusion during hydration of obsidian to form perlite.

White, A.F, 1984

Weathering characteristics of natural gless and influences on atsociated water chemistry"

Journal of Non-Crystalline Solids, in press (LBL-16391)

Weathering rates and mechanisms of volcanic glasses al ambiem temperaure are investigated both experimentally and in the natural environment. As documented previously for man-made glasses, natural silicate Blasses weather by a two step process involving surface corrosion and cation interdiffusion. Diffusion rates display a strong valence state dependence with monovalent species less pH-dependent than bivalent species. Rates of release also decrease with increasing aqueous concentrations and glasssurface to solution-volume ratios. Numerical solutions to Fick"s second law of diffusion are presented for surface-concentration dependent diffusion and diffusion coupled with surface corrosion. Calculated diffusion coefficients of $1 \times 10^{-19} \mathrm{~cm}^{2} \times 5^{-1}$ and activation energies of $95 \mathrm{~N} \cdot \mathrm{mol}^{-1}$ are in agreement with data for man-made glasses.

Geochemical data are presented for short and long term natural weathering of glassy rocks. XPS data for glass phases in the 1980 Mount SL Helens ash fal! indicate rapid loss of readily exchangeable surface cations followed by longer term diffusion release. Incongruent leaching of Tertiary-age vitric tuffs in Nevada is found to control associated ground water chemistry.

White, A.F.. and Yee, A., 1984

Surface oxidization-reduction kinetics essociated with experimental basalt/water reaction at $25^{\circ} \mathrm{C}$

Chemical Geology, in press (LBL-17578)

Distributions of $\mathrm{Fe}(\mathrm{Il})$ and $\mathrm{Fe}(\mathrm{III})$ during basaly/water interaction were experimentally investigated under open and closed system $O$ conditions at $25^{\circ} \mathrm{C}$. XPS analyses showed oxidized iron on the surface of basalt, the concentration of which decreased as a function of reaction pH. Concurrent increases in $\mathrm{Fe}(\mathrm{II})$ and decreases in Fe(III) in sulutions at pHs less than 5 indicated continued surface oxidization by the reaction

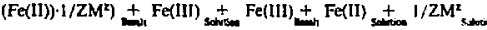

where the electrical charge in solution is balanced by dissolution of a cation from the basalt

Al neutral to basic $\mathrm{pH}, \mathrm{Fe}(\mathrm{I})$ is oxidizated to $\mathrm{Fe}(\mathrm{III})$ and precipitated as ferric oxyhydroxide in the presence of $O_{2}$. Fe(Ii) is also strongly sorbed on the basalt surface resulting in low aqueous concentrations even under anoxic conditions. The rate of $\mathrm{O}_{2}$ uptake increased with decreasing pHs. Diftusion coefficients of the order $10^{-4} \mathrm{~cm}^{2} \mathrm{~s}^{-1}$ were calculated using a onedimensional diffusion model and suggest grain boundary diffusion in 1ron oxides.

Wilson, C.R., Witherspoon, P.A., Long, J.C.S., Galbraith, R.M., DuBois, A.O. and McPherson, M.J., 1983

Large-scale hydraulic conductivity measurements in fractured granite

Intermational Journat of Rock Mechanics and Mining Sciences and Geomechanies Abstracts, v. 20, no. 6. p. 269-276 (LBL-14876)

The large-suale hydraulic conductivity experiment at Stripa, Sweden, was an attempt to produce a macromeasurement of the average hydraulic conductivity of approximately $200,000 \mathrm{~m}^{3}$ of low-permeability fractured granite. Groundwater seepage into a $33 \mathrm{~m}$ long, $5 \mathrm{~m}$ dia drift was measured as the net moisture pickup of a ventilation system. Water pressures were monitored at 90 locations in the rock mass. The experiment was designed to treat the rock as a porous medium. Analysis of test results indicates a behavior approximating radial flow in a porous medium. Tests made at three different drift air temperatures yielded very similar results. Compulations indieate that the average hydraulic conductivity of the monitored rock mass, exclusive of a zone of lower conductivity immediately surrounding the drift, is approximately $9.8 \times 10^{11} \mathrm{~m} / \mathrm{sec}$. 
Wilh, M.J., and Goldstein. N.E., 1984

Interpretation of dipole dipole resistivity monitoring data at Cerro Pripto Geothermics, v. 13. no. 1/2 p. 1.3-25 (LBL-14499)

Repetitive dipole-dipole resistivity dala have been raken on a yearly basis by LBL a1 Cerro Prieto since 1978. Stations along a single profile line extending from the Cucapa Mountains to the eenter of the Mexicali Valley and passinz over the present production zone have been remeasured with sufficient accuracy to detect subsurface changes in resistivity, some of which are probably related to nuid production. The precision of the most recent measurements (November, 1981) averages about 1\%. Results from 2 years of monitoring indicate a $5 \%$ anntral increase in apparent resistivity over the present production area and decreases in apparent resistivity of the same maenitude in the regions immediately eastward and westward from the production zone. The increase in resistivily in the production zone is most bikely due to dilution of reservoir jluids with fresher water, as evidenced by a drop in chloride content of produced waters. An attempt was made to determine whether specific lithologic zones in wellbores show resistivity changes with time by comparing well logs from newly drilled wells with logs from older nearby wells. Results show that lateral resistivity var. ations within stratigraphic units between closely spaced weils are sufficient to obscure possible temporal changes. The area of decreasing resistivity in the eastem part of the field is associated with a steeply dipping conductive body, a zone of higher thermal gradients and an increase in shale thicknes in the section. Well log analysis shows that the low resistivity is mostly due to higher temperatures. Decreasing resistivity in this area may be caused by an influx of hotter and more saline brines from depth. Recent measurements also show dramatic increase in near-surface resjstivity al the westem es.d of the monitored line. This is most likely due to recent chanos in loal irrigation practices which resulted in a seneral improvement in poundwater quality. To investigate the phenomenon of resistivity chanes caused by groundwater movement and chemical reactions, we propose the estabitsh ment of an additional resistivity line crossing both the new eastern production zone and the present survey line at an angle of $60^{\circ}$. This line would permit the acquisition of baseline dan over the future production zone (Сето Prieto II and IIJ areas), in conjunction with the present line, and would establish a grid of stations which could be used to map subsurfice groundwater fronts.

Witherspoon, P.^., and Gale, J.E. 1983

Hydrogeological testing to characterize a fractured granite

Bulletin of the International Association of Engineering Geology, Paris. no. 26-27, p. 515-526 (LBL-17658)

A comprehensive program of in situ testing has been carried out in an iron ore mine in Stripa, Sweden, to investigate the problems of obtaining a bydrogeological characterization of a fractured granite rack mass. The field investigations consisted of: (1) the collection of fracture seometry and borehole injection test data to determine directional permeabilities, (2) a macropermeabjisty experiment to determine the bulk rock mass permeability, (3) groundwater sampling for investigations of geochemistry and isotope hydrology, (4) pump testing of surface wells, and (5) tracer tesis to delermine effective porosity. This report summarizes results from all but the las1 item, the tracer work, which had not been carried out when the field work ended in 1981. 


\section{APPENDIX B: LBL REPORTS, CONFERENCES, PROCEEDINGS}

\section{LBL REPORTS}

LoID-622

Weres, O., 1983. Documentation for computer program CNDSR.

LBID-17

Geochemistry Group, Earth Sciences Division, 1983. Geochemical assessment of nuclear waste isolation. Quarerly report, jenuary I-March 31, 1983.

LBL-9063(SAC-38)

Paulsson, B.N.P., Nelson, P.H., and Kurfurst, P.J., 1983. Characterization of discontinuities in the Stripa graniteFull-scale heater experiments.

LBL-10145

Oppliger, G.L., 1982. Three-dimensional terrain effects in electrical and magnetometric resistivity surveys (Ph.D. dissertation).

LBL-11377

Weres, O., and Tsao, L., 1983. Reaction of hydrogen sulfide with oxygen in the presence of sulfite.

LBL-11654 (SAC-36)

Wollenberg, H., Flexser, S., and Andersson, L., 1980. Petrology and Radiogeology of the Stripa pluton.

LBL-11982 (SAC-39)

Nelson, P.H., Magnussen, KA., and Rachiele, R., 1980. Application of borehole geophysics at an experimental waste storage site.

LBL-12520 (SAC-37)

Wilson, C.R., Long. J.C.S., Galbraith, R.M., Karasaki, K., Endo, H.H., DuBois, A.O., McPherson, M.J., and Ramqvist, G., 1981. Geohydrological data from the macropermeability experiment at. Stripa, Sweden.

LEL-13071(SAC-42)

Rouleau, A., Gale, J.E., and Baleshta, J., 1981. Fracture ntapping in the ventilation drifi at Stripa. Procedures and results.

LBL-1 32 [ 7(SAC-43)

Javandel, ]., and Witherspoon, P.A., 1983. Thermal analysis of the Stripa heater test data from the full scale drif.

LBL-13295

Bodvarsson, M.G., and Benson, S.M., 1982. Well test data from geothermal reservoirs.

LBL-1334

Wang, J.S.Y., Mangold, D.C., Spencer, R.K, and Tsang, C.F., 1982. Thermal impart of waste emplacement and surface cooling associated with geologic disposal of nuclear waste.

LBL-14519

Bodvarsson, G.S., and Laj, C.H., 1982. Injection into naturally fractured reservoirs.

LEL-14605 (GSRMP-12)

Schatz, J.F., 1982. Physical processes of subsidence in geothermal reservoirs.

LBL-14842 (Vol. I and 2)

Pigford, P.L, Fujita, A., Kanki. T, Kobayashi, A., Lung, H., Ting, $H_{-}$Sato, $Y_{\text {, }}$ and Zavoshy, S.J., 1982. Analytical performance models for geologic repositories.
LBL-14900 (CP-28)

Goldstein, N.E., Wilt, M.J., and Corrigan, DJ., 1982. Analysis of the Nuevo Leon Magnetic anomaly and its possible relation to the Cerro Prieto magmatic-hydrothermal systsm.

LBL-15010

Wollenberg H.A., Wang, J.S.Y, and Korbin, G., 1983. An appraisal of nuclear waste isolation in the vadose zone in arid and semiarid regions (with emphasis on the Nevada Test Siie).

LBL-1 5029 (NUREG/CR-2983)

Camahan, C.L., Delany, J.M., Long J.C.S., Silva, R.J., Watkins, D.J., White, A.F., and Wilson, C.R., 1982 Selected hydrologic and geochemical issues in site characterization for nuclear waste disposal: Flood basalts at the Hanford Reservation.

LAL_15227

Pruess, K, 1983. GMINC-A mesh generator for flow simulations in fractured reservoirs.

LBL-15319

Roy, R.N, Gibbons, J.J., and Pizer, K.S., 1982. Thermodynamics of the unsymmetrical mixed electrolyte $\mathrm{HCl}-\mathrm{LaCl}_{3}$.

LBL-15526

Wilt, M.J., and Goldstein, N.E., 1983. Electromagnetic soundings over a geothermal reservoir in Dixie Valley, Nevada.

LBL-15594(CP-31)

Lippmann, M.J., Goldstein, N.E., Halfman, S.E., and Witherspoon, P.A., 1983. Exploration and development of the Certo Prieto geothermal field.

LBL-16045

Geochemistry Group, Earth Sciences Division, 1983. Geochemical assessment of nuclear waste isolation. Report of activities during fiscal year 1982.

LBL-16152

Miller, C.W, 1983. CHEMTRN user's manual.

LBL-16259

Long J.C.S., 1983. Investigation of equivalent porous medium permeability in networks of discontinuous fractures (Ph.D. dissertation).

LBL-16347

Palmer, S.P., 1983. Fracture detection in crystalline rock using ultrasonic reflection techniques (Ph.D. dissertation; Vol 1 and 2).

LBL-16578

Javandel, I., 1983. Techniques for measuring the vertical hydraulic conductivity of flood basalt at the Basalt Waste Isolation Project site.

LBL-16625

Simonson, J.M., 1983. Thermodynamic properties of very concentrated electrolyte solutions (Ph.D. dissertation).

LBL-17084

Tsang, C.F., and Goldstein, N.E., 1983. A review of lessons learned from the DOE/Union Baca geothermal project and their application to CSDP drilling in the Valles Caldera, New Mexico. 


\section{CONFERENCES AND PROCEEDINGS}

Benson, S.M., 1983. Interpretation of interference data from the Klamath Falls, Oregon, Geothermal Resource. Presented at the Ninth Annual Stanford Workshop on Geothermal Reservoir Engineering Stanford, California. December 13-15, 1983 (LBL-16671).

Benson, S.M., and Bodvarsson, G.S., 1983. Pressure transient method for front tracking. Presented at the 58th Annual Technical Conference and Exhibition, Stiziety of Petroleum Engineers of AIME, San Francisco, California, October 5-8, 1983 (LBL-16574).

Bodvarsson, G.S., and Lai, C.H., 1982. Studies of injection into naturally fractured reservoirs. Presented at the Annual Mceting of the Geothermal Resources Council, San Diego, Califor. лia, October 11-14, 1982 (LBL-14519).

Bodvarsson, G.S., and Pruess, K., 1983. Modeling studies of geothermal systems with a free water surface. Presented at the Ninth Annual Stanford Workshop on Geothermal Reservoir Engineering, Stanford, California, December 13-15. 1983 (LBL-17146).

Bodvarsson, G.S., Pruess, K., and O'Sullivan, M J., 1983. Injec. tion and energy recovery in fractured geothermal reservoirs. Presented at the Society of Petroleum Engineers, 53rd An sual California Regional Meeting, Ventura, California, March 23-25, 1983. SPE Paper I1689 (LBL-15344).

Bodvarsson, G.S., Pruess, K., Stefansson, V., and Eliasson, E.T. 1982. Modeling studies of the natural state of the Krafla geothermial field. Iceland. Presented at the 8th A.nnual Workshop on Geothermal Reservoir Engineering, Stanford University. Stanford, California. December 14-16, 1982 (LBL-14978)

Bodvarsson, G.S., Pruess, K., Stefansson, V., and Eliasson, E.T., 1983. A summary of modeling studies of the Krafla geothermal field, Iceland. Prisented at the Annual Mceting of the Geothermal Resources Council, Portland, Oregon, October 24-27, 1983 (LBL-16100).

Bodvarsson, M.G. 1983. A summary of well testing activities at Lawrence Berkeley Laboratory, 1975-1983. Presented at the Annual Meeting of the Geothermal Resources Council, Portland, Oregon, October 24-27, 1983 (LBL-16207).

Carnahan, C.L., 1983. Thermodynamic coupling of heat and matter flows in near-field regions of nuclear waste repositories. Presented at the Materials Research Society 1983 Annual Meeting, Scientific Basis for Nuclear Waste Management, Boston, Massachusetts, November 14-17, 1983 (LBL16732).

Doe, T.W., Hustrulid, W.A., Leijon, B., Ingvald, K., and Strindell, L. 1982. Determination of the state of stress at the Stripa mine, Sweden. Presented at the USGS Conference on Hydraulic Fracturing Stress Measurement, Monterey, California, December 3-5, 1991 (LBL-14202).

Dorninguez A., B., and Lippmann, M.J., 1983, Some comments on the La Primavers geotheninal field. Mexico. Presented at the Ninth Annual Stanford Workshop on Geothermal Reservoir Engineering, Stanford, California, December 13-15, 1983 (LBL-16706).

Doughty, C., and Tsang, C.F., 1\%83. Control of the movement of a fluid plume by injection and production procedures. Presented at the ASME/JSME Thermal Engineering Joint Conference on Heat and Mass Transter in Undereround Media. Honolulu, Hawaii. March 20-23. 1983 (LBL-14984).

Goldstein, N.E. Pruess, K., Wilt, MJ., and Bodvarsson, G.S., 1982. Resistivity monitoring of fluid migration at the Cerro Prieto geothermal field. Presented at the 8th Workshop on
Geothermal Reservoir Engineering Stanford University, Stanfurd, California, December 14-16, 1982 (LBL-14979).

Goyal, K.P., Halfman, S.E., Truesdell, A.H., and Howard, I.H., 1982. Production characteristics of some Cerro Prieto wells. Presented at the Fourh Symposium on the Cerro Prieto Geothermal $F$ id, Guadalajara, Mexico, ?ugust $0-12,1982$ (LAL-14699; CP-27).

Halfman, S.E., Lippmann, M.J., Zelwer, R., and Howard, J.H., 1982. Fluid flow model of the Cerro Prieto geothermal field based on well log interpretation. Presented at the Fourth Symposium on the Cerro Prieto Geothermal Field, Guadalajara, Mexico, August 10-12, 1982 (LBL-14898; CP-26).

Keely, J.F., and Tsang C.F., 1983. Velocity plots and capture zones of pumping centers for ground water investigations. Presented at the 3rd National Symposium on Aquifer Res toration and Groundwater Monitoring, Columbia, Ohio, May 25-27, 1983 (LBL-16101).

Lee, $\mathrm{K} . \mathrm{H}_{\text {, }}$ and Morrison, H.F., 1983. A 2-1/2-dimensional numerical solution for the electromagnetic scattering using a hybrid technique. Presented at the 1983 Ansual International SEG Meering, Las Vegas, Nevada, September 11- I5, 1983 (LBL 15832).

Lippmann, M.J., 1983. Overview of Cerro Prieto stud.2 Presented at the 8th Workshop on Geothermal Reservour Engineering, Stanford, California, December 14-16. 1783 (LBL-15664).

Lippmann, M.J., and Bodvarsson, G.S., 1982. Modeling 5!udes on Cerro Prieto. Presented at the Fo: Irth Symposium on the Cerro Prieto Geothermal Field, Guadalajara, Mexico. Augusi 10-12, 1982 (LBL-14897, CP-25).

Lippmann, M.J., and Bodvarsson, G.S., 1983. A modeling stud: of the natural state of the Heber geothermal field, Californie. Presented at the Annual Meeting of the Geothermat Resources Council, Portland, Oregon, October 24-27. 1953 (LBL-16219).

Lippmann, M.J., and Bodvarsson, G.S., 1983. The generamb capacity of the Heber geothermal field, California. Presented at the Ninth Annual Stanford Workshop on Geotbermul Reservoir Engineering, Stanford, California. December 13-15, 1983 (LBL-16677).

Lippmann, M.J., Goldstein, N.E., Halfman, S.E., and wiste:spoon, P.A., 1983. Exploration and development of the C.rTo Prieto geothermal field. Presented at the $58 \mathrm{th}$ Annual Jechnical Conference and Exhibition, Society of Perroleum Engineers of AlME, San Francisco, California. Oncher $5-8$. 1983 (LBL-16574).

Majer, E.L., and McEvilly, T.V., 1982. Seismologi... siudies a the Cerro Prieto field: 1978-1982. Presentes a ine Fonurth Symposium on the Certo Prieto Geothermi = ytit. Gulatak jara, Mexico, August 10-12, 1982 (LBL- I 450 4 ; $C$-24)

Mangold, D.C., and Tsang, C.F., 1983. A studx oi nomisolhernal chemical transport in geothermal susiems on a three. dimensional coupled thermal and hydroisge pesteel nodet. Presented at the Annual Mecting of the ieuthermal Resources Council. Portland, Oregon. Oraher $24-97.1983$ (LBL-16294).

O'Sullivan, M.J., Bodvarsson. G.S. Pusss, K. and Haketer. M.R., 1983. Fuid and heat thou in gasmeh germbermal recet. voirs. Pn ad at the Ssth Annual Terbmal Conference and Exhibition. Society of Peroleum Engineers of AIME. San

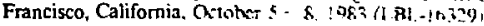

Piptord, T.H., 1983. Long-term environmental inupacts ol eeolo. gic repositories. Presentad at ihe internntional Conference on Radioactive Waste Managemeni. Sponsored by the IAEA.

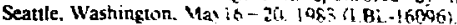


Pigford, T.H., 1983. Geologic disposal of radioactive waste1983. Presented at the American Institute of Chesiial Engineers 75th Anniversary Meeting, Washington, D.C. November 2, 1983 (LBL-16795).

Pitzer, K.S., and Li, Y., 1983. Thermodynamics of aqueous sodium chloride to $823 \mathrm{~K}$ and 1 kbar. Presented at the American Institute of Chemical Engineers International Solvent Extraction Conference, Denver, Colorado, August 26September 2, 1983, and to be published in the Proceedings of the National Academy of Sciences USA (LBL-16561).

Pruess, K, and Bodvassson, G.S., 1983. A seven point finite difference melhod for improved grid orientation performance in pattern stream floods. Presented at the 7th Society of Petroleum Engineers Symposium on Reservoir Simulation, San Francisco, California, November 15-18, 1983 (LBL16430).

Pruess, K, Bodvarsson, G.S., and S.,far sson, V., 1983. Analysis of production data from the Krafla geothermal field, Iceland. Presented at the Ninth innual Stan 1 Workshop on Geothermal Reservoir Engineering, Stanford, California, December 13-15, 1993 (LBL-17145).

Pruess, K., and J.S.Y. Wang, 1983. TOUGH-A numerical model for nonisothermal unsaturated fow to study waste canister heating effects. Presented at the Materials Research Society 1983 Annual Meeting, Scientific Basis for Nuclear Waste Management, Boston, Massachusetts, November 14-19, 1983 (LBL-16\%46).

Pruess, K., Wilt, M., Bodvarsson, G.S., and Goldstein, N.E., 1982. Simulation and resistivity modeling of a geothermal reservoir with waters of different salinity. Presented at the $41 \mathrm{~h}$ Symposium on the Cerro Pricto Geothermal Field, Guadalajara, Mexico, August 10-12, 1982 (LBL-14652. CP-21).

Radke, C.J.. King, M.S., and Witherspoon, P.A., 1983. Foamprotected natural gas storage reservoirs. Presented at the 2 nd Underground Storage Session, Transmission Conference of the American Gas Association, Seatte. Washington, May 2-4, 1983 (LBL-15905).

Silva, R.J., 1983. The behavior of americium in aqueous carbonate systems. Presented at the Materials Research Society 1983 Anrual Mceting. Scientific Basis for Nuclear Wastc Management, Boston, Massachusetis, November $14-17$, 1983 (LBL-16690)

Smith, A.R., and Moed, B.A., 1982. Recent radiochemistry observations at the Riverion and Maybell Tailings Piles. Presented at the Fifth Annual Symposium on Uranium Mill Tailings Management, Colorado State University, For Collins, Colorado, December 10-11. 1982 (LBL-1 5052).

Solbau, R.D., Goranson, C.B., and Benson, S.M., 1983. The development and use of a high temperature downhole flowmeter for geothermal well logging. Presented at the Ninth Annual Stanford Workshop on Geothermal Reservoir
Engincering, Stanford, California, December 13-15, 1983 (LBL-16672).

Thorpe. R.K., Watkins, D.J.. and Ralph. W.E., 1983. Sirength and permeability of an ultra-jarge specimen of granitic rock. Presented at the 24th U. S. Symposium on Rock Mechanics, Texas A \& M University, College Station. Texas, July 20-23, 1983 (LBL-16268)

Tokunaga, T., and Narasimhan, T.N., 1982. Recent hydrological observations from the Riverton and the Maybell tailings piles. Presented at the Sth Annual Symposium on Uranium Mill Tailings Management, Colorado State University, Fon Collins, Colorado, December 10-11 (LBL-15036).

Tsang, C.F., and Doughty, C., 1983. A nonisothermal well test analysis method. Presented at the ASME/JSME Thermal Engineering Joint Conference: Heal and Mass Transfer in Underground Media, Honolulu, Hawaii, March 20-23, 1983 (LBL-14968).

Tsang, C.F., and Doughty, C.. 198j. Numerical analysis of the Mobile, Alabama, aquifer test facility. Presented at the Physical and Chemical Energy Storage Contractor's Meeting, Arlington, Virginia, September 12-14, 1983 (LBL-I65 I9).

Tsang. C.F.. Doughty, C., and Kincaid, C.T., 1982. Numerical modeling of aquifer themal energy storage. Presented at the Energy Storage Contractor's Review Meeting, Arlington. $\mathrm{Vi}_{5}$ ginia, August 23-26, 1982 (LBL-14854).

Tsang, C.F., Mangold, D.C., Doughty, C., and Lippmann, M.J., 1982. Prediction of reinjection effects on the Cerru Prieto geothermal system. Presented at the 4 th Cerro piieto Svmposium, Guadalajara, Mexico, August 10-12, 1982 (LBL-i $18 \dot{\text { S }}$. CP-23).

Verma, A.K. Pruess, K., Bodvarsson. G.S., Tsang, C.F., and Witherspoon, P.A., 1983. Design and development of a test facility to study wo-phase steam/water flow in porous media. Presented at the Ninth Annual Stanford Workshop on Geothermal Reservoir Engineering. Stanford. California. December 13-15, 1983 (LBL-17172).

White, A.F., and Delany, J.M.. 1982. Chemical transpon bencath a uranjum mill tailings pile. Riverton, Wyoming. Presented at the Sth Annual Symposium on Uranium Mill Tailings Management. Colorado Statc Universily, For Collins. Colorado, December 10-11, 1982 (LBL-15038)

Wilt, M.J., and Goldstein, N.E.. 1983. Dipole-dipole monitoring at the Cerro Prieto geothermal field. Presented at the 1983 International Society of Exploration Geophysicists Annual Meeting. Las Vegas. Nevada, September 11-15, 1983 (LBL15831).

Wollenberg. H.A. Wang. J S.Y.. and Korbin, G.. 1982. Nuclear waste isolation in the unsaturated zone of arid regions. Presented at the Spring Meeting. Americ $s$ Geophysical Union, Philadelphia. Pennsylvania, May 31-June 4, 1982 (IBL-14086). 


\section{APPENDIX C: EARTH SCIENCES DIVISION STAFF AND ASSOCIATES}

\author{
Moshen Alavi \\ Robert Andrews \\ John Apps \\ Marilee Bailey ${ }^{\dagger}$ \\ Andre Bell \\ Sally Benson \\ Samuel Blakeslee \\ Gudmundur Bodvarsson \\ Mary Bodvarsson \\ Harry Bowman \\ Glenn Boyce \\ George Brimhall* \\ Mark Bukowinski \\ Ian Carmicha: : \\ Chalon Carnahan \\ Paul Chambré* \\ Sheng-Po Chen \\ Kin-Yip Chun \\ Neville Cook* \\ Ashok Das \\ Joan Delany \\ Edward DeZabala \\ Thomas Doe \\ Christine Doughty \\ Andrew Dubois \\ Doris Edwards \\ Laurel Egenberger \\ Howard Endo \\ Leslie Fairbanks \\ Steve Flexser \\ Dennis Fox \\ Peter Fuller \\ Norman Goldstein \\ Richard Goodman* \\ Jeanette Grant \\ Susan Halfman \\ Lanita Hall \\ Satya Harpalani \\ Diane Heinze \\ Michael Hood* \\ Frank Jahnke \\ Abdul Rahim Jaouni \\ Iraj Javandel \\ Raymond Jeanloz
}

\author{
Janet Jensen \\ Lane Johnson \\ Richard Johnson ${ }^{\dagger}$ \\ Barioara Jones \\ Carrie Joy \\ Kenzi Karasaki \\ Chang-Lak Kim \\ Hideo Kimura \\ Michael King \\ Ellen Klahn \\ Cheng-Hsien Lai \\ Ki Ha Lee \\ Wayne Leung \\ Donald Lippert \\ Marcelo Lippmann \\ Jane Long \\ Han-Chuan Lung \\ Gayle Lux \\ Marila Mackiewicz \\ Peggy Maclean \\ Ernest Majer \\ Donald Mangold \\ Marsha Marquis \\ Thomas McEsilly" \\ Malcolm McPherson* \\ Maynard Michel \\ Constance Miller \\ Barbara Moed \\ i1. Frank Morrison* \\ James Murdoch \\ Larry Myer \\ T.N. Narasimhan \\ Ed Nichols \\ Sher-Ran Nisu \\ Jahandar Noorishad \\ Daniel C'Connell \\ Joyce Olsen \\ Karl Olson \\ Irmgard Orzech \\ Dale Perry \\ John Peterson \\ Ramesh Phutela \\ Thomas Pigford* \\ Alexander Pines* \\ Kenneth Pitzer*
}

\author{
Kársien Pruess \\ Laura Pyrak \\ Clayton Radke* \\ Janet Remer \\ James Rezowalli \\ Mark Rivers \\ Richard Russo \\ William Sailor \\ Jonathan Scheiner \\ Deborah Scherrer \\ Deanna Schmidt \\ Deepah Sharma \\ Eugene Shen \\ Gen-Hua Shi \\ Rober Silva \\ John Simonson \\ Ray Solbau \\ Wilbur Somerton* \\ Ales Soudek \\ Robin Spencer \\ Jonathan Stebbins \\ Hamy Todd \\ Tetsu Tokunaga \\ David Tralli \\ Chin Fu Tsang \\ Yvonne Tsang \\ Lcon Tsao \\ Julie Turnross \\ Donald Vasco \\ Ashok Verma \\ Oliver Wan \\ Joseph Wang \\ Dai Watkins \\ Mary Weeks \\ Oleh Weres \\ Arthur White \\ Linda Williams \\ Michael Wilt \\ Paul Withcrspoon* \\ Harold Wolienberg \\ Elsic Yang \\ Andrew Yec \\ Michacl Zani \\ St.aw Zavoshy
}

-IC Berkeley Faculty member.

TTID supoort personnel. 
This report was done with support from the Department of Energy. Any conclusions or opinions expressed in this report represent solely those of the author(s) and not necessarily those of The Regents of the University of California, the Lawence Berkeley Laboratory or the Department of Energy.

Reference to a company or product name does nol imply approval or recommendation of the product by the University of California or the U.S. Department of Energy to the exclusion of others that may be suitable. 